\title{
Room Q Data Repol: Test Borehole Data from April 1989 through November 1991
}

\author{
A.L. Jensen \\ Fluid Flow and Transport Department 6119 \\ Sandia National Laboratories \\ Albuquerque, NM 87185 \\ C.L. Howard \\ RE/SPEC Inc. \\ Albuquerque, NM 87110 \\ R.L. Jones, T.P. Peterson \\ Tech Reps, Inc. \\ Albuquerque, NM 87110
}

\begin{abstract}
Pore-pressure and fluid-flow tests were performed in 15 boreholes drilled into the bedded evaporites of the Salado Formation from within the Waste Isolation Pilot Plant (WIPP). The tests measured fluid flow and pore pressure within the Salado. The boreholes were drilled into the previously undisturbed host rock around a proposed cylindrical test room, Room Q, located on the west side of the facility about $655 \mathrm{~m}$ below ground surface. The boreholes were about $23 \mathrm{~m}$ deep and ranged over $27.5 \mathrm{~m}$ of stratigraphy. They were completed and instrumented before excavation of Room Q. Tests were conducted in isolated zones at the end of each borehole. Three groups of 5 isolated zones extend above, below, and to the north of Room $Q$ at increasing distances from the room axis. Measurements recorded before, during, and after the mining of the circular test room provided data about borehole closure, pressure, temperature, and brine seepage into the isolated zones. The effects of the circular excavation were recorded. This data report presents the data collected from the borehole test zones between April 25, 1989 and November 25, 1991. The report also describes test development, test equipment, and borehole drilling operations.
\end{abstract}




\section{ACKNOWLEDGMENTS}

The authors thank Rick Beauheim and Ray Ostensen of Department 6119 for their draft review comments, Jeff Palmer of INTERA for his help with the figures, Ed Lorusso and Sally Laundre-Woerner of Tech Reps for their work on the manuscript and the illustrations. 


\section{PREFACE}

Preliminary data from in and around Room $Q$ may have appeared in technical papers, memoranda, and presentation materials by S. Howarth, E. Peterson, S. Finley, and J. Nowak. This report is considered the definitive data report for the Room $Q$ experiments. 


\section{CONTENTS}

1.0 InTRODUCTION $\ldots \ldots \ldots \ldots \ldots \ldots \ldots \ldots \ldots \ldots \ldots \ldots \ldots \ldots \ldots \ldots \ldots \ldots \ldots$

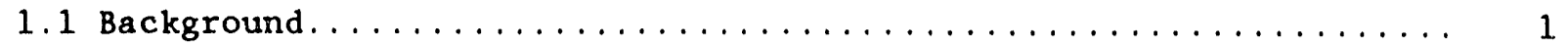

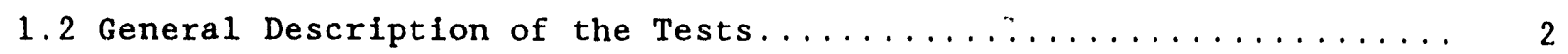

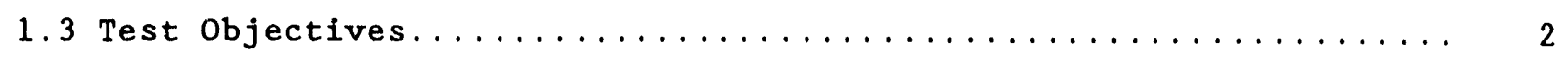

2.0 WIPP UNDERGROUND DEVELOPMENT $\ldots \ldots \ldots \ldots \ldots \ldots \ldots \ldots \ldots \ldots \ldots \ldots \ldots \ldots \ldots$

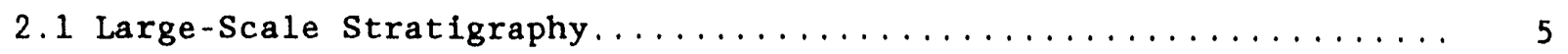

2.2 Underground Facility Construction $\ldots \ldots \ldots \ldots \ldots \ldots \ldots \ldots \ldots \ldots \ldots$

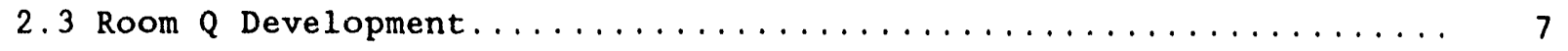

2.3.1 Room Location Relative to Stratigraphy............. 7

2.3.2 Access Drift and Instrument Alcove Mining........... 7

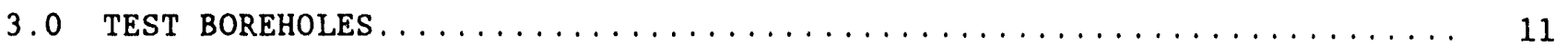

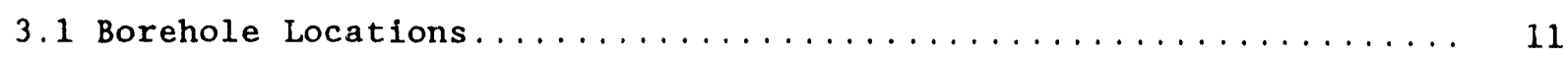

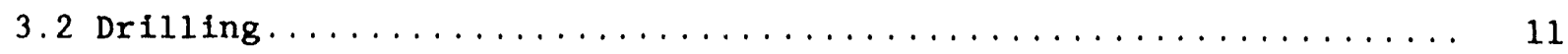

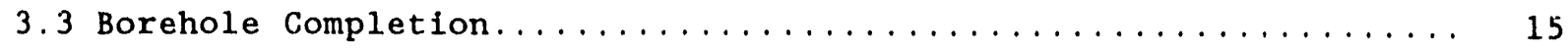

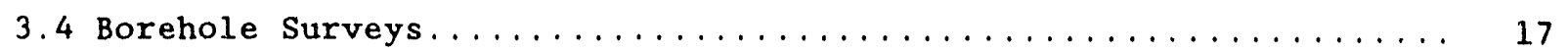

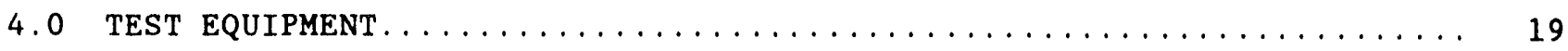

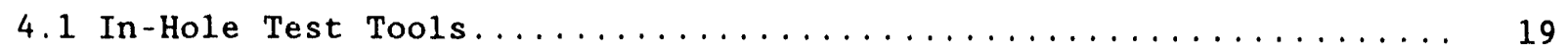

4.1 .1 The slim-Hole single-Packer Test Tool............... 19

4.1 .2 The Slim-Hole Dual-Packer Test Tool................ 20

4.1.3 The Large-Hole Dual-Packer Test Tool................ 21

4.1 .4 Closure Measurement Devices.................... 22

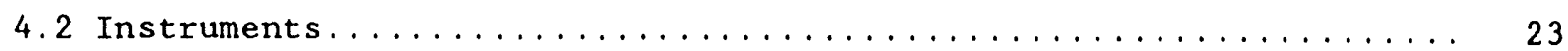

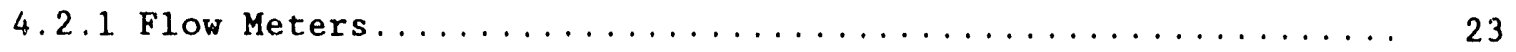

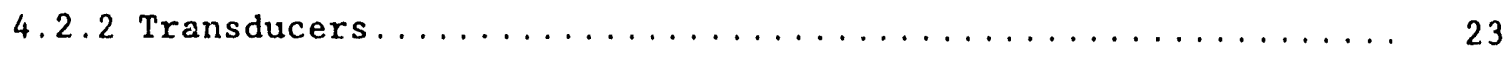

4.2 .3 Linear Variable-Differential Transformers............. 23

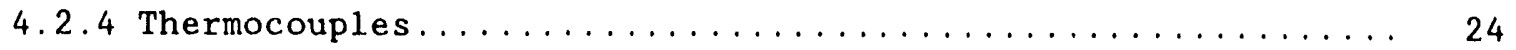

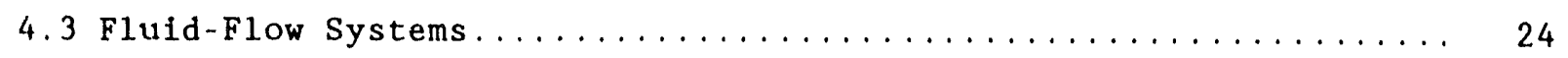

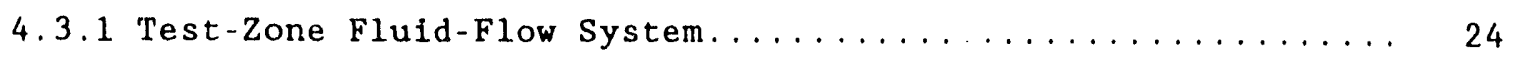

4.3.2 Constant-Pressure Injection/Withdrawal system.......... 27

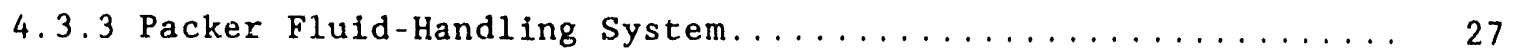

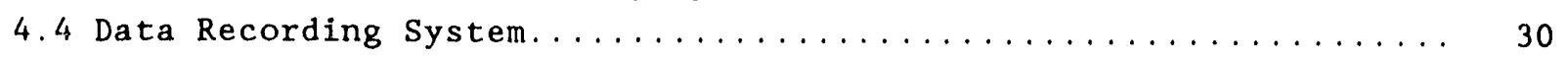

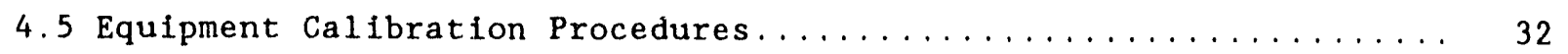

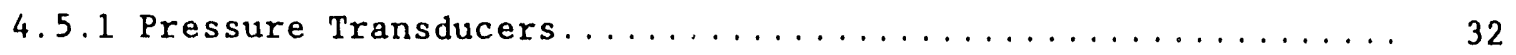

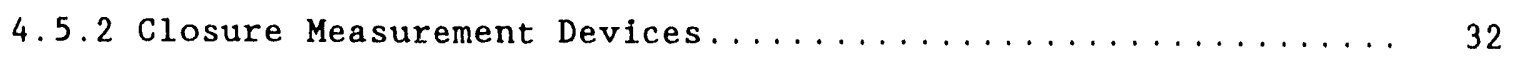

4.5 .3 Thermocouples.......................... 33

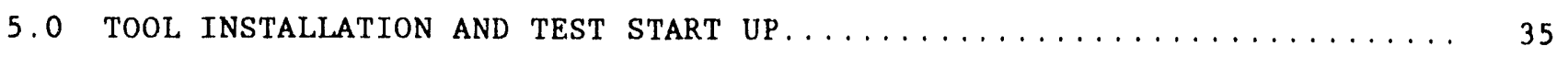

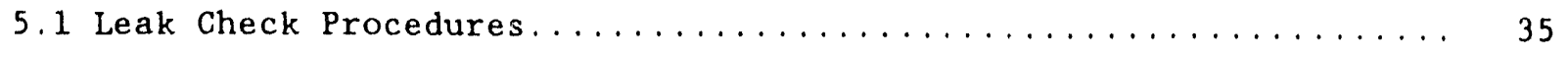

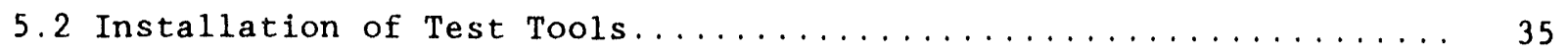


5.1 .1 closure Gauge. ........................... 37

5.1 .2 Brine Supply Connection. . . . . . . . . . . . . . . . . 37

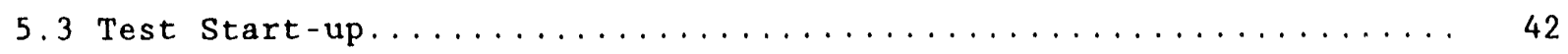

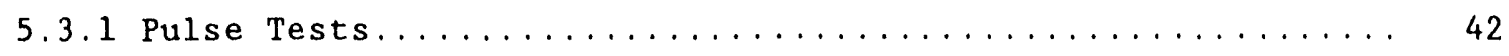

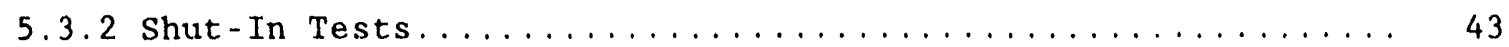

5.3 .3 Flow Tests.............................. 43

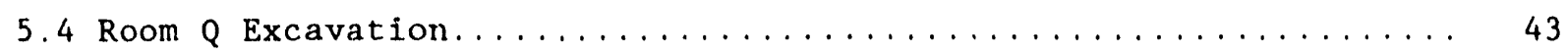

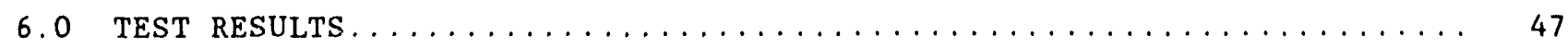

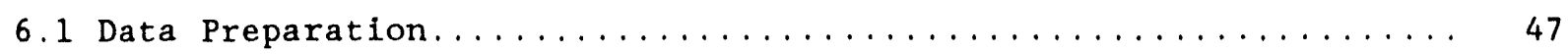

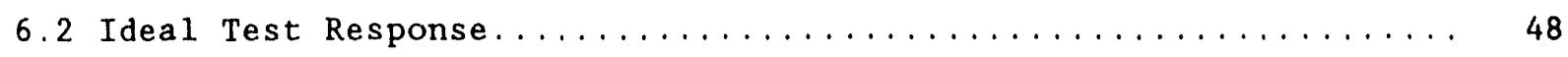

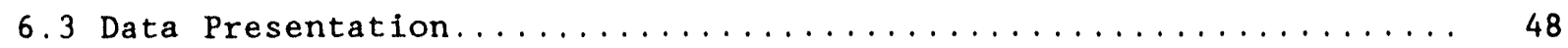

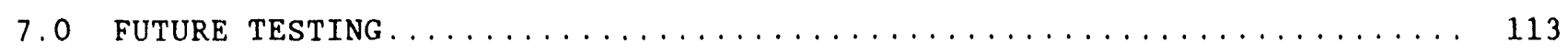

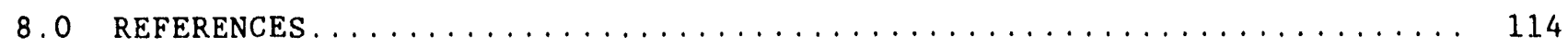

APPENDIX A: DESCRIPTION OF GENERALIZED STRATIGRAPHY .................

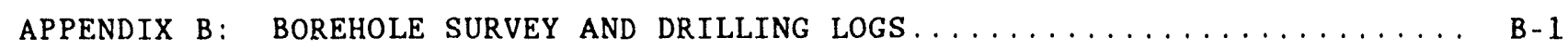

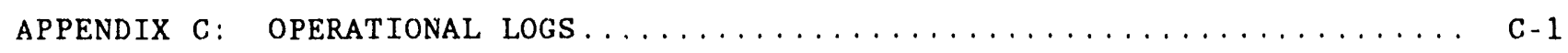




\section{Figures}

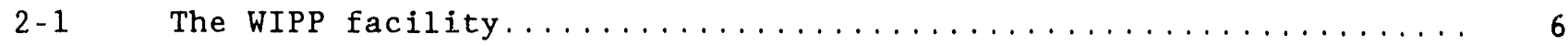

$2-2 \quad$ Location of Room $Q \ldots \ldots \ldots \ldots \ldots \ldots \ldots \ldots \ldots \ldots \ldots \ldots \ldots$

2-3 Development schedule for Room $Q$ activities............... 9

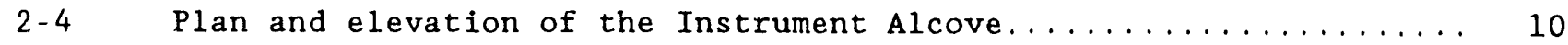

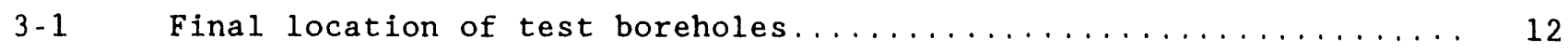

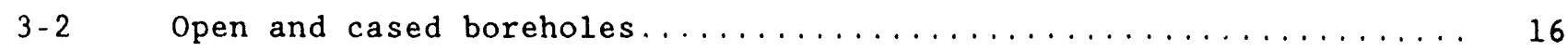

3-3 Test regions relative to extrapolated WIPP stratigraphy......... 18

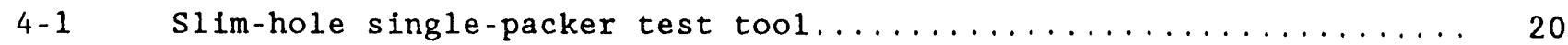

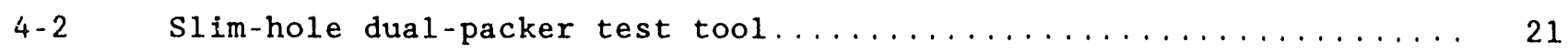

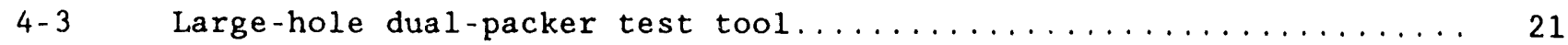

4-4 Schematic of the vertical and horizontal slim-hole closure gauges.. 22

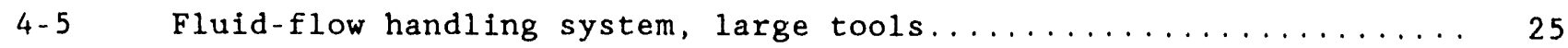

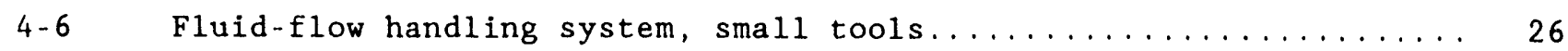

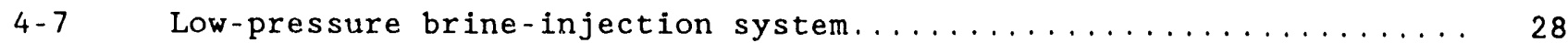

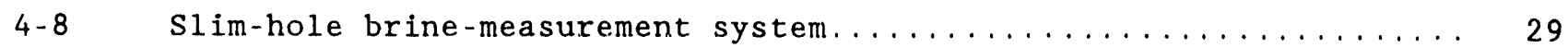

5-1 Installation diagram showing placement of $3.5-\mathrm{cm}$-diameter single-packer tools.......................... 39

5-2 Installation diagram showing placement of $3.5-\mathrm{cm}$-diameter

5-3 Installation diagram showing placement of 8.9 -cm-diameter
dual-packer tools $\ldots \ldots \ldots \ldots \ldots \ldots \ldots \ldots \ldots \ldots \ldots \ldots \ldots \ldots \ldots \ldots \ldots \ldots \ldots \ldots \ldots \ldots \ldots \ldots \ldots$

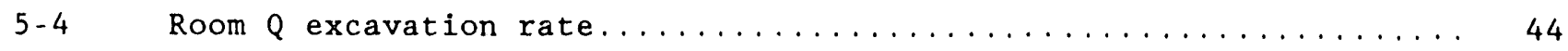

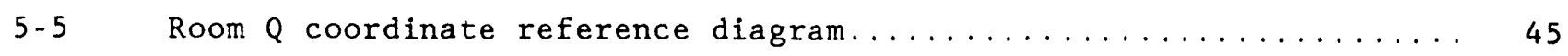

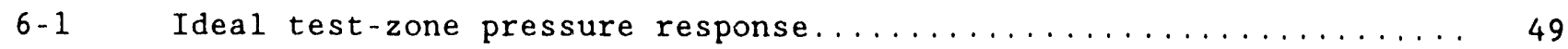

6-2 Vertical closure measured in the test zone of hole QPP01....... 51

6-3 Horizontal closure measured in the test zone of hole QPP01...... 51

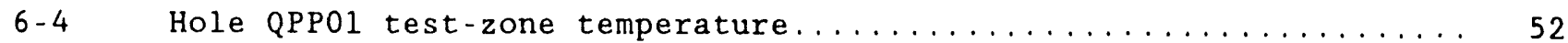

6-5 Brine collected from QPP01 test zone during flow testing....... 52

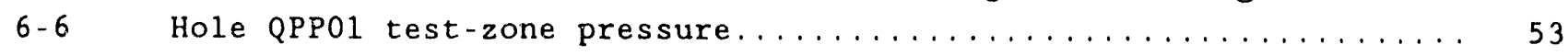

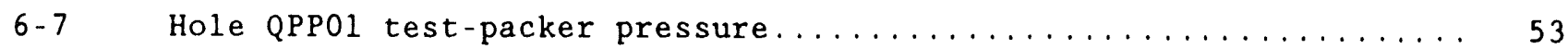

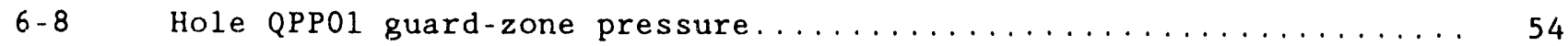

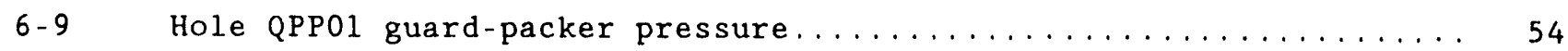

6-10 Vertical closure measured in the test zone of hole QPP02 ...... 55

6-11. Horizontal closure measured in the test zone of hole QPP02...... 55

6-12 Brine collected from QPP02 test zone during flow testing....... 56

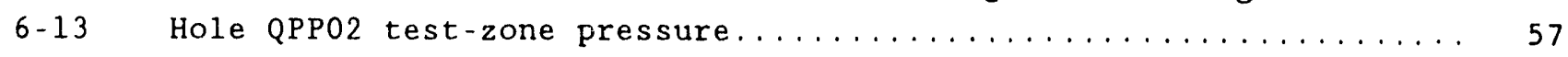

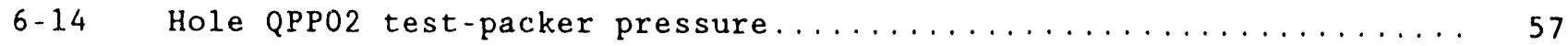

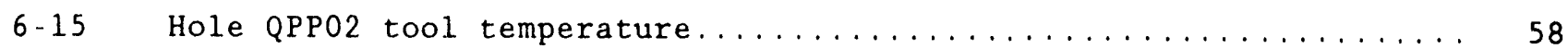

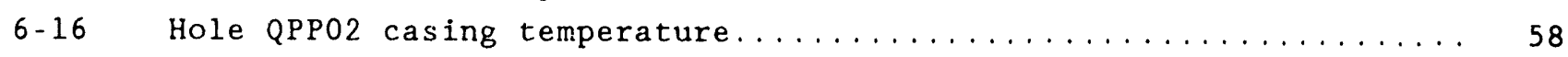




\section{Figures (Continued)}

6-17 Vertical closure measured in the test zone of hole QPP03....... 59

6-18 Horizontal closure measured in the test zone of hole QPP03....... 59

6-19 Brine collected from QPP03 test zone during flow testing........ 60

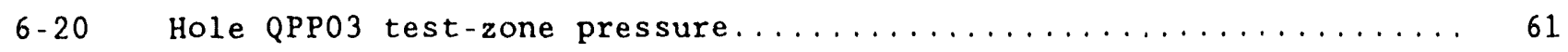

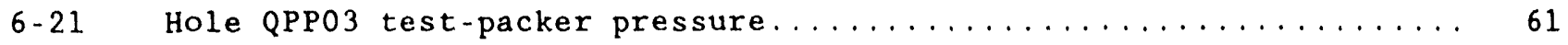

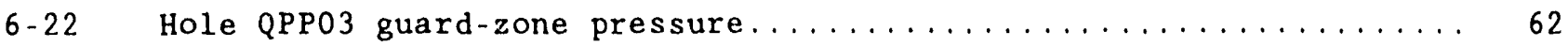

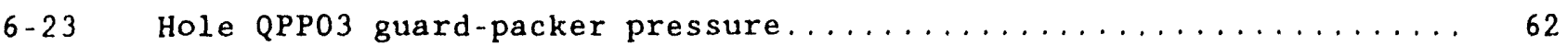

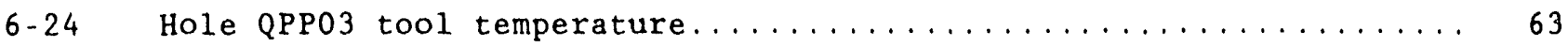

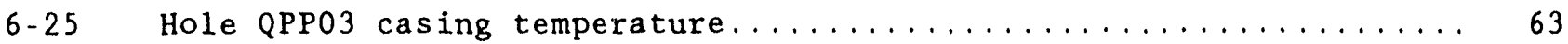

6-26 Vertical closure measured in the test zone of hole QPP04....... 64

6-27 Horizontal closure measured in the test zone of hole QPP04 ...... 64

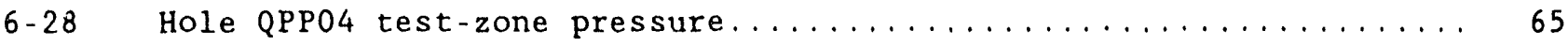

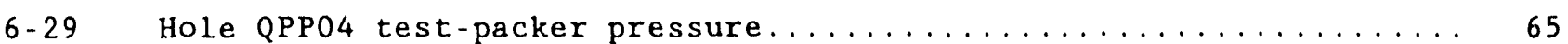

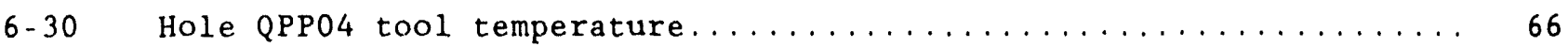

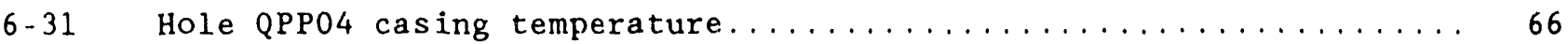

6-32 Vertical closure measured in the test zone of hole QPP05.......667

6-33 Horizontal closure measured in the test zone of hole QPP05 ...... 67

6-34 Brine lost from QPP05 test zone during flow testing.......... 68

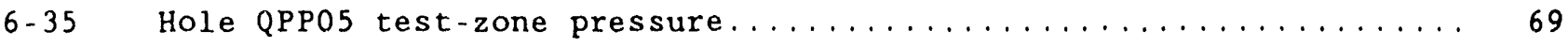

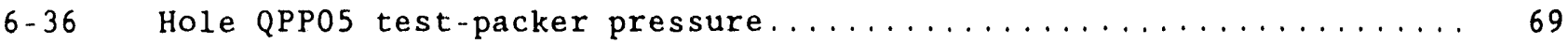

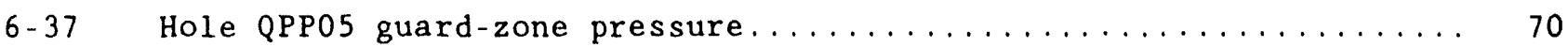

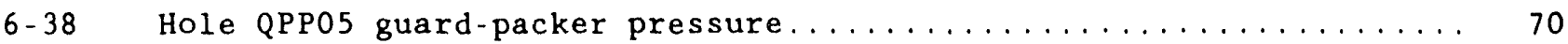

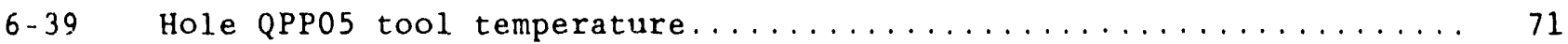

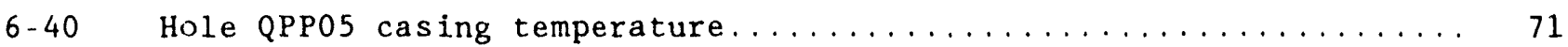

6-41 Vertical closure measured in the test zone of hole QPP11...... 72

6-42 Horizontal closure measured in the test zone of hole QPP11...... 72

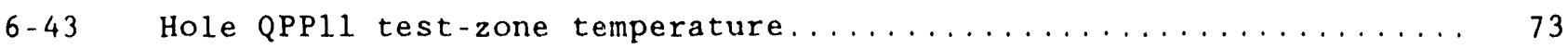

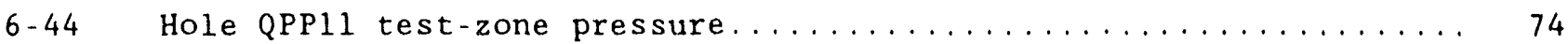

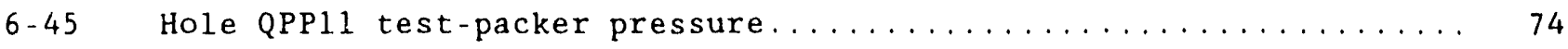

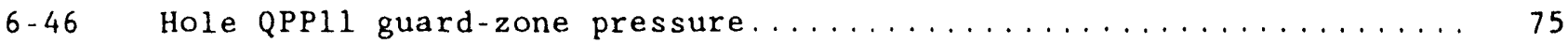

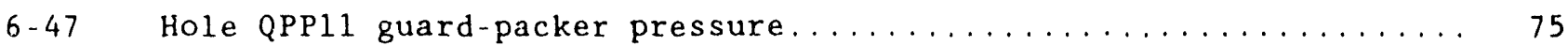

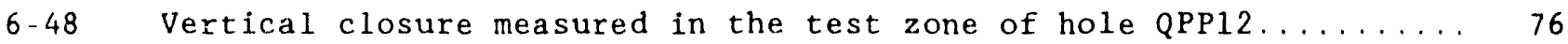

6-49 Horizontal closure measured in the test zone of hole QPP12 ..... 76

6-50 Brine collected from QPP12 test zone during flow testing....... 77

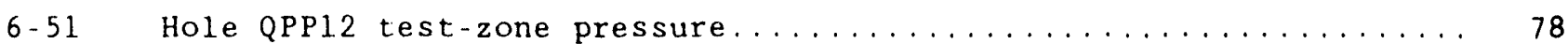

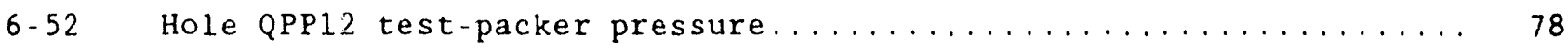

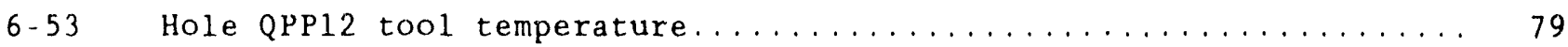

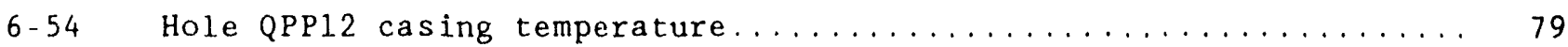

6-55 Vertical closure measured in the test zone of hole QPP13...... 80

6-56 Horizontal closure measured in the test zone of hole QPP13 ..... 80 


\section{Figures (Concluded)}

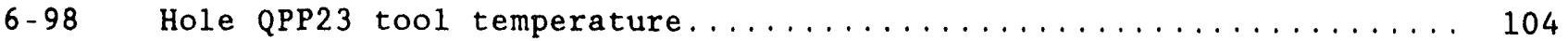

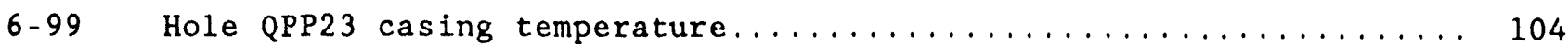

6-100 Vertical closure measured in the test zone of hole QPP24 ...... 105

6-101 Horizontal closure measured in the test zone of hole QPP24 ..... 105

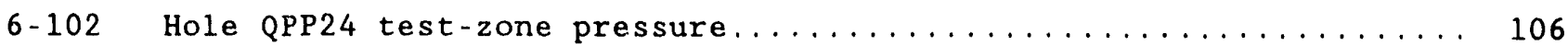

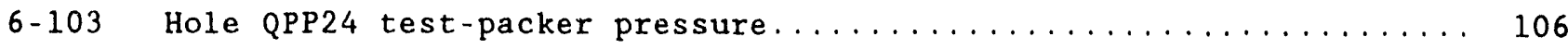

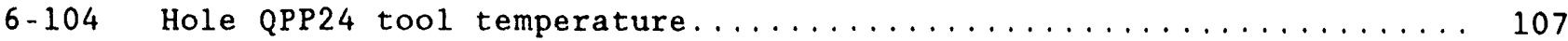

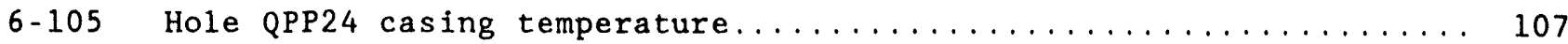

6-106 Vertical closure measured in the test zone of hole QPP25 ....... 108

6-107 Horizontal closure measured in the test zone of hole QPP25 ...... 108

6-108 Brine collected from QPP25 test zone during flow testing........ 109

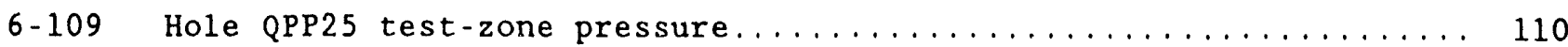

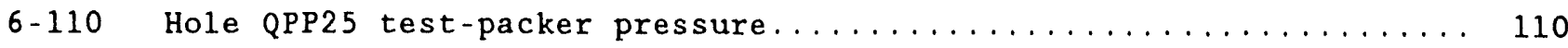

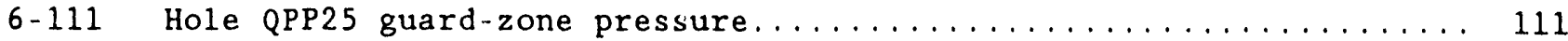

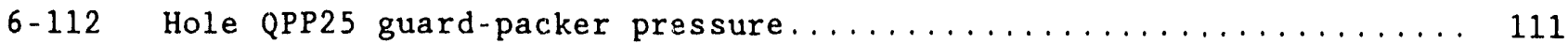

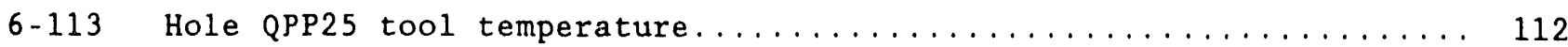

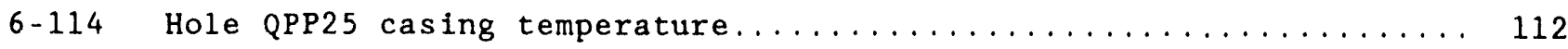

\section{Photographs}

4-1 Test-control panels and computer station................ 31

5-1 Installation with steel conduit..................... 38

\section{Tables}

3-1 As-built Data for Test Boreholes (Initial Drilling Stage) ....... 14

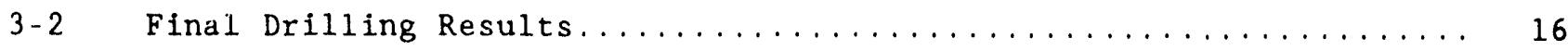

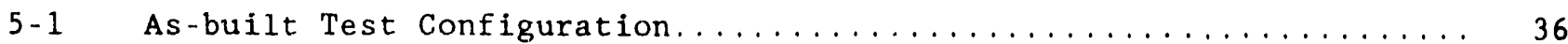

5-2 End and Collar Locations Relative to Room $Q$ Center............ 45 


\section{Figures (Continued)}

6-57 Brine collected from QPP13 test zone during flow testing........ 81

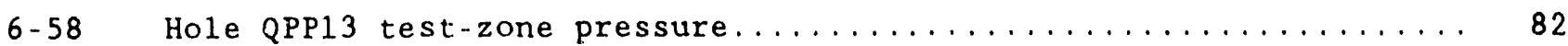

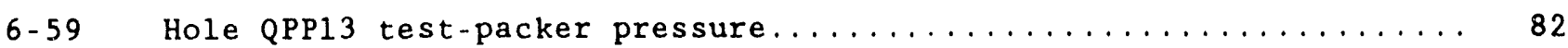

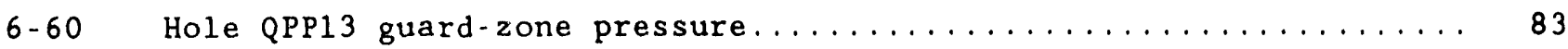

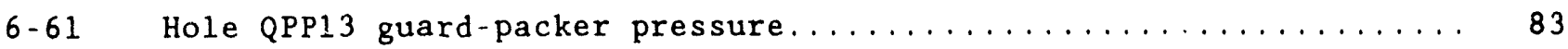

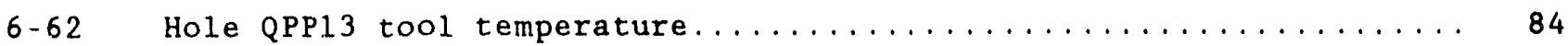

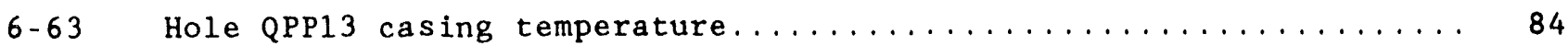

6-64 Vertical closure measured in the test zone of hole QPP14.......

6-65 Horizontal closure measured in the test zone of hole QPP14......85

6-66 Hole QPP14 test-zone pressure......................86

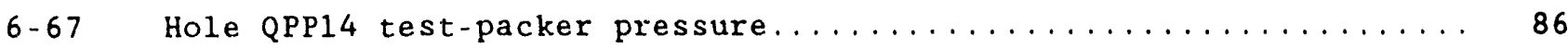

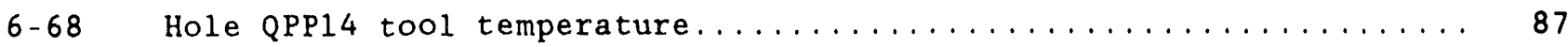

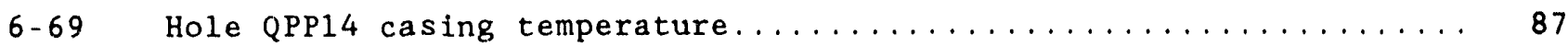

6-70 Vertical closure measured in the test zone of hole QPP15.......

6-71 Horizontal closure measured in the test zone of hole QPP15.......88

6-72 Brine collected from QPP15 test zone during flow testing........ 89

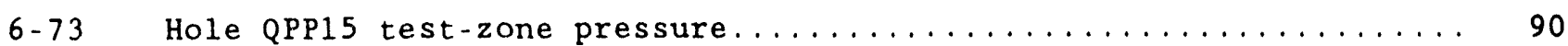

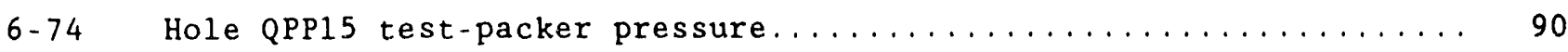

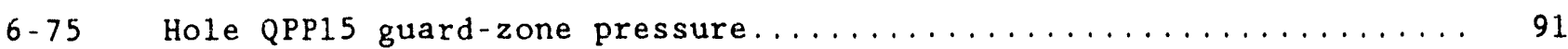

6-76 Hole QPP15 guard-packer pressure......................

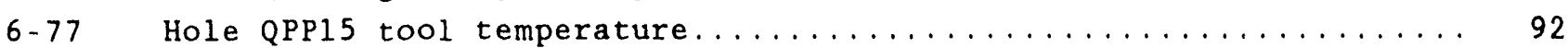

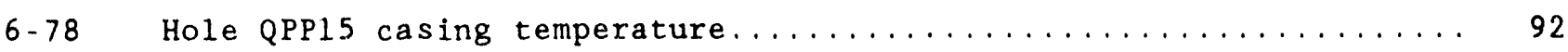

6-79 Hole QPP21 test-zone temperature......................93

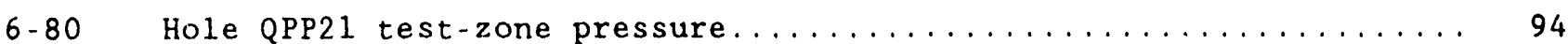

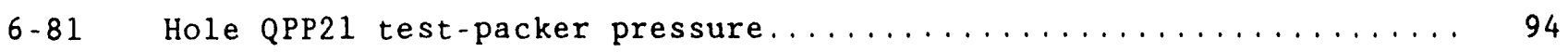

6-82 Hole QPP21 guard-zone pressure.......................95

6-83 Hole QPP21 guard-packer pressure......................

6-84 Vertical closure measured in the test zone of hole QPP22........96

6-85 Horizontal closure measured in the test zone of hole QPP22......

6-86 Brine collected from QPP22 test zone during flow testing ........97

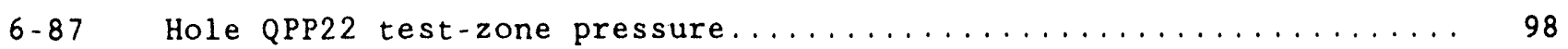

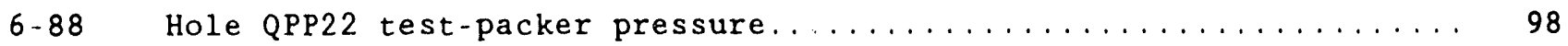

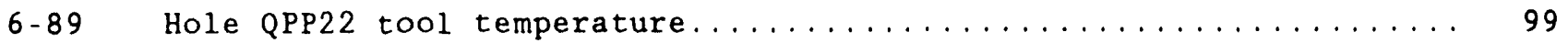

6-90 Hole QPP22 casing temperature.........................99

6-91 Vertical closure measured in the test zone of hole QPP23........100

6-92 Horizontal closure measured in the test zone of hole QPP23...... 100

6-93 Brine collected from QPP23 test zone during flow testing........101

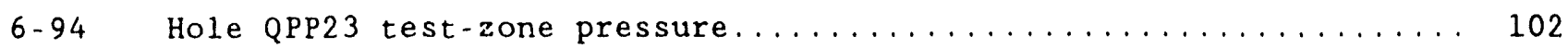

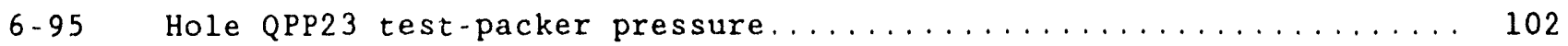

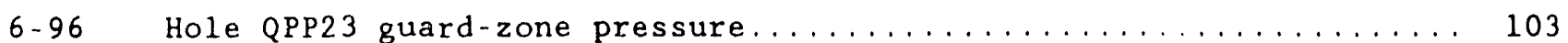

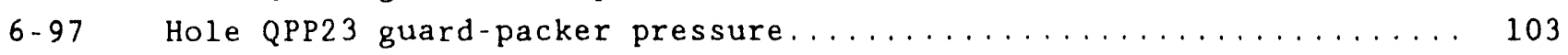




\subsection{INTRODUCTION}

This report presents the data from a series of hydrologic tests conducted at the Waste Isolation Pilot Plant (WIPP) in southeastern New Mexico. The WIPP is a US Department of Energy (DOE) research and development facility designed to examine methods for safe long-term storage of transuranic (TRU) radioactive wastes generated by United States defense programs. The WIPP disposal horizon is located 655 meters below ground in the Permian Salado Formation. The tests described in this data report were designed to provide information on fluid flow and formation pore pressure in the Salado.

The tests were conducted in 15 boreholes drilled from within the WIPP facility. The collars of the boreholes are located just outside a recently excavated test room (Room Q) in the west section of the facility. The boreholes were drilled and instrumented before the mining of Room Q. They formed isolated test zones above, below, and beside the room for gathering data regarding pressure, temperature, closure, and brine inflow. The isolated test zones lie within $27.5 \mathrm{~m}$ of local stratigraphy.

In addition to the test data from the boreholes, this report describes test development, testing tools and procedures, as-built information, and borehole-drilling techniques.

Data from other measurements taken from inside Room Q--such as resistivity, brine inflow, closure, barometric pressure, humidity, and air temperature-will be addressed in a companion report.

\subsection{Background}

The WIPP repository horizon is located $655 \mathrm{~m}$ underground in the Salado Formation, a $600-m$-thick layer of bedded salt. One major advantage of salt as a host for radioactive waste isolation is its ability to creep and enclose the waste within the formation. However, testing in the underground has shown that the salt contains pockets of brine that could have potentially deleterious effects on the repository. 1) The brine may become entrapped in the repository, preventing creep closure of the formation. 2) Brine entrapment in pockets may degrade the crushed salt seal material (Nowak and Stormont, 1987). 3) The presence of brine and high relative humidity may increase pressurized gas generation (Lappin et al., 1989), in turn increasing mechanical loads on seal structures. However, some reports show that a moderate rate of brine inflow could speed the desired reconsolidation of crushed salt seal components and backfills that will be used to fill voids in repository waste panels (Holcomb and Shields, 1987). 
The tests conducted in the boreholes around Room $Q$ were designed to help reduce uncertainties about brine inflow.

\subsection{General Description of the Tests}

The tests performed in the boreholes around Room $Q$ were intended to provide data from which permeability, flow potential, and pore pressure of the host rock could be inferred. These parameters are needed to formulate a model of brine seepage into Room Q. Test measurements were made with tools installed approximately $23 \mathrm{~m}$ into previously undisturbed rock. Fifteen test boreholes were drilled at several different angles relative to the proposed entrance of Room $Q$ so that test intervals could be placed at specific radial distances from the centerline of the room. The borehole-drilling procedure is described in Section 3.2. Drilling was completed and tools were installed before Room $Q$ was excavated. The circular cross-sectional shape chosen for Room $Q$ provides a uniform stress field around the excavation.

Data were acquired before, during, and after excavation. These data will be used to understand brine seepage rates into Room $Q$, and that understanding will be used to estimate the rate of brine seepage into the repository, a factor that will ultimately affect the repository consolidation process. Analysis of the data provided by these tests will thus reduce the level of uncertainty in hydrologic parameters used in performance assessment. calculations for the WIPP repository.

\subsection{Test Objectives}

The borehole hydrologic tests around Room $Q$ were designed to provide information on the formation pore pressure, permeability, and flow potential of the Salado Formation both within the zone of influence of the WIPP excavations and in the undisturbed "far field" parts of the Salado. The immediate test objectives were to create a comprehensive data set to determine formation permeability, pore pressure, and fluid flow before and after Room $Q$ mine-by. Additional data about permeability measurements and/or gas-flow testing of the Salado at and near the underground-facility horizon can be found in Peterson et al. (1987), Stormont et al. (1987), Stormont (1990), Beauheim et al. (1991), and Saulnier et al. (1991).

Data were collected to measure pressures in the host rock surrounding Room $Q$ before, during, and after excavation in order to characterize the pore-pressure gradient as it developed in response to inining and to subsequent brine inflow. Data from testing activities were acquired from two distinct types of tests: 1) constant-pressure flow tests, and 2) long-term 
pressure-buildup tests. While both activities can be analyzed using the same numerical model, they require the use of different analytical solutions. The current analysis of flow testing is accomplished by using the Graph Theoretic Field Model. (GTFM) as the nunierical model (Pickens et al., 1987) and comparing the results with Doe fractional-dimension type curves (Doe, 1991), an analytical method. The current analysis of the long-term pressure buildup is accomplished using GTFM as the numerical model and comparing the results with the analytical solution of Gringarten (1979) included in the Interpret/2 well-test-interpretation code developed by Scientific Software-Intercomp. Comparisons of the numerical models with the analytical solutions provide confidence in the results. From these analytical results, values for formation pressure, permeability, transmissivity, and diffusivity can be assigned to the formation around Room $Q$. The first analytical evaluation of these data is currently in the report preparation stage.

The local pore-pressure gradients induced by the excavation of the WIPP test rooms are predicted to extend only a few meters into the surrounding host rock, so hydrologic understanding of the region is limited. A locally bounded region of interconnected porosity in the Salado Formation might account for current inflow data, and pore pressure may still be nearly equal to pre-excavation values within a few meters of WIPP excavations (Nowak, 1990; Finley et al., 1992). If the local pore system is saturated and isolated from overlying aquifers, the pre-excavation value should be close to Iithostatic pressure (approximately $14.8 \mathrm{MPa}$, or $2150 \mathrm{psi}$ ). If, on the other hand, the pore system is globally interconnected and saturated, the preexcavation value could be closer to hydrostatic pressure (approximately 6.9 $\mathrm{MPa}$, or $1000 \mathrm{psi}$ ).

Design calculations support the notion that pore-pressure measurements in boreholes of moderate lengths can be used to determine formation pressure (Nowak et al., 1988). Data from these measurements can be used to quantify the pore-pressure gradient near an excavation for comparison with model predictions. The data can also be used to determine far-field pore pressure as an approximation of the pre-excavation value. Inferences about the size of the flow regime (locally limited or global) could also be made from the estimated pre-excavation pore pressure. Integrated brine-inflow and porepressure measurements for the same excavation are essential for understanding the mechanistic relationships in the region.

A detailed description of the measurement system appears in Section 5. 


\subsection{WIPP UNDERGROUND DEVELOPMENT}

The WIPP is a DOE facility built for the permanent disposal of TRU waste from defense-related activities. The WIPP is located in the northern part of the Delaware Basin in southeast New Mexico. Figure 2-1 is a threedimensional representation of the facility currently under construction. The disposal areas are situated about $655 \mathrm{~m}$ below ground surface within the Salado geologic formation-a bedded evaporite sequence consisting primarily of halite.

\subsection{Large-Scale Stratigraphy}

The WIPP repository is situated in the middle of the 250-million-yearold Salado Formation, a salt bed that extends from 250 to 850 meters below the land surface. The Salado is bounded by the Rustler Formation above and the Castile formation below. The Salado is intact in the WIPP area, and brine flow within it is exceptionally slow because primary porosity is low and open fractures are absent in the pliant salt. Low effective porosity allows for very little brine movement.

The Salado consists of three informal members: an upper member of halite interbedded with polyhalite, anhydrite, and sandstone; a middle member, the McNutt Potash Zone, composed of halite, sylvite, and langbeinite; and a lower member of halite with lesser amounts of anhydrite, polyhalite, and glauberite. The repository is located in this last and lowest member, $655 \mathrm{~m}$ below the land surface and about one meter above an anhydritic bed known as Marker Bed 139.

The lithologic layers that make up the Salado are nearly horizontal at the WIPP, having a regional dip of less than one degree.

\subsection{Underground Facility Construction}

Construction of the underground facility began in July 1981 when the first of four existing shafts was mined. Excavation with continuous miners then proceeded off and on for two years until the underground facility approached the size and shape shown in Figure 2-1. Of the eight storage panels shown, only Panel 1 has been mined to date; the other seven panels of the repository area are planned.

The underground rooms and drifts of the WIPP facility were excavated with continuous-mining machinery. Blasting techniques were not used. Creep 


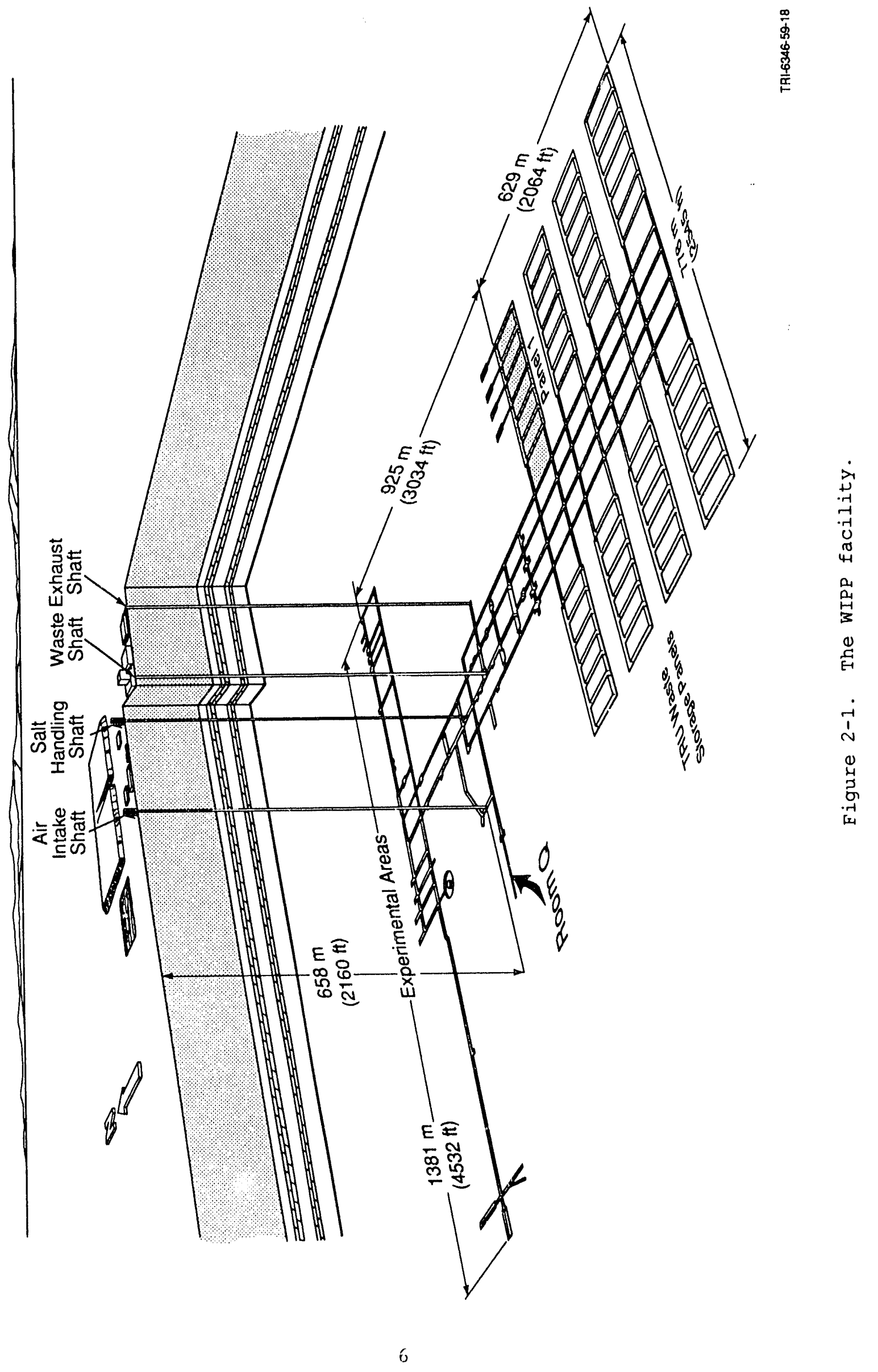


closure of the rooms began immediately after excavation, with early closure rates of several centimeters per year. Closure effects are discussed in Munson et al. (1989). Current plans call for each disposal room to be filled with up to 6,800 55-gallon steel drums of contact-handled (CH) TRU waste.

\subsection{Room Q Development}

The focus of this report, Room $Q$, is one of several rooms developed for Sandia National Laboratories (SNL) tests. All such test rooms are identified with an alphabetic character. Figure 2-2 highlights these test rooms, situated mostly in the northern extent of the underground facilicy. Room $Q$ is a recent (1989) excavation located approximately $92 \mathrm{~m}$ west-southwest of the Air Intake Shaft. Access to the room required construction of a drift extending westward from the existing ventilation airway.

\subsubsection{Room Location Relative to Stratigraphy}

Room $Q$ was located in the upper host rock strata of the planned waste disposal stratigraphic interval--the same stratigraphy found in the repository rooms to the southeast-so that tests could be conducted in an isolated, undisturbed area where baseline (pre-mining) values for pressure and fluid flow could be established in a far-field location. The crown of Room $\mathrm{Q}$ was designed to peak at $2.1 \mathrm{~m}$ above the orange marker band (OMB), a thin layer of polyhalite and halite. The $O M B$ is a distinctive reference stratum routinely used to establish grade for mining operations at the WIPP. Current design specifies that the roof of each waste disposal room should be approximately $2.1 \mathrm{~m}$ above the $O M B$ and the floor of each disposal room should be $1.8 \mathrm{~m}$ below the $O M B$. The $O M B$ was also used to guide excavation of the access drift and instrument area. Underground surveys indicate that the OMB drops about $1.5 \mathrm{~m}$ between Room $\mathrm{Q}$ and Panel 1 , resulting in a slight negative grade to the southeast of less than $1 / 2 z$.

\subsubsection{Access Drift and Instrument Alcove Mining}

In November 1988 the $Q$ access drift was completed to final length. The S90 drift was extended $91.4 \mathrm{~m}$ beyond the Air Intake Shaft. One month later the Room Q Instrument Alcove was mined. Figure 2-3 presents the development schedule for all Room $Q$ activities beginning with the mining of the Room $Q$ access drift in November 1988 and ending with the excavation of Room $Q$ in August 1989 


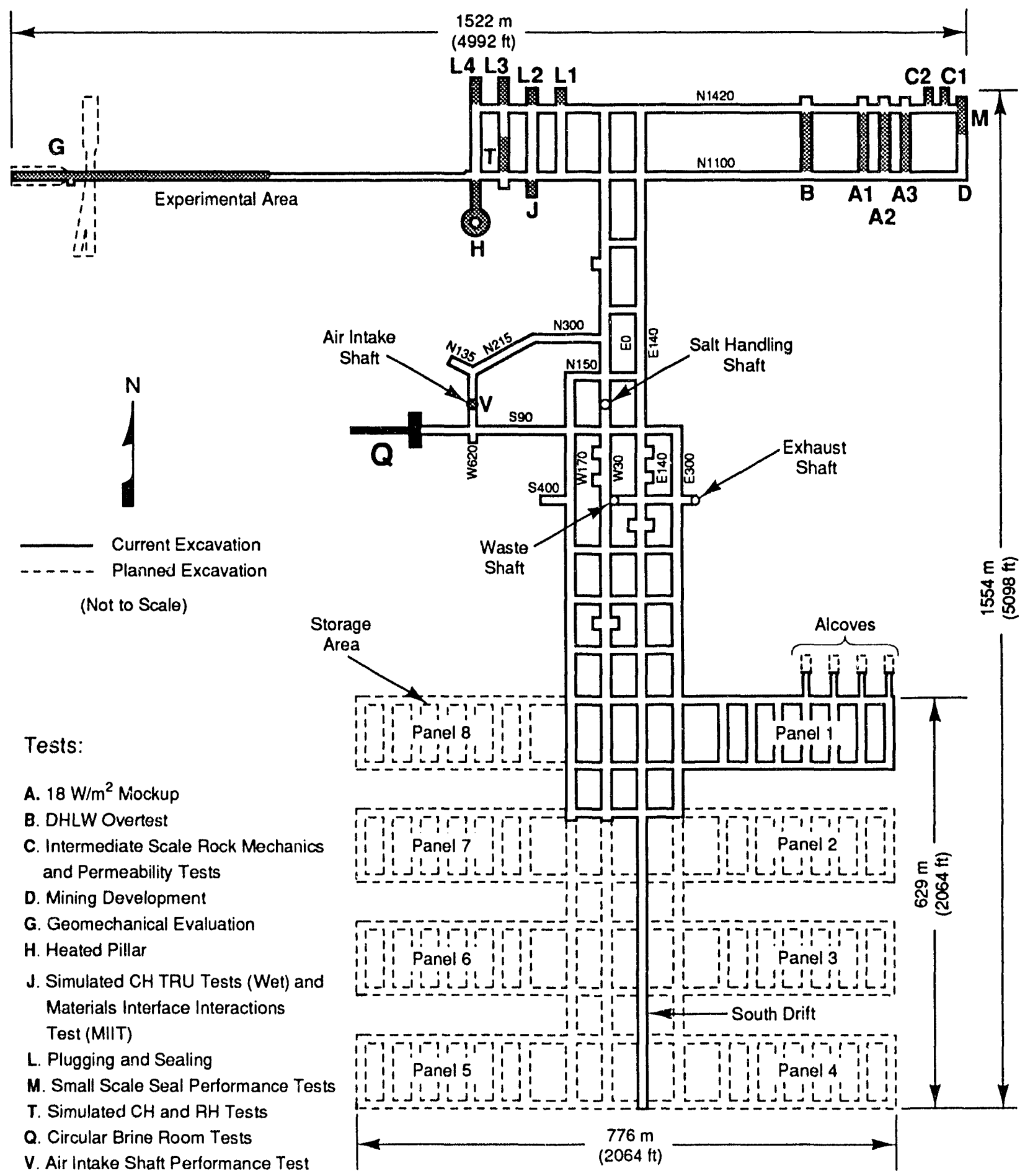

TRI-6330-129.6

Figure 2-2. Location of Room $Q$. 


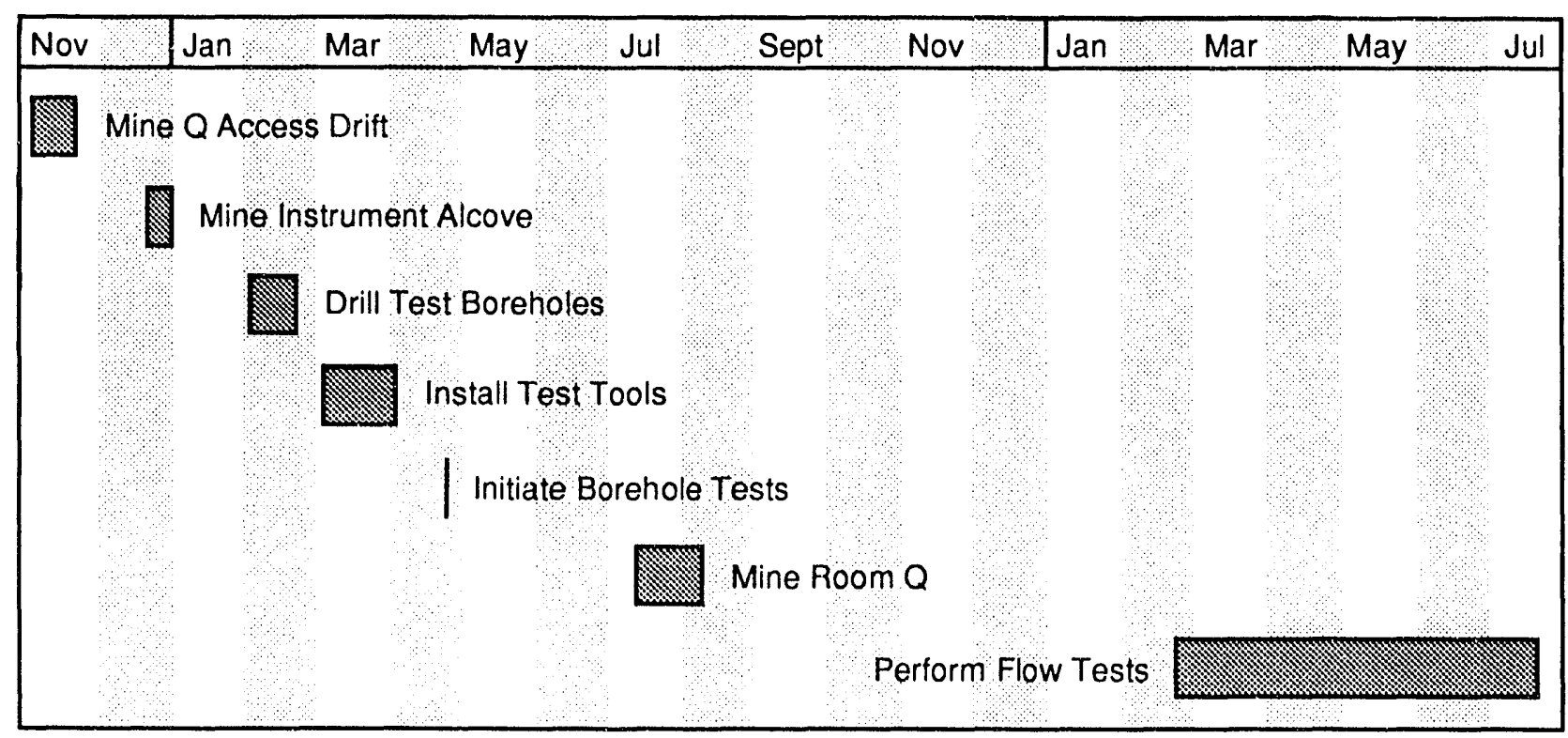

TRI-6119.5.1

Figure 2-3. Development schedule for Room $Q$ activities.

In December 1988, the west end of the $Q$ access drift was enlarged to form a $24.4 \times 9.1-\mathrm{m}$ Room $Q$ Instrument Alcove-a large area for housing instrument panels and data-acquisition equipment. The Instrument Alcove became the staging area for the borehole pressure tests.

Excavation of the Instrument Alcove involved mining a rectangular opening $4.9-\mathrm{m}$ high by $9.1 \mathrm{-m}$ wide by $24.4 \mathrm{-m}$ long. Since the Room $\mathrm{Q}$ access drift was only $3.7 \mathrm{~m}$ high and did not provide enough clearance for tunnel boring and drilling operations, the roof height was increased to $4.9 \mathrm{~m}$ by angle cutting an additional $1.2 \mathrm{~m}$ over a horizontal distance of $7.6 \mathrm{~m}$ to form an inverted ramp at the entry to the Instrument Alcove. The Alcove then provided both an undisturbed wall to drill the test boreholes and ample space for instrument panels, a data-acquisition shed, tool maintenance, and equipment storage. The Instrument Alcove was also an ideal area for assembling and operating the tunnel-boring machine used to mine Room Q. Plan and elevation views of the access drift and the Instrument Alcove are presented in Figure 2-4. 


\section{Plan}

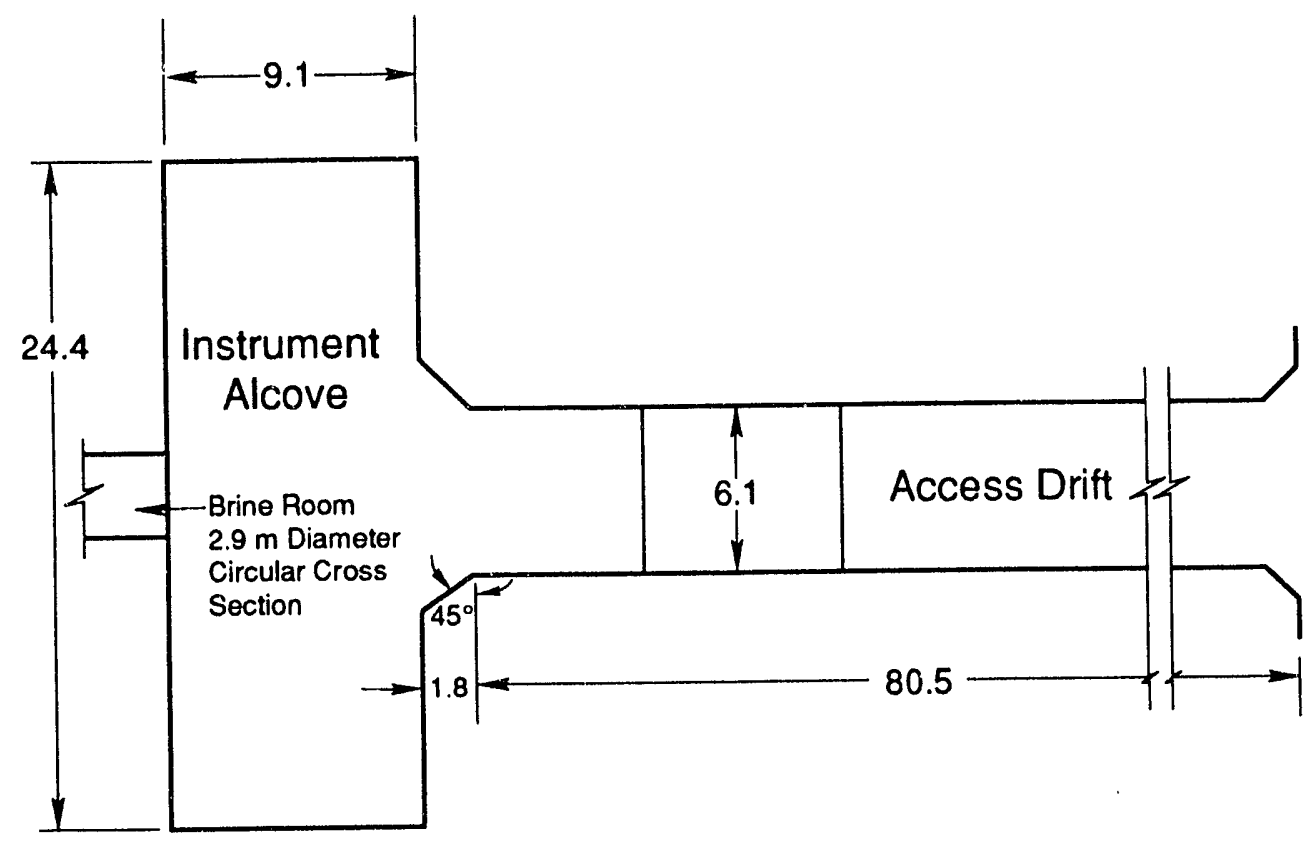

Elevation

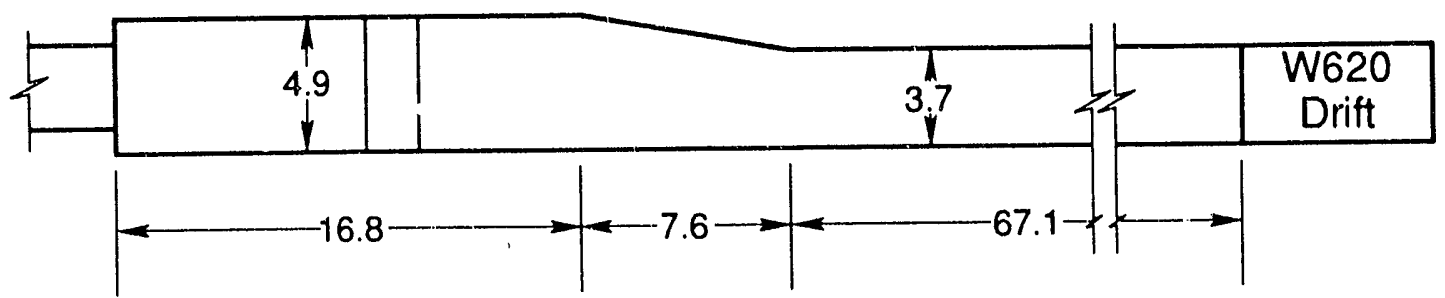

Note: All Dimensions in Meters

TR1.6119.4.0

Figure 2-4. Plan and elevation of the Instrument Alcove. 


\subsection{TEST BOREHOLES}

The tests that are the focus of this data report were conducted in 15 boreholes drilled into the west face of the Room $Q$ Instrument Alcove after the Alcove was mined. Because these boreholes were vital to the generation of an integrated data set, accurate drilling for test-region placement was crucial. The test boreholes were drilled and completed between February 15 and March 23, 1989. All but three holes were lined and grouted to isolate a test region deep within the formation. The three holes farthest from the intended location of Room Q were left unlined to accommodate the three $8.9-\mathrm{cm}$ tools left from previous testing.

\subsection{Borehole Locations}

Figure 3-1 shows the final location of the test boreholes relative to the Instrument Alcove. The Alcove and the boreholes are represented in both two- and three-dimensional perspectives. The plane circumscribed by the phantom lines in the three-dimensional drawing corresponds to the border around the figure and represents a slice of the stratigraphy $23 \mathrm{~m}$ west of the Instrument Alcove. Note that test holes QPP01 through QPP05 slope up at oblique angles relative to the Instrument Alcove and terminate in a vertical plane above Room Q. Holes QPP11 through QPP15 slope down at oblique angles from the Alcove and terminate in a vertical plane below Room Q. Holes QPP21 through QPP25 fan out from the Alcove and terminate in a horizontal plane north of the center of Room $Q$.

As shown in Figure 3-1, all test zones lie in a plane that extends radially outward from the proposed cylindrical brine room. One group of test zones extends vertically upward, another vertically downward, and another horizontally northward. The collars of the boreholes are located at the Instrument Alcove west face. All of the test boreholes extend approximately $23 \mathrm{~m}$ west from the collars, forming test regions of approximately $2 \mathrm{~m}$ in length. The test regions include both the test zones and guard zones. The test zones are the deepest zones in the test regions.

\subsection{Drilling}

As shown in Figure 3-1, the Room Q tests required a complex array of holes drilled into the west wall of the Instrument Alcove. The boreholes were drilled with a Diamec 230 dual-column mounted rotary drill. All test boreholes began with a $10.2-\mathrm{cm}-\mathrm{diameter}$ opening until they reached the approximate length designated for the test region. Holes QPP01, QPP11, and 


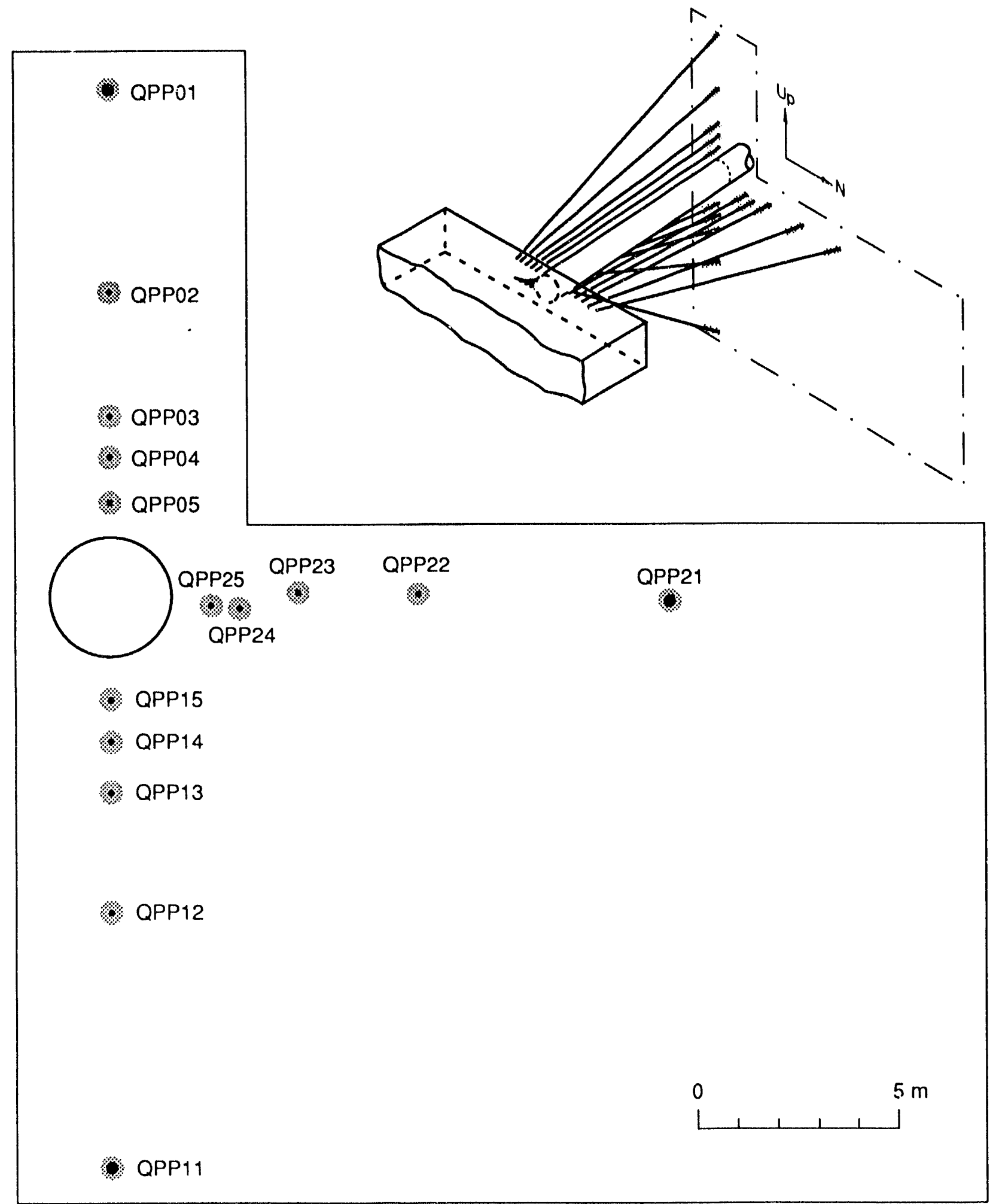

TH1.6119233-O

Figure 3-1. Final location of test boreholes. 
QPP21 (holes farthest from Room Q) were intended to contain 8.9-cm-diameter tools, so they were drilled at $10.2 \mathrm{~cm}$ to the end of the test region and were not cased and grouted. The remaining holes were designated to hold $3.5-\mathrm{cm}$ tools, so drilling with the $10.2 \mathrm{~cm}$ bit was stopped short of the test region. The $3.8 \mathrm{-cm} \mathrm{slim}$ hole test regions were drilled later. First a $6.0-\mathrm{cm}$ outside diameter steel casing was inserted in the hole and grouted. Then a tapered centering plug on the end of the casing was used to guide the drill for later drilling of the slim hole test regions.

The drilling plan called for 15 holes with endpoints placed at precise locations deep within the salt. Three groups of five holes were planned to terminate in a plane intersecting the $+30.5-\mathrm{m}$ station point of Room Q: 5 above, 5 below, and 5 horizontal. These skewed boreholes presented a challenge to surveyors and drillers, since they had to be drilled at different oblique angles and to different depths in order to terminate in the same plane. The challenge was overcome by first marking and drilling a set of practice holes in the N1420 drift between Rooms 2 and 3 in the north end of the Experimental Area. These practice holes were successfully completed, and they provided the setup procedures used to drill the test holes in the Instrument Alcove. First, computations were made to determine angles, total depths, collar locations, and corresponding backsights for each hole. Then surveyors located and marked foresights, backsights, and hole labels on the Instrument Alcove ribs. (The holes for these tests were labeled "QPP": "Q" indicates the test room and "PP" identifies the pore pressure tests.) The final step involved setting up and properly aligning the drill, which was accomplished by chaining a section of drill rod to the marked collar location (foresight), then aligning the drill with a stringline stretched tightly through the hollow rod towards the backsight mark. The drill-rig frame was carefully adjusted using come-alongs and clamps until the stringline and drill rod axis were concentric.

A11 QPP holes were started with a $10.2-\mathrm{cm}$-diameter diamond plug bit, except QPP05. This last hole was cored with a 10.2-cm-diameter diamond core bit so that a core sample could be obtained. Unfortunately, none of the retrieved core was acceptable for logging purposes: the sample fractured into small grains that were impossible to recover as a core.

For the initial stage of drilling, the 10.2-cm-diameter bits were used instead of the smaller diameter bits because large holes provide more control when drilling a straight 1ine. Holes QPP01, QPP11, and QPP21 were a11 drilled to total depth with the $10.2-\mathrm{cm}-\mathrm{diameter}$ bit. The remaining twelve test holes were stopped about $2 \mathrm{~m}$ short of total planned distance and then fitted with steel casing, a PVC cap, and grout. The as-built length, diameter, collar coordinates, angle, and drill dates for the initial drilling 
of each borehole are presented in Table 3-1. Table 3-1 was created from actual survey results. Underground surveys at the WIPP utilize a local rectangular coordinate system established by WIPP engineers, as described in Gonzales (1989). Under this system, coordinates are based on a marker located at the corner common to sections 20, 21, 28, and 29 in Township 22S, Range 31E. The WIPP engineers modified the state-plane coordinates of this marker by subtracting $66,000 \mathrm{ft}$ from the east coordinate and 49,000 ft from the north coordinate. The resulting numbers have fewer digits and are thus easier to use. They also are more appropriate to the scale of the WIPP underground. Table 3-1 was developed from survey results reported in U.S. units of feet and inches. For this report, the units were metricized for consistency.

Note that the total depths of QPP01, QPP11, and QPP21 (the 10.2-cm holes located farthest from Room Q) are greater than the depths of the other 12 holes because they were drilled to total depth during the initial drilling stage.

Table 3-1. As-built Data for Test Boreholes (Initial Drilling Stage)

\begin{tabular}{|c|c|c|c|c|c|c|c|c|}
\hline $\begin{array}{l}\text { Hole } \\
\text { Number }\end{array}$ & $\begin{array}{c}\text { Collar } \\
\text { Coord. } \\
\text { North } \\
(\mathrm{m})\end{array}$ & $\begin{array}{c}\text { Collax } \\
\text { Coord. } \\
\text { East } \\
(\mathrm{m})\end{array}$ & $\begin{array}{c}\text { Collar } \\
\text { Coord. } \\
\text { Elev. } \\
\text { (m) }\end{array}$ & Drill Date (s) & $\begin{array}{l}\text { Depth } \\
\text { of Hole } \\
\text { (m) }\end{array}$ & $\begin{array}{l}\text { Diam. } \\
\text { of Bole } \\
(\mathrm{cm})\end{array}$ & $\begin{array}{l}\text { Vort. } \\
\text { Drill } \\
\text { Angle } \\
\text { (deg.) } \\
\end{array}$ & $\begin{array}{l}\text { Horiz. } \\
\text { Drill } \\
\text { Angle } \\
\text { (deg.) } \\
\end{array}$ \\
\hline QPP01 & 2918.23 & 1816.52 & 388.61 & $3-7-89$ to $3-8-89$ & 26.37 & 10.16 & 27.426 & 12.832 \\
\hline QPP02 & 2918.82 & 1816.53 & 388.59 & $3-6-89$ & 22.65 & 10.16 & 14.599 & 10.755 \\
\hline QPP03 & 2919.42 & 1816.58 & 388.56 & $3-4-89$ to $3-5-89$ & 40 & 10.16 & 6.920 & 9.174 \\
\hline QPPO4 & 2920.05 & 1816.60 & 388.57 & $3-3-89$ to $3-4$ & 23.13 & 10.16 & 4.111 & 7.976 \\
\hline QPP05 & 2920.65 & 1816.63 & 388.61 & $2-27-89$ to $3-3-89$ & 21.03 & 10.16 & 1.925 & 5.922 \\
\hline QPP11 & 2918.19 & 1816.60 & 386.17 & $2-21-89$ to $2-22-89$ & 26.64 & 10.16 & -29.017 & 12.095 \\
\hline QPP12 & 2918.81 & 1816.60 & 386.18 & $2-18-89$ to $2-20-89$ & 22.80 & 10.16 & -16.298 & 11.15 \\
\hline QPP13 & 2919.43 & 1816.61 & 386.18 & $2-17-89$ to $2-18-89$ & 21.52 & 10.16 & -9.522 & 9.31 \\
\hline QPP14 & 2920.04 & 1816.62 & 386.17 & $2-15-89$ & 21.79 & 10.16 & -6.577 & 7.73 \\
\hline QPP15 & 2.920 .64 & 1816.65 & 386.16 & $2-7-89$ to $2-9-89$ & 21.09 & 10.16 & -3.870 & 6.126 \\
\hline QPP21 & 2927.92 & 1816.65 & 387.88 & $3-13-89$ to $3-15-89$ & 24.54 & 10.16 & 2.250 & 20.59 \\
\hline QPE22 & 2927.32 & 1816.64 & 387.87 & $3-11-89$ to $3-13-89$ & 21.70 & 10.16 & 2.001 & .651 \\
\hline QPP23 & 2926.71 & 1816.69 & 387.89 & $3-11-89$ & 20.94 & 10.16 & 1.929 & 2.213 \\
\hline QPP24 & 2926.08 & 1816.67 & 387.85 & $-10-89$ & 1.49 & 10.16 & -2.839 & 0.13 \\
\hline QPP25 & 2925.50 & 1816.67 & 387.88 & $3-10-89$ & 20.91 & 10.16 & -2.726 & 0.000 \\
\hline
\end{tabular}




\subsection{Borehole Completion}

After all 15 boreholes were drilled, the 12 shorter holes were "completed" by the insertion of a steel pipe into the borehole. Figure 3-2 shows the two variations of holes created for the tests. The first variation is an open hole with no casing or grouting requirements, measuring $10.2 \mathrm{~cm}$ from end to end, and ready for tool emplacement as drilled. The second variation is a cased hole with a narrower, slim hole test region. The casing used to line the finished holes was made of schedule 60 wrought steel. Each pipe was cut to fit the specific length of each cased hole and fitted with a welded flange collar. A polyvinyl chloride cap was permanently attached to the casing end to serve as a centering device and to prevent grout and debris from filling the pipe during insertion and later grouting of the pipe in the hole.

An annulus of approximately $2.1 \mathrm{~cm}$ was formed between the wall of the borehole and the outer wall of the pipe. Grout was injected to completely fill the annulus and secure the pipe. Lining the 12 holes with casing and grout provided several advantages over unlined or open holes. First, the lining limited deformation and fracturing along the entire borehole length. Second, only brine from a defined interval in the last $2 \mathrm{~m}$ of the hole could enter the hole. Third, the casing and cap acted as a guide for the final slim hole drilling operations and tool installation.

After a curing period of at least 7 days, the drill was set up to reenter the lined holes with a smaller-diameter bit and rod. A solid-faced, $3.8-\mathrm{cm}$ diamond plug bit penetrated the PVC cap at the back of the hole to complete the final $2 \mathrm{~m}$ of drilling, finishing the slim hole test region. These regions were subsequently divided into test and guard zones after installation of the test equipment.

The final drilling results are presented in Table 3-2. Final depth coordinates in this table are based on the same coordinate system as described for Table 3-1. Note, for example, that hole QPP02 was initially drilled at $10.2 \mathrm{~cm}$ to a length of $22.6 \mathrm{~m}$ on March 6 (see Table 3-1). The hole was cased and grouted and allowed to cure until March 23, when it was drilled to total depth of $24 \mathrm{~m}$ with the $3.8-\mathrm{cm}$ plug bit. Detailed drilling logs for all test boreholes are provided in Appendix $B$. The as-built coordinates given in Tables $3-1$ and $3-2$ were derived from the field survey notes, drill logs, laser alignment data, and hole deviation data that is also listed in Appendix B.

Drilling operations were successful, with all holes terminating within one degree of the theoretical locations specified in the Test Plan. 


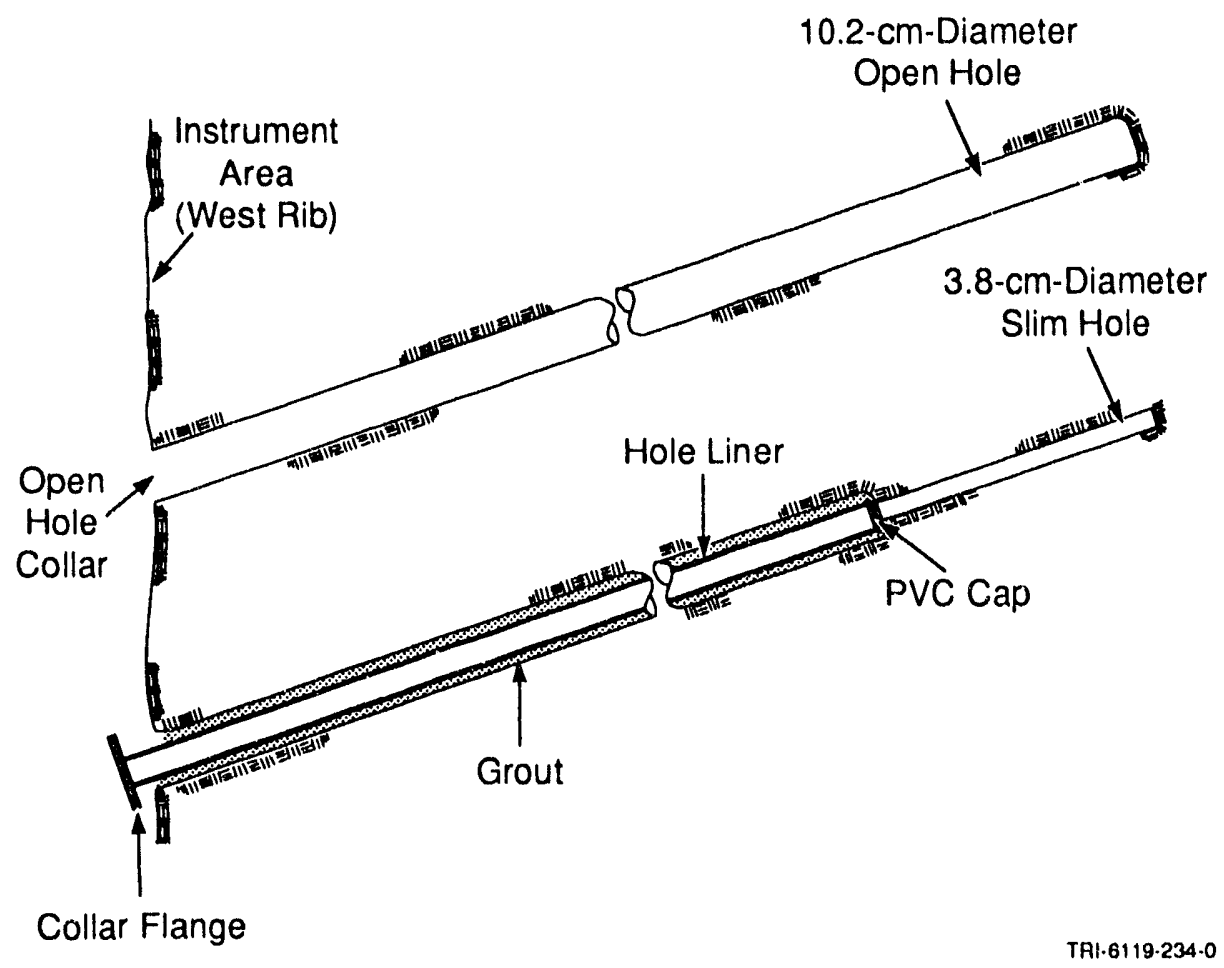

Figure 3-2. Open and cased boreholes.

Table 3-2. Final Drilling Results

\begin{tabular}{|c|c|c|c|c|c|c|}
\hline $\begin{array}{c}\text { Hole } \\
\text { Number }\end{array}$ & $\begin{array}{c}\text { Final } \\
\text { Dopth } \\
\text { Coord. } \\
\text { North } \\
\text { (m) }\end{array}$ & $\begin{array}{c}\text { Final } \\
\text { Depth } \\
\text { Coord. } \\
\text { East } \\
\text { (m) }\end{array}$ & $\begin{array}{c}\text { Final } \\
\text { Depth } \\
\text { Coord. } \\
\text { Elev. } \\
\text { (m) }\end{array}$ & Drill Date (s) & $\begin{array}{c}\text { Total } \\
\text { Depth } \\
\text { of } \\
\text { Hole } \\
\text { (m) } \\
\end{array}$ & $\begin{array}{l}\text { Diam. } \\
\text { of Hole } \\
\text { (cm) }\end{array}$ \\
\hline QPP01 & 2923.43 & 1793.71 & 400.75 & $3-7-89$ to $3-8-89$ & 26.37 & 10.16 \\
\hline QPP02 & 2923.16 & 1793.67 & 394.65 & $3-23-89$ & 24.05 & 3.81 \\
\hline QPP03 & 2923.09 & 1793.70 & 391.38 & $3-23-89$ & 23.35 & 3.81 \\
\hline QPPO4 & 2923.45 & 1792.37 & 390.38 & $3-23-89$ & 24.54 & 3.81 \\
\hline QPP05 & 2923.04 & 1793.90 & 389.30 & $3-23-89$ & 22.98 & 3.81 \\
\hline QPP 11 & 2923.08 & 1793.82 & 373.25 & $2-21-89$ to $2-22-89$ & 26.64 & 10.16 \\
\hline QPP 12 & 2923.31 & 1793.80 & 379.39 & $2-24-89$ & 24.20 & 3.81 \\
\hline QPP13 & 2923.17 & 1793.79 & 382.30 & $2-24-89$ & 23.44 & 3.81 \\
\hline QPP 14 & 2923.14 & 1793.79 & 383.52 & $2-24-89$ & 23.20 & 3.81 \\
\hline QPP15 & 2923.09 & 1793.80 & 384.61 & $2-27-89$ & 23.04 & 3.81 \\
\hline QPP21 & 2936.54 & 1793.71 & 386.91 & $3-7-89$ to $3-8-89$ & 24.54 & 10.16 \\
\hline QPP22 & 2930.49 & 1793.81 & 387.07 & $3-20-89$ & 23.10 & 3.81 \\
\hline QPP23 & 2927.59 & 1793.83 & 387.12 & $3-20-89$ & 22.89 & 3.81 \\
\hline QPP24 & 2926.13 & 1793.83 & 386.71 & $3-21-89$ & 22.86 & 3.81 \\
\hline QP 25 & 2925.50 & 1793.82 & 386.79 & $3-21-89$ & 22.86 & 3.81 \\
\hline
\end{tabular}




\subsection{Borehole Surveys}

After drilling, an optical survey was performed to locate the collar and corresponding backsight coordinates used to align the drill. By placing a laser in the hole and pointing it back out towards the backsight, the actual drill alignment was measured. Hole deviation or curvature was measured with in-hole magnetic surveys. Using these hole-direction measurements along with hole lengths from drilling logs, the as-built coordinates that define the back of the hole were derived.

The borehole surveys showed that the test regions intersect the host rock around koom $Q$ in a plane approximately $23 \mathrm{~m}$ from the wall of the Instrument Alcove. Figure 3-3 shows the location of these test regions relative to the stratigraphy around Room $Q$, assuming that stratigraphic makeup is constant throughout the repository. The figure combines a vertical projection of the local stratigraphy and a projection of the borehole test region locations. The stratigraphic projection is based on the map units listed in Appendix A. Data on near-field WIPP stratigraphy were obtained from studies conducted by Deal et al. (1989). The borehole-test-region lccations are derived from the survey data, which is presented in Appendix $A$.

Figure $3-3$ illustrates the stratigraphic layers intersected by each of the test boreholes and shows how the test regions appear in one slice of the stratigraphy $23 \mathrm{~m}$ west of the borehole collars. 


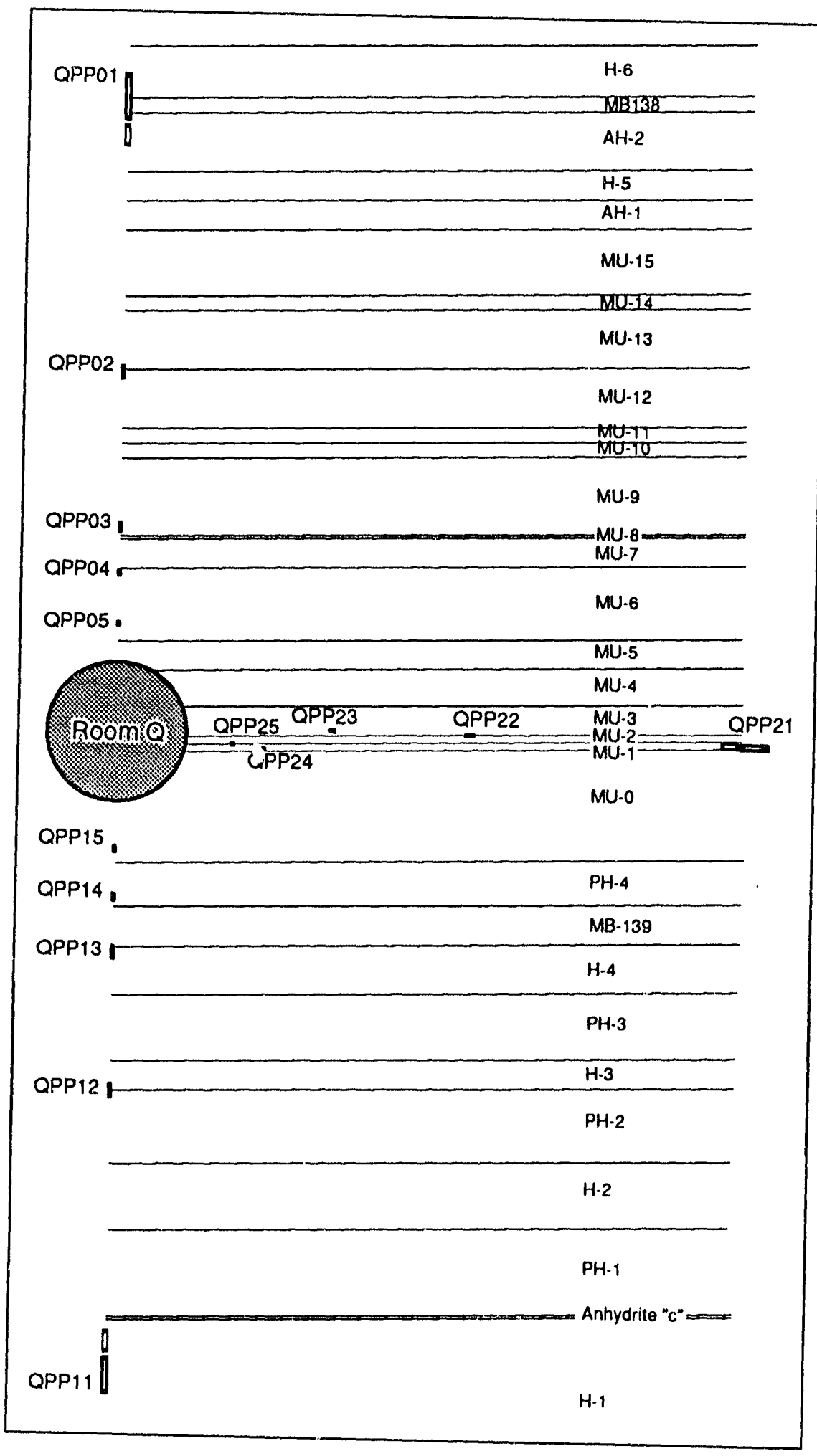

TRI.61 18-246.0

Figure 3-3. Test-egions relative to extrapolated wIPp stratigraphy. 


\subsection{TEST EQUIPMENT}

This section describes the test tools and instruments used to conduct the borehole tests in the host rock surrounding Room Q. Equipment calibration methods are also discussed. Test equipment included single-packer and dualpacker test tools, data-acquisition instruments, a constant-pressure fluid volume measurement system, and devices to measure borehole diameter.

\subsection{In-Hole Test Tools}

Three different tool configurations were used in the tests. The largediameter holes accepted the $8.9-\mathrm{cm}$ dual-packer tools. The small-diameter holes held the $3.5-\mathrm{cm}$ single-packer and dual-packer test tools. All the packers were designed and built specifically for the borehole-testing program by TAM International of Houston, TX. All the tools isolated a test zone at the bottom of the borehole. The test zone extended from the bottom of the hole to the seal contact of the deepest packer. The dual packers provided an isolated guard zone in addition to the test zone. The guard zone was the area between the seals of the two packers. All the packers had sliding ends. In the slim tools, these ends were oriented away from the guard zones on the dual-packer tools and away from the test zone on the single-packer tools. In the large holes, the sliding ends were oriented toward the top of the hole. All tools were mounted on an open mandrel through which stainless steel tubing and wiring passed, connecting the closure gauges, packers, test zone, and guard zone with the transducers and instruments in the Instrument Alcove. Injection and vent ports to the test and guard zones enabled technicians to apply underpressures and overpressures to the isolated zones. Boreholeclosure measuring devices were mounted on the lower end of the test-tool assembly. Packer-inflation pressures were monitored by transducers attached to the packer-inflation lines. Thermocouples measured test-zone temperatures in the three $8.9-\mathrm{cm}$ dual-packer tools. Additional thermocouples were attached to the slim-hole tools at the outer end of the slim hole for monitoring temperature changes during mine-by.

\subsubsection{The Slim-Hole Single-Packer Test Tool}

Six of the 12 slim-hole tools were single-packer tools. The single sliding-end packer test tool shown in Figure 4-1 formed one test zone within the borehole. It held one 3.5-cin outside-diameter packer mounted on an open mandre1. The packer had a 50.8-cm-1ong, inflatable 6101-natural-rubber 
element with a seal length of approximately $40 \mathrm{~cm}$ in a 3.8 -cm-diameter borehole. The test-zone length in the six single-packer holes was $85 \mathrm{~cm}$.

The downhole sections of the test tool had an outside diameter of $3.5 \mathrm{~cm}$ in order to minimize the brine volume in the $3.8-\mathrm{cm}-\mathrm{diameter}$ hole. Minimizing the brine volume within the test zones reduces the response times to applied pressure pulses, allowing more rapid equilibration between borehole and formation pressures.

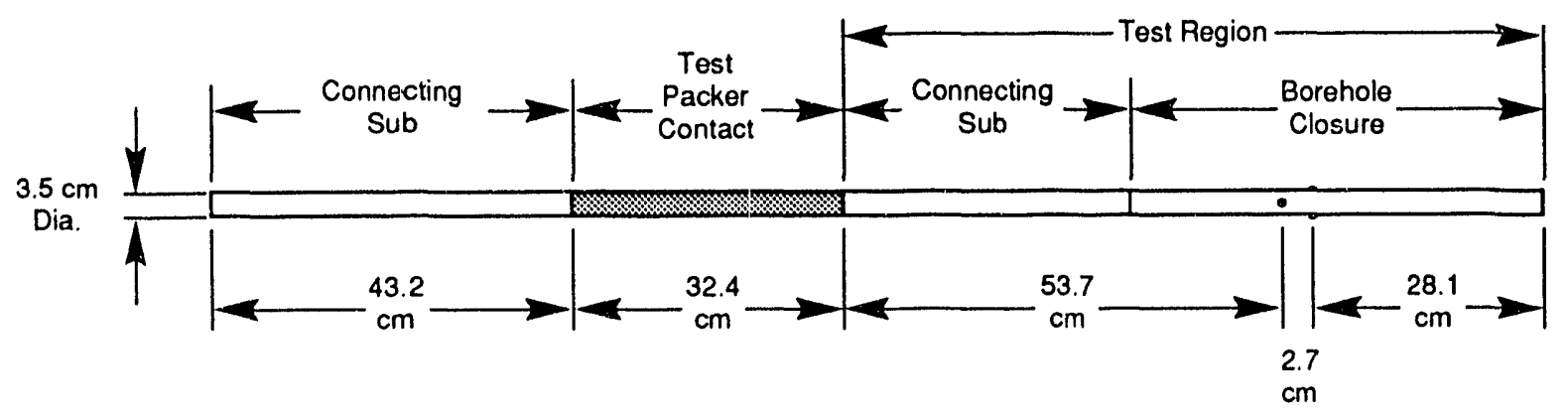

TRI.61 19-240-0

Figure 4-1. Slim-hole single-packer test tool.

\subsubsection{The Slim-Hole Dual-Packer Test Tool}

The dual-packer tools isolated both a test zone and a guard zone. Guard zones can be used to detect leakage or to secure additional measurements.

The dual-packer test tool used two $3.5-\mathrm{cm}$ outside-diameter sliding-end packers mounted on an open mandrel. Each packer had two 50.8-cm-long, inflatable 6101-natural-rubber elements that had a borehole seal length of about $40 \mathrm{~cm}$ in a $3.8-\mathrm{cm}$-diameter borehole. The downhole sections of the test tool had an outside diameter of $3.5 \mathrm{~cm}$. When inflated, the dual packers isolated a $14-\mathrm{cm}$ guard zone and a $90 \mathrm{~cm}$ test zone. In the slim-hole tools, the sliding ends were opposing and the fixed ends were adjacent to the guard zone. As the packers inflated, the sliding ends moved in response to the expansion of the rubber. The sliding ends moved toward the guard zone along the mandrel as the packer inflated. Guard-zone length was relatively fixed in these holes because most of the packer movenent was at the top and bottom of the tool. The slin-hole dual-packer tool is shown in Figure 4-2. 


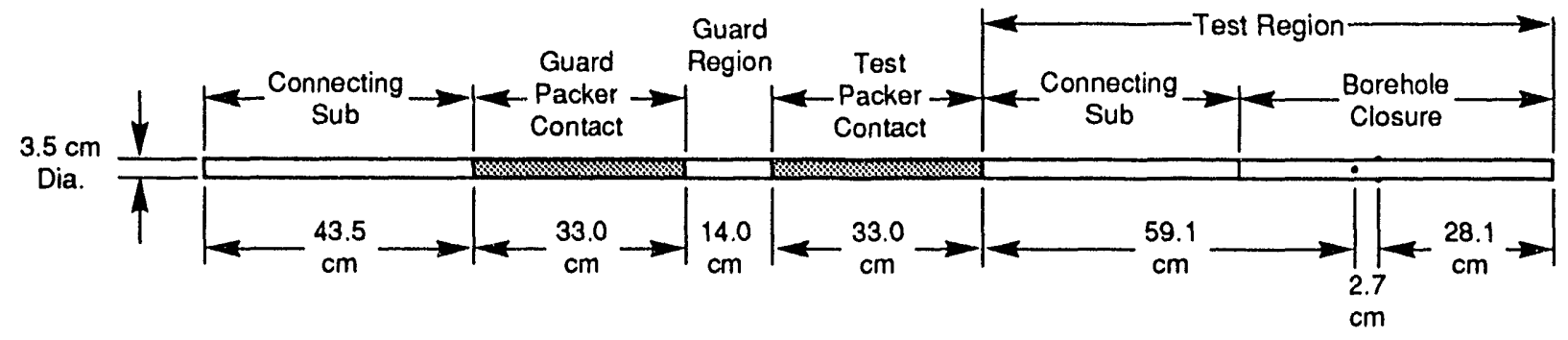

TRI.6119-241.0

Figure 4-2. Slim-hole dual-packer test tool.

\subsubsection{The Large-Hole Dual-Packer Test Tool}

The dual-packer $8.9-\mathrm{cm}$-diameter tools were installed in the three uncased boreholes farthest from Room Q. The large-hole dual-packer tool held two sliding-end, $8.9-\mathrm{cm}$ outside-diameter inflatable packers mounted on a $4.8-\mathrm{cm}$ outside-diameter mandrel and oriented with the fixed ends toward the bottom of the hole. The packers had two $92 \mathrm{-cm}-1$ ong inflatable rubber elements that had an $81-\mathrm{cm}$ seal length when inflated in the $10.2-\mathrm{cm}-\mathrm{diameter}$ hole. The dual-packer tools formed a guard zone $76 \mathrm{~cm}$ long. Test zones lengths in the three open holes ranged from 135 to $188 \mathrm{~cm}$.

Each dual-packer tool was equipped with ports to connect the test zone, guard zone, and packers to the control panel. One electrical bundle contained the wire bypass that transmitted electrical signals from the closure gauges and the thermocouples. Figure 4-3 shows the $8.9-\mathrm{cm}$ dualpacker tool and the nominal dimensions of the tool parts.

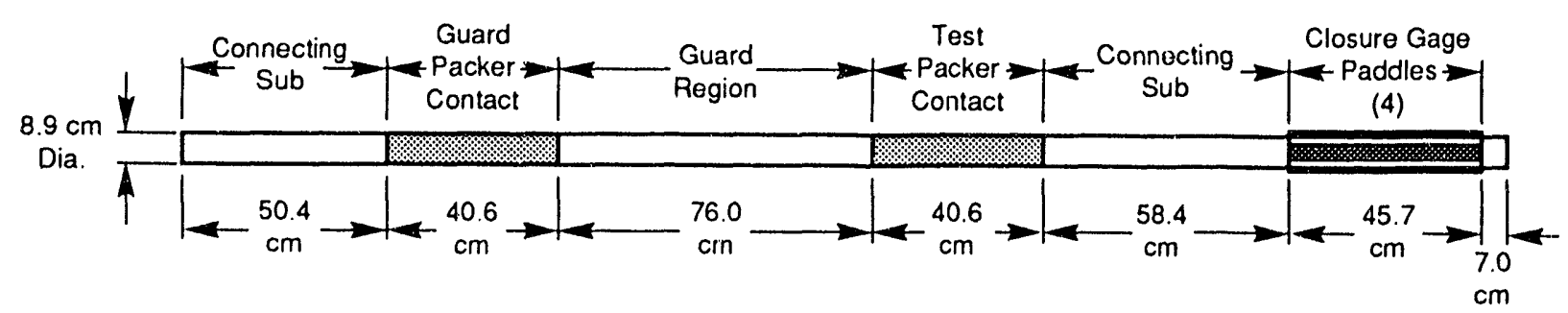

TRI-6119.242-0

Figure 4-3. Large-hole dual-packer test tool. 


\subsubsection{Closure-Measurement Devices}

Closure-measurement devices were made up and then installed in the downhole section of the tools. The devices were attached to the packer assembly with steel pins. Two types of closure-measurement devices were used: a hydraulically actuated, opposing plunger closure gauge in the slim holes; and a mechanically actuated, opposing plate gauge in the large holes.

The $3.5-\mathrm{cm}$ tool closure gauge consisted of two sets of opposing plungers. The plungers made point contact with the borehole. Each set of plungers transmitted its diametrical change via a hydraulic reservoir to a linear variable-differential transformer (LVDT) mounted on-axis in the tool. An onaxis piston moved the LVDT core. The magnitude of the voltage output from the LVDT varied directly with the diameter of the borehole. The application of calibration coefficients converted this signal into engineering units. However, the hydraulic reservoirs in these closure gauges appear to have developed air bubbles during the testing phase. The existence of gas bubbles in the hydraulic reservoir is documented in the field test notes for June 1990. Several attempts were made to quantify the approximate size of these gas bubbles. The closure data for the slim holes should be viewed with skepticism since it is unclear whether the measurements reflect actual borehole closure or instead result from the compressibility of the small gas bubbles. The opposing plunger closure gauge is shown in Figure 4-4.

The $8.9-\mathrm{cm}$ tool closure gauges consisted of two sets of opposing paddles that contacted the borehole along a $45.7-\mathrm{cm}$ length. An LVDT was mounted between each set of opposing paddles; it measured the total diametrical change of the paddles as the hole closed in the vertical and horizontal axes. These mechanical closure gauges gave true borehole diameters. Borehole deformation changes were then calculated during data reduction.

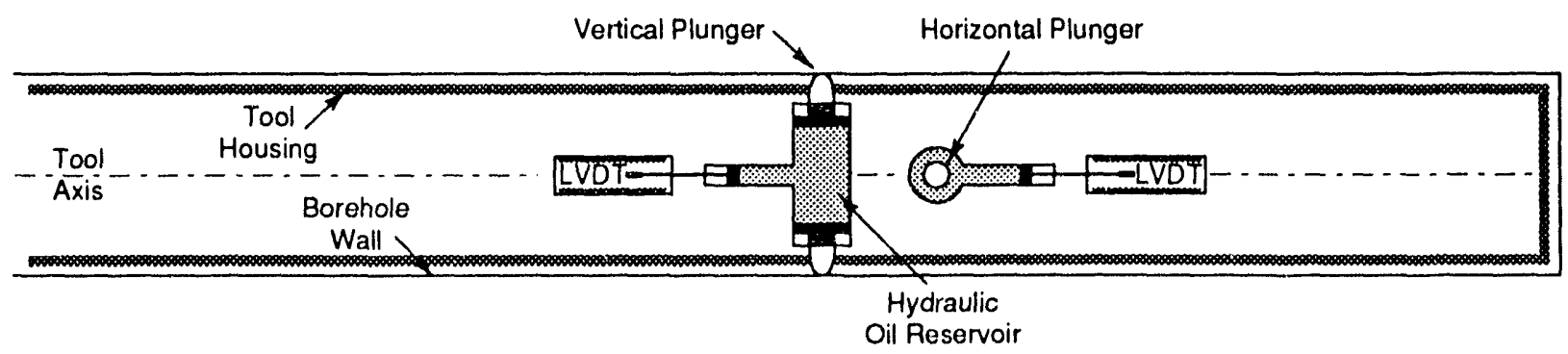

TRI.6119-274.0

Figure 4-4. Schematic of the vertical and horizontal slim-hole closure gauges. 


\subsection{Instruments}

The instruments used in the borehole tests included flowmeters, pressure transducers, differential pressure transducers, thermocouples, and LVDTs. Most of the instruments used were housed in cabinets in the Instrument Alcove.

\subsubsection{Flow Meters}

Flow testing with the $8.9-\mathrm{cm}$ tools was monitored through a control and flow manifold consisting of individual flow-control panels for each of the three tools. In addition, the flow-control manifold contained a number of brine supply/inflow reservoirs to supply brine to the test and guard zones. Two systems measured inflow and outflow of brine from the test zone. Two additional systems measured inflow and outflow from the guard zones.

\subsubsection{Transducers}

Test- and guard-zone fluid pressures were measured to within $1 \mathrm{kPa}$, and fluid volumes were measured to within $0.01 \mathrm{cc}$ using transducers calibrated to a National Institute of Standards and Technology (NIST) reference. The fluid and inflation pressures in the test zones, guard zones, and packers were monitored with externally mounted Foxboro/ICT model 1225 and Data Instruments model SA transducers. Sensotek AD111 AP differential pressure transducers monitored zone inflow and brine volumes in the slim-hole tools.

Each transducer was calibrated only once, before test installation, according to procedures described in section 4.4. The transducers were mounted outside the boreholes on the control panels located in the Instrument Alcove. They were connected to the test and guard zones and packers via $0.32-\mathrm{cm}$ outside-diameter stainless steel tubing, which was fed through the mandrel to the monitored zones.

\subsubsection{Linear Variable-Differential Transformers}

An LVDT converts mechanically sensed borehole diameters into an output voltage by responding to the position of a magnetic core relative to a surrounding coil. This type of instrument is capable of accurately detecting very small changes in borehole diameters. Each closure gauge (two in each 
test zone) was fitted with an LVDT, resulting in a total of 30 for these tests. The LVDTs were located inside the tool body. The LVDTs used in the borehole tests were manufactured by Trans-Tek Inc.

\subsubsection{Thermocouples}

Because the thermal expansion of water in an isolated test zone can have a significant effect on the measured fluid-pressure response during testing, the three $8.9 \mathrm{-cm}$ dual-packer test tools were equipped with a thermocouple in the test zone. The remaining slim-hole tools were equipped with two thermocouples mounted outside the test region. These latter thermocouples allowed the instrument operators to monitor the thermal effects from excavation; however, because of their location, they could not be used for interpretation of test-zone data. All thermocouples were equipped with weather-sealed connectors and junction boxes for protection from the saline environment of the WIPP underground facility.

\subsection{Fluid Flow Systems}

The fluid-flow systems used in the borehole tests were actuated by compressed gas. Figure $4-5$ is a schematic representation of the fluid-flow system for the large tools. Figure 4-6 represents the fluid-flow system for the small tools and the packer-inflation and test-region fluid-management systems for each of the slim-hole tools.

\subsubsection{Test-Zone Fluid-Flow System}

The fluid-injection system was the same for all the tools, but the method used to inject fluid into the test and guard zones varied depending on the angle of the borehole in the salt. The tools that were angled upward required that a vent be placed near the end of the hole and that the fluid be injected at the outer, guard-zone packer. The entire test region was filled with brine. A vacuum was usually drawn on the test region during filling to eliminate any trapped air pockets that could change the compressibility of the test region.

The holes that were angled downward or horizontally were easier to fi.11. The test region could be filled before the tool was positioned in the borehole and che packers had been inflated. In all cases, the outermost packer was inflated first to isolate the test region. Efforts to eliminate trapped gases were followed in all holes. 


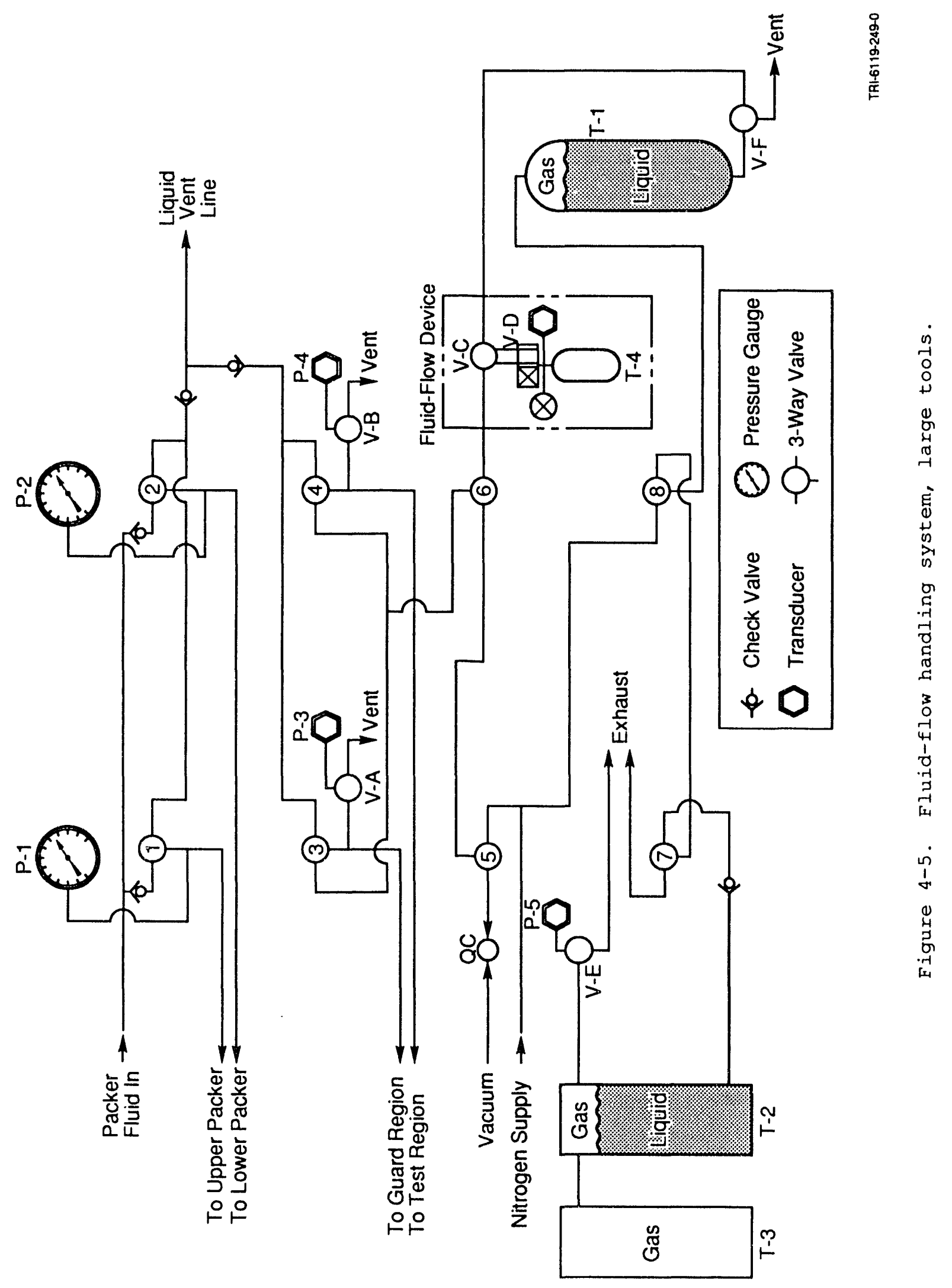



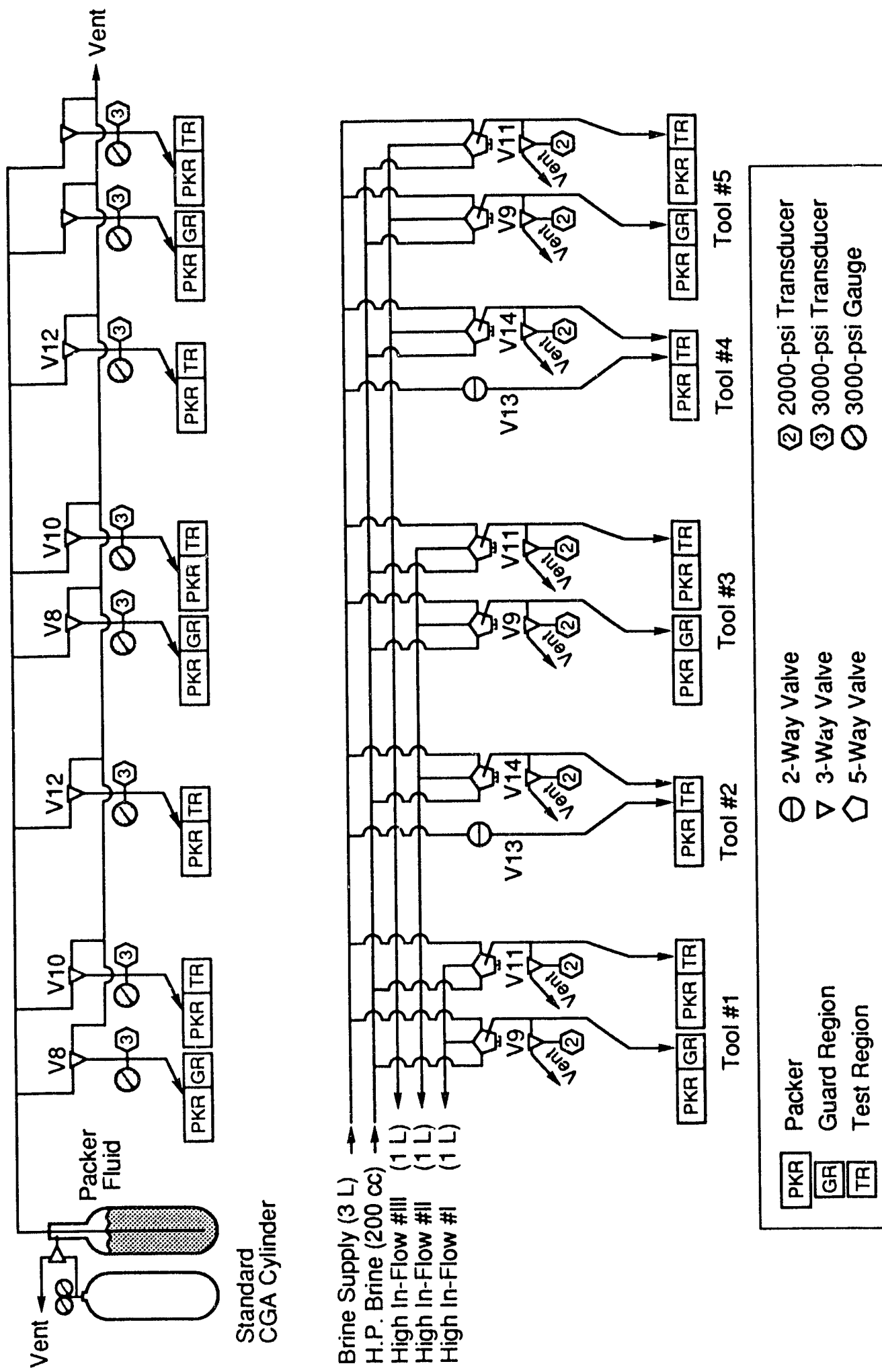

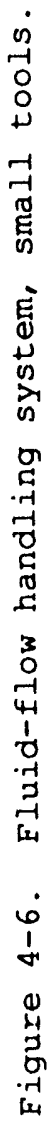


The fluid-injection system consisted of a brine reservoir and a lowpressure gas supply regulated at $68 \mathrm{kPa}$. Using the low-pressure gas supply and selecting the proper valve for each tool, the test region was filled with brine until all the air in the hole was displaced. After the test regions were filled with bine, the valves were closed. The packers that isolate the test zones from the guard zones were then inflated. Figure $4-7$ is a schematic representation of the low-pressure brine-injection system.

\subsubsection{Constant Pressure Injection/Withdrawal System}

During the flow testing phase, it is important to know the pressure at which the brine is flowing into or out of the formation. To accomplish this pressure monitoring, each of the slim-hole tool control panels is equipped with an instrument that measures the amount of brine injected or withdrawn from the test region at a preselected constant pressure. Each instrument consists of three stainless-steel tubes of the same diameter. Figure 4-8 illustrates the configuration of the system and the flow paths that relate to the injection/withdrawal measurement system. The leftmost tube provides the reservoir for injecting or collecting brine from the test region. The center tube is used as a buffer for the gas head supply. The rightmost tube is filled with a measured volume of brine; this is the reference volume. Because the three tubes are the same diameter and length, any brine volume in the left tube can be directly related to the volume in the reference tube. The volume is measured with a differential pressure gauge located between the bottom of the reference tube and the bottom of the collection tube. Since both sides of the gauge are influenced by the injection/withdrawal pressure head supplied by the compressed nitrogen, the difference in the pressure head of the two tubes is the ratio of the brine-column height in the reference tube to the brine-column height of the fluid in the injection/withdrawal tube.

\subsubsection{Packer Fluid-Handling System}

The packer-inflation method is similar to the method used for injecting brine into the test region; however, the system operates under high pressure and uses fresh water as the injection fluid.

After the lines connecting the packers have been flushed free of gases and the tool is positioned in the borehole, the packers can be inflated. Packer inflation is accomplished by filling the supply reservoir tank with fresh water and then connecting a compressed nitrogen bottle and regulator to the top of the reservoir. The regulator on the gas bottle is adjusted to the 


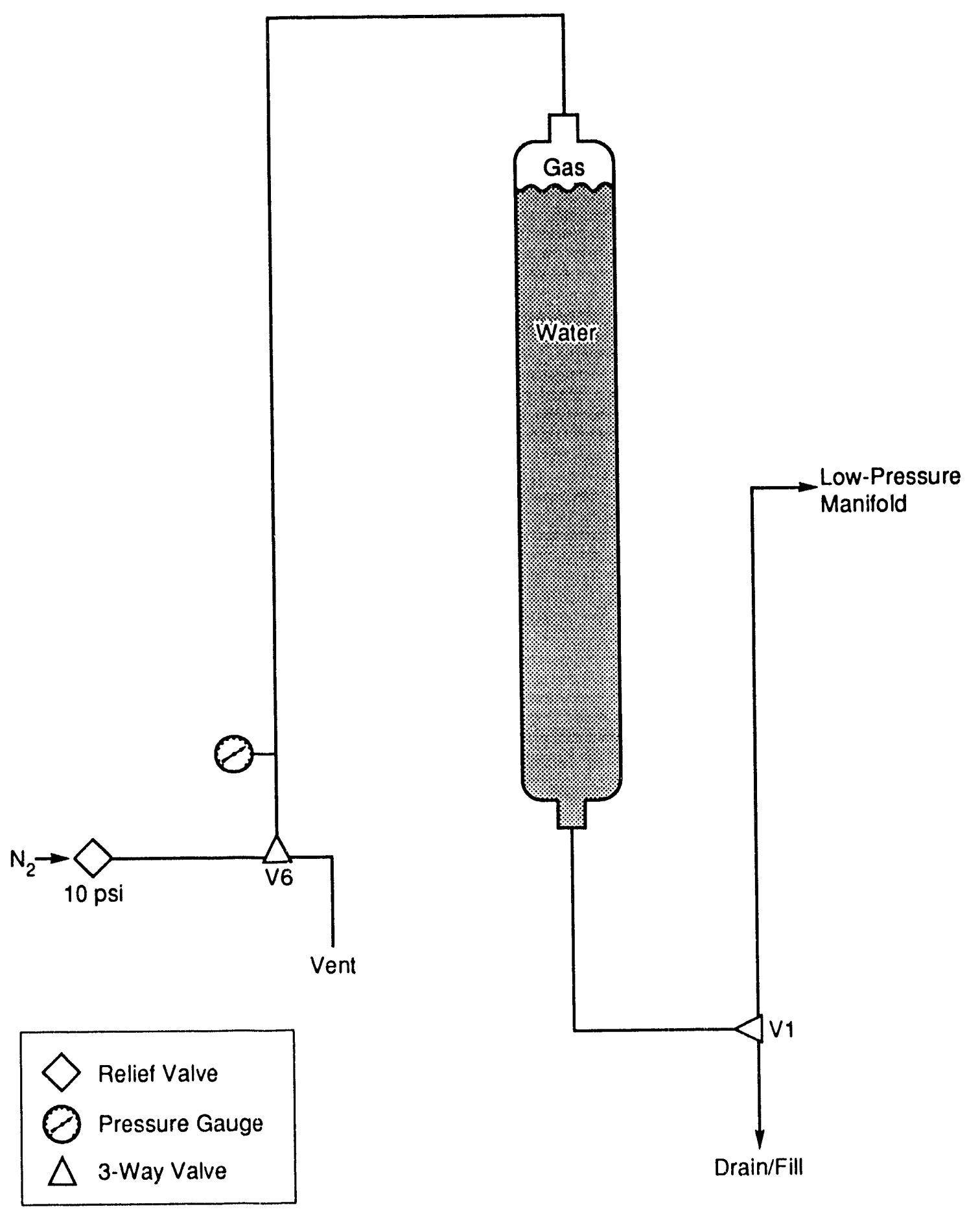

TRI.6119.248.0

Figure 4-7. Low-pressure brine-injection system. 


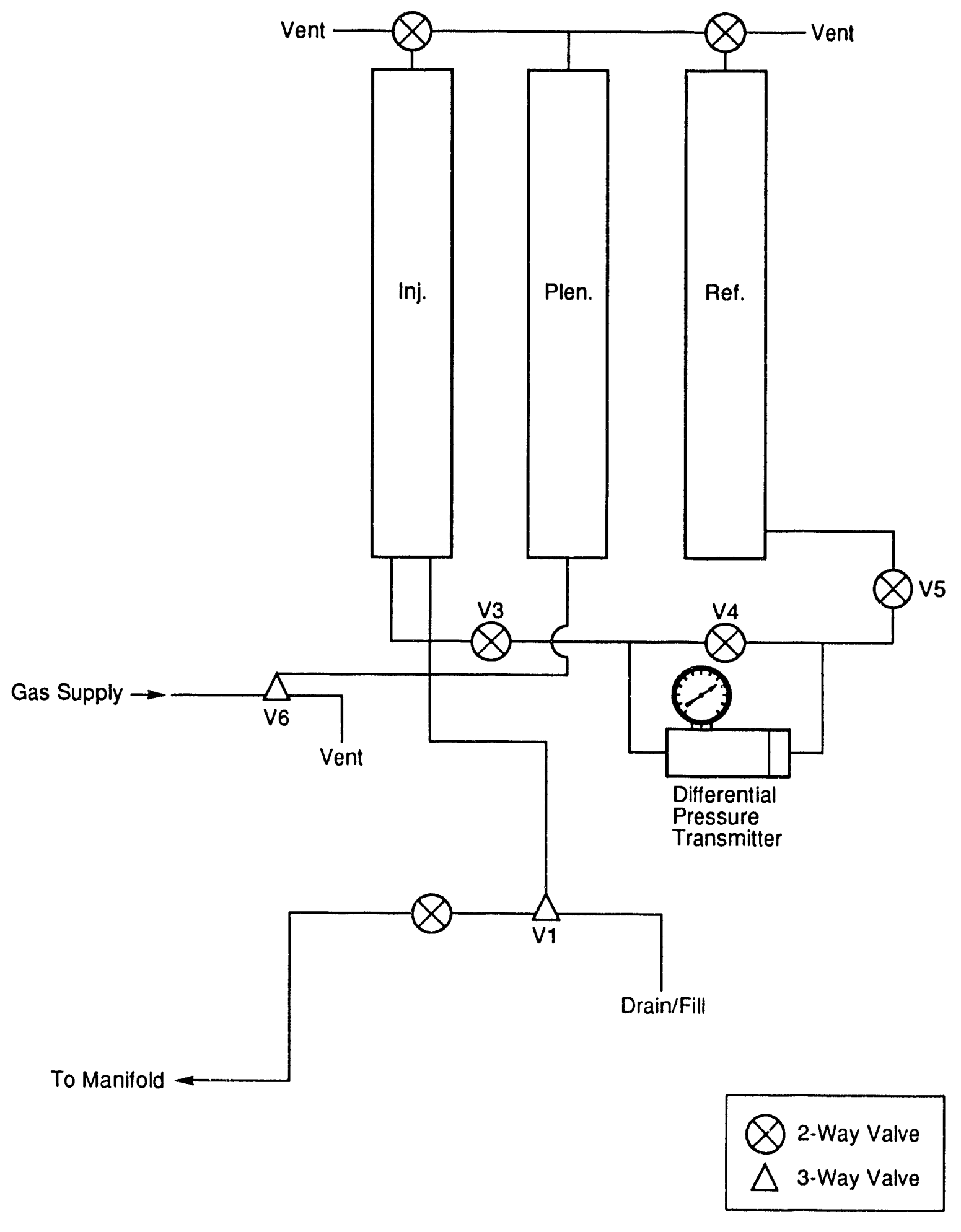

TRI.6119.251-0

Figure 4-8. Slim-hole brine-measurement system. 
pre-selected packer-inflation pressure. Then the valve to that packer is opened, allowing fluid in the pressurized reservoir to flow into the inflatable rubber element and pressurize the packer. After the packer pressure stabilizes, the packer is shut in, and the pressure is removed from the fluid supply reservoir. Adjustments to packer pressures are accomplished using the same technique.

The packer-inflation plumbing and manifold connections for both large and small holes are presented above in Figures 4-5 and 4-6.

\subsection{Data Recording System}

A computer-controlled data-acquisition system (DAS) monitored the progress of the tests and recorded output from the transducers, thermocouples, and LVDTs. The DAS contained a line conditioner, power supplies to activate the sensors, a digital voltmeter to read the sensor signals, and a microcomputer to control test progress and store and process the data. The DAS was designed to accept and condition signals from the large variety of sensors and equipment used in the borehole tests. All pressure transducers and flow-measurement systems were contained in the control panel/DAS cabinet. Packer and zone pressures were displayed by dial gauges and digital meters for operational purposes and were monitored as part of daily maintenance. The high-pressure system had a 15 MPa maximum allowable working pressure. Transducers used in pressure measurements were located on the control panel. The DAS and general configuration of the test control panels and computer station are shown in Photo 4-1.

The DAS consisted of a Leading Edge computer using Labtech Notebook software to monitor the data. All pressure, flow, and closure data were transmitted to the computer using HANZON 4000 series 20 channel (16 input and 4 output) data loggers. The data loggers were connected in series, with channels 0 through 19 as the master data logger and the remaining channels slaved to the master. Software developed and assembled by $\mathrm{S}$-Cubed automated the DAS to re-boot after power failures and to direct personnel with minimal computer experience to perform scheduled maintenance, such as copying data to floppy disks for transport to SNL quality assurance and S-Cubed. The DAS computer crashed in early November 1991 and was not recoverable. The unit was subsequently replaced by a Texas Microsystems B-386 S/16-4 megabyte computer, which was installed and operable for data recovery after late November 1991. 


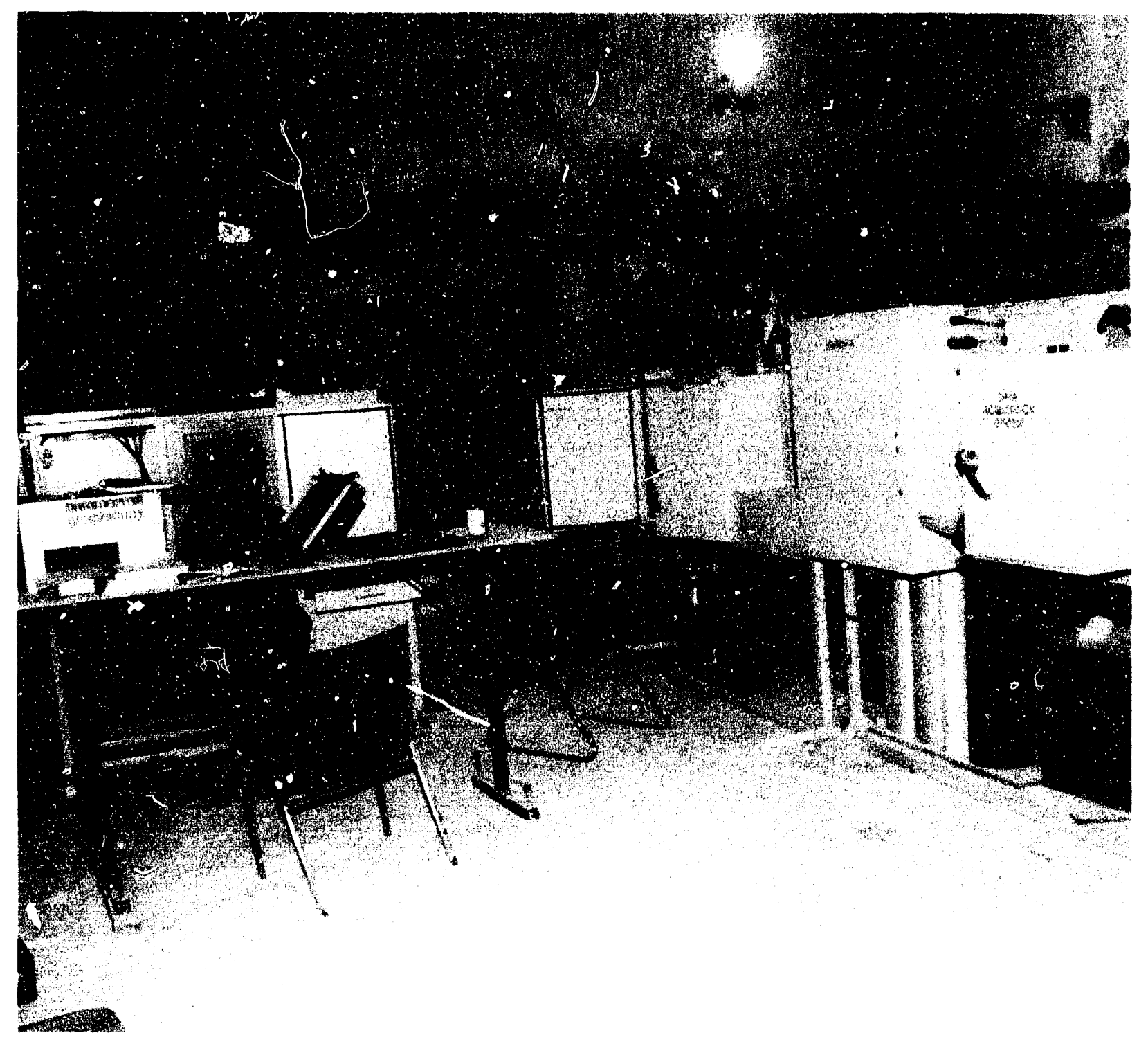

Photo $\hat{\imath}-1$. Test-c rtrol panels and computer station. 
All data were recorded on the computer hard disk. Preselected parameters measured at the test locations could be displayed on the screen in real-time to aid in test setup or interpretation. The computer provided easy access to test data and permanent records for later detailed analyses. The maximum file-length period was limited to seven days. At each scheduled interval, the file for that period was closed and a new file was started for the next seven-day period. The data on the hard disk were transferred to two diskettes and then archived on the hard disk. To prevent loss of data from power interruptions, the data files were closed after each reading. If power was lost, software written by $\mathrm{S}$-Cubed would automatically close the existing data file on a re-boot and create a new data file when power was regained.

\subsection{Equipment Calibration Procedures}

\subsubsection{Pressure Transducers}

The pressure transducers were calibrated by the manufacturer and then calibrated onsite by testing them in a pressure-calibration fixture. The fixture was connected to three cylinders of compressed gas which were set to deliver three different delivery pressures. The cylinders were connected by a common manifold to a $0-3000$ psig dial gauge which was calibrated to NIST standards. The transducers were plumbed to a common input line and the pressure calibration fixture was connected to the line. Pressures on the fixture were set to $0,500,1500$, and 2000 psig in sequence. Transducer readings were then plotted against known standard values, and a linear equation was written to convert the logged transducer voltage to the pressure valve for each transducer. Coefficients obtained from calibration were converted to parameters of scale and offset and then entered into the datalogging system for each pressure channel.

\subsubsection{Closure-Measurement Devices}

The closure-measurement devices were calibrated using ring fixtures of known diameters. The devices were inserted into the calibrated ring fixture; then the output voltages generated by each device were measured. A computer logged the closure gauge voltage sequentially for on-axis and cross-axis gauges in the large-, intermediate-, and small-diameter rings. A leastsquares fit equation was then performed to relate closure gauge voltages and ring diameters. Coefficients were converted and entered into the datalogging program as they were for the pressure transducers. 


\subsubsection{Thermocouples}

Thermocouples were calibrated before delivery to the WIPP Site. Thermocouple wire is manufactured to specifications that conform to National Bureau of Standards tables. Typically, the manufacturer will calibrate the wire as a quality assurance check on fabrication, operation, and material specifications. Wires were not recalibrated at the WIPP calibration laboratory.

Thermocouple voltages were read directly by the DAS, and voltages were then converted to temperatures based on equations generated by the National Bureau of Standards for type $E$ thermocouples. Polarity checks involved attaching a multimeter to the thermocouple leads, then heating the tips to verify that voltage readings became more positive as the temperature increased. 


\subsection{TOOL INSTALLATION AND TEST STARTUP}

Fifteen test tools were emplaced in the boreholes around Room $Q$ to form a plane of test zones located $23 \mathrm{~m}$ west of the room collar. Tools were emplaced before the beginning of the Room $Q$ excavation process. To obtain data on the responses of the host rock to the boring process, measurements were made before, during, and after Room $Q$ was bored. The objective was to obtain a significant data base to support the development of a mechanistic model that describes brine flow from the host rock to an excavation. Tests were performed in the uncased end regions of the cased boreholes and the end regions of the uncased boreholes. The uncased test zones were filled with brine and isolated from the remainder of the borehole with an inflatable packer system.

The test tools and their calibration procedures are described above in Section 4. All test tools were pre-assembled as much as possible, with final assembly completed onsite.

Table 5-1 lists all the pertinent information concerning tool types and test-region dimensions for each test hole.

\subsection{Leak-Check Procedures}

A leak-check test was performed on each test tool before installation in the hole by installing and testing the system in a length of steel oil field casing.

Prior to installation, leak integrity of the flow- and packer-control manifolds was evaluated by connecting the flow and control manifolds to a supply of compressed nitrogen and then using a soapy solution to monitor the system for signs of leakage. Manifold pressure was monitored with a transducer.

\subsection{Installation of Test Tools}

Test boreholes were drilled, lined, grouted, and instrumented before the Room $Q$ mine-by so that baseline measurements could be logged and the effect of the mine-by could be recorded. After the test tool installation was completed, baseline data were recorded for 77 days. Mine-by occurred from day 78 through day 105. The boring machine actually passed the plane containing the test zones on day 90 . 
Table 5-1. As-built Test Confjguration

\begin{tabular}{|c|c|c|c|c|c|c|c|c|c|}
\hline $\begin{array}{c}\text { Tool/hole } \\
\text { Number }\end{array}$ & $\begin{array}{r}\text { Radial } \\
\text { Distance } \\
\text { from Q } \\
\text { Axis (m) }\end{array}$ & $\begin{array}{c}\text { Hole } \\
\text { Diam. } \\
\text { (cm) }\end{array}$ & $\begin{array}{c}\text { Tool } \\
\text { Type } \\
\star\end{array}$ & $\begin{array}{c}\text { Tool } \\
\text { Diam. } \\
\text { (cm) }\end{array}$ & $\begin{array}{l}\text { Test } \\
\text { zorie } \\
\text { Length } \\
(\mathrm{cm}\rangle\end{array}$ & $\begin{array}{r}\text { Test } \\
\text { zone } \\
\text { Vol ume } \\
\text { (cc) }\end{array}$ & $\begin{array}{l}\text { Guard } \\
\text { zone } \\
\text { length } \\
\text { (cm) }\end{array}$ & $\begin{array}{l}\text { Guard } \\
\text { Zone } \\
\text { Volume } \\
\text { (cc) }\end{array}$ & $\begin{array}{c}\text { Install } \\
\text { Date }\end{array}$ \\
\hline QPP 01 & 13.73 & 10.16 & DP & 8.89 & 188 & 5100 & 76 & 2000 & $5 / 7 / 89$ \\
\hline QPP 02 & 7.63 & 3.81 & SP & 3.49 & 85 & 290 & - & - & $4 / 24 / 89$ \\
\hline QPP03 & 4.36 & 3.81 & DP & 3.49 & 90 & 300 & 14 & 135 & $4 / 24 / 89$ \\
\hline QPP 04 & 3.38 & 3.81 & SP & 3.49 & 85 & 290 & - & - & $4 / 24 / 89$ \\
\hline CPPDS & 2.28 & 3.81 & $\mathrm{DP}$ & 3.49 & 90 & 300 & 14 & 135 & $4 / 24 / 89$ \\
\hline QPP 11 & 13.77 & 10.16 & $\mathrm{DP}$ & 8.89 & 135 & 6000 & 76 & 2000 & $5 / 6 / 89$ \\
\hline QPP 12 & 7.63 & 3.81 & $\mathrm{SP}$ & 3.49 & 85 & 290 & - & - & $4 / 19 / 89$ \\
\hline QPP 13 & 4.72 & 3.81 & $\mathrm{DP}$ & 3.49 & 90 & 300 & 14 & 135 & $4 / 19 / 89$ \\
\hline QPP 14 & 3.50 & 3.81 & SP & 3.49 & 85 & 290 & - & - & $4 / 19 / 89$ \\
\hline QPP 15 & 2.41 & 3.81 & DP & 3.49 & 90 & 300 & 14 & 135 & $4 / 19 / 89$ \\
\hline QPP 21 & 13.44 & 10.16 & $D P$ & 8.89 & 1.36 & 6100 & 76 & 2000 & $5 / 8 / 89$ \\
\hline $\mathrm{QPP} 22$ & 7.39 & 3.81 & $\mathrm{SP}$ & 3.49 & 8.5 & 290 & - & 135 & $4 / 23 / 89$ \\
\hline QFP 23 & 4.49 & 3.81 & $D P$ & 3.49 & 90 & 300 & 1.4 & - & $4 / 23 / 89$ \\
\hline QPP 24 & 3.05 & 3.81 & SP & 3.49 & 85 & 290 & - & 135 & $4 / 23 / 89$ \\
\hline QPP 25 & 2.41 & 3.81 & DP & 3.49 & 90 & 300 & 14 & - & $4 / 23 / 89$ \\
\hline
\end{tabular}

* DP = Dual Packor SP Sirigle Parker

Notes:

1. Test hone length is the distaroe betwoen the hro le end and borebole contact of the deepest packer.

2. Test and juard zone volumes include the volume of tre connecting lines.

3. Guard zone length is the distance betwoen packer borehole contacs.

4. The elevation of Room o a is (at test location) is 387.02 m amsl.

5. Install dates refer to the time when tool installation was complete. 
Holes were cased soon after drilling, but the test zones sat open for up to two months before tool installation. To prepare the holes for tool installation, they were cleaned and then sized: calipers were run into the holes to check hole diameters for compliance with tool size.

All holes were blown out with compressed air. Holes that sloped up were squared off at the end with a hand-held rod. Horizontal and downward-sloping holes were swabbed to remove accumulated brine. Installation technicians noted a substantial amount of mud or clay at the end of QPP01, so an 86.3-cm extension or "bullnose" was added to the end of the tool for that hole to ensure that the closure gauges and test-zone packer would be located off the hole bottom where the borehole walls were more competent.

To ease installation, $1.3-\mathrm{cm}$ steel conduit was attached to the outer end of the tools and used as a push rod to run the tools to total depth (see Photo 5-1). Some of the tools were difficult to install because of borehole deformation that occurred between the time of drilling and installation. Technicians sometimes used come-alongs or ratchets to force these tools to the desired setting depth.

Three different tool configurations were installed: the single-packer $3.5 \mathrm{~cm}$ tools were set in six holes, the dual-packer $3.5 \mathrm{~cm}$ tools were set in six holes, and the dual-packer $8.9 \mathrm{~cm}$ tools were set in three uncased holes. Figures 5-1 through 5-3 show the tool placement in each of the holes. The tools shown in Figure 5-3 are identical except for the $86-\mathrm{cm}$ bullnose attached to the downhole end of the QPP01 tool.

\subsubsection{Closure Gauge}

The closure gauges were located in the test zones and measured changes in vertical- and horizontal-borehole diameters within 1 micron. They were connected to the DAS with wire leads. The electrical leads for the borehole closure gauge LVDTs were run through the packer mandrel and the $1.3-\mathrm{cm}$ conduit to the hole collar and then to the appropriate DAS.

\subsubsection{Brine Supply Connection}

Three brine-supply reservoirs supplied fluid to the test regions via $3.2-\mathrm{mm}$ stainless steel tubing. The supply lines were bled and brine reservoirs filled immediately before calibration of the reservoir transducers. Volume requirements were established from the known capacity of the test region ininus the volume displaced by the tool. 


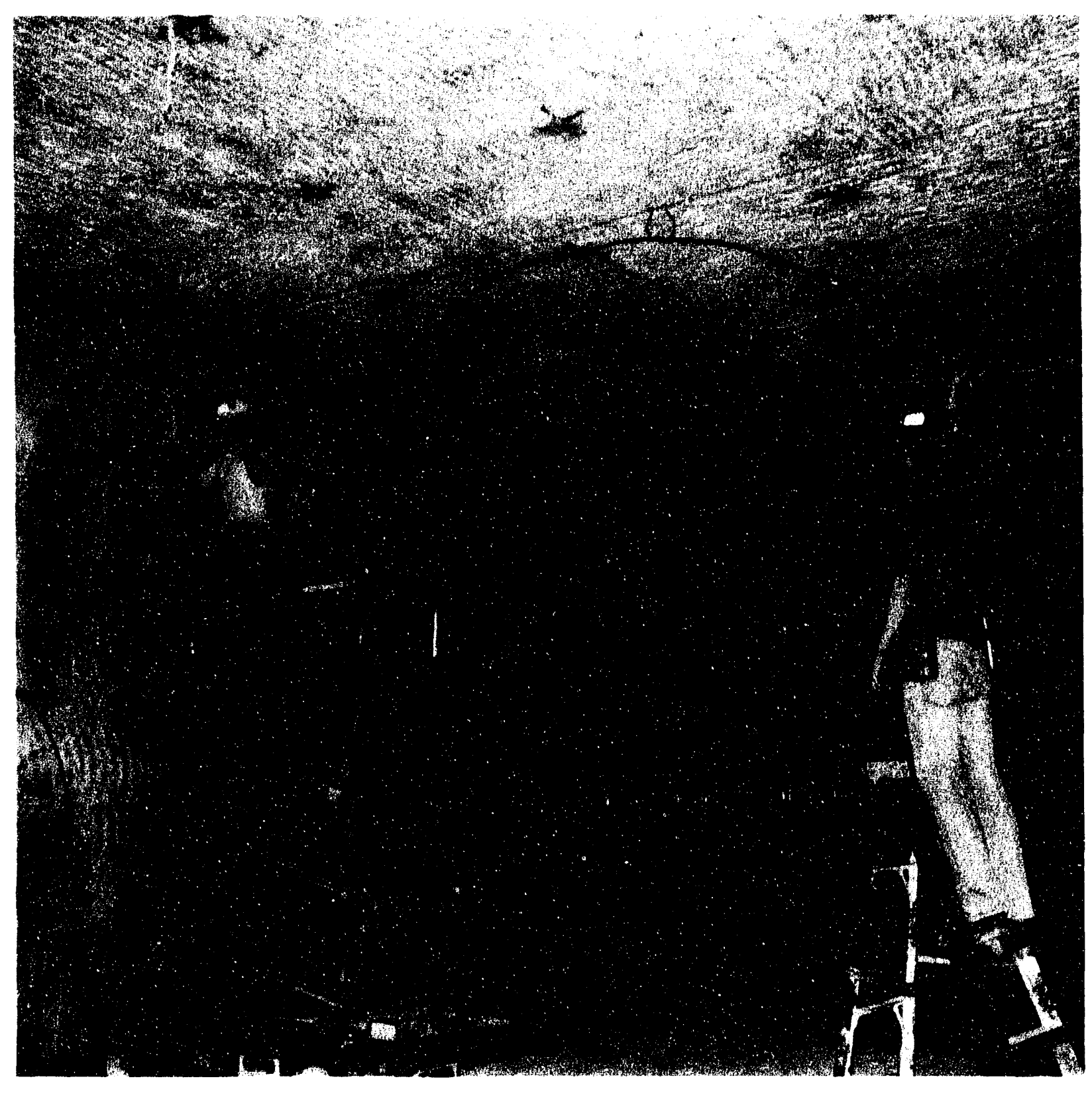

Photo 5-1. Installation with steel conduit. 


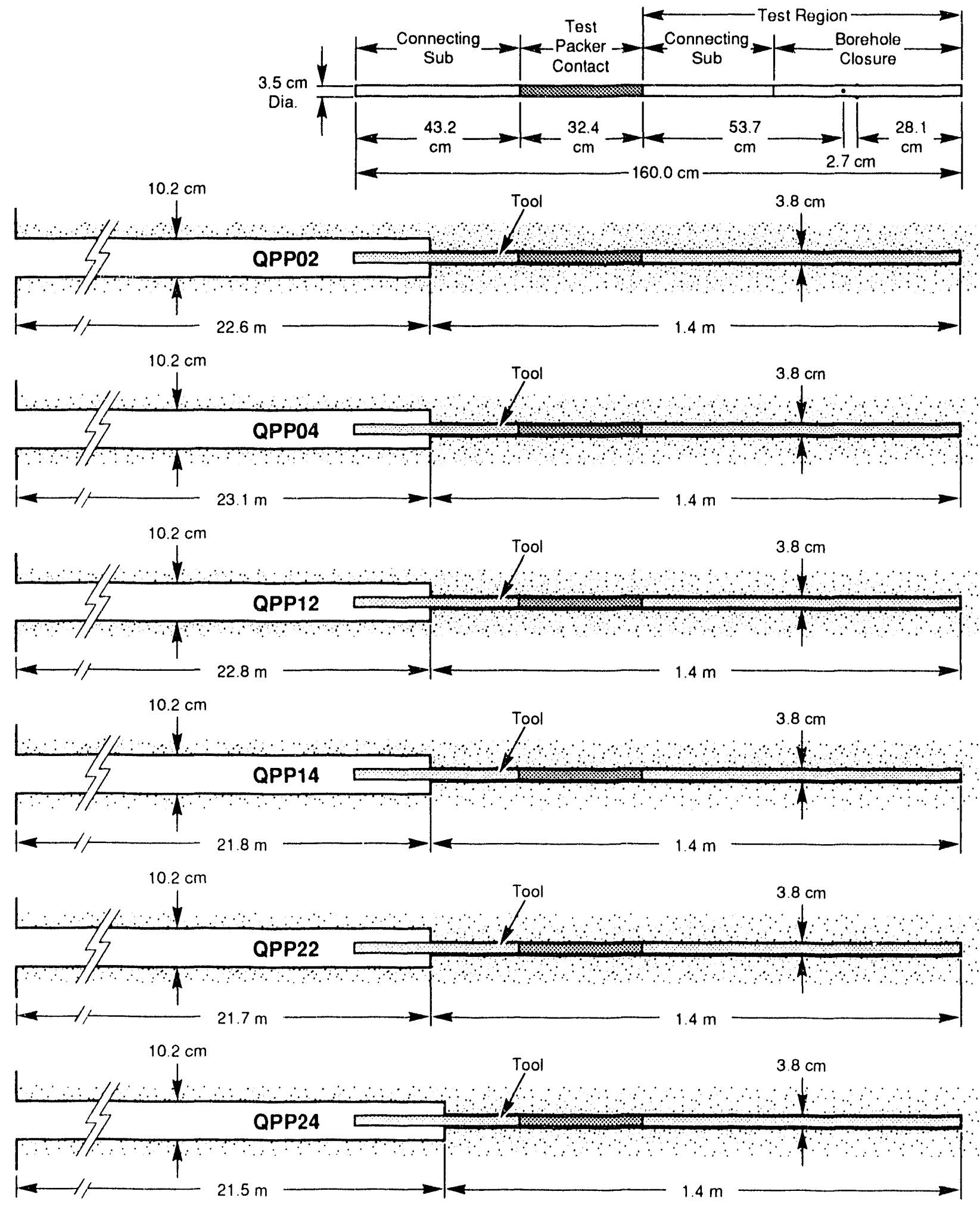

TRI.6119.237.0

Eigure 5-1. Installation diagram showing placement of 3.5-cm-diameter single-packer tools. 

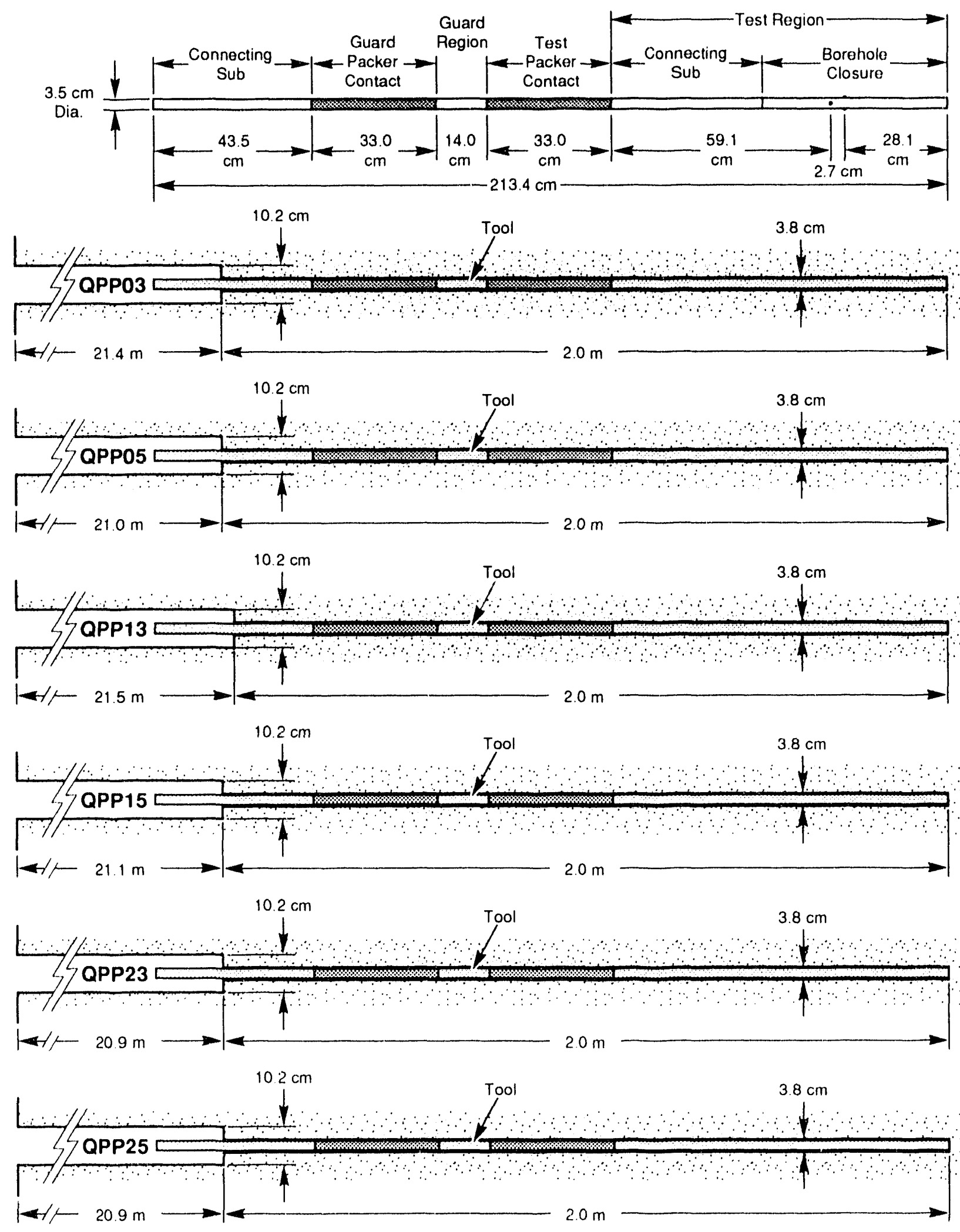

IBI. 61192380

Fiqure b-2. Instaltation diagram showing placement of 3.b-am-diameter hal-paker tools. 


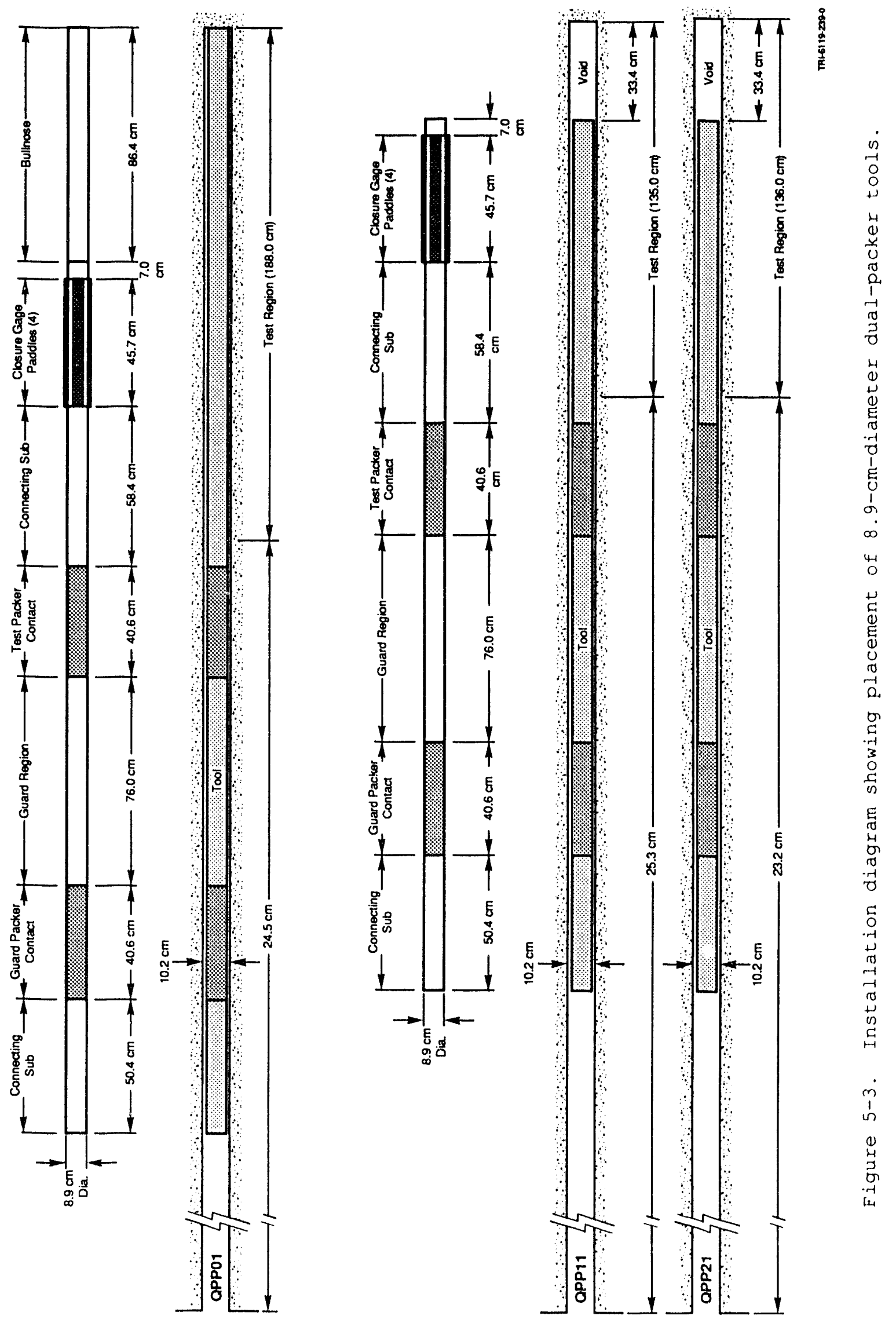


For the dual-packer systems, the guard-region packer was pressurized and inflated. Fluid was then circulated from the low-pressure brine reservoir to the test region until the air in the region was displaced completely with fluid. The test-region packer was inflated, and a prescribed amount of fluid was injected into the test region. Any pressure changes were noted. If ro unacceptable leakage was detected, testing proceeded.

\subsection{Test Startup}

Tools were inserted into the 15 holes. Packers were then inflated with fresh water via the packer fluid-handling system and monitored until they stabilized. The test regions were then filled with brine. Test and guard zones were shut in, and fluid pressures increased as zone pressures equilibrated with formation pressure. Testing was initiated after the rate of pressure-increase in the test zone slowed, and the pressure curve flattened.

Tests were initiated between Apri: 25 and May 8, 1989 and continued for 911 days, until October 22, 1991. Three types of tests were performed: a pulse test to measure formation reaction to high-pressure pulse injection or low-pressure pulse withdrawal, a shut-in test to estimate pore pressure buildup, and a long-term flow test for estimating brine inflow at constant pressure. Borehole closure was continuously monitored so that post-test data analysis could incorporate hole deformation influence on pressure response.

\subsubsection{Pulse Tests}

Pulse-withdrawal tests were initiated in the test zones by opening the vent valves and allowing fluid to flow from the zone until the shut-in pressure had decreased to a predetermined level. After venting, the test zone was again shut in by closing the valves. The volume of fluid released from each withdrawal test was measured and recorded. After shut in, the reequilibration of the zone-fluid pressure and the formation-pore pressure were monitored by the DAS. After the zone pressure had recovered to approximately pre-test values, the test was repeated to ensure that pressure responses were reproducible.

For the pulse-injection tests, the pressure in the test zones was increased and the zone was shut in. The time required for the fluid pressure to decrease to relative stability was then observed and recorded. For example, in the pulse-injection test for QPP11 (see below, Figure 6-44) operators increased pressure in the test zone by about $5 \mathrm{MPa}$. In this test, fluid pressure stabilized before mine-by. 


\subsubsection{Shut-in Tests}

For the shut-in tests, the guard and test regions were isolated while the pressure equlibration between the formation and the test regions was measured.

\subsubsection{Flow Tests}

For the flow tests, pressure in the test zones was reduced and controlled at a pre-determined value by a regulated gas pressure head on the flow columns connected to the zone. Pressure was held constant at the regulated level for about 150 days. Fluid was drained from the flow columns periodically while maintaining the pressure head using the valve system on the control panel. After the flow test, the test zone was again shut in to measure pressure response over time.

\subsection{Room Q Excavation}

Almost three months after test startup, excavation of Room $Q$ began. The room was mined in one pass with a Robbins Hard Rock Tunnel Boring Machine (TBM). A launching frame was used to position the TBM above the elevation selected for the floor of the Instrument Alcove and align it with Room Q. Boring began on July 12, 1989, at the west wall of the Alcove. Progress was slow for the first few days because of alignment problems, but excavation progressed more rapidly after about ten days. Figure $5-4$ shows the Room $Q$ excavation sequence and the point when the boring machine progressed past the station at $+30.5 \mathrm{~m}$ at about noon on July $24,1989$.

The excavation of Room $Q$ impacted the data collected in the test boreholes. Data impact can be seen in the figures that accompany section 6 .

Measurement stations are located in terms of stations along the axis of Room Q. The origin, Station 0 , is at the midpoint of the Room $Q$ axis. The station at $+53.3 \mathrm{~m}$ is the west face of the Instrument Alcove where the collars to the test boreholes are located. All the test boreholes terminate at station $+30.5 \mathrm{~m}$ to establish the location of the test regions, which include both the test and guard zones. The test zone is deepest, and is defined by the area between the deepest packer and the end of the borehole. As shown in Figures $3-1$ and $3-3$, all the test zones lie in a plane that extends radially outward from the centerline of Room $Q$. Three groups of five test zones are located at distances of approximately 2.4,3.3, 4.6, 7.6, and 13.6 meters from the room centerline. 


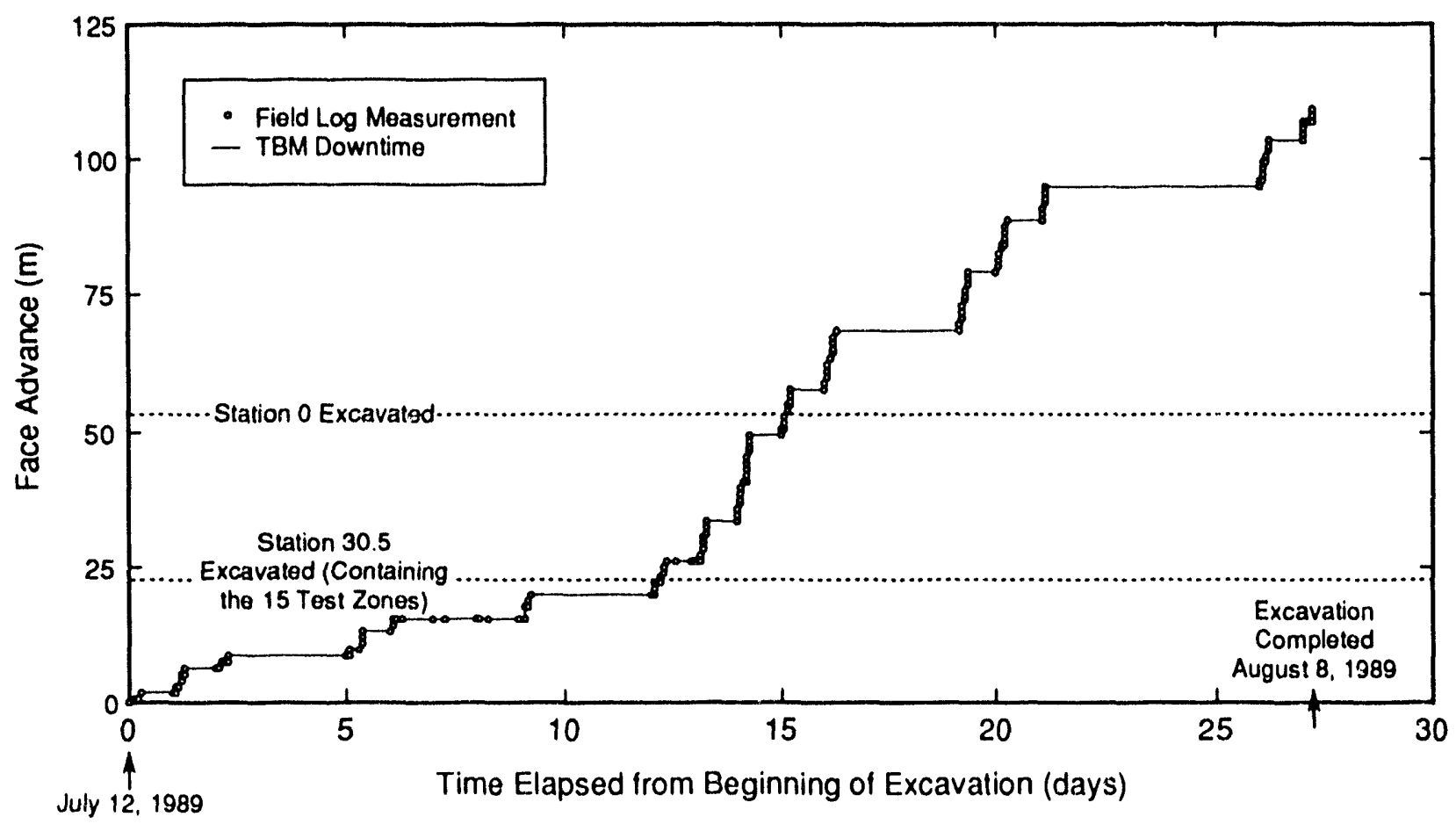

Figure 5-4. Room $Q$ excavation rate.

Table 5-2 presents cartesian coordinates that describe the end and collar location of each test borehole relative to the axis of Room $Q$ at station 0 . The coordinates are based on the same WIPP survey system as described for Table 3-1. Two sets of coordinates are given here, one for the collar and another for the end. Thus the collar of hole QPPO1 is located $4.87 \mathrm{~m}$ south, $53.32 \mathrm{~m}$ east, and $1.26 \mathrm{~m}$ above the approximate geometric center of Room $Q$ at Station 0 . The test-zone end of the same hole is $0.33 \mathrm{~m}$ north, $30.5 \mathrm{~m}$ east, and $13.41 \mathrm{~m}$ above the same reference point. 
Table 5-2. End and Collar Locations Relative to Room Q Center

\begin{tabular}{|c|c|c|c|c|c|c|}
\hline \multirow[b]{2}{*}{$\begin{array}{l}\text { Bole } \\
\text { Number }\end{array}$} & \multirow[b]{2}{*}{$\begin{array}{l}\text { North } \\
(+) \text { of } \\
\text { Center }\end{array}$} & \multirow{2}{*}{$\begin{array}{c}\text { Hole Collar } \\
\text { East } \\
(+) \text { of } \\
\text { Center } \\
\end{array}$} & \multicolumn{2}{|c|}{ Room $Q$ Coordinates $(\mathrm{m})$} & \multirow{2}{*}{$\begin{array}{l}\text { Hole End } \\
\text { East } \\
(+) \text { of } \\
\text { Center }\end{array}$} & \multirow[b]{2}{*}{$\begin{array}{r}\text { Above } \\
(+) \\
\text { Center }\end{array}$} \\
\hline & & & $\begin{array}{r}\text { Above } \\
(+) \\
\text { Canter } \\
\end{array}$ & $\begin{array}{l}\text { North } \\
(+) \text { of } \\
\text { Centar }\end{array}$ & & \\
\hline QPP01 & -4.87 & 53.32 & 1.26 & 0.33 & 30.50 & 13.41 \\
\hline QPP02 & -4.28 & 53.32 & 1.24 & 0.06 & 30.47 & 7.30 \\
\hline QPP03 & -3.68 & 53.38 & 1.21 & -0.01 & 30.50 & 4.03 \\
\hline QPPO4 & -3.05 & 53.40 & 1.22 & 0.35 & 29.16 & 3.03 \\
\hline QPP05 & -2.45 & 53.42 & 1.26 & -0.07 & 30.69 & 1.95 \\
\hline QPP11 & $-4.9]$ & 53.39 & -1.18 & -0.02 & 30.61 & -14.10 \\
\hline QPP12 & -4.29 & 53.39 & -1.17 & 0.21 & 30.59 & -7.96 \\
\hline QPP13 & -3.67 & 53.40 & -1.17 & 0.07 & 30.58 & -5.05 \\
\hline QPP14 & -3.06 & 53.41 & -1.18 & 0.04 & 30.58 & -3.83 \\
\hline QPP15 & -2.46 & 53.45 & -1.19 & -0.01 & 30.60 & -2.74 \\
\hline QPP21 & 4.82 & 53.44 & 0.53 & 13.44 & 30.50 & -0.44 \\
\hline QPP22 & 4.22 & 53.44 & 0.52 & 7.39 & 30.60 & -0.28 \\
\hline QPP23 & 3.61 & 53.48 & 0.54 & 4.49 & 30.62 & -0.23 \\
\hline QPP21 & 2.98 & 53.46 & 0.50 & 3.03 & 30.62 & -0.64 \\
\hline QPP25 & 2.40 & 53.46 & 0.53 & 2.40 & 30.62 & -0.56 \\
\hline
\end{tabular}

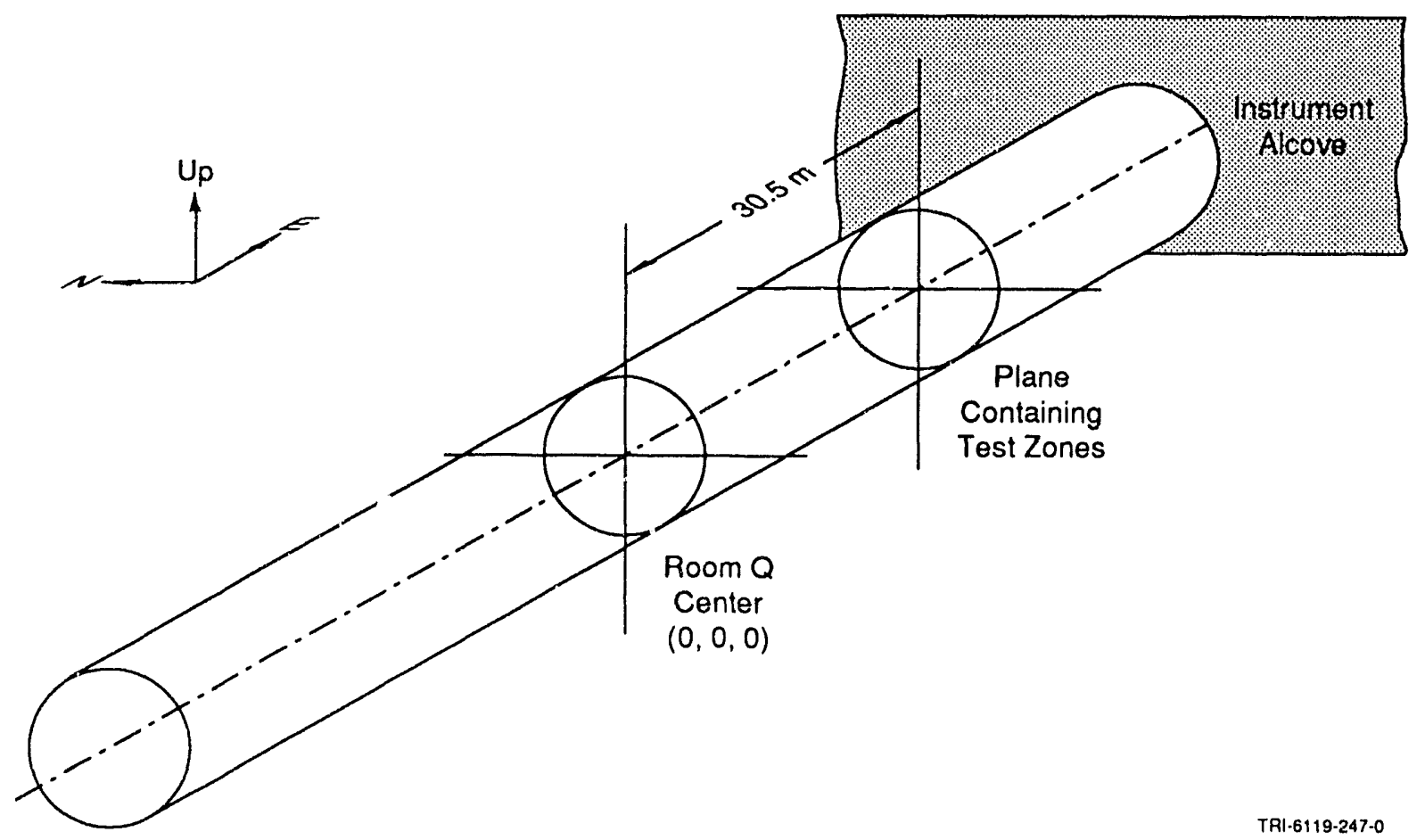

Figure 5-5. Room Q coordinate reference diagram. 


\subsection{TEST RESULTS}

This section reports on the sequence of events from the recovery of the raw data files in the DAS to the creation of the final plot files. The raw data were received from the test tools and stored in a mix of engineering units (both U.S. and metric) depending on the instrument output. For instance, the output data were given in pressure units of psig, temperature units of degrees centigrade, test zone diameters of inches, and fluid volume of cubic centimeters. These data had to be standardized before data reduction and presentation.

The DAS recorded time values of days, hours, minutes and seconds. Readings were recorded once every six minutes for the first few hours, with time increasing to every six hours. Data were routinely dumped to floppy disks every few days.

\subsection{Data Preparation}

Data preparation involved several steps: file organization, conversion to standard units, reduction of the number of data points. The DAS monitored all data channels regardless of operational activities, so the raw data sets contained all data, including non-operational information. Thus, at times when tools were off-line, anomalous data were recorded (as noted in the field notes). Anomalous points were usually the result of signal spikes or signal conditioning problems. To eliminate this extraneous data, an annotated data set was developed. The procedure is explained in Appendix C. An annotated and full set of original data are available from SNL WIPP quality assurance and Department 6119.

Further data reduction of the annotated set was necessary for presentation in this report. The annotated data files contained over 10,000 data points for each gauge because data were recorded at a high frequency for about 1000 days. Therefore, data reduction was performed to increase the clarity of the data plots. First, the data were sorted according to borehole number, recording time, and measurement type (e.g., "vertical closure"). Second, the time interval since zero-hour of April 25, 1989, was calculated. Third, the data for pressure and test zone diameters were converted from U.S. to metric units (i.e., psig to $\mathrm{MPa}$ and inches to $\mathrm{mm}$ ). Fourth, closure values were calculated by subtracting the initial hole diameter from all subsequent measured diameters. The change in diameter became the plotted value. Fifth, redundant values were filtered out with a data filter that responded to both the reading frequency and the amount of change between measured values. That 
is, in cases where the $y$-axis value was flat because of little change over time, the data were systematically reduced. However, at times when the yaxis value changed rapidly, all data were retained.

\subsection{Ideal Test Response}

For comparison with the actual test data, an ideal test-zone pressure response from a typical Room $Q$ borehole test is presented in Figure 6-1. Under perfect conditions, a test zone is shut in at constant volume to begin the test. Pressure then rises in the test zone until it approaches formation pressure. A pulse test (pressure withdrawal in this example) is initiated. Fluid is vented from the test zone to reduce pressure by a predetermined amount, and the released fluid volume is measured. Then the test zone is again shut in, and the time required for the pressure to return to pre-pulse test levels is noted.

About 80 days into the test, the mine-by alters formation stresses and accelerates the change in test-zone pressure. The proximity of the test zone to the excavation influences the magnitude of the pressure change. After the pressure levels off, or stabilizes, long-term flow tests are initiated: fluid and pressures are vented from the test zone and held constant at a specified pressure with the fluid-withdrawal system. After about 150 days of data collection, the test zone is shut in again and pressure increases are recorded.

\subsection{Data Presentation}

Data plots are presented here in a series of figures that are grouped by borehole number. The plots are then ordered according to the depth of the measurement location within each borehole. Thus data from the deepest gauge in borehole QPPO1 are presented in the first data plot, Figure 6-2.

In all the figures, time is represented on the $x$ ordinate in units of days from test startup. Day zero is April 25, 1989, the arbitrary date designated for the initiation of the Room $Q$ borehole tests. All tools were installed and recording data within 14 days after this date. The data plots presented here normally give a range from zero to 1000 days, except in two cases: 1) tests where gauges became inoperable, and 2) flow tests, which normally ranged for 150 days, from about day 300 to day 450 . 


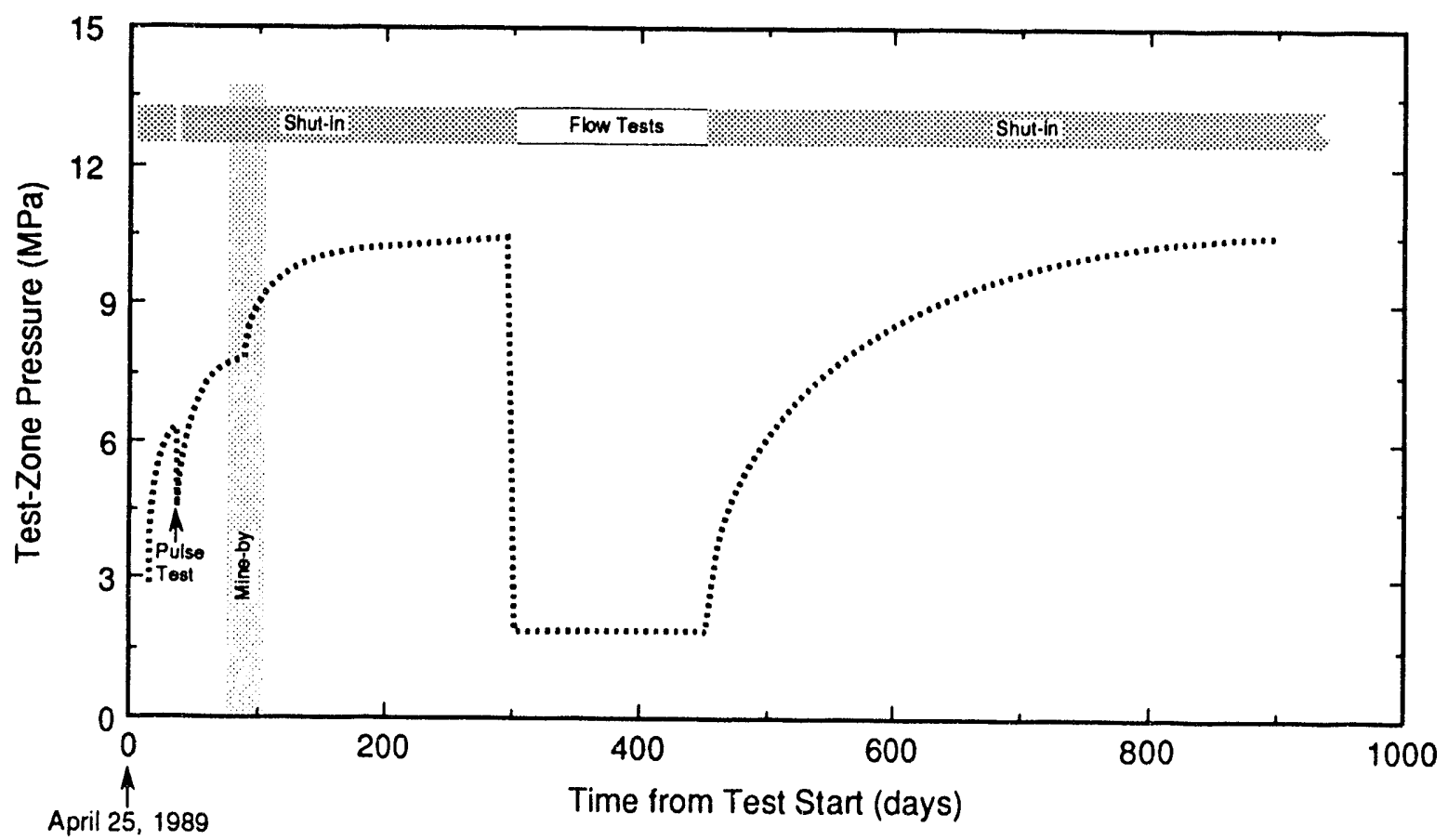

TRI-6119-245.0

Figure 6-1. Ideal test-zone pressure response.

The $y$ ordinates in the figures reflect positive changes in measured test values, except for the closure tests. Closure, or decreasing hole diameter, is shown as a negative slope. Most closure plots demonstrate both negative and positive slope, possibly caused by the response of the borehole wall or the instrument to pressure buildup during shut in.

Some data are not provided because of instrument failure or loss of data. In particular, no data are shown for the closure gauges in hole QPP21 and no flow data are shown for hole QPP11. Tests performed in holes QPP14 and QPP15 show a data anomaly about 380 days into the tests: between day 383 and day 447, pressure transducer data channels were transposed. This pressure data anomaly affects calculated closure data for these holes. Operational logs offered no explanation for the transposition problem (see Appendix C).

Icons have been inserted into the figures to aid intexpretation of the data. Diagrams set within the chart identify the test region under discussion and show its location relative to Room Q. The test borehole is identified by a darkened square. 
Test activities are also displayed within the bounds of the chart by two methods: 1) a stipled bar is used to indicate the time period for the shutin tests, flow tests, and mine-by; 2) callouts refer to single or short-term events like the pulse tests, the draining of the brine accumulator, or the opening of a guard zone. The activity logs in Appendix $C$ are the information source for these events.

Analysis and evaluation of the data exceed the scope of this report. 


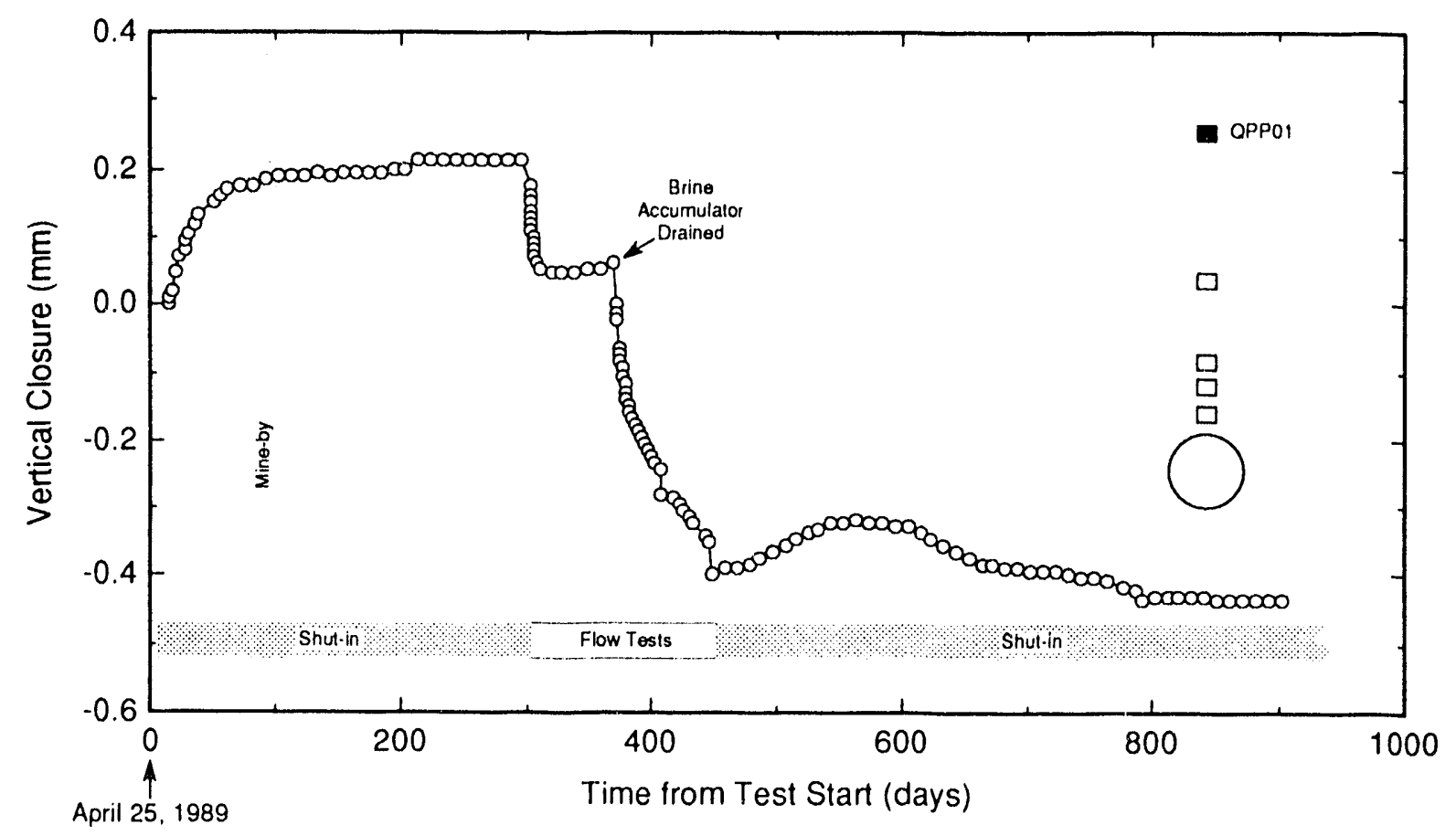

TRI-6119-75.0

Figure 6-2. Vertical closure measured in the test zone of hole QPP01.

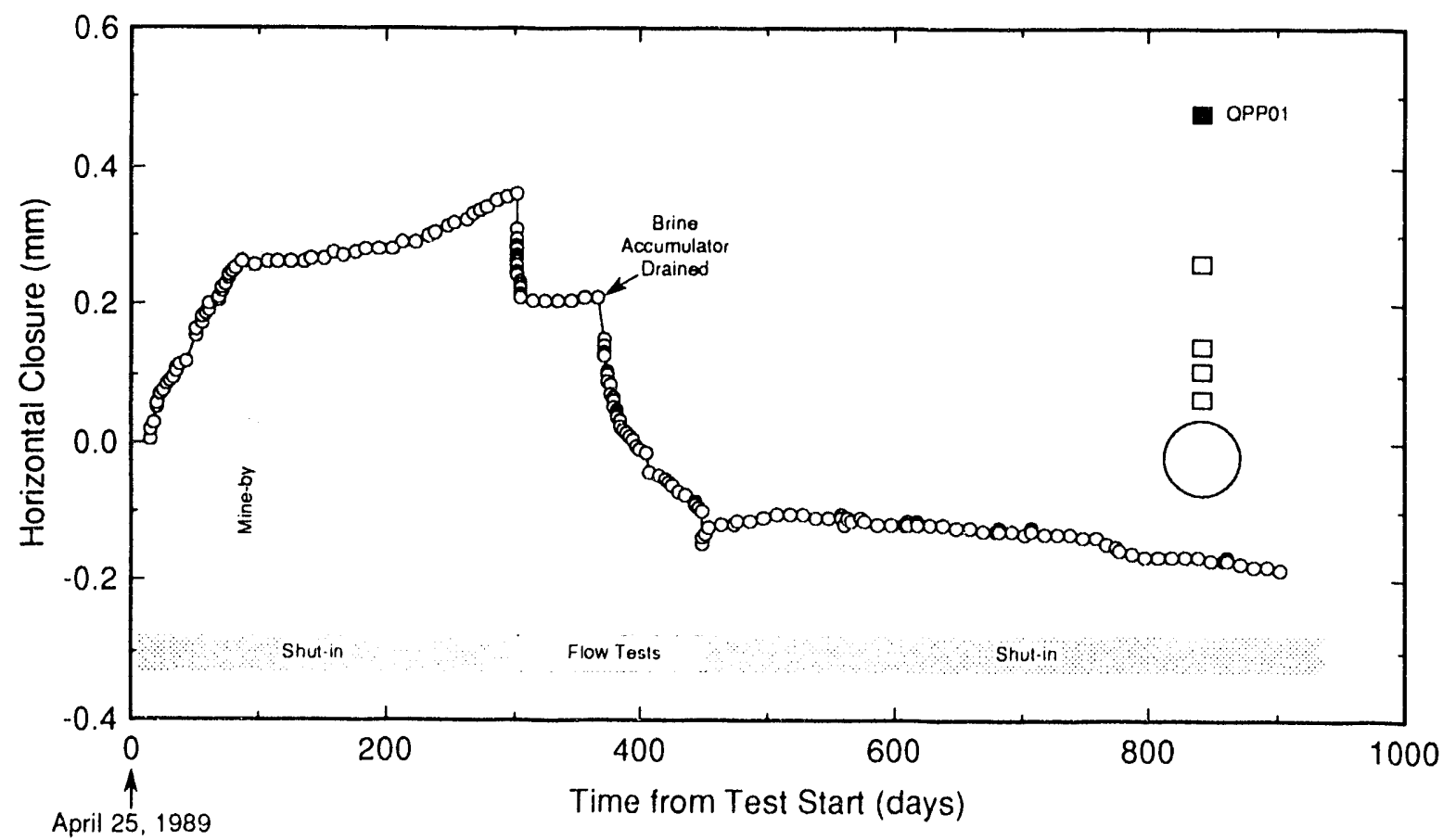

TRI.6119.76.0

Figure 6-3. Horizontal closure measured in the test zone of hole QPP01. 


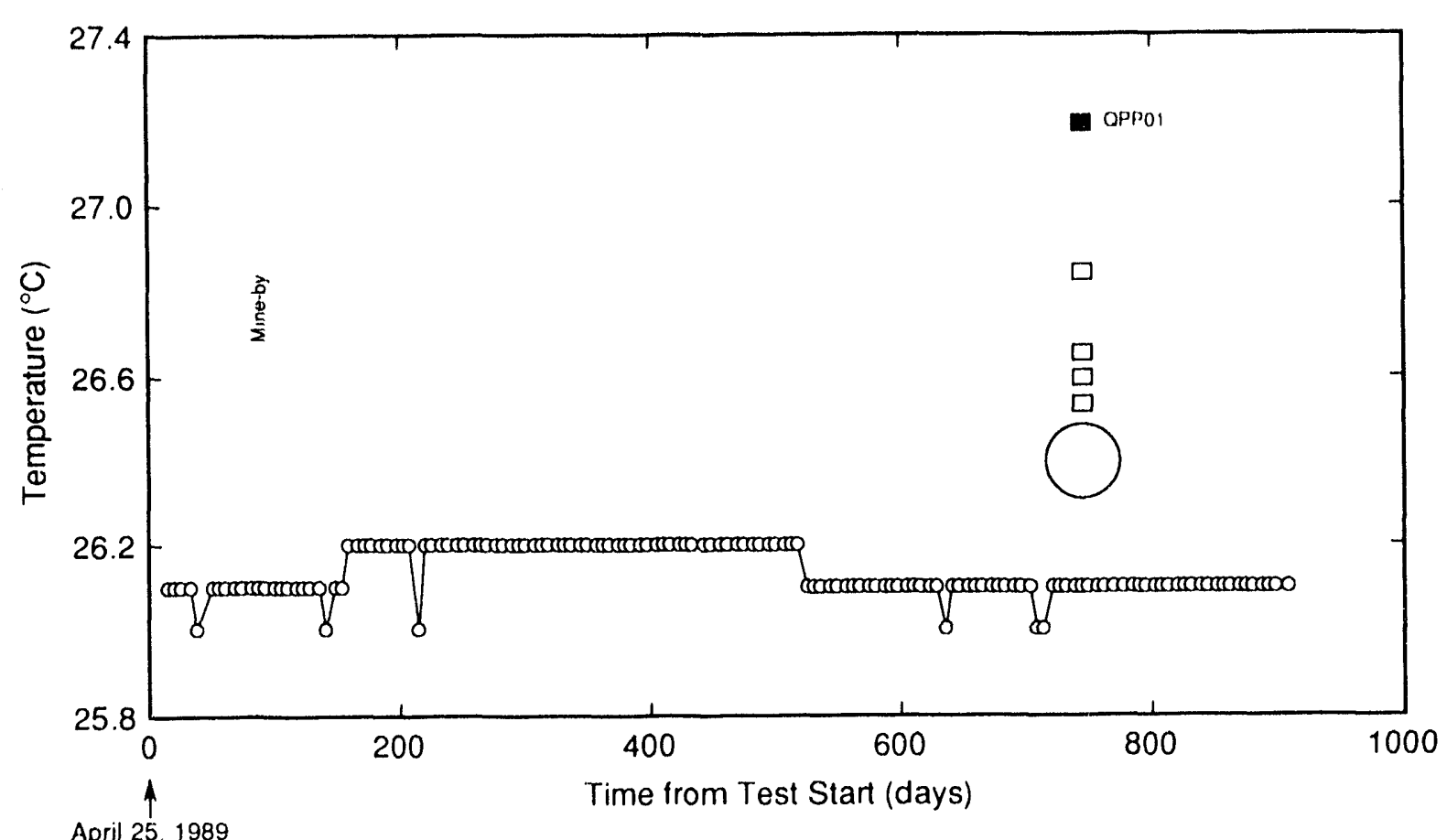

TH1.6119.47.0

Figure 6-4. Hole QPPO1 test-zone temperature.

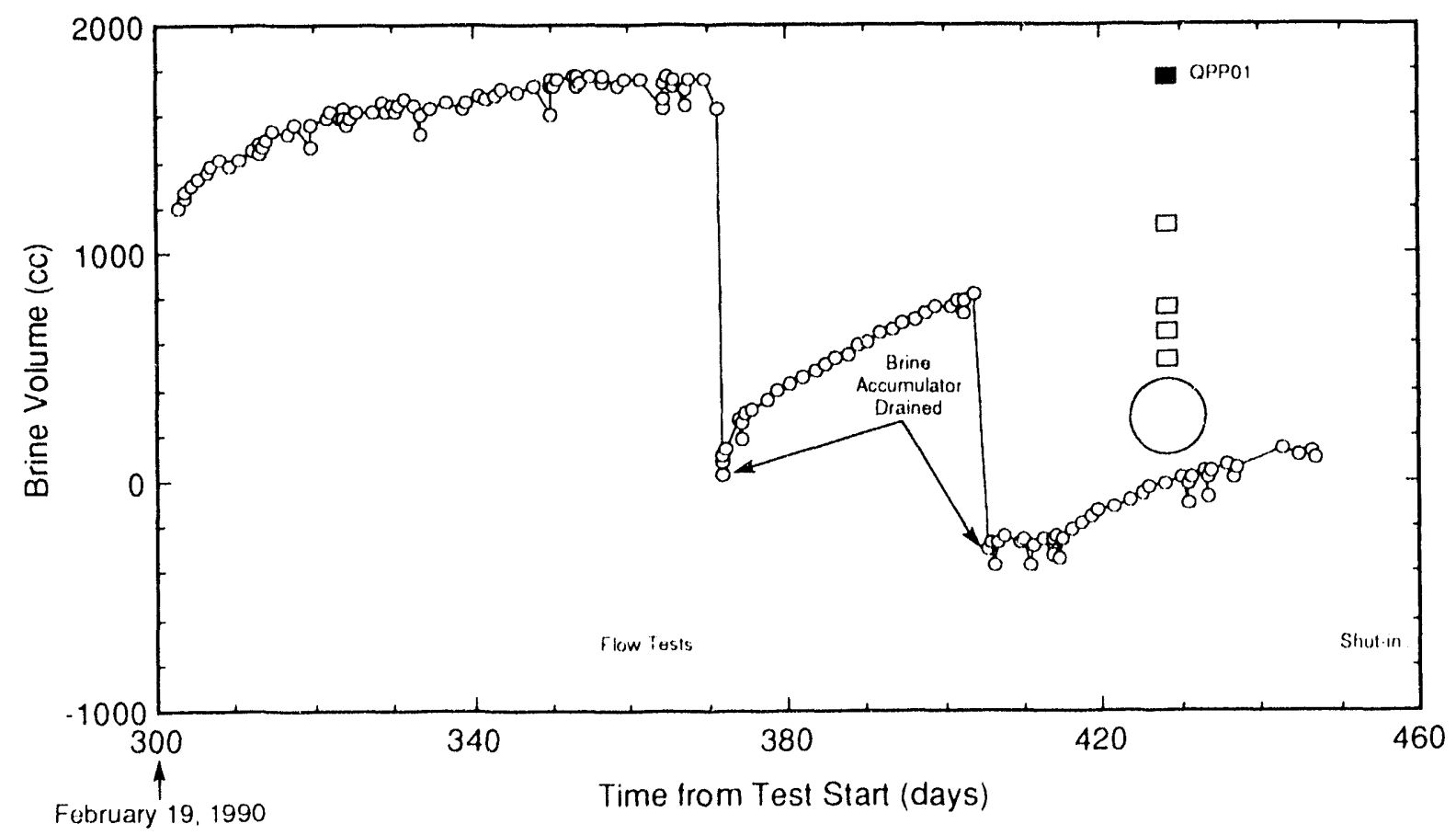

Eigure 6-5. Brine collected from gppol test zone during flow test ing. 


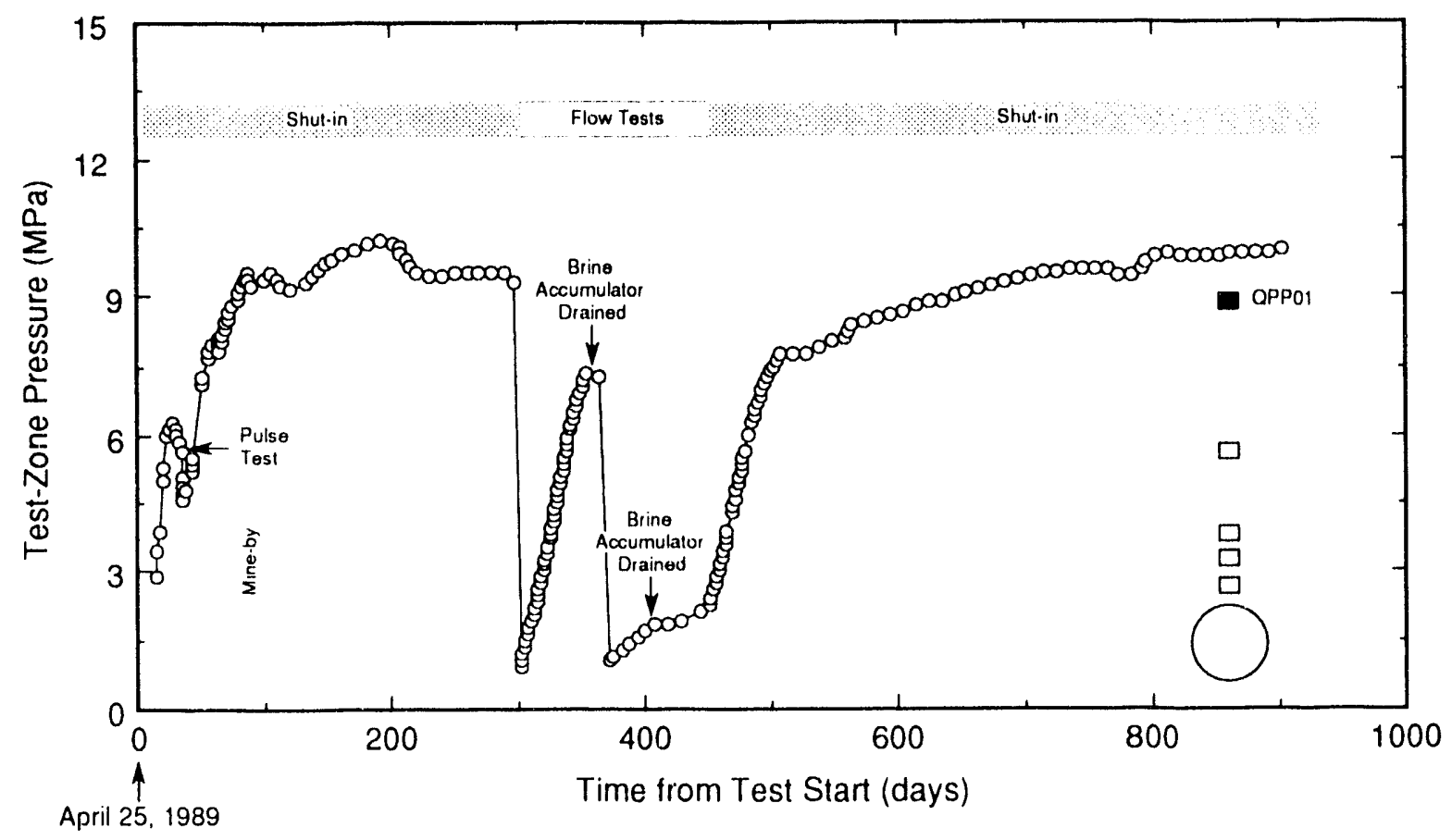

Figure 6-6. Hole QPP01 test-zone pressure.

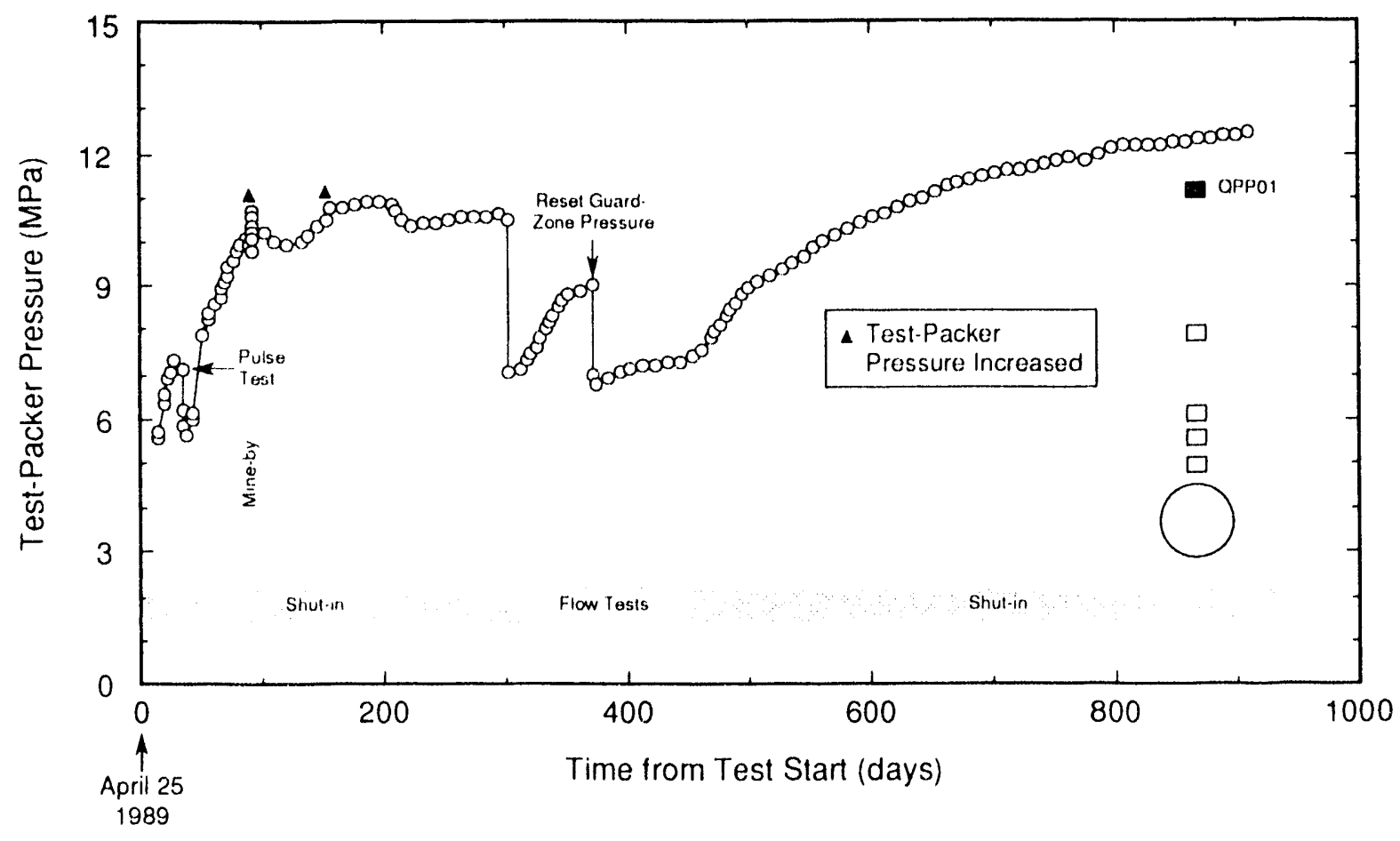

Figure 6-7. Hole gppol test-packer pressure. 


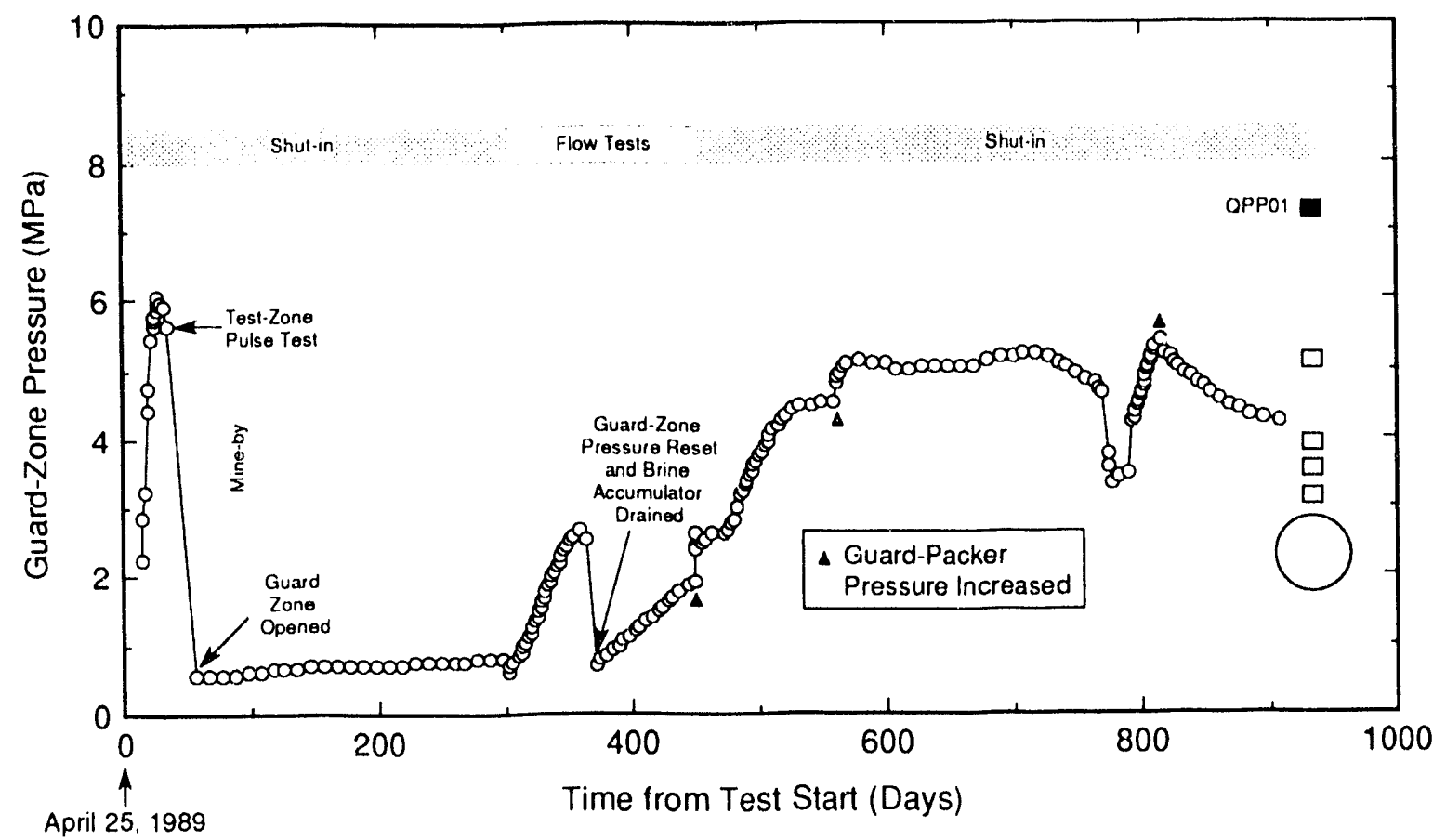

TRI.6119.80.0

Figure 6-8. Hole QPP01 guard-zone pressure.

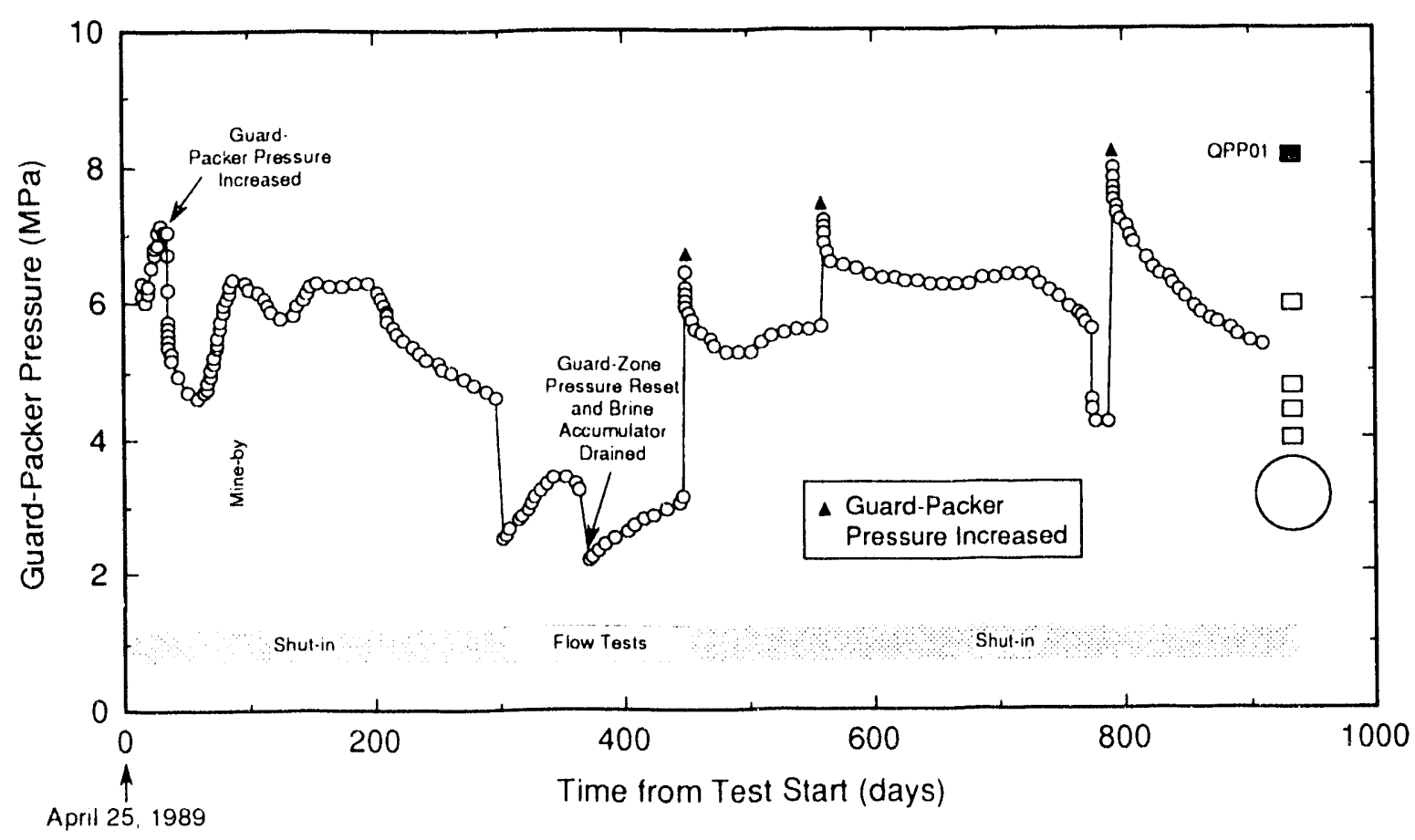

Figure 6-9. Hole QPPO1 guard-packer pressure. 


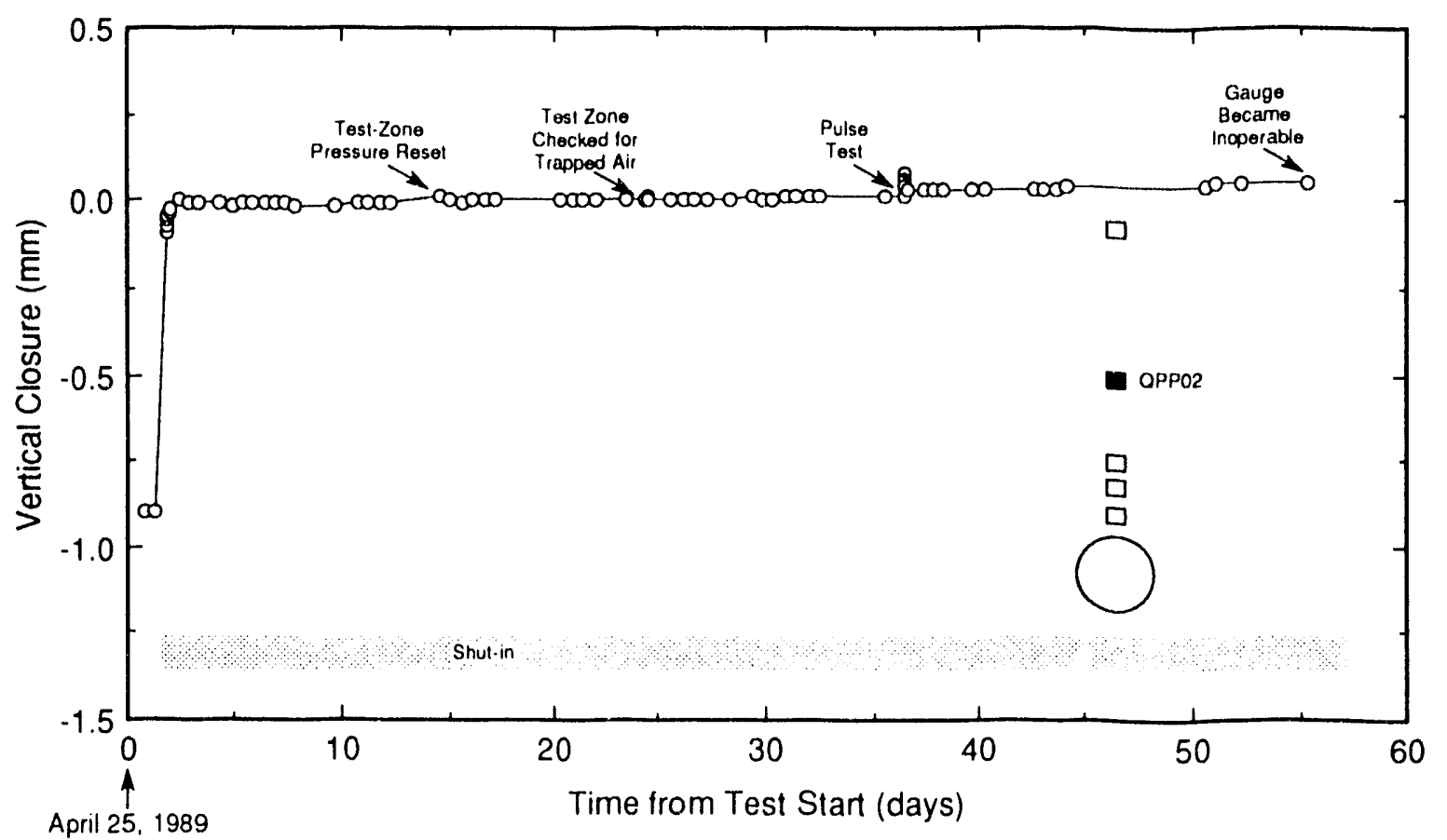

TR1.6119-82.0

Figure 6-10. Vertical closure measured in the test zone of hole QPP02.

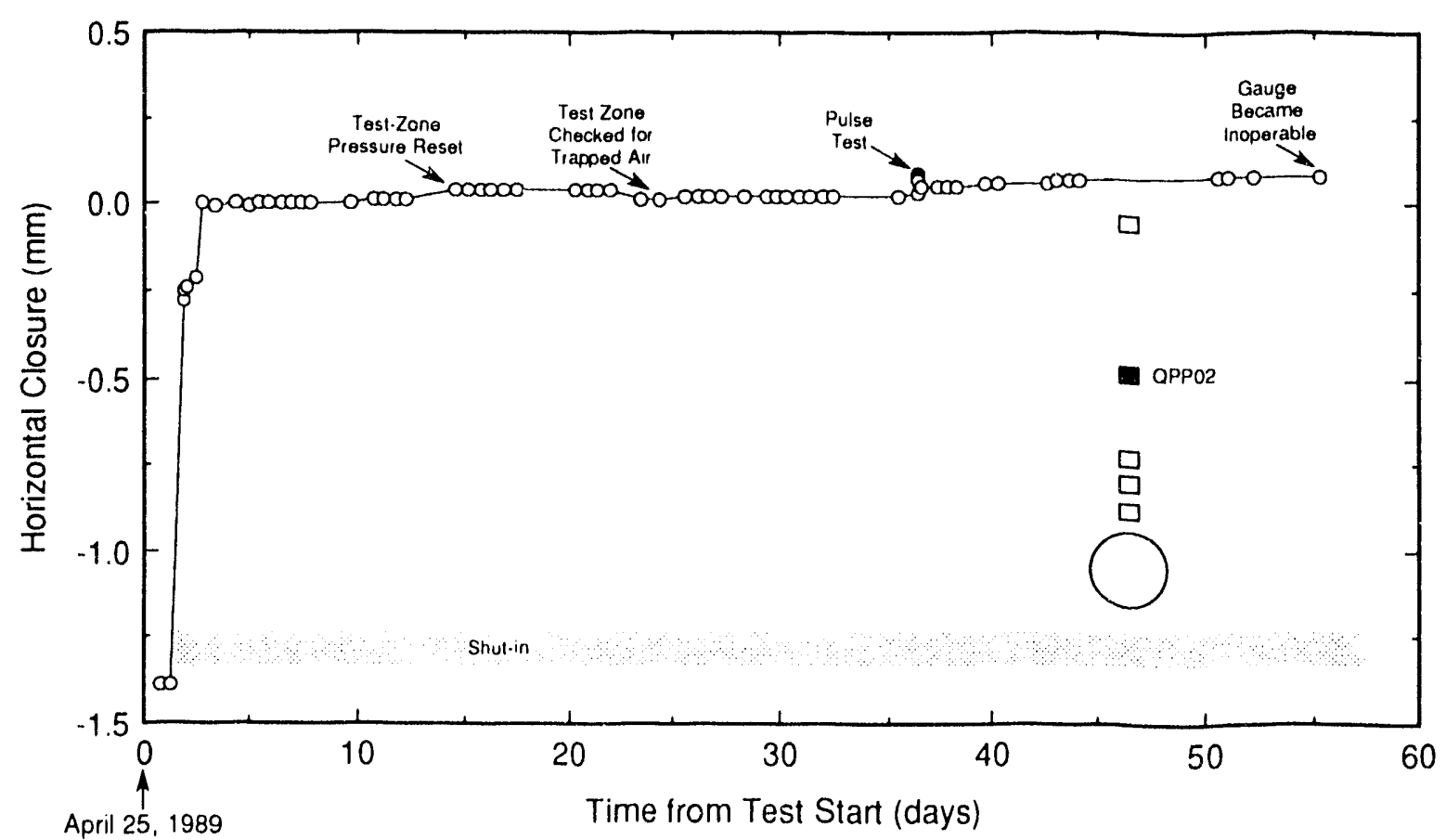

TRI.6119.83.0

Figure 6-11. Horizontal closure measured in the test zone of hole QPP02. 


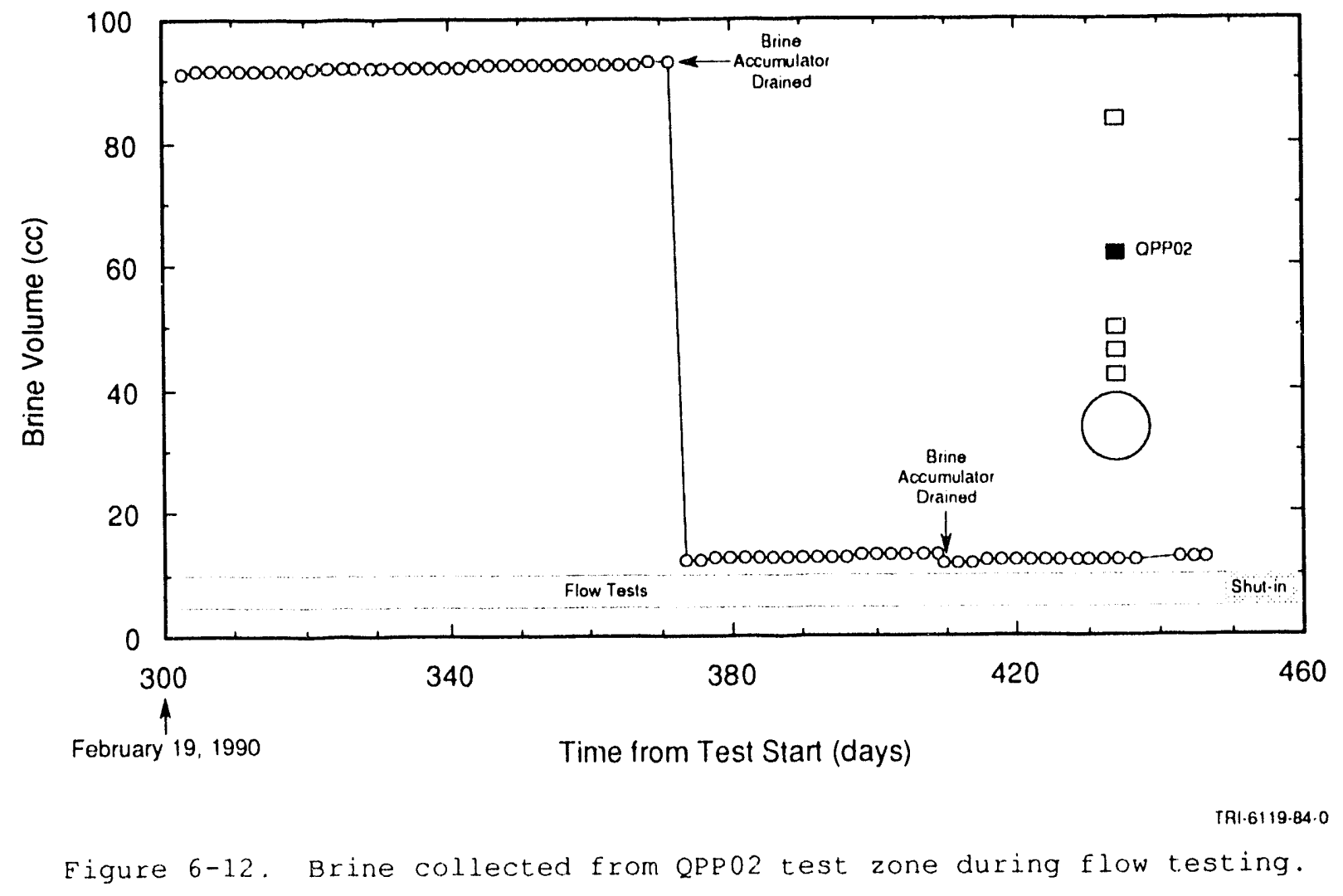




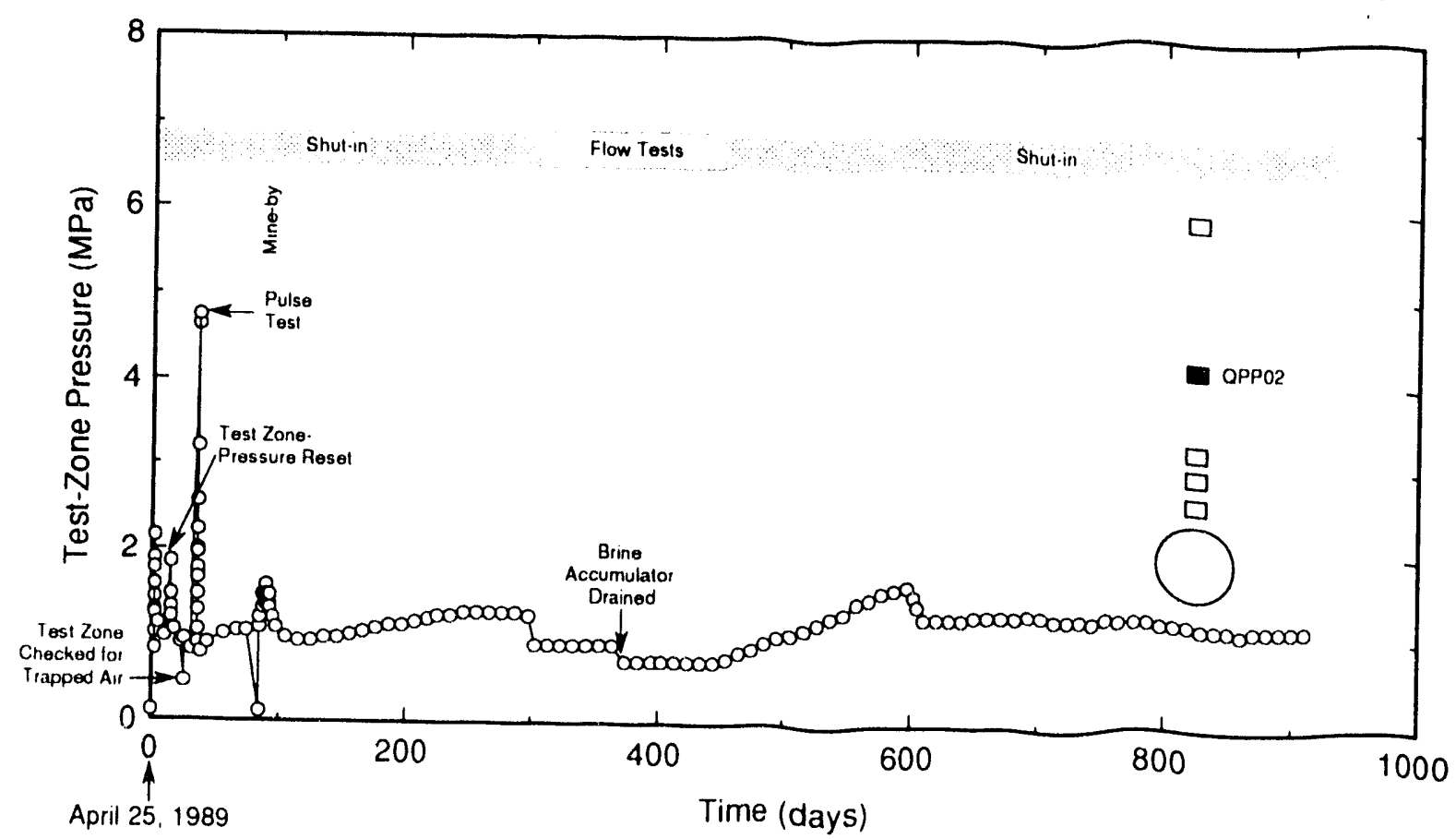

Figure 6-13. Hole QPPO2 test-zone pressure.

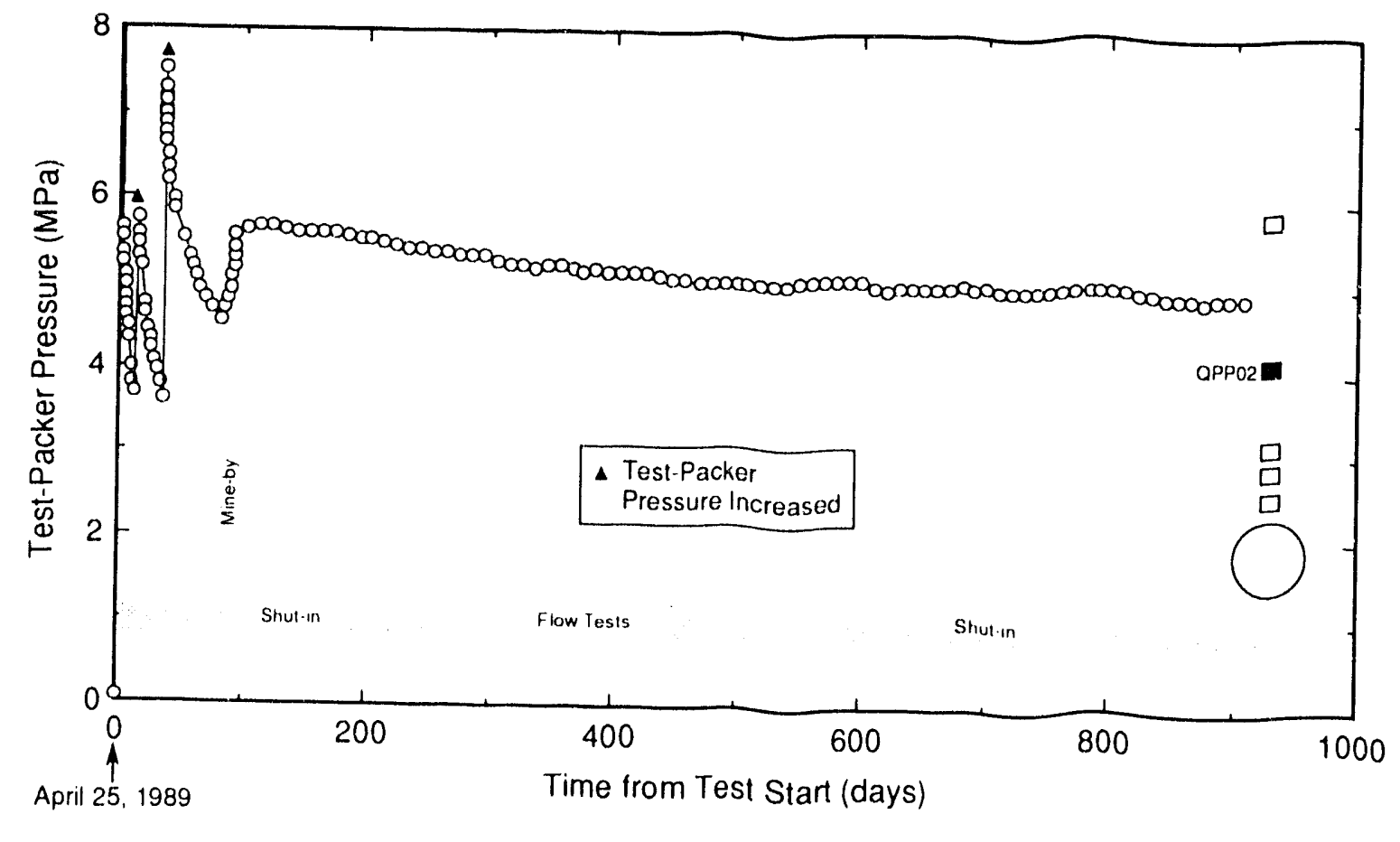

Figure 6-14. Hole QPP02 test-packer pressure. 


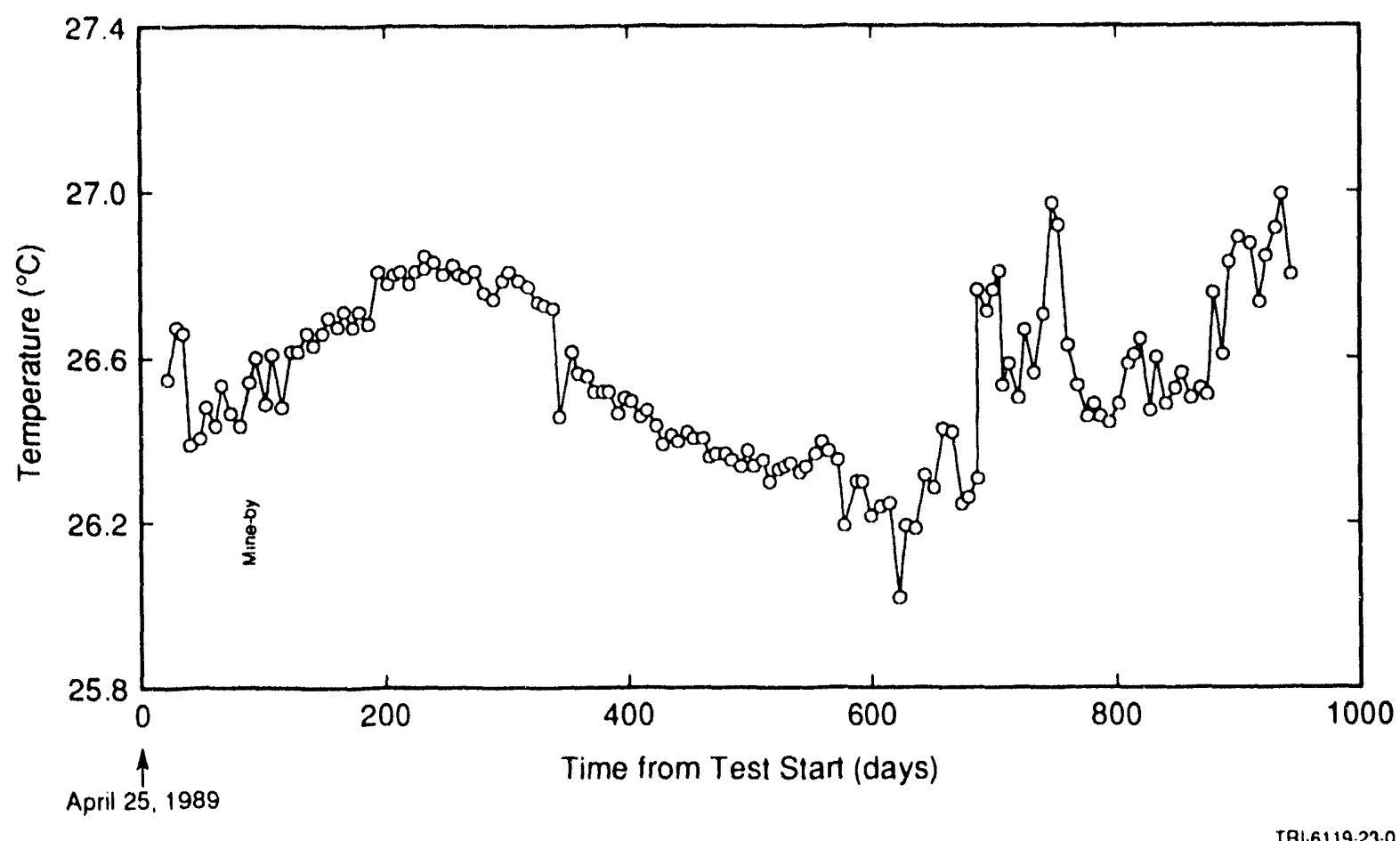

Figure 6-15. Hole QPP02 tool temperature.

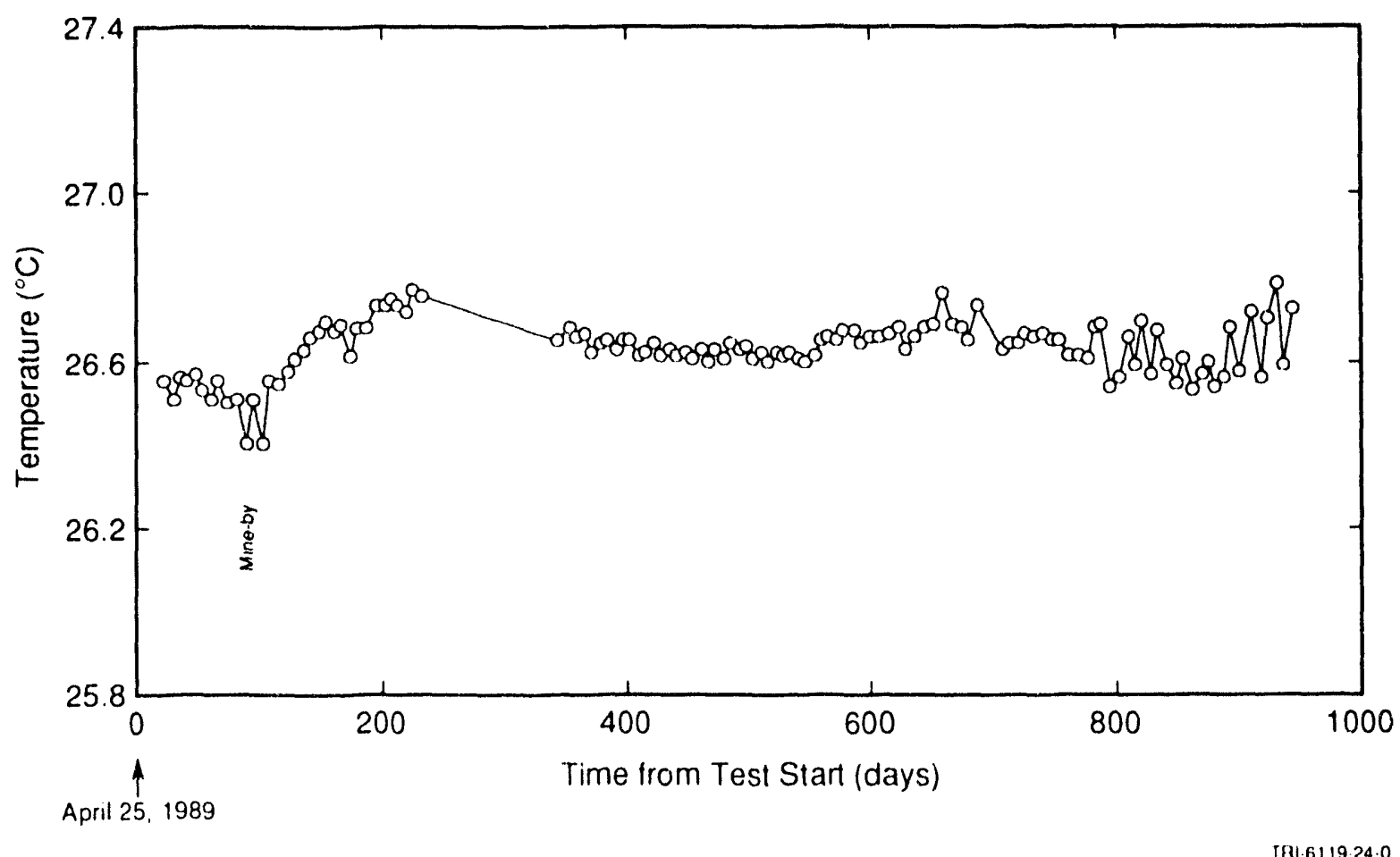

Figure 6-16. Hole QPP02 casing temperature. 


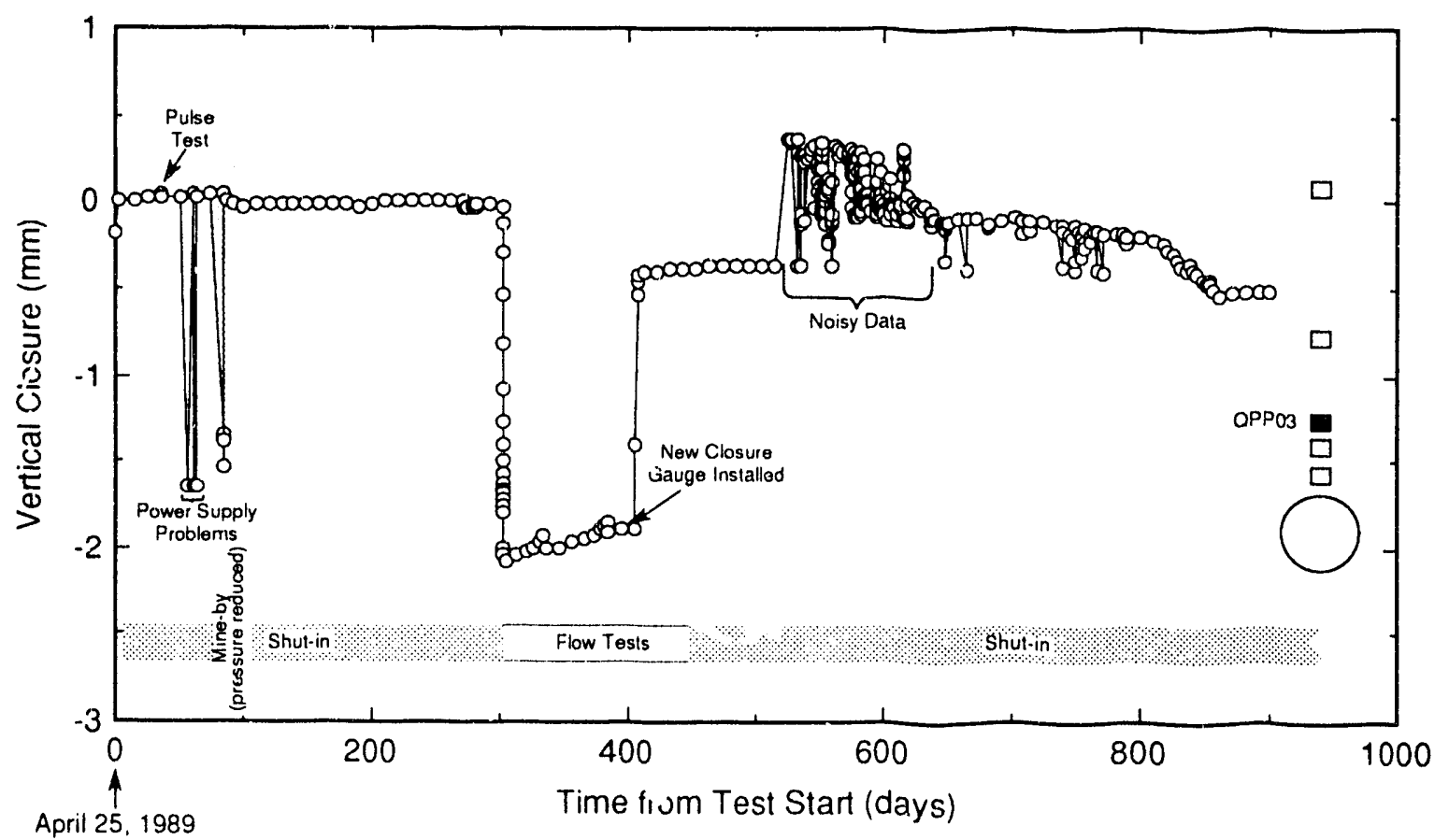

TRI-6119.87.0

Figure 6-17. Vertical closure measured in the test zone of hole QPP03.

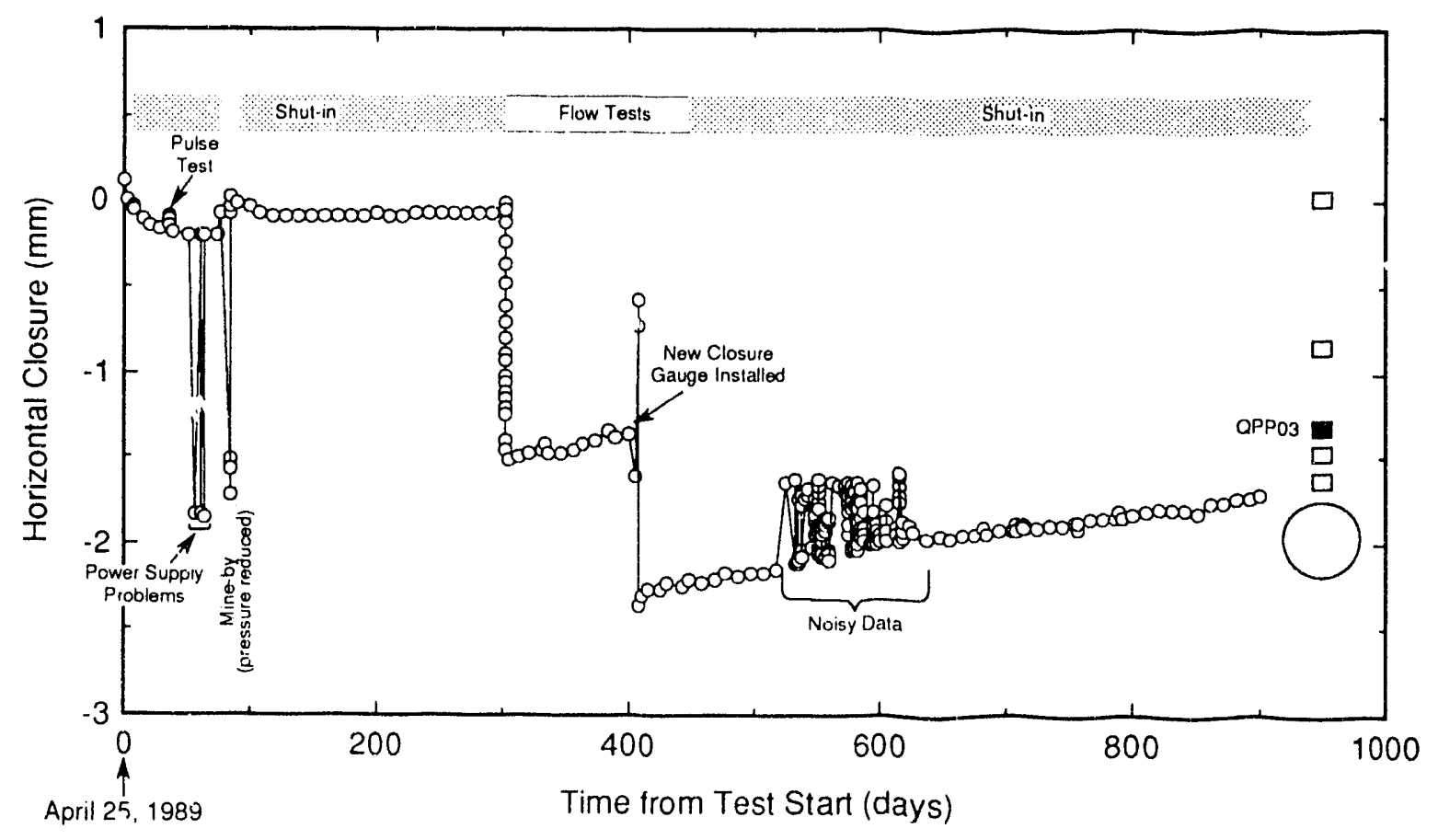

TAI-6119.88-0

Figure 6-18. Horizontal closure measured in the test zone of hole QPP03. 


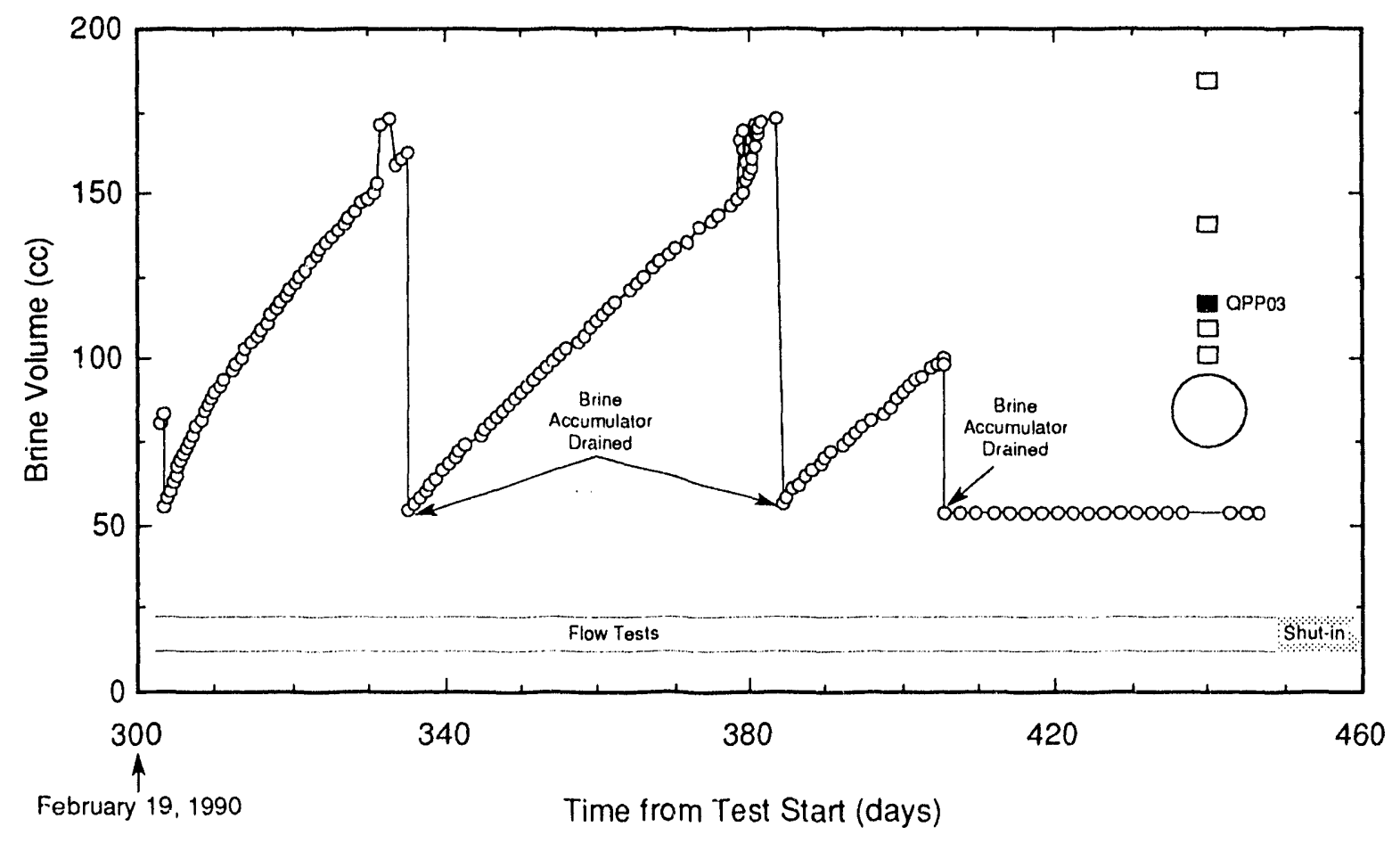

TRI-6119-89-0

Figure 6-19. Brine collected from QPP03 test zone during flow testing. 


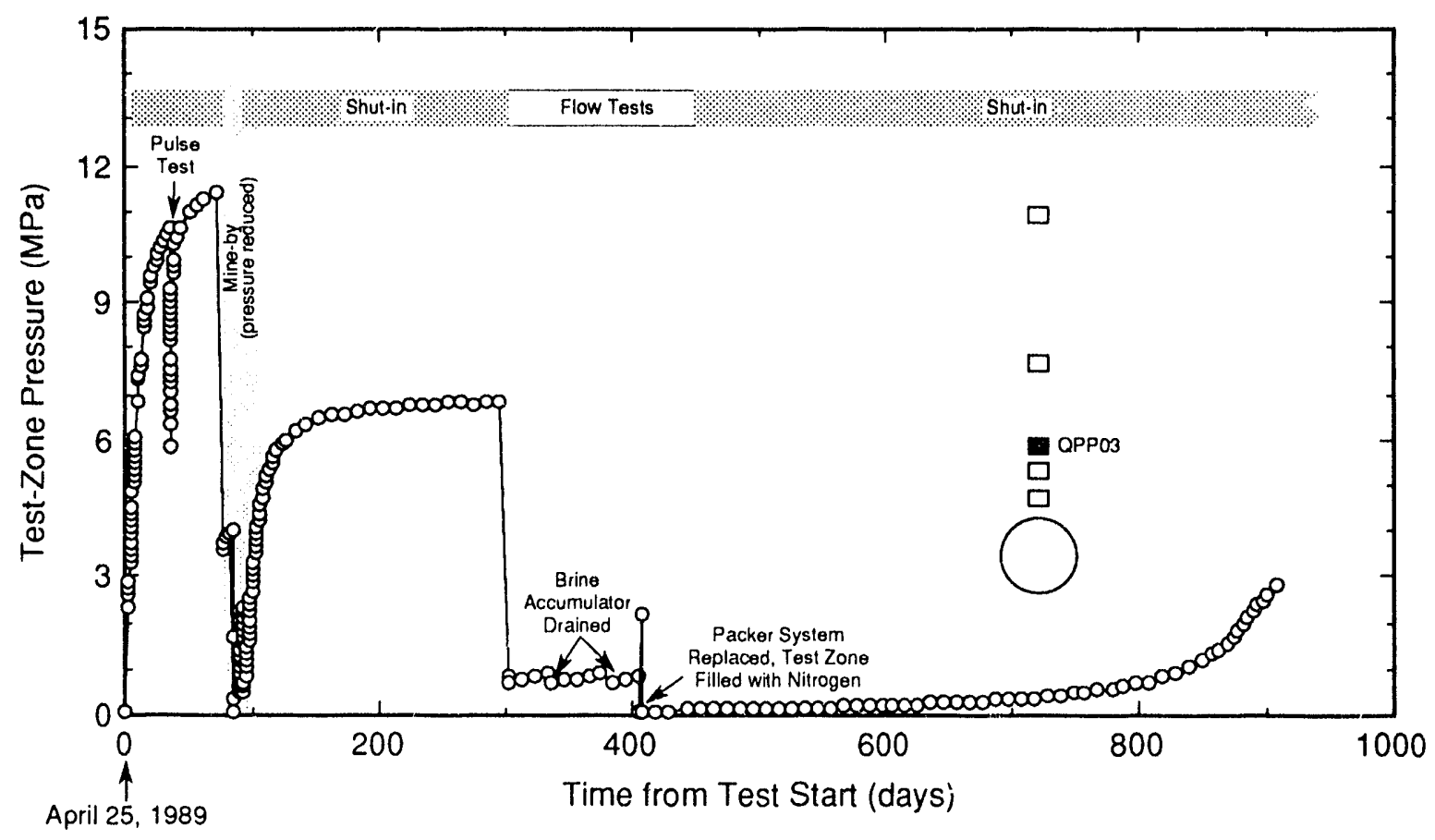

TAI.6119-90.0

Figure 6-20. Hole QPP03 test-zone pressure.

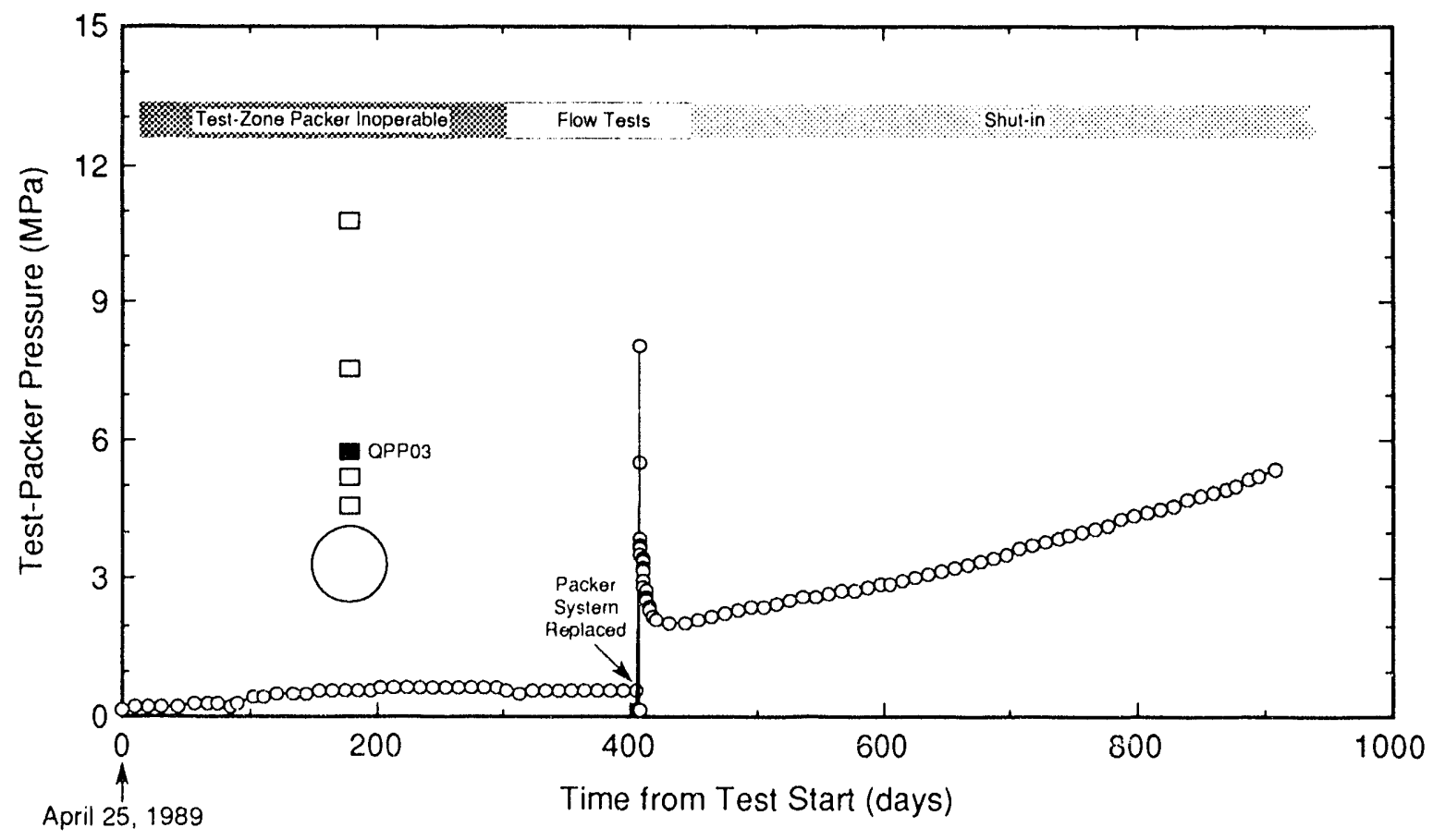

TRI-6119.91-0

Eigure 6-21. Hole QPP03 test-packer pressure. 


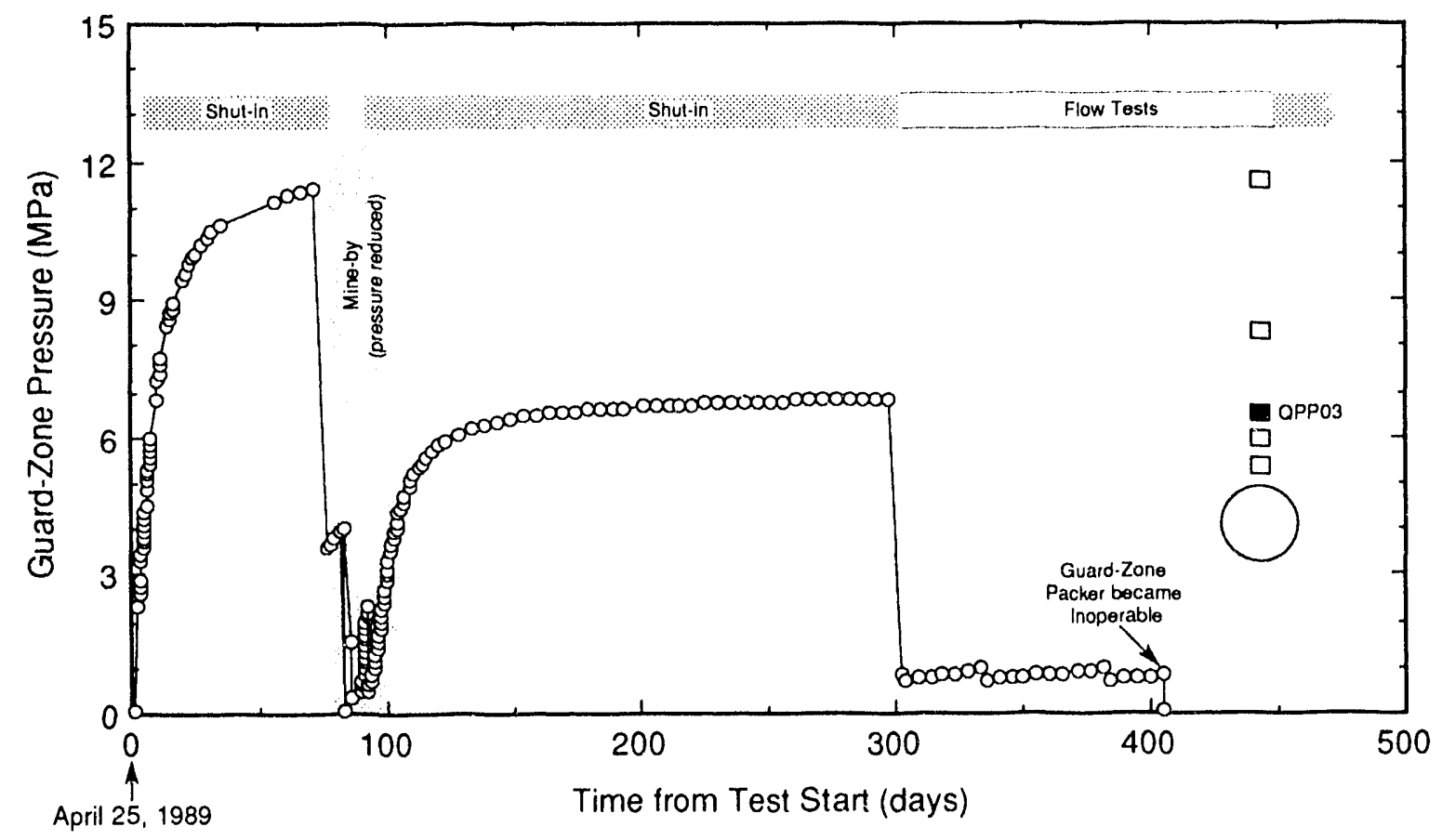

Figure 6-22. Hole QPP03 guard-zone pressure.

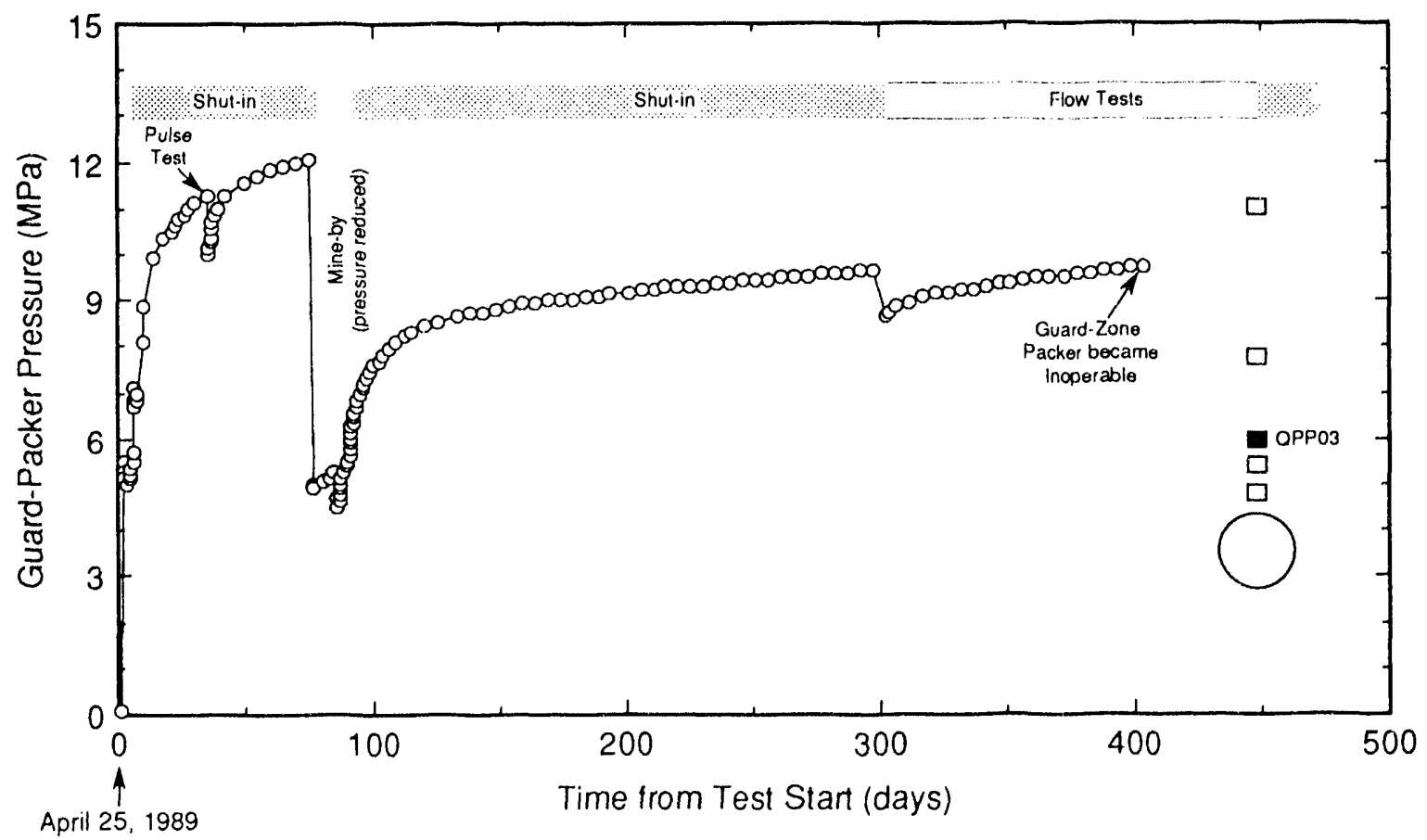

Figure 6-23. Hole QPP03 guard-packer pressure. 


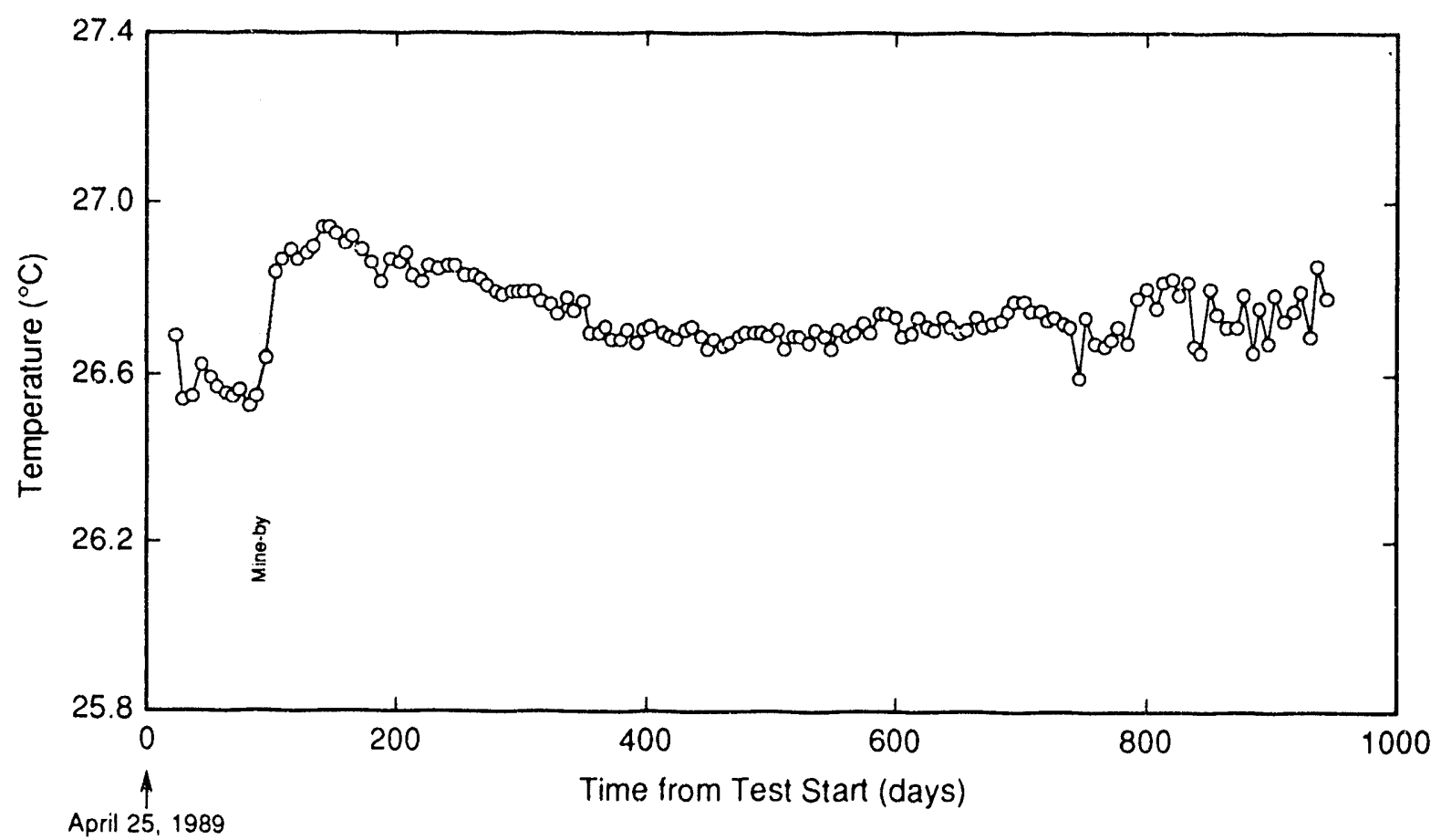

TRI.6119-25-0

Figure 6-24. Hole QPPO3 tool temperature.

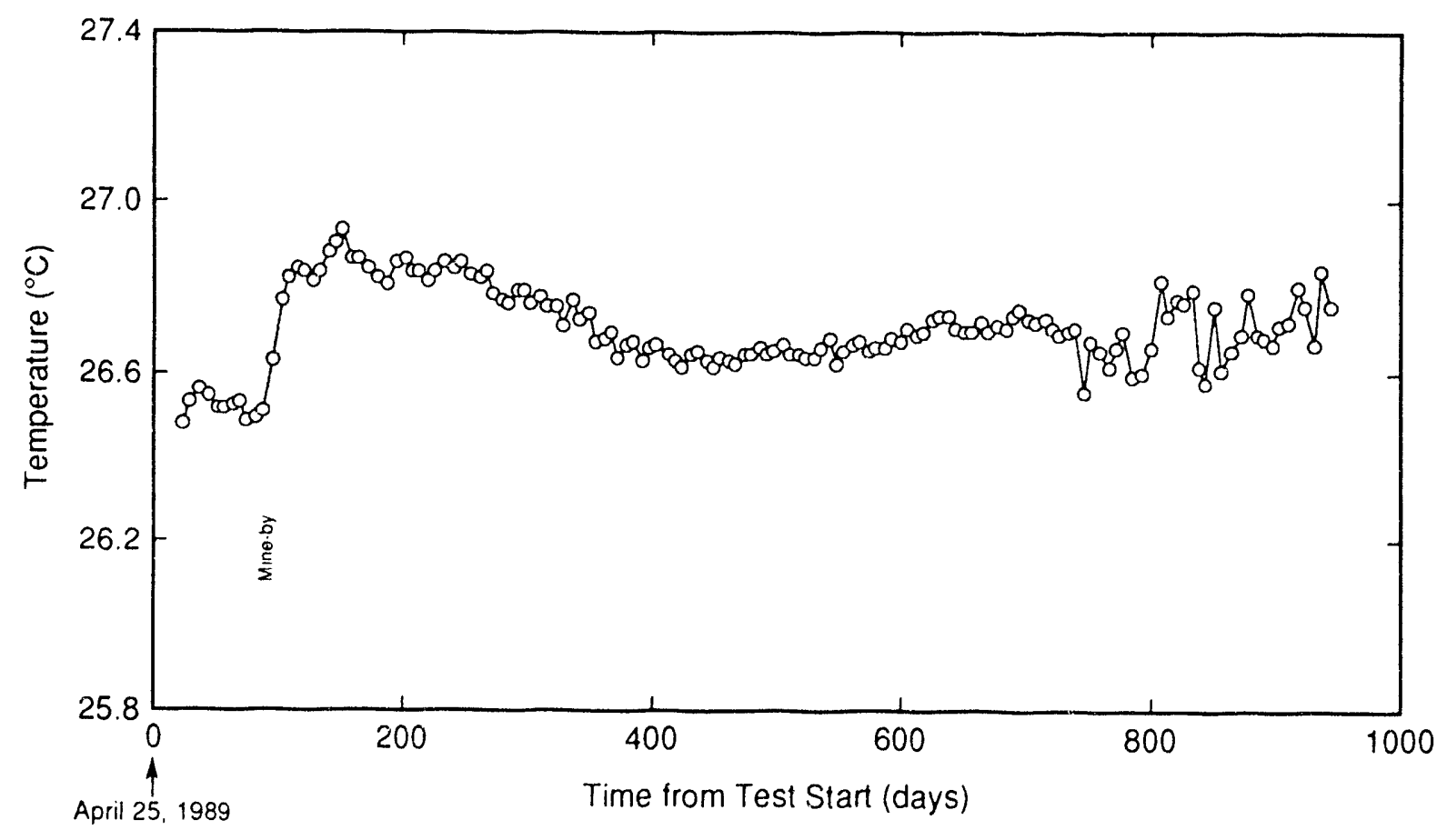

Eigure 6-25. Hole QPPO3 casing temperature. 


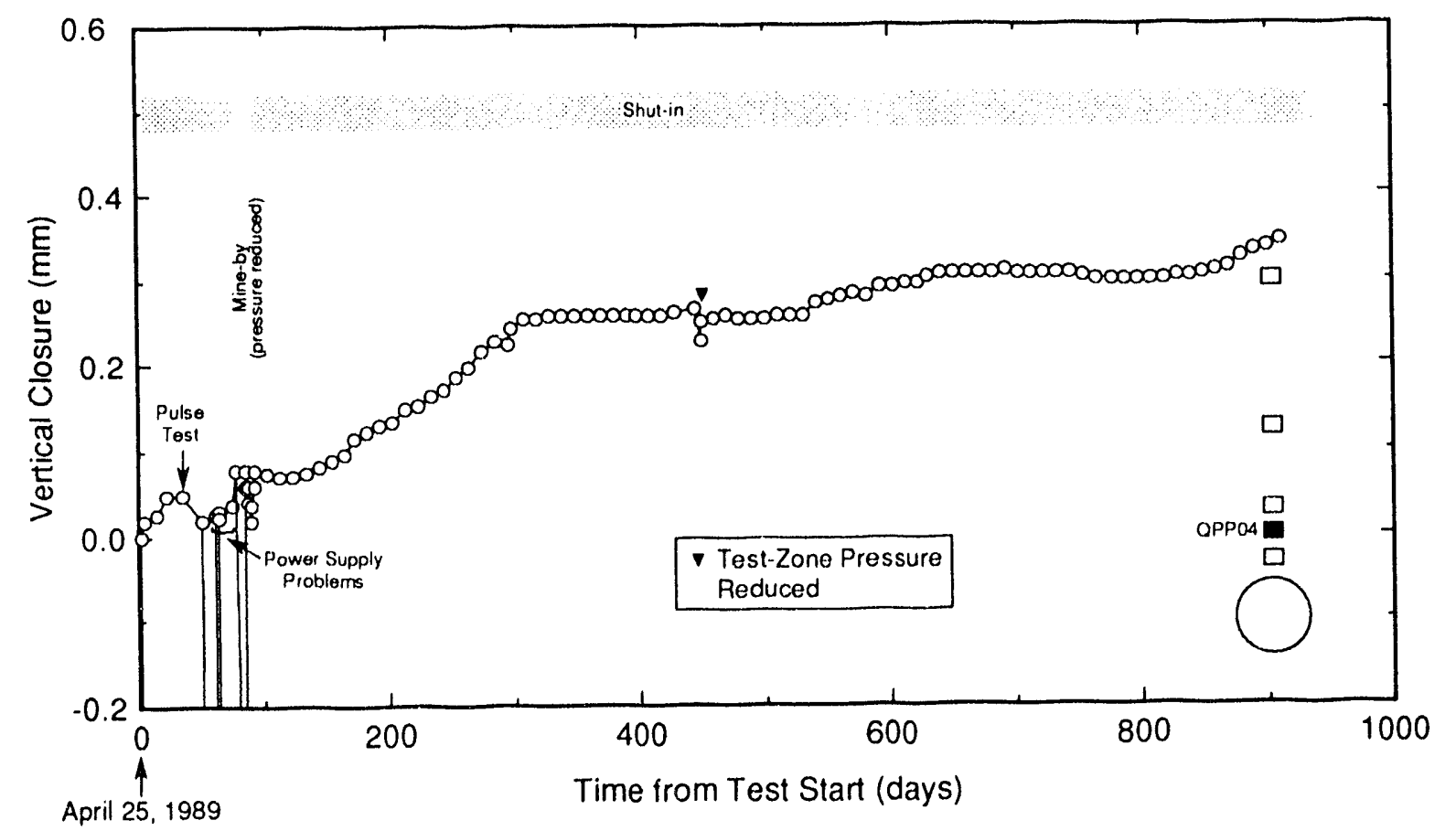

TRI-6119-94-0

Figure 6-26. Vertical closure measured in the test zone of hole QPP04.

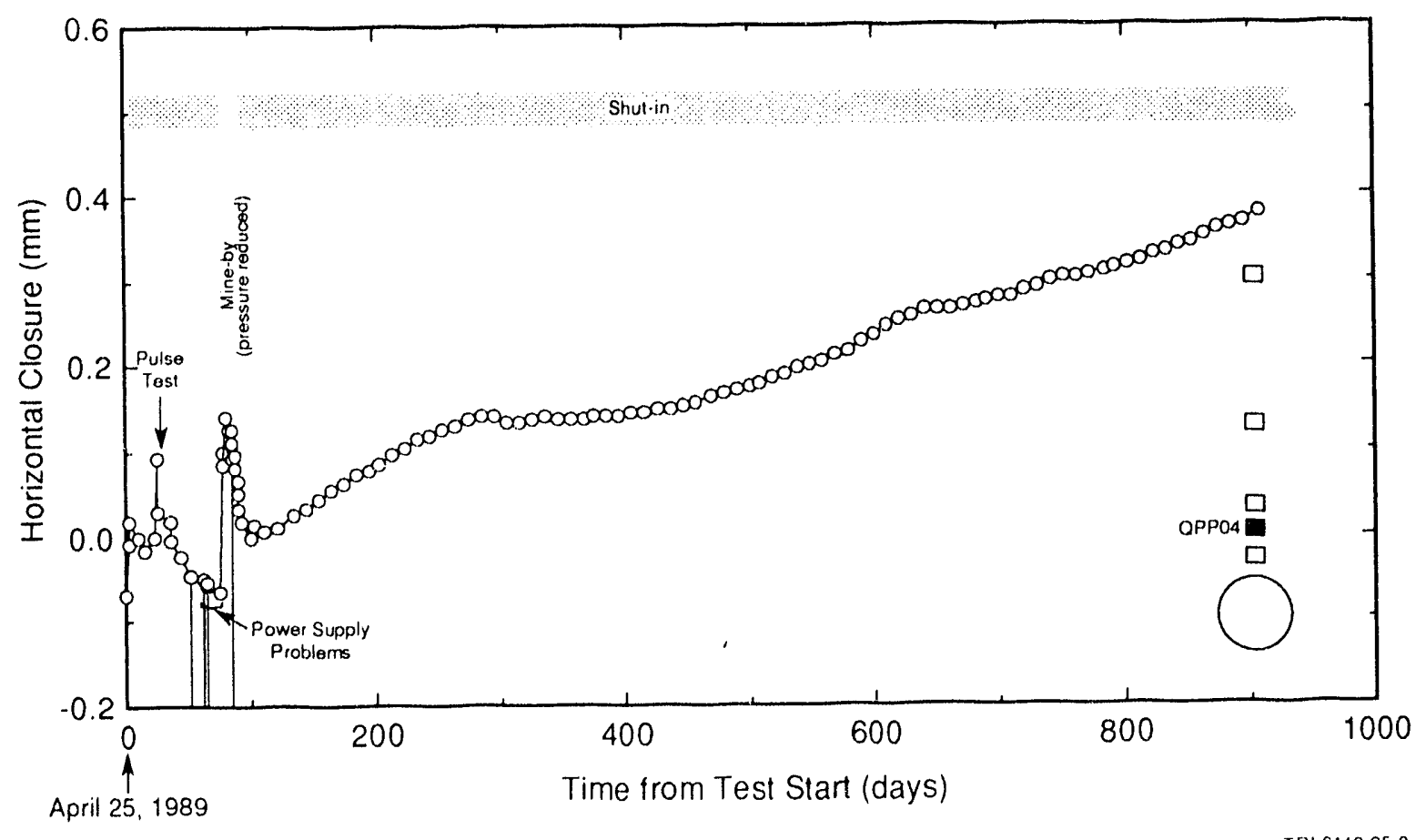

Figure 6-27. Horizontal closure measured in the test zone of hole QPPO4. 


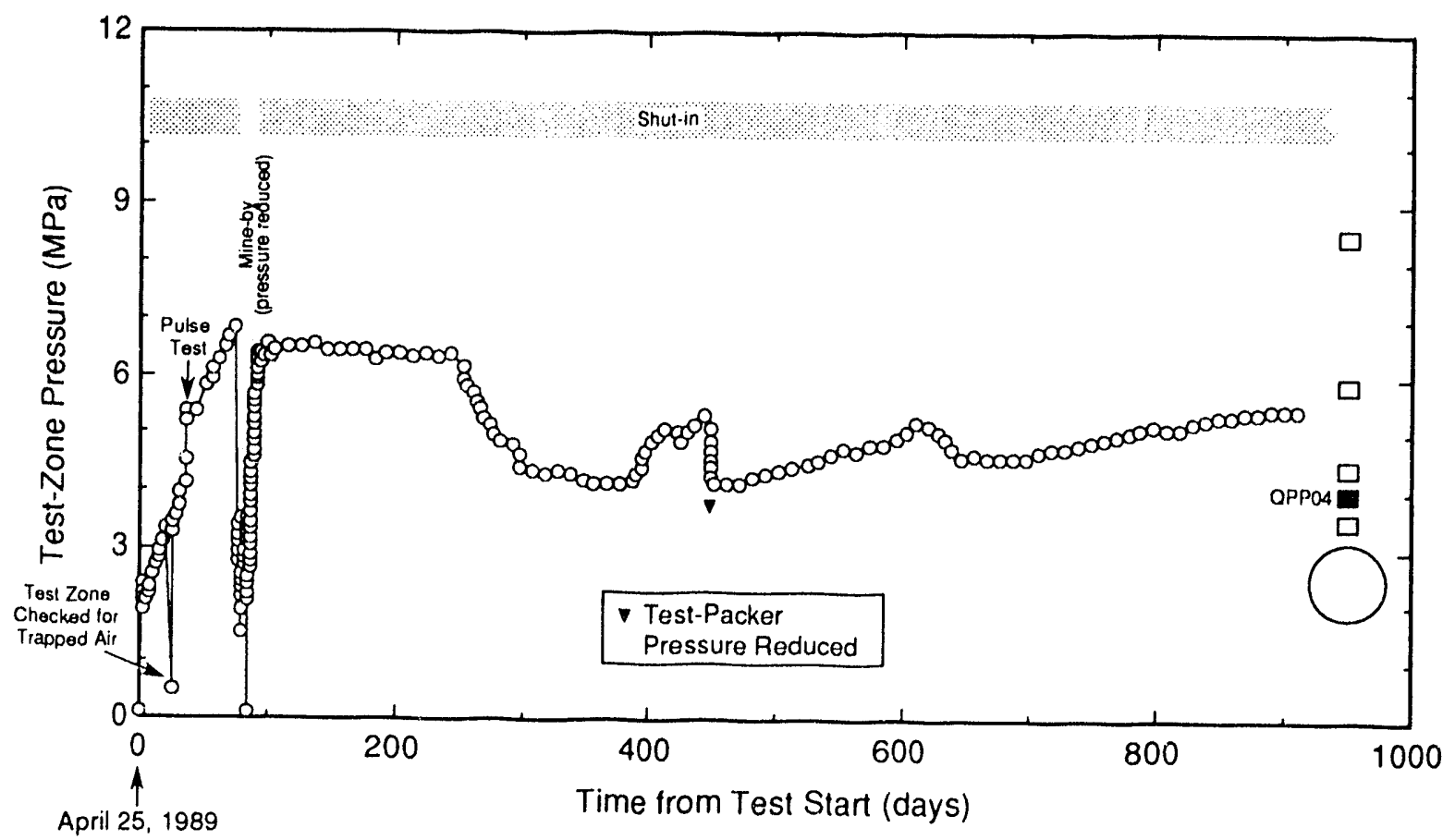

TR1-6119.96.0

Figure 6-28. Hole QPPO4 test-zone pressure.

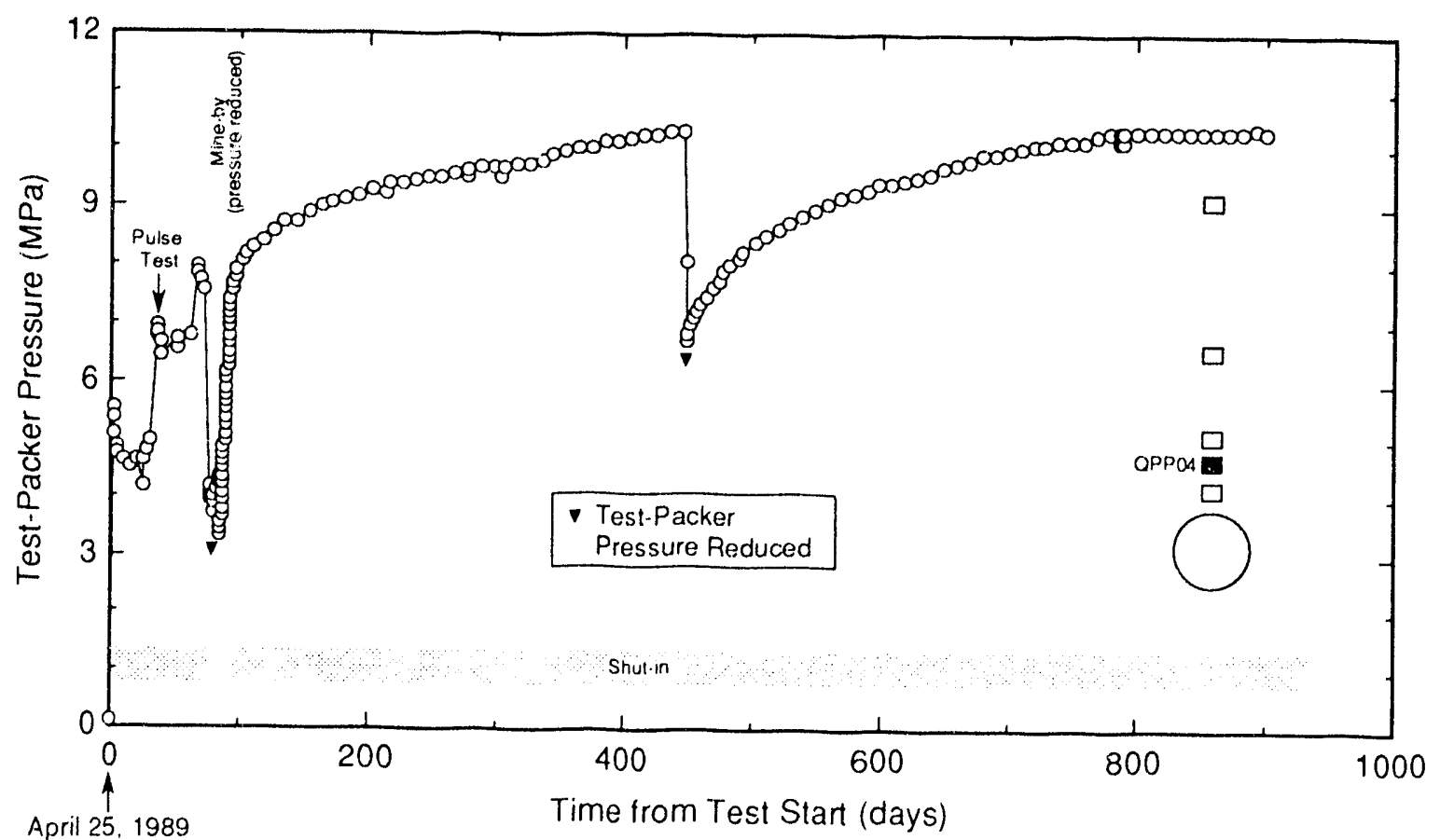

TRI.6119.97.0

Figure 6-29. Hole QPP04 test-packer pressure. 


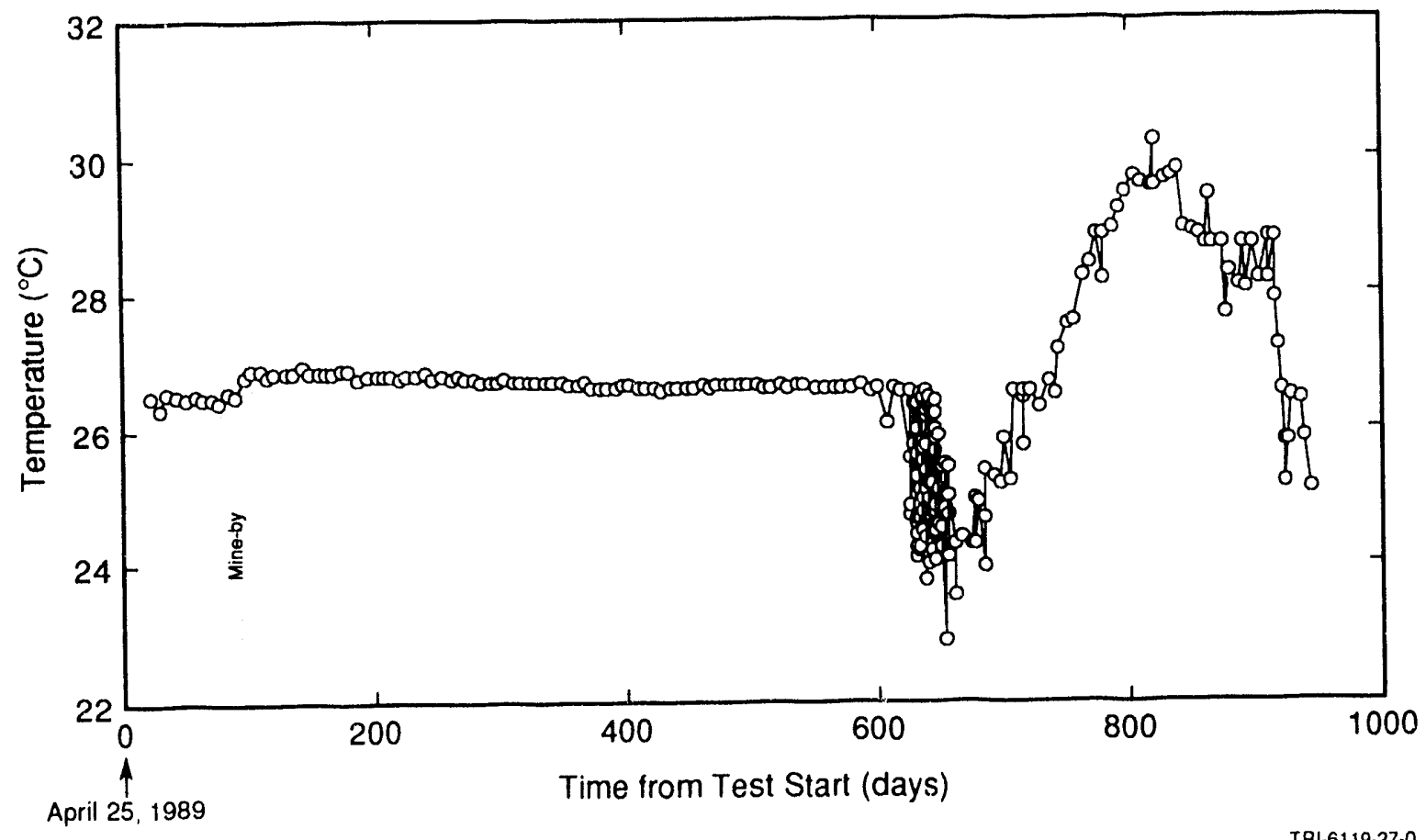

Eigure 6-30. Hole QPP04 tool temperature.

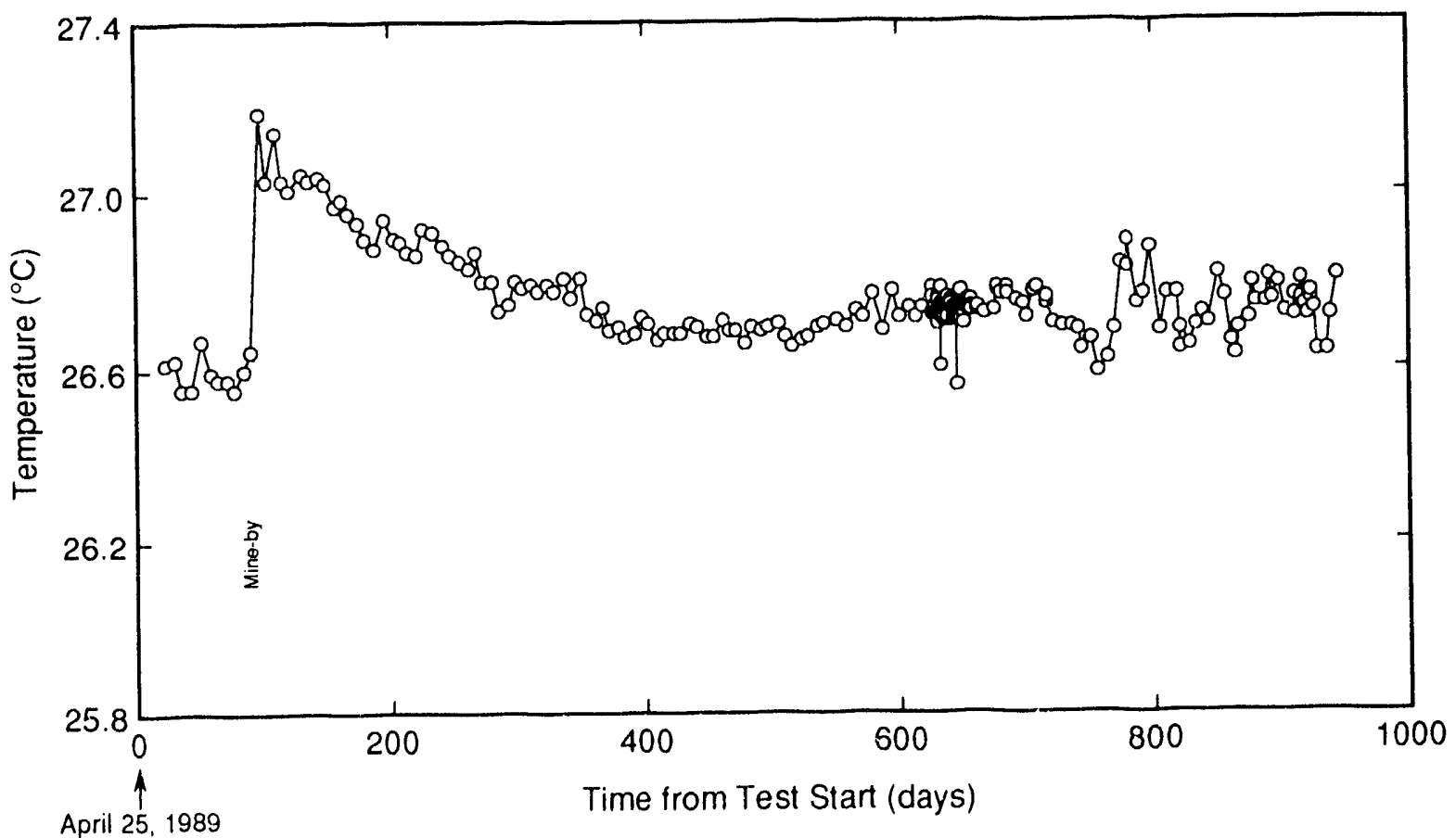

Eigure 6-31. Hole QPPO4 casing temperature. 


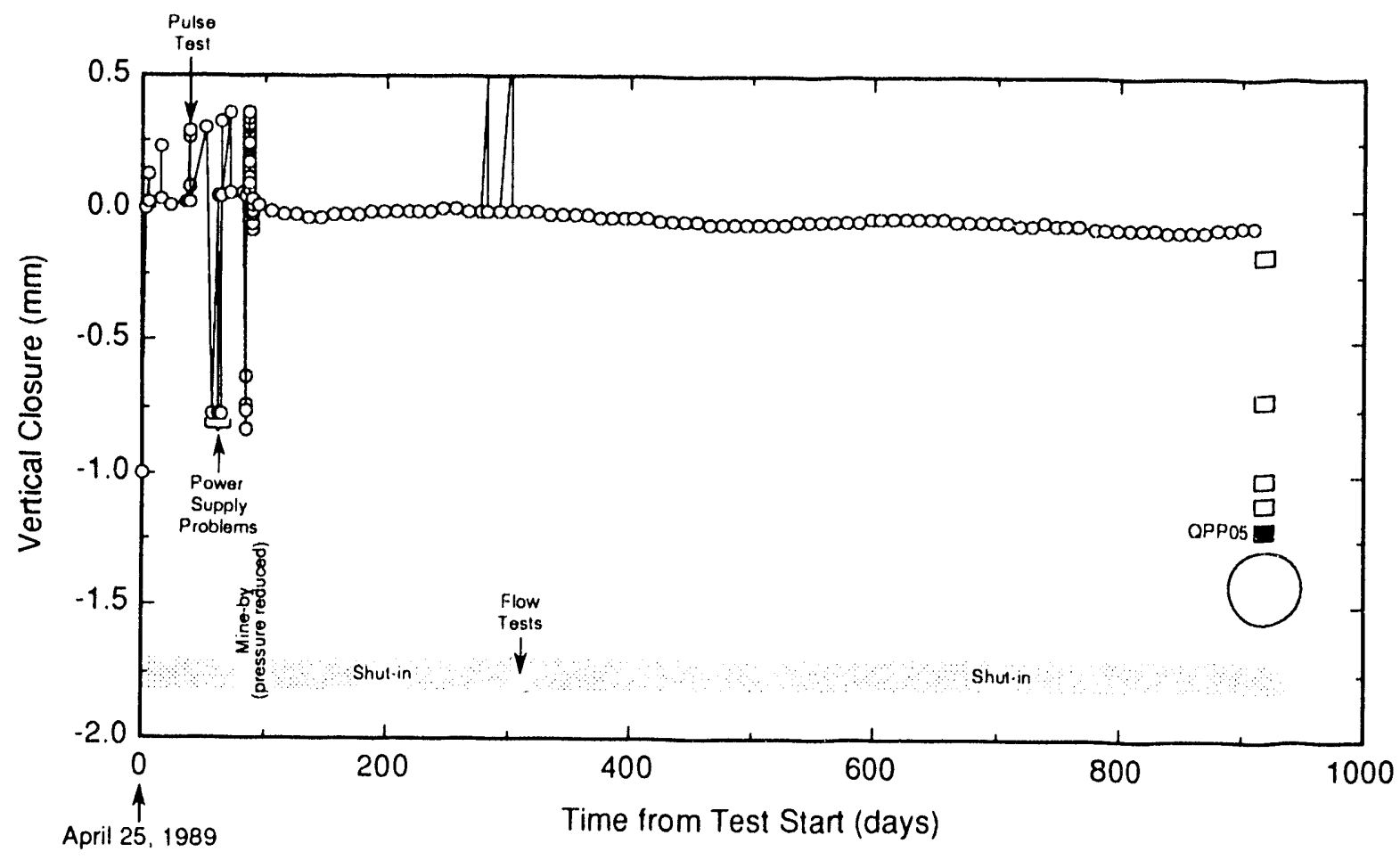

TRI.6119.98.0

Figure 6-32. Vertical closure measured in the test zone of hole QPP05.

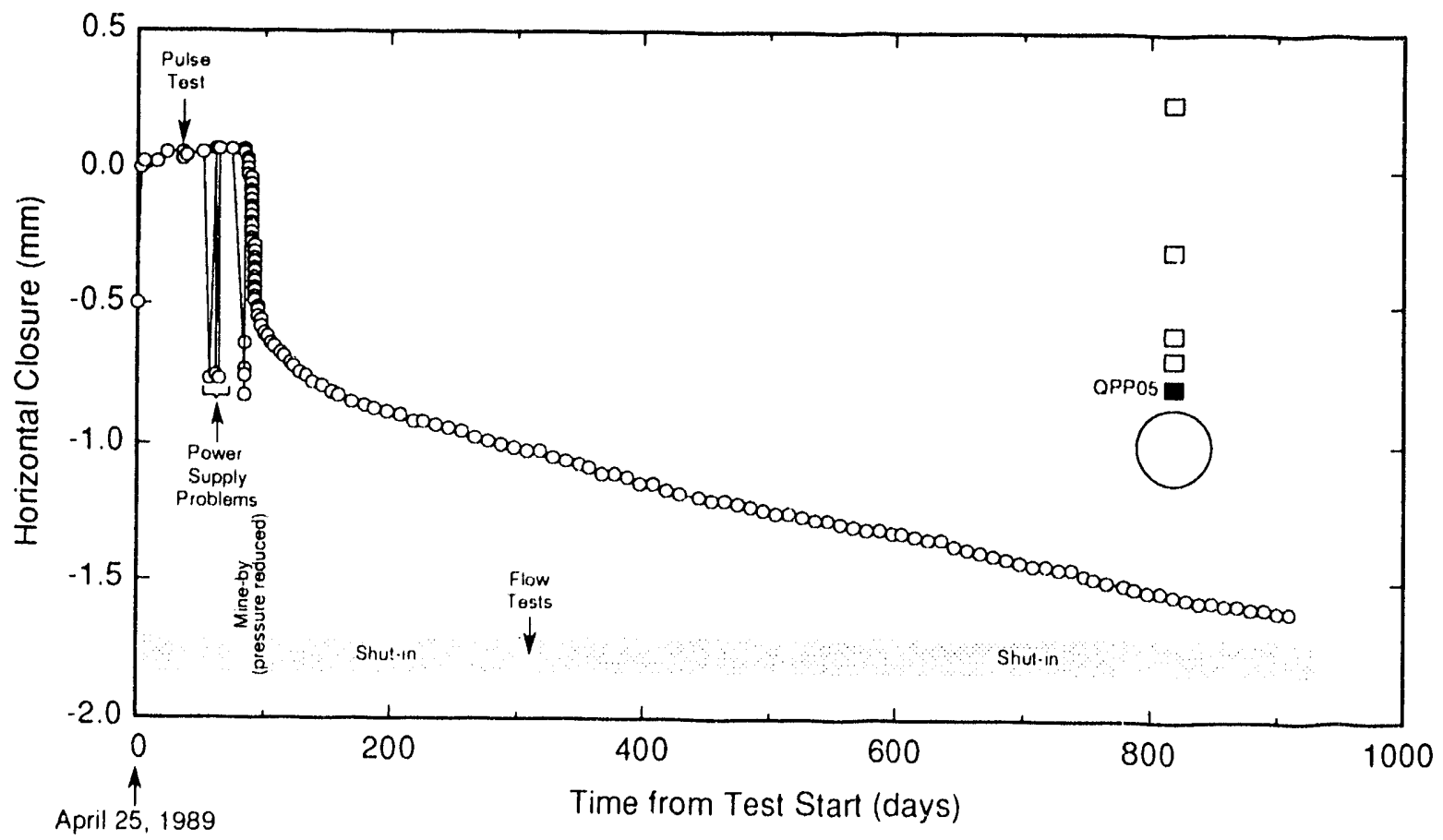

TP1.6119.99.0

Eigure 6-33. Horizontal closure measured in the test zone of hole QPP05. 


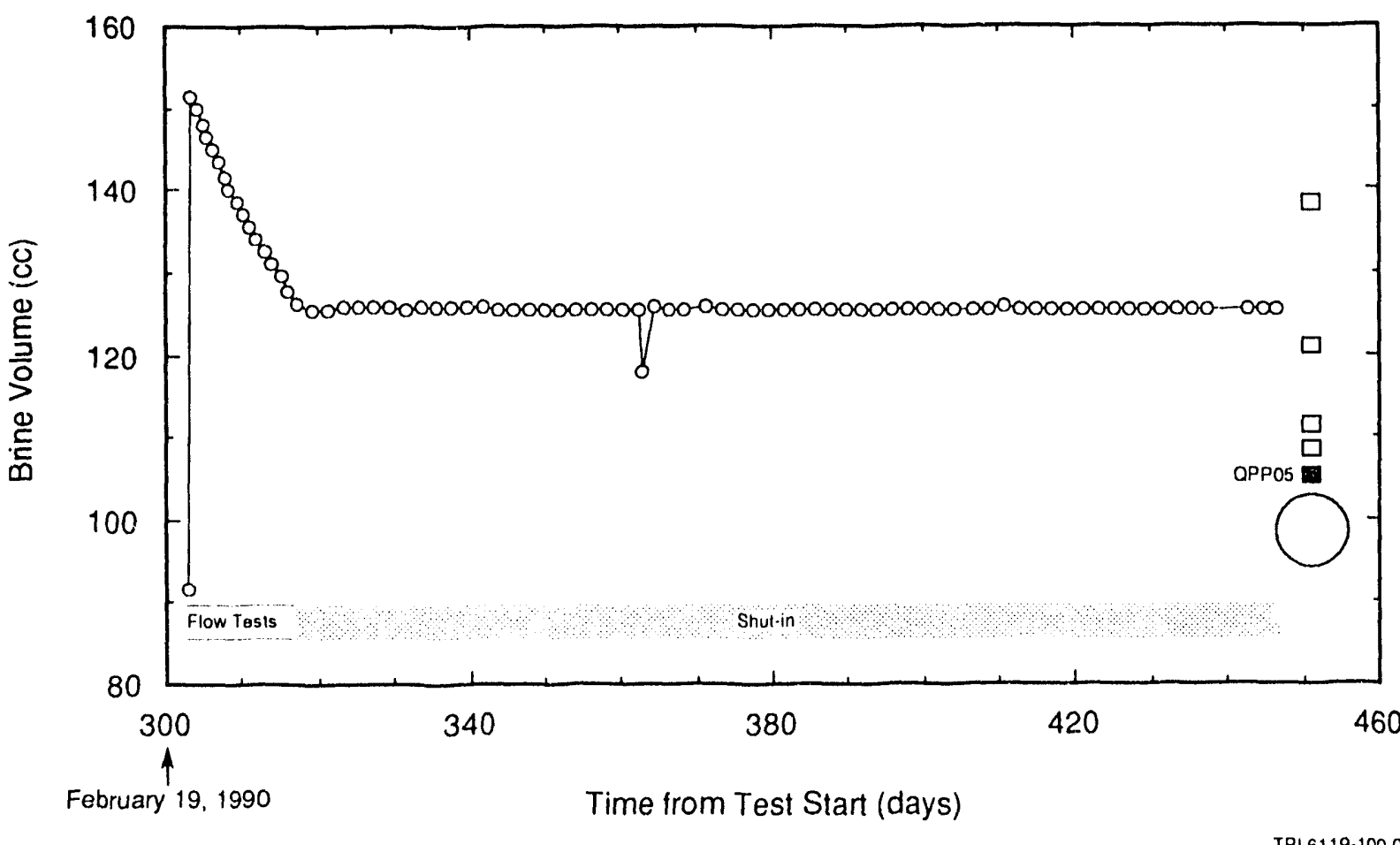

Figure 6-34. Brine lost from QPP05 test zone during flow testing. 


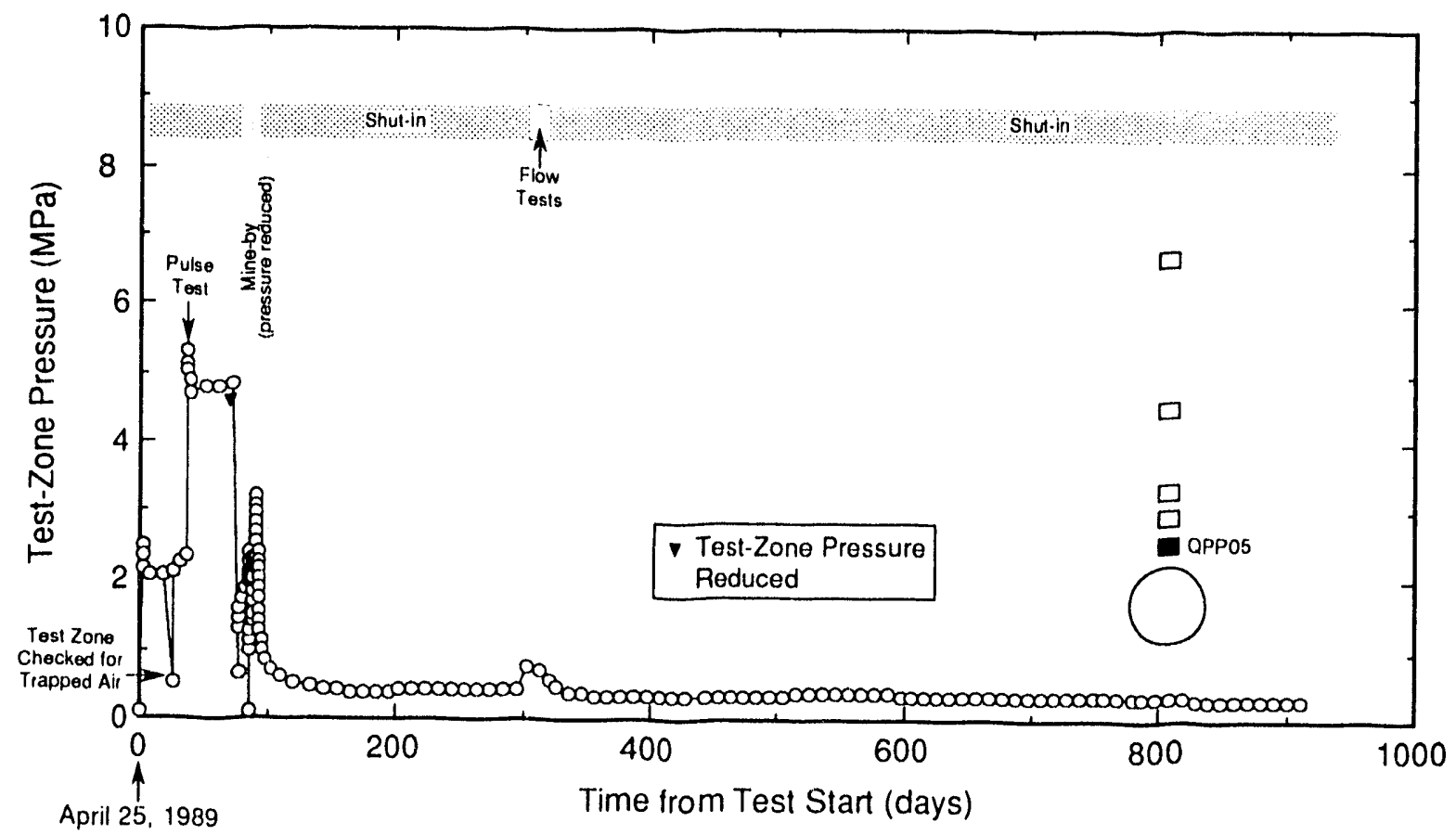

TR1.6119.173.0

Figure 6-35. Hole QPP05 test-zone pressure.

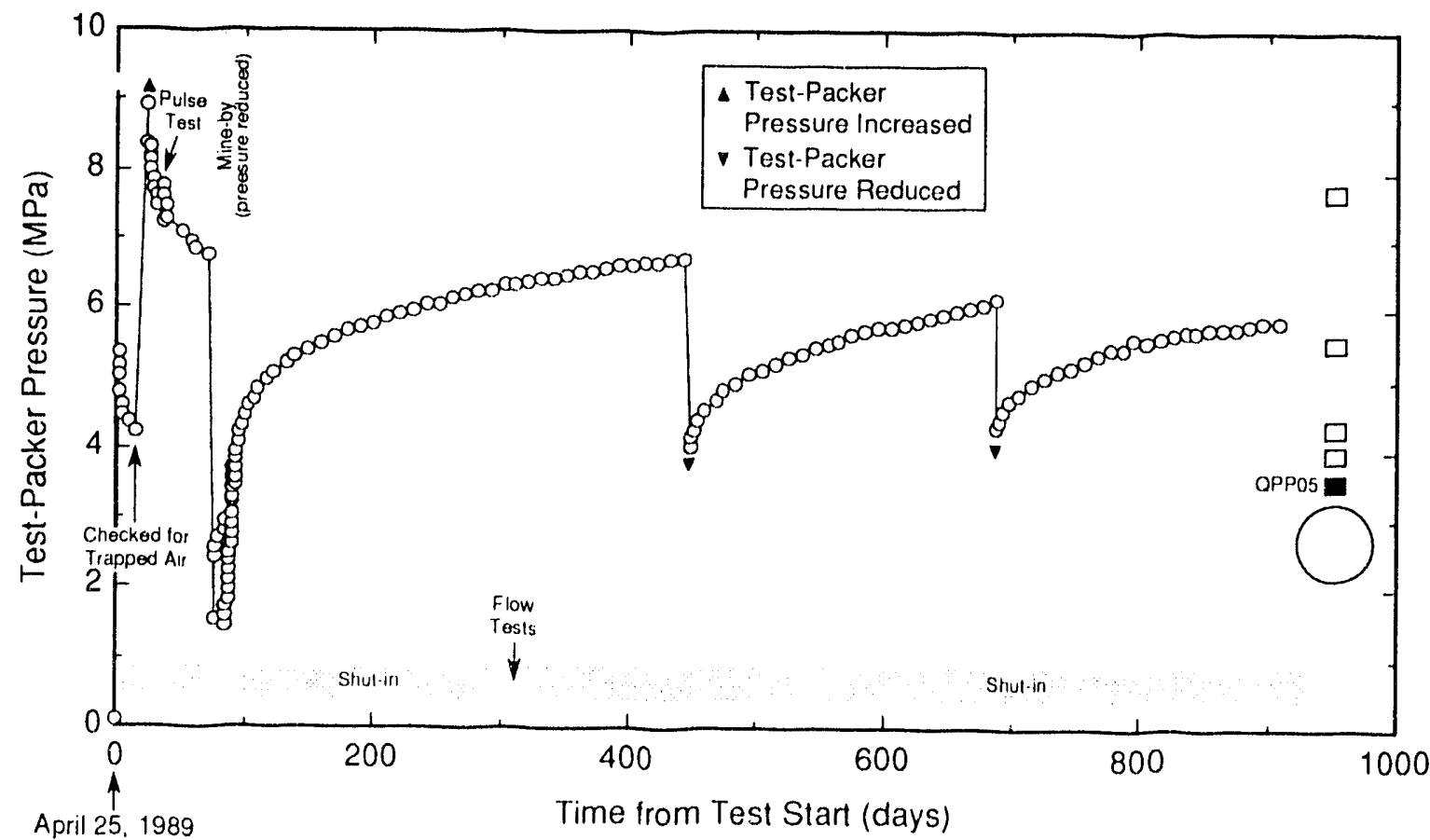

TR1.6119.174.0

Figure 6-36. Hole QPP05 test-packer pressure. 


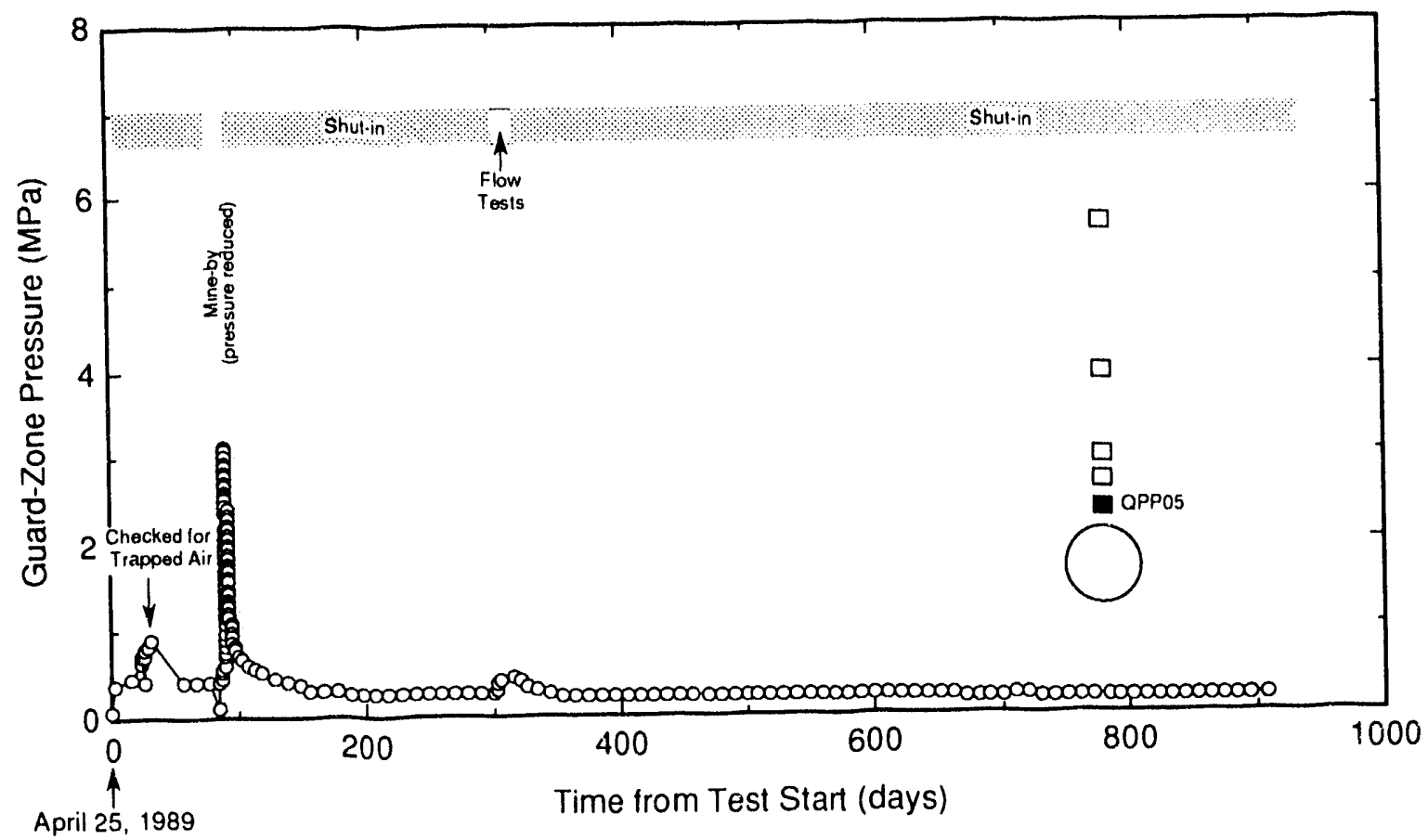

Figure 6-37. Hole QPP05 guard-zone pressure.

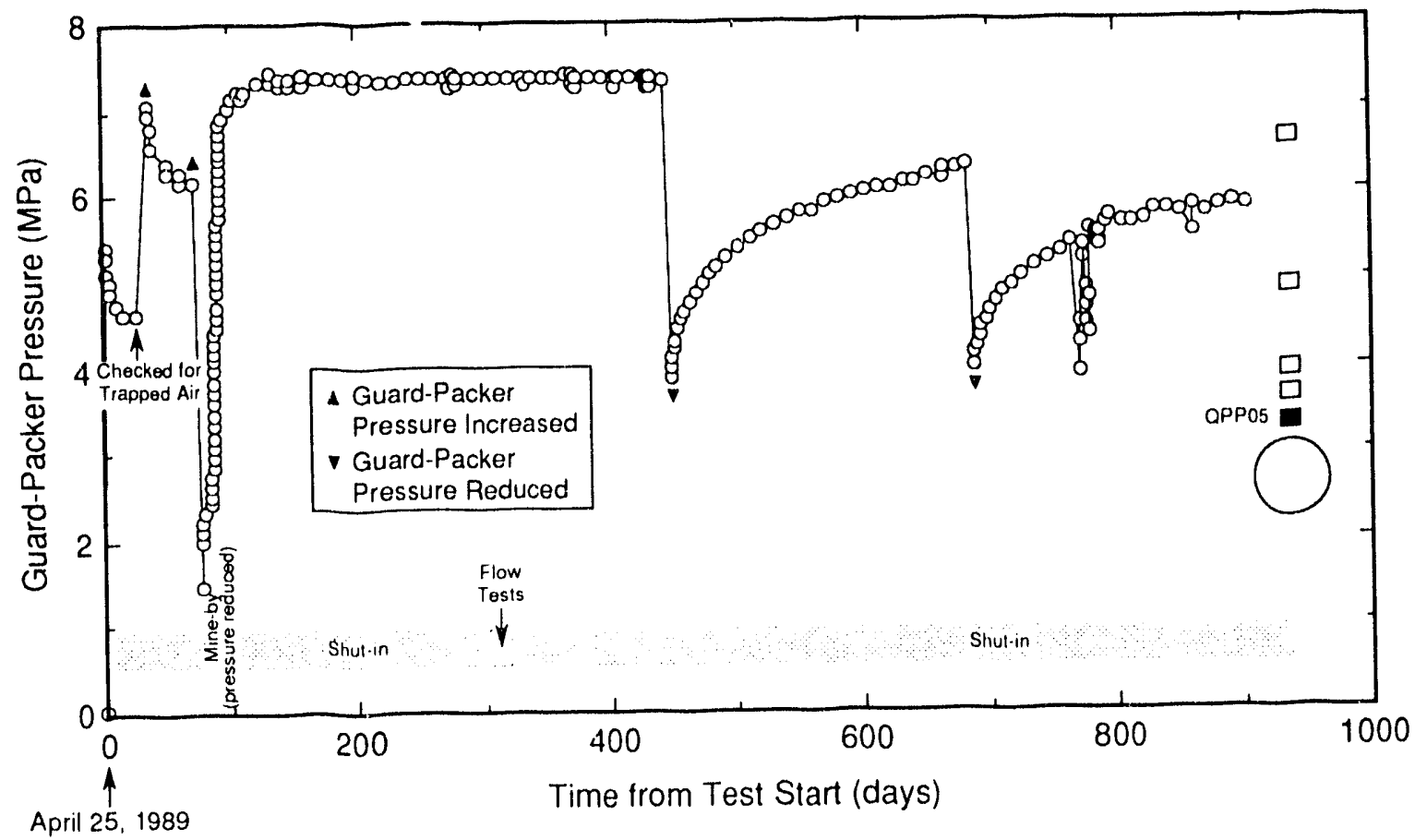

Eigure 6-38. Hole QPP05 guard-packer pressure. 


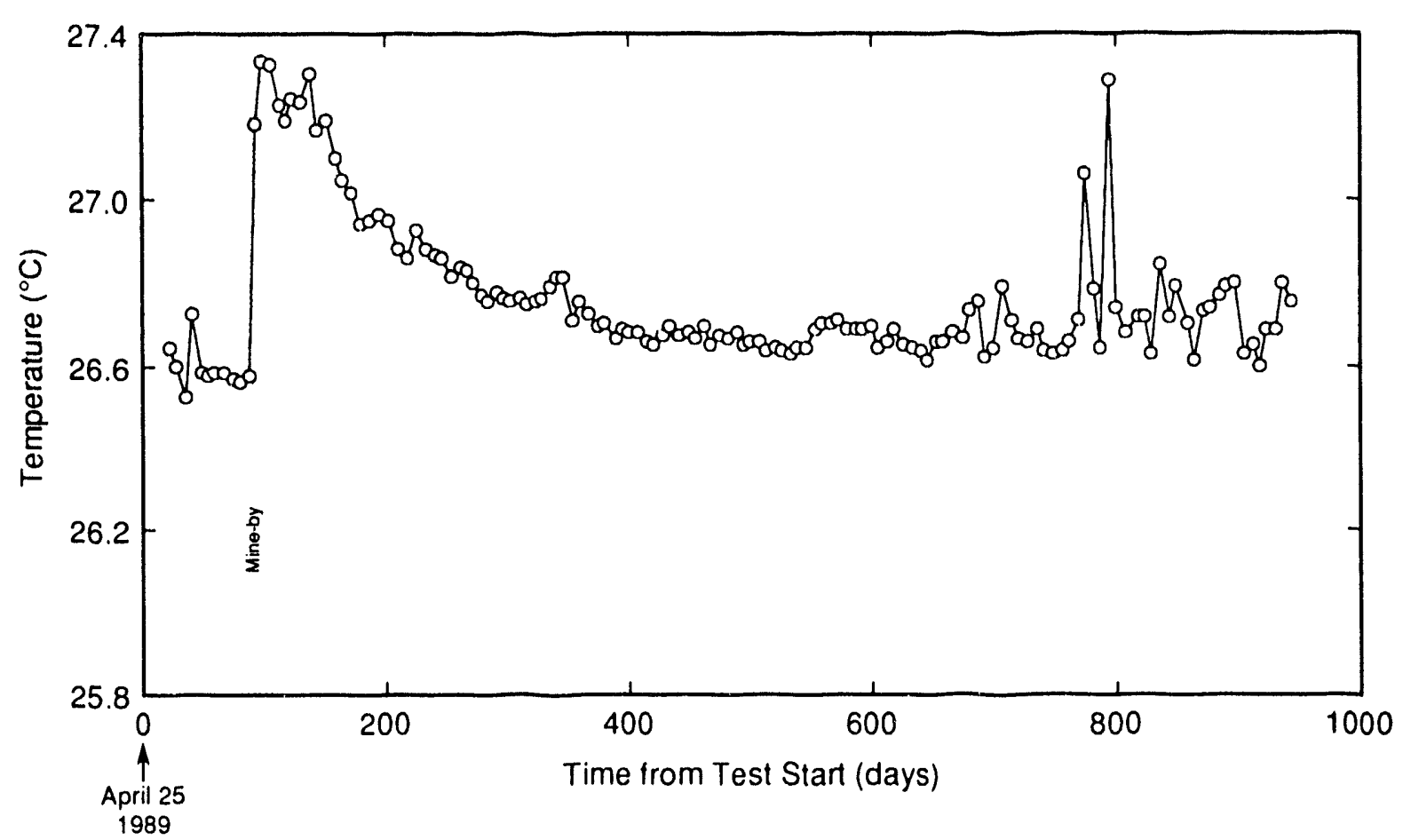

TR1.6119.29.0

Figure 6-39. Hole QPP05 tool temperature.

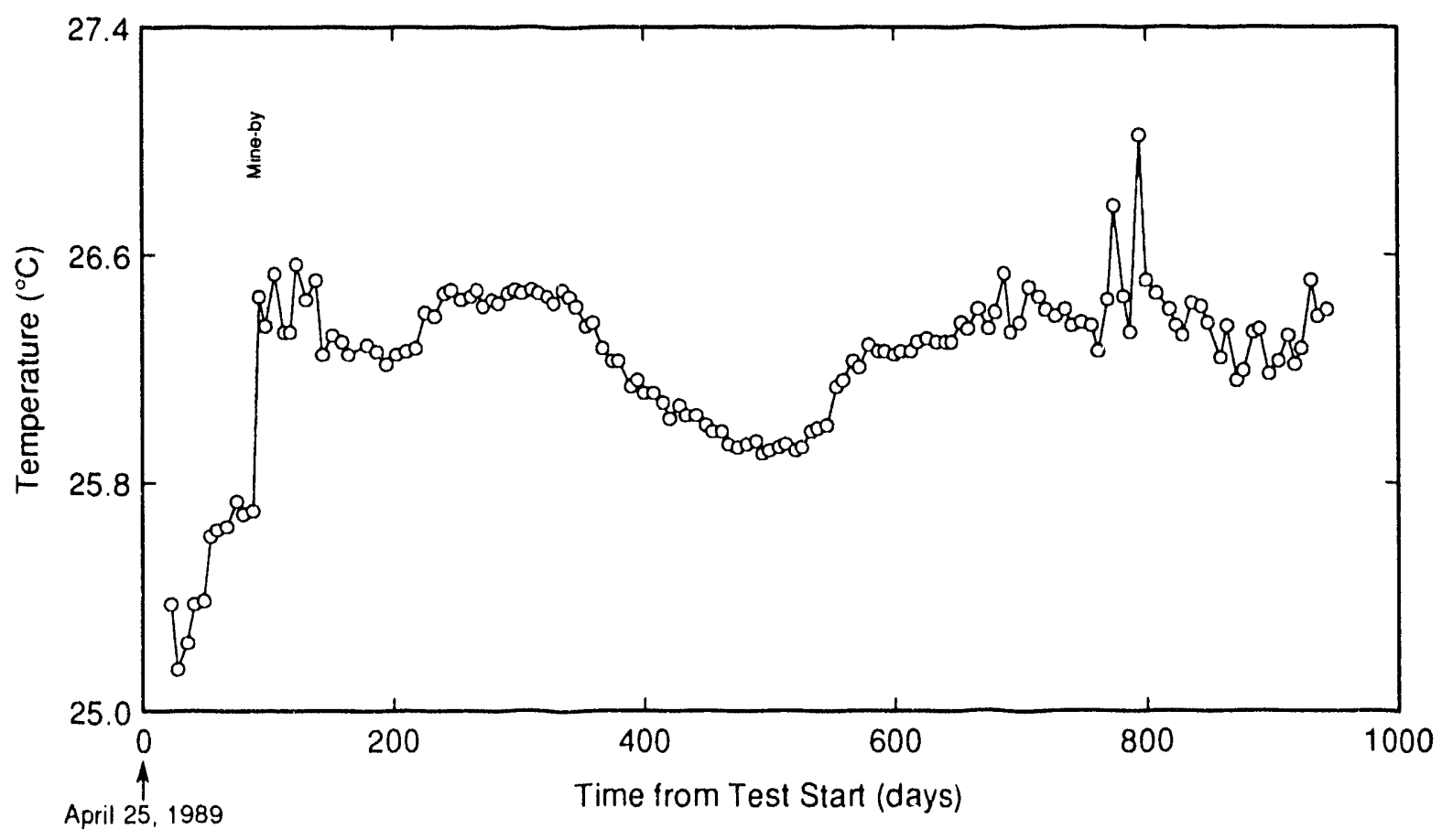

TR1.6119.30.0

Figure 6-40. Hole QPP05 casing temperature. 


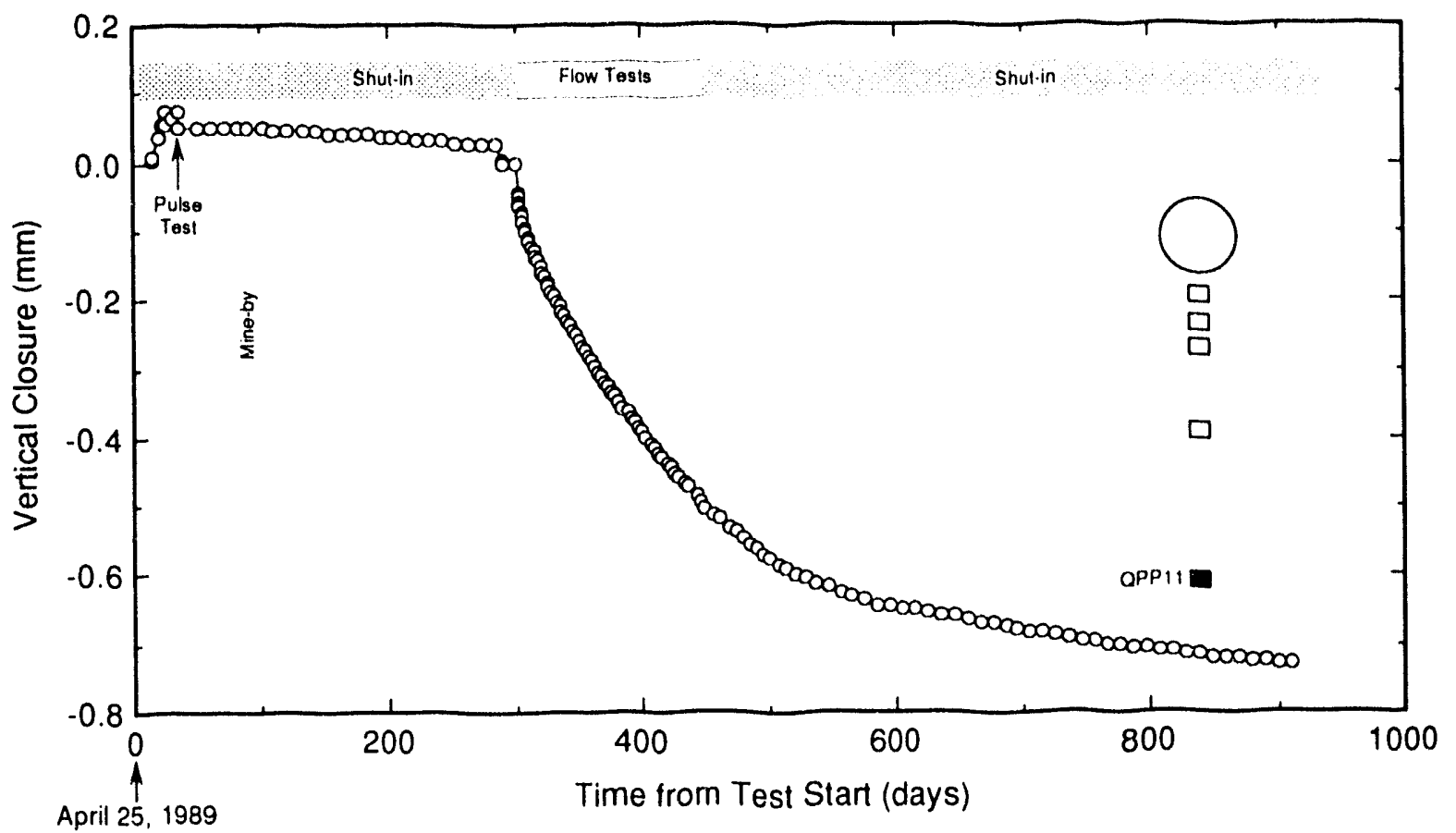

TRI.6119-177.0

Figure 6-41. Vertical closure measured in the test zone of hole QPP11.

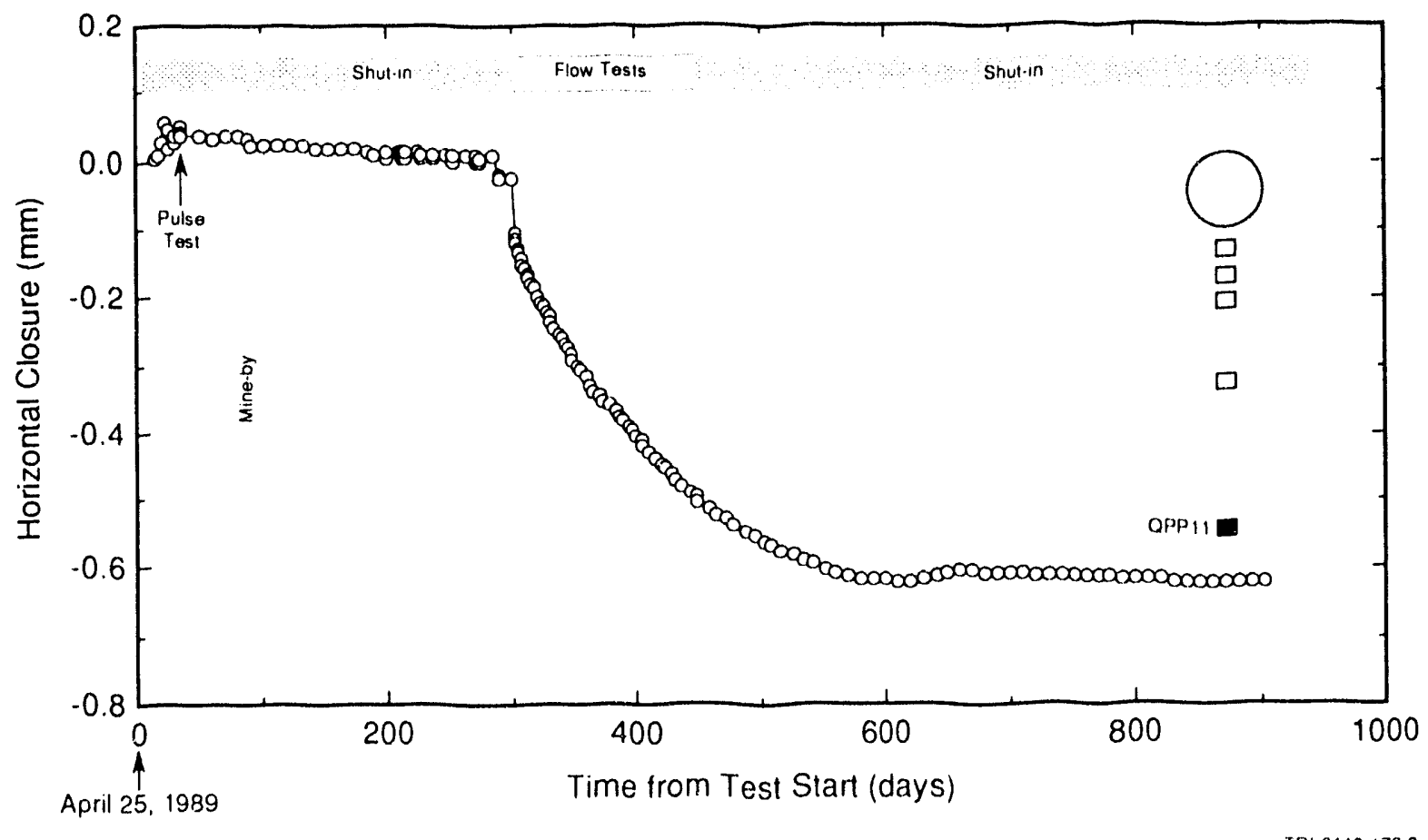

Eigure 6-42. Horizontal closure measured in the test zone of hole QPP11. 


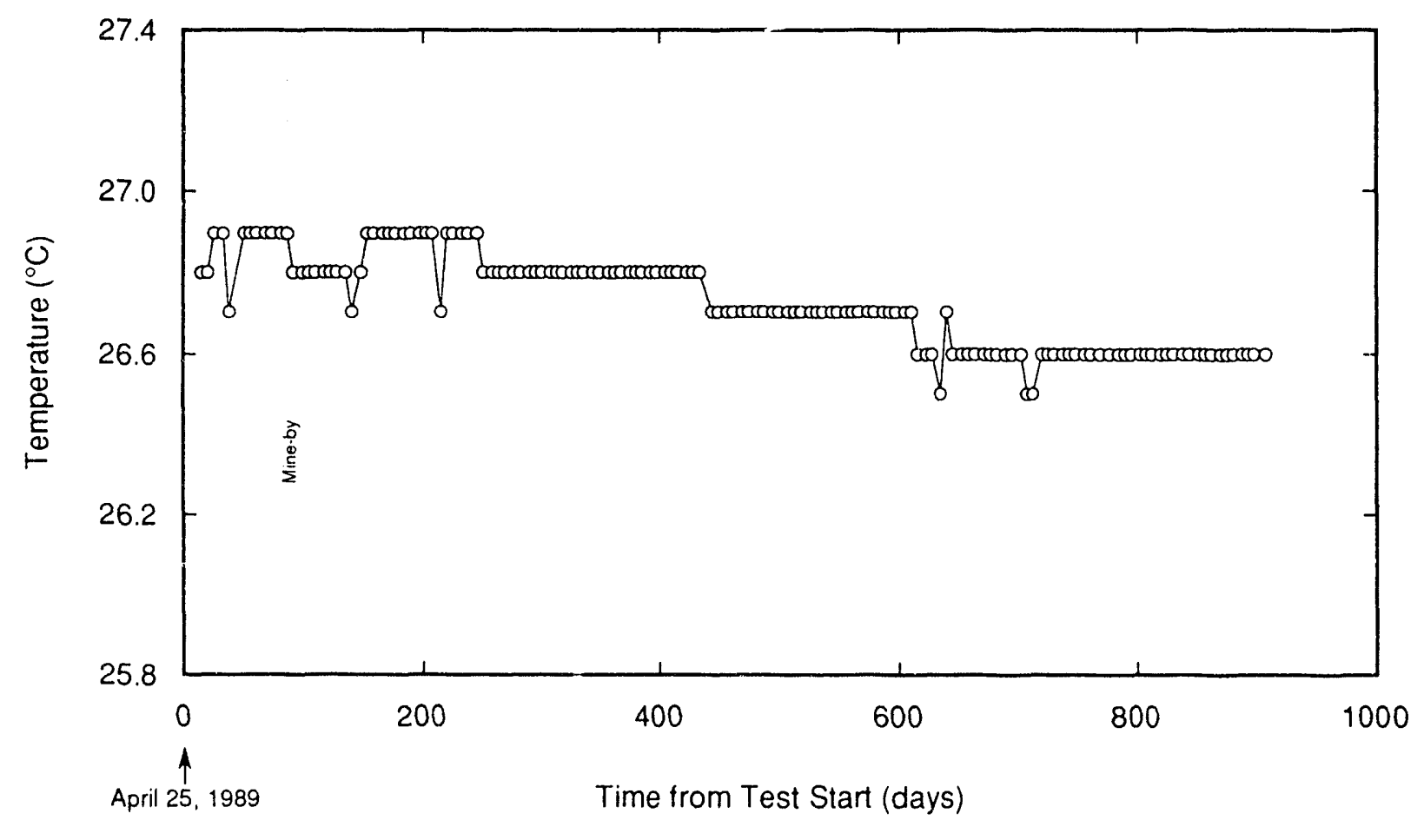

TRI.6119.48.0

Figure 6-43. Hole QPP11 test-zone temperature. 


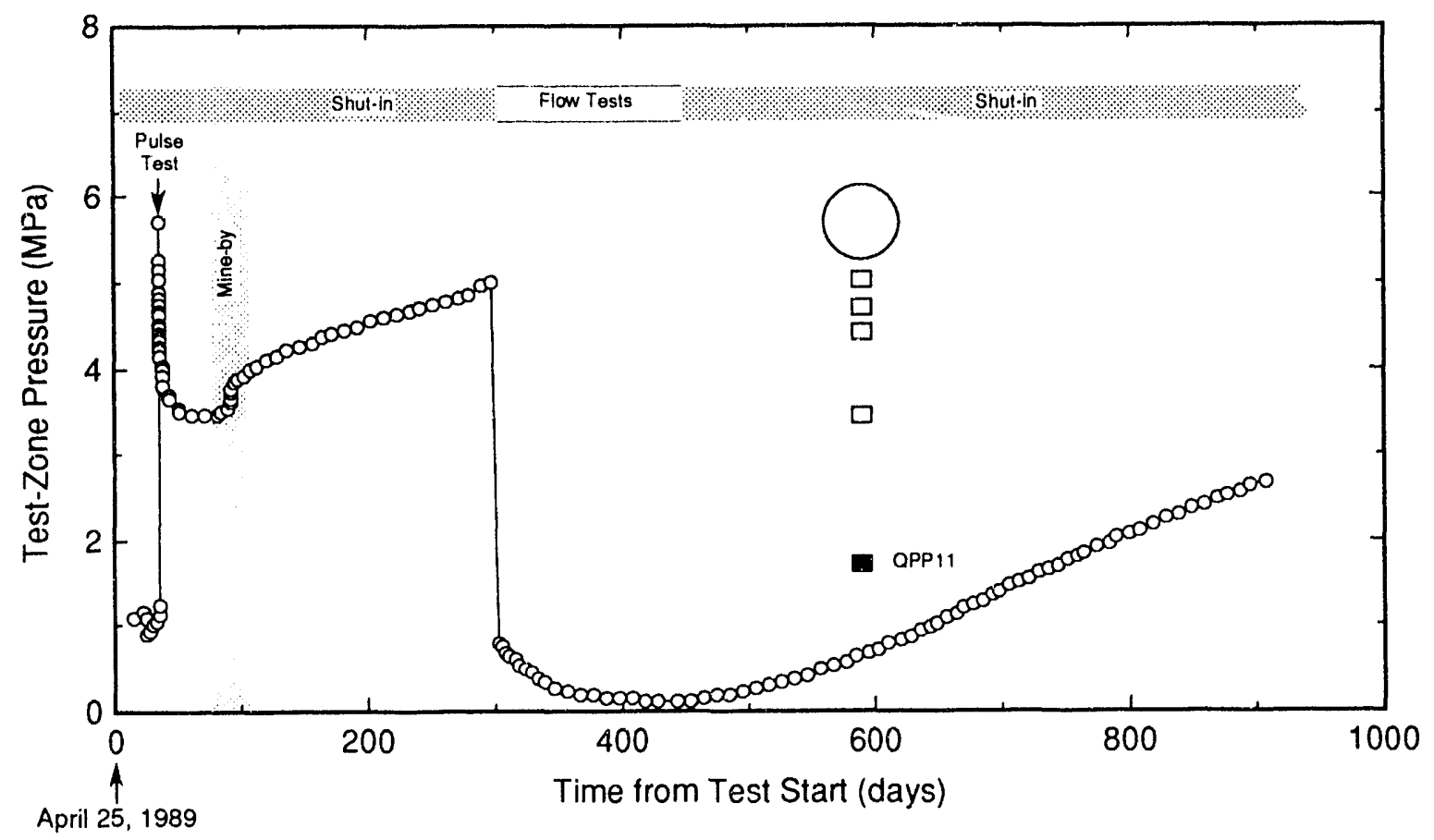

Figure 6-44. Hole QPP11 test-zone pressure.

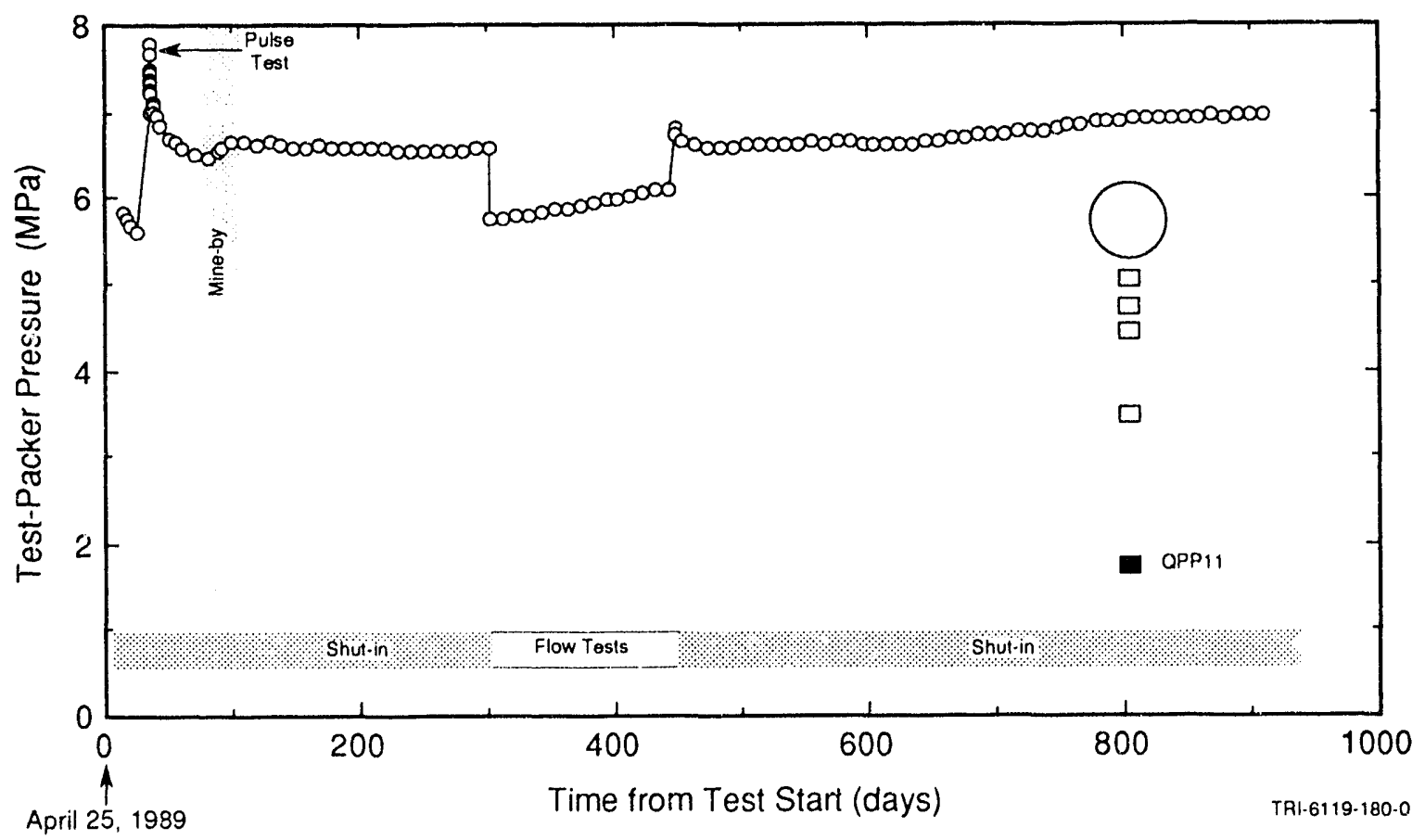

Figure 6-45. Hole QPPJ1 test-packer pressure. 


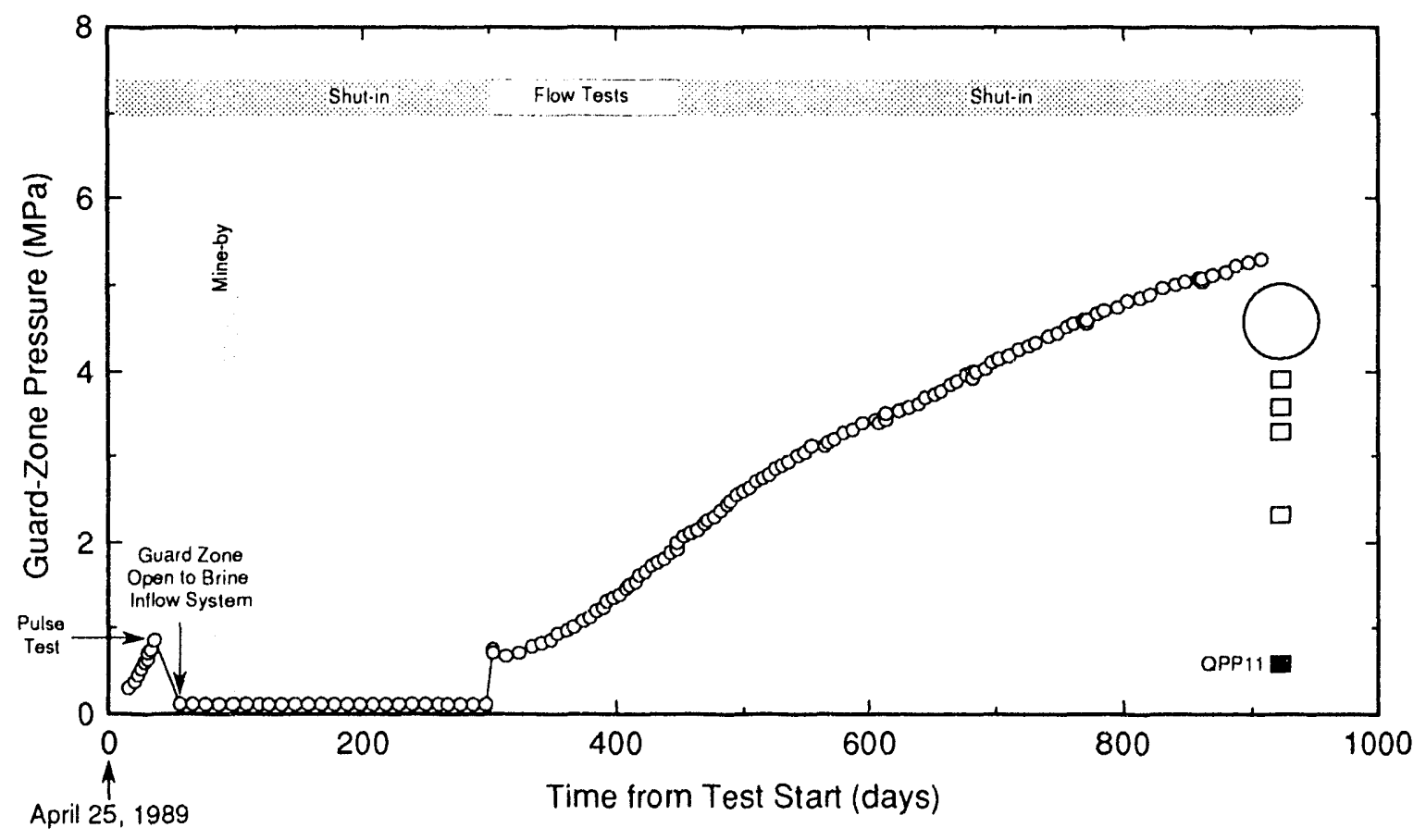

TRI.6119.181.0

Figure 6-46. Hole QPP11 guard-zone pressure.

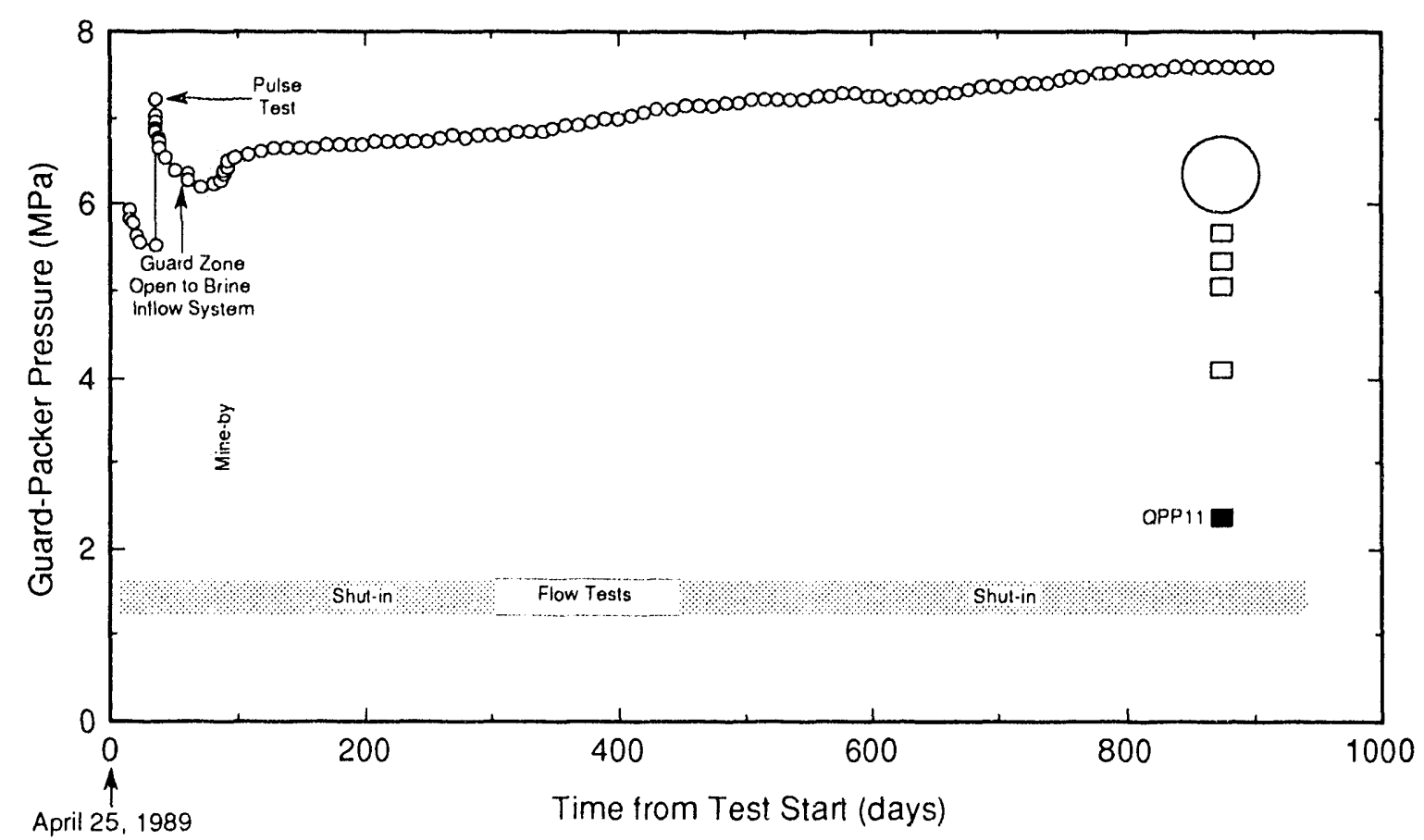

Eigure 6-47. Hole QPP11 guard-packer pressure. 


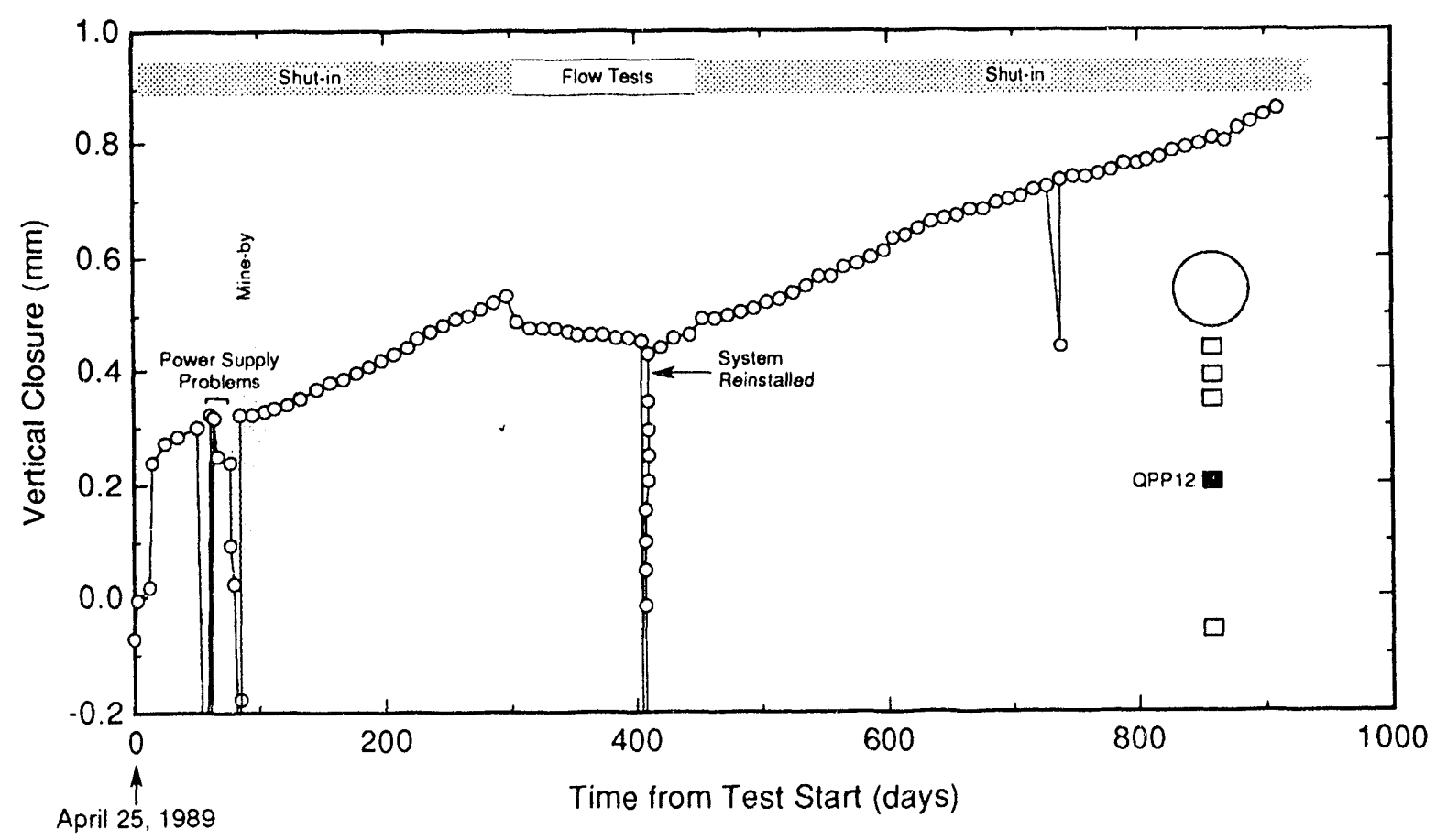

TR1.6119-183.0

Figure 6-48. Vertical closure measured in the test zone of hole QPP12.

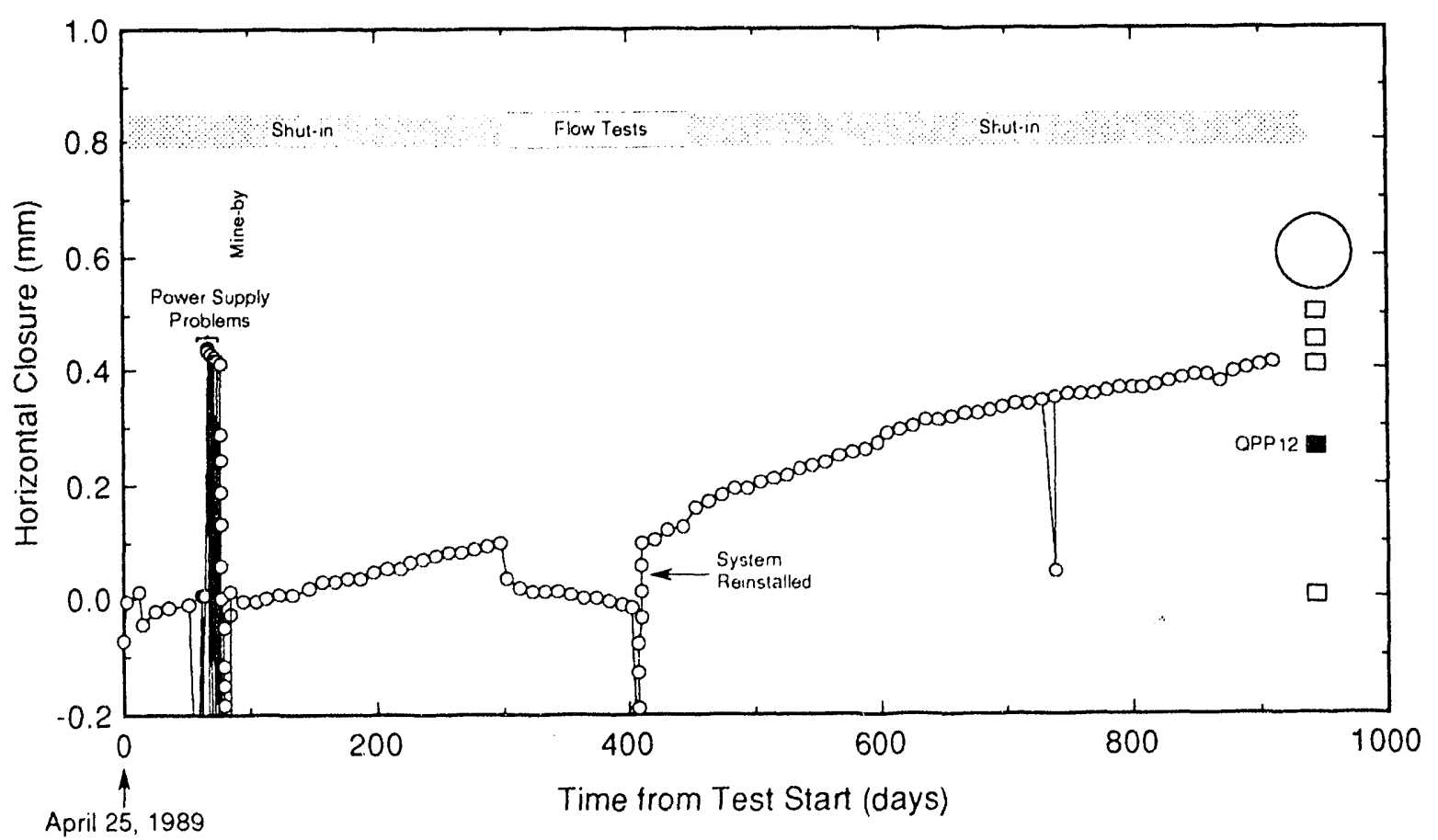

Figure 6-49. Horizotal closure measured in the test zone of hole QPP12. 


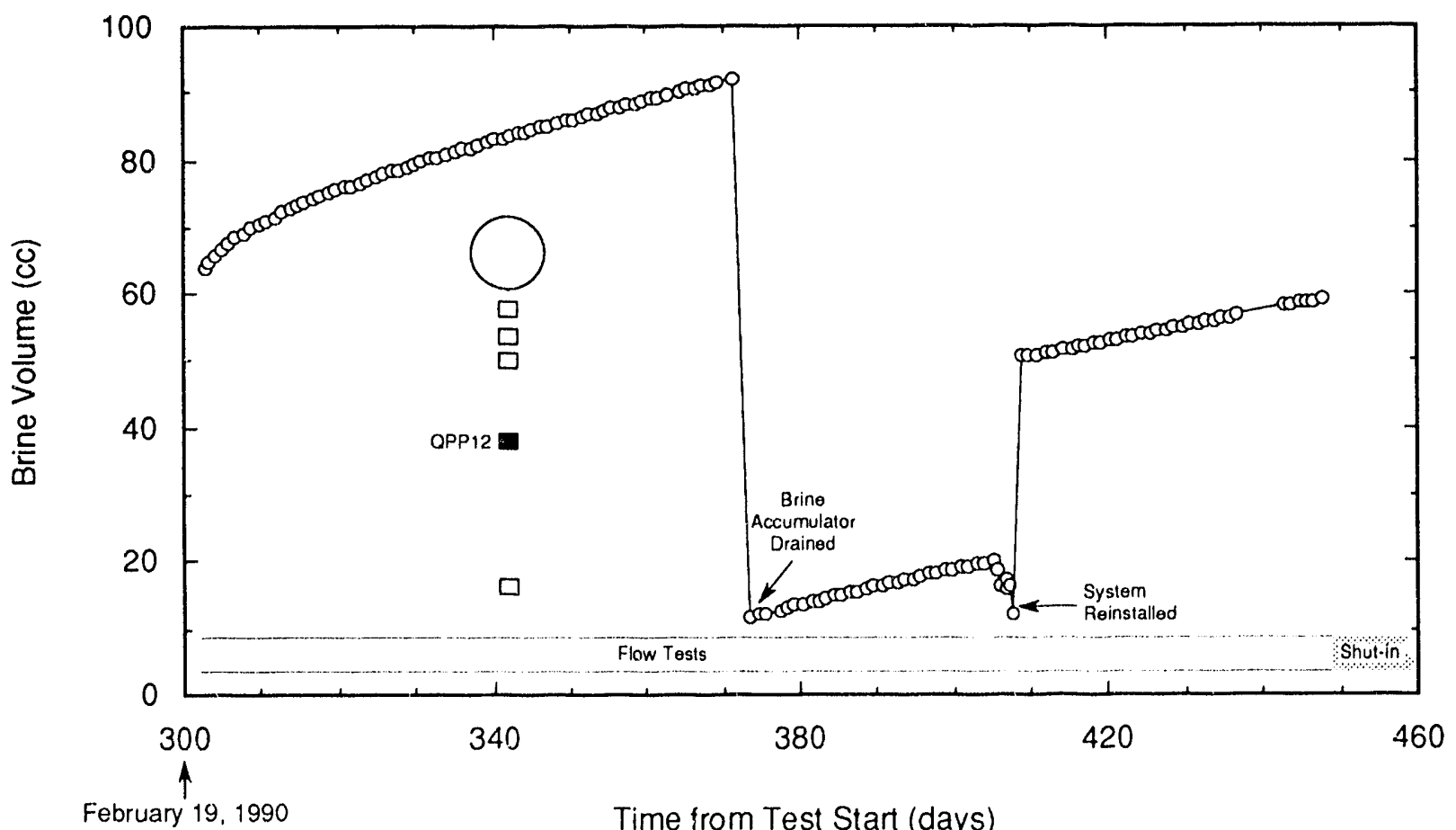

TRI.6119.185.0

Figure 6-50. Brine collected from QPP12 test zone during flow testing. 


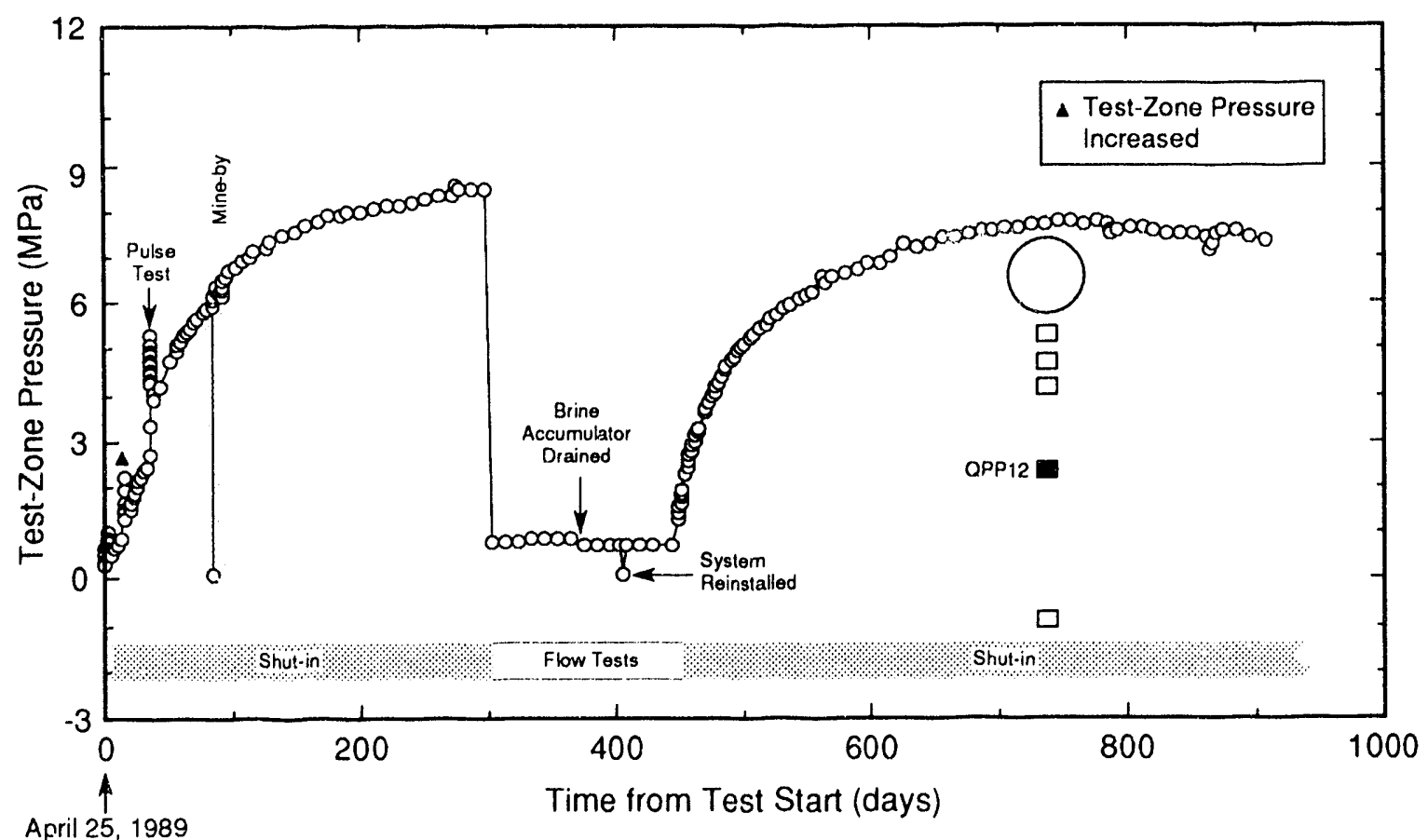

April 25, 1989

TR1-6119-186-0

Eigure 6-51. Hole QPP12 test-zone pressure.

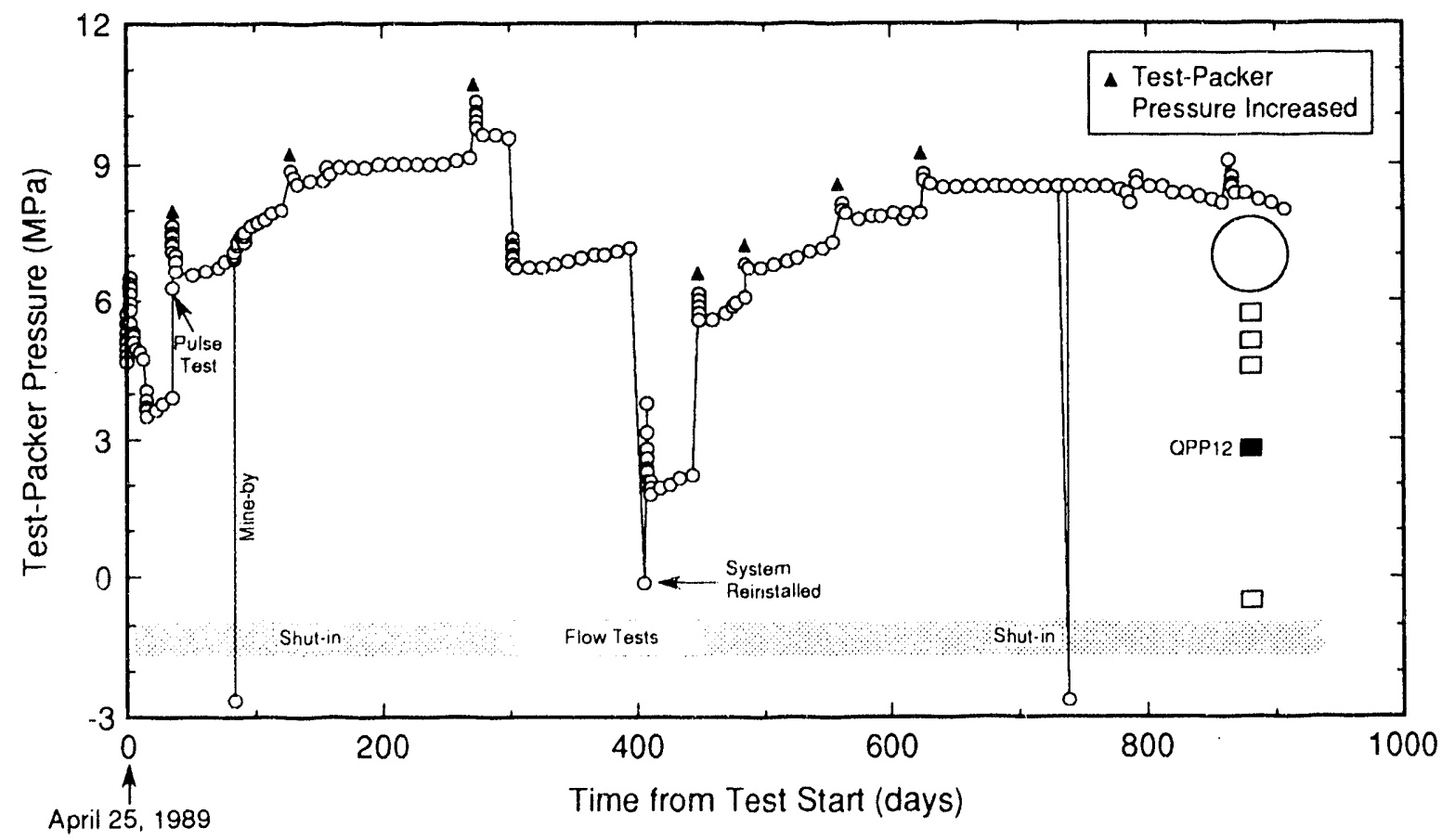

Figure 6-52. Hole QPP12 test-packer pressure. 


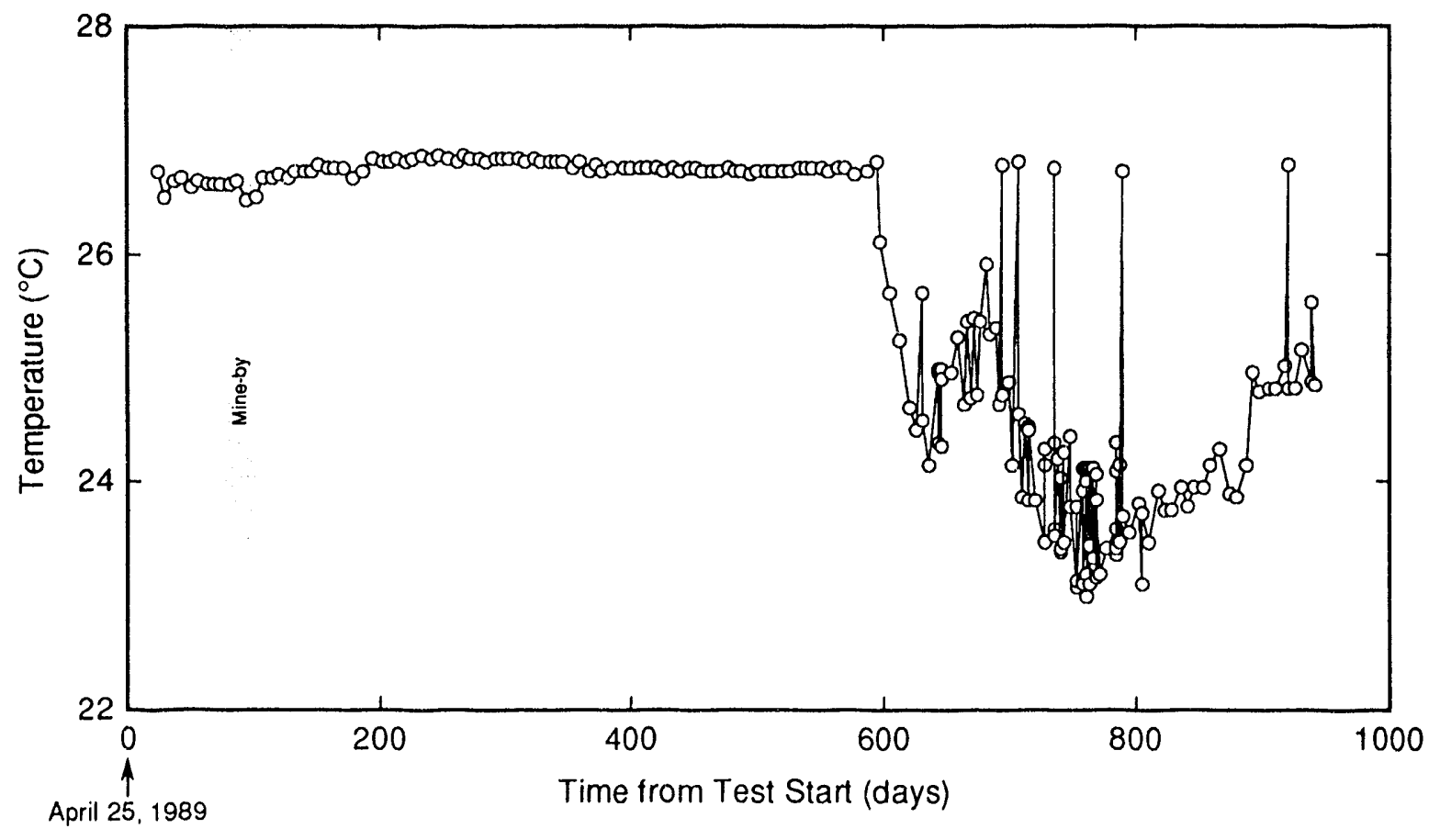

Figure 6-53. Hole QPP12 tool temperature.

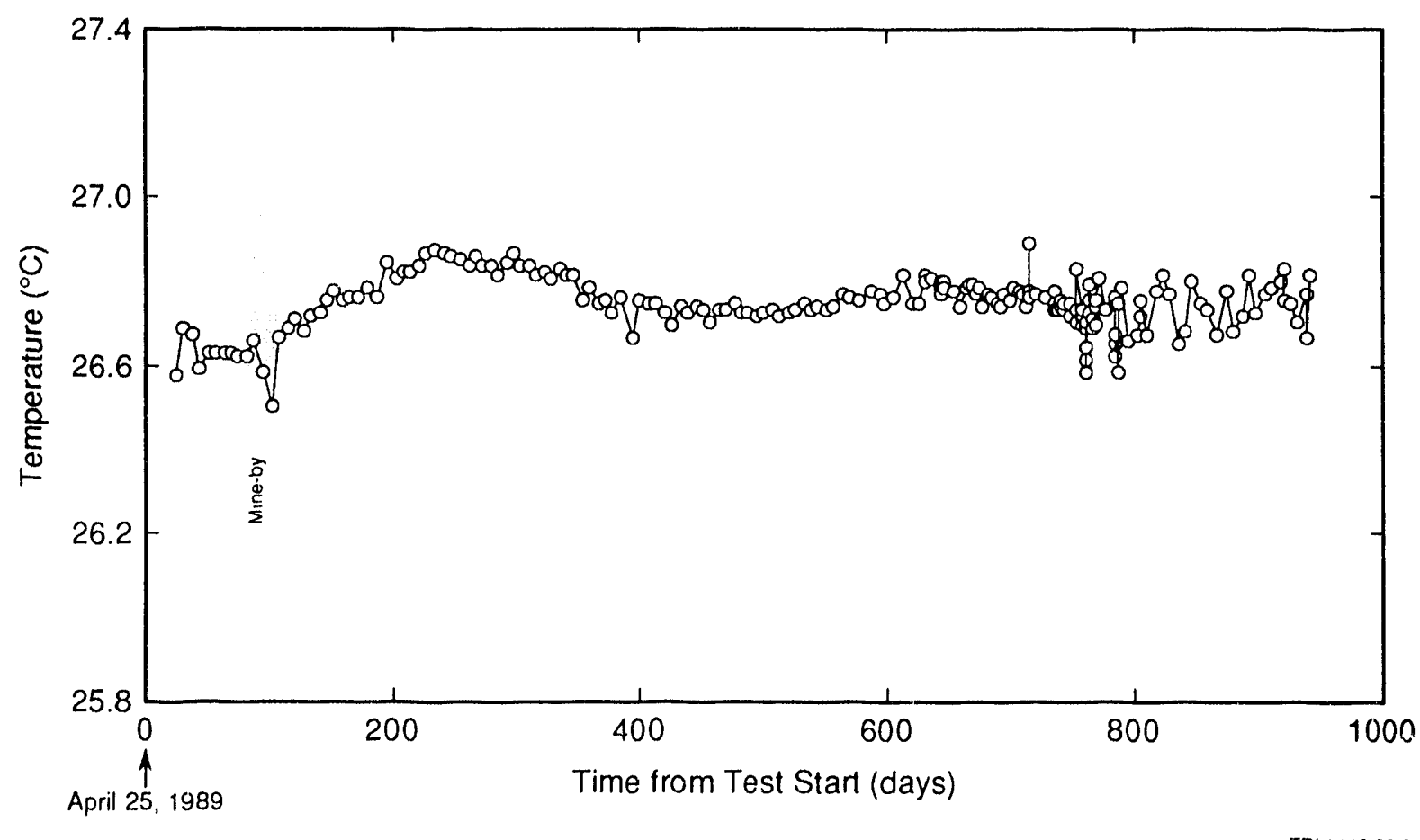

Figure 6-54. Hole QPP12 casing temperature. 


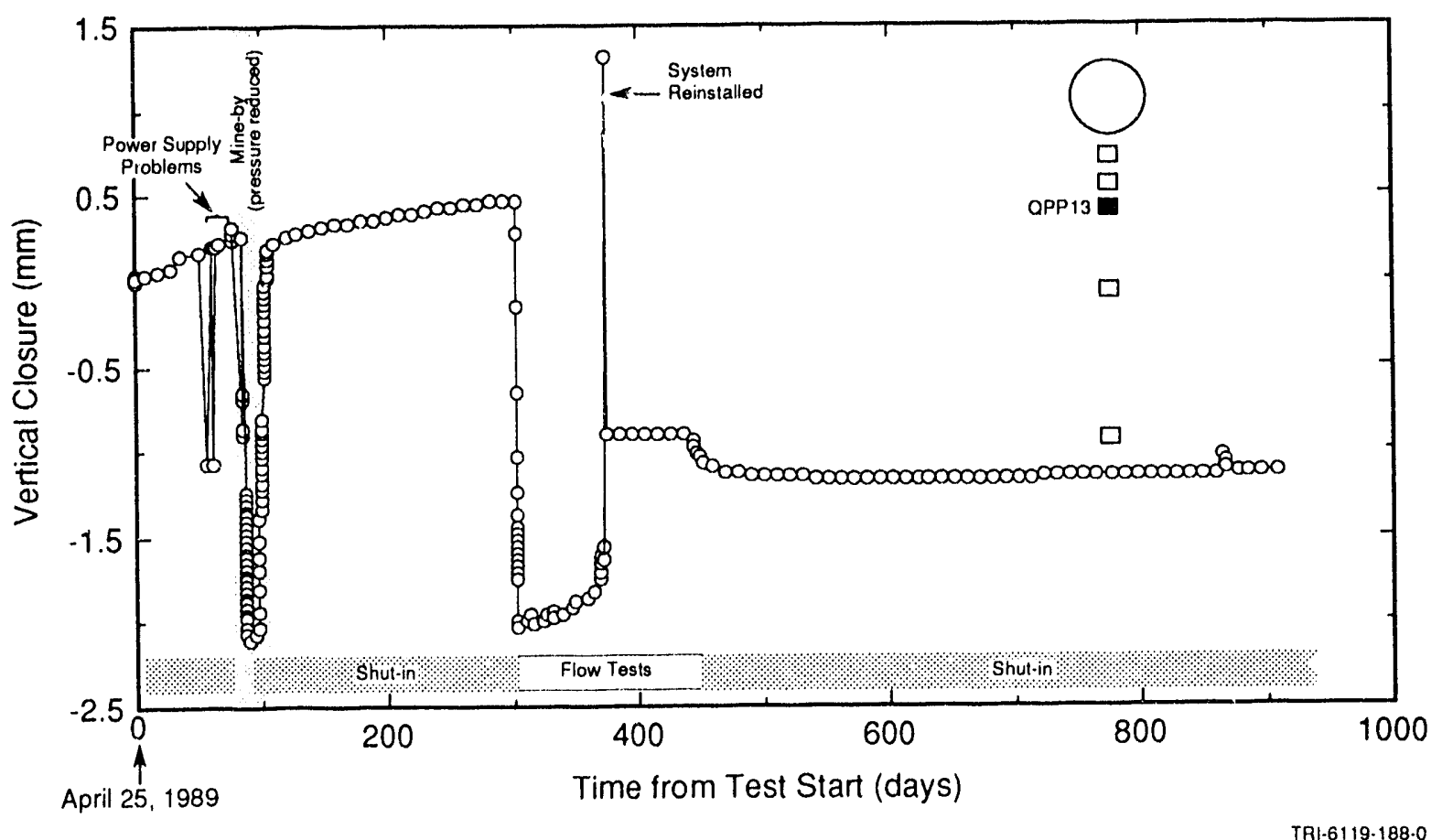

Figure 6-55. Vertical closure measured in the test zone of hole QPP13.

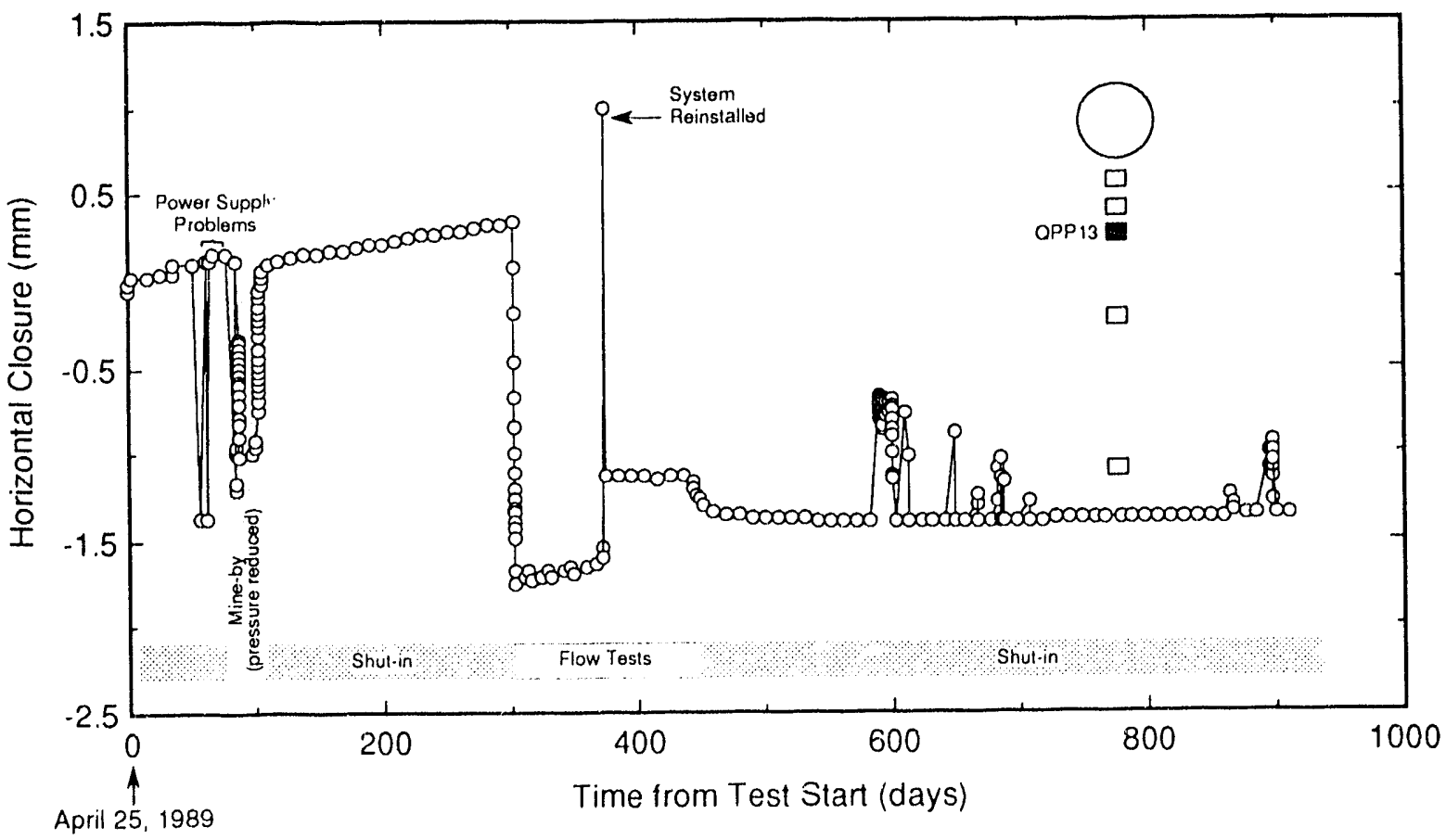

Figure 6-56. Horizontal closure measured in the test zone of hole QPP13. 


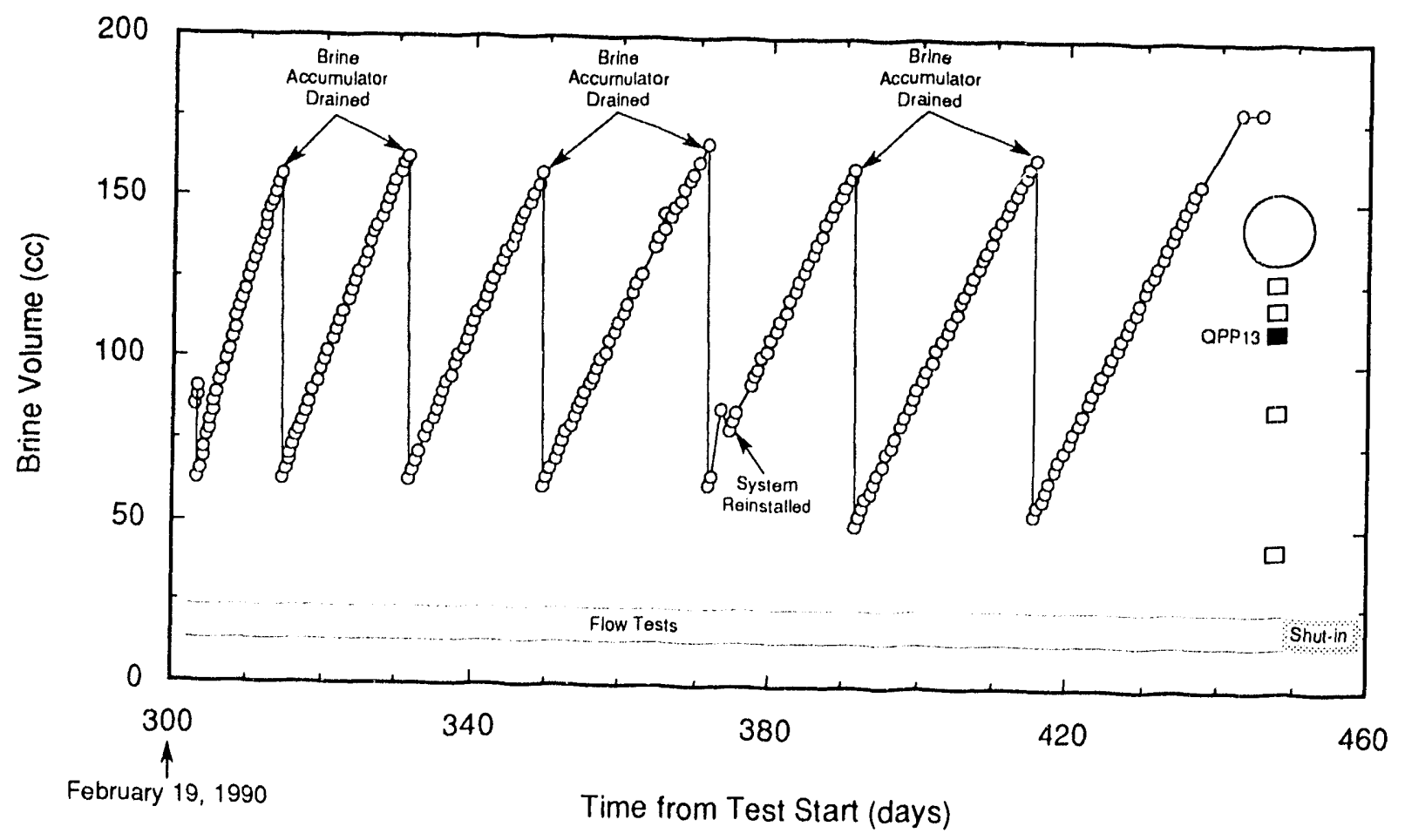

TRI.6119.190-0

Figure 6-57. Brine collected from QPP13 test zone during flow testing. 


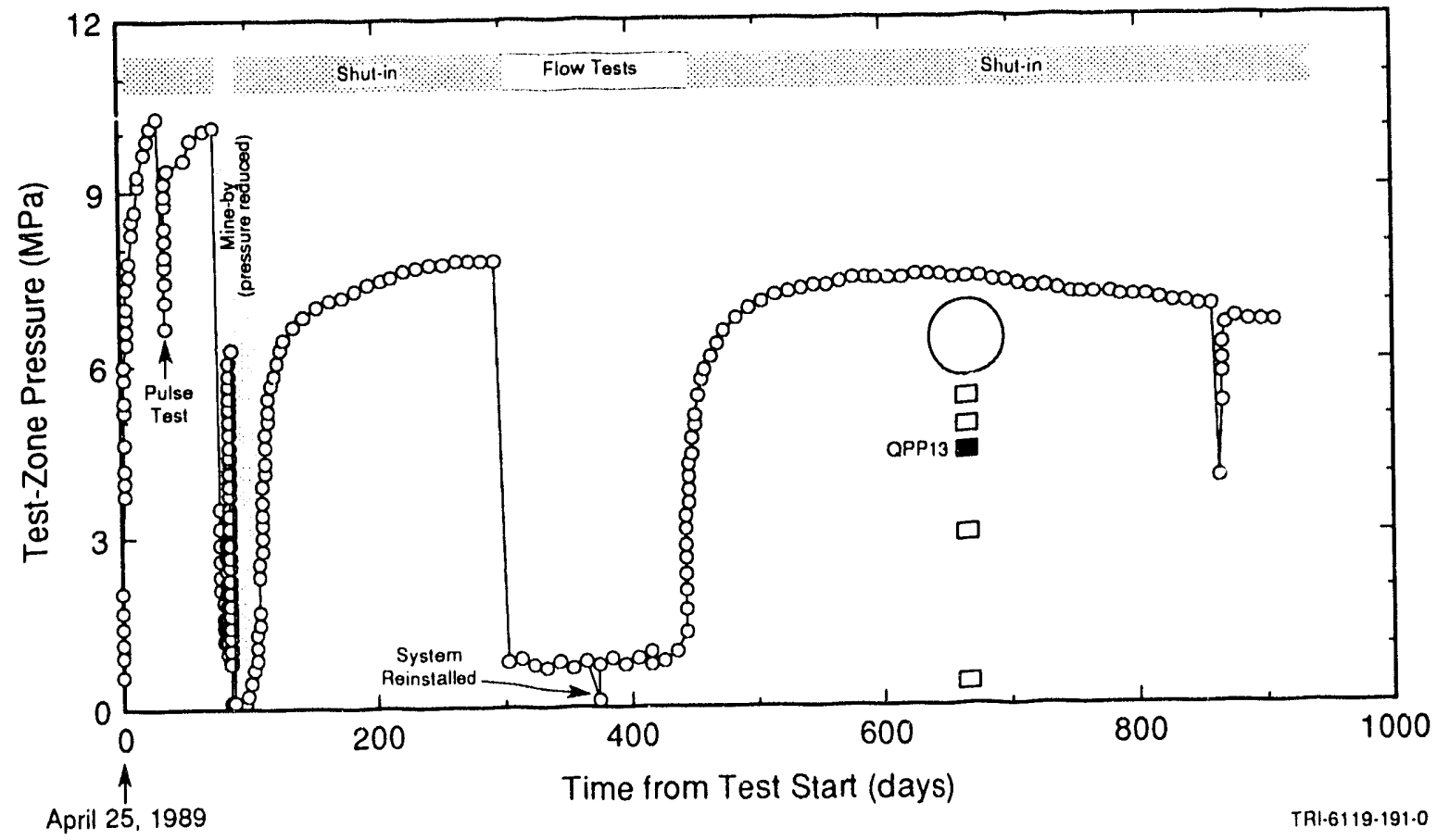

Figure 6-58. Hole QPP13 test-zone pressure.

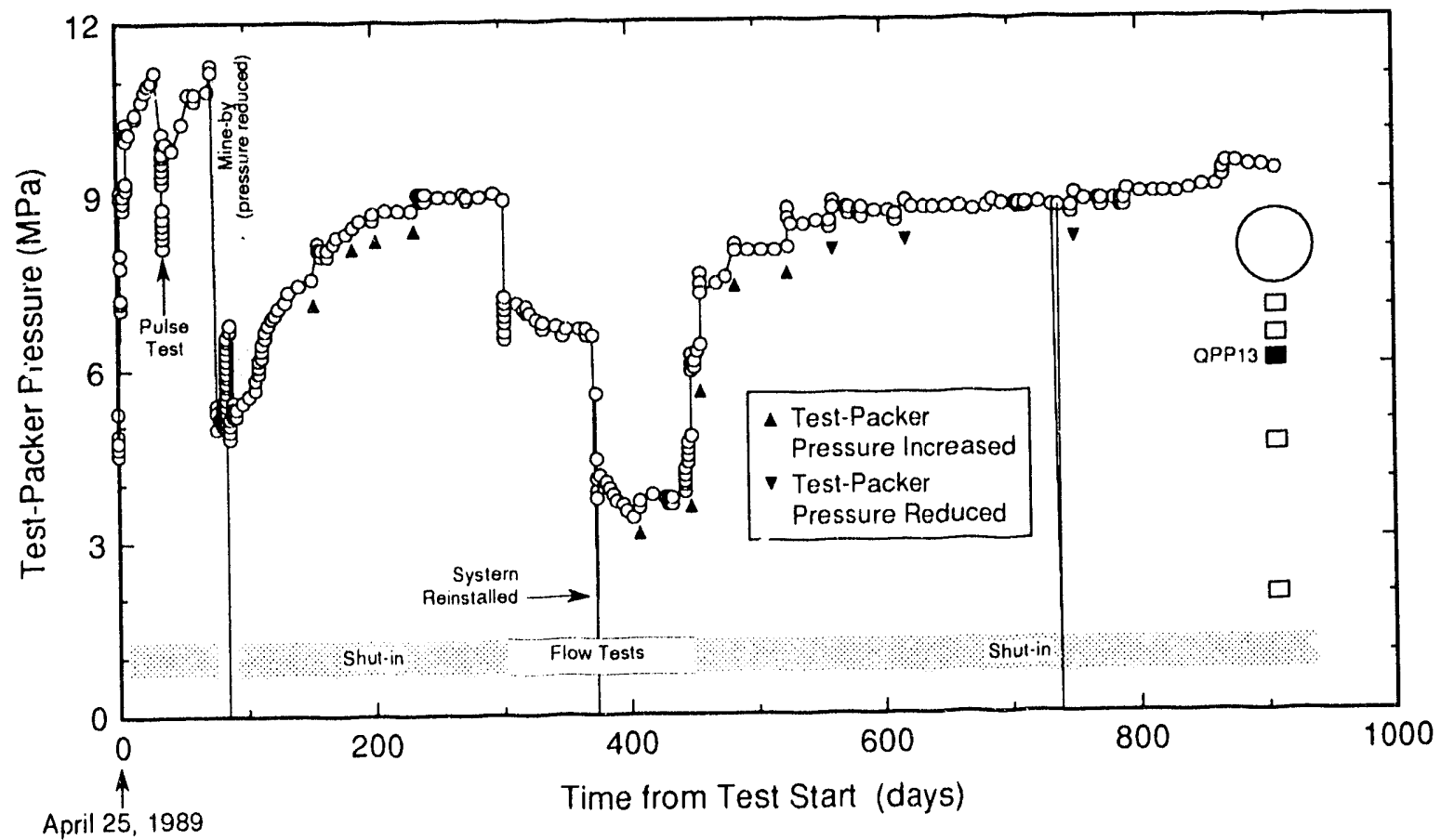

Eigure 6-59. Hole QPP13 test-packer pressure. 


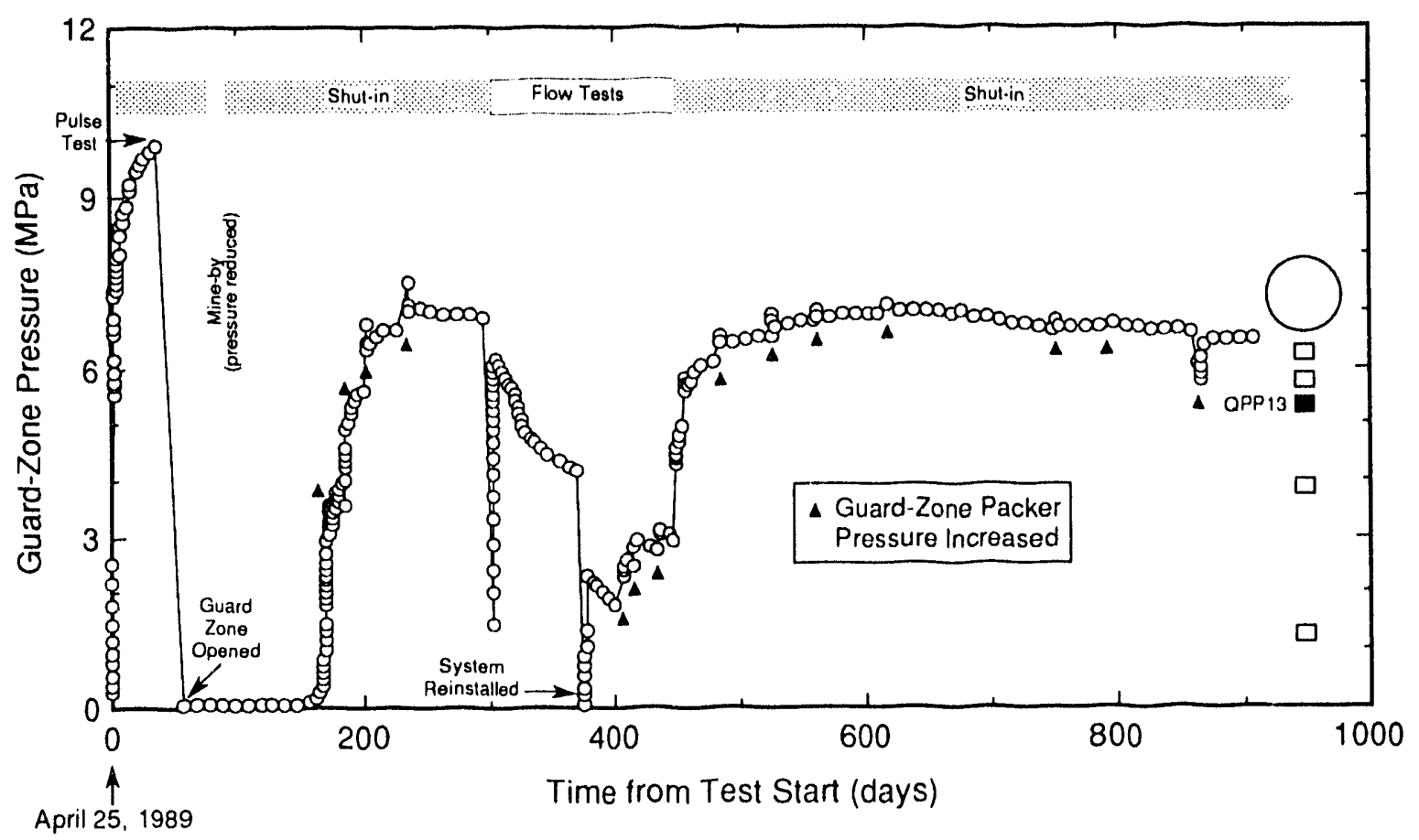

Figure 6-60. Hole QPP13 guard-zone pressure.

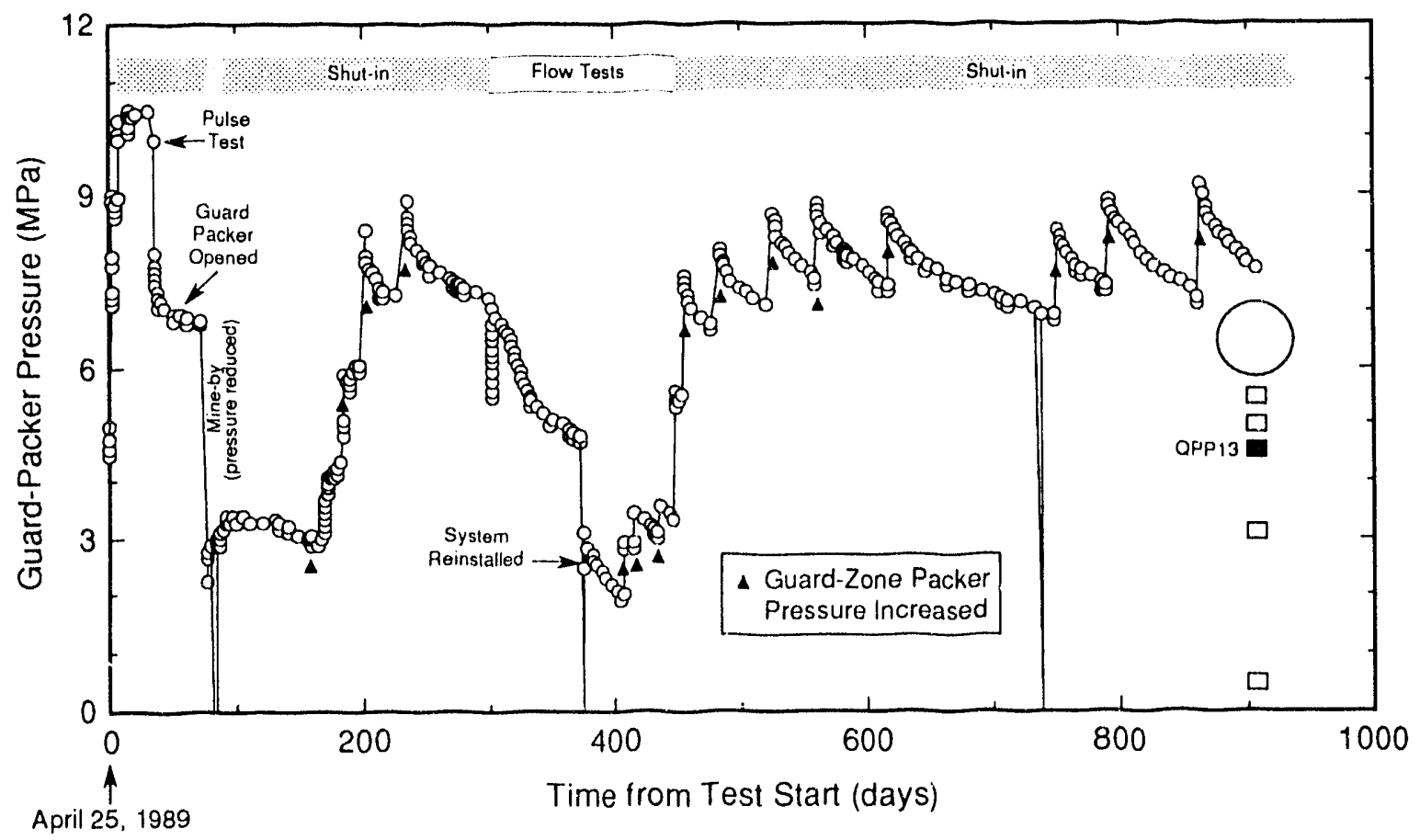

Figure 6-61. Hole QPP13 guard-packer pressure. 


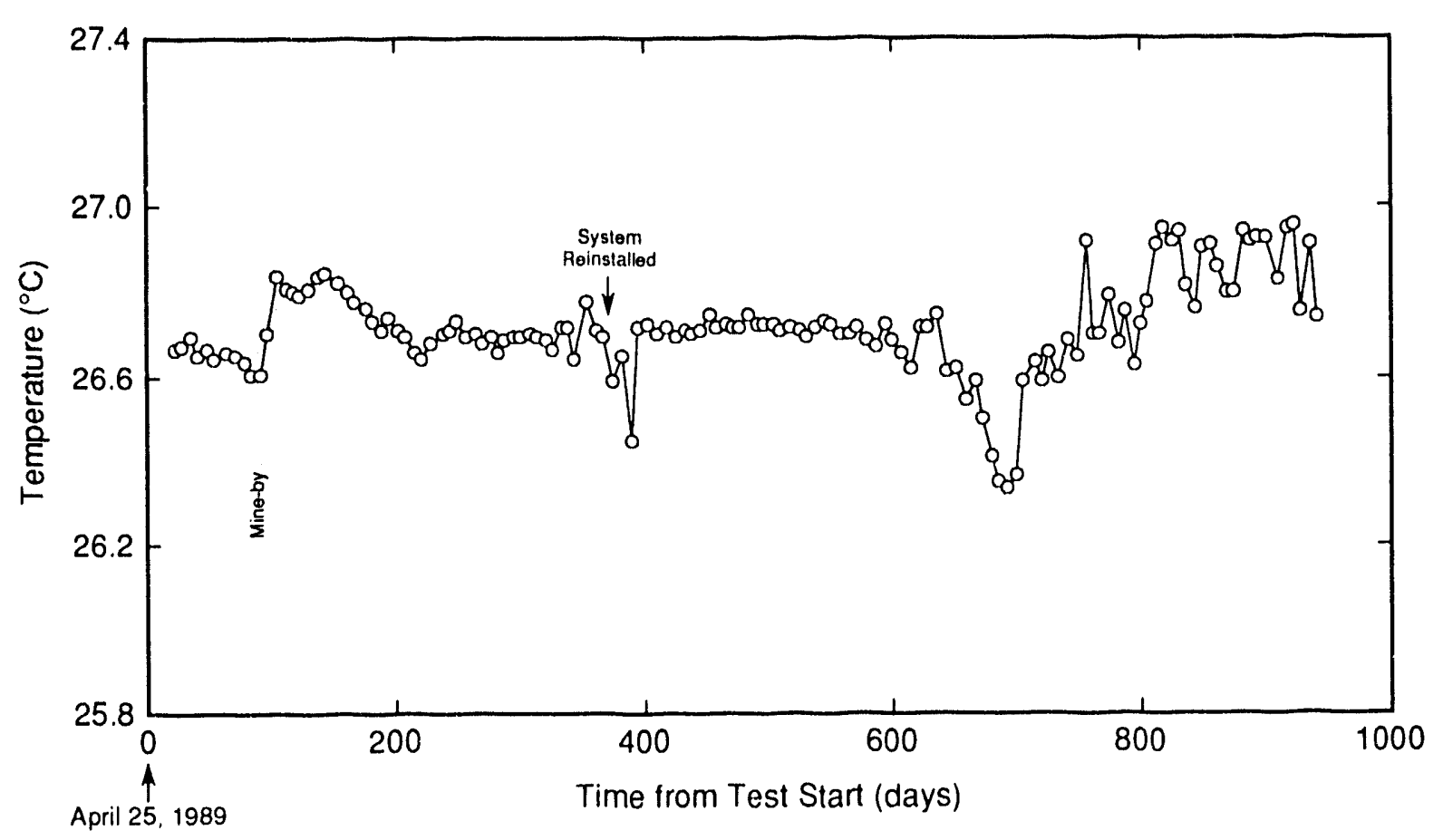

Figure 6-62. Hole QPP13 tool temperature.

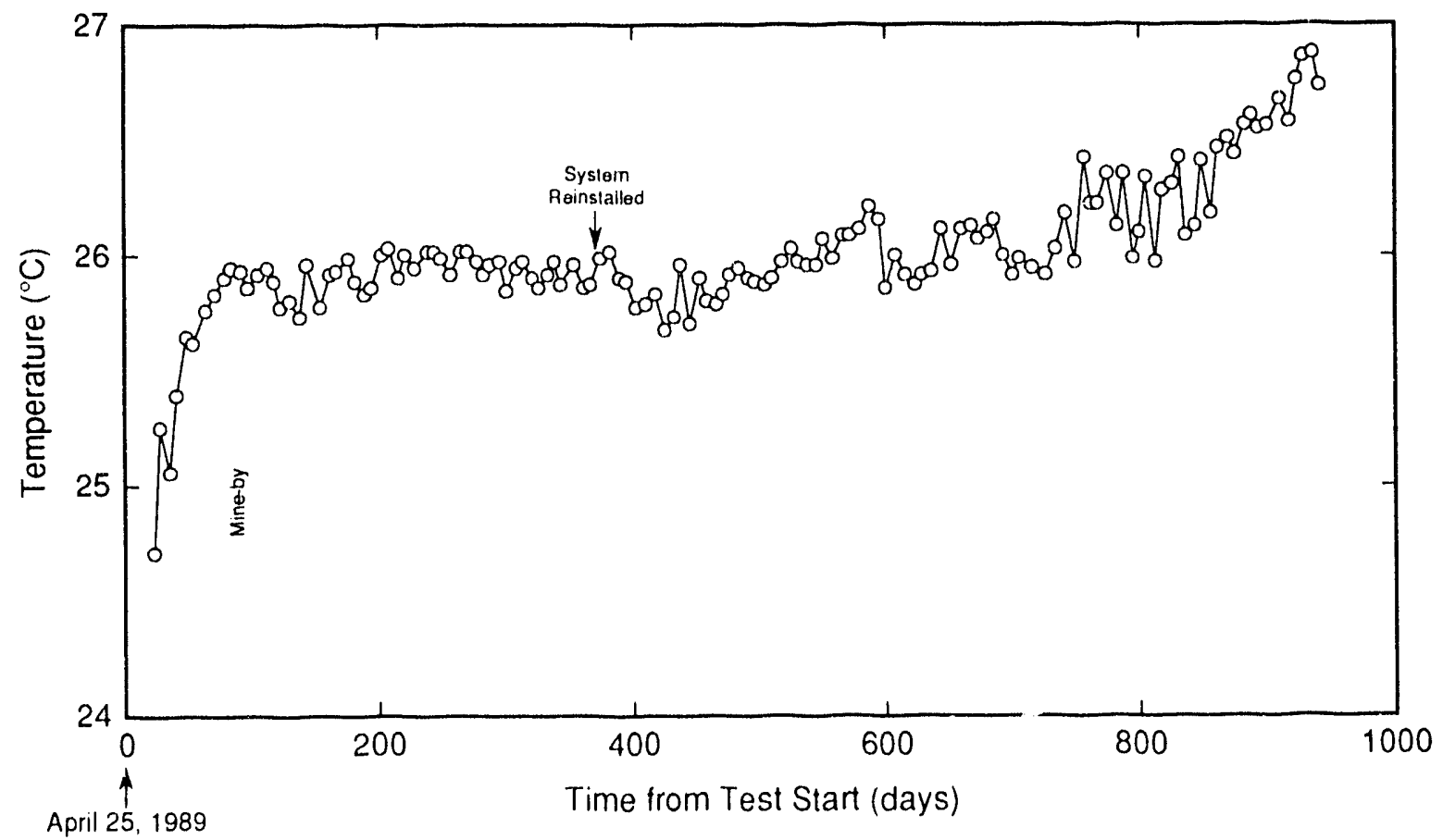

Eigure 6-63. Hole QPP13 casing temperature. 


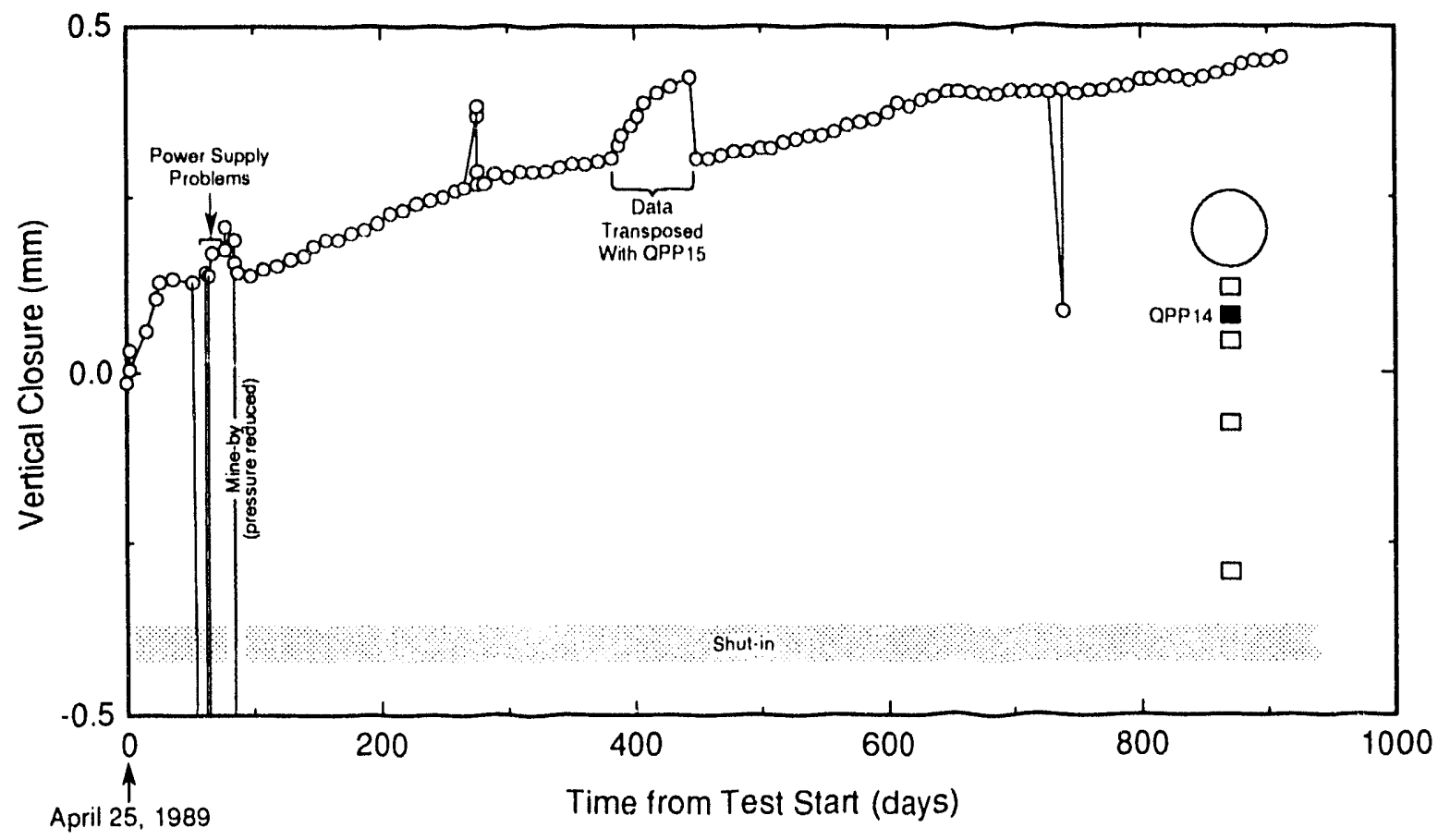

TRI.6119.195.0

Figure 6-64. Vertical closure measured in the test zone of hole QPP14.

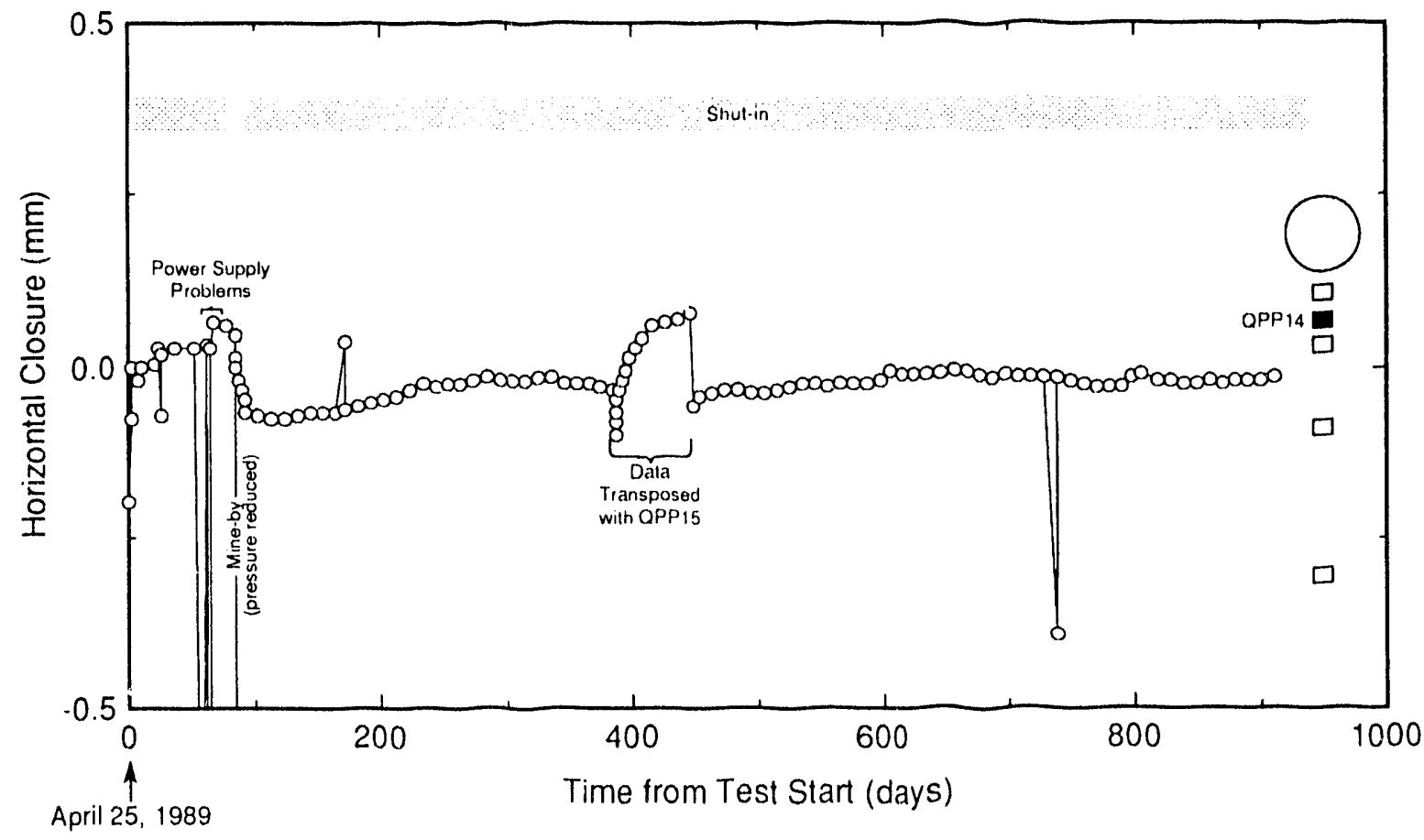

TRI.6119.196.0

Eigur: 6-65. Horizontal closure measured in the test zone of hole QPP14. 


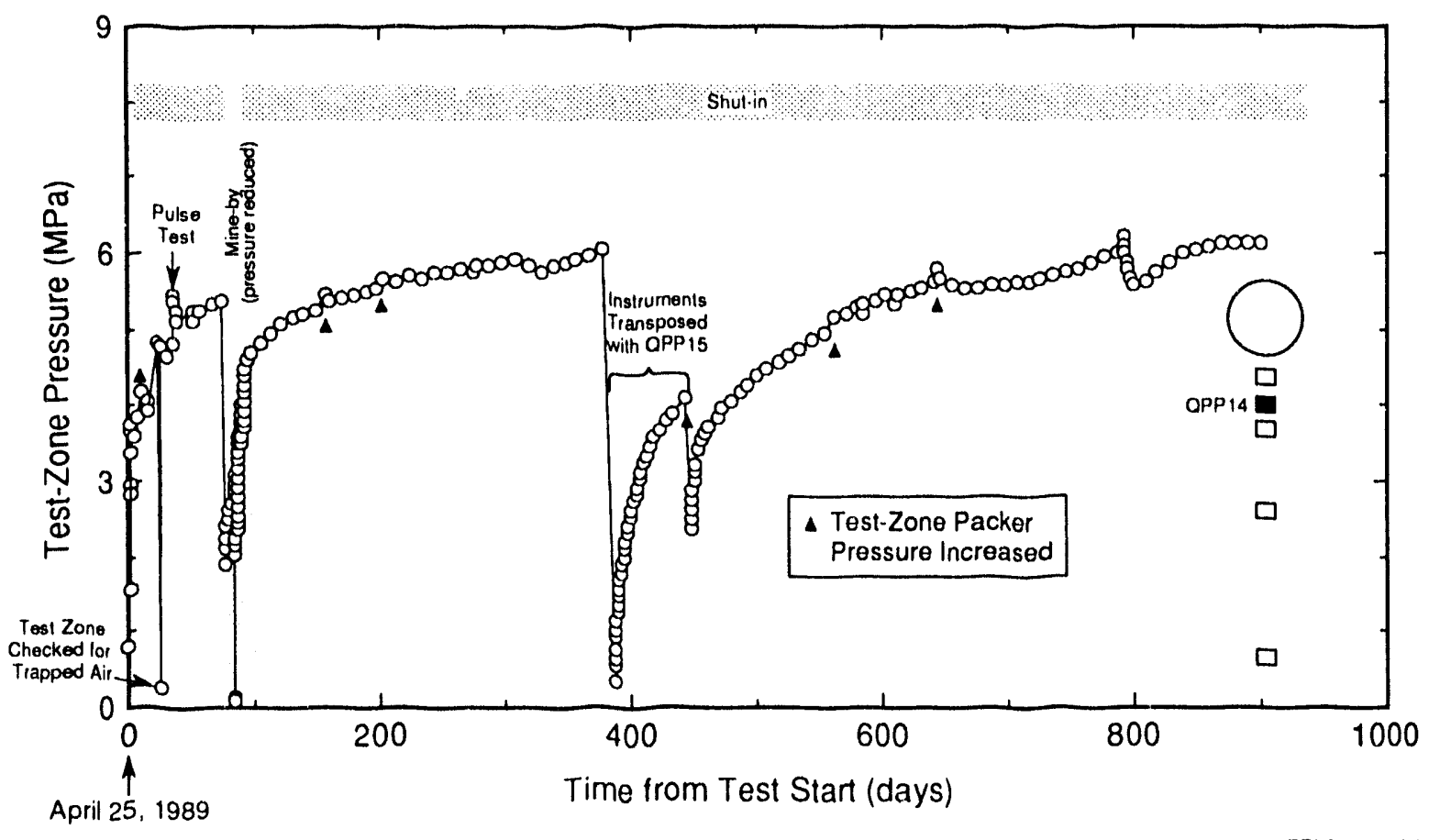

Figure 6-66. Hole QPP14 test-zone pressure.

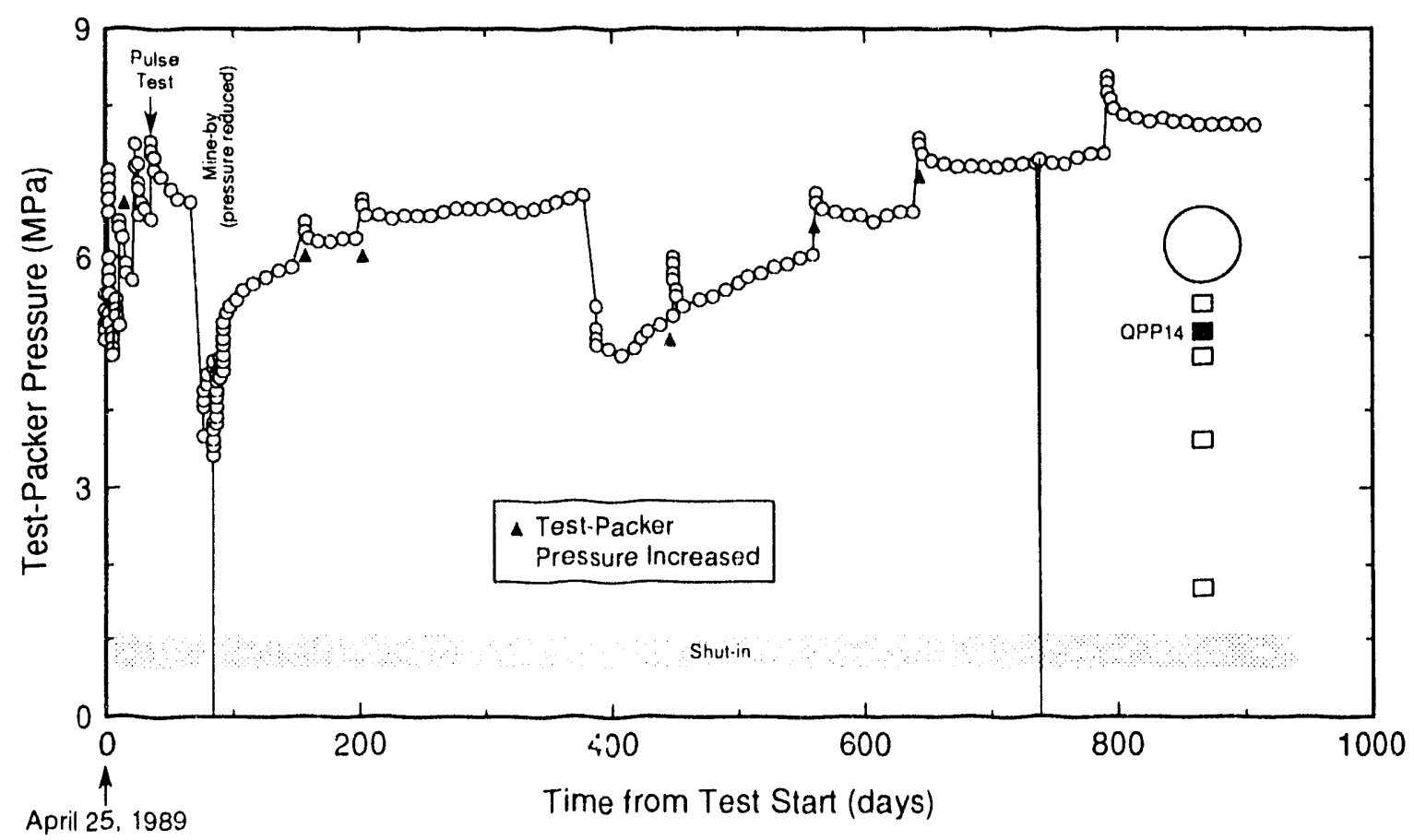

Figure 6-67. Hole QPP14 test-packer pressure. 


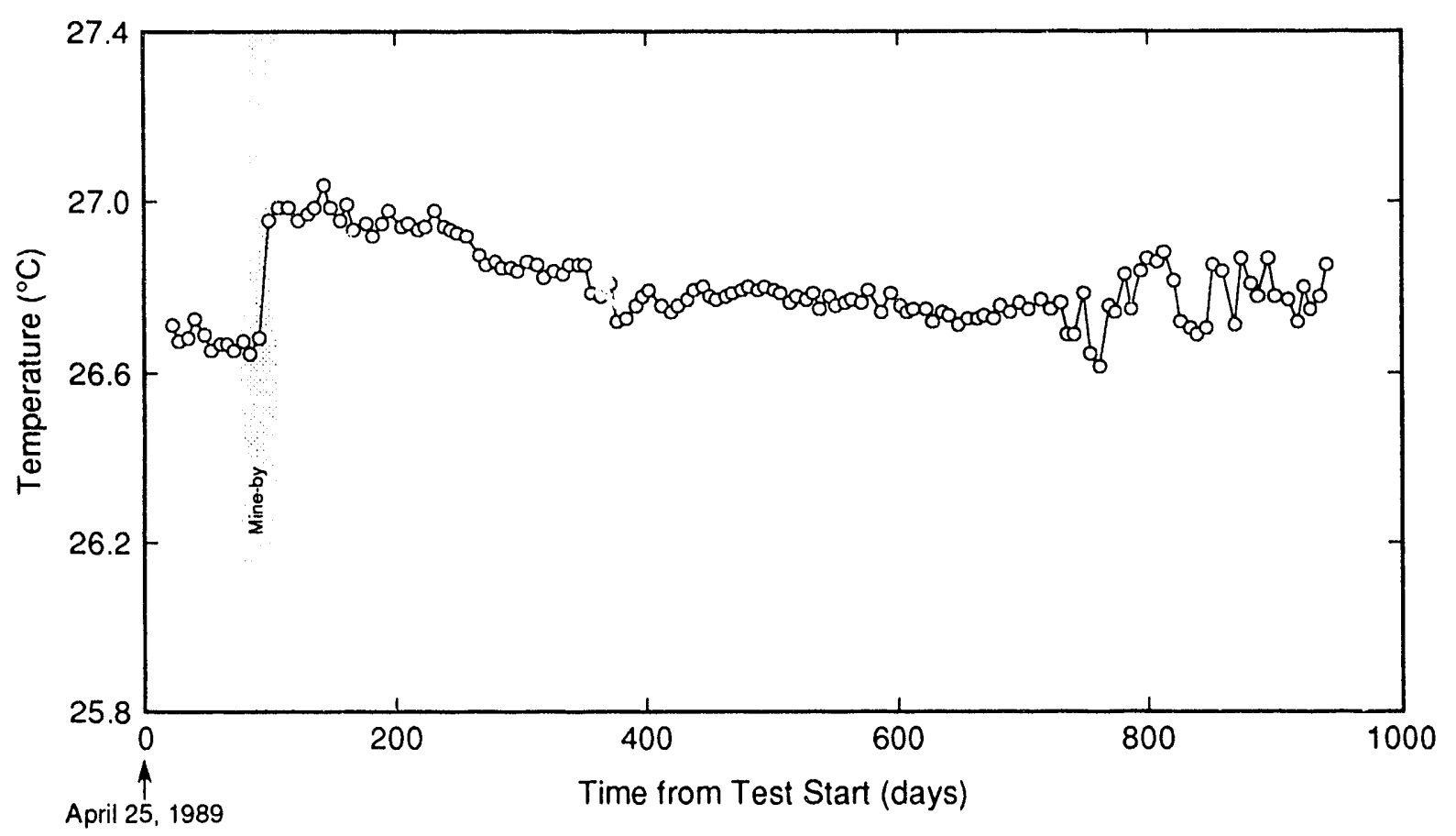

Eigure 6-68. Hole QPP14 tool temperature.

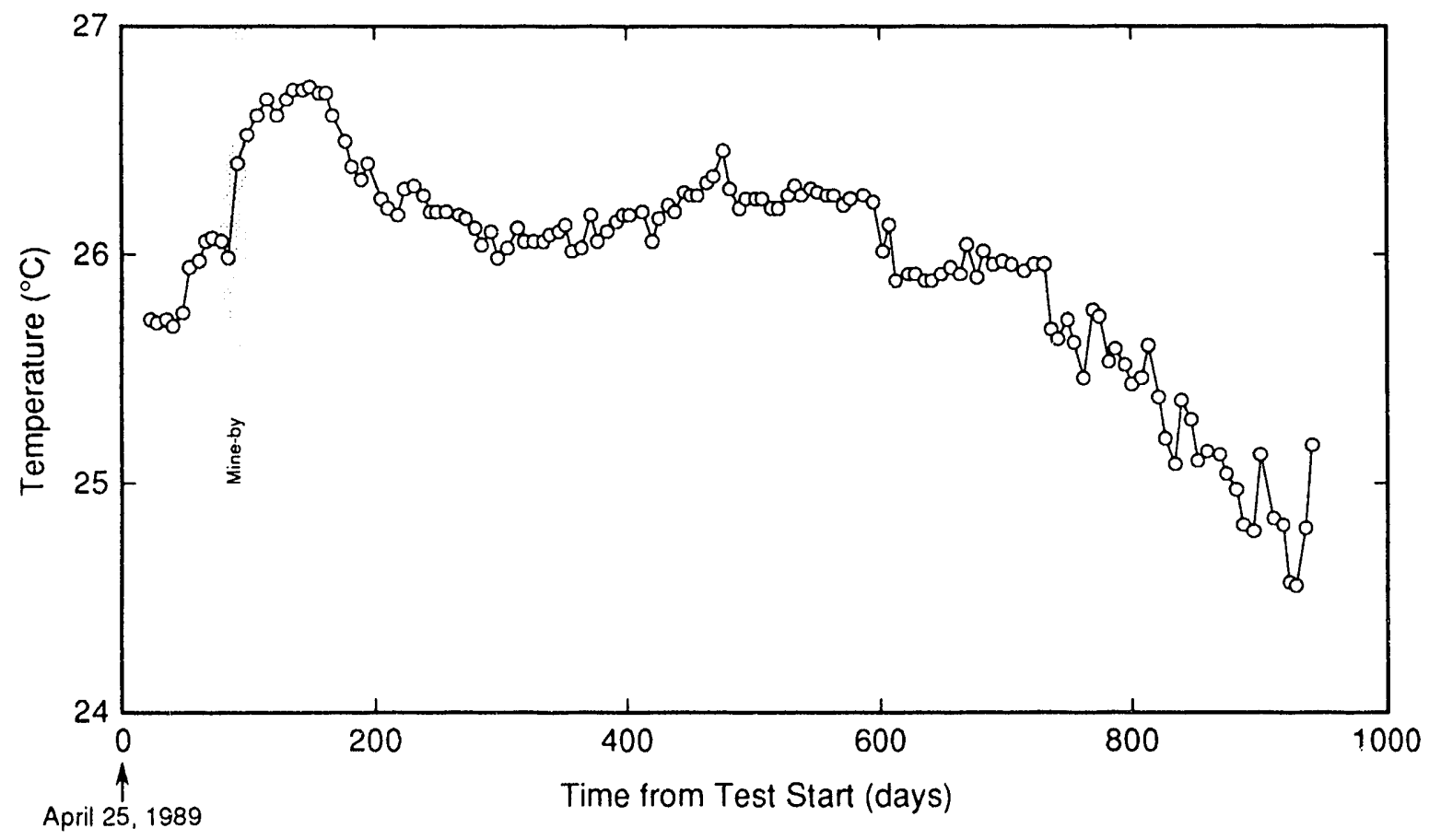

Figure 6-69. Hole QPP14 casing temperature. 


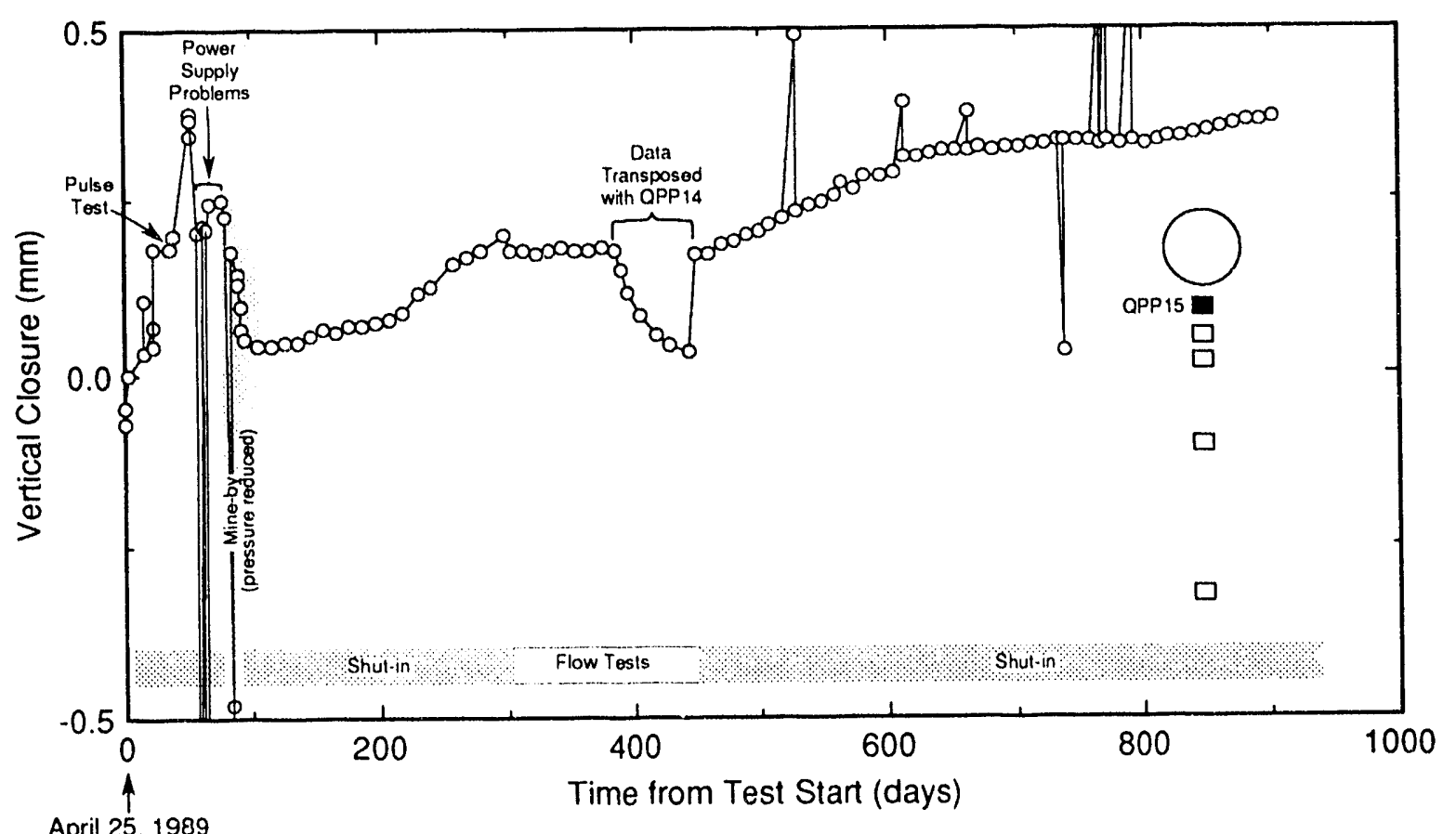

TR1.6119.199.0

Figure 6-70. Vertical closure measured in the test zone of hole QPP15.

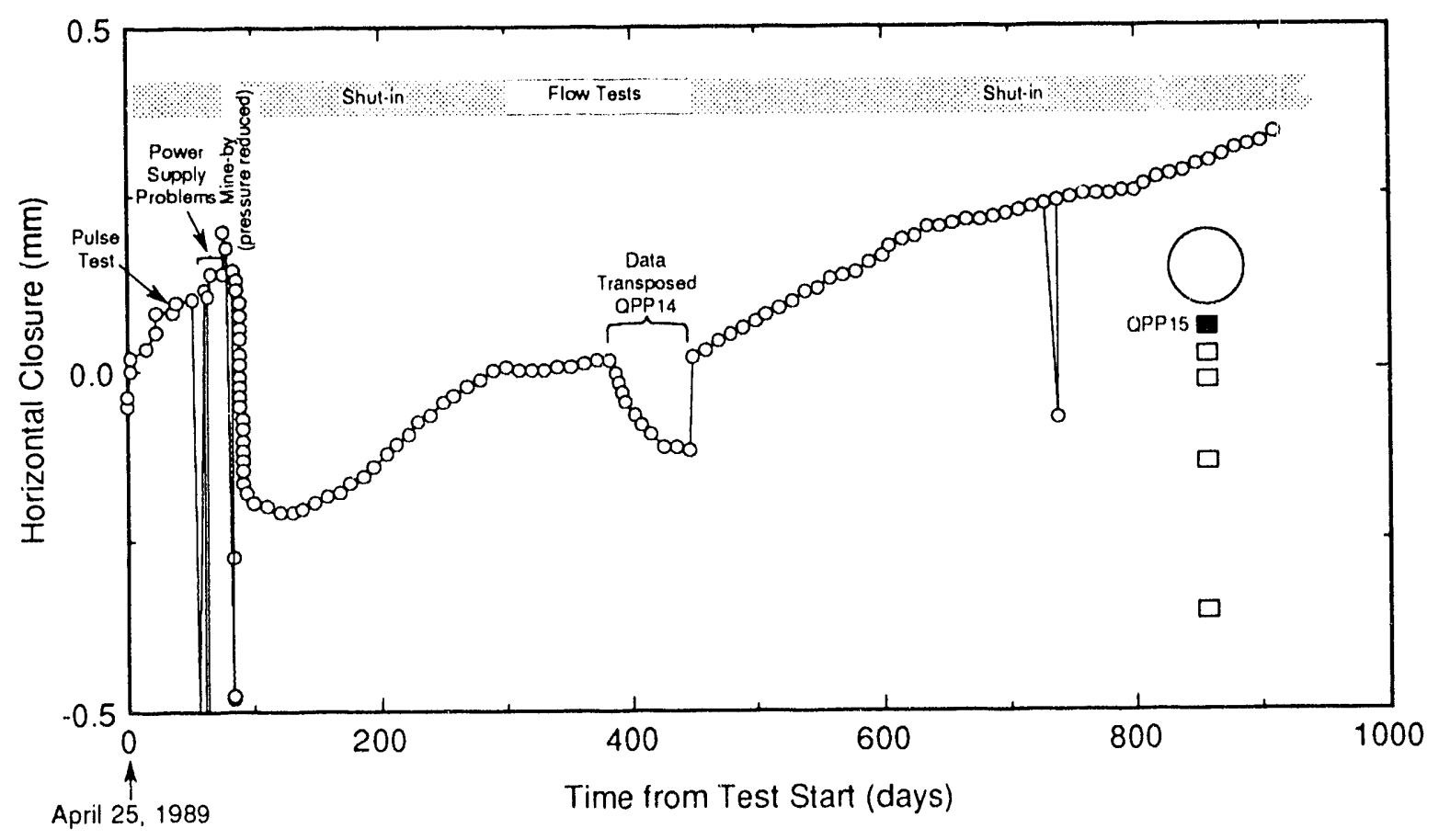

Tค1.6119.200-0

Figure 6-71. Horizontal closure measured in the test zone of hole QPP15. 


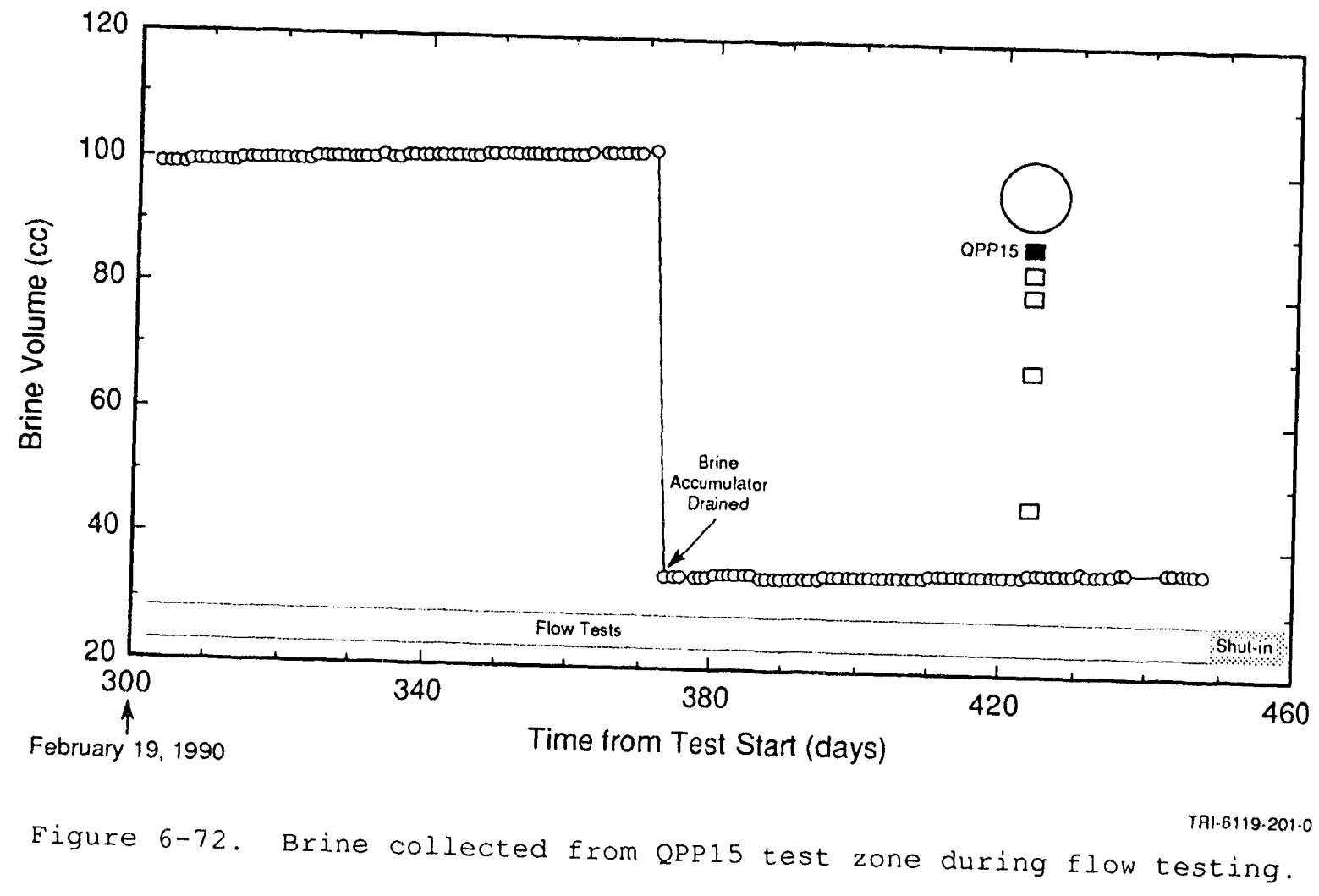




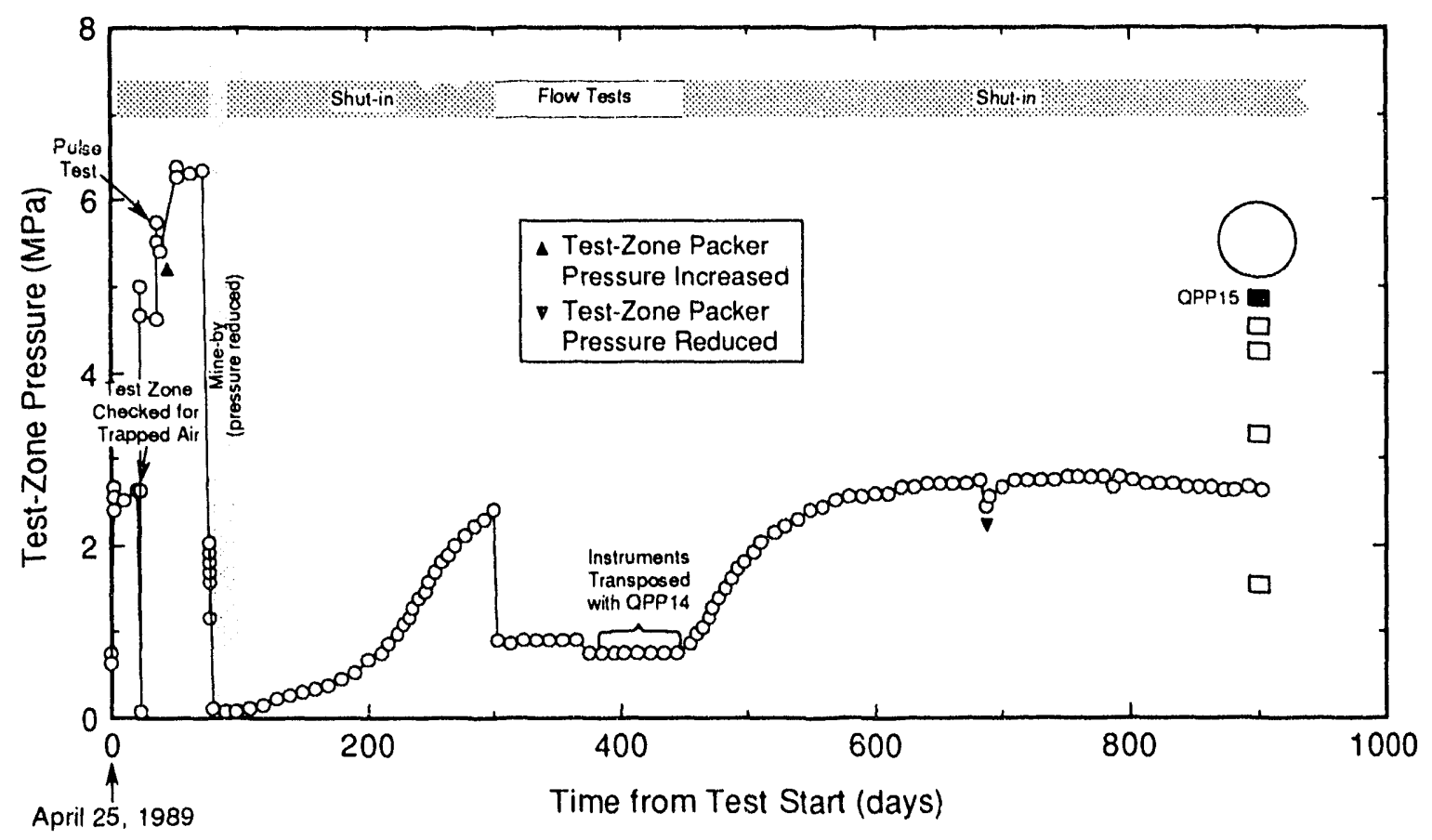

Figure 6-73. Hole QPP15 test-zone pressure.

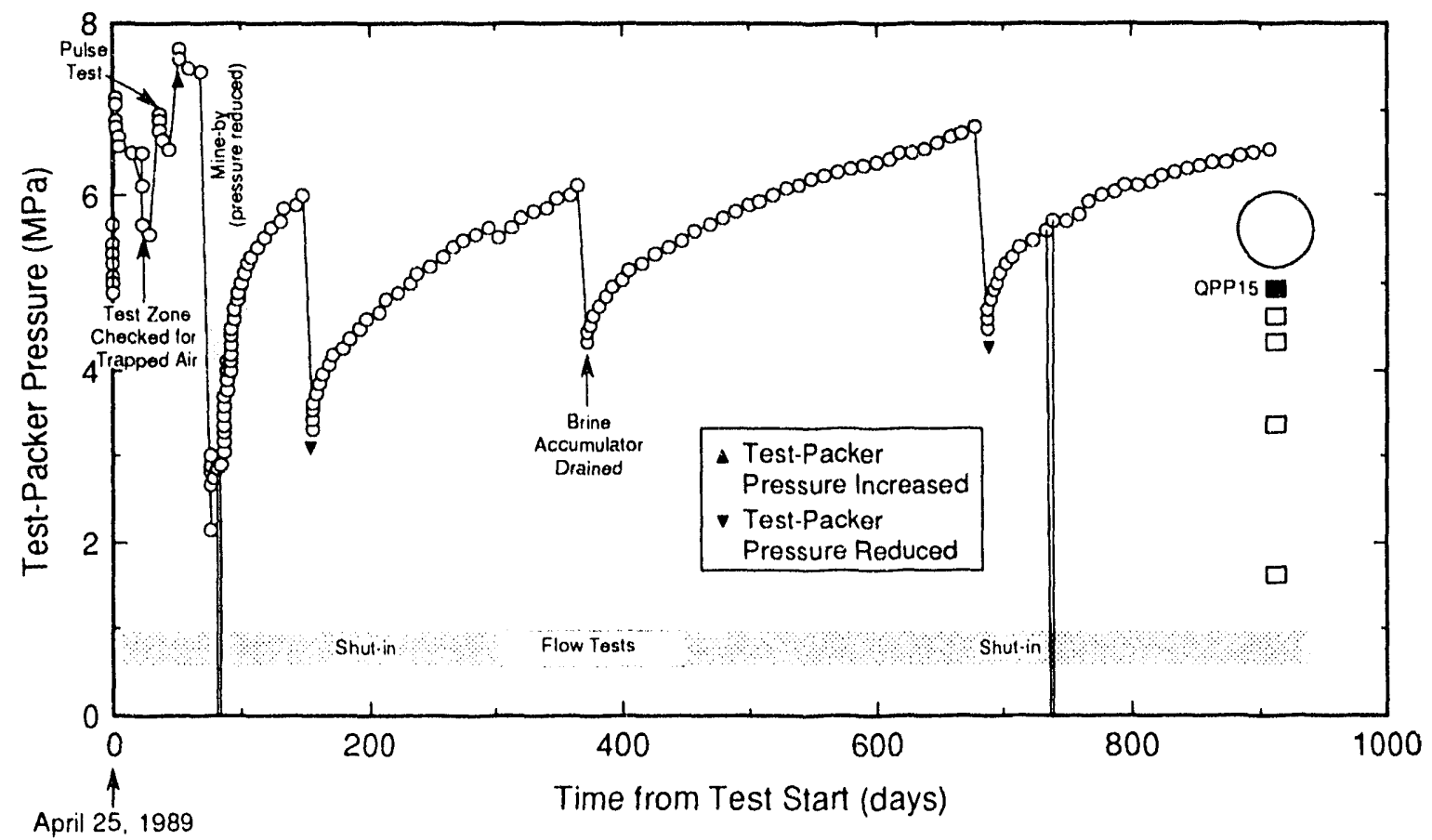

Figure 6-74. Hole QPP15 test-packer pressure. 


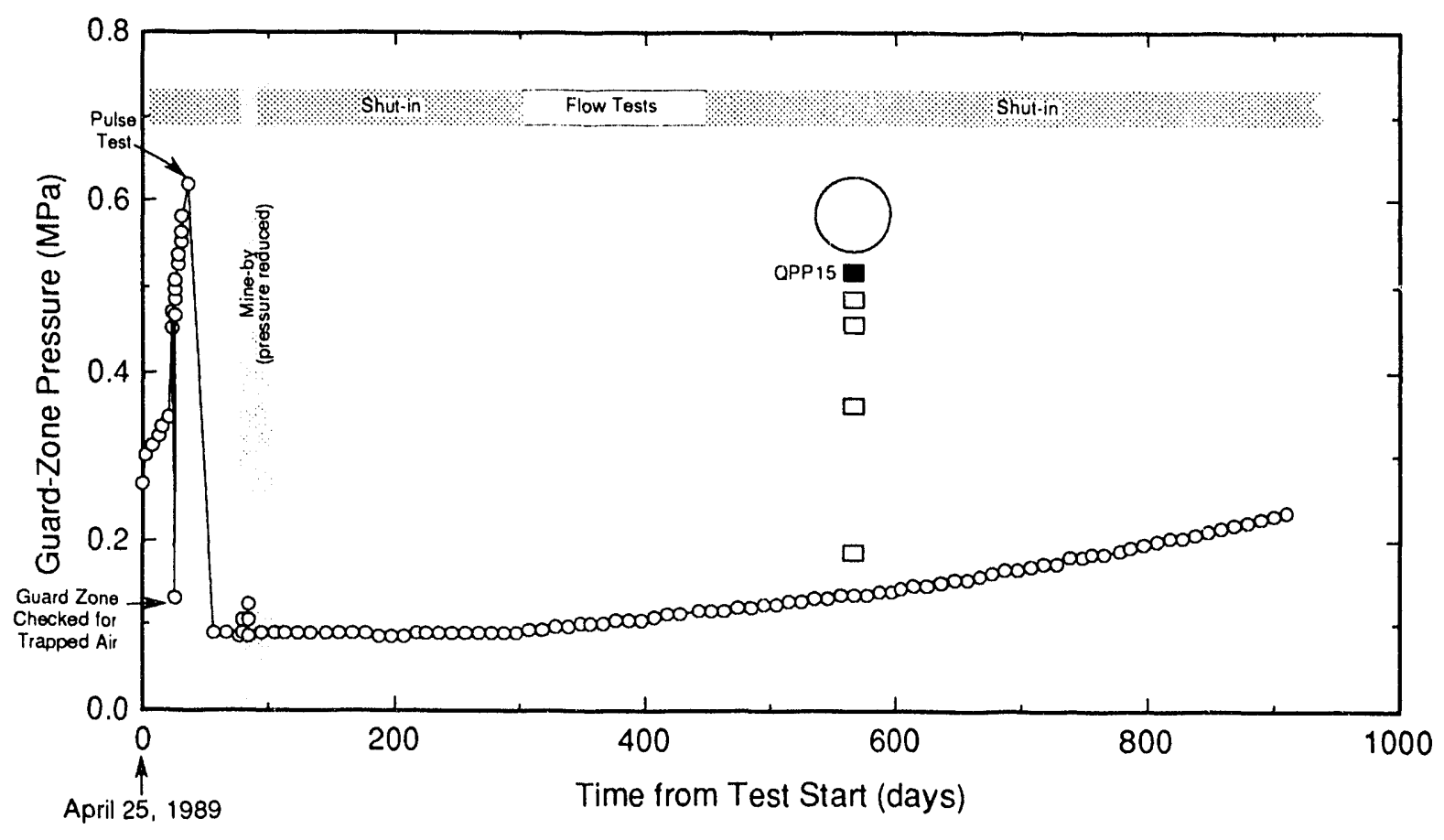

TR1-6119-204.0

Figure 6-75. Hole QPP15 guard-zone pressure.

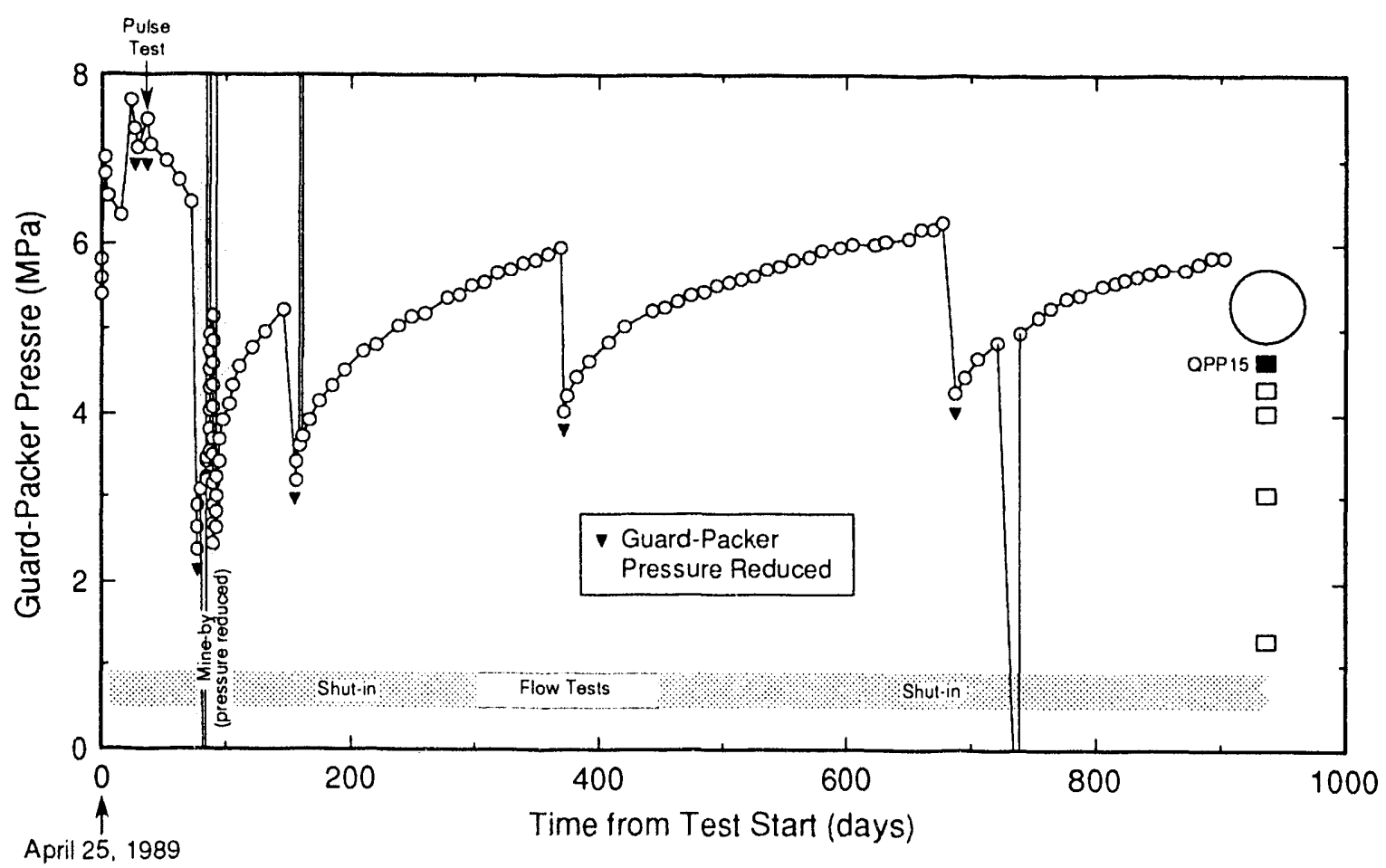

TR1.6119.205.0

Figure 6-76. Hole QPP15 guard-packer pressure. 


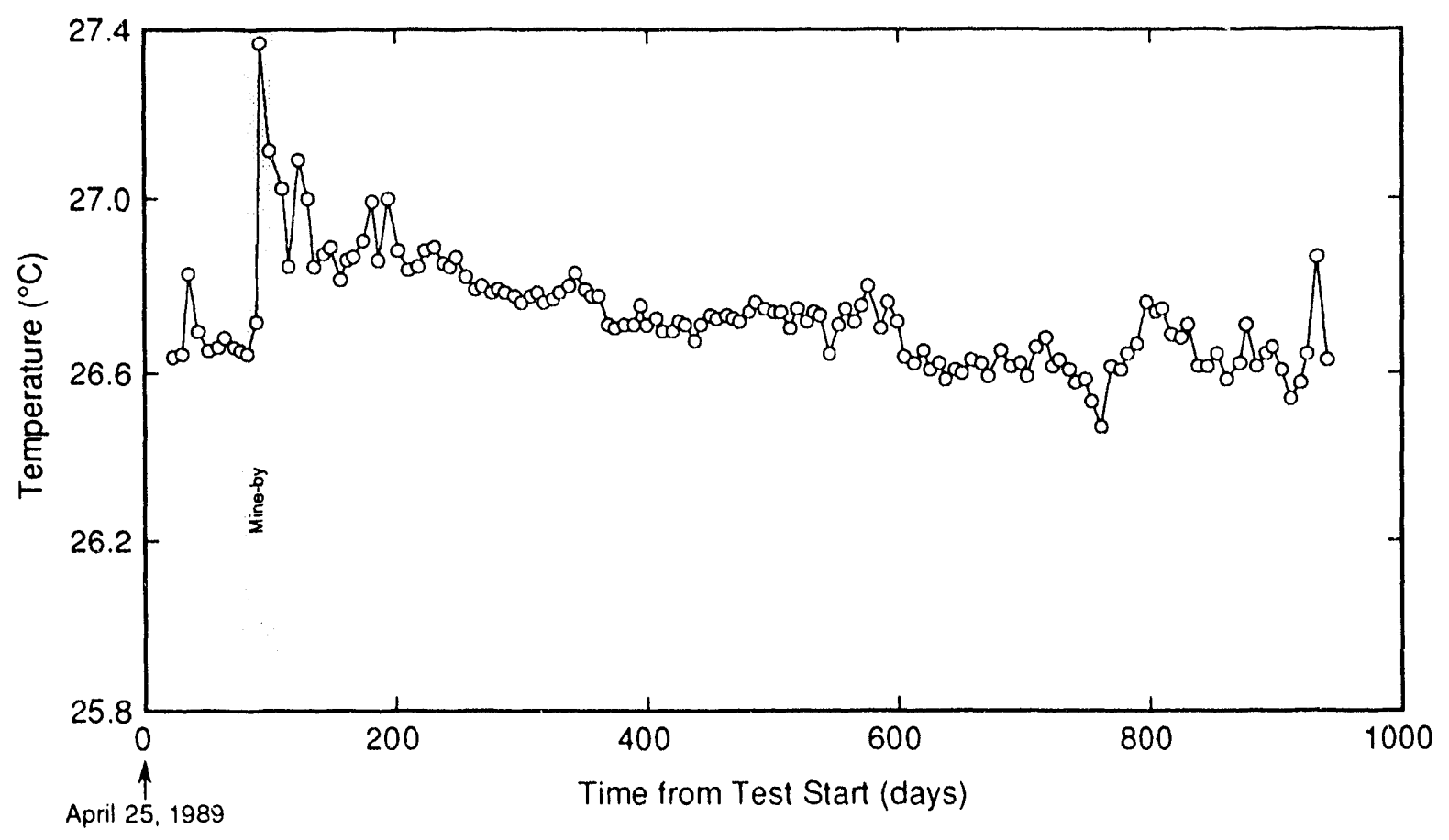

Eigure 6-77. Hole QPP15 tool temperature.

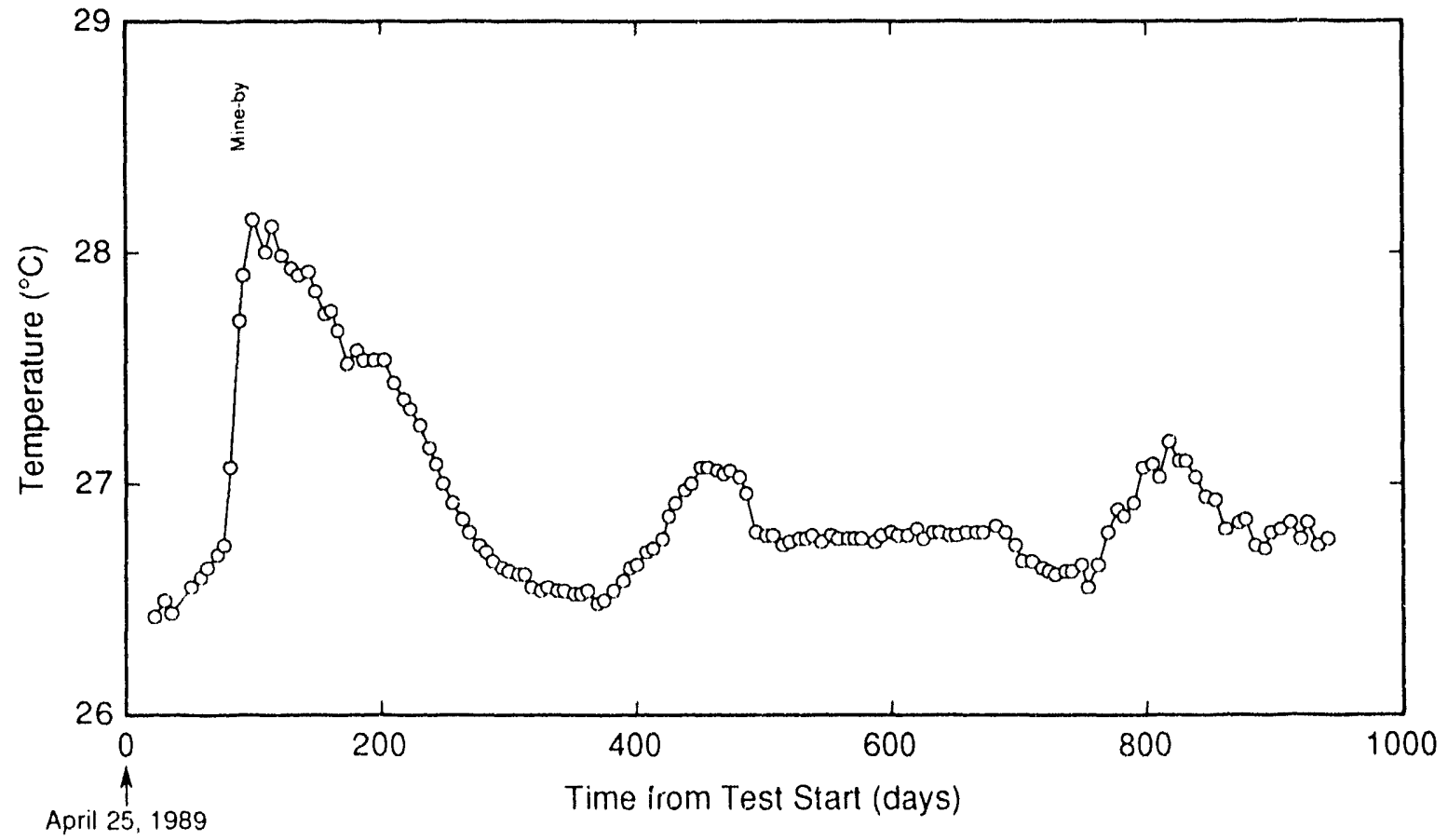

Figure 6-78. Hole QPP15 casing temperature. 


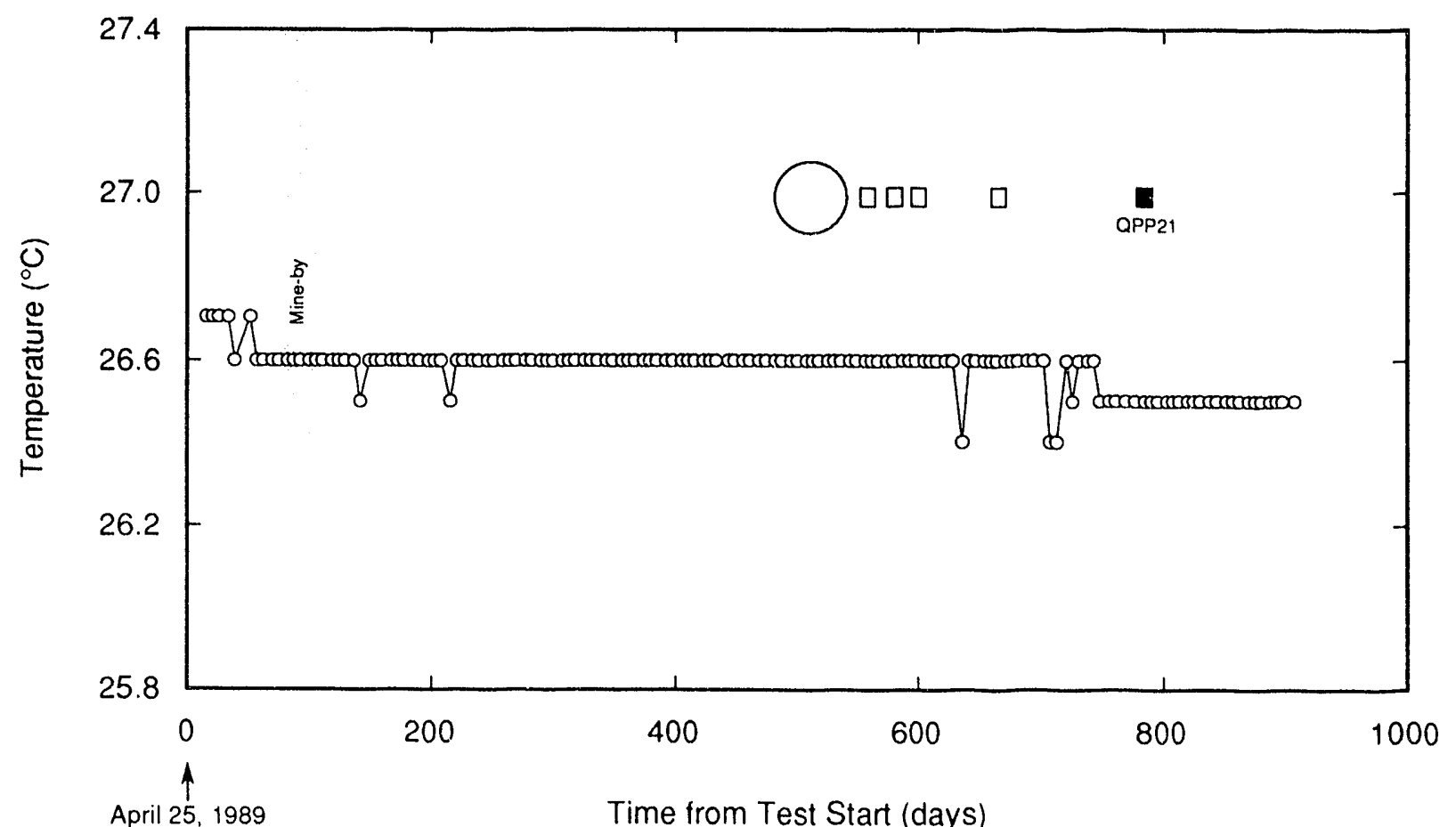

April 25, 1989

Time from Test Start (days)

TRI-6119-49.0

Eigure 6-79. Hole QPP21 test-zone temperature. 


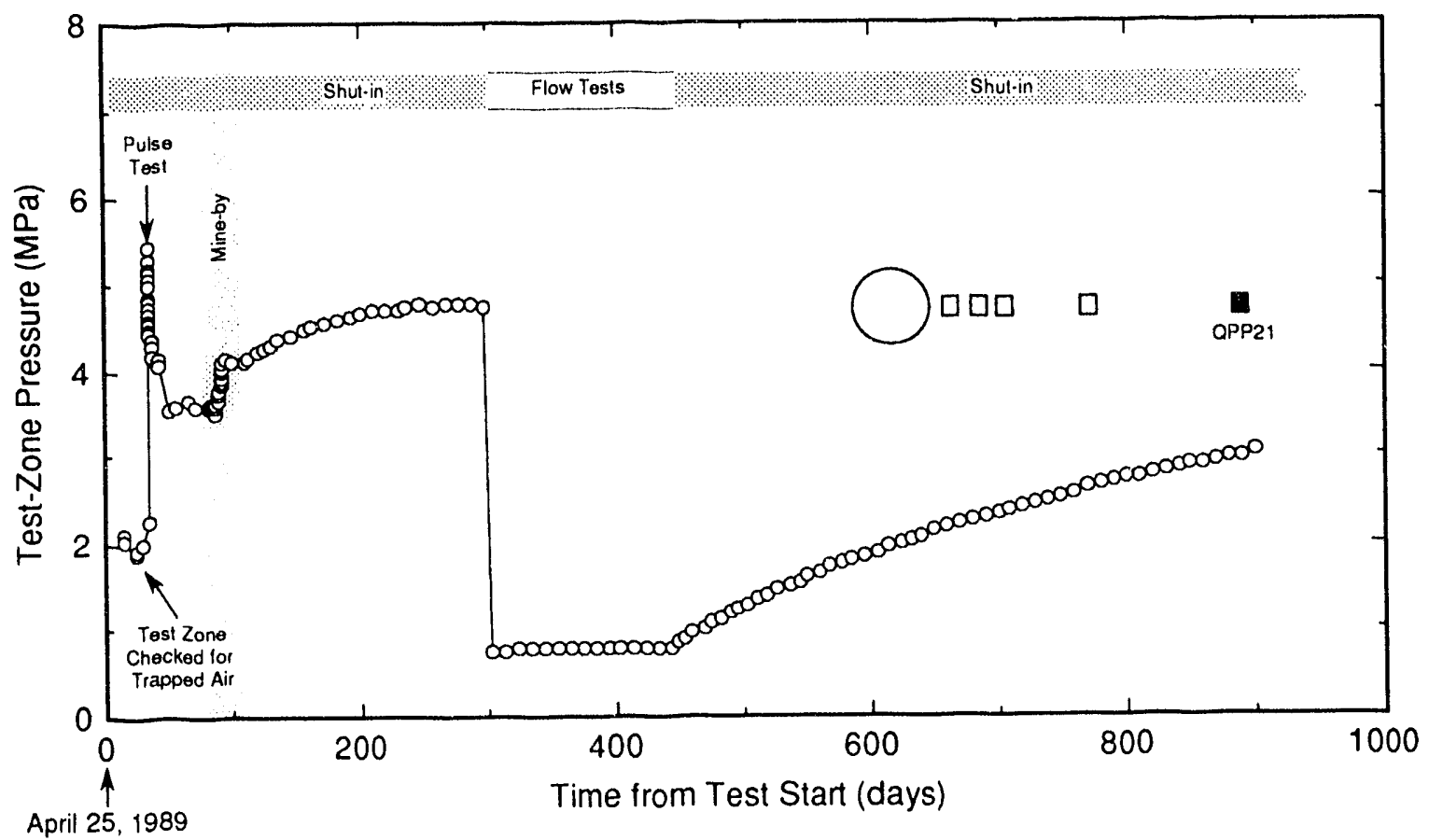

Figure 6-80. Hole QPP21 test-zone pressure.

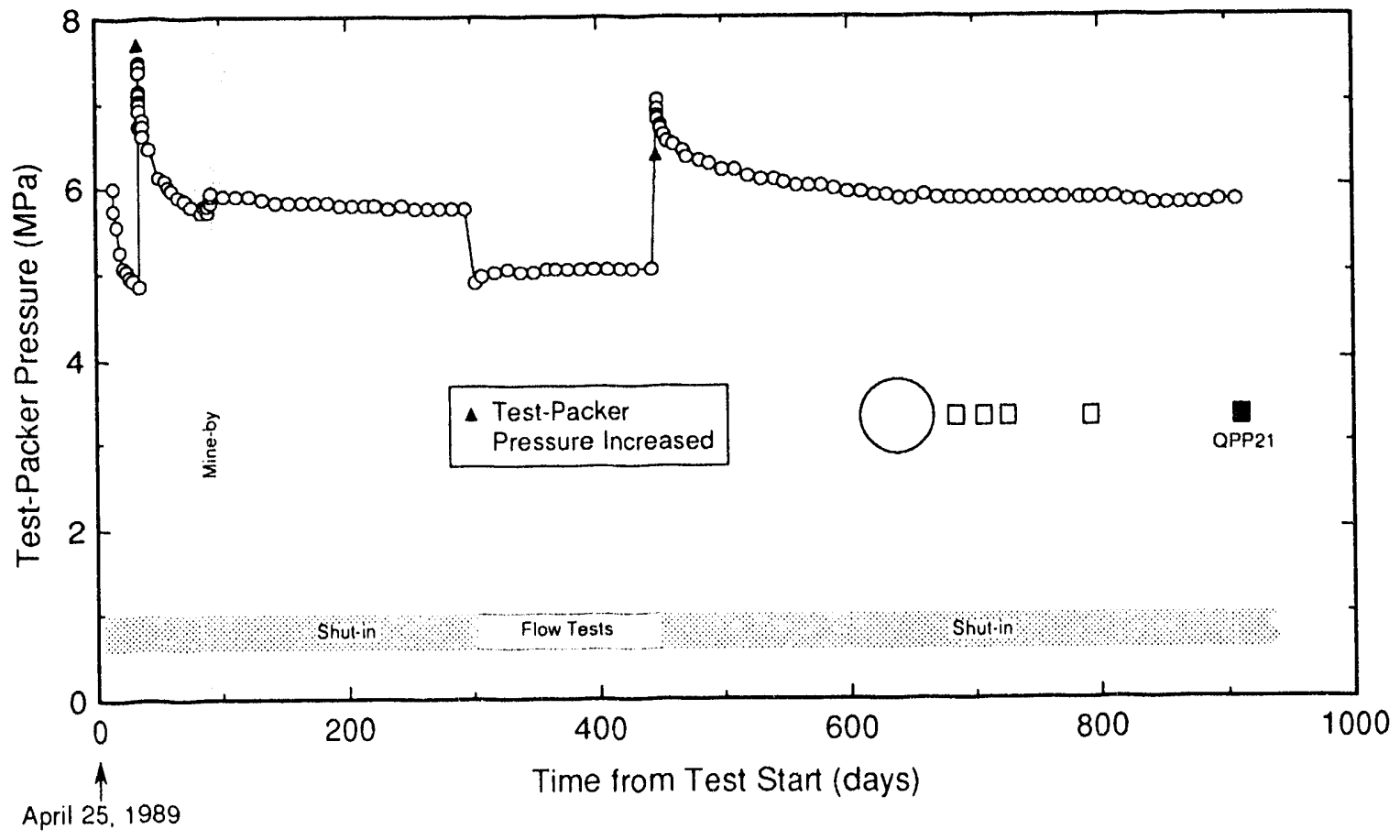

Figure 6-81. Hole QPP21 test-packer pressure. 


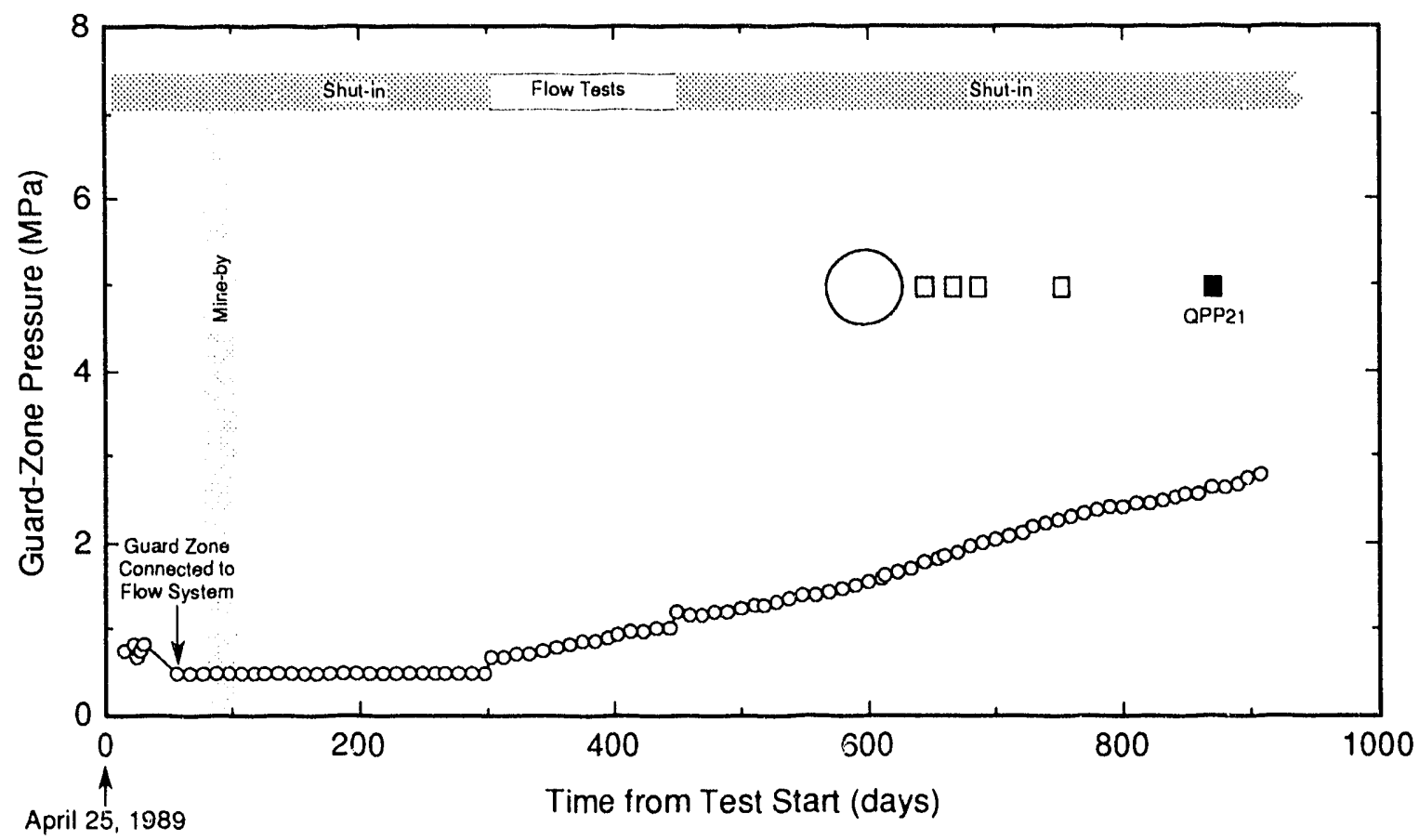

TR1-6119-208-0

Figure 6-82. Hole QPP21 guard-zone pressure.

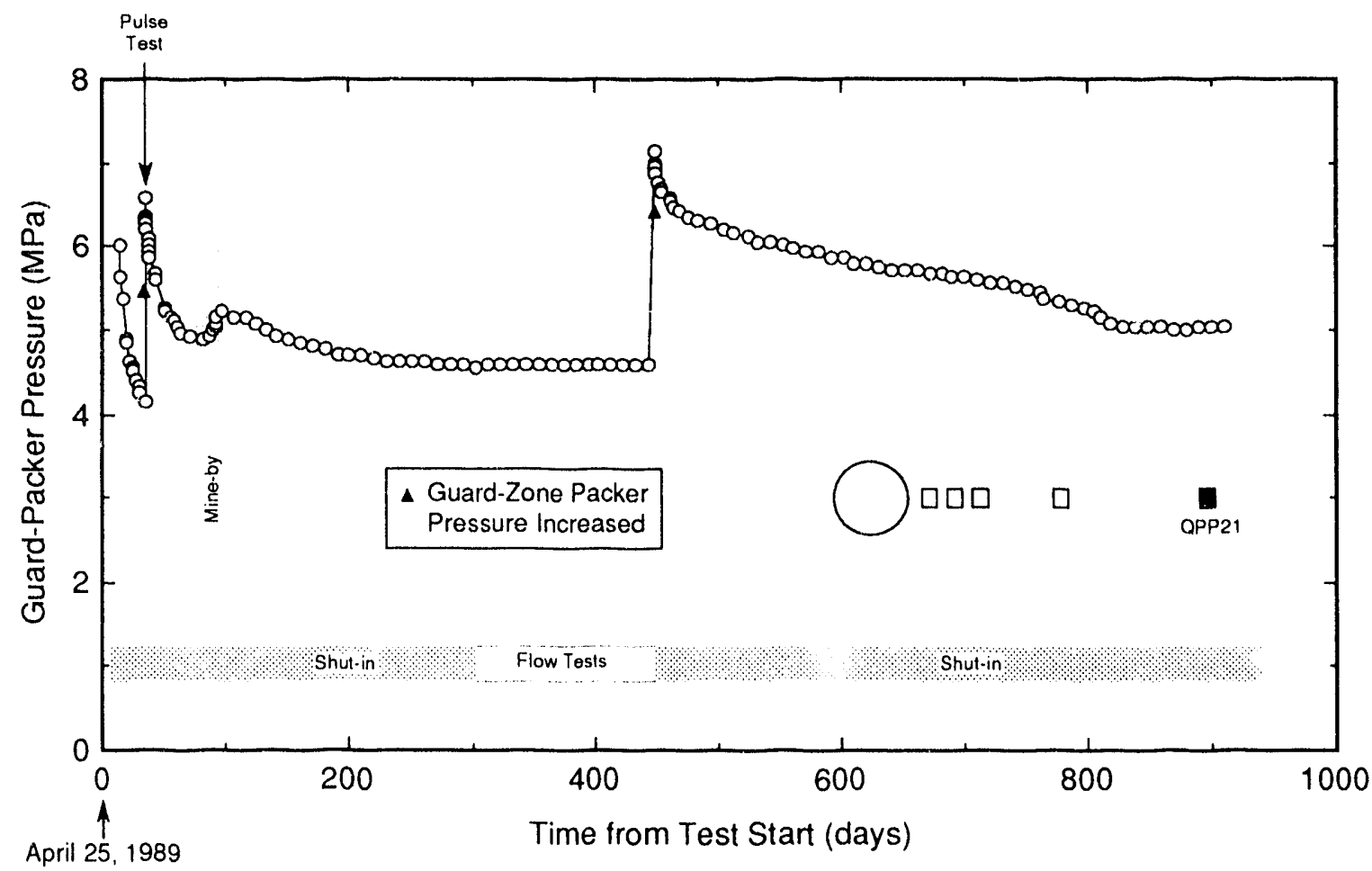

TR1-61 19-209-0

Figure 6-83. Hole QPP21 guard-packer pressure. 


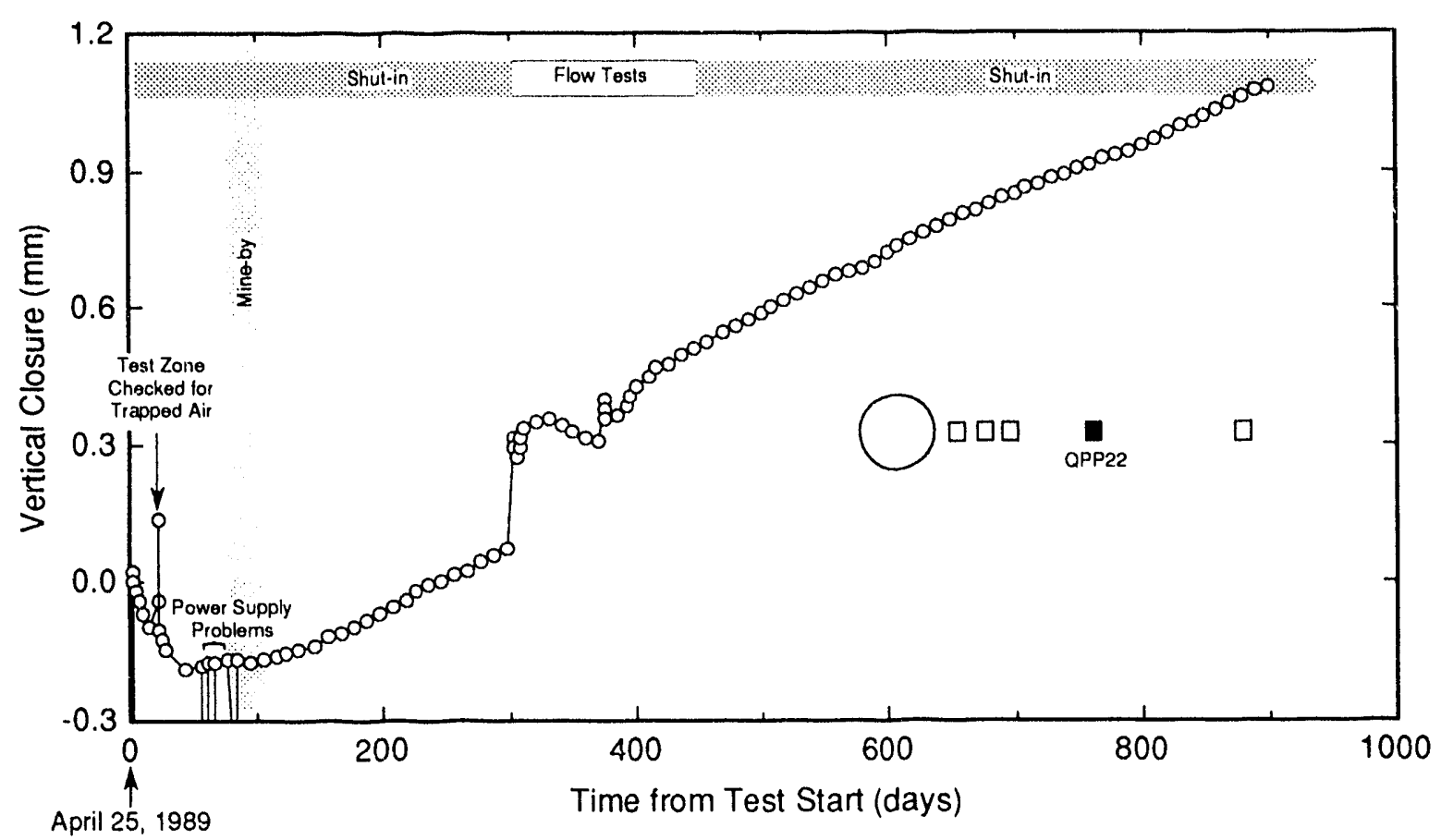

TRI-6119-210-0

Figure 6-84. Vertical closure measured in the test zone of hole QPP22.

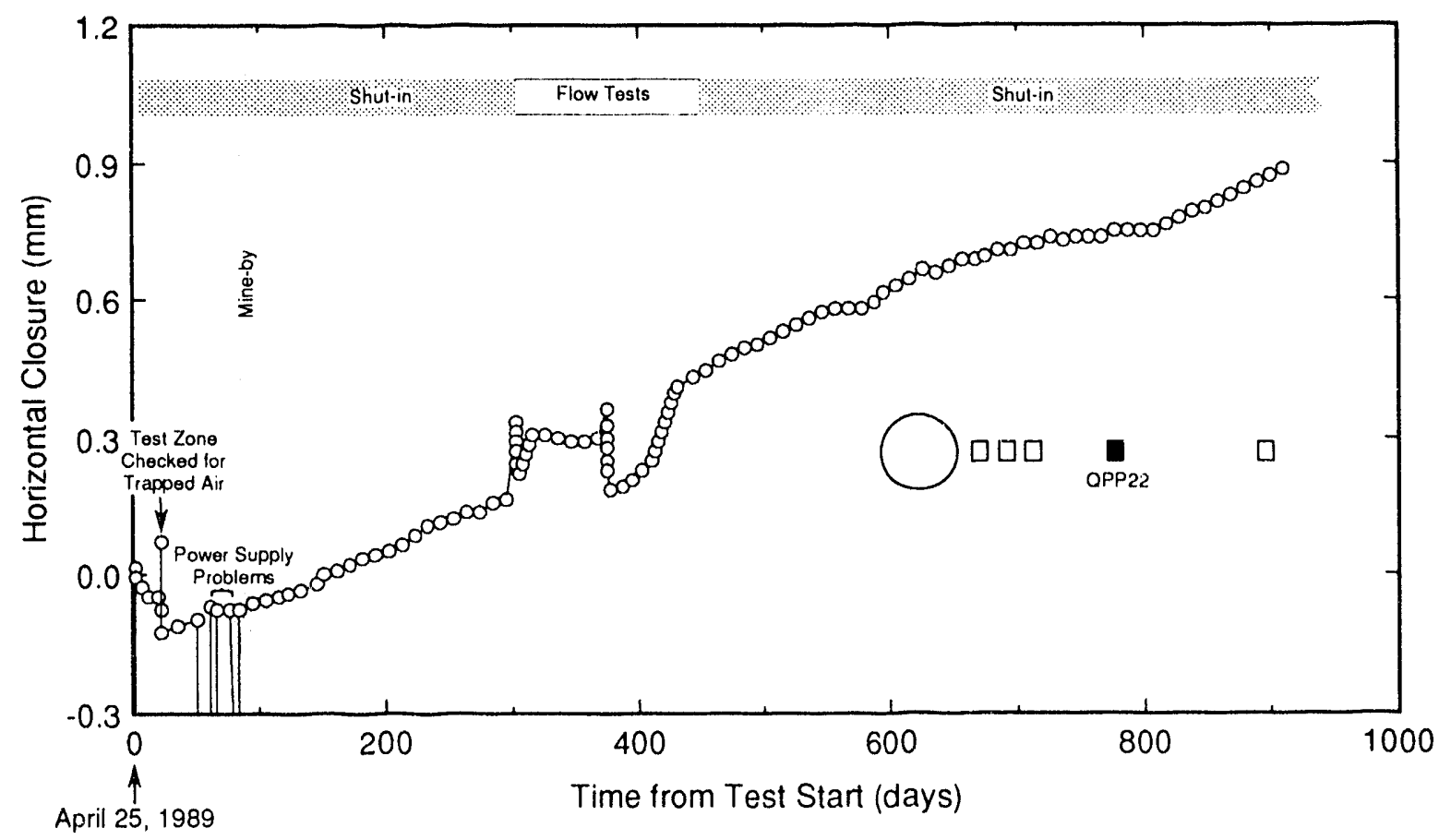

TRI-6119.211-0

Figure 6-85. Horizontal closure measured in the test zone of hole QPP22. 


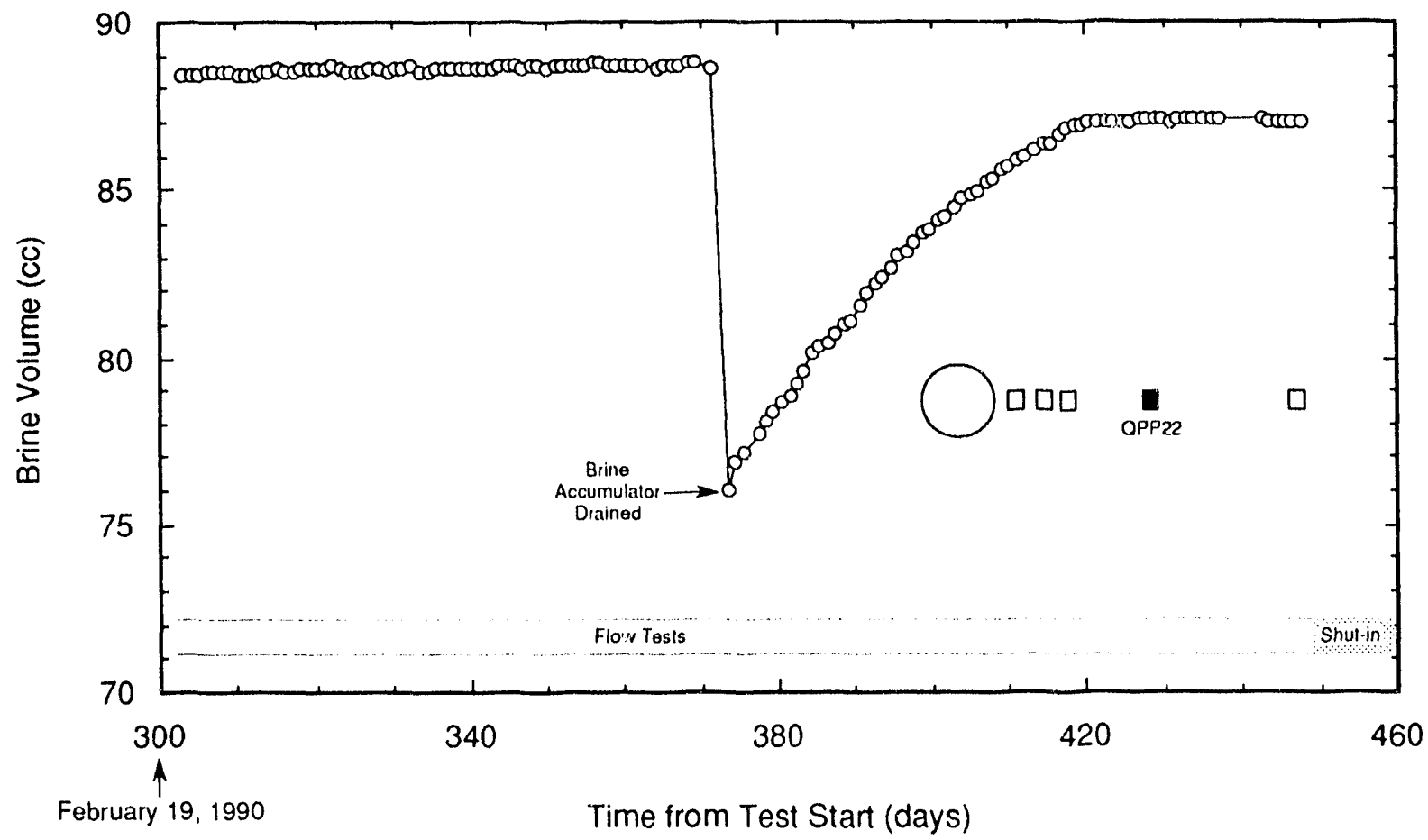

TRI.6119.212.0

Figure 6-86. Brine collected from QPP22 test zone during flow testing. 


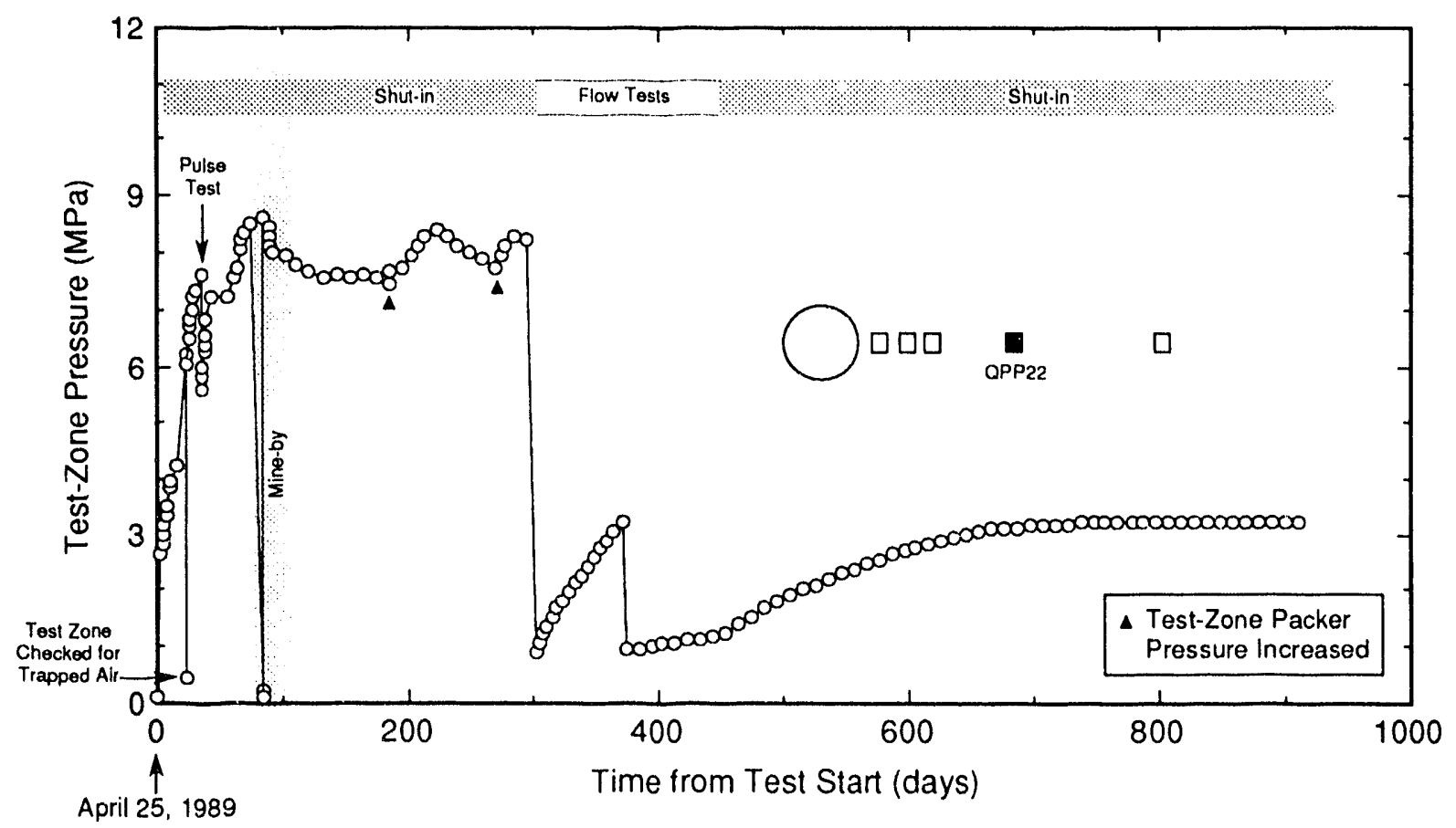

TRI.6119.213-0

Figure 6-87. Hole QPP22 test-zone pressure.

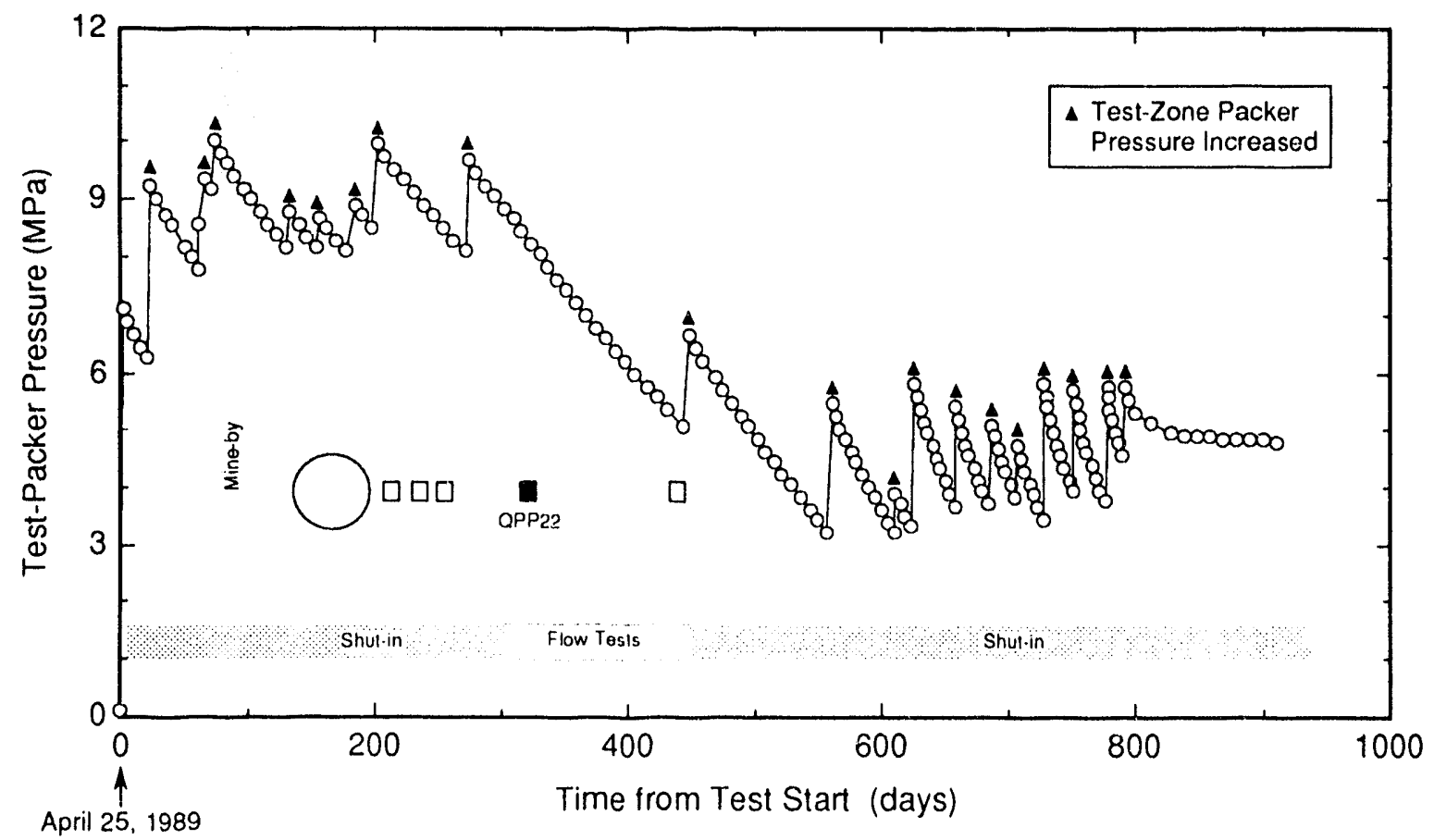

TRI.6119.214.0

Figure 6-88. Hole QPP22 test-packer pressure. 


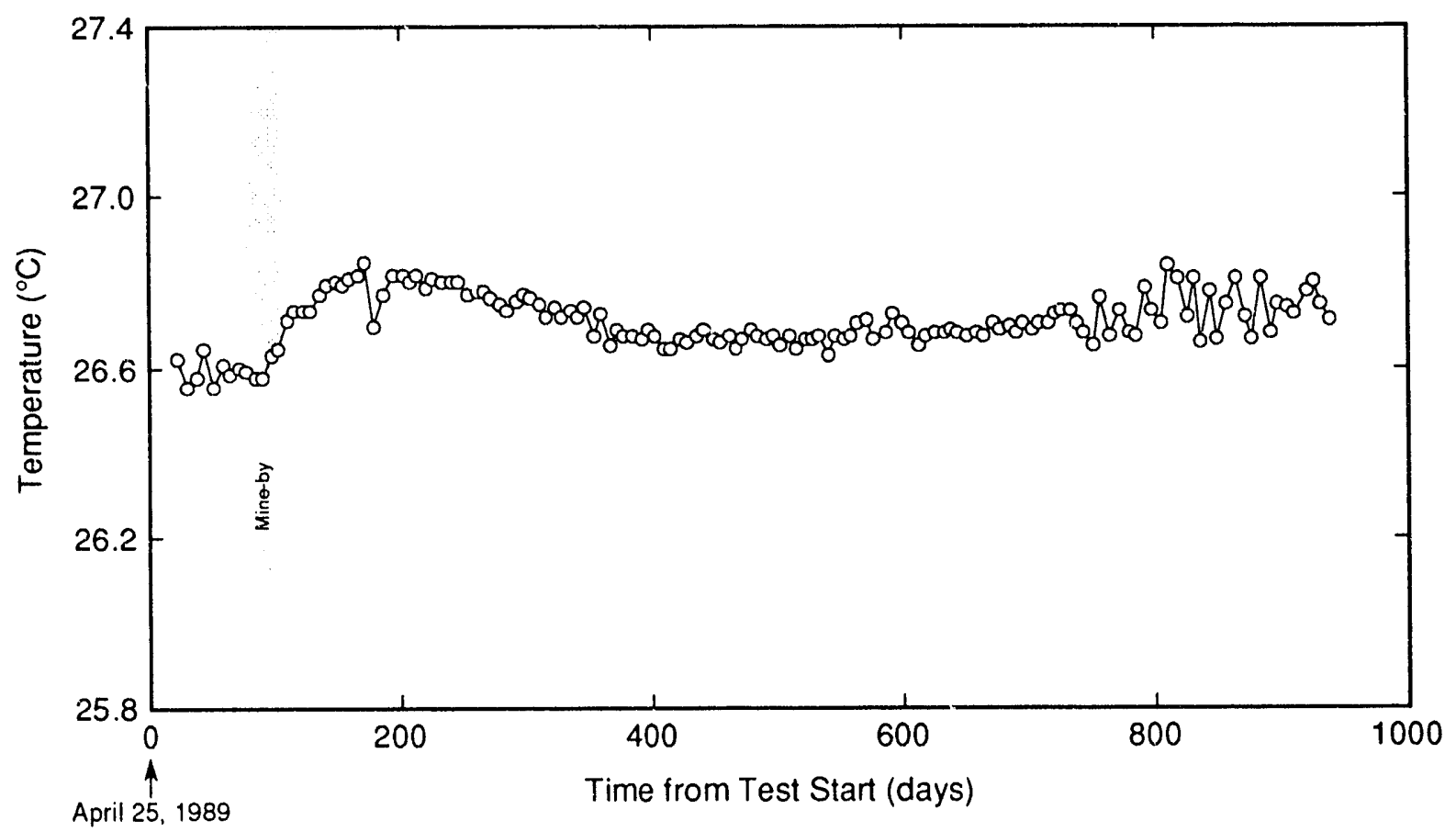

Figure 6-89. Hole QPP22 tool temperature.

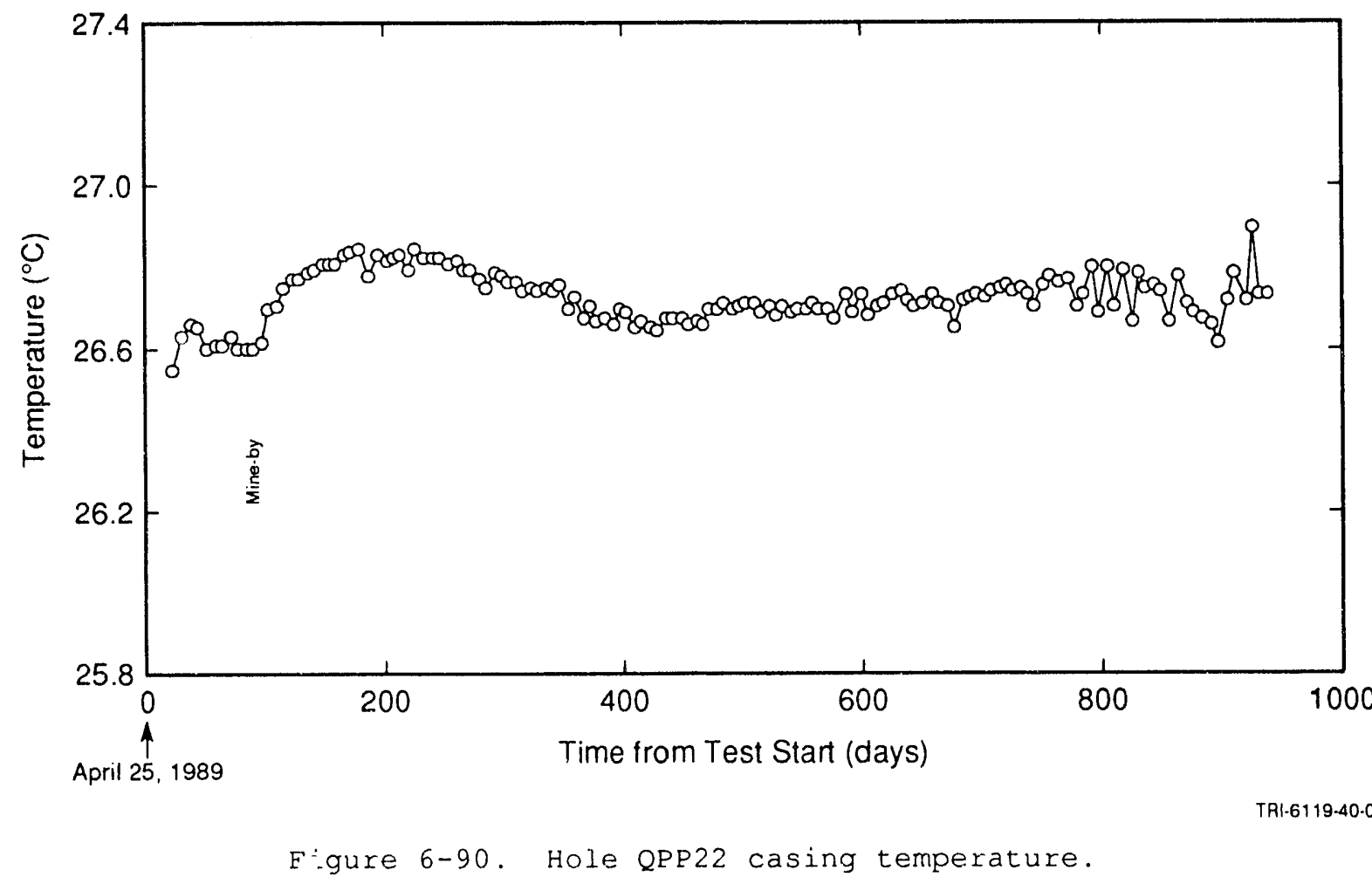




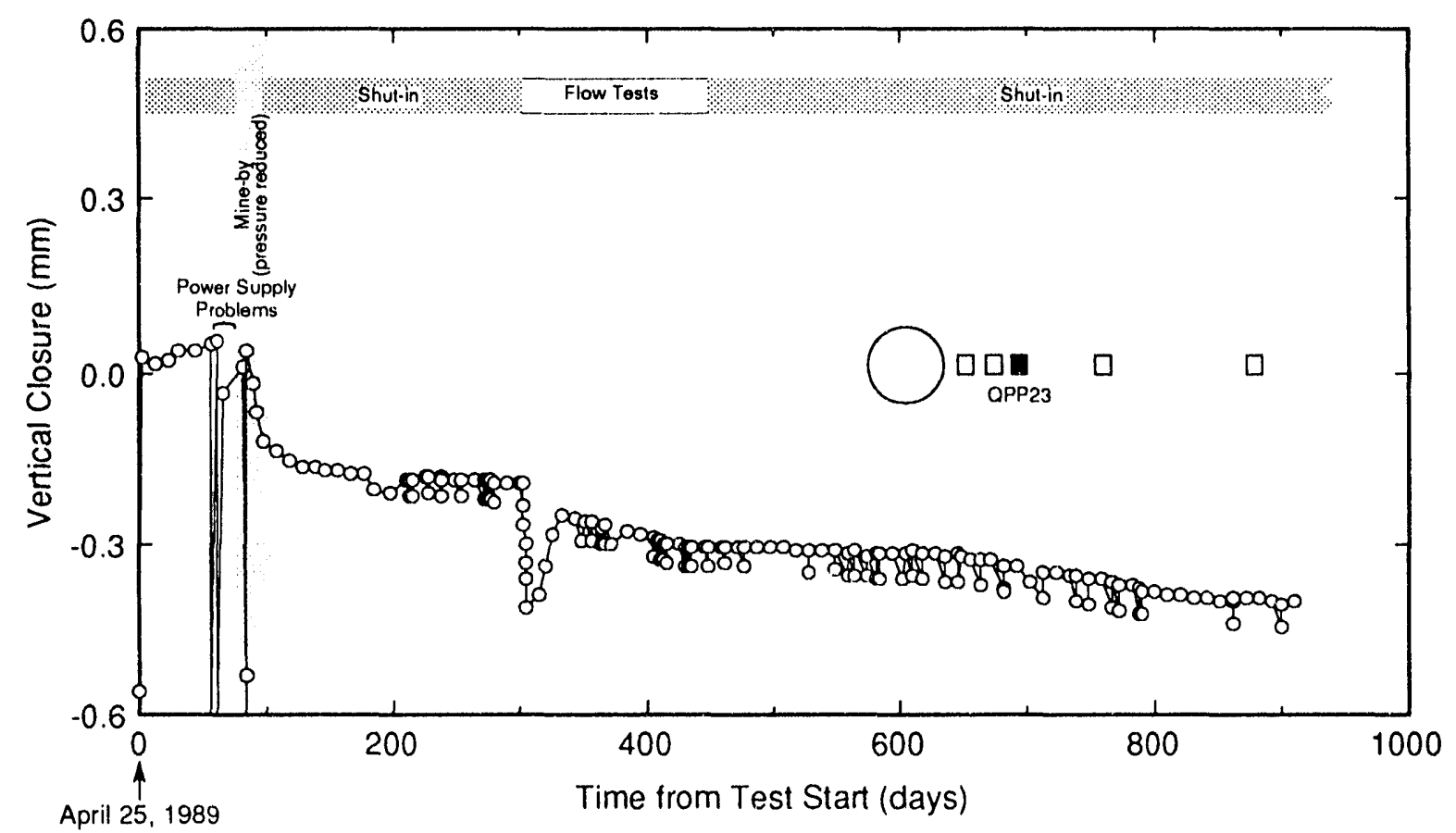

TR1.6119.215.0

Figure 6-91. Vertical closure measured in the test zone of hole QPP23.

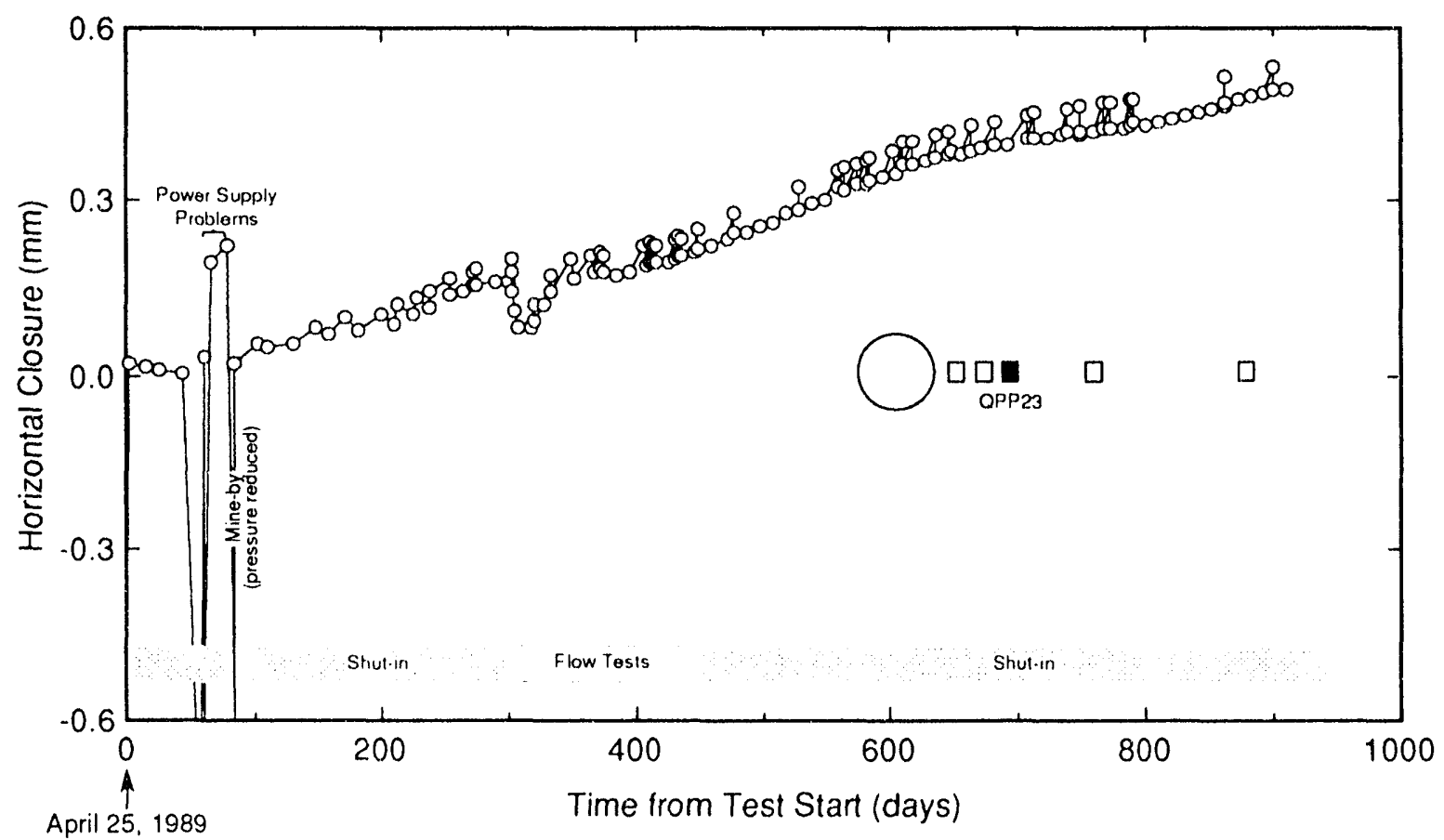

TR1.6119.216.0

Eigure 6-92. Horizontal closure measured in the test zone of hole QPp23. 


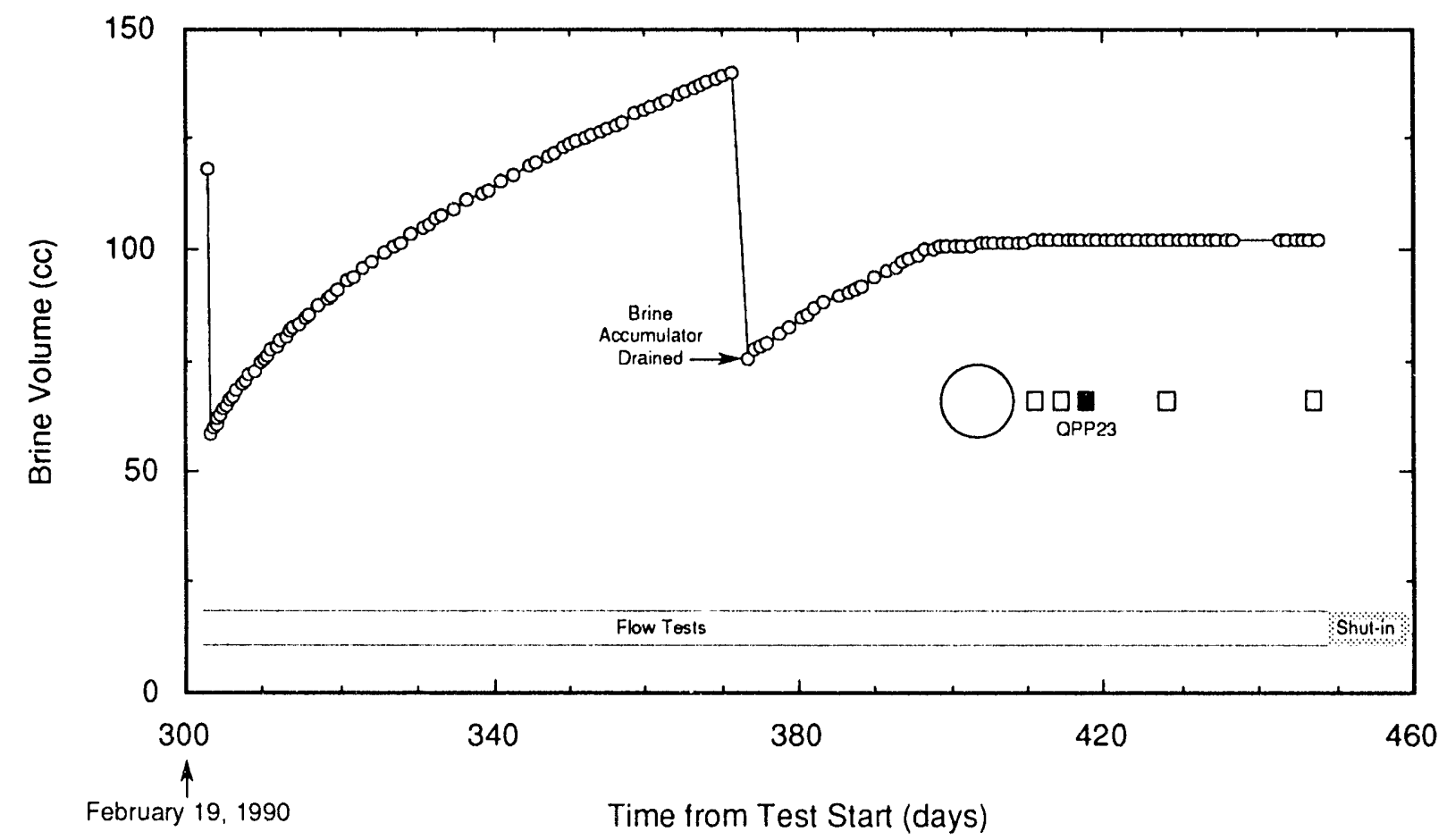

TRI-6119.217.0

Figure 6-93. Brine collected from QPP23 test zone during flow testing. 


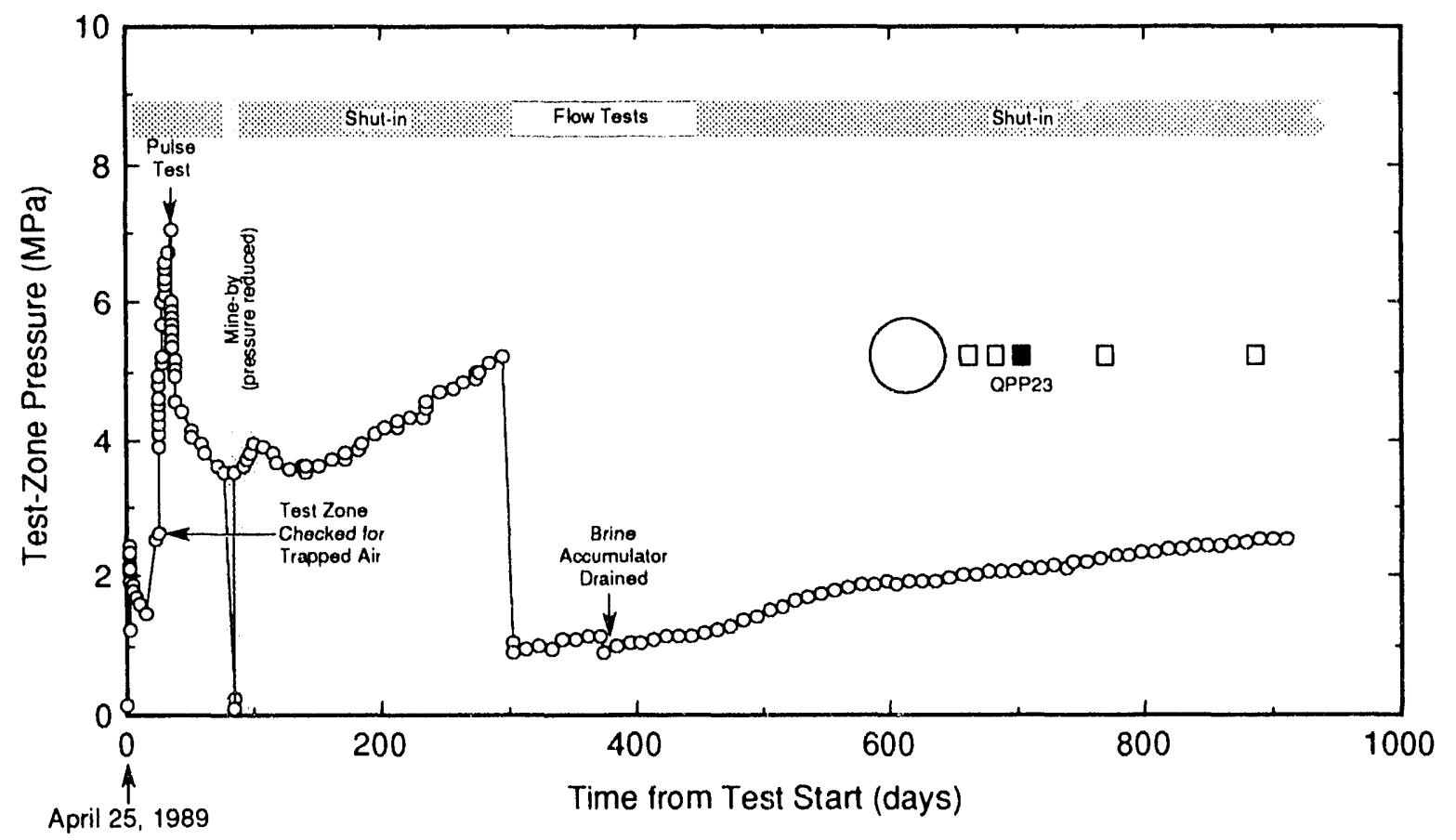

TRI.6119-2.18.0

Figure 6-94. Hole QPP23 test-zone pressure.

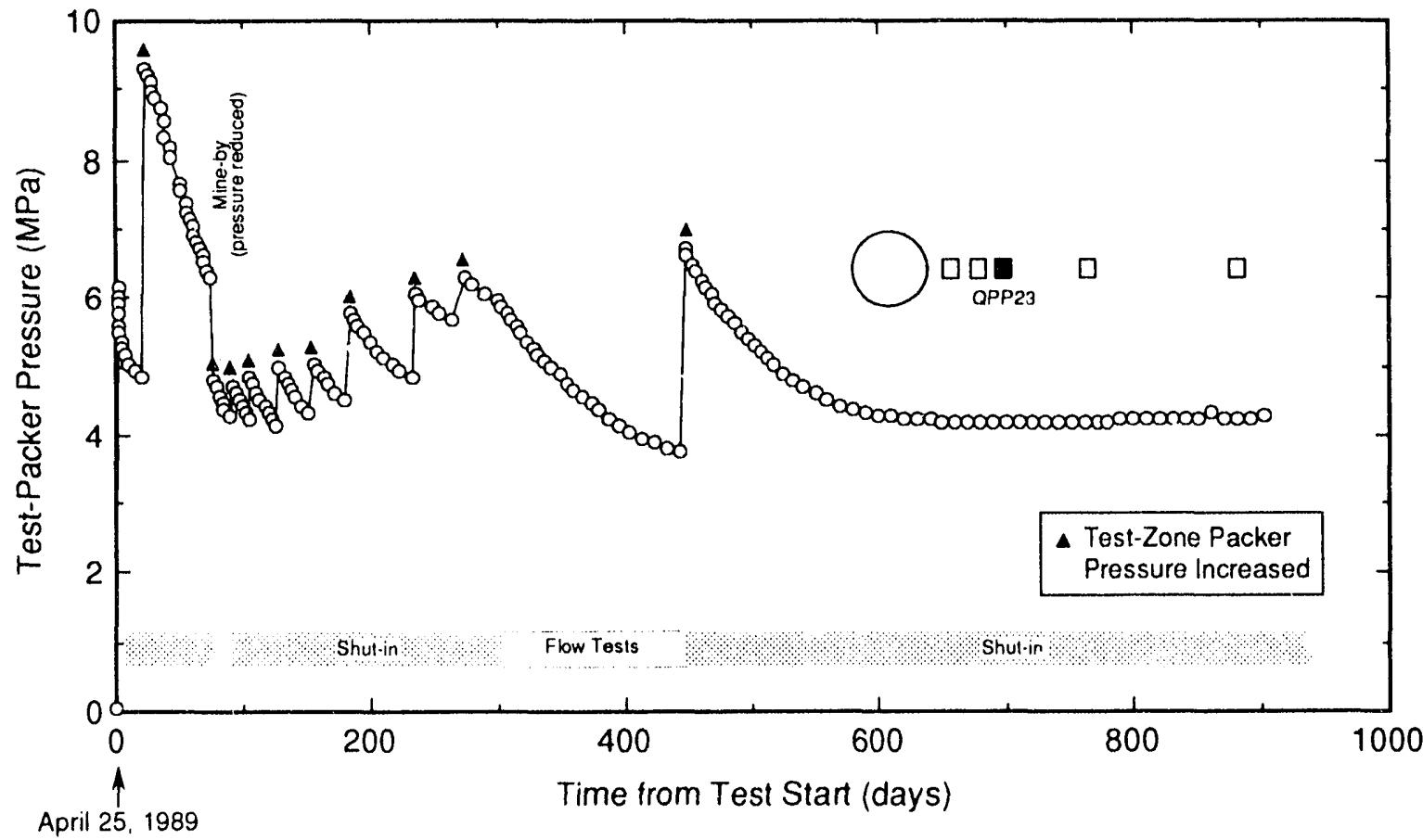

TA1.6119-219-0

Figure 6-95. Hole QPP23 test-packer pressure. 


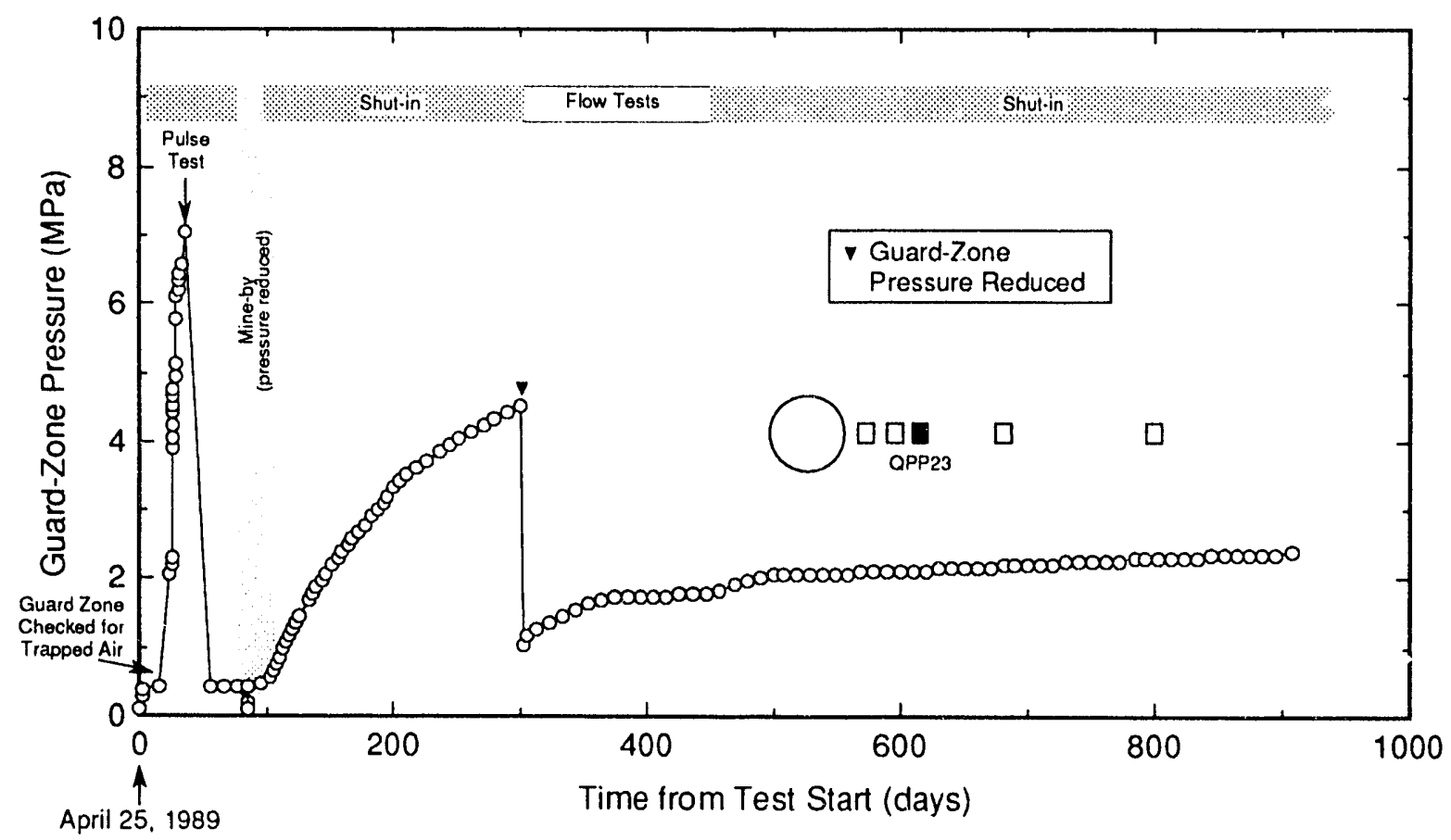

TR1.6119.220.0

Figure 6-96. Hole QPP23 guard-zone pressure.

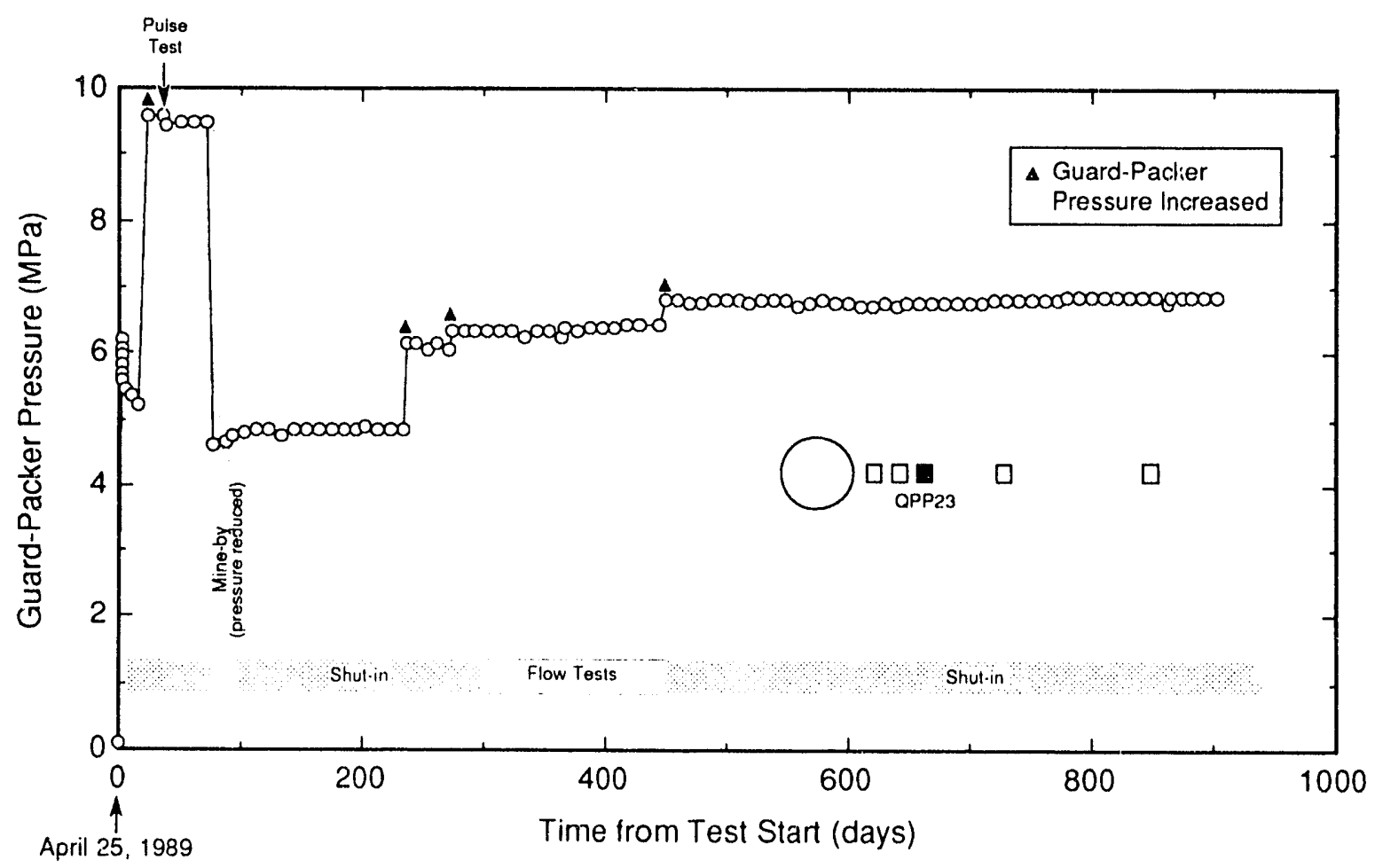

TRI.6119-221.0

Figure 6-97. Hole QPP23 guard-packer pressure. 


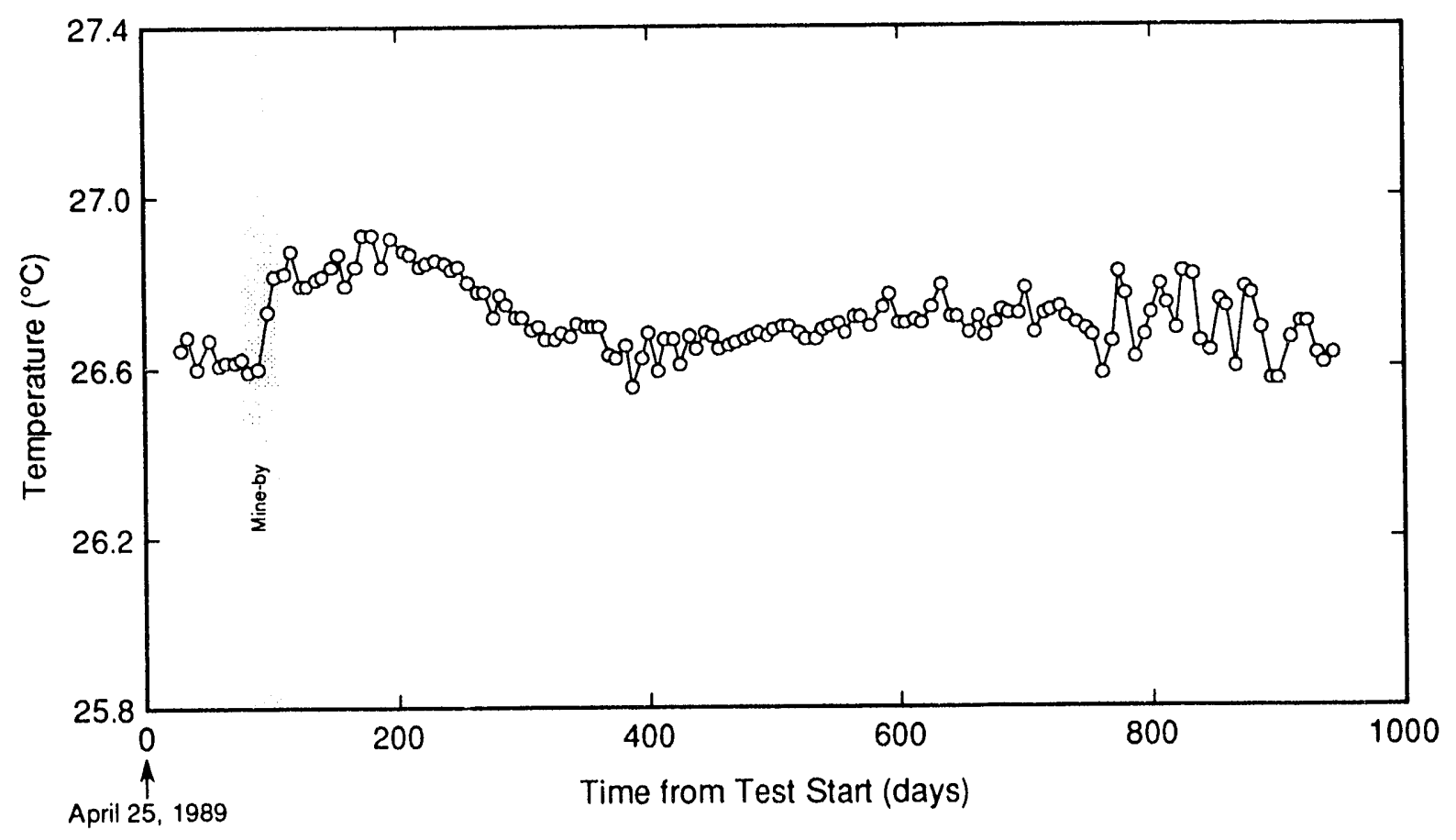

Eigure 6-98. Hole QPP23 tool temperature.

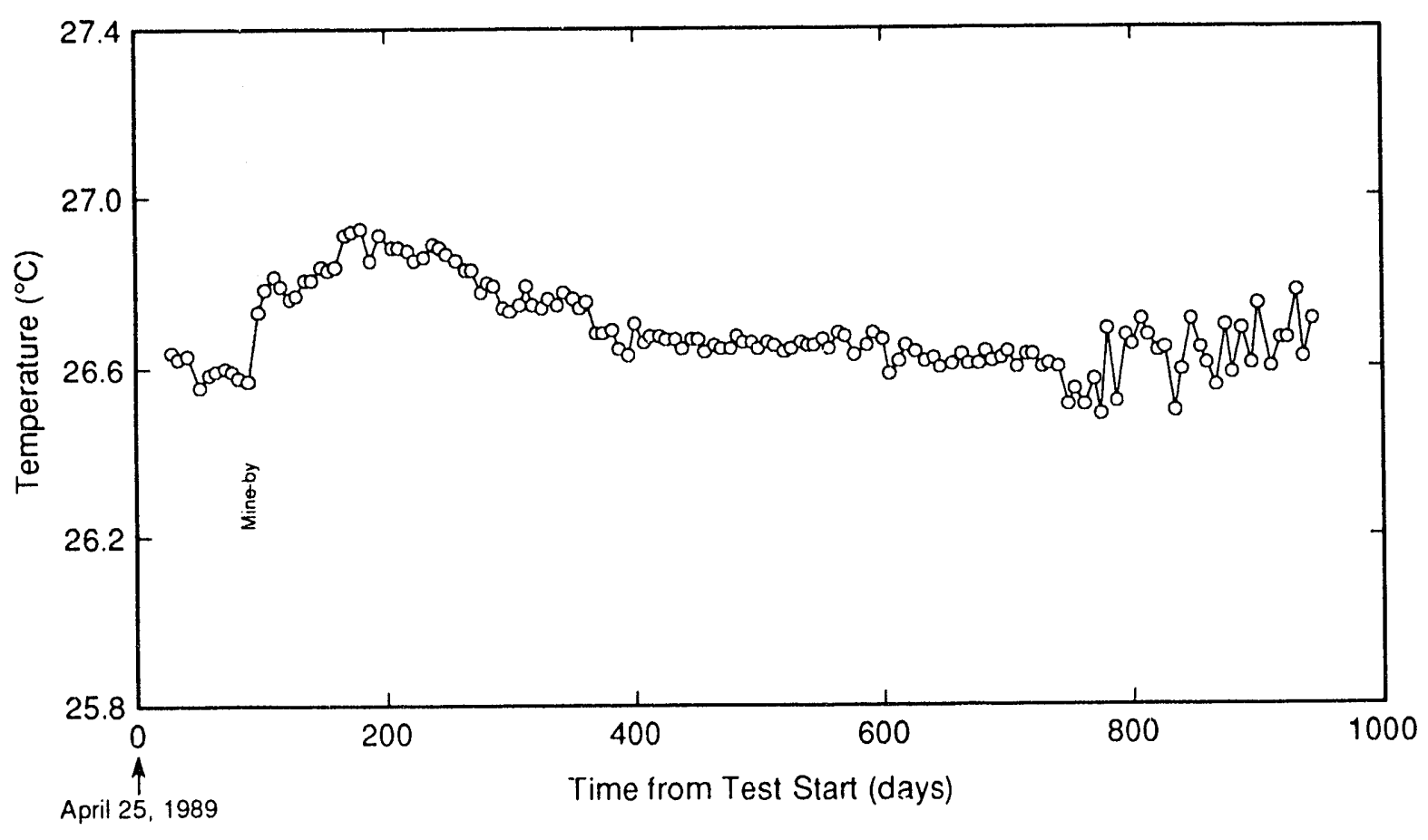

Figure 6-99. Hole QPP23 casing temperature. 


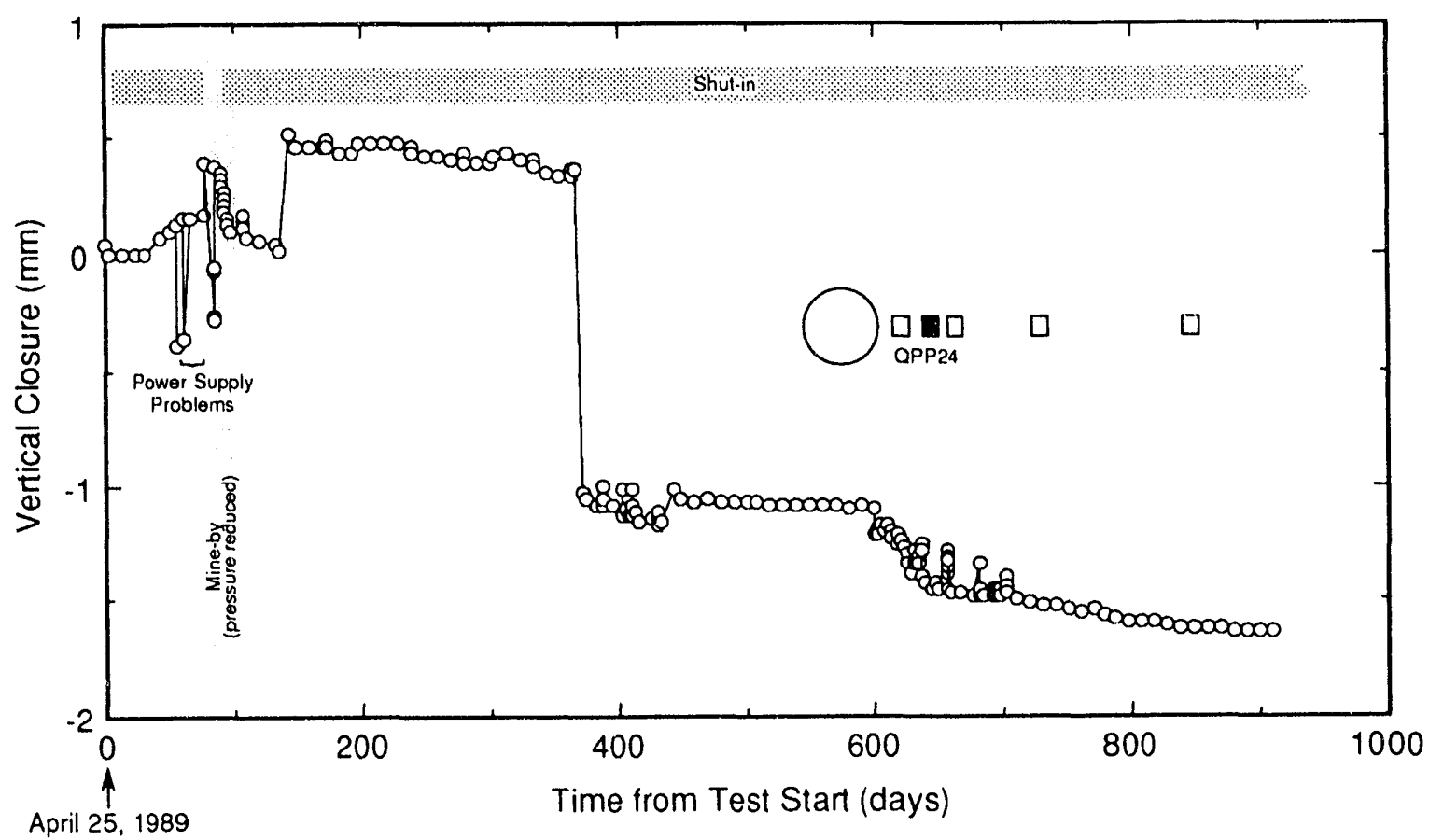

TRI-6119-222-0

Figure 6-100. Vertical closure measured in the test zone of hole QPP24.

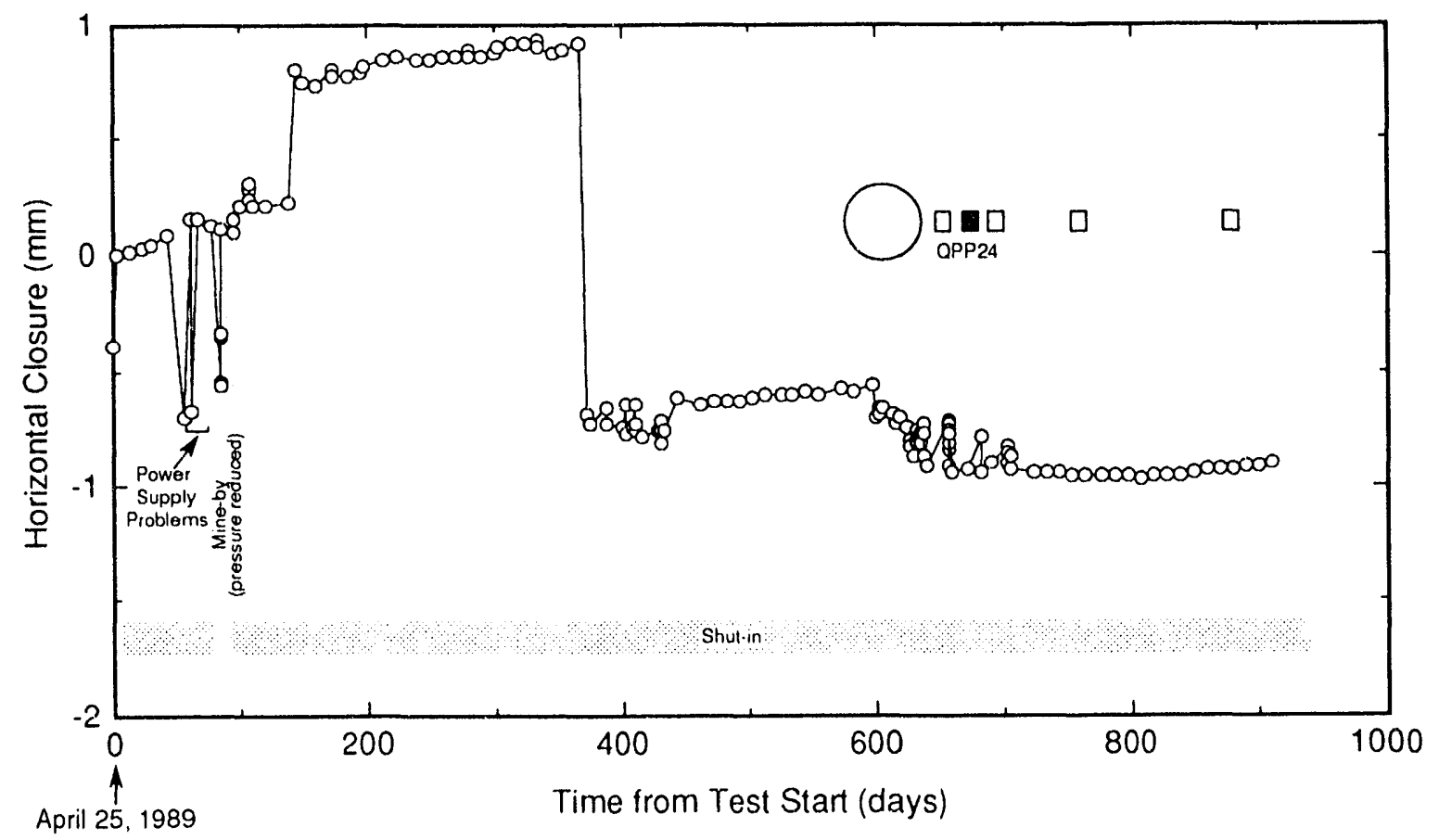

TRI.6119.223.0

Figure 6-101. Horizontal closure measured in the test zone of hole QPP24. 


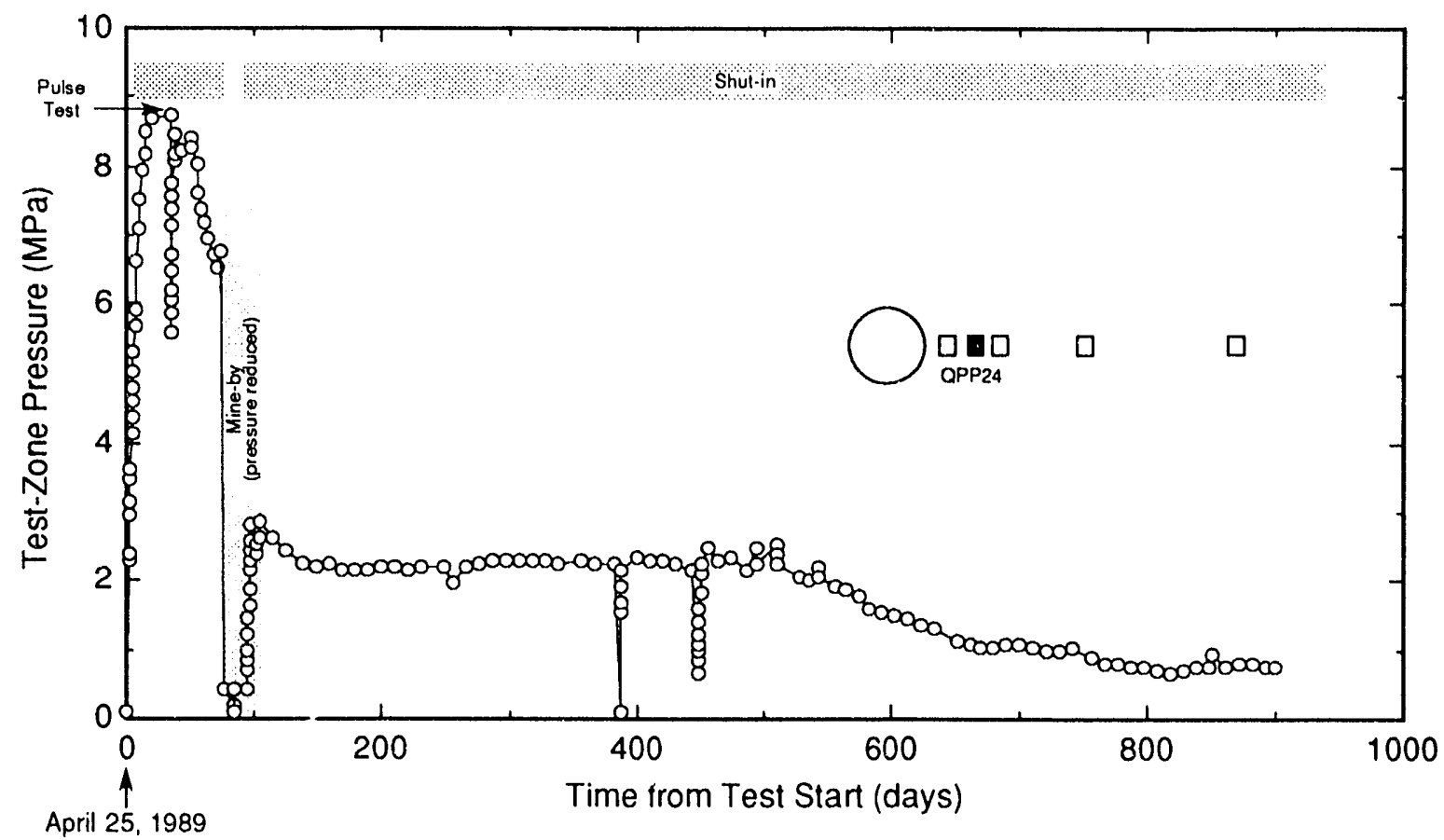

TR1.6119.224-0

Figure 6-102. Hole QPP24 test-zone pressure.

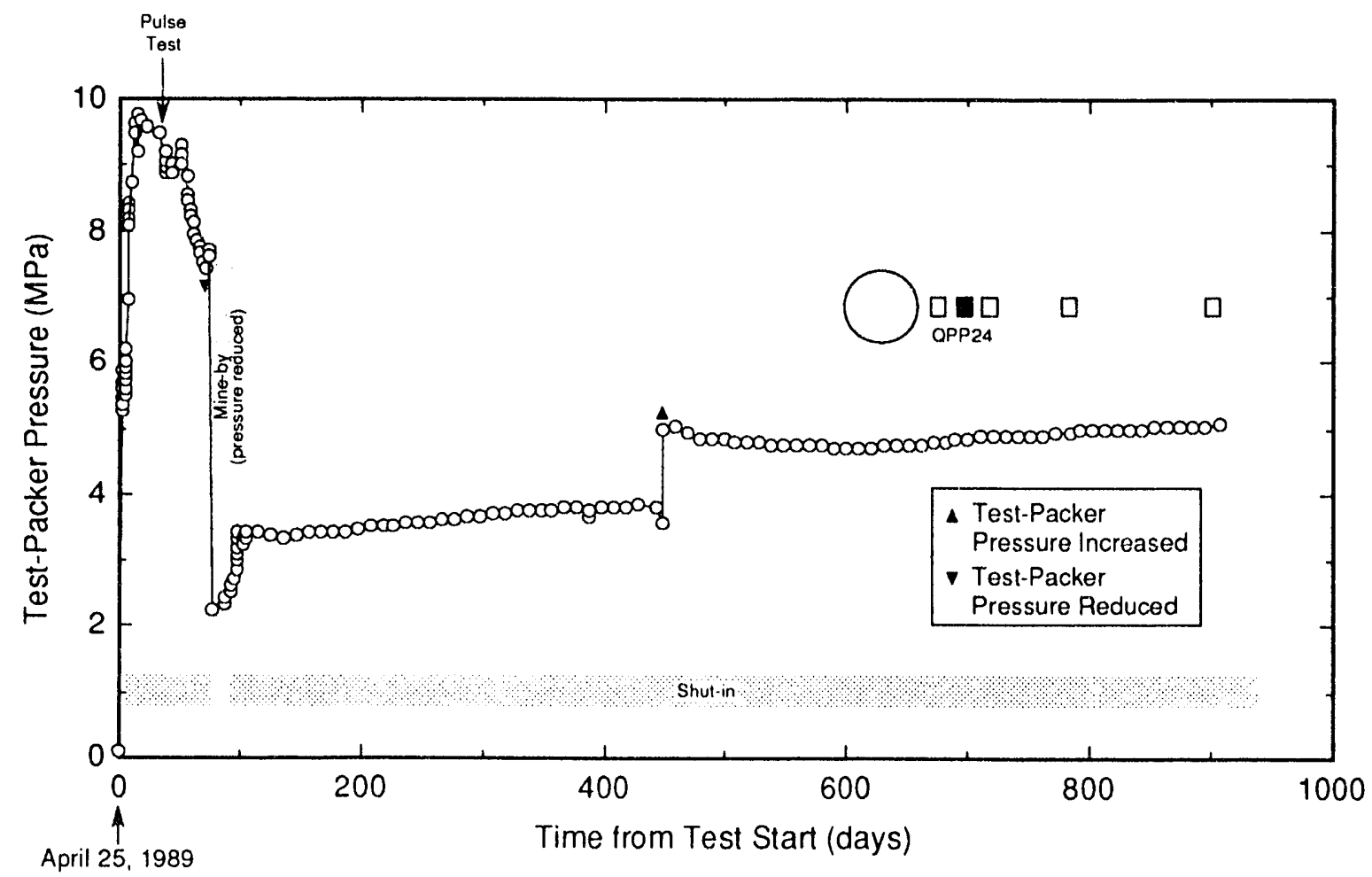

TA1.6119.225.0

Figure 6-103. Hole QPE24 test-packer pressure. 


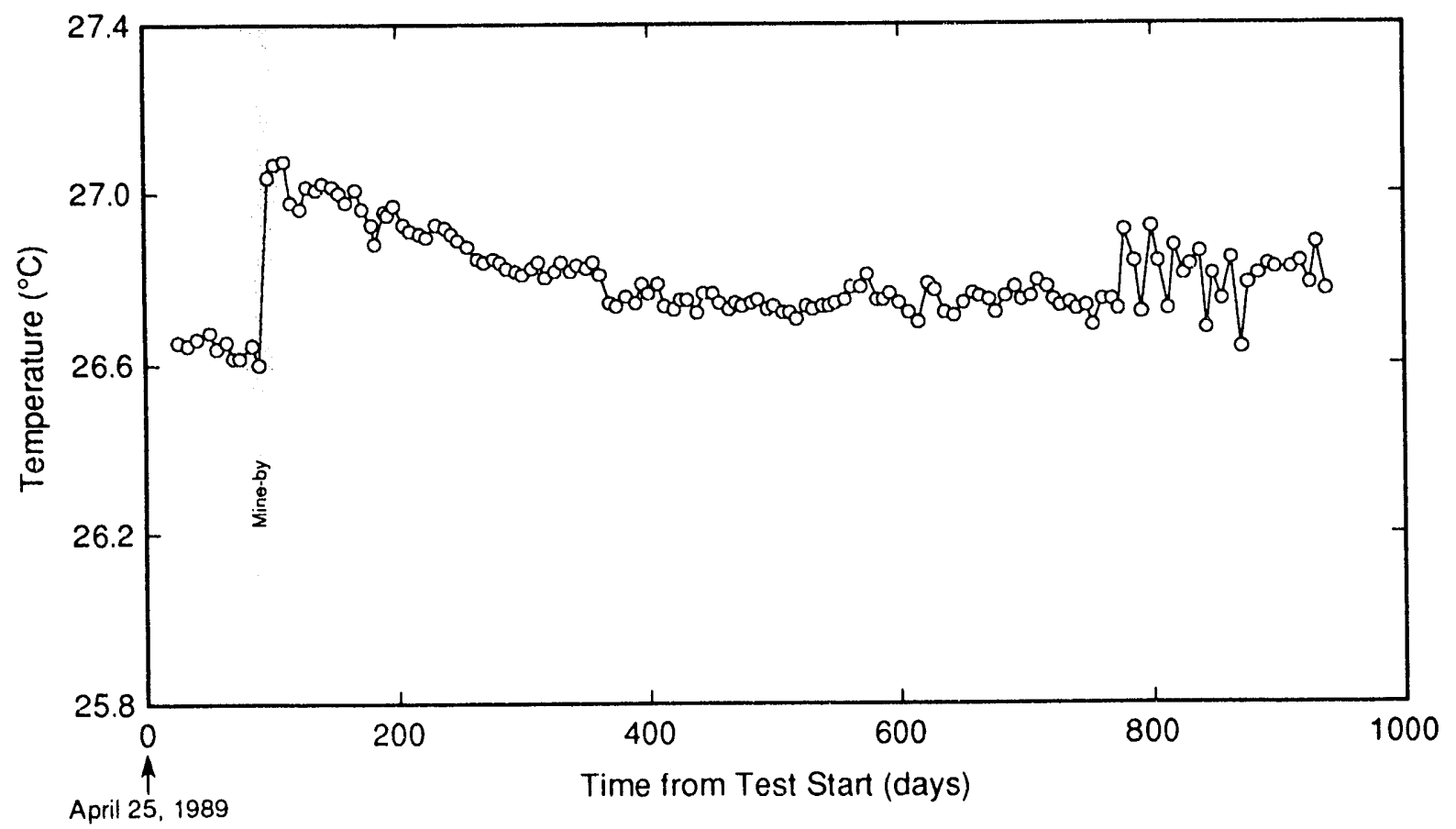

Figure 6-104. Hole QPP24 tool temperature.

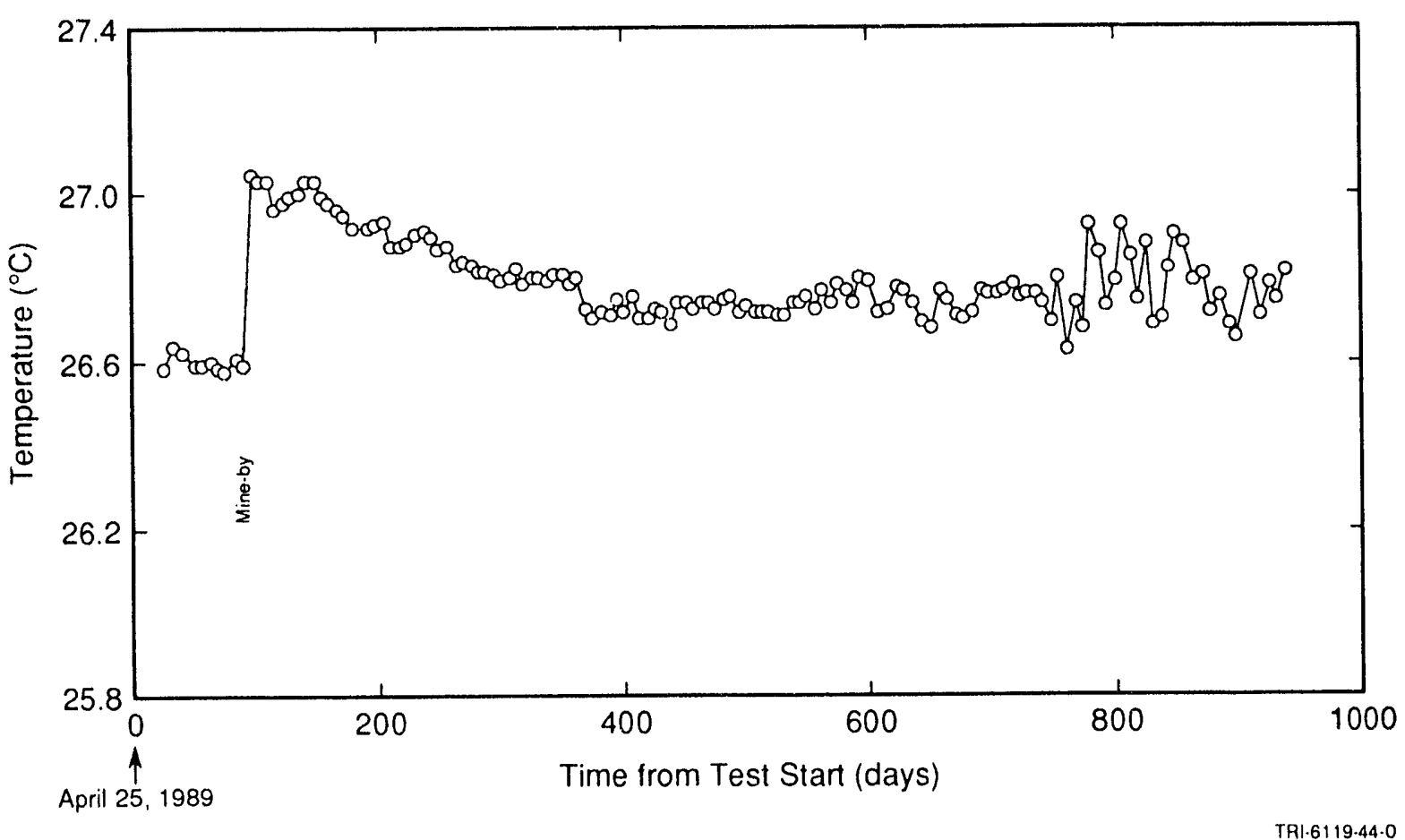

Figure 6-105. Hole QPP24 casing temperature. 


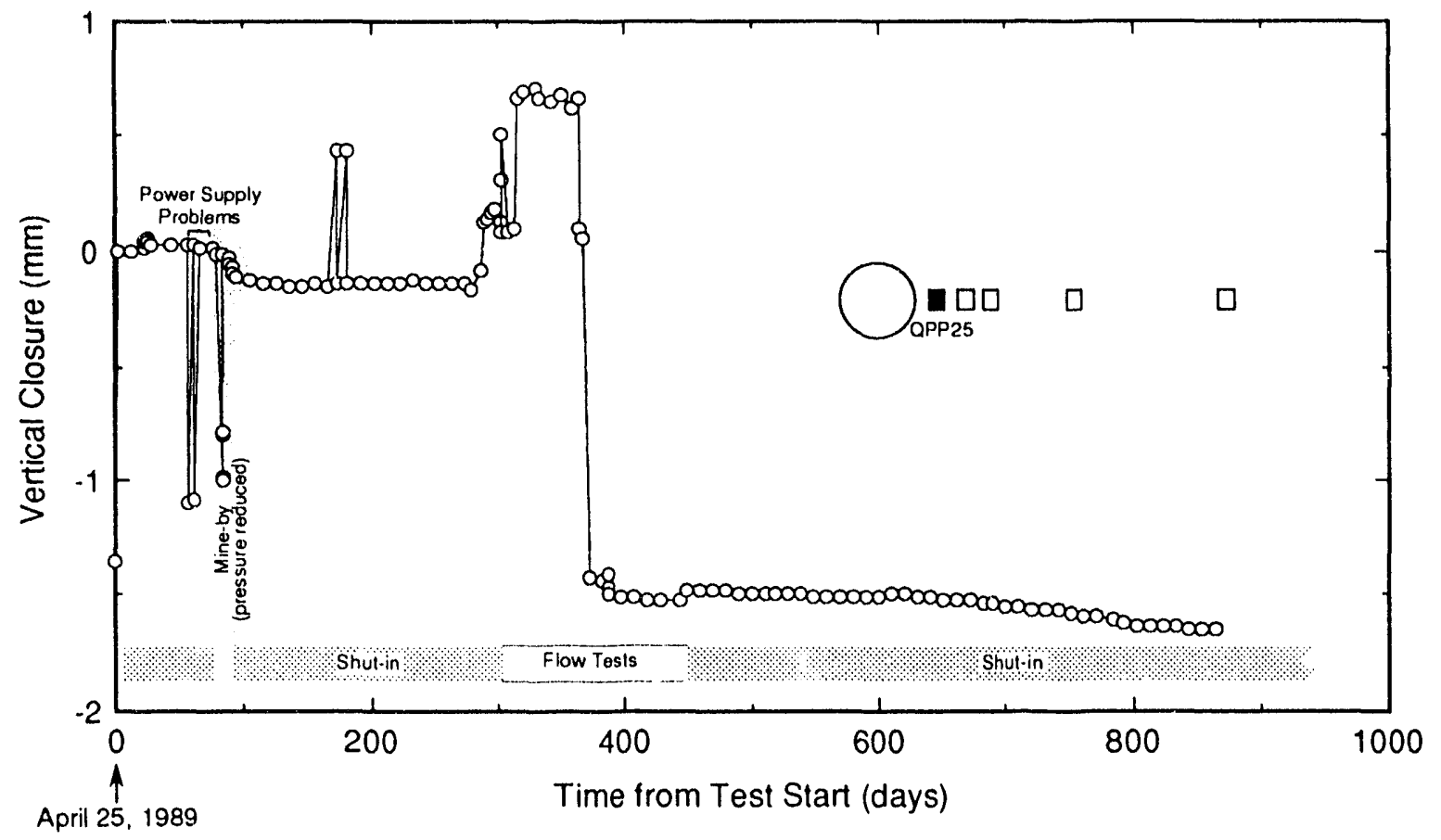

TR1.6119.226.0

Figure 6-106. Vertical closure measured in the test zone of hole QPP25.

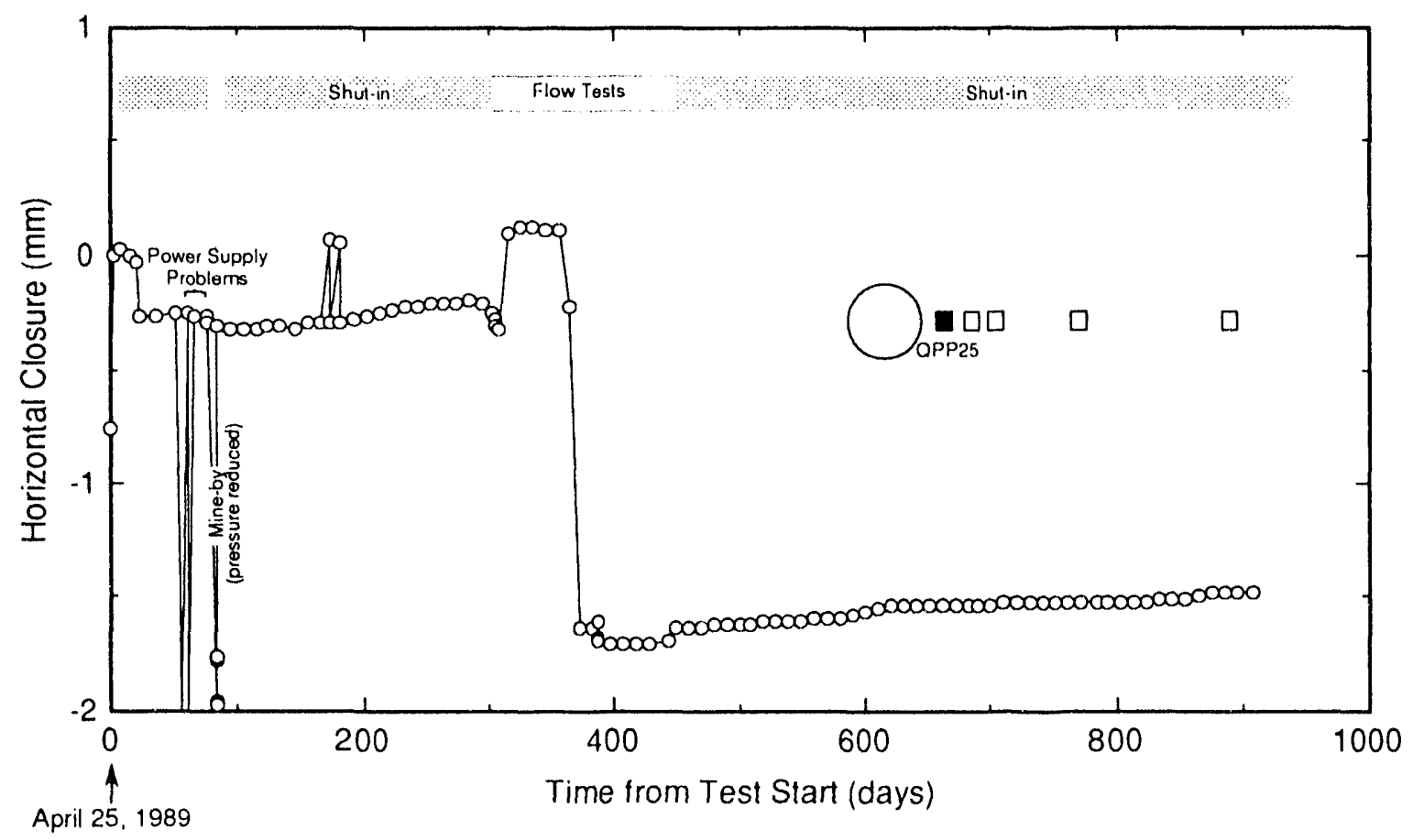

TRI.6119.227.0

Figure 6-107. Horizontal closure measured in the test zone of hole QPP25. 


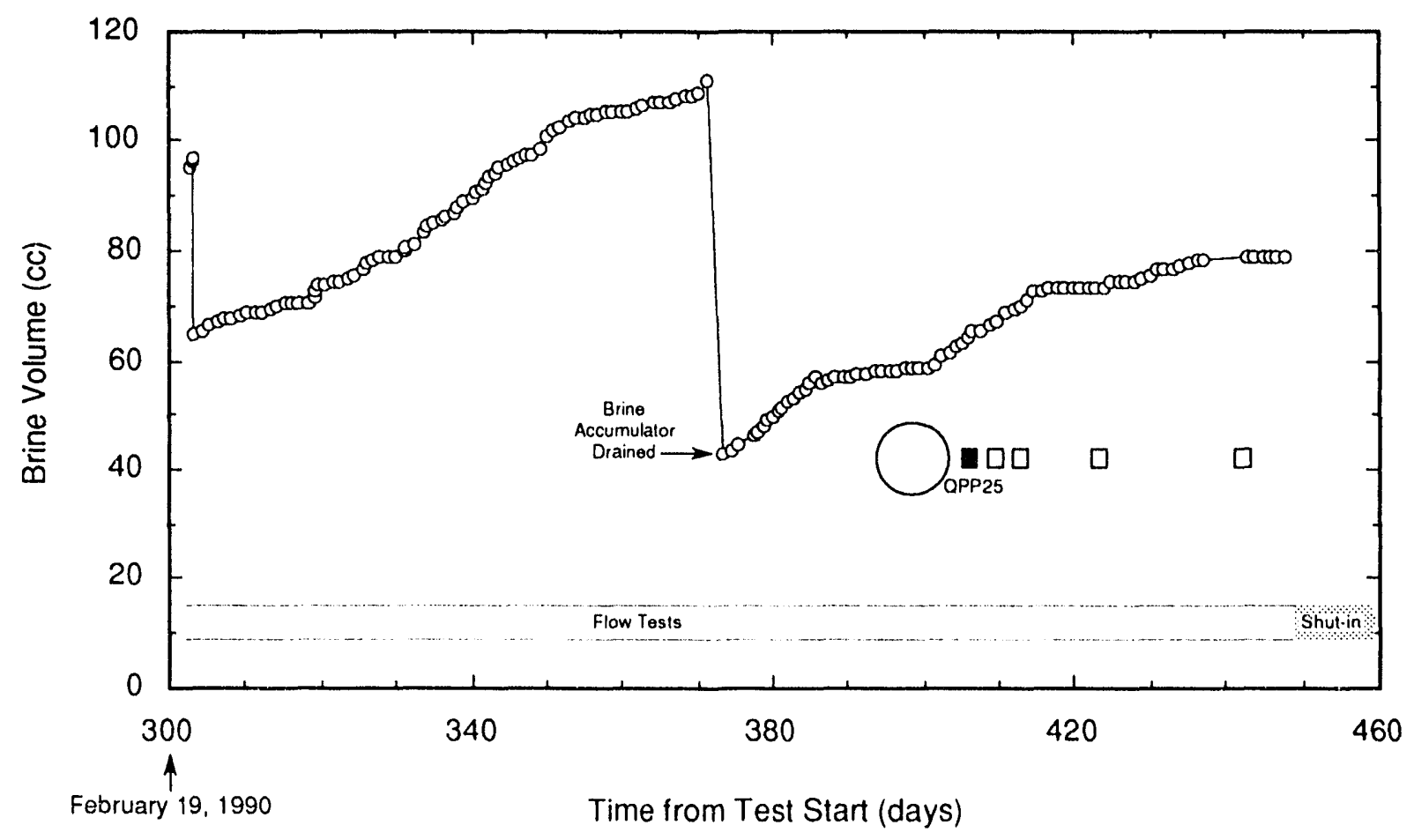

TRI-6119-228.0

Figure 6-108. Brine collected from QPP25 test zone during flow testing. 


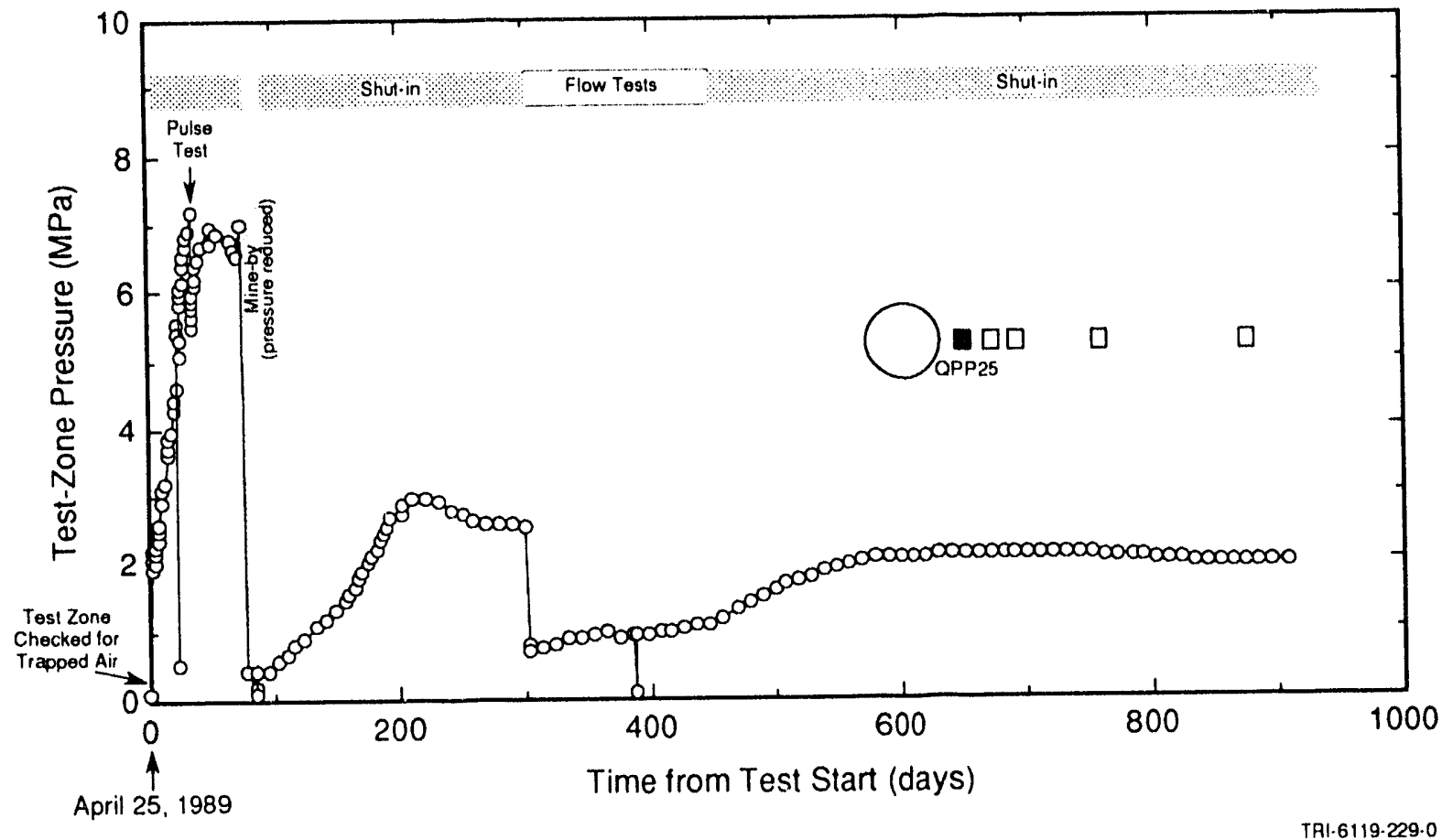

Figure 6-109. Hole QPP25 test-zone pressure.

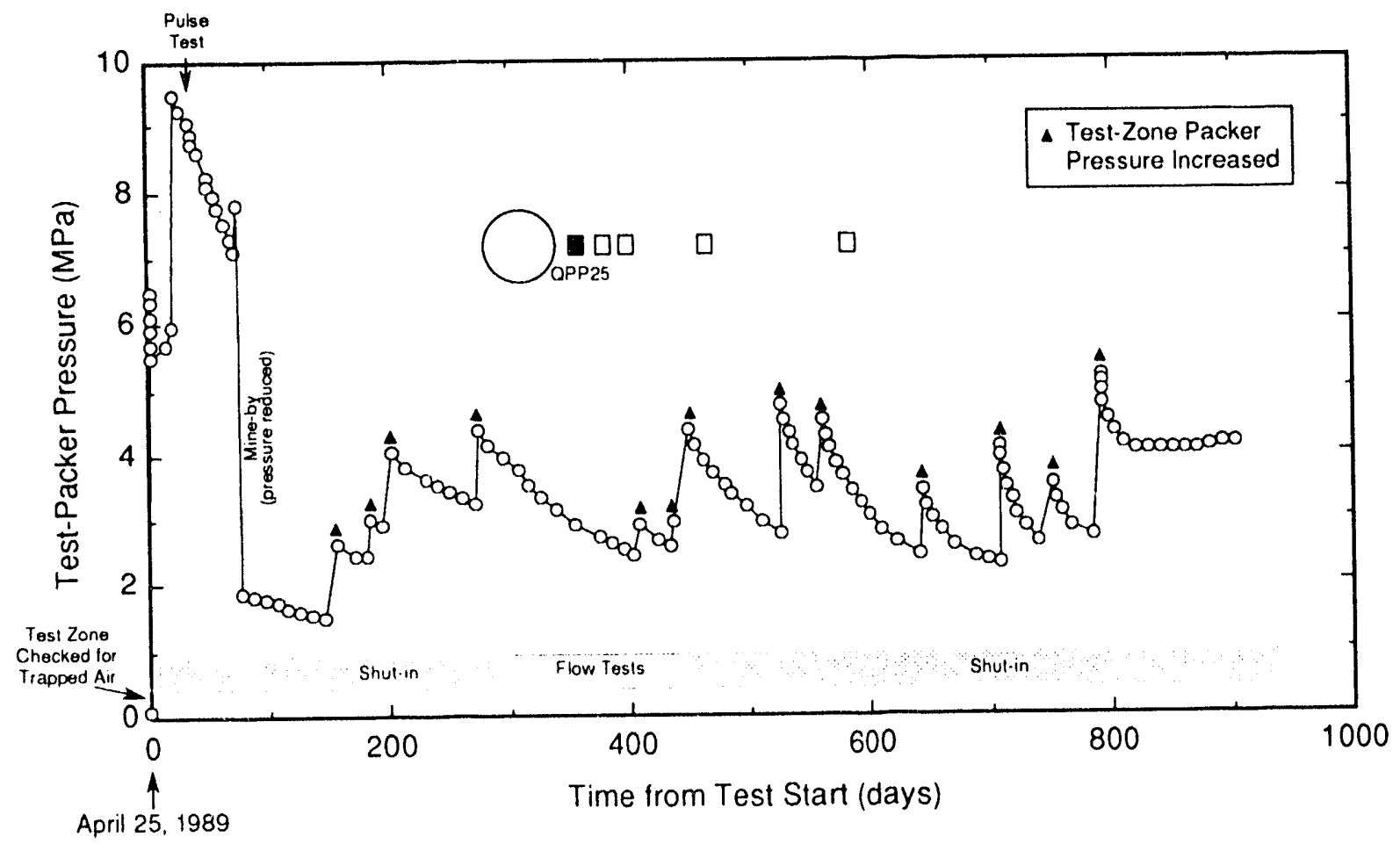

Figure 6-110. Hole QPP25 test-packer pressure. 


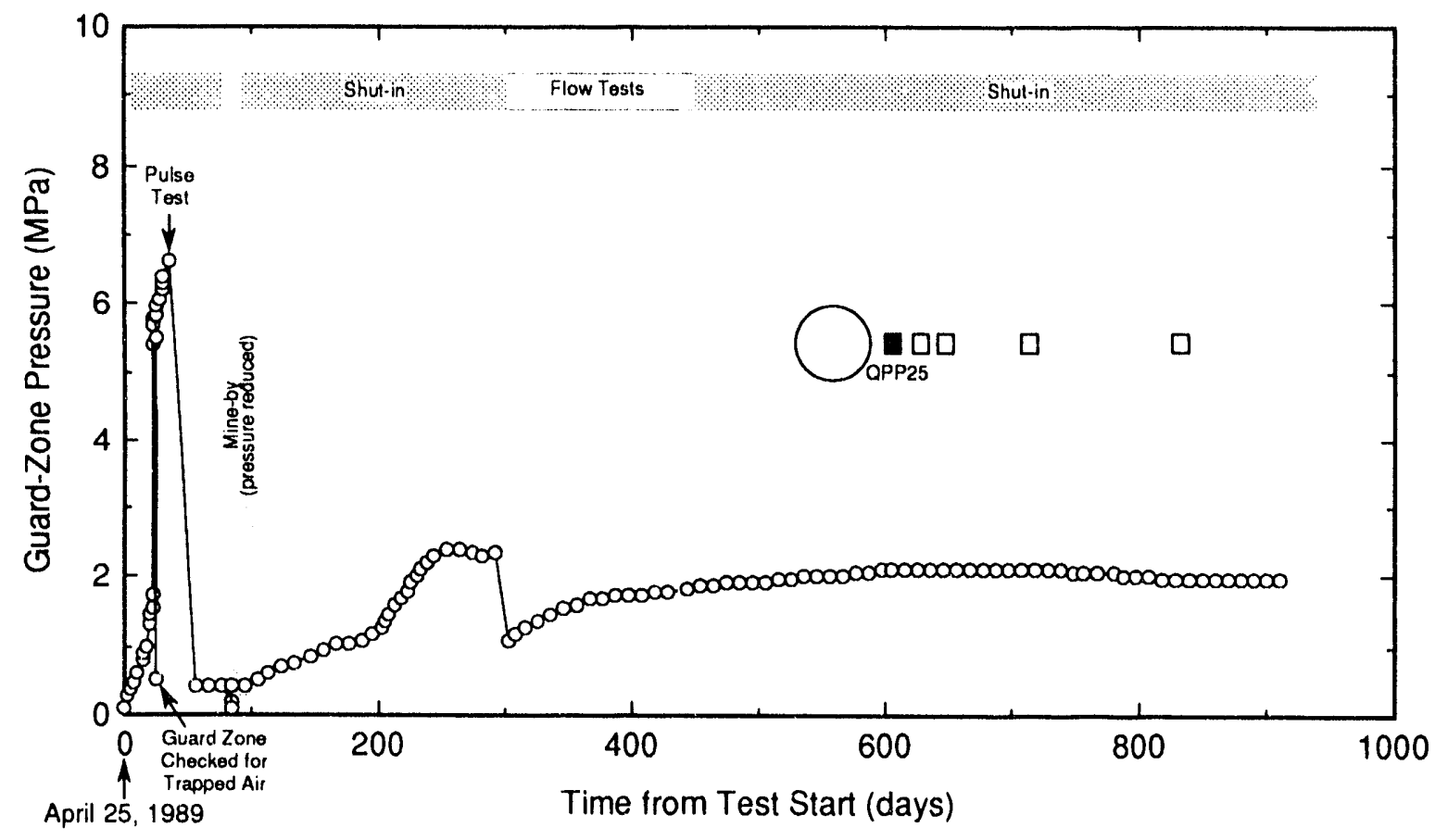

TRI.6119-231-0

Figure 6-111. Hole QPP25 guard-zone pressure.

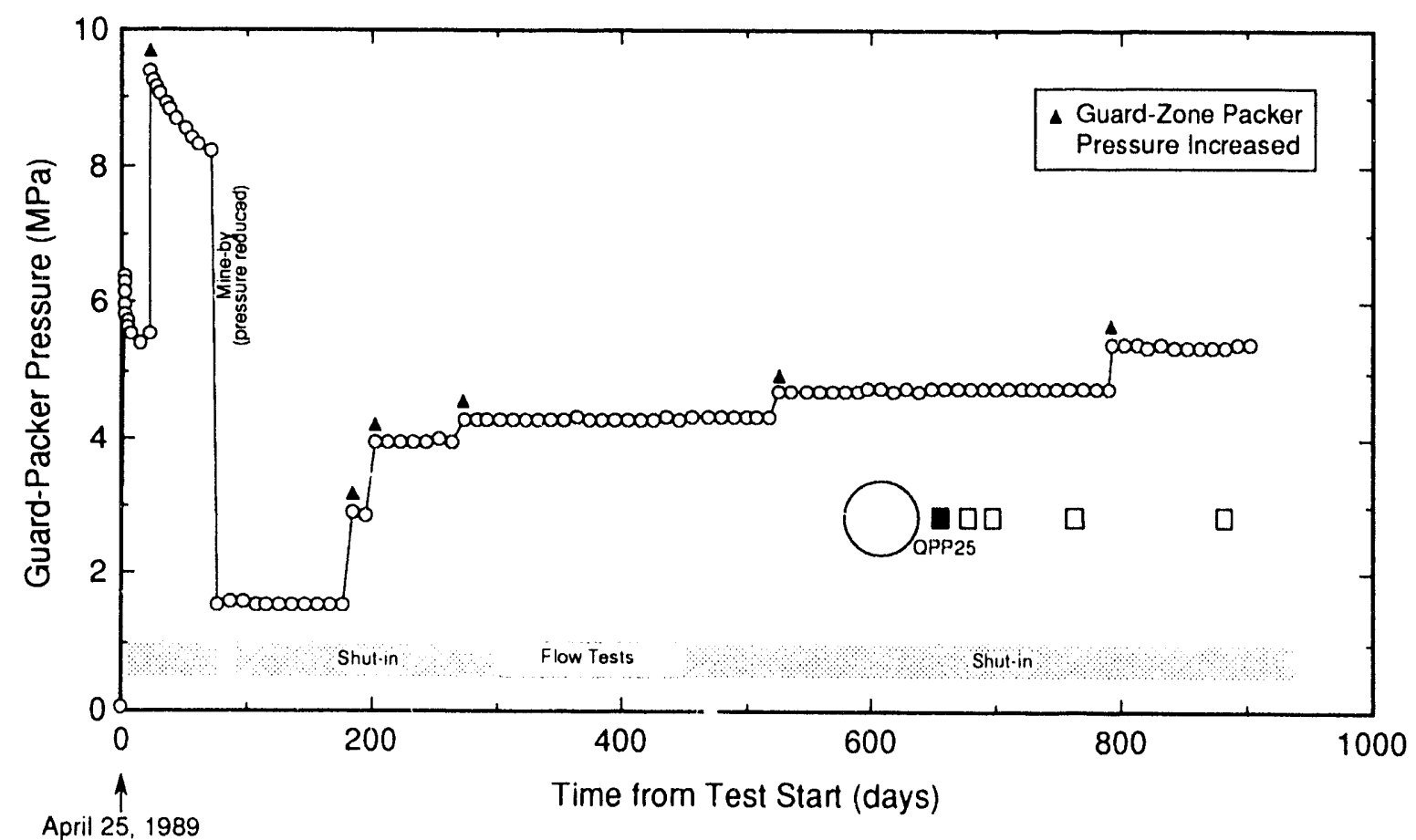

TRI.6119.232.0

Figure 6-112. Hole QPP25 guard-packer pressure. 


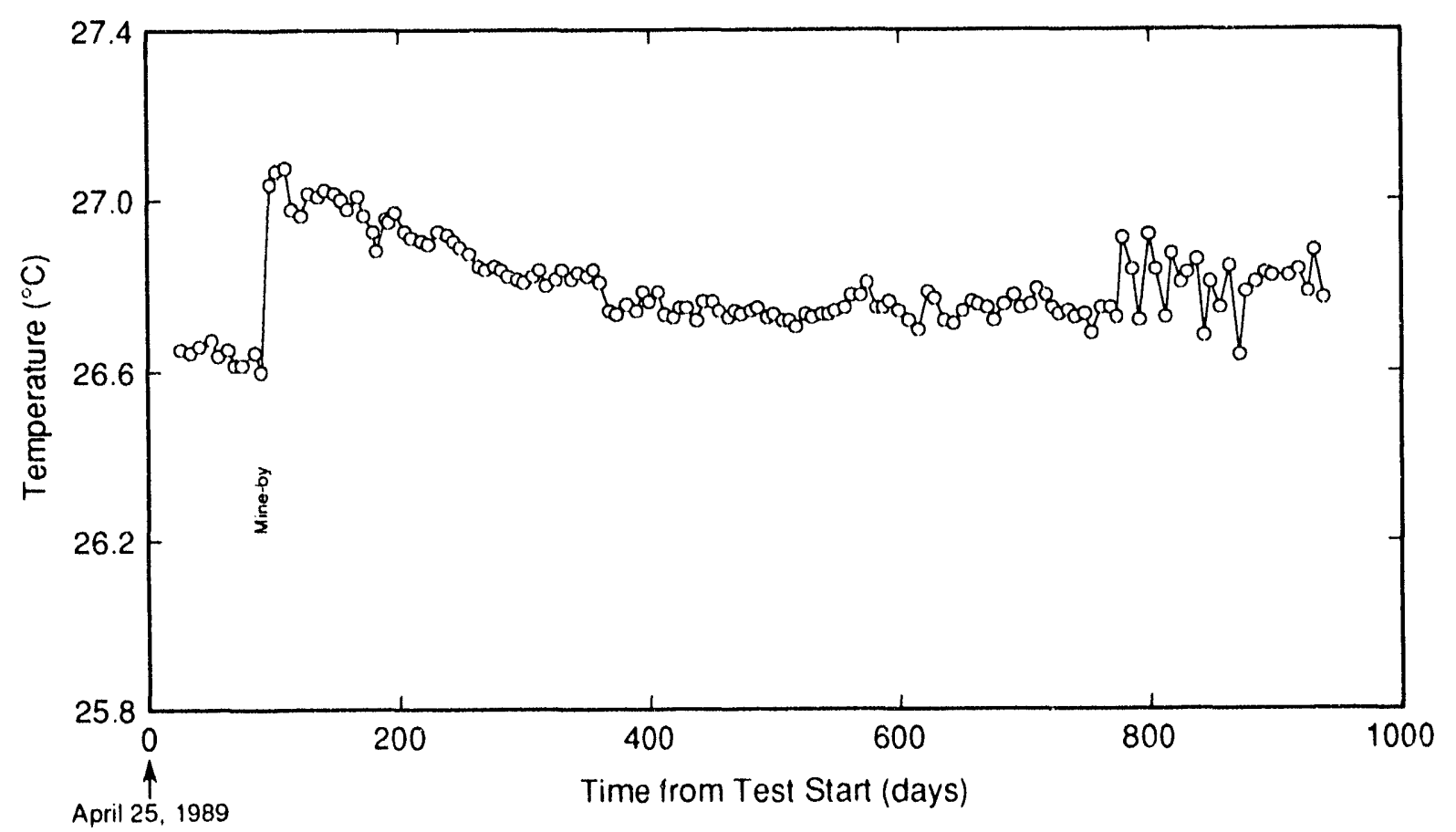

Figure 6-113. Hole QPP25 tool temperature.

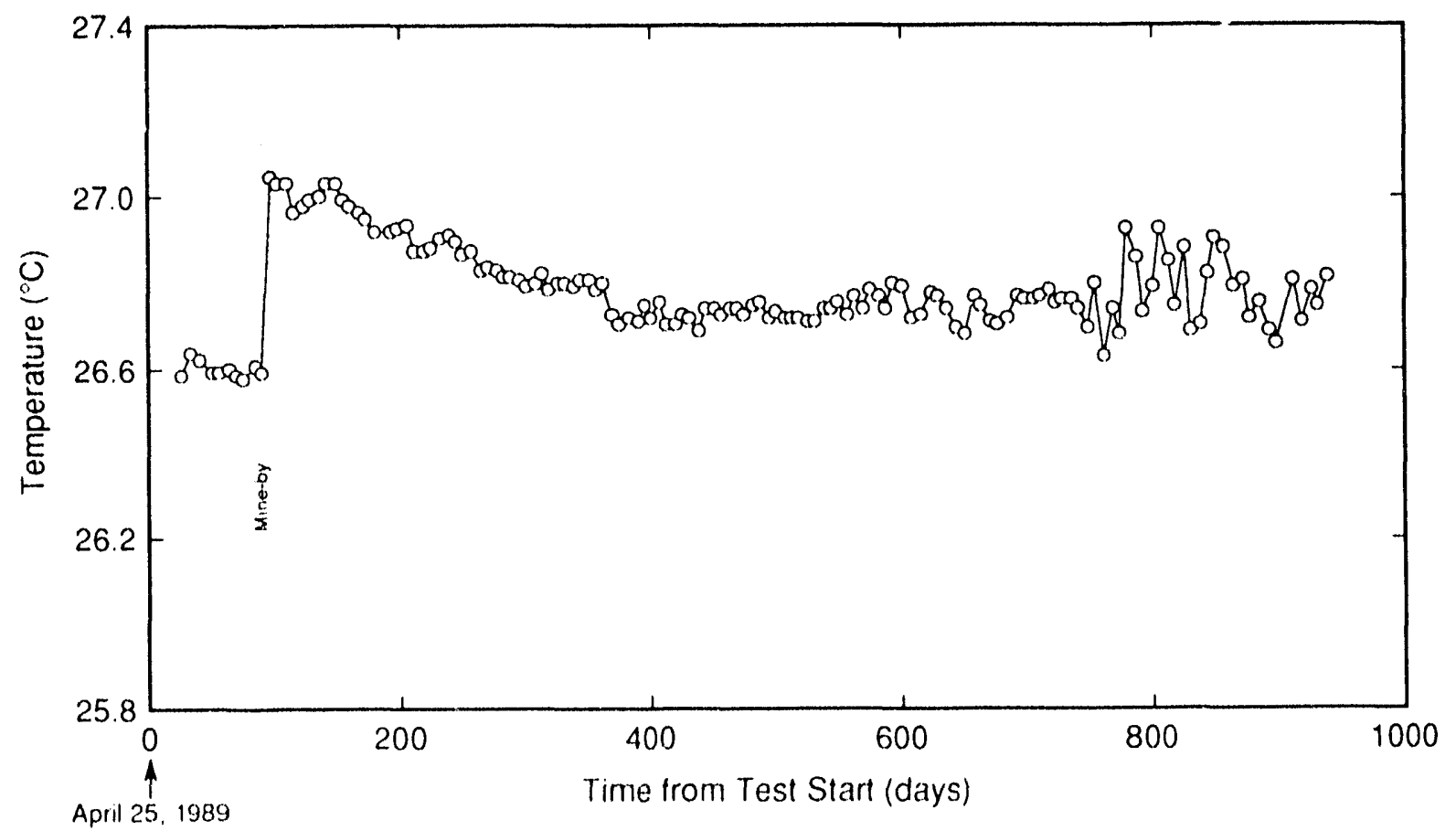

Figure 6-119. Hole QPPas casing temperature. 


\subsection{FUTURE TESTING}

Plans are under way to refurbish and improve the systems used for borehole testing around Room Q. Several improvements are needed so that more accurate and reliable data can be obtained in the future. These improvements are 1 isted below.

- Tools will be pulled and their condition inspected. The closure assemblies will be removed from all the slim-hole tools. A new system will measure test-zone length variation (axial movement of all the tools). Radial measurements currently taken with the $3.5-\mathrm{cm}$ diameter tools will cuntinue.

- All of the existing pressure transducers will be recalibrated.

- The instriment panel will be redesigned to allow pressure transducer calibration while the to.s is in the hole during the testing phase.

- Compliance and compressibility tests to determine tool reaction to applied pressures will be performed.

- The sensitivity of the existing thermal measurements taken in the 10.2-cm-diameter tesc holes will be increased, and test zone thermal measurements will be taken with the slim hole test tool.

- The DAS will be redesigned to monitor each group of five tools by using three individual DASs. The new system will record raw data in addition to enginering units. Data recorded for the tests described in this report did not include raw data in the form of voltages. Voltage data are useful when there is an error in instrument calibration.

- A series of tests will. be performed to establish the pore pressure gradient around Room Q. Flow testing will be performed to understand conductivity between test holes. These tests will provide comparisons with existing data.

- All hoites will be video mapped to establish actual elevations of the contacts between stratigraphic units. 


\subsection{REFERENCES}

Beauheim, R.L., G.J. Saulnier, Jr., and J.D. Avis. 1991. Interpretation of Brine-Permeability Tests of the Salado Formation at the Waste Isolation Pilot Plant Site: First Interim Report. SAND90-0083. Albuquerque, NM: Sandia National Laboratories.

Deal, D.E., R.J. Abitz, D.S. Belski, J.B. Case, M.E. Crawley, R.M. Deshler, P.E. Drez, C.A. Givens, R.B. King, B.A. Lauctes, J. Meyers, S. Niou, J.M. Pietz, W.M. Roggenthen, J.R. Tyburski, and M.G. Wallace. 1989. Brine Sampling and Evaluation Program 1988 Report. DOE/WIPP 89-015. Carlsbad, NM: Westinghouse Electric Corporation.

Doe, T.W. 1991. "Fractional Dimension Analysis of Constant-Pressure Wel1 Tests," Proceedings of the 1991 SPE Annual Technical Conference and Exhibition, Formation and Reservoir Geology Proceedings, Dallas, TX, October 6-9, 1991. SPE 15368. Richardson, TX: Society of Petroleum Engineers of AIME. 461-467.

Finley, S.J., D.J. Hanson, and R. Parsons. 1992. Small-Scale Brine Inflow Experiments-Data Report Through 6/6/91. SAND91-1956. Albuquerque, NM: Sandia National Laboratories.

Gringarten, A. 1979. "A Comparison Between Different Skin and Wellbore Storage Type-Curves for Early-Time Transient Analysis," Society of Petroleum Engineers 54th Annual Technical Conference and Exhibition, Las Vegas, NV, September 23-26, 1979. SPE 8205. Richardson, TX: Society of Petroleum Engineers.

Gonzales, M.M. 1989. Compilation and Comparison of Test-Hole Location Surveys in the Vicinity of the Waste Isolation Pilot Plant Site. SAND88-1065. Albuquerque, NM: Sandia National Laboratories.

Holcomb, D.J., and M. Shields. 1987. Hydrostatic Creep Consolidation of Crushed Salt With Added Water. SAND87-1990. Albuquerque, NM: Sandia National Laboratories.

Jensen, A.L. 1990. Borehole Closure and Test Zone Volume Determination Program for Brine-Permeability Test Results Within the Waste Isolation Pilot Plant Underground Facility. SAND90-0228. Albuquerque, NM: Sandia National Laboratories.

Lappin, A.R. 1988. Summary of Site-Characterization Studies Conducted From 1983 Through 1987 at the Waste Isolation Pilot Plant (WIPP) Site, Southeastern New Mexico. SAND88-0157. Albuquerque, NM: Sandia National Laboratories. 
Lappin, A.R., R.L. Hunter, D.P. Garber, and P.B. Davies, eds. 1989. Systems Analysis, Long-Term Radionuclide Transport, and Dose Assessments, Waste Isolation Pilot Plant (WIPP), Southeastern New Mexico; March 1989. SAND89-0462. Albuquerque, NM: Sandia National Laboratories.

Nowak, E.J. 1990. "Test Plan: Brine Inflow and Related Tests in the Brine Inflow Room (Room Q) of the Waste Isolation Pilot Plant (WIPP)." Albuquerque, NM: Sandia National Laboratories.

Nowak, E.J., and J.C. Stormont. 1987. Scoping Model Calculations of the Reconsolidation of Crushed Salt in WIPP Shafts. SAND87-0879. Albuquerque, NM: Sandia National Laboratories.

Nowak, E.J., D.F. McTigue, and R. Beraun. 1988. Brine Inflow to WIPP Disposal Rooms: Data, Modeling, and Assessment. SAND88-0112. Albuquerque, NM: Sandia National Laboratories.

Peterson, E.W., P.L. Lagus, and K. Lie. 1987. WIPP Horizon Free Field Fluid Transport Characteristics. SAND87-7164. Albuquerque, NM: Sandia National Laboratories.

Pickens, J.F., G.E. Grisak, J.D. Avis, D.W. Belanger, and M. Thury. 1987. "Analysis and Interpretation of Borehole Hydraulic Tests in Deep Boreholes: Principles, Model Development, and Applications," Water Resources Research. Vol. 23, no. 7, 1341-1375.

Powers, D.W., S.J. Lambert, S-E. Shaffer, L.R. Hill, and W.D. Weart, eds. 1978. Geologic Characterization Report, Waste Isolation Pilot Plant (WIPP) Site, Southeastern New Mexico. SAND78-1596. Albuquerque, NM: Sandia National Laboratories. Vols. I-II.

Roedder, E., and H.E. Belkin. 1979. "Applications of Studies of Fluid Inclusions in Permian Salado Salt, New Mexico, to Problems of Siting the Waste Isolation Plant," Scientific Basis for Nuclear Waste Management, Proceedings of the Symposium on "Science Underlying Radioactive Waste Management," Boston, MA, November 28-December 1, 1978. Ed. G.J. McCarthy. New York, NY: Plenum Press Vol. 1, 313-321.

Saulnier, G.J., Jr. 1988. "Field Operations Plan for Permeability Testing in the WIPP-Site Underground Facility." Albuquerque, NM: Sandia National Laboratories; Austin, TX: Intera Technologies, Inc.

Saulnier, G.J., Jr., P.S. Domski, J.B. Palmer, R.M. Roberts, W.A. Stensrud, and A.L. Jensen. 1991. WIPP Salado Hydrology Program Data Report \#1. SAND90-7000. Albuquerque, NM: Sandia National Laboratories. 
Stormont, J.C. 1990. Summary of 1988 WIPP Facility Horizon Gas Flow Measurements. SAND89-2497. Albuquerque, NM: Sandia National Laboratories.

Stormont, J.C., E.W. Peterson, and P.L. Lagus. 1987. Summary of and Observations About WIPP Facility Horizon Flow Measurements Through 1986. SAND87-0176. Albuquerque, NM: Sandia National Laboratories.

U.S. Department of Energy. 1983. Results of Site Validation Experiments. TME 3177, Rev. 2.0. [Albuquerque, NM: US Department of Energy.] Vo1. II.

Westinghouse Electric Corporation. 1989. Geotechnical Field Data and Analysis Report, June 1987-June 1988. DOE/WIPP 89-009. Carlsbad, NM: Westinghouse Electric Corporation. Vol. 2. 
APPENDIX A

STRATIGRAPHIC UNITS (MAP UNITS) NEAR THE WISP FACILITY HORIZON

An 


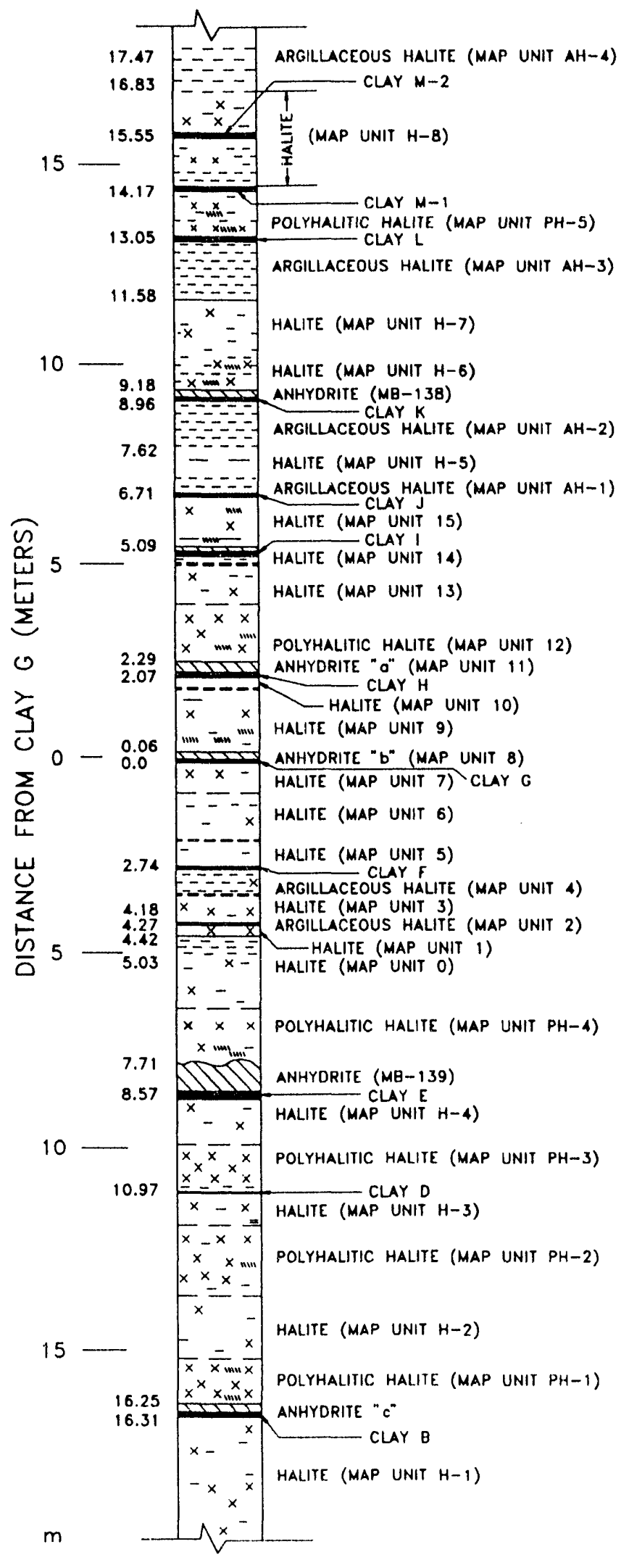

NOTES:

1. DISTANCES IN METERS ARE MEASURED FROM THE BASE OF ANHYDRITE " $b$ " (CLAY G) AND ARE AVERAGED FROM REPRESENTATIVE COREHOLE LOGS, SHAFT AND TEST-ROOM MAPPING. ACTUAL DISTANCE AND UNIT THICKNESSES MAY VARY LOCALLY FROM THOSE SHOWN.

2. DESCRIPTIONS OF UNITS ARE BASED ON COREHOLE DATA, SHAFT MAPPING AND VISUAL INSPECTION OF EXPOSURES IN UNDERGROUND DRIFTS AND ROOMS.

ADAPTED FROM WESTINCHOUSE (1989)

AND DEAL ET AL. (1989)

DATE: $\quad 03-11 / 92$

REF: LEE/UGSTRAT $1 / 59$

Figure A-1. Detailed Stratigraphy Near the WIPP Underground Facility. 


\section{Description of Generalized Stratigraphy*}

\begin{tabular}{|c|c|c|}
\hline $\begin{array}{l}\text { Approximate } \\
\text { Distance From } \\
\text { Clay G (Meters) }\end{array}$ & Stratigraphic Unit & Description \\
\hline 20.1 to 21.2 & $\begin{array}{l}\text { Polyhalitic halite } \\
\text { (PH-7) }\end{array}$ & $\begin{array}{l}\text { Clear to moderate reddish orange/brown, fine to coarsely } \\
\text { crystalline, }<1-3 \% \text { polyhalite. }\end{array}$ \\
\hline 19.3 to 20.1 & Halite $(H-9)$ & $\begin{array}{l}\text { Clear to light moderate reddish orange, medium to } \\
\text { coarsely crystalline, } \leq 1 \% \text { polyhalite. May contain } \leq 1 \% \\
\text { brown and gray clay. }\end{array}$ \\
\hline 17.5 to 19.3 & $\begin{array}{l}\text { Polyhalitic halite } \\
\text { (PH-6) }\end{array}$ & $\begin{array}{l}\text { Clear to moderate reddish orange/brown, medium to } \\
\text { coarsely crystalline, }<1-3 \% \text { polyhalite. May contain } \\
\text { traces of gray clay and/or scattered anhydrite. }\end{array}$ \\
\hline 16.8 to 17.5 & $\begin{array}{l}\text { Argillaceous halite } \\
\text { (AH-4) }\end{array}$ & $\begin{array}{l}\text { Clear to moderate brown, medium to coarsely crystalline. } \\
<1 \text { to } 3 \% \text { brown clay. Intercrystalline and discontinuous } \\
\text { breaks. In one core hole, consists of a } 2.54 \text { centimeter } \\
\text { thick clay seam. Unit can vary up to } 1.2 \text { meters in } \\
\text { thickness. Contact with lower unit is gradational. }\end{array}$ \\
\hline 14.2 to 15.8 & Halite $(H-8)$ & $\begin{array}{l}\text { Clear to moderate reddish orange and moderate brown, } \\
\text { coarsely crystalline, some medium. } \leq 1 \% \text { brown clay, } \\
\text { locally argillaceous (clays } M-1 \text { and } M-2 \text { ). Scattered } \\
\text { anhydrite stringers locally. }\end{array}$ \\
\hline 13.0 to 14.2 & $\begin{array}{l}\text { Polyhalitic halite } \\
\text { (PH-5) }\end{array}$ & $\begin{array}{l}\text { Clear to moderate reddish orange, some moderate } \\
\text { brown, coarsely crystalline. }<1 \text { to } 3 \% \text { polyhalite. None to } \\
1 \% \text { brown and some gray clay. Scattered anhydrite } \\
\text { locally. Contact with unit below is fairly sharp. }\end{array}$ \\
\hline 11.6 to 13.0 & $\begin{array}{l}\text { Argillaceous halite } \\
\text { (AH-3) }\end{array}$ & $\begin{array}{l}\text { Clear to moderate brown, medium to coarsely crystalline, } \\
\text { some fine. }<1 \text { to } 5 \% \text { brown clay. Locally contains } 10 \% \\
\text { clay. Intercrystalline and scattered breaks. Locally } \\
\text { contains partings and seams. Contact with lower unit is } \\
\text { gradational based on increased clay content. Average } \\
\text { range of unit is } 11.6 \text { to } 13.0 \text { meters above clay G but } \\
\text { does vary from } 10.3 \text { to } 14.0 \text { meters. }\end{array}$ \\
\hline 10.4 to 11.6 & Halite $(H-7)$ & $\begin{array}{l}\text { Clear to moderate brown, some moderate reddish brown, } \\
\text { coarsely crystalline, some fine and medium. } \leq 1 \% \text { brown } \\
\text { clay, trace gray clay locally. Scattered breaks. Locally } \\
\text { argillaceous. < } 1 \% \text { polyhalite. Contact with unit below is } \\
\text { gradational based on clay and polyhalite content. }\end{array}$ \\
\hline
\end{tabular}

"From Brine Sampling and Evaluation Program 1988 Report, DOENIPP 89-015, Deal et al. (1989). 


\section{Description of Generalized Stratigraphy (Continued)}

\begin{tabular}{|c|c|c|}
\hline $\begin{array}{l}\text { Approximate } \\
\text { Distance From } \\
\text { Clay G (Meters) }\end{array}$ & Stratigraphic Unit & Description \\
\hline 9.2 to 10.4 & Halite $(H-6)$ & $\begin{array}{l}\text { Clear to moderate reddish orange, coarsely crystalline. } \\
<1 \text { to } 3 \% \text { polyhalite. Commonly polyhalitic. Scattered } \\
\text { anhydrite stringers with anhydrite layers up to } 1.27 \\
\text { centimeters thick locally. Scattered brown clay locally. } \\
\text { Contact with MB-138 below is sharp. }\end{array}$ \\
\hline 9.0 to 9.2 & Anhydrite (MB-138) & $\begin{array}{l}\text { Light to medium gray, microcrystalline. Partly lami- } \\
\text { nated. Scattered halite growths. Clay seam K found at } \\
\text { base of unit. }\end{array}$ \\
\hline 7.6 to 9.0 & $\begin{array}{l}\text { Argillaceous halite } \\
\text { (AH-2) }\end{array}$ & $\begin{array}{l}\text { Clear to moderate brown, some light moderate reddish } \\
\text { orange. Medium to coarsely crystalline. }<1 \text { to } 3 \% \\
\text { brown clay, some gray. Locally up to } 5 \% \text { clay. Clay is } \\
\text { intercrystalline with scattered breaks and partings } \\
\text { present. }<1 / 2 \% \text { dispersed polyhalite. Contact with } \\
\text { lower unit is gradational based on clay content. Upper } \\
\text { contact with clay K is sharp. }\end{array}$ \\
\hline 7.0 to 7.6 & Halite $(H-5)$ & $\begin{array}{l}\text { Clear, some light moderate brown, coarsely crystalline. } \\
<1 / 2 \% \text { brown clay. Contact with clay } \mathrm{J} \text { below varies } \\
\text { from sharp to gradational depending if clay } \mathrm{J} \text { is a distinct } \\
\text { seam or merely an argillaceous zone. }\end{array}$ \\
\hline 6.4 to 7.0 & $\begin{array}{l}\text { Argillaceous halite } \\
\text { (clay J; } A H-1 \text { ) }\end{array}$ & $\begin{array}{l}\text { Usually consists of scattered breaks or argillaceous } \\
\text { zone containing }<1 \text { to } 3 \% \text { brown clay. In C\&SH shaft, it } \\
\text { is a } 1.27 \text { centimeters thick brown clay seam. }\end{array}$ \\
\hline 5.1 to 6.4 & Halite (map unit 15) & $\begin{array}{l}\text { Clear, coarsely crystalline, scattered medium. Up to } 1 \% \\
\text { dispersed polyhalite and brown clay. Scattered anhy- } \\
\text { drite. Lower contact is sharp with clay I. }\end{array}$ \\
\hline 4.8 to 5.1 & Halite (map unit 14) & $\begin{array}{l}\text { Clear to grayish orange-pink, coarsely crystalline, some } \\
\text { medium. < } 1 / 2 \% \text { dispersed polyhalite. Scattered } \\
\text { discontinuous gray clay stringers. Clay l is along upper } \\
\text { contact. Contact with lower unit is diffuse. }\end{array}$ \\
\hline 3.5 to 4.8 & Halite (map unit 13) & $\begin{array}{l}\text { Clear to moderate reddish orange and moderate brown, } \\
\text { mediuin to coarsely crystalline, some fine. } \leq 1 \% \text { brown } \\
\text { clay, locally up to } 3 \% \text {. Trace of gray clay. Scattered } \\
\text { discontinuous breaks. <1\% dispersed polyhalite and } \\
\text { poiyhalite blebs. Contact with unit below is gradational } \\
\text { based on clay and polyhalite content. }\end{array}$ \\
\hline
\end{tabular}


Table A-1

\section{Description of Generalized Stratigraphy (Continued)}

\begin{tabular}{|c|c|c|}
\hline $\begin{array}{l}\text { Approximate } \\
\text { Distance From } \\
\text { Clay G (Meters) }\end{array}$ & Stratigraphic Unit & Description \\
\hline 2.3 to 3.5 & $\begin{array}{l}\text { Polyhalitic halite } \\
\text { (map urit 12) }\end{array}$ & $\begin{array}{l}\text { Clear to moderate reddish orange, coarsely crystalline. } \\
\leq 1 \text { to } 3 \% \text { dispersed polyhalite and polyhalite blebs. } \\
\text { Scattered anhydrite stringers. Contact is sharp with unit } \\
\text { below. }\end{array}$ \\
\hline 2.1 to 2.3 & $\begin{array}{l}\text { Anhydrite } \\
\text { ("a" - map unit 11) }\end{array}$ & $\begin{array}{l}\text { Light to medium gray, light brownish gray and some- } \\
\text { times light moderate reddish orange. Microcrystalline. } \\
\text { Halite growths within. Partly laminated. Clear, coarsely } \\
\text { crystalline halite layer up to } 5.1 \text { centimeters wide, found } \\
\text { within exposures in waste experimental area. Thin gray } \\
\text { clay seam } \mathrm{H} \text { at base of unit. }\end{array}$ \\
\hline 1.7 to 2.1 & Halite (map unit 10) & $\begin{array}{l}\text { Clear to moderate reddish orange/brown, fine to } \\
\text { coarsely crystalline. } \leq 1 \% \text { brown and/or gray clay and } \\
\text { dispersed polyhalite. Discontinuous clay stringers } \\
\text { locally. Contact with lower unit is diffuse based on } \\
\text { crystal size and varying amounts of clay and polyhalite. }\end{array}$ \\
\hline 0.1 to 1.7 & Halite (map unit 9) & $\begin{array}{l}\text { Clear to light moderately reddish orange, coarsely } \\
\text { crystalline, some medium. None to }<1 \% \text { polyhalite. } \\
\text { Trace of gray clay locally. Scattered anhydrite stringers. } \\
\text { Contact with unit below is sharp. }\end{array}$ \\
\hline 0.0 to 0.1 & $\begin{array}{l}\text { Anhydrite } \\
\text { ("b" - map unit 8) }\end{array}$ & $\begin{array}{l}\text { Light to medium gray, microcrystalline anhydrite. } \\
\text { Scattered halite growhs. Thin gray clay seam } G \text { at } \\
\text { base of unit. }\end{array}$ \\
\hline 0.0 to -0.7 & Halite (map unit 7) & $\begin{array}{l}\text { Clean to light/medium gray, some moderate reddish } \\
\text { orange/brown. Coarsely crystalline, some fine and } \\
\text { medium. } \leq 1 \% \text { brown and gray clay. Locally up to } 2 \% \\
\text { clay. }<1 \% \text { dispersed polyhalite. Upper contact is sharp } \\
\text { with clay G. Contact with lower unit is gradational. }\end{array}$ \\
\hline-0.7 to -2.1 & Halite (map unit 6) & $\begin{array}{l}\text { Clear, some moderate reddish orange, coarsely crystal- } \\
\text { line, some fine to medium locally. }<1 / 2 \% \text { gray clay and } \\
\text { polyhalite. Contact with lower unit gradational and/or } \\
\text { diffuse. }\end{array}$ \\
\hline-2.1 to -2.7 & Halite (map unit 5) & $\begin{array}{l}\text { Clear, coarsely crystalline. }<1 / 2 \% \text { gray clay. Contact } \\
\text { with lower unit usually sharp with clay F. }\end{array}$ \\
\hline
\end{tabular}




\section{Description of Generalized Stratigraphy (Continued)}

\begin{tabular}{|c|c|c|}
\hline $\begin{array}{l}\text { Approximate } \\
\text { Distance From } \\
\text { Clay G (Meters) }\end{array}$ & Stratigraphic Unit & Description \\
\hline-2.7 to -3.5 & $\begin{array}{l}\text { Argillaceous halite } \\
\text { (map unit 4) }\end{array}$ & $\begin{array}{l}\text { Clear to moderate brown and moderate reddish brown, } \\
\text { coarsely crystalline. }<1 \% \text { polyhalite. }<1 \text { to } 5 \% \text { argilla- } \\
\text { ceous material; predominantly brown, some gray, } \\
\text { locally. Intercrystalline and discontinuous breaks and } \\
\text { partings common in upper part of unit. Decreasing } \\
\text { argillaceous content downward. Contact with lower unit } \\
\text { is gradational. }\end{array}$ \\
\hline-3.5 to -4.2 & Halite (map unit 3) & $\begin{array}{l}\text { Clear to moderate reddish orange, coarsely crystalline. } \\
\leq 1 \% \text { dispersed polyhalite and polyhalite blebs. Locally } \\
\text { polyhalitic. Scattered gray clay locally. Contact with } \\
\text { lower unit is sharp. }\end{array}$ \\
\hline-4.2 to -4.3 & $\begin{array}{l}\text { Argillaceous halite } \\
\text { (map unit 2) }\end{array}$ & $\begin{array}{l}\text { Moderate reddish brown to medium gray, medium to } \\
\text { coarsely crystalline. }<1 \text { to } 3 \% \text { argillaceous material. } \\
\text { Contact with lower unit is usually sharp. }\end{array}$ \\
\hline-4.3 to -4.4 & Halite (map unit 1) & $\begin{array}{l}\text { Light reddish orange to moderate reddish orange, } \\
\text { medium to coarsely crystalline. } \leq 1 \% \text { dispersed } \\
\text { polyhalite. Contact with lower unit is sharp. }\end{array}$ \\
\hline-4.4 to -6.7 & Halite (map unit 0) & $\begin{array}{l}\text { Clear to moderate reddish orange/brown, moderate } \\
\text { brown and grayish brown. Medium to coarsely crystal- } \\
\text { line. <1 to } 5 \% \text { argillaceous material. Predominantly } \\
\text { brown, some gray, intercrystalline argillaceous material } \\
\text { and discontinuous breaks and partings. Upper } 0.6 \\
\text { meters of unit is argillaceous halite decreasing in } \\
\text { argillaceous material content downward. None to }<1 \% \\
\text { polyhalite. Contact with lower unit is gradational based } \\
\text { on polyhalite content. }\end{array}$ \\
\hline-6.7 to -7.7 & $\begin{array}{l}\text { Polyhalitic halite } \\
(\mathrm{PH}-4)\end{array}$ & $\begin{array}{l}\text { Clear to moderate reddish orange. Coarsely crystalline, } \\
\text { some medium locally. <1 to } 3 \% \text { polyhalite. Scattered } \\
\text { anhydrite. Scattered gray clay locally. Contact with } \\
\text { lower unit (MB-139) is sharp, but commonly irregular } \\
\text { and undulating. Trace of gray locally present along this } \\
\text { contact. }\end{array}$ \\
\hline-7.7 to -8.6 & Anhydrite (MB-139) & $\begin{array}{l}\text { Moderate reddish orange/brown to light and medium } \\
\text { gray, microcrystalline anhydrite. "Swallowtail" pattern, } \\
\text { consisting of halite growths within anhydrite, common in } \\
\text { upper part of unit. Locally, hairline, clay-filled, low-angle }\end{array}$ \\
\hline
\end{tabular}




\section{Description of Generalized Stratigraphy (Continued)}

\begin{tabular}{|c|c|c|}
\hline $\begin{array}{l}\text { Approximate } \\
\text { Distance From } \\
\text { Clay G (Meters) }\end{array}$ & Stratigraphic Unit & Description \\
\hline & & $\begin{array}{l}\text { fractures found in lower part of unit. Thin halite layer } \\
\text { common close to lower contact. Clay seam } E \text { found at } \\
\text { base of unit. Upper contact is irregular, undulating and } \\
\text { sometimes contains }<0.16 \text { centimeters gray clay. }\end{array}$ \\
\hline-8.6 to -9.5 & Halite $(H-4)$ & $\begin{array}{l}\text { Clear to moderate reddish orange, and light gray. } \\
\text { Coarsely crystalline, some fine and medium. } \leq 1 \% \\
\text { polyhalite and intercrystalline gray clay. Contact with } \\
\text { lower unit is gradational based on increased polyhalite } \\
\text { content. }\end{array}$ \\
\hline-9.5 to -11.0 & $\begin{array}{l}\text { Polyhalitic halite } \\
\text { (PH-3) }\end{array}$ & $\begin{array}{l}\text { Clear to moderate reddish orange, coarsely crystalline. } \\
<1 \text { to } 3 \% \text { polyhalite. Contact with lower unit is usually } \\
\text { sharp along clay } D .\end{array}$ \\
\hline-11.0 to -11.5 & Halite $(H-3)$ & $\begin{array}{l}\text { Clear to moderate reddish orange, some light gray. } \\
\text { Medium to coarsely crystalline. } \leq 1 \% \text { polyhalite and gray } \\
\text { clay. Contact with lower unit is gradational based on } \\
\text { increased polyhalite content. }\end{array}$ \\
\hline-11.5 to 13.0 & $\begin{array}{l}\text { Polyhalitic halite } \\
\text { (PH-2) }\end{array}$ & $\begin{array}{l}\text { Clear to moderate reddish orange/brown, coarsely } \\
\text { crystalline. < } 1 \text { to } 3 \% \text { polyhalite. Trace of clay locally. } \\
\text { Scattered anhydrite locally. Contact with lower unit is } \\
\text { gradational, based on decreased polyhalite content. }\end{array}$ \\
\hline-13.0 to 14.4 & Halite $(\mathrm{H}-2)$ & $\begin{array}{l}\text { Clear to moderate reddish orange, medium to coarsely } \\
\text { crystalline. }<1 \% \text { dispersed polyhalite. }<1 \% \text { brown and } \\
\text { or gray clay. Contact with lower unit is gradational and } \\
\text { or diffuse. }\end{array}$ \\
\hline-14.4 to $\cdot 16.2$ & $\begin{array}{l}\text { Polyhalitic halite } \\
(\mathrm{PH}-1)\end{array}$ & $\begin{array}{l}\text { Clear to moderate reddish orange. Coarsely crystalline } \\
\text { with some medium sometimes present close to lower } \\
\text { contact. < } 1 \text { to } 3 \% \text { polyhalite. Scattered anhydrite } \\
\text { especially common close to anhydrite "c". Lower } \\
\text { contact is sharp with anhydrite "c". }\end{array}$ \\
\hline-16.2 to -16.3 & Anhydrite ("c") & $\begin{array}{l}\text { Light to medium gray, microcrystalline anhydrite. } \\
\text { Scattered halite growths. Faintly laminated locally. Clay } \\
\text { seam B found at base of unit. }\end{array}$ \\
\hline
\end{tabular}


Table A-1

Description of Generalized Stratigraphy (Concluded)

\begin{tabular}{lll}
\hline Approximate & & \\
Distance From \\
Clay G (Meters) & Stratigraphic Unit & Description \\
\hline
\end{tabular}

-16.3 to $-20.0 \quad$ Halite $(H-1)$

Clear to medium gray and moderate brown.

Medium to coarsely crystalline, some fine

locally. $\leq 1 \%$ polyhalite, locally polyhalitic. $<1$ to

$3 \%$ clay, both brown and gray. Intercrystalline

clay with discontinuous breaks and partings.

Zones of argillaceous halite found within unit.

Seams of clay mixed with halite crystals present

locally. Upper montact of this unit is sharp with

clay $B$. 
APPENDIX B: BOREHOLE SURVEY AND DRILLING LOGS

B-1 
B - 2 
Survey notes transmitted include Electronic Data Collection File which in this case include beginning and backsight coordinates and then a series of radial side shots recording horizontal and vertical angles. Distance is not measured in this collection because it was not possible to use the prisms.

Next is the field Data File Log. This gives you the calculated bearing of your backsight or reference line and your HI (Height Instrument). On this file we key in the slope distance (SD) which makes it possible to calculate the coordinates.

Finally, the finished product. Beginning point coordinates, bearings of all foresights and horizontal distance to calculate all $X, Y, Z$ coordinates.

Note: B.S. Qpp 22, 24, \& 25 were destroyed and are not in file.

Should you have any questions please feel free to call (887-8191).

By:

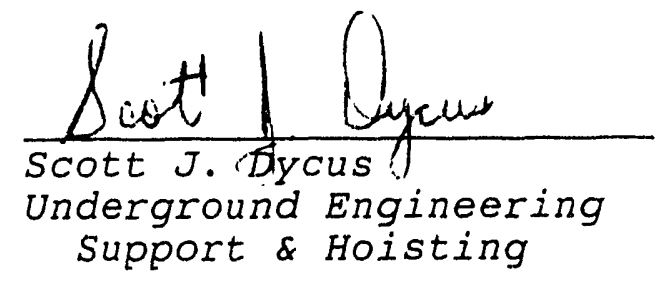




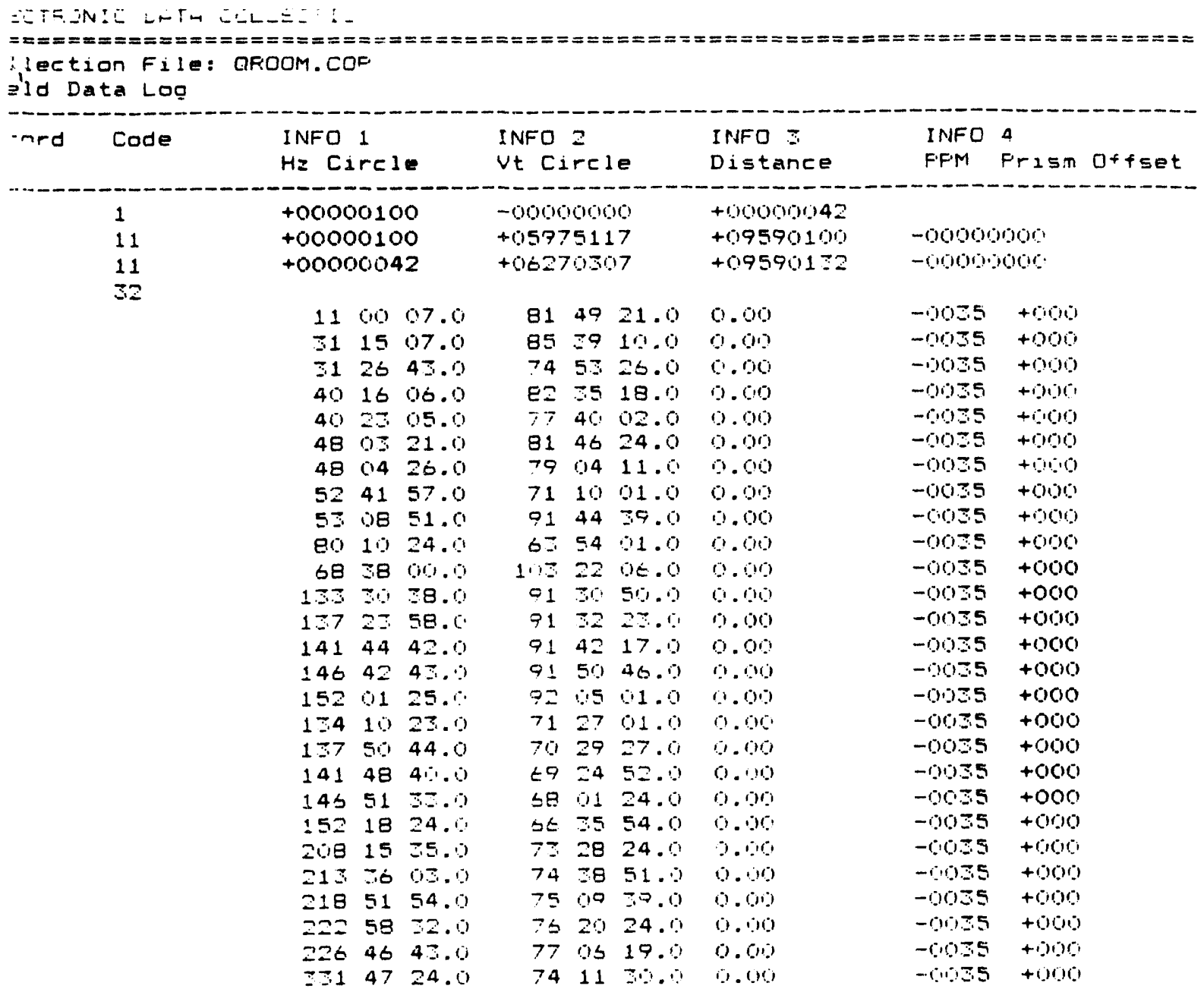




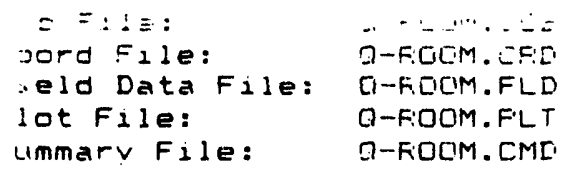

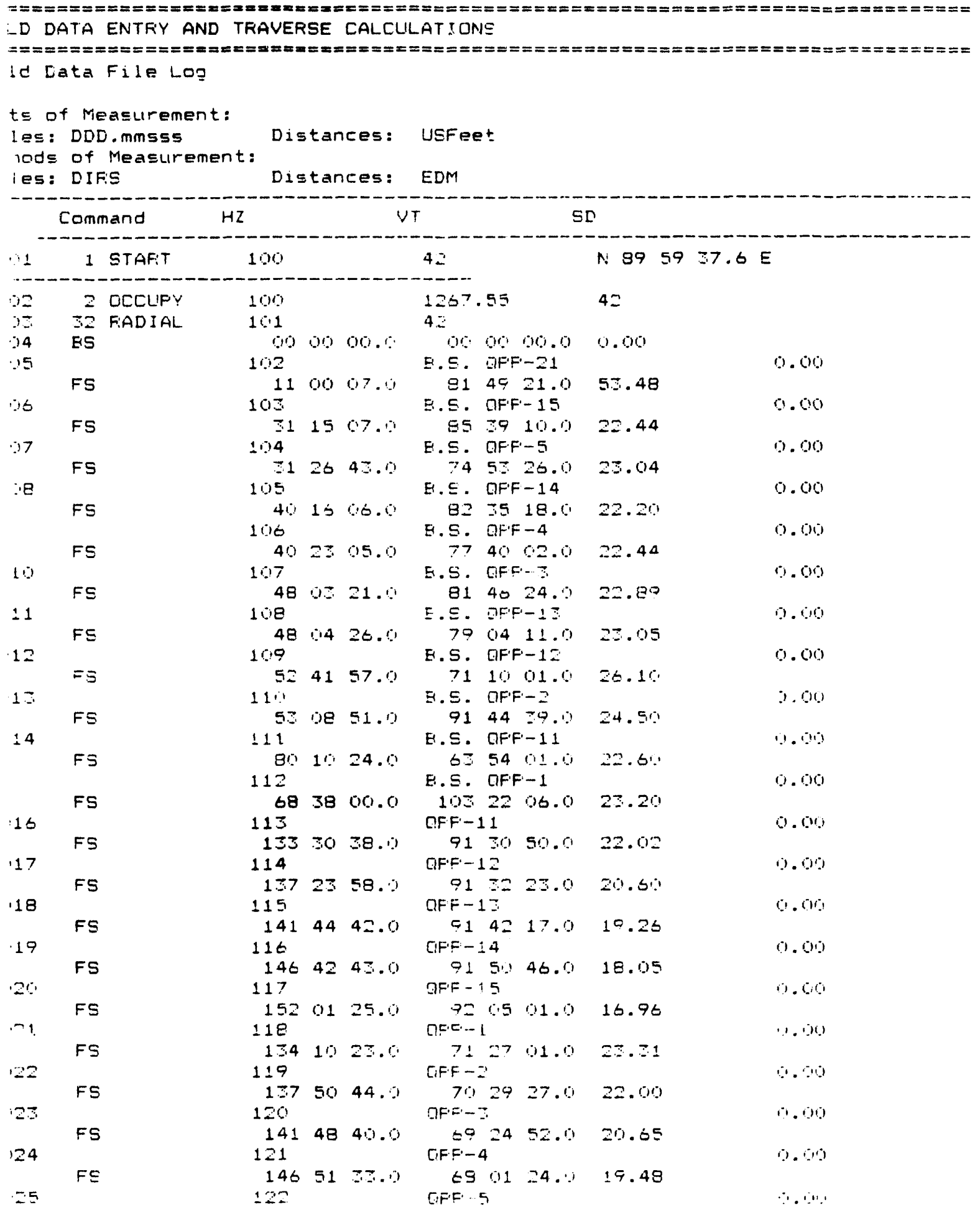




$\begin{array}{rr}20 & \\ \therefore 27 & F S \\ 128 & F S \\ & F S \\ 130 & F S \\ 131 & F S \\ & F S\end{array}$

$$
\begin{array}{lll}
122 & & \\
208 & 15 & 55.6 \\
124 & & \\
213 & 36 & 05.0 \\
125 & & \\
218 & 51 & 54.0 \\
126 & & \\
222 & 58 & 32.0 \\
127 & & \\
226 & 46 & 43.0 \\
128 & & \\
351 & 47 & 24.0
\end{array}
$$

$\therefore F=-2$

$77=9 \quad 24.917 .55$

$Q F^{\prime} F^{\prime}-24$

$7458 \quad 51.0 \quad 18.56$

QFF' $F-25$

750939.019 .72

QFF' -22

TE $2024.0 \quad 21.09$

QFF -21

$\begin{array}{llll}77 & 06 & 19.0 & 22.44\end{array}$

E.S. QFF-2S

$\begin{array}{llll}74 & 11 & 50.0 \quad 23.08\end{array}$

$\therefore 0$
0.00
0.00
0.00
0.00
0.00 


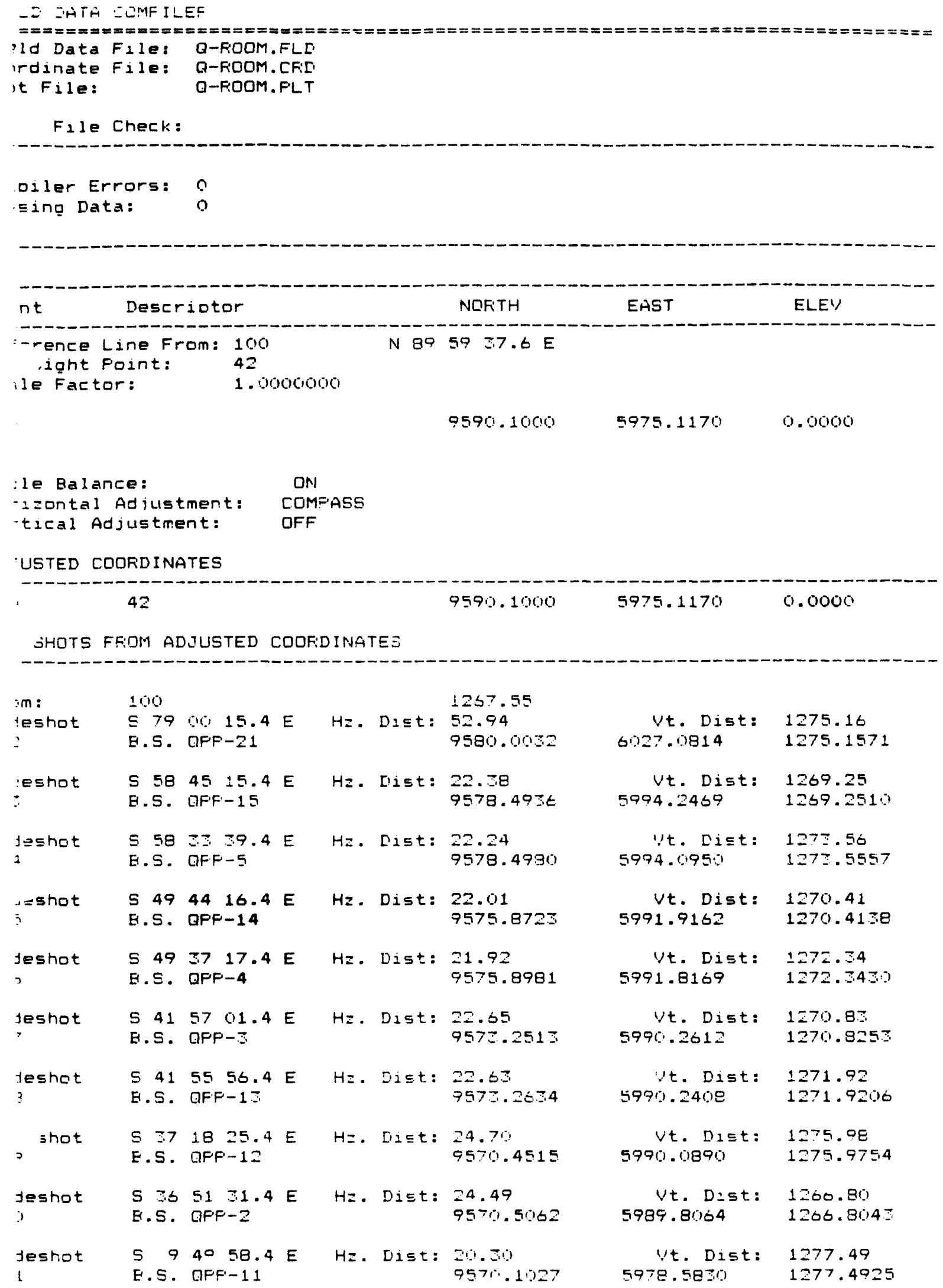




\begin{tabular}{|c|c|c|c|c|c|c|c|c|}
\hline$\equiv \equiv$ rict & 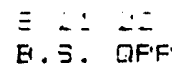 & $\begin{array}{l}\therefore-4 \\
-1\end{array}$ & $\Xi$ & 4 & $-3::$ & 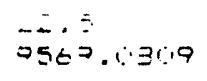 & 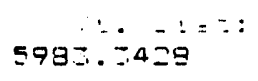 & $\begin{array}{l}X \\
\therefore=\end{array}$ \\
\hline leshot & $\begin{array}{l}54=30 \\
Q F F-11\end{array}$ & 15.6 & $w$ & $H=$. & Dist: & $\begin{array}{l}22.011 \\
95>4.1340\end{array}$ & $\begin{array}{l}\text { Vt. Dist: } \\
5959.9655\end{array}$ & $\begin{array}{l}1266.97 \\
1266.9683\end{array}$ \\
\hline not & $\begin{array}{l}54723 \\
Q P P-12\end{array}$ & 35.6 & $w$ & $H=$. & Dist: & $\begin{array}{l}20.59 \\
9576.1596\end{array}$ & $\begin{array}{c}v t . D_{15 t} \\
5959.9605\end{array}$ & $\begin{array}{l}1=67.00 \\
1=30.9965\end{array}$ \\
\hline leshot & $\begin{array}{l}55144 \\
Q F^{\prime} F^{\prime}-1\end{array}$ & 19.6 & $w$ & $H=$. & D1st: & $\begin{array}{l}19.25 \\
9578.1786\end{array}$ & $\begin{array}{l}\text { Vt. D1st: } \\
5960.0008\end{array}$ & $\begin{array}{l}120 t .98 \\
1265.9770\end{array}$ \\
\hline iestiot & $\begin{array}{l}55642 \\
Q P F-14\end{array}$ & 20.6 & $w$ & $H=$. & Dist: & $\begin{array}{l}18.04 \\
9580.1968\end{array}$ & $\begin{array}{c}\text { Vt. Dist: } \\
5960.0375\end{array}$ & $\begin{array}{l}1266.97 \\
1266.9685\end{array}$ \\
\hline ieshot & $\begin{array}{l}S 6201 \\
Q F \cdot-15\end{array}$ & 02.6 & $w$ & $H=$. & Dist: & $\begin{array}{l}16.95 \\
9582.1476\end{array}$ & $\begin{array}{c}\text { Vt. Dist: } \\
5960.1497\end{array}$ & $\begin{array}{l}1266.93 \\
1266.952 .4\end{array}$ \\
\hline hot & $\begin{array}{l}544 \quad 10 \\
Q F F^{\prime}-1\end{array}$ & 00.6 & $w$ & $H z$ & $n_{i} \leq t:$ & $\begin{array}{l}22.10 \\
9574.2481\end{array}$ & $\begin{array}{l}\text { Wt. Dist: } \\
5959.7195\end{array}$ & $\begin{array}{l}1274.97 \\
1274.9656\end{array}$ \\
\hline teshot & $\begin{array}{l}54750 \\
Q F^{\prime} F^{\prime}-2\end{array}$ & 21.6 & $w$ & $H z$. & Dist: & $\begin{array}{l}20.74 \\
9570.1811\end{array}$ & $\begin{array}{l}\text { Vt. Dist: } \\
5959.7454\end{array}$ & $\begin{array}{l}1274.90 \\
1274.8971\end{array}$ \\
\hline teshot & $\begin{array}{l}55148 \\
\text { GPF-? }\end{array}$ & 17.6 & $w$ & $H=$. & Dist: & $\begin{array}{l}19.35 \\
9578.1466\end{array}$ & $\begin{array}{l}\text { Vt. Dist: } \\
5959.9242\end{array}$ & $\begin{array}{l}1274.81 \\
1274.8107\end{array}$ \\
\hline teshot & $\begin{array}{l}55051 \\
Q F P-4\end{array}$ & 10.6 & $w$ & $H=$. & $D_{1} \leq t:$ & $\begin{array}{l}18.06 \\
9580.2=25\end{array}$ & $\begin{array}{c}\text { Vt. Dist: } \\
5959.9921\end{array}$ & $\begin{array}{l}1274.84 \\
1274.8400\end{array}$ \\
\hline teshot & $\begin{array}{l}50218 \\
\text { QFF'-5 }\end{array}$ & 01.6 & $w$ & $H=$. & {$[15 \pm:$} & $\begin{array}{l}17.00 \\
7582.1994\end{array}$ & $\begin{array}{l}\text { Vt. Dist: } \\
5960.068 \mathrm{~S}\end{array}$ & $\begin{array}{l}1274.91 \\
1274.9057\end{array}$ \\
\hline jeshot & $\begin{array}{l}N \$ 144 \\
Q F F-25\end{array}$ & 47.4 & $w$ & $H=$. & I1st: & $\begin{array}{l}16.02 \\
9598.1009\end{array}$ & $\begin{array}{c}\text { Vt. D1st: } \\
5960.2121\end{array}$ & $\begin{array}{l}1272.57 \\
1272.5708\end{array}$ \\
\hline jeshot & $\begin{array}{l}N 56=4 \\
\text { OFF- } 24\end{array}$ & 10.4 & w & $H=$. & $D_{1} \leq t:$ & $\begin{array}{l}17.90 \\
9600.0050\end{array}$ & $\begin{array}{l}\text { Vt. Dist: } \\
5960.2087\end{array}$ & $\begin{array}{l}1272.46 \\
1272.4630\end{array}$ \\
\hline ieshot & $\begin{array}{l}N 51 \quad 98 \\
O F F-2:\end{array}$ & 29.4 & $w$ & $H=$. & $D_{i} \equiv t:$ & $\begin{array}{l}19.06 \\
9602.0598\end{array}$ & $\begin{array}{l}\text { Ut. Dist: } \\
5960.2725\end{array}$ & $\begin{array}{l}1272.00 \\
1272.0004\end{array}$ \\
\hline $\begin{array}{l}\text { jeshot } \\
\text { : }\end{array}$ & $\begin{array}{l}N 47 \quad 01 \\
\text { QFF-Z2 }\end{array}$ & 59.4 & $w$ & $H=$. & $D_{1} \leq t:$ & $\begin{array}{l}20.49 \\
9004.0585\end{array}$ & $\begin{array}{c}\text { Ut. Dist: } \\
59 t 0.1216\end{array}$ & $\begin{array}{l}1272.53 \\
1272.5306\end{array}$ \\
\hline ieshot & $\begin{array}{l}N 4313 \\
Q F F-21\end{array}$ & 39.4 & $w$ & $H z$. & Dist: & $\begin{array}{l}21.87 \\
9606.0383\end{array}$ & $\begin{array}{c}\text { Vt. D1st: } \\
5960.1355\end{array}$ & $\begin{array}{l}1272.56 \\
1272.5577\end{array}$ \\
\hline Jeshot & 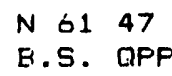 & $\begin{array}{l}01.6 \\
-23\end{array}$ & $E$ & $H=$. & $D_{1} \subseteq t:$ & $\begin{array}{l}22.21 \\
7000.5995\end{array}$ & $\begin{array}{c}\text { yt. Dist: } \\
5994.6852\end{array}$ & $\begin{array}{l}1275.84 \\
1275.3 \pm 75\end{array}$ \\
\hline
\end{tabular}




WIPP
WASTE ISOLATION
PILOT PLANT

TITLE: DRILLING LOG

\begin{tabular}{|c|c|c|c|}
\hline 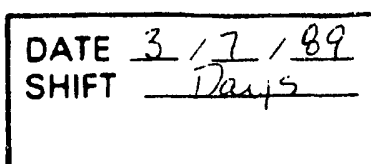 & $\begin{array}{l}\text { ROOM Q Bime } R_{10} \\
\text { STATION }\end{array}$ & $\begin{array}{l}\text { HOLE NO. QPPOL } \\
\text { GAGE NO. } \\
\text { GAGE TYPE }\end{array}$ & 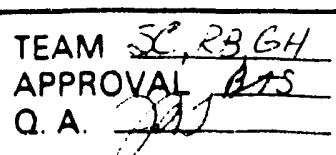 \\
\hline
\end{tabular}

\begin{tabular}{|c|c|c|}
\hline TIME & DEPTH & \\
\hline 1400 to $E 10$ & $0^{\prime}$ to $/ 7^{\prime}$ & \\
\hline $06 \% \hat{v}$ to 1400 & $17^{\prime}$ to $\hat{\varepsilon} 6^{\prime} 6^{\prime \prime}$ & \\
\hline & & \\
\hline & & \\
\hline & & \\
\hline & & \\
\hline & & \\
\hline & & \\
\hline & & \\
\hline
\end{tabular}

\begin{tabular}{|l|l|l|l|l|l|l|}
\hline & $X_{1}\left(R_{1}\right)$ & $x_{2}\left(R_{2}\right)$ & $Y_{1}\left(\theta_{1}\right)$ & $r_{2}\left(\theta_{2}\right)$ & $z_{1}$ & $z_{2}$ \\
\hline SPECIFIED HOLE CORD. & 0 & $y_{-25}$ & -16 & 0 & 5 & 45 \\
\hline
\end{tabular}

ACTUAL HOLE LENGTH $86^{\prime} 66^{\prime \prime}$ SPECIFIED DIA. $4 "$ ACTUAL DIA. 4 "

DRILL RIG \& BIT TYPE Diame 230 4 - Dia. Plug

\section{NOTES:}

1. SUBSCRIPT 1 SIGNIFIES BEGINNING OF HOLE \& SUBSCRIPT 2 SIGNIFIES END OF HOLE

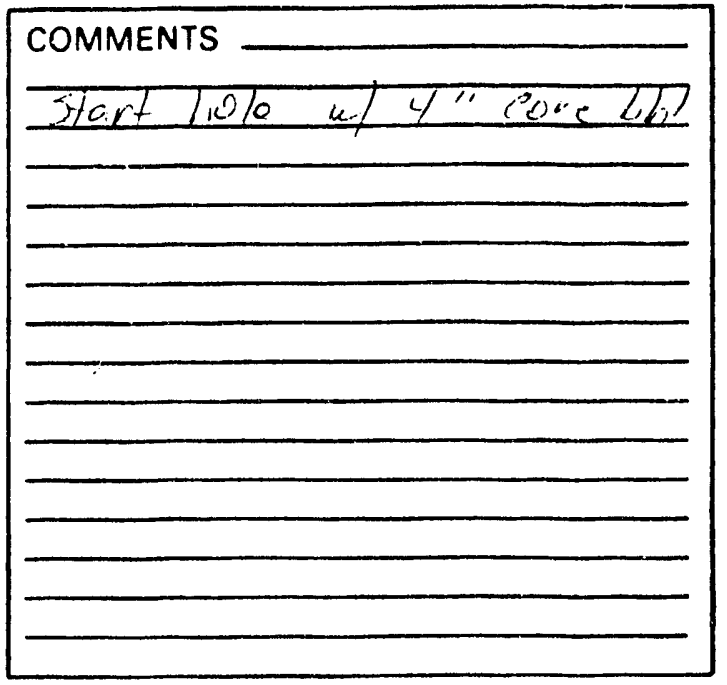




WIPP
WASTE ISOLATION
PILOT PLANT

TITLE: DRILLING LOG

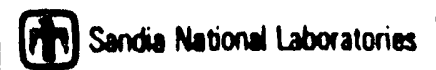
PROCEDURE

REVISION 0

\begin{tabular}{|c|c|c|c|}
\hline $\begin{array}{l}\text { DATE } 3 / \frac{6}{3} / 89 \\
\text { SHIFT D.4 }\end{array}$ & $\begin{array}{l}\text { ROOM Q } 2 \text { BBine } \\
\text { STATION }\end{array}$ & $\begin{array}{l}\text { HOLE NO. QPPOZ } \\
\text { GAGE NO. } \\
\text { GAGE TYPE }\end{array}$ & 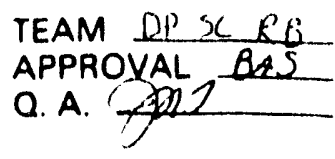 \\
\hline
\end{tabular}

\begin{tabular}{|c|c|c|c|}
\hline \multirow{9}{*}{$3 \cdot 6 \cdot 84$} & TIME & DEPTH & REMARKS \\
\hline & $0415 / 1440$ & $0+074^{\prime} 3 / 2$ & 4" Depth \\
\hline & & & Drilled $1 / 2$ inde \\
\hline & & & $55^{\prime \prime}$ dee $3 / 23189$ \\
\hline & & & \\
\hline & & & \\
\hline & & & \\
\hline & & & \\
\hline & & & \\
\hline
\end{tabular}

\begin{tabular}{|l|c|c|c|c|c|c|}
\hline & $x_{1}\left(R_{1}\right)$ & $x_{2}\left(R_{2}\right)$ & $r_{1}\left(\theta_{1}\right)$ & $r_{2}\left(\theta_{2}\right)$ & $z_{1}$ & $z_{2}$ \\
\hline SPECIFIED HOLE CORD. & 0 & -75 & -14 & 0 & 5 & -25 \\
\hline
\end{tabular}

ACTUAL HOLE LENGTH $28^{\prime} 10^{\frac{1}{2}}=$ SPECIFIED DIA. $4^{\prime \prime}$ ACTUAL DIA. $4^{\prime \prime}$

DRILL RIG \& BIT TYPE Diamec $230-4^{\prime \prime}$ Diamad Plug bit

NOTES:

1. SUBSCRIPT I SIGNIFIES BEGINNING OF HOLE \& SUBSCRIPT 2 SIGNIFIES END OF HOLE

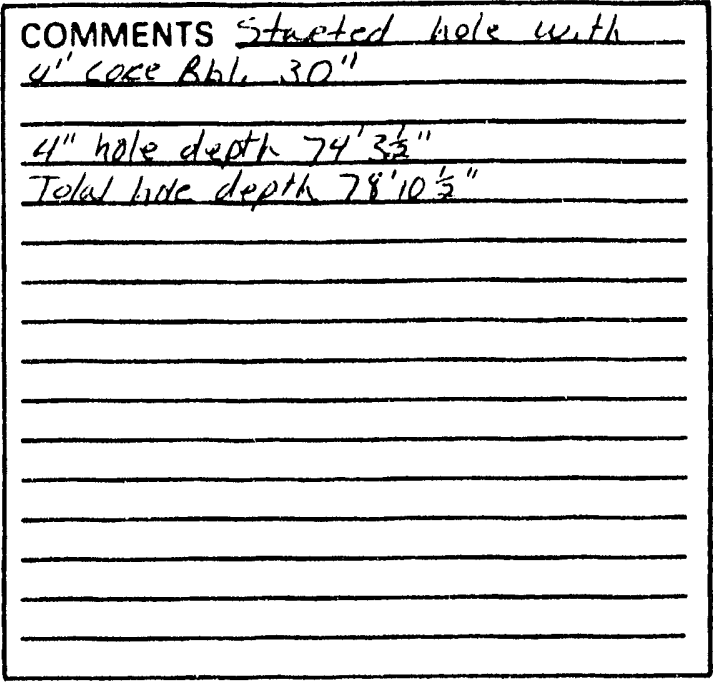




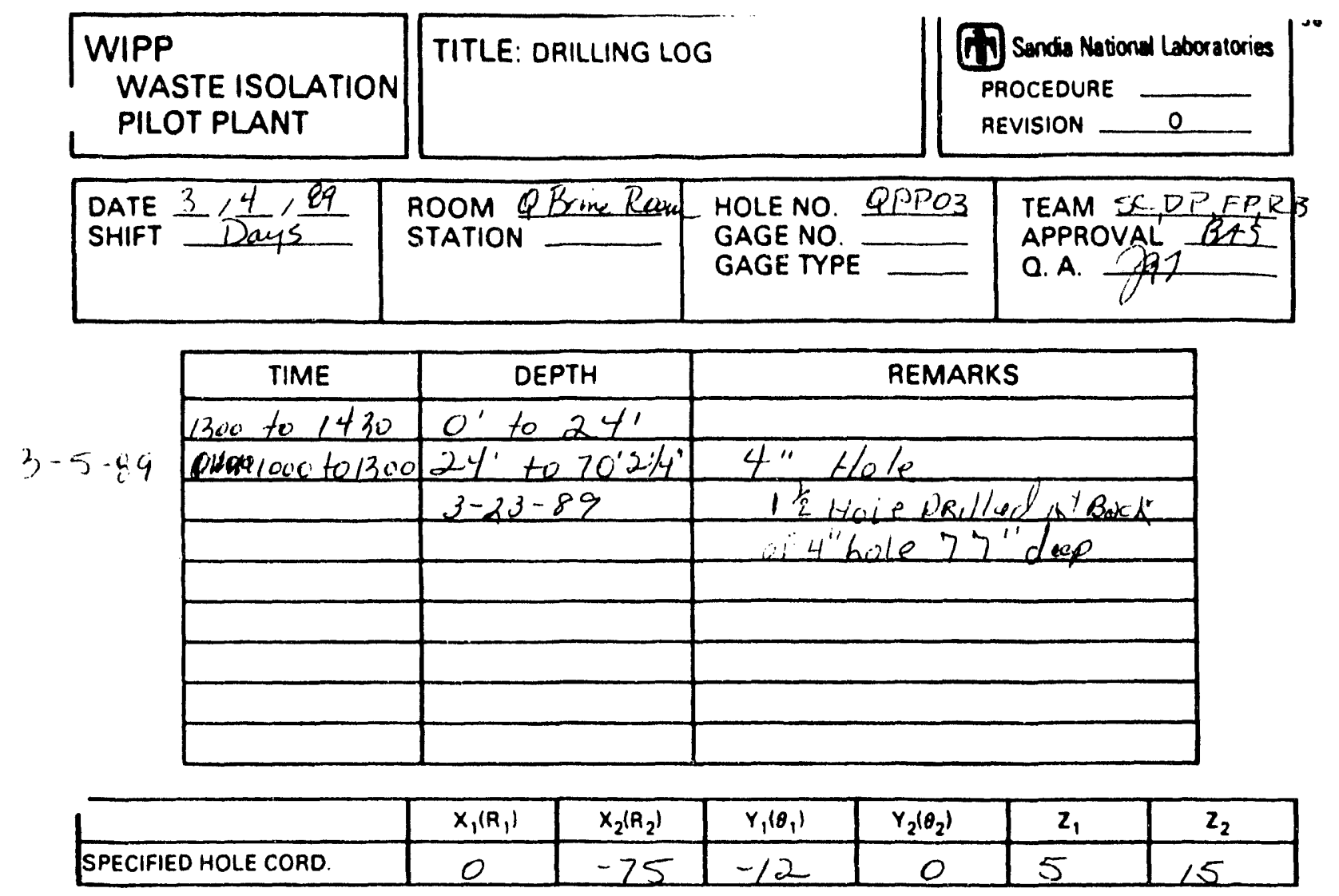

ACTUAL HOLE LENGTH $76^{\prime} 74^{\prime \prime}$ SPECIFIED DIA. 4 ACTUAL DIA. $4 "$

DRILL RIG \& BIT TYPE Diamec 230 4" Dia, P/ug
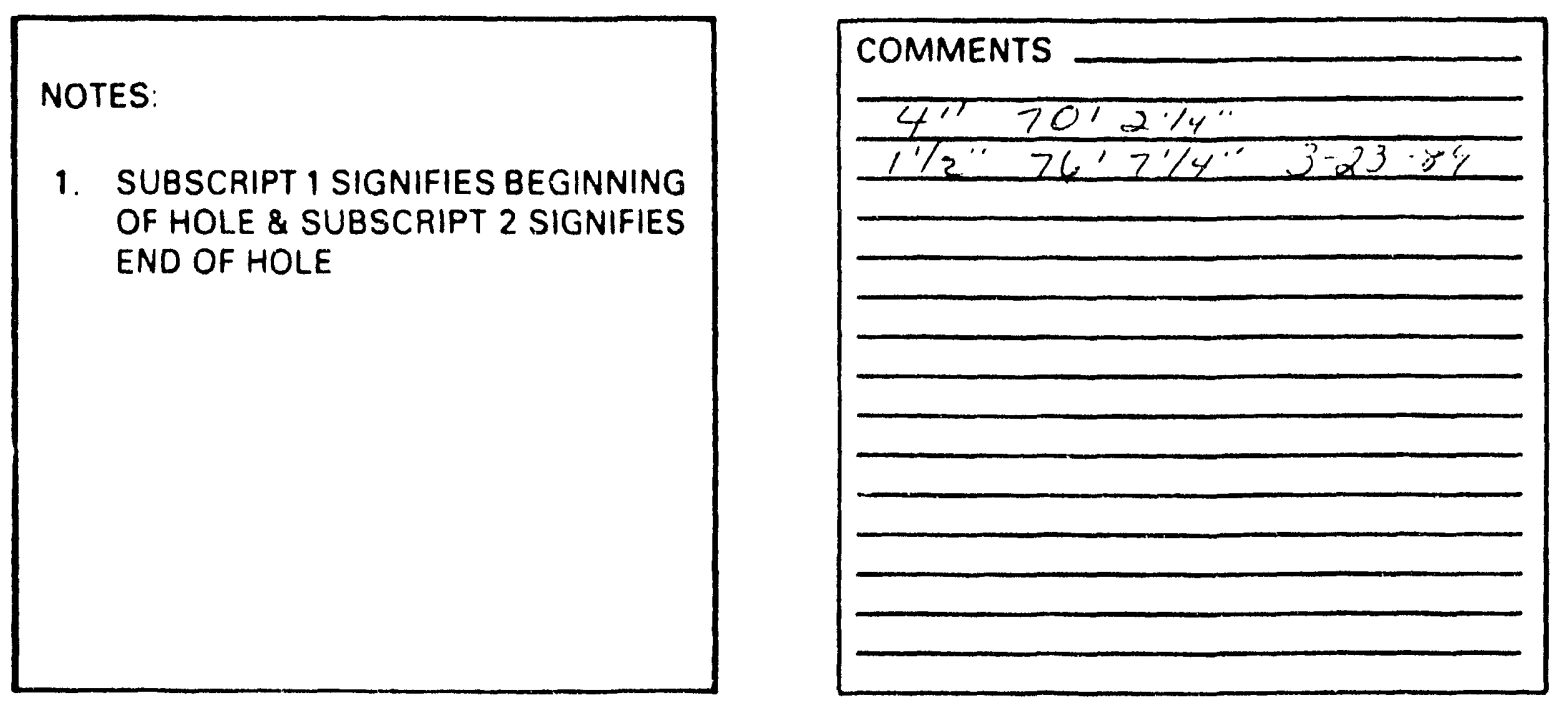


\section{WIPP \\ WASTE ISOLATION PILOT PLANT}

TITLE: ORILLING LOG

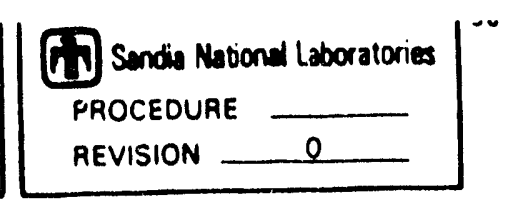

PROCEDURE

REVISION

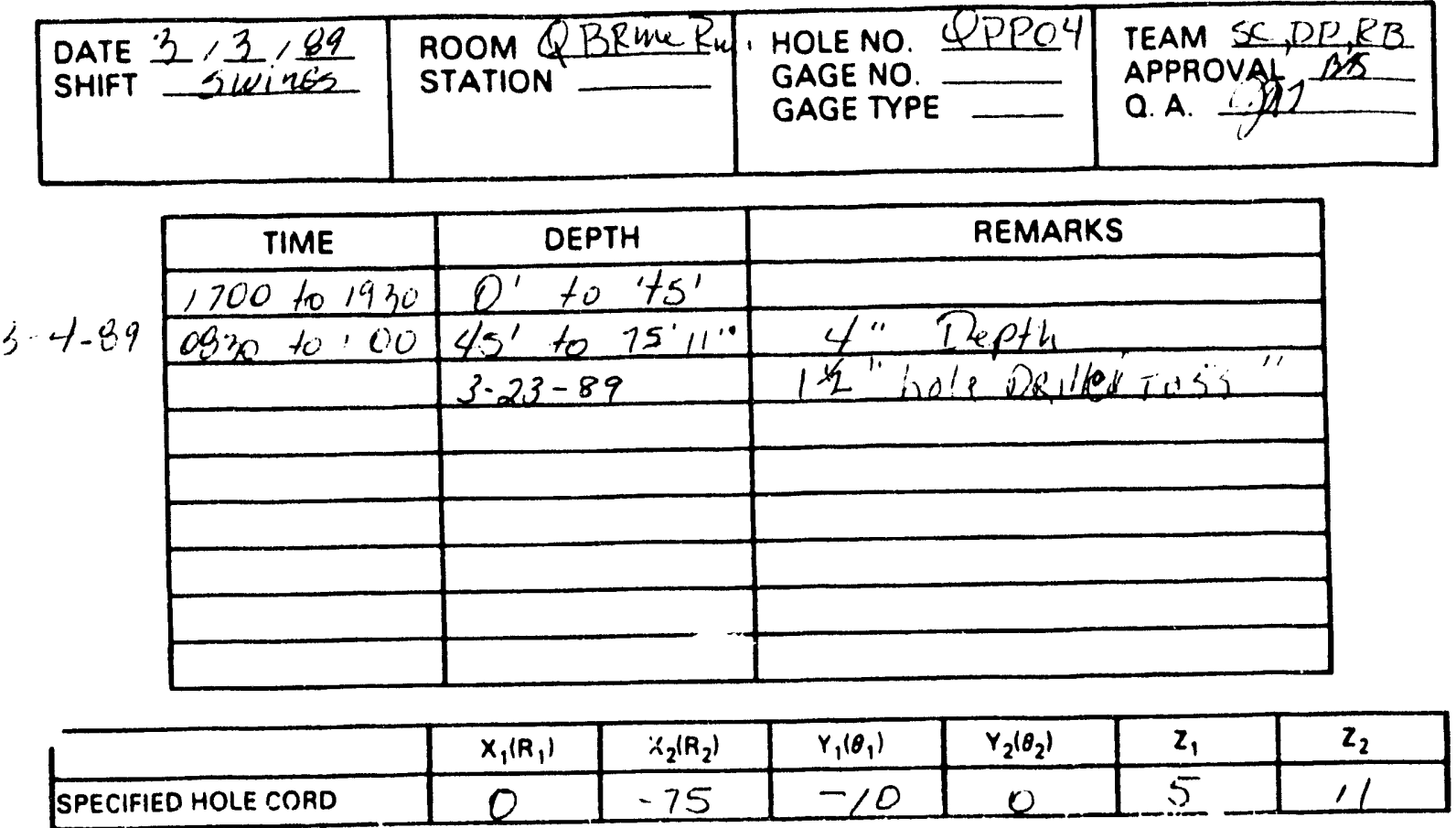

ACTUAL HOLE LENGTH $75^{\prime} / 1^{\prime \prime}$ SPECIFIED DIA. $4 "$ ACTUAL DIA. 4 -

DRILL RIG \& BIT TYPE Diarme 230 4" Da. Plus

NOTES:

1. SUBSCRIPT 1 SIGNIFIES BEGINNING OF HOLE \& SUBSCRIPT 2 SIGNIFIES END OF HOLE

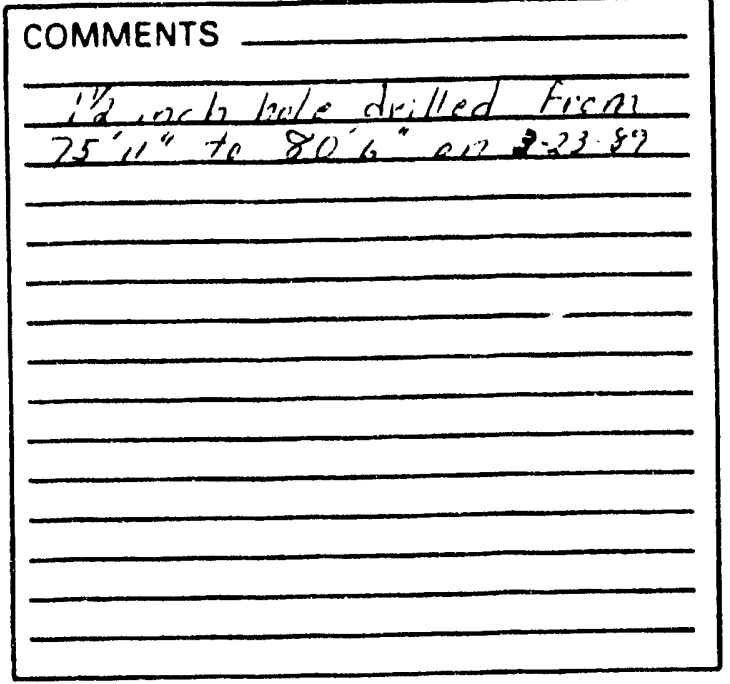




\begin{tabular}{|c|c|c|c|}
\hline $\begin{array}{l}\text { WIPP } \\
\text { WASTE ISOLATION } \\
\text { PILOT PLANT }\end{array}$ & \multicolumn{2}{|c|}{ TITLE: CORE DRILLING DATA } & $\begin{array}{ll}\text { Cid) } \\
\text { PAOCEOUAE } \\
\text { REVISION }\end{array}$ \\
\hline $\begin{array}{l}\text { CATE } \geq 1 \frac{27}{D_{445}}=84 \\
\text { SHIFT }\end{array}$ & $\begin{array}{l}\text { ROOM Brine Reom } \\
\text { STATION } \\
\text { MINE COORDINATES }\end{array}$ & HOLE NO QPPOS & 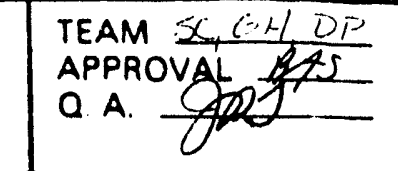 \\
\hline $\begin{array}{l}\text { DRILL SPECS DIQX } \\
\text { CORE BARREL SPECS } \\
\text { DRILLING FLUID }\end{array}$ & $\frac{4^{\prime \prime} \times 34 "}{\text { Air }}$ & $\begin{array}{l}\text { HOLE DIA. } \frac{4 "}{4} \\
\text { - HOLE LENGTH }\end{array}$ & $75.6 "$ \\
\hline
\end{tabular}

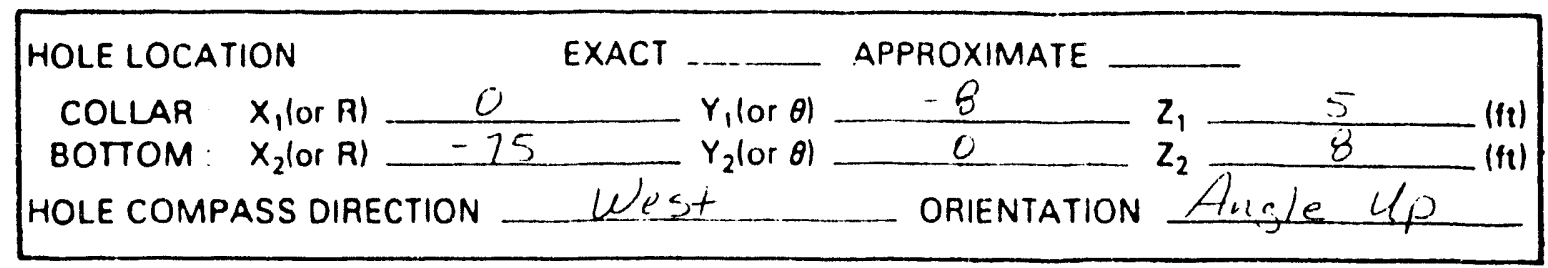

\begin{tabular}{|c|c|c|c|c|}
\hline \multirow{2}{*}{ DATE } & \multirow{2}{*}{$\begin{array}{l}\text { SEGMENT OR } \\
\text { BOX NUMBER }\end{array}$} & \multicolumn{2}{|c|}{ CORE INTERVAL (DEPTHS) } & \multirow{2}{*}{$\begin{array}{l}\text { STORAGE LOCATION/ } \\
\text { REMARKS }\end{array}$} \\
\hline & & BEGINNING & END & \\
\hline 2.27 .89 & Rusit $\# 1$ & $0^{\prime \prime}$ & $22^{\prime \prime}$ & If"Ritrieviref \\
\hline \multirow[t]{9}{*}{$2-28-89$} & $\# 2$ & $22 "$ & $48 \cdot$ & L" Retricued \\
\hline & \pm 3 & $4^{\prime}$ & $6^{\prime} 9^{\prime \prime}$ & $x^{\prime \prime}$ \\
\hline & $\# 4$ & $6.9 "$ & $9^{\prime}$ & $16^{\prime} 9+099^{\prime} 7$ \\
\hline & $\$ 5$ & $9^{\prime}$ & $12^{\prime} 10^{\prime \prime}$ & Ne Recairy \\
\hline & $\equiv 6$ & $\angle 2^{\prime} 10^{\prime \prime}$ & $15^{\prime} 6^{\prime \prime}$ & \\
\hline & Ef 2 & $15^{\prime} 6^{\prime \prime}$ & $18^{\prime} 2^{\prime \prime}$ & \\
\hline & $\pm x$ & $18^{\prime} 7^{\prime \prime}$ & $25^{\prime} 8^{\prime \prime}$ & \\
\hline & \pm 4 & $2 c^{\prime} 8^{\prime \prime}$ & $23^{\prime} 6^{\prime \prime}$ & \\
\hline & 411 & $.2316^{\prime \prime}$ & $25 \cdot c 3^{\prime \prime}$ & \\
\hline \multirow[t]{5}{*}{$3-1-84$} & +11 & $25 \cdot 9 \cdot$ & $23^{\prime} 7^{\prime \prime}$ & \\
\hline & 212 & 27711 & $30^{\prime} 6^{\prime \prime}$ & Lost s"of core \\
\hline & $2+13$ & $3 L^{\prime \prime \prime}$ & $33^{\prime} 11^{\prime}$ & \\
\hline & \pm 14 & $3311 \frac{1}{2}$ & $32^{\prime} 5^{\prime \prime}$ & \\
\hline & 715 & $375^{\prime \prime}$ & $41^{\prime} 10^{\prime \prime}$ & Kecsuered $3 C^{\prime \prime}$ \\
\hline $\begin{array}{l}\text { COMMENTS } \\
\text { trattis } \\
\text { litaking at }\end{array}$ & $\begin{array}{l}\text { dery clear } \\
\text { ard beins }\end{array}$ & $\begin{array}{l}\text { cere grea } \\
\text { a ciet of }\end{array}$ & $\begin{array}{l}\text { Its ievy } \\
\text { the hacle. }\end{array}$ & Eittle ance ic \\
\hline
\end{tabular}




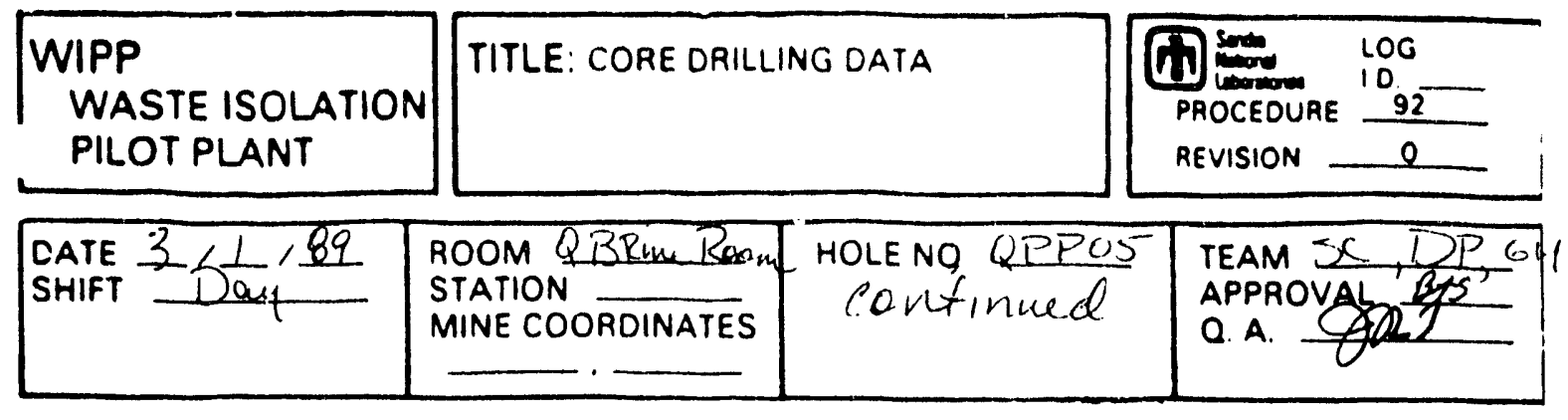

\begin{tabular}{|c|c|}
\hline 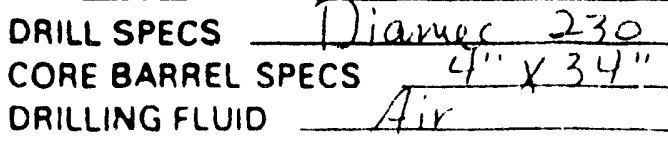 & HOLE DIA. $\frac{44^{\prime \prime}}{\text { HOLE LENGTH }}$ (in) \\
\hline
\end{tabular}

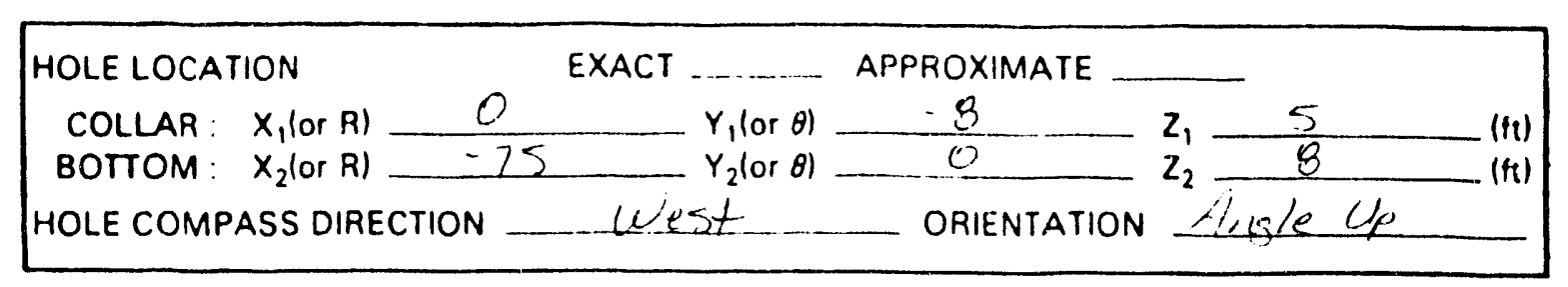

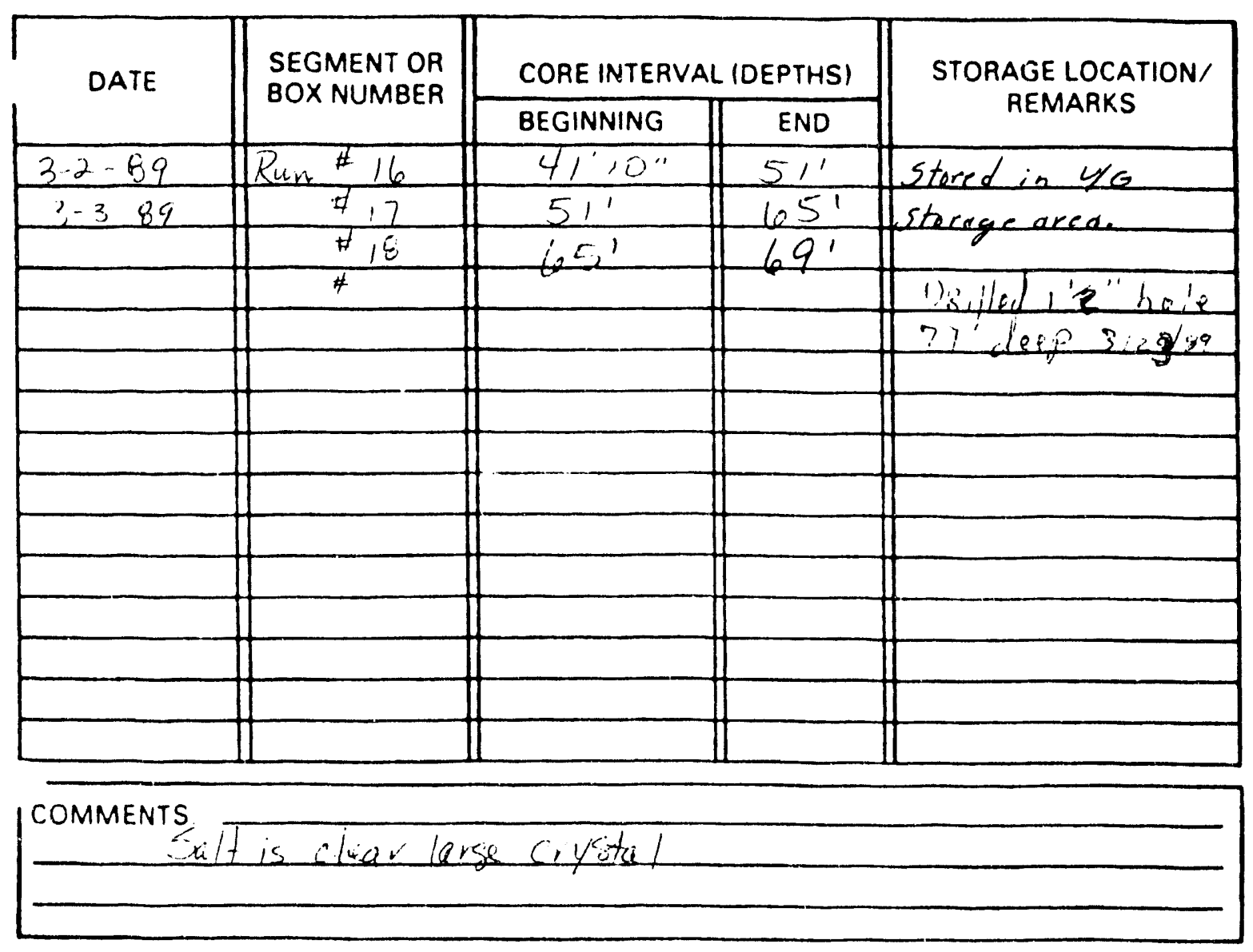




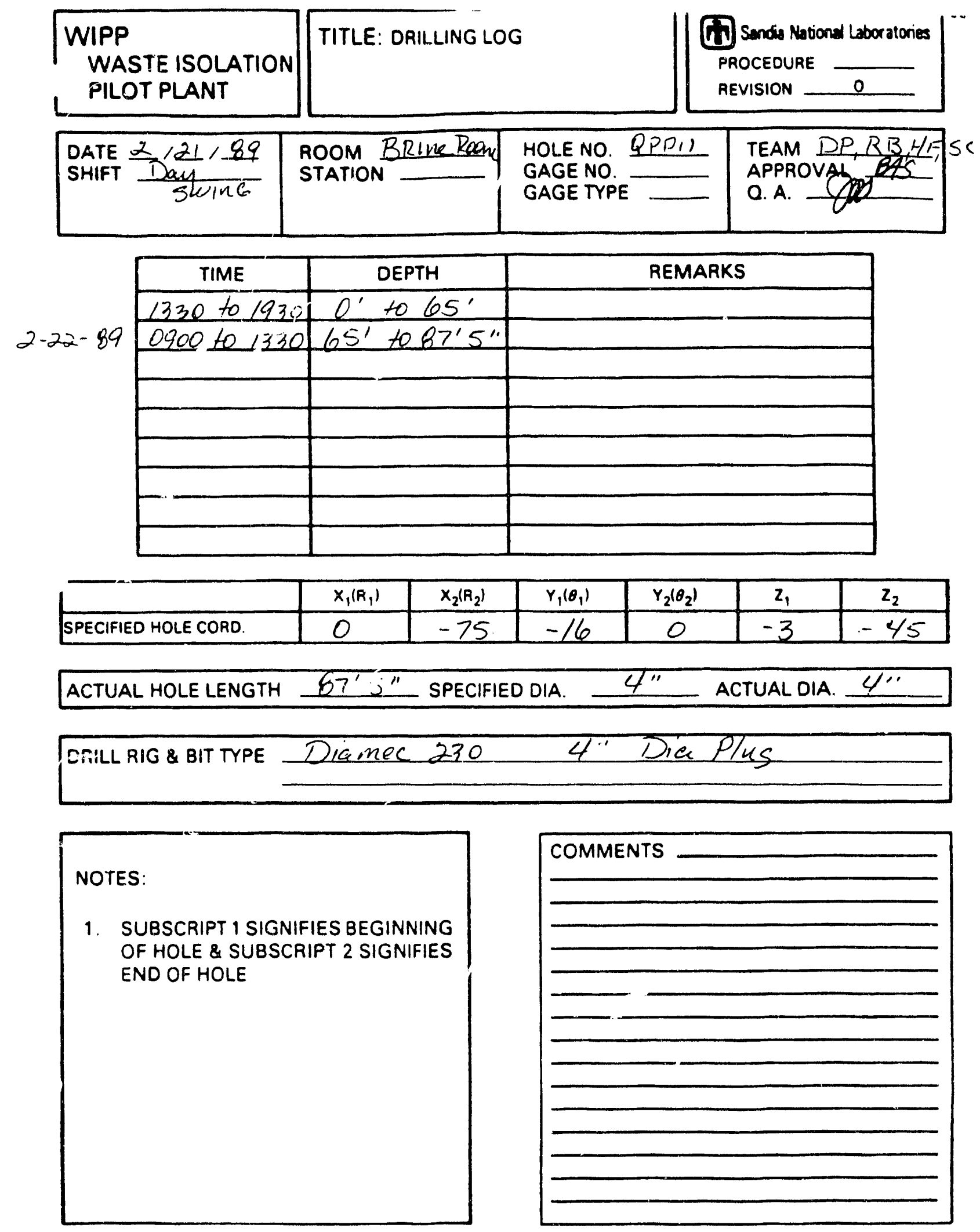




\section{WIPP \\ WASTE ISOLATION PILOT PLANT}

TITLE: ORILLING LOG

$$
\text { DATs } 2+18 / 89
$$

DATE $2 / 18 / 89$ ROOM Brive Roond

SHIFT $\frac{\text { Dey }}{\text { Swint }}$
HOLE NO. QPPIZ GAGE NO. GAGE TYPE

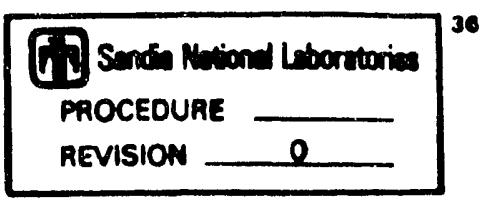

TEAM SC,EP, $6 H$ APPROYAY BES

Q. A.

\begin{tabular}{|c|c|c|}
\hline TIME & DEPTH & REMARKS \\
\hline 1320 to 1500 & $0^{\prime}$ to $14^{\prime}$ & \\
\hline 0900 to 1900 & $14^{\prime}$ to $74^{\prime} 10^{\prime \prime}$ & $4^{\prime \prime}$ Hole DeAth \\
\hline 0900 to 1100 & $74^{\prime} 10^{\prime \prime}$ to $79^{\prime} 5^{\prime \prime}$ & $1^{\prime} / 2^{\prime \prime}$ Hole drilled ot Bottere \\
\hline & & of $4^{\prime \prime}$ Hole \\
\hline & & \\
\hline & & \\
\hline & & \\
\hline & & \\
\hline & & \\
\hline
\end{tabular}

\begin{tabular}{|l|c|c|c|c|c|c|}
\hline & $x_{1}\left(\boldsymbol{A}_{1}\right)$ & $x_{2}\left(\boldsymbol{A}_{2}\right)$ & $r_{1}\left(\boldsymbol{\theta}_{1}\right)$ & $r_{2}\left(\boldsymbol{o}_{2}\right)$ & $\boldsymbol{z}_{1}$ & $\boldsymbol{z}_{\mathbf{2}}$ \\
\hline SPECIFIED HOLE CORD. & 0 & -75 & -14 & 0 & -3 & -25 \\
\hline
\end{tabular}

ACTUAL HOLE LENGTH $79^{\prime} 5^{\prime \prime}$ SPECIFIED DIA. $4^{\prime \prime}$ ACTUAL DIA. $4 "$

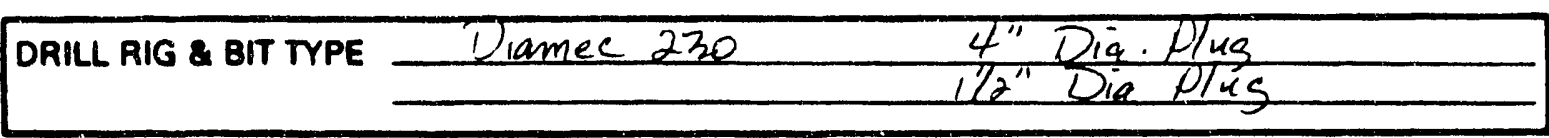

NOTES:

1. SUBSCAIPT 1 SIGNIFIES BEGINNING OF HOLE \& SUBSCRIPT 2 SIGNIFIES END OF HOLE

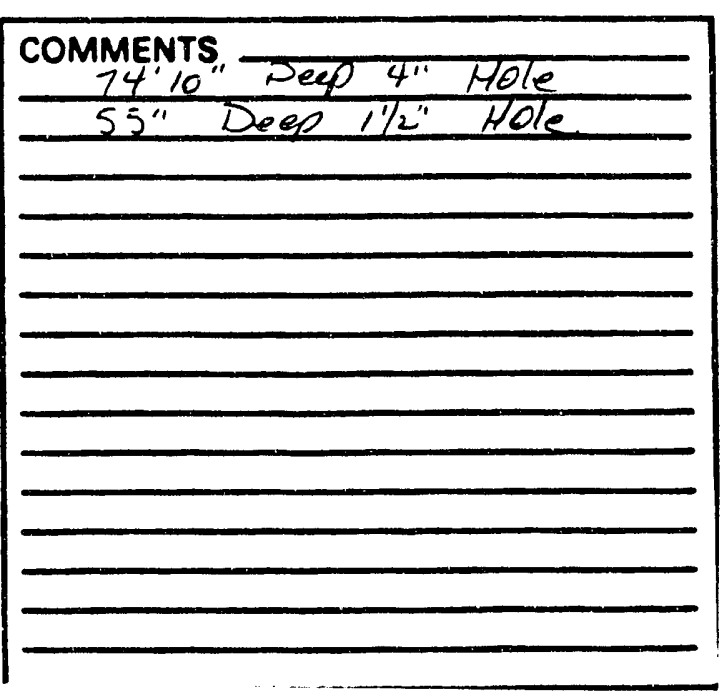




\section{WIPP}

WASTE ISOLATION

PILOT PLANT

\section{TITLE: ORILLING LOG}

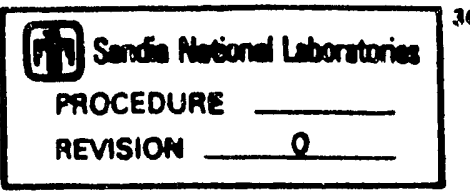

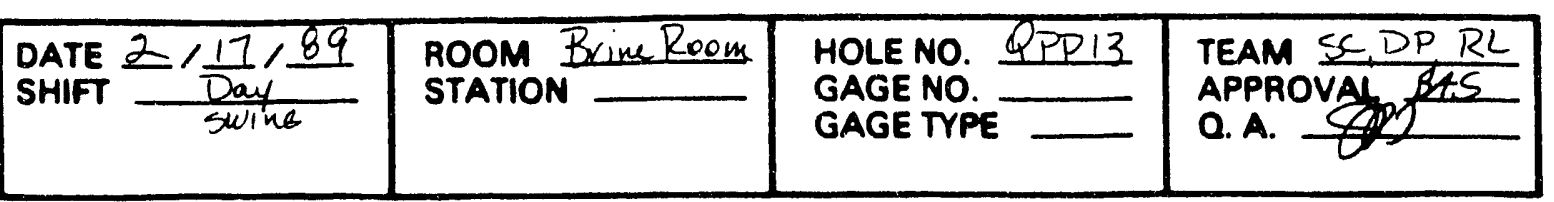

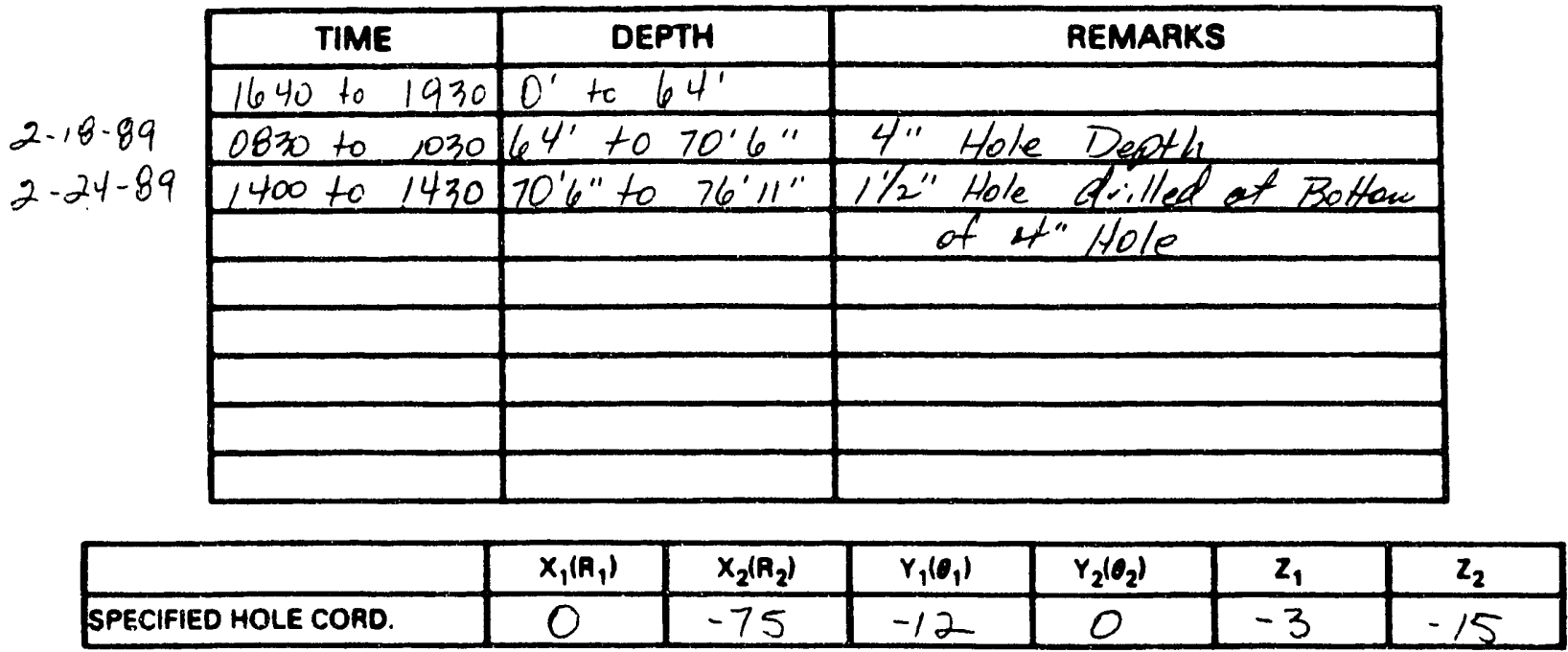

ACTUAL HOLE LENGTH $16^{\prime} / 1^{\prime \prime}$ SPECIFIED DIA. $4 "$ ACTUAL DIA. 4"
DRILL RIG \& BIT TYPE \begin{tabular}{rl} 
Diamec 230 & $4 "$ Dia, D/us \\
\hline $1 / 2 "$ Dia P/us
\end{tabular}

\section{NOTES:}

1. SUBSCRIPT I SIGNIFIES BEGINNING OF HOLE \& SUBSCRIPT 2 SIGNIFIES END OF HOLE

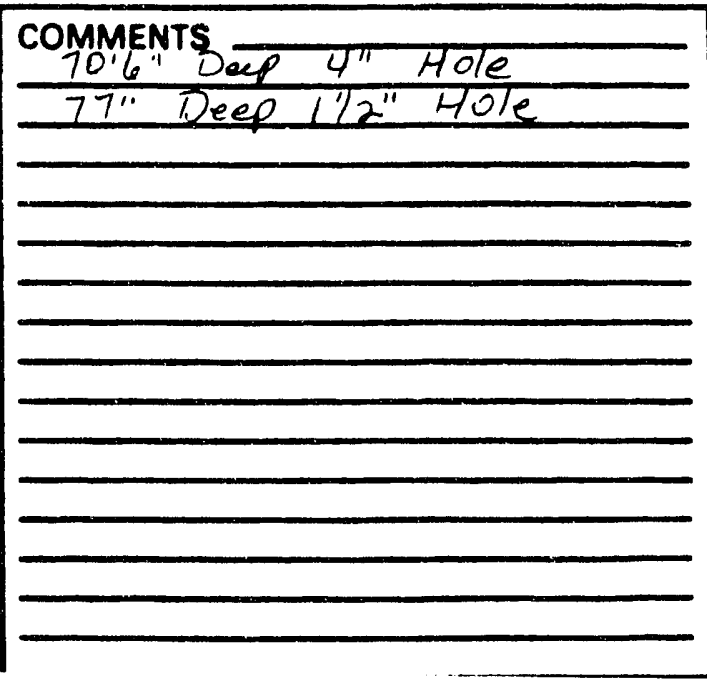




WIPP
WASTE ISOLATION
PILOT PLANT

\begin{tabular}{|l|l} 
DATE $\frac{2 / 15}{\text { Jay }} / 89$ & $\begin{array}{l}\text { ROOM BRINe RoOm } \\
\text { SHIVT }\end{array}$ \\
STATION
\end{tabular}
TITLE: ORILLING LOG

HOLE NO. QPPI2

GAGE NO.

GAGE TYPE

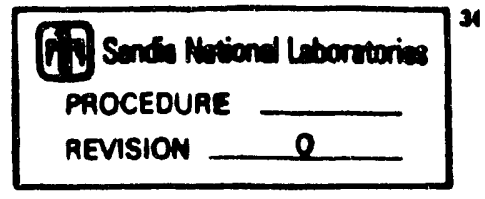

TEAM SK DP,GH APPROYAI BAS

Q. A

\begin{tabular}{|c|c|c|}
\hline TIME & DEPTH & \multicolumn{1}{c|}{ REMARKS } \\
\cline { 2 - 4 } $1230 / 1930$ & $0^{\prime}$ to $71^{\prime} 6^{\prime \prime}$ & $4^{\prime \prime}$ Hole Depth \\
\hline $104-89 / 1730$ & $71^{\prime} 6^{\prime \prime}$ to $76^{\prime} \prime^{\prime \prime}$ & $1^{\prime \prime}$ Hole Drilled at Bottem \\
\hline & & Of 4" Hole \\
\hline & & \\
\hline & & \\
\hline & & \\
\hline & & \\
\hline & & \\
\hline & & \\
\hline
\end{tabular}

\begin{tabular}{|l|c|c|c|c|c|c|}
\hline & $X_{1}\left(R_{1}\right)$ & $x_{2}\left(R_{2}\right)$ & $Y_{1}\left(\theta_{1}\right)$ & $Y_{2}\left(\theta_{2}\right)$ & $z_{1}$ & $z_{2}$ \\
\hline SPECIFIED HOLE CORD. & 0 & -75 & -10 & 0 & -3 & -11 \\
\hline
\end{tabular}

ACTUAL HOLE LENGTH $76^{\prime} 1^{\prime \prime}$ SPECIFIED DIA. $4^{\prime \prime}$ ACTUAL DIA. $4 " 4$

DRILL RIG a BIT TYPE Diames $230 \quad 4 "$ Dia.Plus

NOTES:

1. SUBSCRIPT 1 SIGNIFIES BEGINNING OF HOLE \& SUBSCRIPT 2 SIGNIFIES END OF HOLE

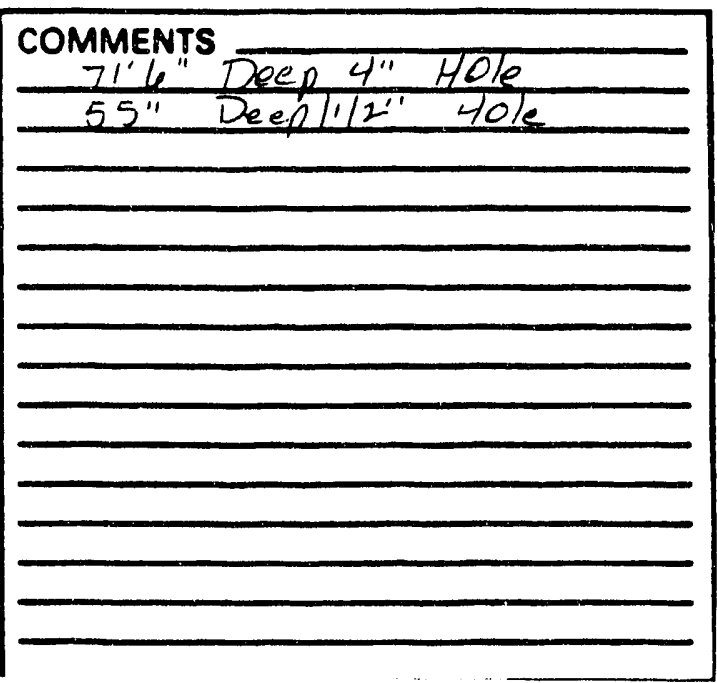




\section{WIPP \\ WASTE ISOLATION PILOT PLANT}

\begin{tabular}{|l|l|}
\hline DATE $2 / \frac{7}{189}$ & ROOM Brive RoOM \\
SHIFT & STATION \\
\hline
\end{tabular}

TITLE: DRILUNG LOG

HOLE NO. QPP 15 GAGE NO.

GAGE TYPE

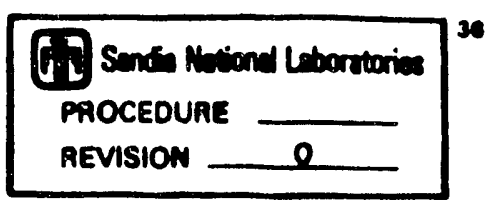

TEAM SC,DPGH APPROVAL BAS

\begin{tabular}{|c|c|c|c|}
\hline & TIME & DEPTH & REMARKS \\
\hline \multirow{4}{*}{$\begin{array}{r}2-8-89 \\
2-9-89\end{array}$} & $1440 / 1500$ & $0^{\prime}$ to $29^{\prime \prime}$ & Liaht seurce and hazer \\
\hline & 09301330 & $2^{\prime} 5^{\prime \prime}$ to $47.5^{\prime}$ & survey showed hole to \\
\hline & \begin{tabular}{ll|l}
0930 & 1000 \\
\end{tabular} & $7.5^{\prime}+0 \quad 52.5^{\prime}$ & be online and strainkt \\
\hline & $1210 / 14 / 5$ & $525^{\prime}$ to $69^{\prime} 2^{\prime \prime}$ & \\
\hline \multirow[t]{4}{*}{$2-27.59$} & 0930 to 1000 & $69^{\prime} 2^{\prime \prime}$ to $75^{\prime} 7^{\prime \prime}$ & Extend hole $77^{\prime \prime} \times 12^{\prime \prime}$ \\
\hline & & & \\
\hline & & & \\
\hline & & & \\
\hline
\end{tabular}

\begin{tabular}{|l|c|c|c|c|c|c|}
\hline & $x_{1}\left(R_{1}\right)$ & $x_{2}\left(R_{2}\right)$ & $r_{1}\left(\theta_{1}\right)$ & $r_{2}\left(\theta_{2}\right)$ & $z_{1}$ & $z_{2}$ \\
\hline SPECIFIED HOLE CORD. & 0 & -75 & -5 & 0 & -3 & $-\varepsilon$ \\
\hline
\end{tabular}

ACTUAL HOLE LENGTH GQR SPECIFIED DIA. $4 "$ ACTUAL DIA. 4 "

DRILL RIG \& BIT TYPE

Diames 230 4" Dia Plug
Started liade with 4"X32" Dia. Core $3 B L$

NOTES:

1. SUBSCRIPT 1 SIGNIFIES BEGINNING OF HOLE \& SUBSCRIPT 2 SIGNIFIES END OF HOLE

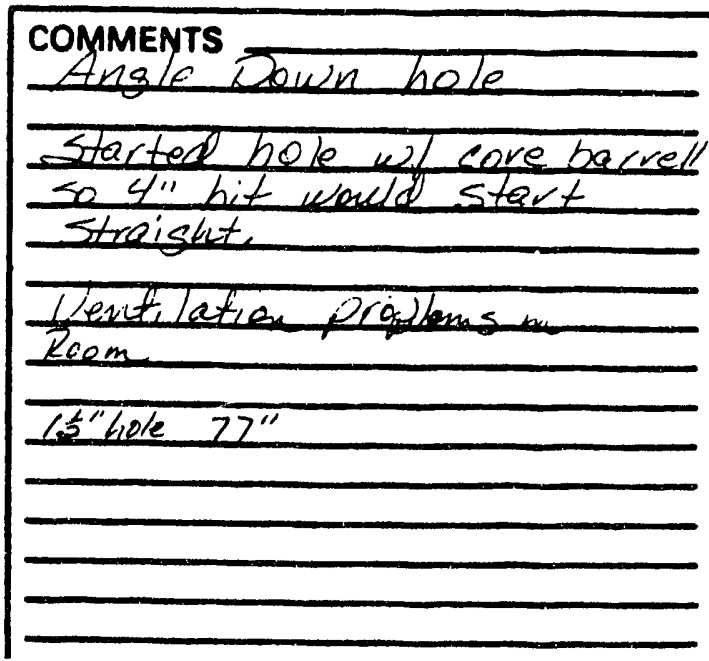




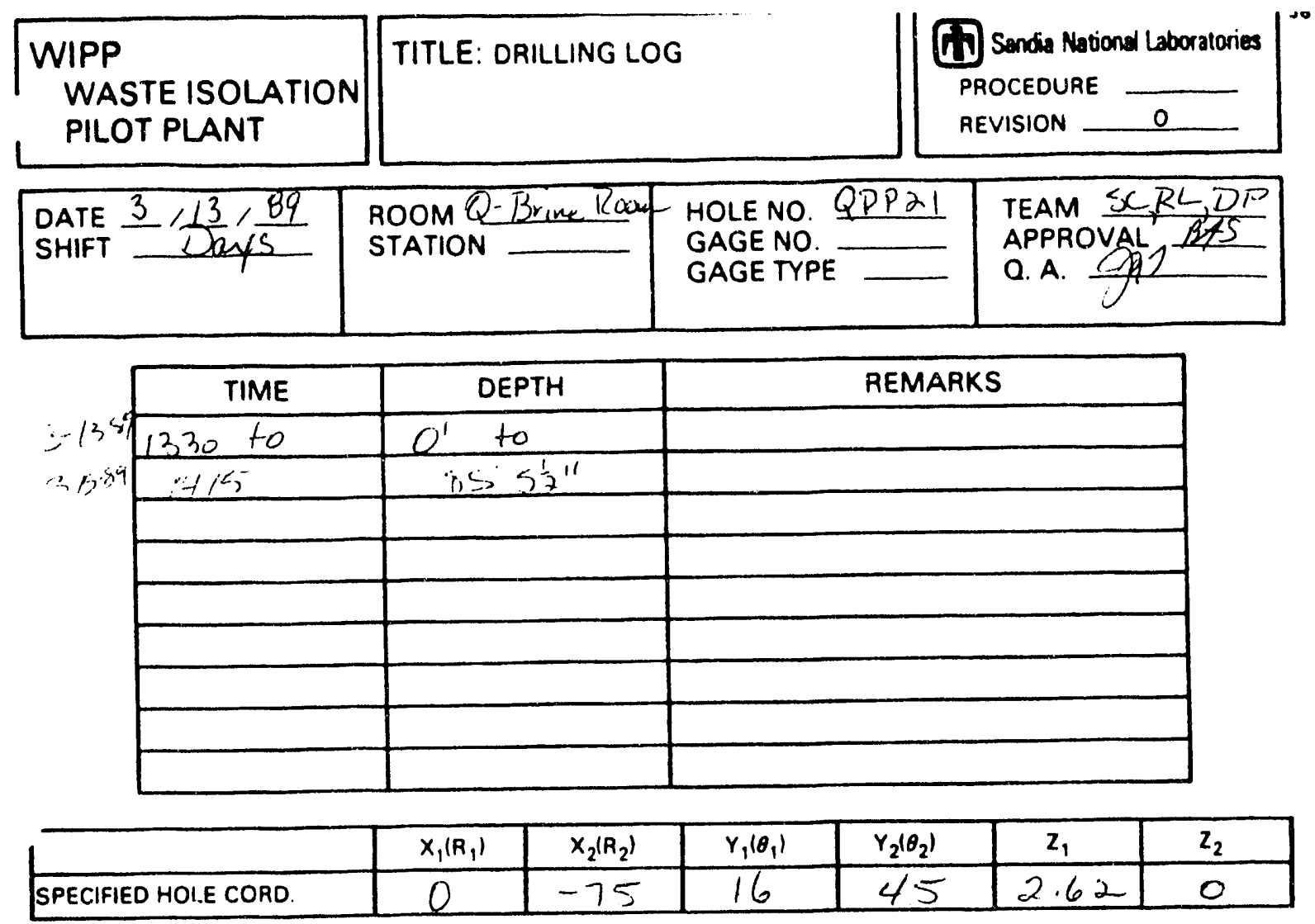

ACTUAL HOLE LENGTH $80^{\prime} 5^{1 / 2}$ "SPECIFIED DIA. 4" ACTUAL DIA. 4" DRILL RIG \& BIT TYPE DIamec $230 \quad 4^{*}$ Dia. PluS

NOTES:

1. SUBSCRIPT 1 SIGNIFIES BEGINNING OF HOLE \& SUBSCRIPT 2 SIGNIFIES END OF HOLE

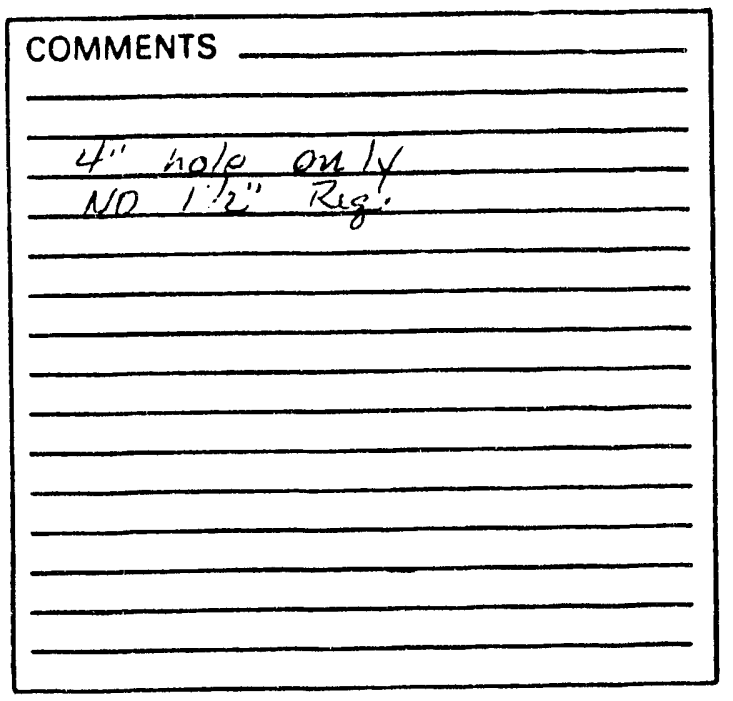




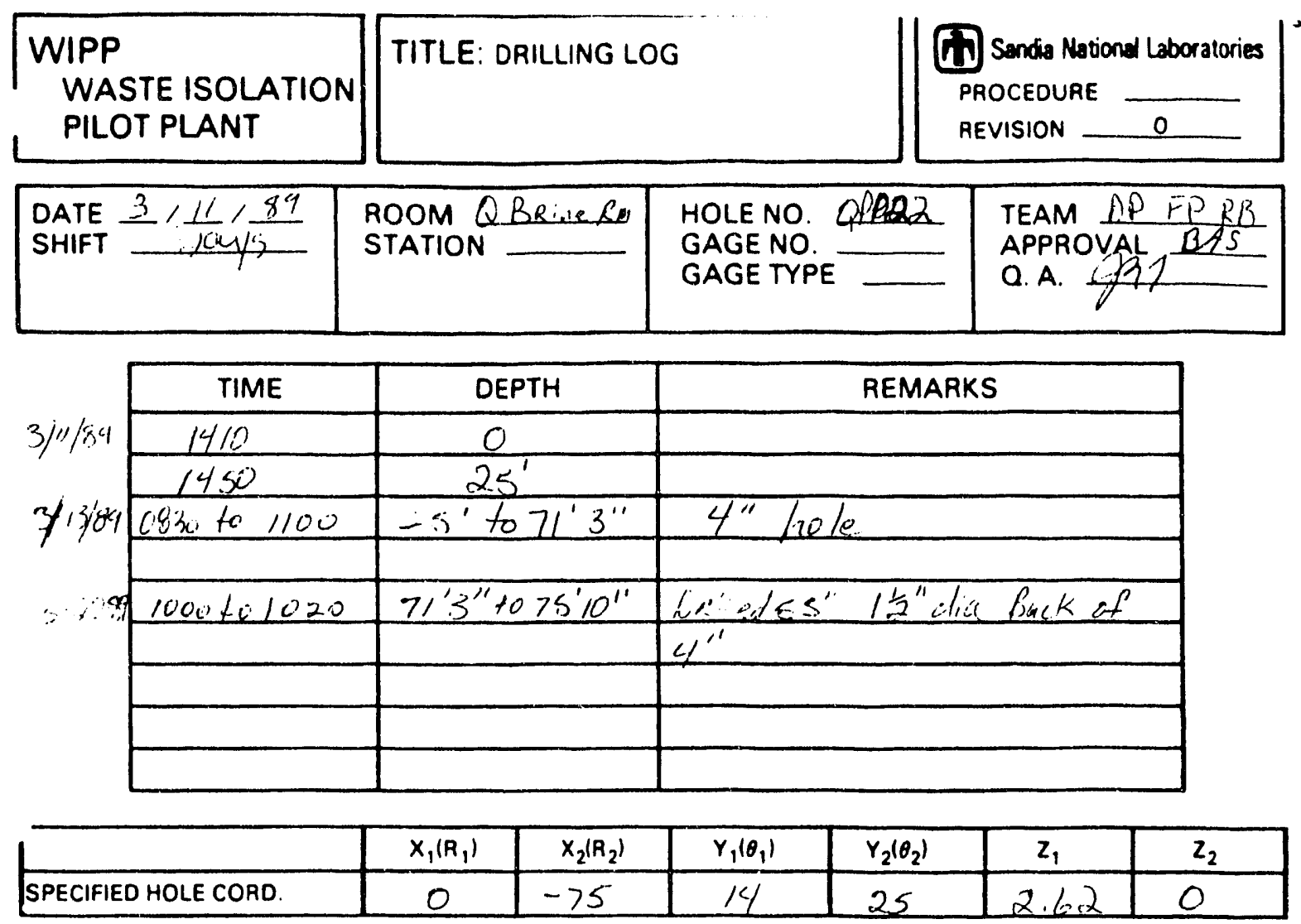

ACTUAL HOLE LENGTH $7510^{\prime \prime}$ SPECIFIED DIA. $\psi^{\prime \prime}$ ACTUAL DIA. $y^{\prime \prime}$

DRILL RIG \& BIT TYPE Diance $2304^{\prime \prime}$ dicipmend pluy
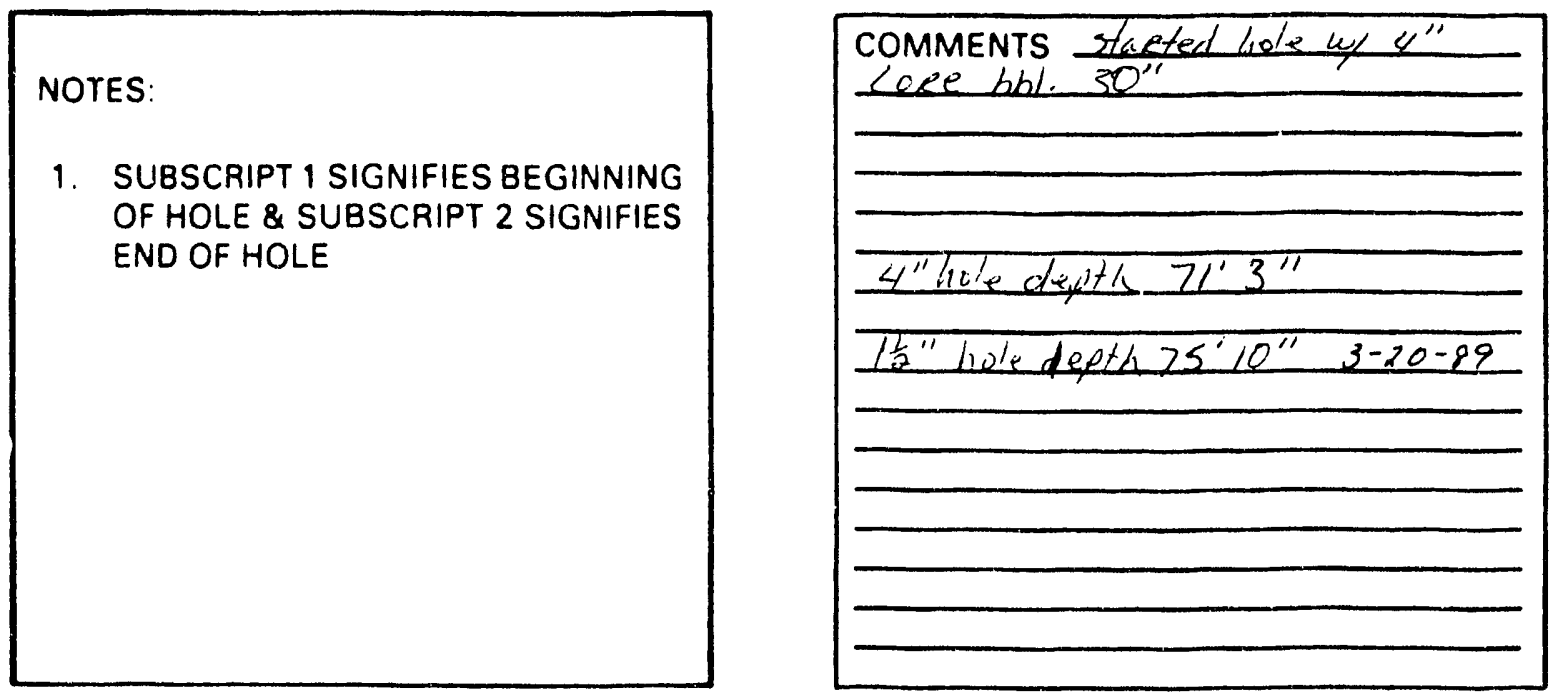


WIPP
WASTE ISOLATION
PILOT PLANT

\begin{tabular}{|l|l|}
\hline DATE $i / \frac{11}{D a 4} 89$ & $\begin{array}{l}\text { ROOM QBRine RM } \\
\text { SHIFT }\end{array}$ \\
\hline
\end{tabular}

TITLE: DRILLING LOG

HOLE NO. QPP23 GAGE NO GAGE TYPE

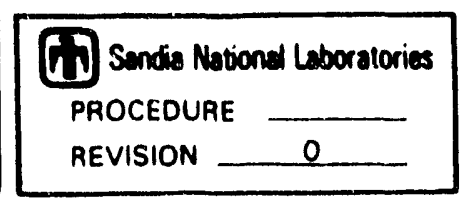

REVISION

\begin{tabular}{|c|c|c|c|}
\hline \multirow{3}{*}{$3 / 11 / 89$} & TIME & DEPTH & REMARKS \\
\hline & $09 \times 5$ & 0 & \\
\hline & 11.45 & $68^{\prime} 8 \frac{1}{4}=$ & \\
\hline \multirow[t]{6}{*}{$3 \cdot 20 \cdot 49$} & 1100 to 1120 & $68^{\prime} 8 \%^{\prime \prime} 4^{\prime \prime}$ to $75^{\prime} 1 \%$ & Irrilled 77" 11/2" D. \\
\hline & & & Lack of 4" hole \\
\hline & & & \\
\hline & & & \\
\hline & & & \\
\hline & & & \\
\hline
\end{tabular}

\begin{tabular}{|l|c|c|c|c|c|c|}
\hline & $x_{1}\left(R_{1}\right)$ & $x_{2}\left(R_{2}\right)$ & $r_{1}\left(\theta_{1}\right)$ & $r_{2}\left(\theta_{2}\right)$ & $z_{1}$ & $z_{2}$ \\
\hline SPECIFIED HOLE CORD. & 0 & -75 & 12 & 15 & 2,62 & 0 \\
\hline
\end{tabular}

ACTUAL HOLE LENGTH $75 / \frac{1}{4}$ " SPECIFIED DIA. $4^{\prime \prime}$ ACTUAL DIA. $4^{\prime \prime}$

DRILL RIG \& BIT TYPE Dianee 230 4" Diamond fluy
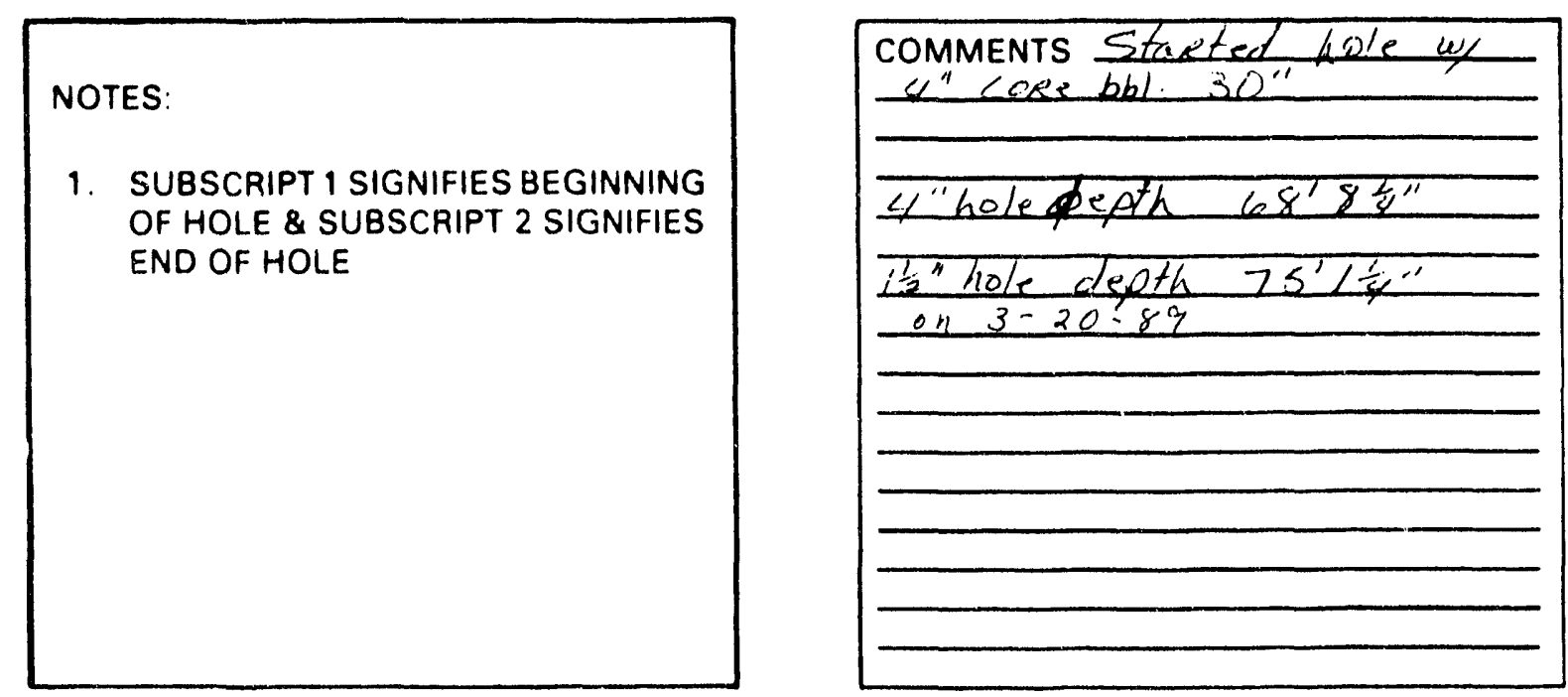


WIPP
WASTE ISOLATION
PILOT PLANT

\begin{tabular}{|l|l|}
\hline DATE $\frac{3 / 10 / 89}{\text { SHIFT }}$ & $\begin{array}{l}\text { ROOM Q Reine Ray } \\
\text { STATION }\end{array}$ \\
\end{tabular}

TITLE: DRILLING LOG

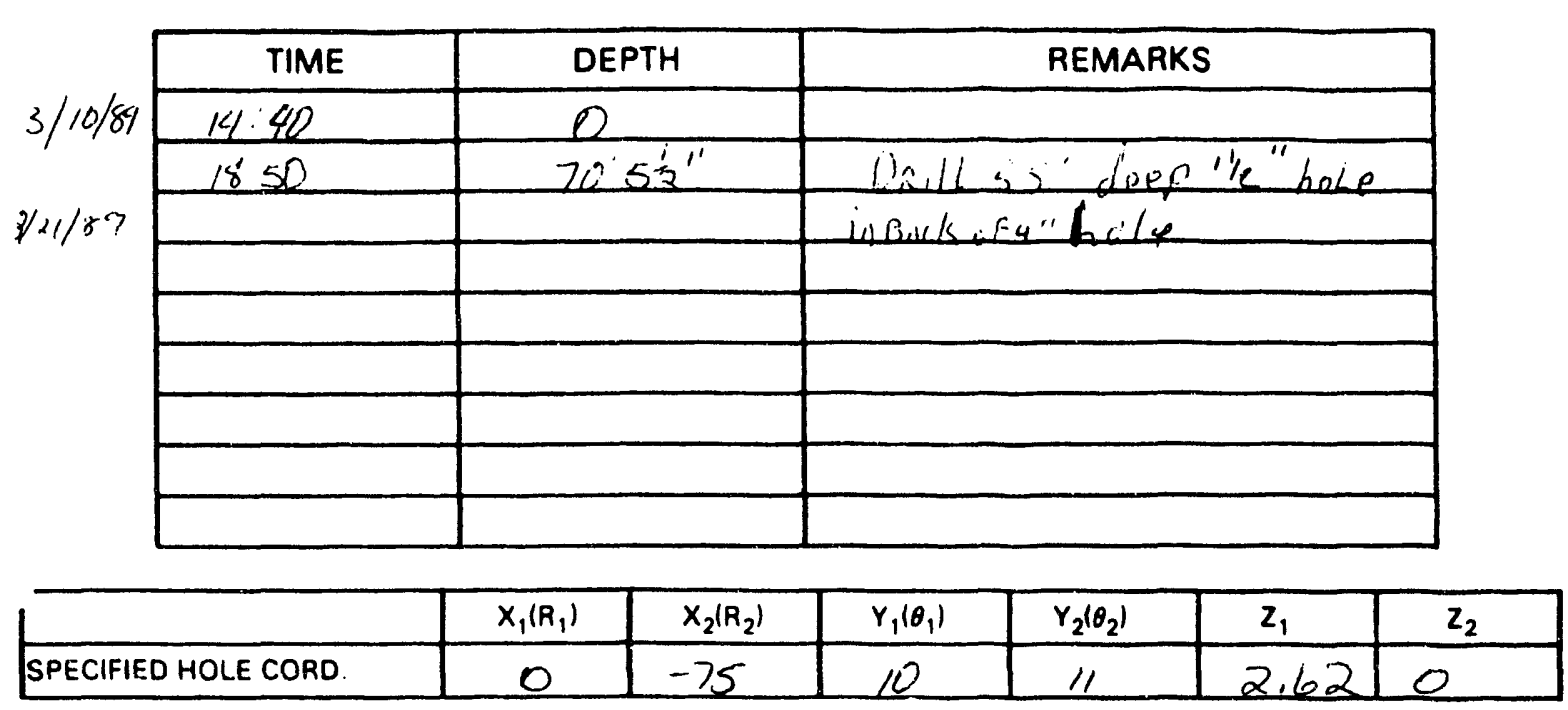

ACTUAL HOLE LENGTH $75^{\prime} \frac{1}{2}$. SPECIFIED DIA. $4^{\prime \prime}$ ACTUAL DIA. $4^{\prime \prime}$

DRILL RIG \& BIT TYPE Diamec 230 - 4" Diamend Aluy

\section{NOTES:}

1. SUBSCRIPT 1 SIGNIFIES BEGINNING OF HOLE \& SUBSCRIPT 2 SIGNIFIES END OF HOLE
HOLENO. QPP24 TEAM DLSLRL GAGENO GAGE TYPE APPROVAL BAS
PROCEDURE

REVISION

Q. A. 


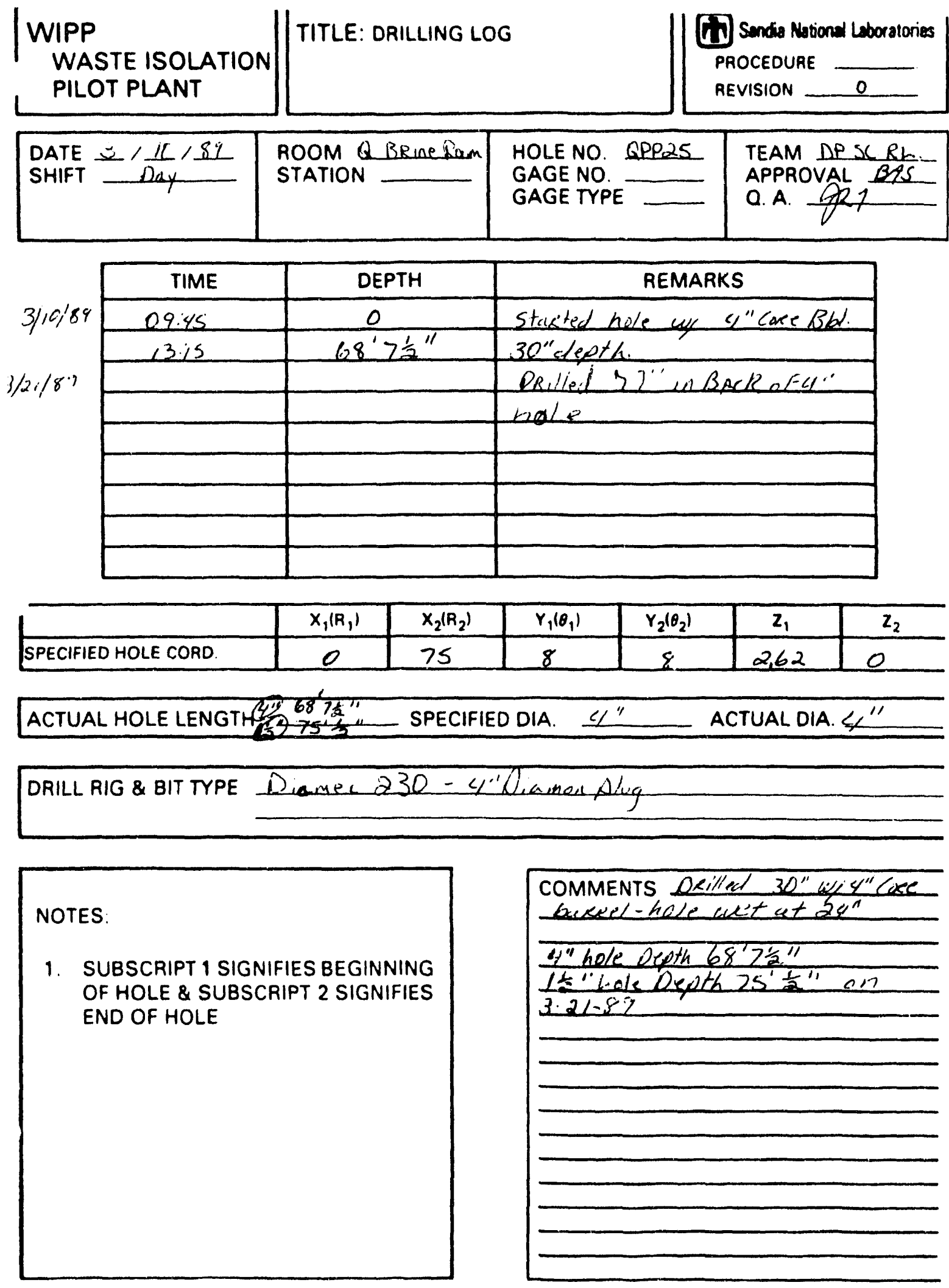



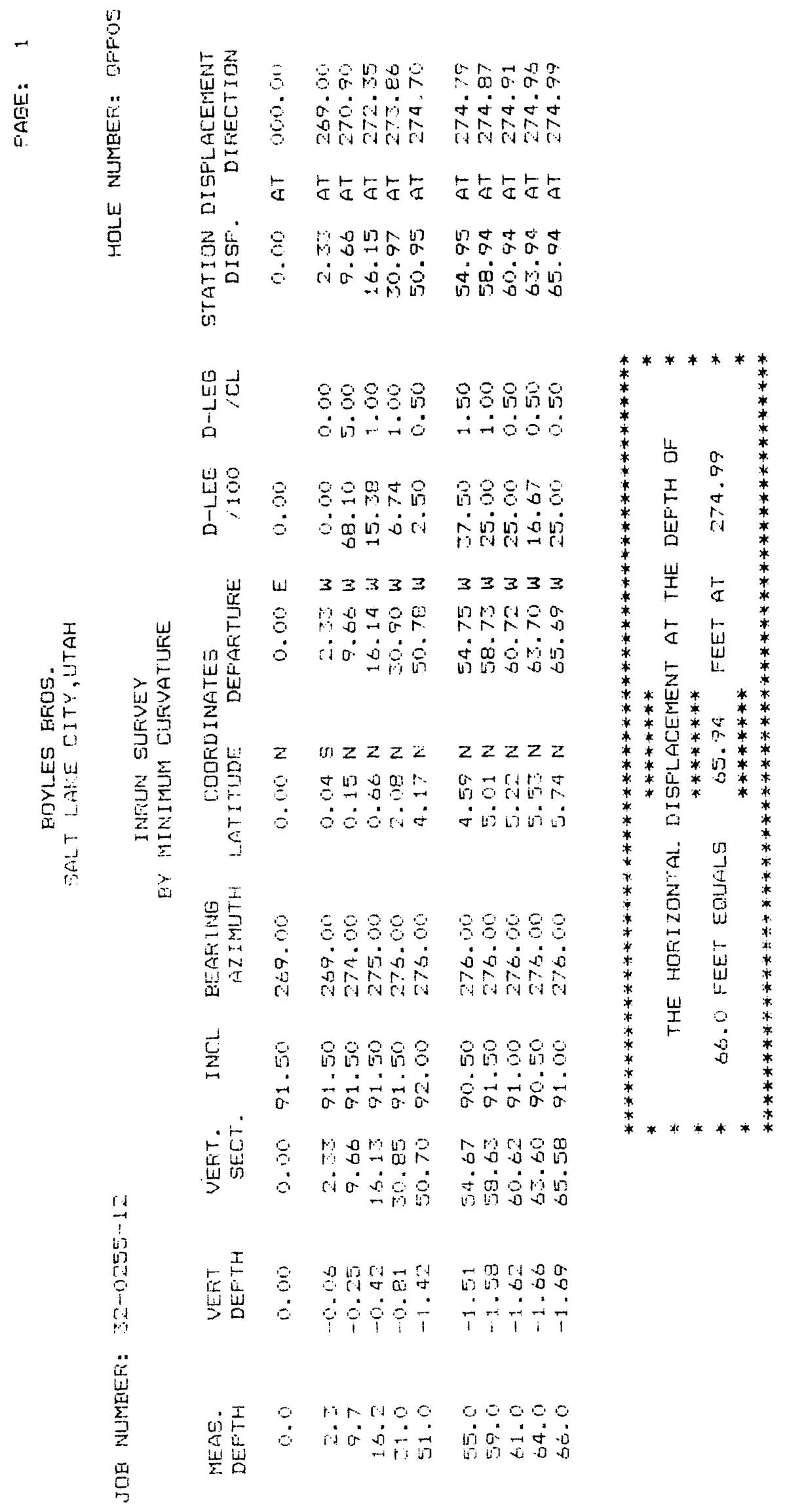


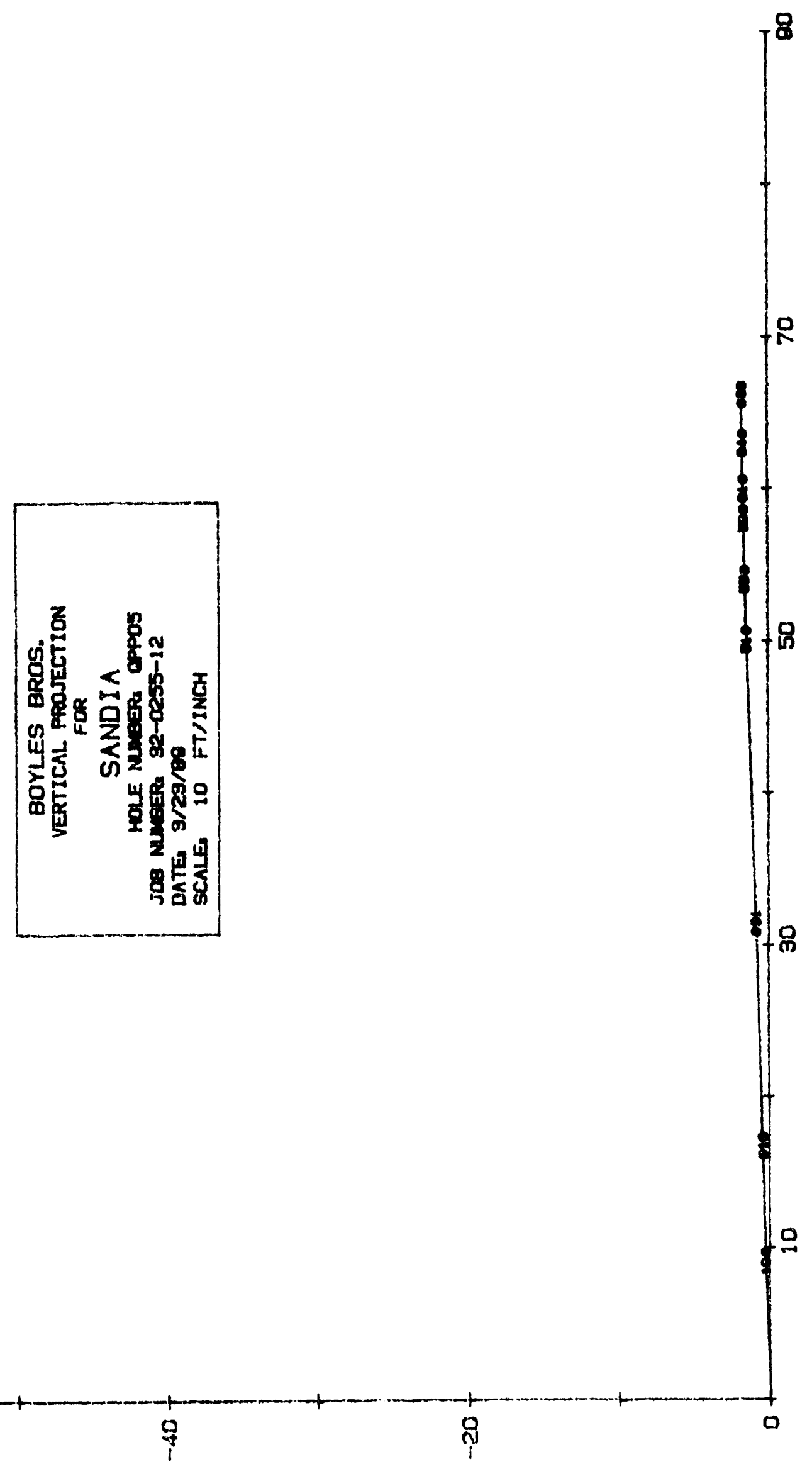

B - 26 


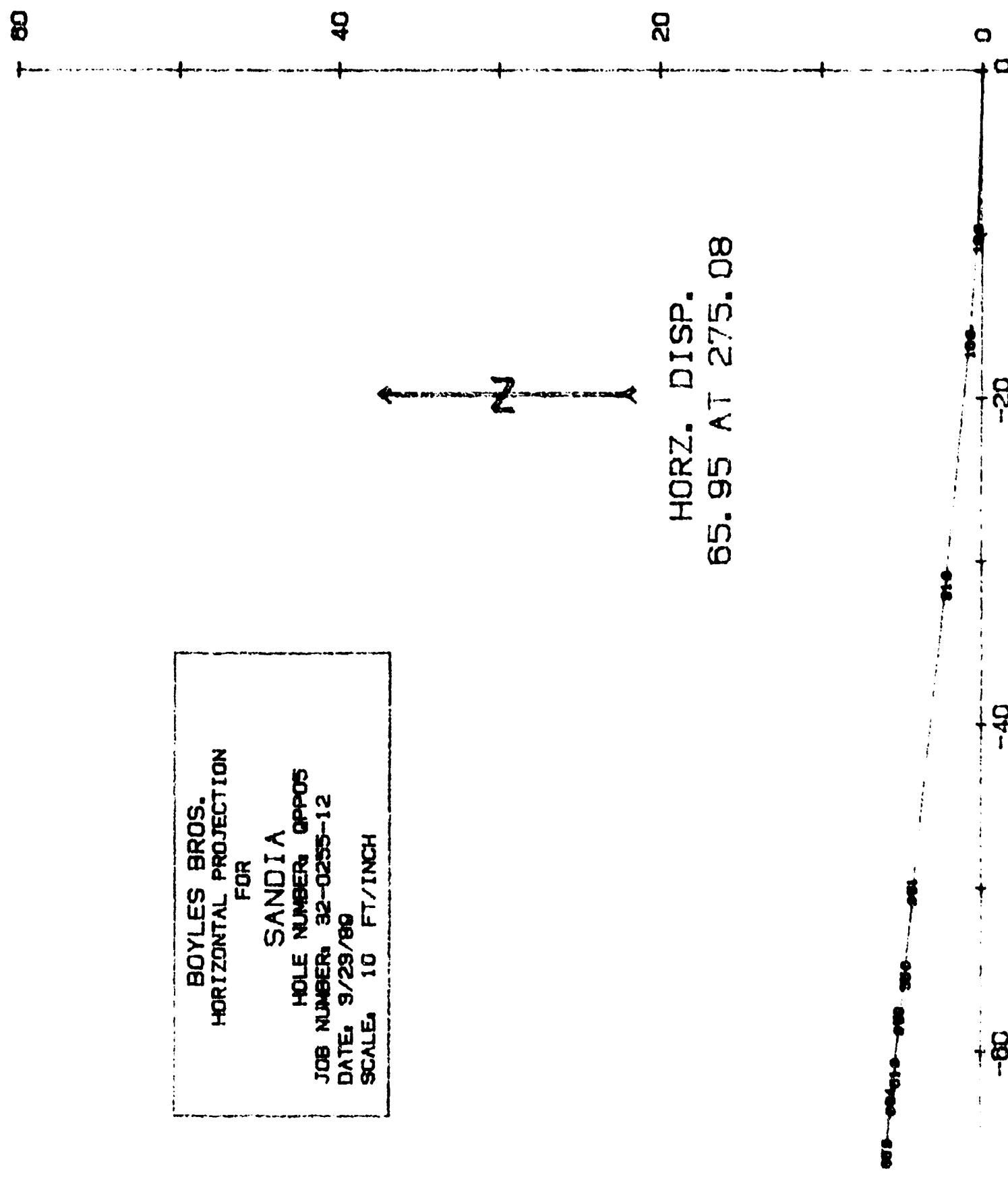

+
+9
+9 

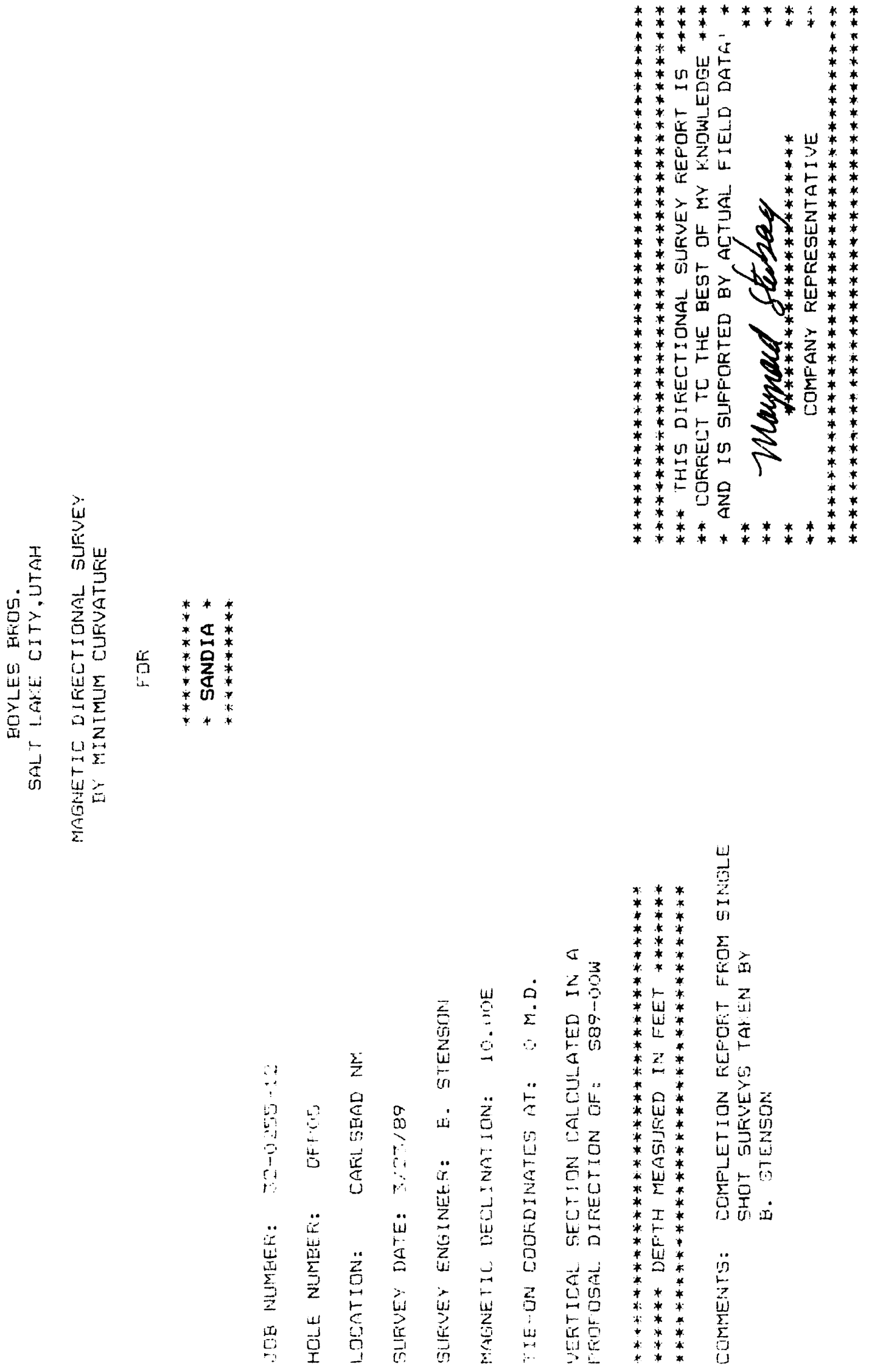

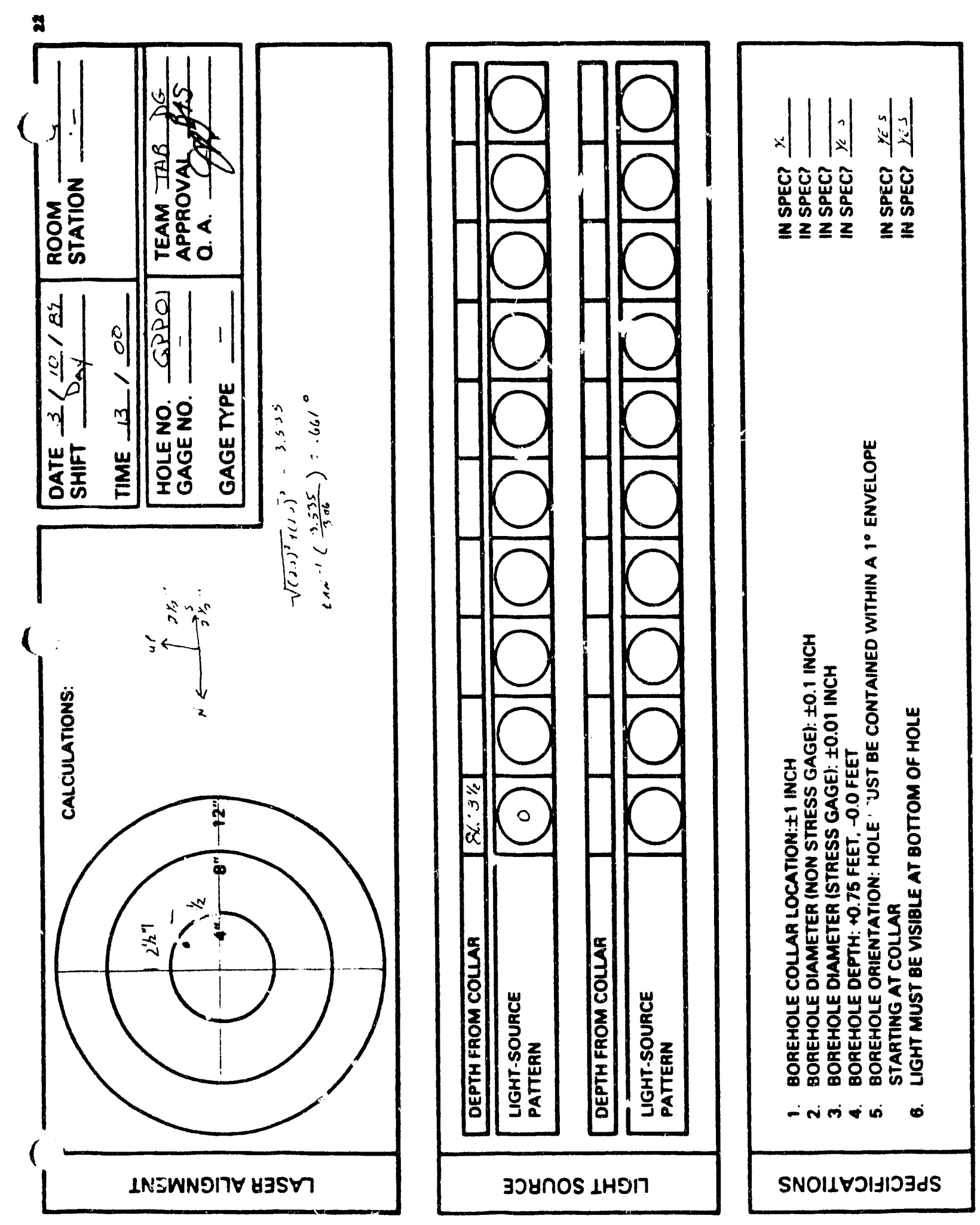

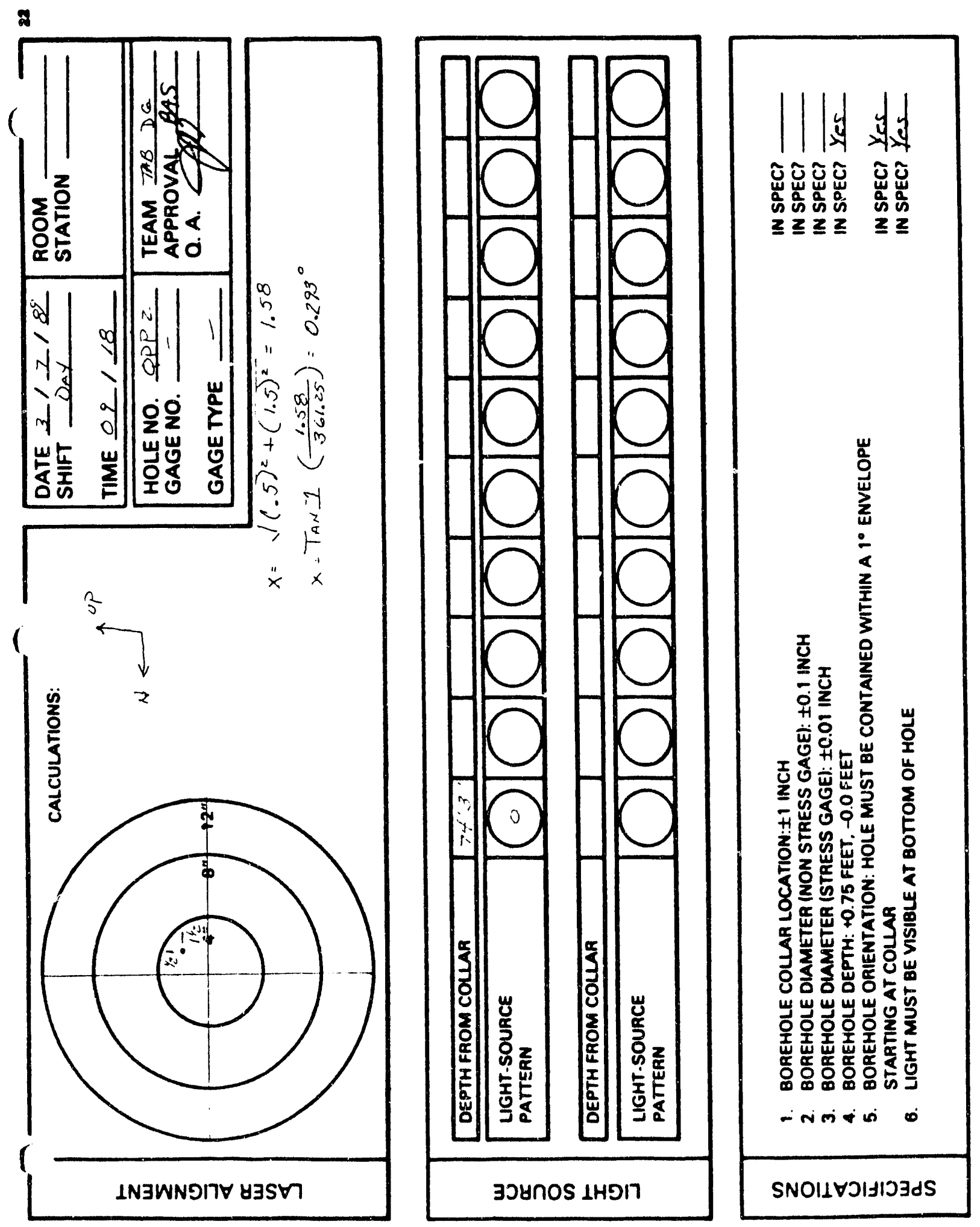

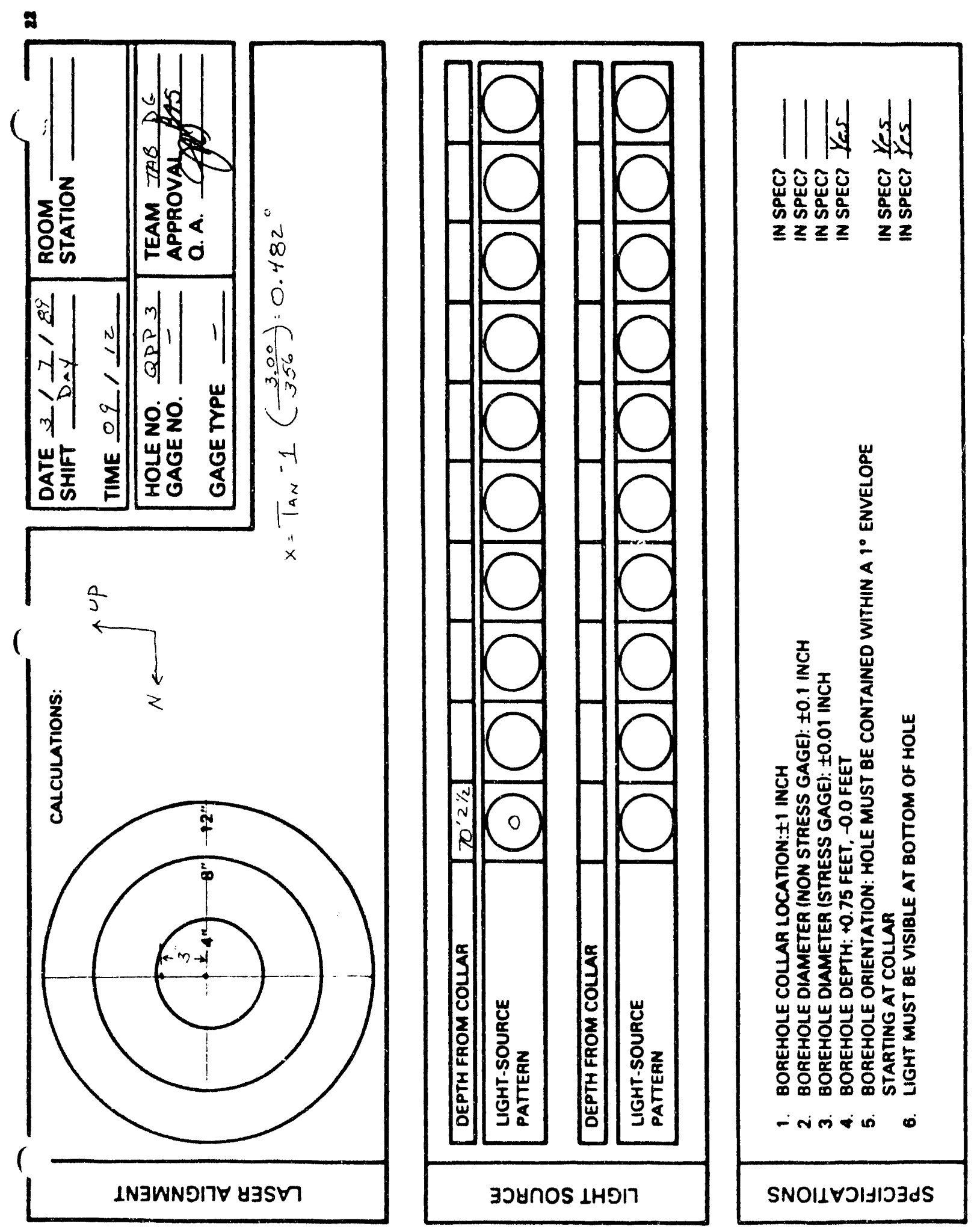

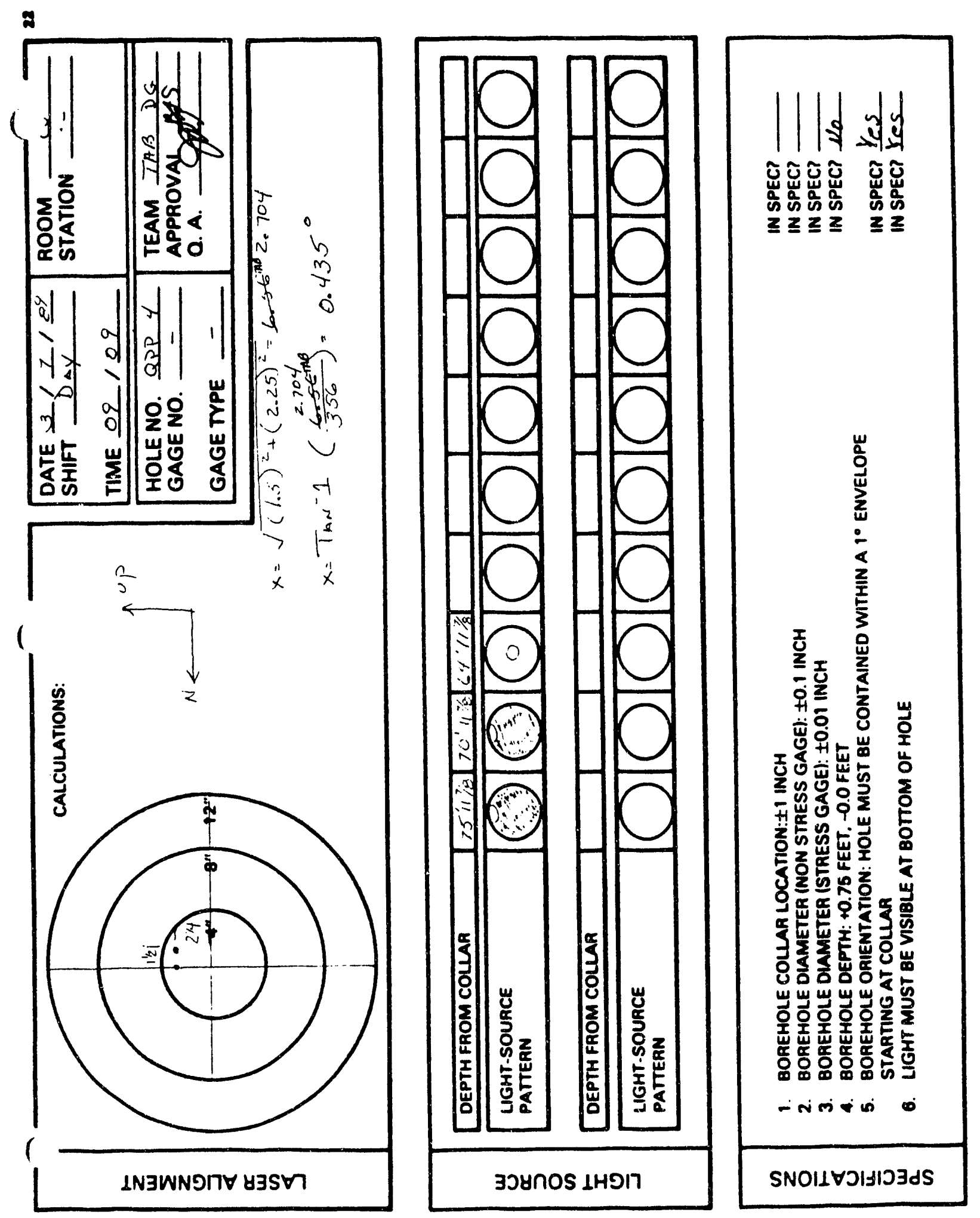

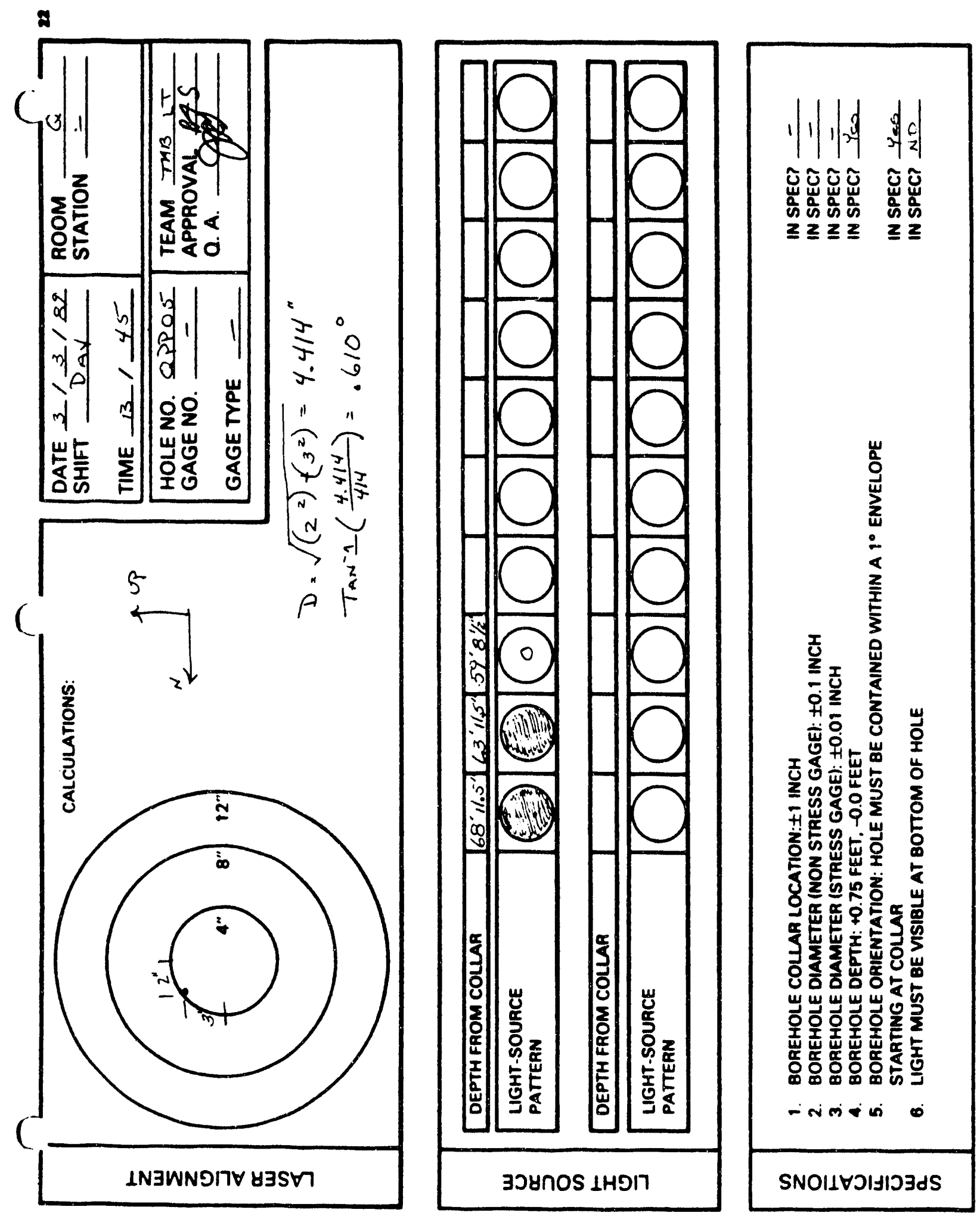

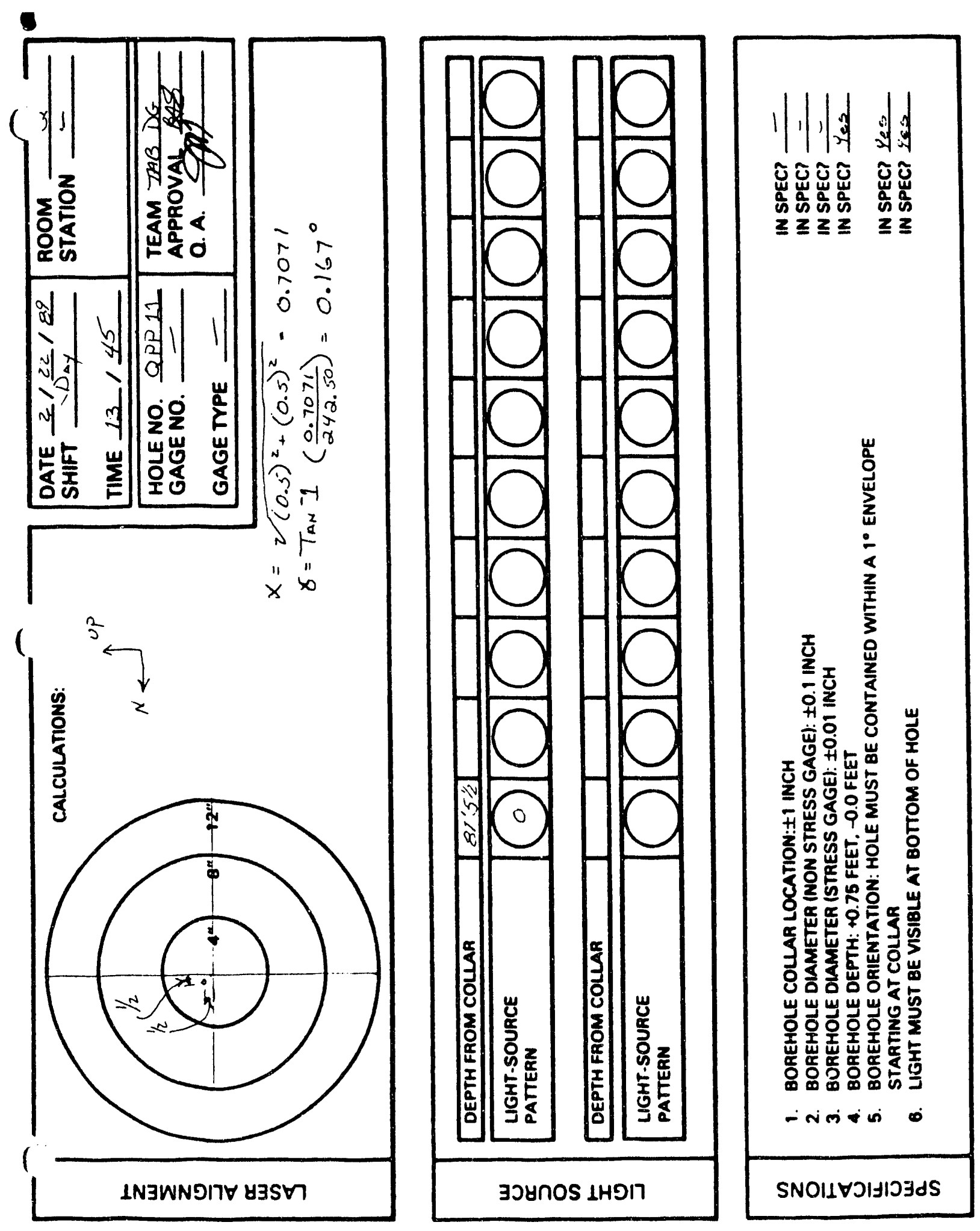

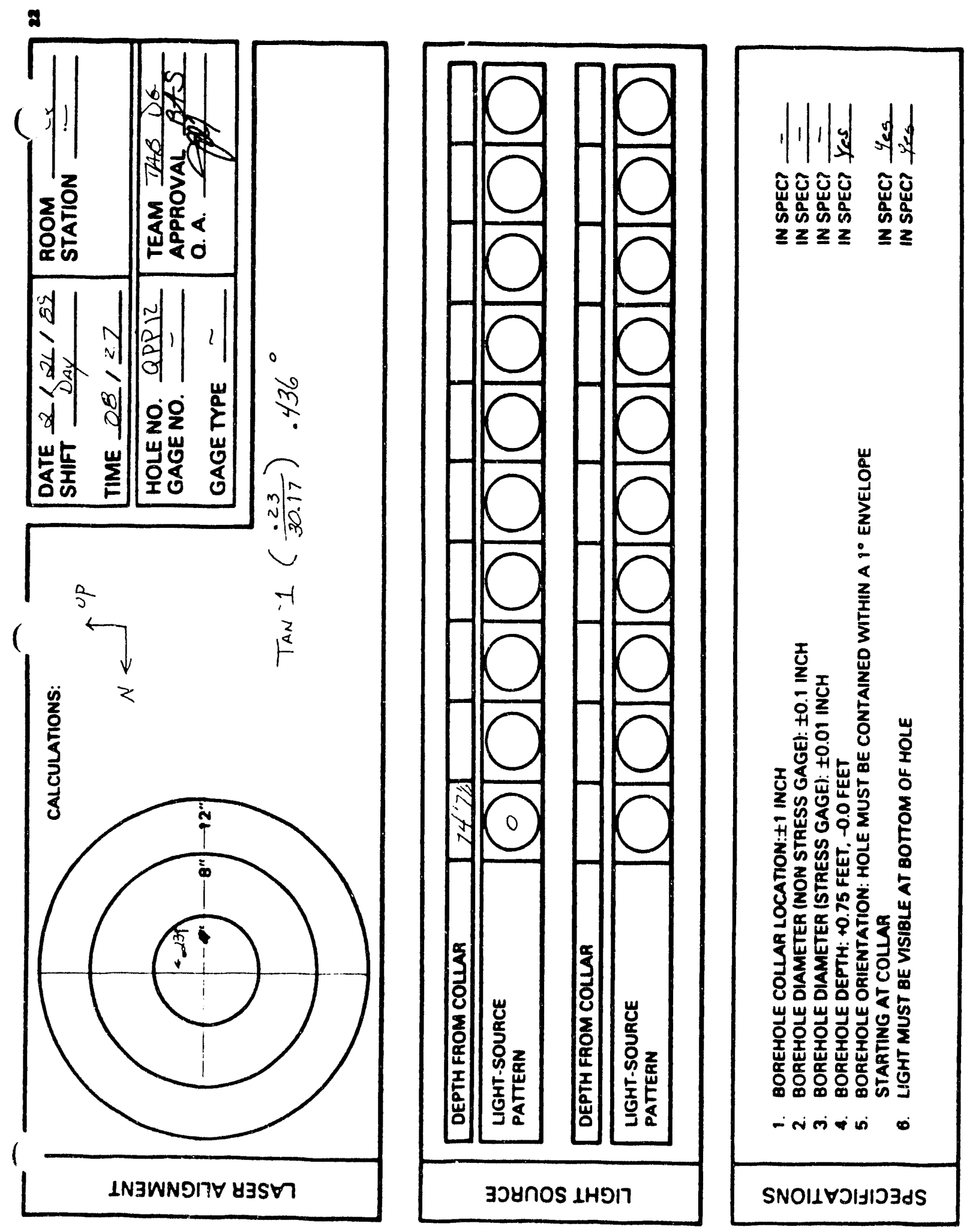

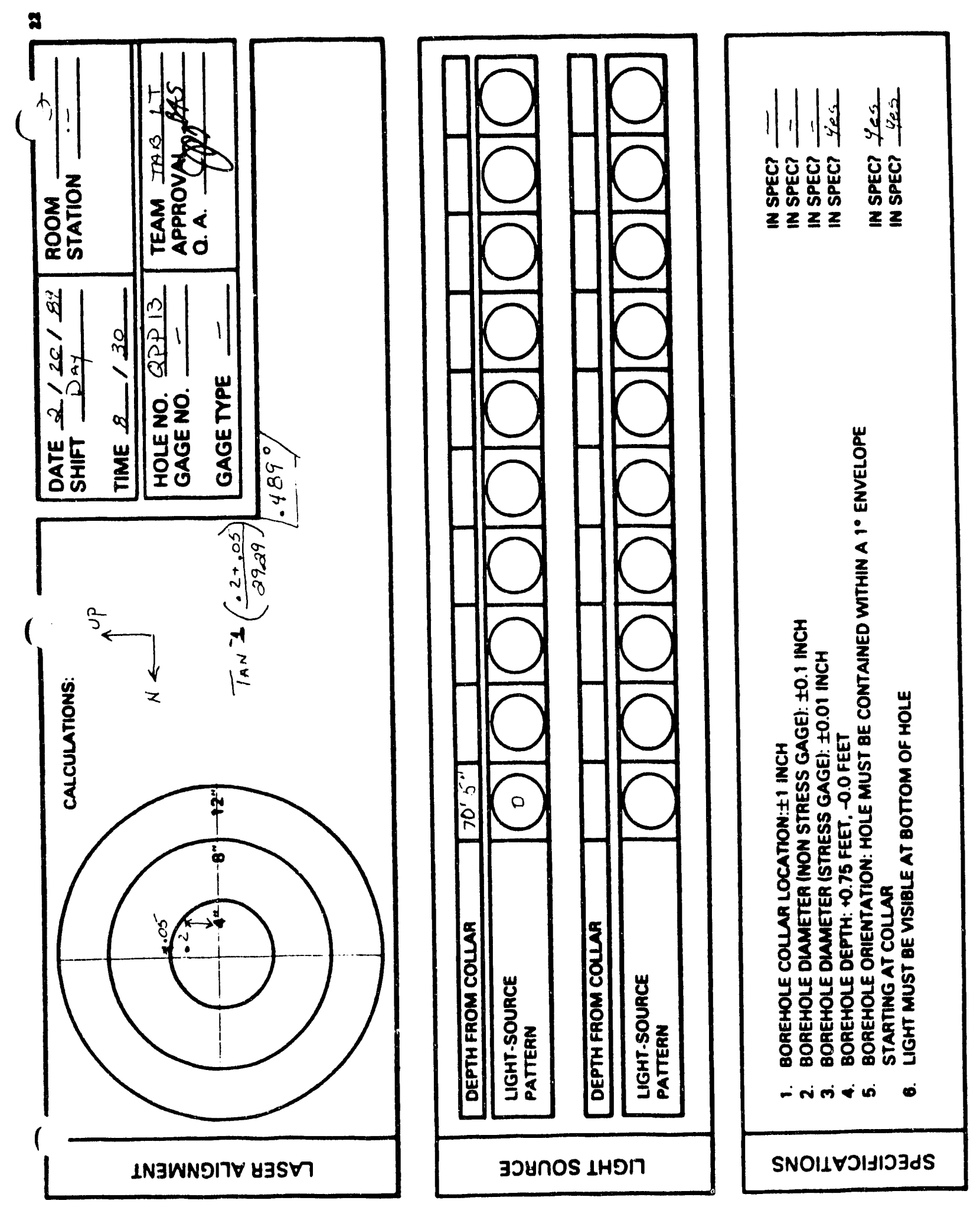

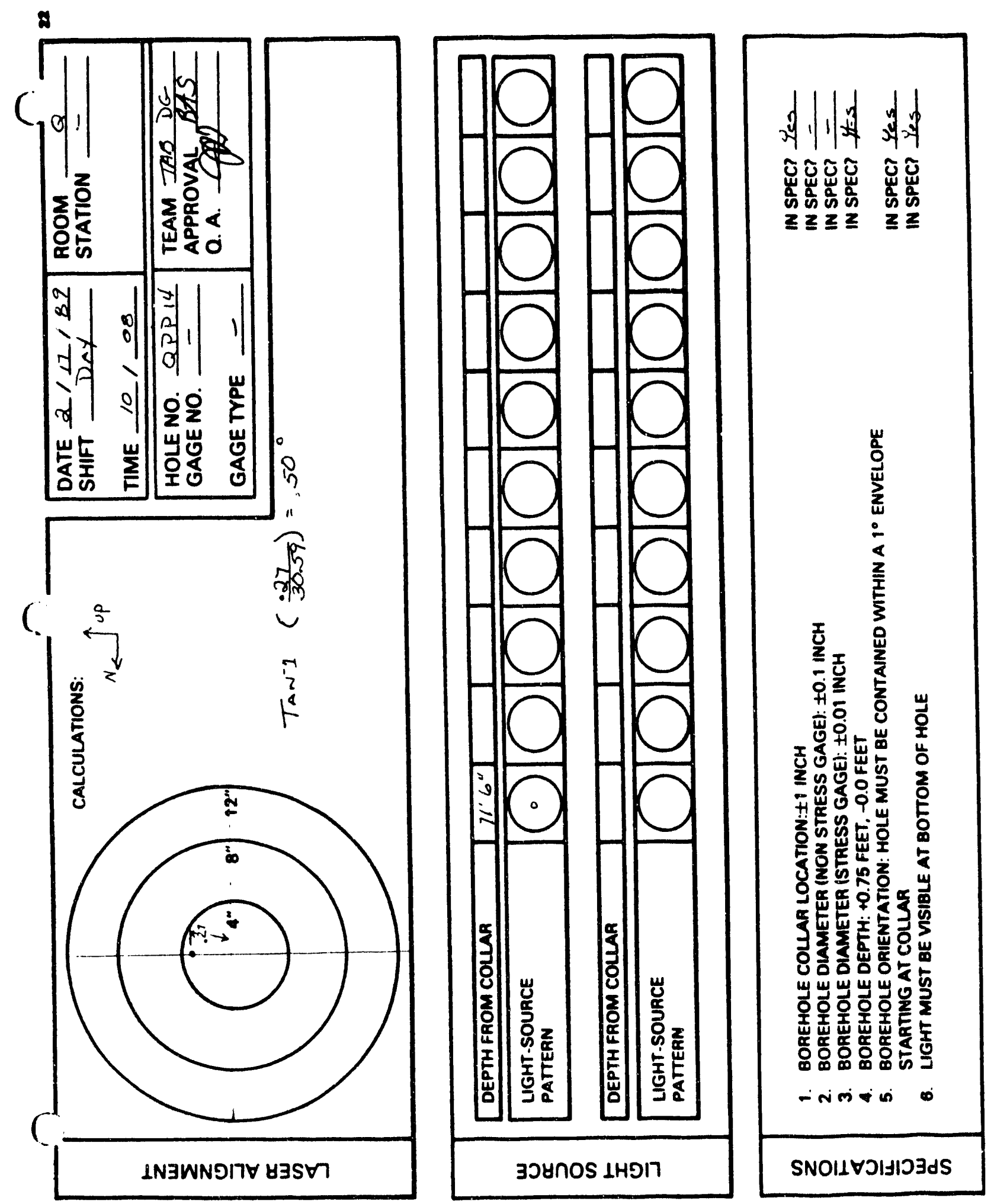

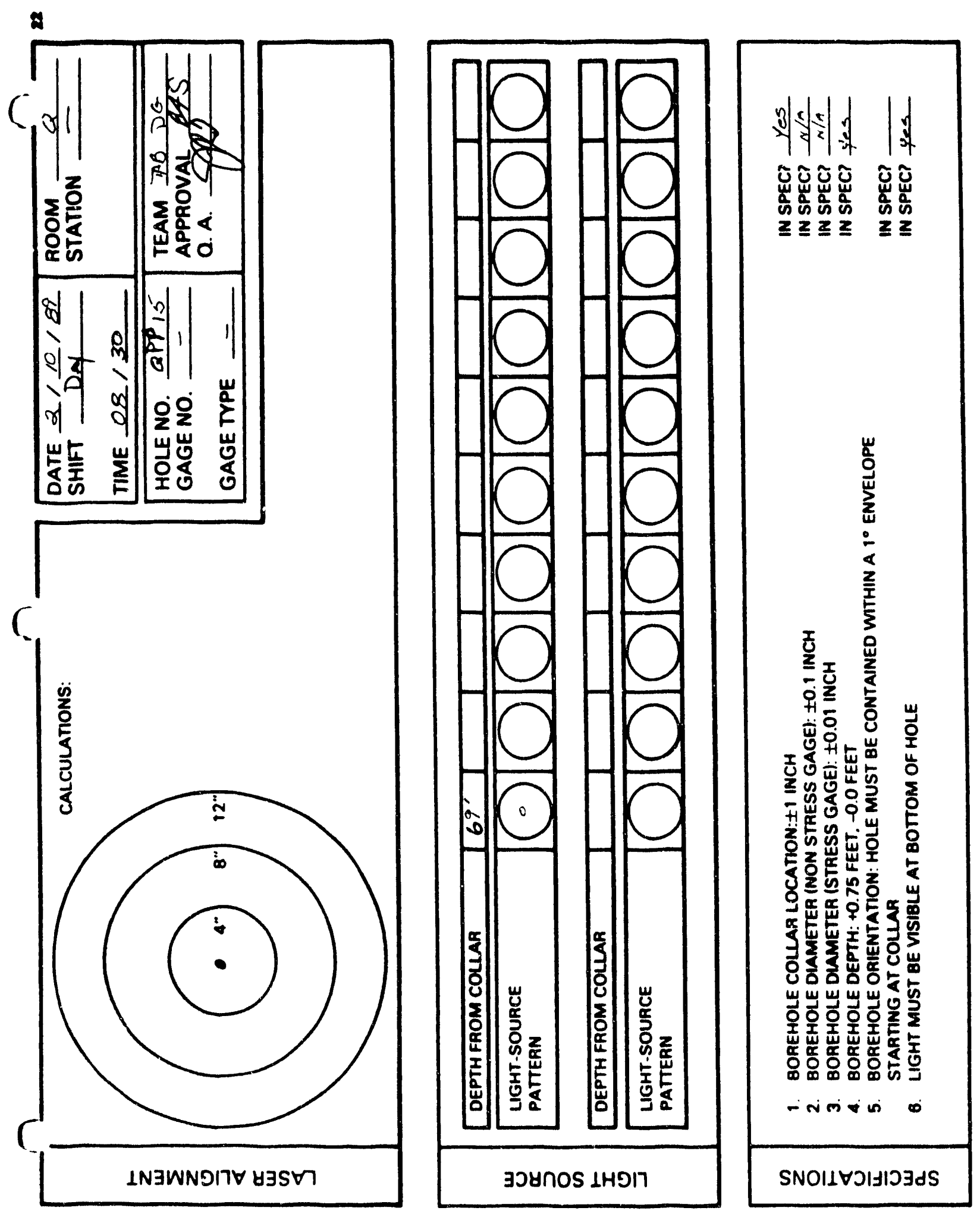

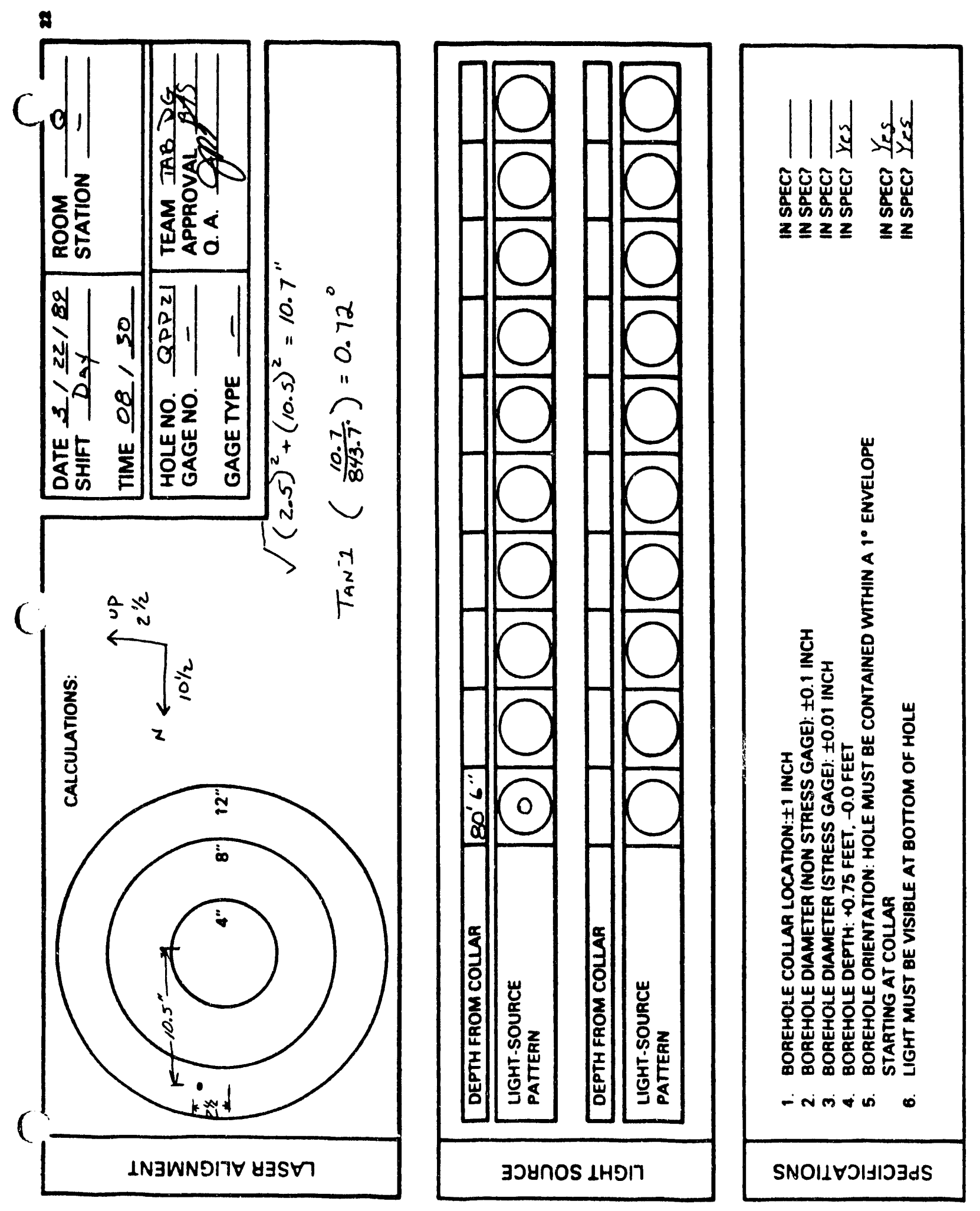

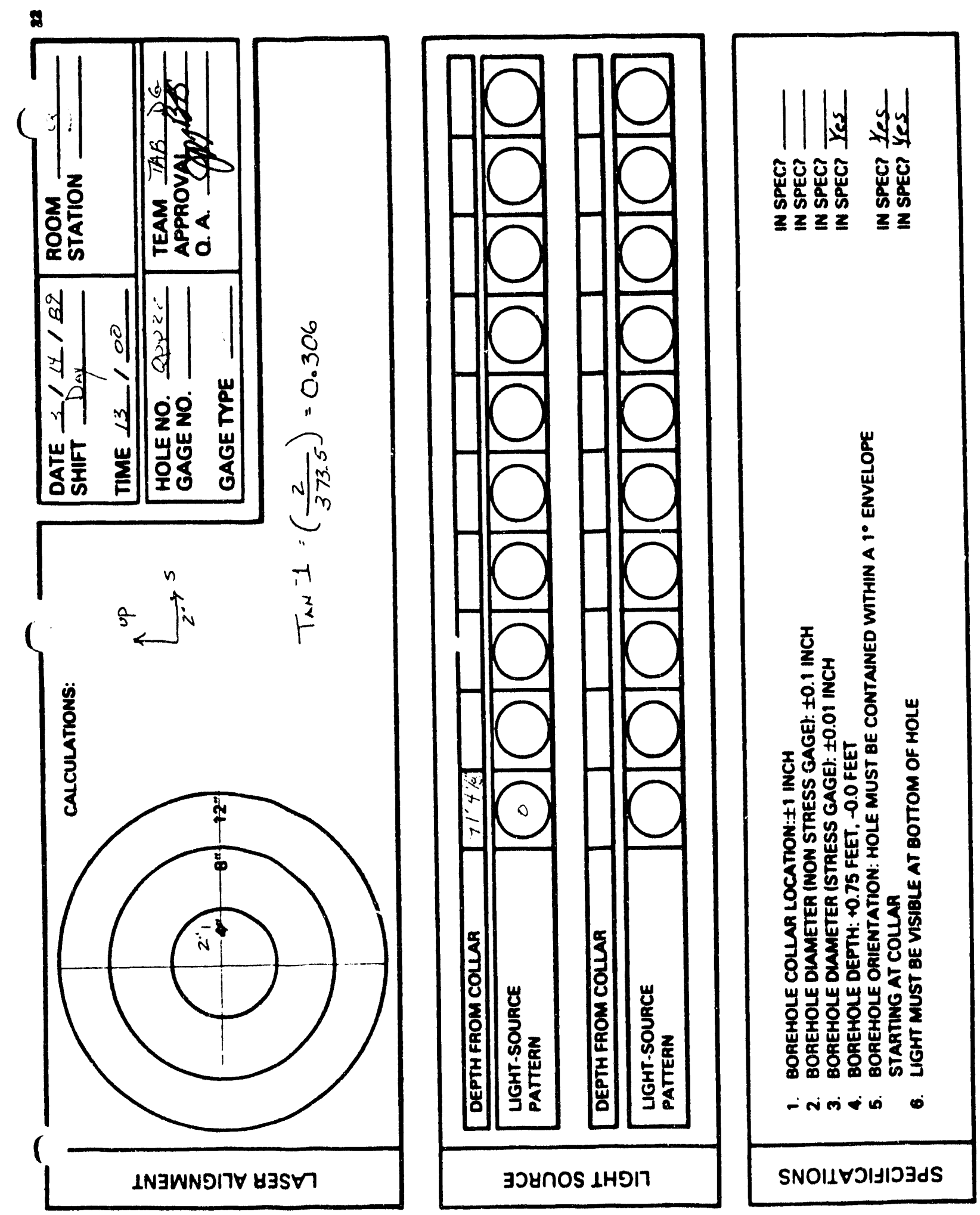

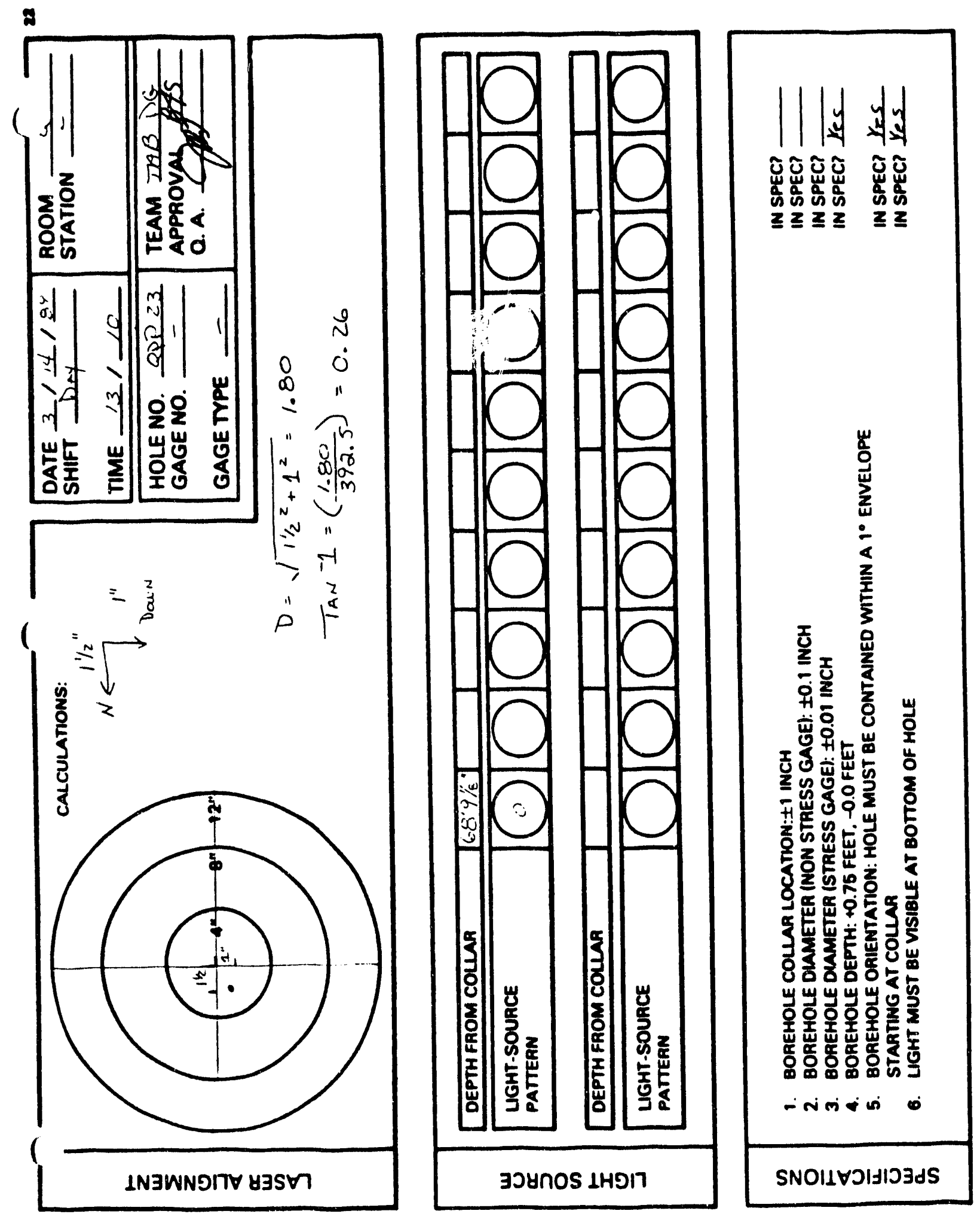

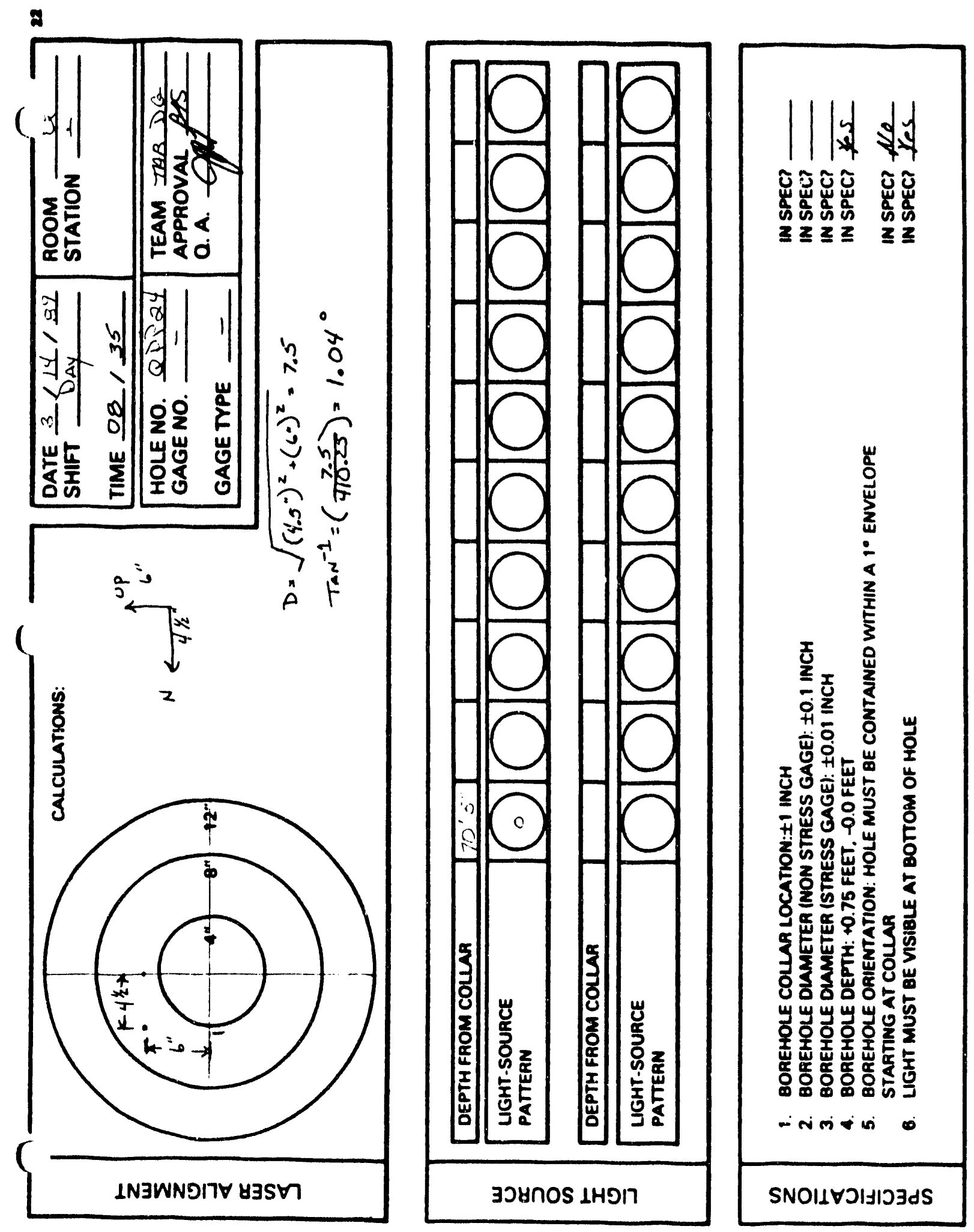

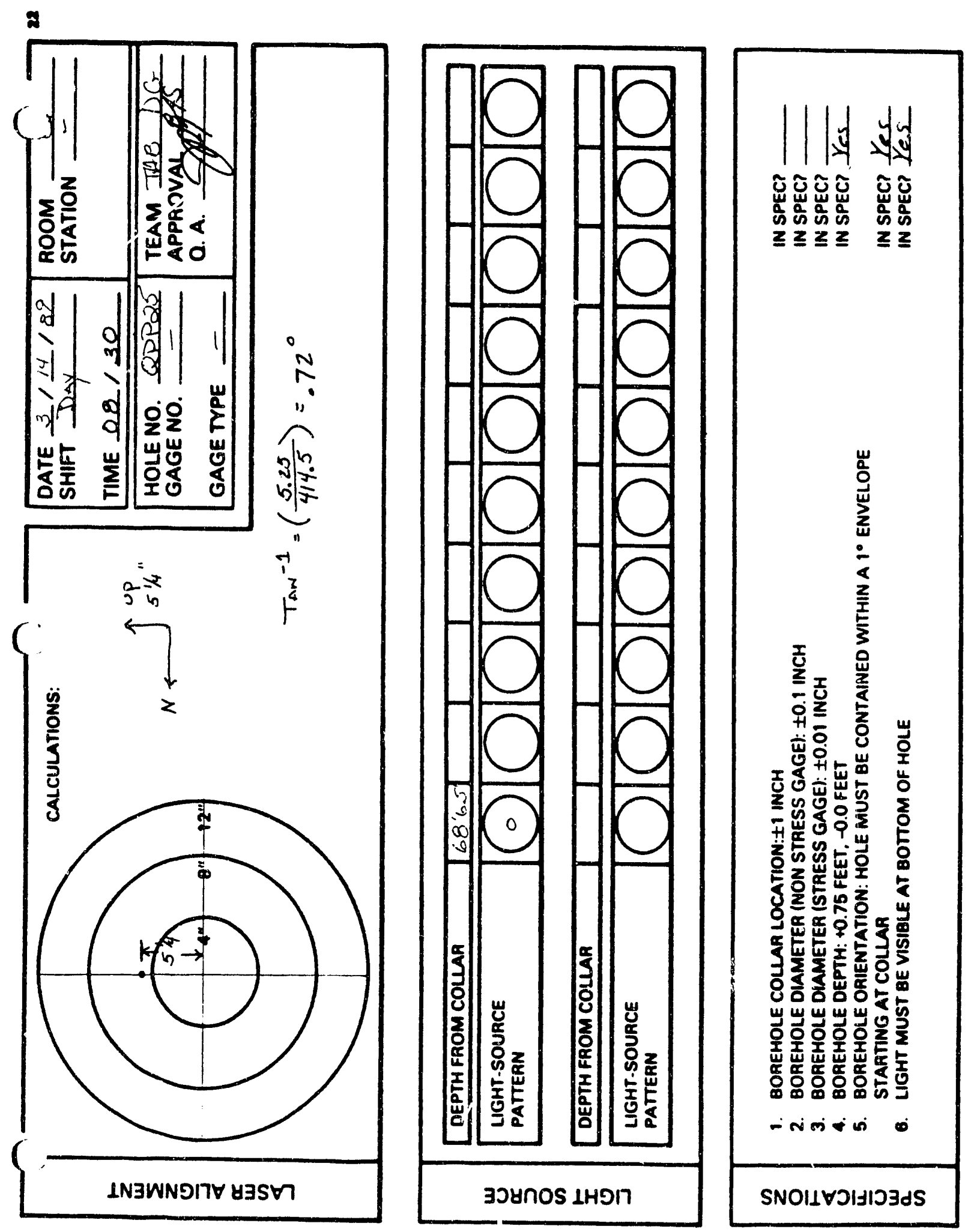
APPENDIX C: TEST OPERATIONAL LOGS

C- 1 
C- 2 


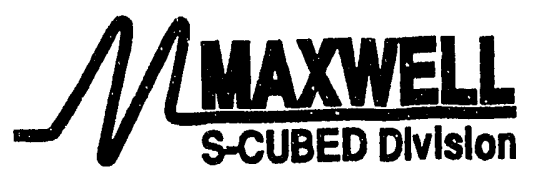

SSS-DPR-91-12902/R1

\section{OPERATIONAL LOG \\ Room $Q$ Boreholes \\ QPP01-05, 11-15, 21-25}

T. Barker

F. Howard

E. Peterson

Maxwell Laboratories, Inc.

S-Cubed Division

P.O. Box 1620

La Jolla, CA 92038-1620

Revised: January 1992

Contract No. 66-2646

Prepared for

Sandia National Laboratories

Albuquerque, New Mexico 
January 30, 1992

Mr. L. Jensen

Sandia National Laboratories

Organization No. 6344

P.O. Box 5800

Albuquerque, NM 87185

Dear Lee:

Two complete sets of floppy discs that contain the Room $Q$ borehole data collected between April 25, 1989, and October 22, 1991 are enclosed. Data on these sets of discs are referred to either as "usable" or "all".

Data on the set of discs referred to as "usable" are windowed in that extraneous information has been removed. Deleted information include data collected during the time a system may have been removed from the borehole, brine accumulation data obtained during a shut-in test, closure values obtained during the period when the power supplies were not working properly, etc. These extraneous data are obtained because the data acquisition system continuously monitors all data channels. The windowed data were generated at the request of the SNL Delegated Representative acting at the time the data set was prepared. Operational activities that affect these Room $Q$ data are described in the S-Cubed document SSS-DPR-91. 12902R1. Plots showing the data included on these discs are provided in document SSS-DPR-91-12094R1. This set of information was previously transferred to Sandia in November 1991.

The set of discs referred to as "all" represent a complete set of raw data. Again, operational activities that affect these data are described in document SSS-DPR-91-1290R1. Plots showing the data included on this second set of discs are provided in document SSS-DPR-92-13051. Please note that when the Room $Q$ data are taken, on approximate weekly intervals, from the hard 


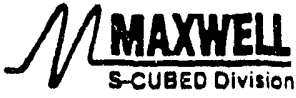

disc on the computer located in the Room $Q$ alcove, two floppy discs are made. One disc, written to an ASCII file, is retained by SNL and one is sent to SCubed. Data included on the set of floppy discs labeled "all", generated in response 10 the request of the SNL Delegated Representative at the November 14, 1991 meeting with S-Cubed, are identical to the data contained on the set of discs retained by SNL.

Data on the 84 floppy discs include the test zone pressure (tzp), test zone packer pressure (tpp), brine accumulation (bin), on-axis closure (oac), crossaxis closure (cac), guard zone pressure (gzp), and guard zone packer pressure (gpp). As requested, the format on the discs is the same as for the previously transmitted sets. For each sample (logical record), the time in days, the calendar date, the time of day, and the measured parameter are written. The pressure is given in $\mathrm{MPa}$, brine accumulation in cubic centimeters, and borehole diameter change (e.g. closure) in centimeters. The file names have the form QPPxx.var, where QPPxx denotes the Room $Q$ hole identifier, and "var" is one of the previously identified variables. Note that the on-axis and cross-axis gauges are oriented in the vertical and horizontal directions respectively.

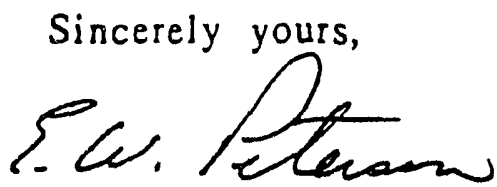

E. W. Peterson

Enclosures: 1.) Windowed Data (Includes 42 floppy discs labeled "usable").

2.) Raw Data (Includes 42 floppy discs labeled "all").

3.) Document SSS-DPR-91-12902R1 titled "Operational Log, Room Q Boreholes QPP01-05, 11-15, 21-25".

4.) Document SSS-DPR-91-12904R1 titled "Summary of Room Q Windowed Data".

5.) Document SSS-DPR-92-13051 titled "Summary of Room Q Raw Data". 


\section{INTRODUCTION}

Operational activities, conducted between April 25, 1989 and October 22, 1991, that affect the Room $Q$ borehole data contained on the floppy disks sent to SNL, are described in this document. Plots of these data are provided in SCubed document SSS-DPR-91-12904/R1 and

Abbreviations found in this document refer to the

- test region pressure (TZP), and

- brine accumulation data (BIN),

- guard region pressure (GZP),

- test region packer pressure (TPP),

- guard region packer pressure (GPP),

- cross-axis closure data (CAC), and

- on-axis closure data (OAC).

This document provides a $\log$ of those activities that produce observable changes in data. For example, these changes result from procedures such as:

- changing a packer pressure,

- the replacement of a power supply,

- the removal of a system from the borehole,

- the termination of a slow test and initiation of a shut-in test.

Note that the data acquisition system continuously monitors all data channels. As a result, the raw data current contained on disks retained by SNL QA include extraneous information such as data collected during the time a system may have been removed from the borehole, brine accumulation data collected during a shut-in test, closure data obtained during the period when the power supplies were not working properly, etc. 


\section{TEST HISTORY FOR ALL BOREHOLES}




\title{
TEST HISTORY FOR ALL BOREHOLES
}

\author{
DAYS \\ SINCE \\ DATE(s) 4/25/89 \\ 4/25/89-5/6/89 $\quad 0-11 \quad$ Tests are initiated. \\ 5/31/89 $36 \quad$ Pulse test. Test regions shut-in after test region \\ pressure reset to $\sim 5.6 \mathrm{MPa}$. \\ 7/12/89-8/8/89 78-105 Mined Room Q. \\ - Boreholes QPP01, 02, 11, 12, 21, and 22 test \\ regions remain shut-in. \\ - The QPP03, 04, 05, 13, 14, 15, 23, 24, and 25 test \\ and guard regions were connected to common \\ flow manifolds in order to prevent the \\ downhole pressures from approaching \\ potential hydrofracture values during the \\ excavation process. These data were not \\ intended to be used for analyses. \\ - After the excavation, these test regions were \\ shut-in. \\ - All brine inflow systems for $13 / 8^{\prime \prime}$ tools were \\ replaced. \\ 2/21/90-7/18/90 302-449 Flow tests initiated on boreholes QPP01, 02, 03, 05, \\ $11,12,13,15,21,22,23$, and 25. QPP04, 14, and 24 \\ test regions remain shut-in. All guard regions \\ shut-in. \\ 7/17/90 All test and guard regions shut-in.
}

\section{GENERAL PARAGRAPHS}

QPP01, 11, 21 - Use mechanical closure gauges with 19" platens that contact borehole wali.

QPP02, 03, 04, 05, 12, 13, 14, 15, 22, 23, 24, 25 - Use hydraulic closure gauges with $5 / 16$ "diameter pins that contact the borehole wall. 
Changes in test region pressures will induce changes in packer pressures and also result in offsets on borehole diameter measurements. A change in packer pressure may also result in a smaller change in the test region or guard region pressures. Closure data represent changes in borehole diameter, not absolute values.

We have indicated in this log offsets which are the result of maintenance procedures (such as changes in packer pressure) or in experimental status (flowing or shutin). 


\section{INDIVIDUAL BOREHOLE TEST HISTORIES}




\section{TZP}

$5 / 31 / 89$

$2 / 21 / 90$

302

370

406

$6 / 5 / 90$

$7 / 14 / 90$

448

BIN

$5 / 4 / 90$

$6 / 4 / 90$

$7 / 14 / 90$

448

TPP

$7 / 24 / 89$

90

$9 / 27 / 89$

155

GZP

$5 / 1 / 89$

$5 / 27 / 89-6 / 20 / 89$

$32-56$

56

$2 / 21 / 90$
405

374

Pulse test conducted.

Flow test initiated.

Brine accumulator drained.

Brine accumulator drained.

All test and guard regions shut-in.

Brine accumulator drained (it was overfilled prior to draining).

Brine accumulator drained.

All test and guard regions shut-in; flow meter valve closed.

Test region packer increased.

Test region packer increased.

Tests initiated by shu'ting-in guard region.

Data gap - data channels in use for flow meter calibration.

Guard region open to brine flow system.

All guard regions shut-in. 
$5 / 1 / 90$

371

$7 / 17 / 90$

$10 / 27 / 90$

448

560

GPP

$7 / 9 / 90$

$10 / 27 / 90$

560

$6 / 25 / 91$

791

302

370

448

\section{OAC and CAC}

$2 / 21 / 90$

$4 / 30 / 90$

$7 / 9 / 90$
448
Brine accumulator drained, guard region pressure reset at 93.4 psi.

Guard region packer increased.

Guard region packer increased.

Guard region packer increased.

Guard region packer increased.

Guard region packer pressure increased due to decrease in guard region pressure starting near day $720(4 / 15 / 91)$. 


\section{QPP02}

TZP

$\begin{array}{lcl}\text { 4/25/89-5/6/89 } & 0-11 & \text { Test initiated by shutting in test region. } \\ 5 / 7 / 89-5 / 9 / 89 & 12-14 & \text { Test region pressure reset. } \\ 5 / 19 / 89 & 24 & \text { Test region checked for trapped air and shut-in. } \\ 5 / 31 / 89 & 36 & \text { Pulse test conducted. } \\ 2 / 21 / 90 & 302 & \text { Flow test initiated. } \\ 5 / 1 / 90 & 371 & \text { Brine accumulator drained. } \\ 7 / 18 / 90 & 449 & \text { Shut-in. } \\ \text { BIN } & & \end{array}$

$5 / 1 / 90$

371

$6 / 4 / 90$

410

TPP

$5 / 9 / 89$

$5 / 31 / 89$

OAC and CAC

$6 / 20 / 89$
14

36

56
Brine accumulator drained.

Brine level reset.
Test region packer pressure increased.

Test region packer pressure increased. 
TZP

$4 / 25 / 89-5 / 6 / 89$

$5 / 31 / 89$

7/12/89-8/8/89

$7 / 26 / 89$

$2 / 21 / 90$

$3 / 25 / 90$

$5 / 16 / 90$

$6 / 1 / 90$
$0-11$ 36

78-105

92

302

334

386

402

335

384

405

$6 / 4 / 90$

TPP

$4 / 25 / 89-6 / 1 / 90$

Flow test initiated.

Test initiated by shutting in test region.

Pulse test conducted.

Mining. Test region pressures were reduced to prevent hydrofracture of the boreholes during the excavation process.

Test region shut-in.

Flow test initiated.

Brine accumulator drained.

Brine accumulator drained.

Entire QPP03 packer system replaced with an identical system. Test region filled with $\mathrm{N}_{2}$ and shut-in. Test region packer located at previous position of guard region packer in order to maintain the same test region length.

Brine accumulator drained.

Brine accumulator drained.

Brine accumulator drained. Flow test terminated.

Up to day 402, test region packer was inoperable. 
$6 / 2 / 90$

403

$6 / 6 / 90$

407

GZP

$5 / 30 / 89-6 / 20 / 89$

$6 / 4 / 90$

New system installed in borehole. Test region packer located at previous position of guard region packer. Test region packer shut-in.

New packer set to $1170 \mathrm{psi}(8 \mathrm{MPa})$.

Data channels in use for flow meter calibration. Guard region pressure history is identical to test region pressure history until day 402 since test region packer not seated.

Guard region packer pressure is zero since guard region packer inoperable.

\section{GPP}

$7 / 10 / 89$

Guard region packer pressure reduced.

$6 / 2 / 90$

403

Guard region packer inoperable.

\section{OAC and CAC}

$6 / 20 / 89-7 / 20 / 89$

$56.6-76.4$

Power supply problems.

$6 / 2 / 90$

New closure gauge installed.

$10 / 1 / 91-1 / 20 / 91$

Noisy data. 


\section{QPP04}

TZP

$4 / 25 / 89-5 / 6 / 89 \quad 0-1$

$5 / 19 / 89 \quad 24$

$5 / 31 / 89$

$7 / 12 / 89-8 / 8 / 89$

$7 / 26 / 89$

$7 / 17 / 90$

TPP

$5 / 31 / 89$

$6 / 30 / 89$

$7 / 17 / 90$

OAC and CAC
Test initiated by shutting in test region.

Checked test region for trapped air and then shutin.

Pulse test conducted.

Mining. Test region open to flow until day 92 .

Test region shut-in.

Test region packer pressure reduced.

Test region packer pressure increased.

Test region packer pressure reduced.

Test region packer pressure reduced to $1000 \mathrm{psi}$.

6/20/89-7/20/89 56.6-76.4 Power supply problems. 


\section{QPP05}

\section{TZP}

$4 / 25 / 89-5 / 6 / 89$

$5 / 19 / 89$

$5 / 31 / 89$

$7 / 10 / 89$

$7 / 12 / 89-8 / 8 / 89$

$7 / 26 / 89$

$2 / 21 / 90$

$3 / 8 / 90$

78-105

BIN

$2 / 21 / 90-3 / 8 / 90$

302-317

TPP

$5 / 18 / 89$

$7 / 10 / 89$

$7 / 17 / 90$

$3 / 13 / 91$

GZP

$5 / 19 / 89$
317

92

302

$0-11$

24

36

76

Mining. Test region open to flow until day 92

Test region shut-in.

Flow test initiated.

Shut-in test region because brine was flowing from accumulator into formation.
Test region pressure reduced prior to mining.

Checked test region for trapped air and then shutin.

Pulse test conducted.

Flow test.

23 Test region packer pressure increased.

$76 \quad$ Test region packer pressure reduced.

448 Test region packer pressure reduced.

687 Test region packer pressure reduced.

Checked test region for trapped air and then shutin. 
30-55 Data gap - data channels in use for flow meter calibration. Guard region pressure history is identical to test region pressure history.

78-105 Mining. Guard region open to flow.

$2 / 21 / 90$

302

Guard region shut-in, guard region pressure is similar to test region pressure.

\section{GPP}

$5 / 30 / 89$

$7 / 10 / 89$

$7 / 17 / 90$

$3 / 13 / 91$

\section{OAC and CAC}

$6 / 20 / 89-7 / 20 / 89 \quad 56.6-76.4$
687
Test region packer pressure increased.

Test region packer pressure increased.

Test region packer pressure reduced.

Test region packer pressure reduced. 
TZP

$4 / 25 / 89-5 / 6 / 89$

$0-11$

$5 / 31 / 89$

$7 / 12 / 89-8 / 8 / 89$

$2 / 21 / 90$

$7 / 18 / 90$

\section{HBP / BIN}

36

302

449
78-105

Test initiated by shutting in test region.

Pulse test conducted.

Mining.

Flow test initiated.

Flow test terminated. Shut-in.

Data is questionable because data obtained subsequent to termination of test on day 442 suggests that Anders and Hauser measurement system is operating erratically and/or brine accumulator system may leak.

\section{TPP}

$5 / 30 / 89$

Test region packer pressure increased.

$7 / 17 / 90$

448

Packer pressure increased.

\section{GZP}

$5 / 30 / 89-6 / 20 / 89$

$35-56$

Data gap - data channels in use for flow meter calibration. Guard region pressure history is identical to test region pressure history.

$6 / 20 / 89$

Guard region is open to brine inflow system.

302 Guard region shut-in.

\section{GPP}

$5 / 30 / 89$

Guard region packer pressure reduced.

OAC and CAC

No action taken. 
TZP

$4 / 25 / 89-5 / 6 / 89$

$5 / 9 / 89$

$5 / 31 / 89$

$2 / 21 / 90$

$5 / 2 / 90$

$6 / 4 / 90-6 / 7 / 90$

$7 / 18 / 90$

\section{BIN}

$2 / 21 / 90$

$7 / 18 / 90$

TPP

$5 / 30 / 89$

$8 / 31 / 89$

$1 / 23 / 90$

$6 / 4 / 90-6 / 7 / 90$

$7 / 17 / 90$
302

372

$405-408$

449

0-11

14

36

78-105

302

372

$405-408$

449

372

34.8

128.5

272.6

$405-408$

447.7
Test initiated by shutting in test region.

Increased test region pressure and re-initiated test.

Pulse test conducted.

Mining. Test region open to flow.

Flow test initiated.

Drained brine accumulator.

System removed from hole. Borehole diameter gauge calibration checked and test re-initialized.

Flow test terminated. Shut-in.
Flow test initiated.

Drained brine accumulator.

System removed from hole. Borehole diameter gauge calibration checked and test re-initialized.

Flow test terminated. Shut-in.
Test region packer pressure increased.

Test region packer pressure increased.

Test region packer pressure increased.

System removed from hole.

Test region packer pressure increased. 
$8 / 22 / 90$

$11 / 6 / 90$

$1 / 9 / 91$

OAC and CAC

$6 / 4 / 90-6 / 7 / 90 \quad 405-408$
Test region packer pressure increased.

Test region packer pressure increased.

\subsection{Test region packer pressure increased.}

\section{6/20/89-7/20/89 56.6-76.4 Power supply problems.}

System removed from hole. 
TZP

$4 / 25 / 89-5 / 6 / 89$

$0-11$

$5 / 31 / 89$

$7 / 10 / 89$

$7 / 12 / 89-8 / 8 / 89$

$7 / 26 / 89$

$2 / 21 / 90$

$3 / 5 / 90$

$3 / 22 / 90$

$4 / 9 / 90$

$5 / 1 / 90$

$5 / 3 / 90$

$5 / 20 / 90$

$6 / 14 / 90$

$7 / 18 / 90$

BIN

$5 / 30 / 89-6 / 20 / 89$
$35-56$

56

36

76

78-105

92

302

314.4

331.1

349.4

371.3

373.9

390.2

415.3

449

158
Test initiated by shutting in test region.

Pulse test conducted.

Test region pressure reduced prior to mining.

Mining. Test region open to flow until day 92 .

Test region shut-in.

Flow test initiated.

Brine accumulator drained.

Brine accumulator drained.

Brine accumulator drained.

Brine accumulator drained.

Removed system from the hole and removed borehole diameter measurement gauges and then re-initiated brine inflow tests.

Brine accumulator drained.

Brine accumulator drained.

Flow test terminated. Shut-in.
$9 / 30 / 89$

$6 / 20 / 89$

89


$2 / 21 / 90$

$3 / 5 / 90$

$3 / 22 / 90$

$4 / 9 / 90$

$5 / 1 / 90$

$5 / 3 / 90$

$5 / 20 / 90$

$6 / 14 / 90$

$7 / 18 / 90$

TPP

$5 / 31 / 89$

$7 / 7 / 89$

$7 / 10 / 89$

$9 / 26 / 89$

$9 / 27 / 89$

$10 / 27 / 89$

$11 / 13 / 89$

$12 / 15 / 89$

$2 / 21 / 90$

$5 / 2 / 90$

$6 / 6 / 90$

$6 / 15 / 90$
349.4

371.3

373.9

390.2

415.3

449

36

73.4

76.2

154.2

155.5

185.7

202.4

234.5

302

372.2

407.3

416.1
Flow test initiated.

Brine accumulator drained.

Brine accumulator drained.

Brine accumulator drained.

Brine accumulator drained.

Removed system from the hole and removed borehole diameter measurement gauges and then re-initiated brine inflow tests.

Brine accumulator drained.

Brine accumulator drained.

Flow test terminated. Shut-in.

Pulse test conducted.

Test region packer pressure increased.

Test region packer pressure reduced.

Test region packer pressure increased.

Test region packer pressure increased.

Test region packer pressure increased.

Test region packer pressure increased.

Test region packer pressure increased.

Flow test initiated.

System removed from hole.

Test region packer pressure increased.

Test region packer pressure increased. 


\begin{tabular}{|c|c|c|}
\hline $7 / 17 / 90$ & 448.4 & Test region packer pressure increased. \\
\hline $7 / 25 / 90$ & 456.5 & Test region packer pressure increased. \\
\hline $8 / 23 / 90$ & 485.4 & Test region packer pressure increased. \\
\hline $10 / 3 / 90$ & 526.4 & Test region packer pressure increased. \\
\hline $11 / 6 / 90$ & 560.4 & Test region packer pressure reduced. \\
\hline $1 / 2 / 91$ & 617.6 & Test region packer pressure reduced. \\
\hline $5 / 17 / 91$ & 752.4 & Test region packer pressure reduced. \\
\hline \multicolumn{3}{|l|}{ GZP } \\
\hline $5 / 30 / 89-6 / 20 / 89$ & $35-56$ & $\begin{array}{l}\text { Data gap - data channels in use for flow meter } \\
\text { calibration. Guard region pressure history is } \\
\text { identical to test region pressure history. }\end{array}$ \\
\hline $6 / 20 / 89$ & 56 & Guard region is open to brine inflow system. \\
\hline $10 / 2 / 89$ & 160 & Guard region shut-in. \\
\hline $10 / 5 / 89$ & 163 & Guard region packer pressure increased. \\
\hline $10 / 26 / 89$ & 184.3 & Guard region packer pressure increased. \\
\hline $11 / 13 / 89$ & 202.4 & Guard region packer pressure increased. \\
\hline $12 / 15 / 89$ & 234.5 & Guard region packer pressure increased. \\
\hline $2 / 21 / 90$ & 302 & Flow test initiated. \\
\hline $5 / 2 / 90$ & 372.2 & System removed from hole. \\
\hline $6 / 6 / 90$ & 407.3 & Guard region packer pressure increased. \\
\hline $6 / 15 / 90$ & 416.1 & Guard region packer pressure increased. \\
\hline $7 / 3 / 90$ & 434.4 & Guard region packer pressure increased. \\
\hline $7 / 17 / 90$ & 448.4 & Guard region packer pressure increased. \\
\hline $7 / 25 / 90$ & 456.5 & Guard region packer pressure increased. \\
\hline
\end{tabular}




$\begin{array}{lll}8 / 23 / 90 & 485.4 & \text { Guard region packer pressure increased. } \\ 10 / 3 / 90 & 526.4 & \text { Guard region packer pressure increased. } \\ 11 / 6 / 90 & 560.4 & \text { Guard region packer pressure increased. } \\ 1 / 2 / 91 & 617.6 & \text { Guard region packer pressure increased. } \\ 5 / 17 / 91 & 752.4 & \text { Guard region packer pressure increased. } \\ 6 / 25 / 91 & 791.5 & \text { Guard region packer pressure increased. } \\ 9 / 7 / 91 & 865.2 & \text { Guard region packer pressure increased. }\end{array}$

\section{GPP}

Data gap - data channels in use for flow meter calibration. Guard region pressure history is identical to test region pressure history.

$6 / 20 / 89$

$10 / 2 / 89$

$10 / 5 / 89$

$10 / 26 / 89$

$11 / 13 / 89$

$12 / 15 / 89$

$2 / 21 / 90$

$5 / 2 / 90$

$6 / 6 / 90$

$6 / 15 / 90$

$7 / 3 / 90$

$7 / 17 / 90$

$7 / 25 / 90$
Guard region is open to brine inflow system.

Guard region shut-in.

Guard region packer pressure increased.

Guard region packer pressure increased.

Guard region packer pressure increased.

Guard region packer pressure increased.

Flow test initiated.

System removed from hole.

Guard region packer pressure increased.

Guard region packer pressure increased.

Guard region packer pressure increased.

Guard region packer pressure increased.

Guard region packer pressure increased. 


$\begin{array}{lll}8 / 23 / 90 & 485.4 & \text { Guard region packer pressure increased. } \\ 10 / 3 / 90 & 526.4 & \text { Guard region packer pressure increased. } \\ 11 / 6 / 90 & 560.4 & \text { Guard region packer pressure increased. } \\ 1 / 2 / 91 & 617.6 & \text { Guard region packer pressure increased. } \\ 5 / 17 / 91 & 752.4 & \text { Guard region packer pressure increased. } \\ 6 / 25 / 91 & 791.5 & \text { Guard region packer pressure increased. } \\ 9 / 7 / 91 & 865.2 & \text { Guard region packer pressure increased. }\end{array}$

\section{OAC and CAC}

6/20/89-7/20/89 56.6-76.4 Power supply problems.

$4 / 30 / 90 \quad 370 \quad$ System removed from hole. 


\section{QPP14}

TZP

$4 / 25 / 89-5 / 6 / 89$

$5 / 5 / 89$

$5 / 19 / 89$

$5 / 31 / 89$

7/10/89

$7 / 12 / 89-8 / 8 / 89$

$7 / 26 / 89$

$9 / 27 / 89$

$11 / 13 / 89$

7/17/90

$11 / 6 / 90$

$1 / 28 / 91$

$5 / 13 / 90-7 / 16 / 9 n$

$6 / 24 / 91$

\section{TPP}

$5 / 5 / 89$

$9 / 27 / 89$

$11 / 13 / 89$
$0-11$

10.8

24

36

76

78-105

92

155.6

202.4

448.4

560.4

643.5

$383-447$

791.5

10.8

155.6

202.4
Test initiated by shutting in test region.

Test region packer pressure increased.

Checked test region for trapped air and then shutin.

Pulse test conducted.

Test region pressure reduced prior to mining.

Mining. Test region open to flow until day 92.

Test region shut-in.

Test region packer pressure increased.

Test region packer pressure increased.

Test region packer pressure increased.

Test region packer pressure increased.

Test region packer pressure increased.

QPP14 test region pressure was measured using the QPP15 test region pressure transducer during this period. The pressure excursions at those two days result from changing the transducers.

Test region packer pressure increased.

Test region packer pressure increased.

Test region packer pressure increased.

Test region packer pressure increased. 
$7 / 17 / 90$

448.4

$11 / 6 / 90$

560.4

$1 / 28 / 91$

643.5

$5 / 13 / 90-7 / 16 / 90$

$383-447$

$6 / 24 / 91$

791.5

OAC and CAC

$6 / 20 / 89-7 / 20 / 89 \quad 56.6-76.4$

$5 / 13 / 90-7 / 16 / 90 \quad 383-447$
Test region packer pressure increased.

Test region packer pressure increased.

Test region packer pressure increased.

QPP14 test region pressure was measured using the QPP15 test region pressure transducer during this period. The pressure excursions at those two days result from changing the transducers.

Test region packer pressure increased.

Power supply problems.

QPP14 test region pressure was measured using the QPP15 test region pressure transducer during this period. Closure data are compensated for test region pressure and should therefore be ignored in this period. 
TZP

4/25/89-5/6/89

$6 / 8 / 89$

$5 / 19 / 89$

$5 / 31 / 89$

$7 / 10 / 89$

7/12/89-8/8/89

$7 / 26 / 89$

$9 / 27 / 89$

$2 / 21 / 90$

$5 / 1 / 90$

$5 / 13 / 90-7 / 16 / 90$

$383-447$

$7 / 18 / 90$

$3 / 13 / 91$

TPP

$6 / 8 / 89$

$9 / 27 / 89$

$5 / 1 / 90$

$3 / 13 / 91$
$0-11$

44

24

36

76

78-105

92

155

302

371

389

449

687

44

155

371

687
Test initiated by shutting in test region.

Test region packer pressure increased.

Checked test region for trapped air and then shutin.

Pulse test conducted.

Test region pressure reduced prior to mining.

Mining. Test region open to flow until day 92.

Test region shut-in.

Test region packer pressure reduced.

Flow test initiated.

Test region packer pressure reduced.

QPP15 test region pressure was measured using the QPP14 test region pressure transducer during this period. The pressure excursions at those two days result from changing the transducers.

Flow test terminated. Shut-in.

Test region packer pressure reduced.

Test region packer pressure increased.

Test region packer pressure reduced.

Test region packer pressure reduced.

Test region packer pressure reduced. 
BIN

$2 / 21 / 90$

$5 / 2 / 90$

$7 / 18 / 90$

449

GZP

$7 / 12 / 89-8 / 8 / 89$

$5 / 19 / 89$

$5 / 30 / 89-6 / 20 / 89$

$35-56$

$6 / 20 / 89-2 / 21 / 90$

$2 / 21 / 90$

GPP

372

24

302
302

78-105

$56-302$

1.2

22.4

35.5

76.1

155.5

371.3

687.4

OAC and CAC

$6 / 20 / 89-7 / 20 / 89$

$5 / 13 / 90-7 / 16 / 90$
$56.6-76.4$

$383-447$
Flow test initiated.

Brine accumulator drained.

Flow test terminated. Shut-in.

Mining.

Checked test region for trapped air and then shutin.

Data gap - data channels in use for flow meter calibration. Guard region pressure history is identical to test region pressure history.

Guard zone connected to flow system.

Guard region shut-in.

Guard region packer pressure increased.

Guard region packer pressure increased.

Guard region packer pressure increased.

Guard region packer pressure reduced.

Guard region packer pressure reduced.

Guard region packer pressure reduced.

Guard region packer pressure reduced.

Power supply problems.

QPP14 test region pressure was measured using the QPP15 test region pressure transducer during this period. Closure data are compensated for test region pressure and should therefore be ignored in this period. 


\section{QPP21}

TZP

$4 / 25 / 89-5 / 6 / 89$

$0-11$

24

$5 / 19 / 89$

36

78-105

$7 / 12 / 89-8 / 8 / 89$

302

$2 / 21 / 90$

$7 / 18 / 90$

HPB (BIN)
Test initiated by shutting in test region.

Checked test region for trapped air and then shutin.

Pulse test conducted.

Mining. Test region shut-in.

Flow test initiated.

Flow test terminated. Shut-in.

Brine inflow system inoperable.

\section{TPP}

$5 / 30 / 89$

35.1

Test region packer pressure increased.

$7 / 17 / 90$

448

Test region packer pressure increased.

GZP

$5 / 30 / 89-6 / 20 / 89$

35-56

Data gap - data channels in use for flow meter calibration. Guard region pressure history is identical to test region pressure history.

$6 / 20 / 89-2 / 21 / 90$

$56-302$

Guard zone connected to flow system.

$2 / 21 / 90$

302

Guard region shut-in.

\section{GPP}

$5 / 30 / 89$

35

Guard packer pressure inciease, pulse test.

$7 / 17 / 90$

448

Guard region packer pressure increased.

OAC and CAC

Cross-axis and on-axis closure gauges inoperable. 


\section{QPP22}

TZP

4/25/89-5/6/89 $\quad 0-1$

$5 / 19 / 89$

24

36

78-105

90.7

132.8

154.9

$9 / 26 / 89$

$10 / 25 / 89$

$11 / 12 / 89$

$1 / 22 / 90$

$2 / 21 / 90$

$7 / 17 / 90$

$7 / 18 / 90$

$11 / 5 / 90$

$12 / 25 / 90$

$1 / 9 / 91$

$2 / 12 / 91$

$3 / 12 / 91$
183.6

201.7

272.6

302.2

448

449

559

609

624

658

686
Test initiated by shutting in test region.

Checked test region for trapped air and then shutin.

Pulse test conducted.

Mining. Test region open to flow.

Test region packer pressure increased.

Test region packer pressure increased.

Test region packer pressure increased.

Test region packer pressure increased.

Test region packer pressure increased.

Test region packer pressure increased.

Test region connected to brine inflow system.

Flow to brine inflow system apparently restricted resulting in test region pressure increase.

Repaired on day 372.

Test region packer pressure increased.

Flow test terminated. Shut-in.

Test region packer pressure increased.

Test region packer pressure increased.

Test region packer pressure increased.

Test region packer pressure increased.

Test region packer pressure increased. 


$\begin{array}{lll}4 / 2 / 91 & 707 & \text { Test region packer pressure increased. } \\ 4 / 23 / 91 & 728 & \text { Test region packer pressure increased. } \\ 5 / 15 / 91 & 751 & \text { Test region packer pressure increased. } \\ 6 / 12 / 91 & 778 & \text { Test region packer pressure increased. } \\ 6 / 25 / 91 & 791 & \text { Test region packer pressure increased. }\end{array}$

\section{BIN}

$2 / 21 / 90-5 / 2 / 90 \quad 302-372$

Test region connected to brine inflow system.

Flow to brine inflow system apparently restricted resulting in test region pressure increase.

Repaired on day 372.

370 Drain brine accumulator.

$7 / 18 / 90$

449

Flow test terminated. Shut-in.

\section{TPP}

$5 / 18 / 89$

$6 / 26 / 89$

$6 / 30 / 89$

$9 / 4 / 89$

$9 / 26 / 89$

$10 / 25 / 89$

$11 / 12 / 89$

$: 1 / 22 / 90$

$7 / 17 / 90$

$7 / 18 / 90$

$11 / 5 / 90$

\section{3}

62.4

66.3

132.8

154.9

183.6

201.7

272.6

448

449

559
Test region packer pressure increased.

Test region packer pressure increased.

Test region packer pressure increased.

Test region packer pressure increased.

Test region packer pressure increased.

Test region packer pressure increased.

Test region packer pressure increased.

Test region packer pressure increased.

Test region packer pressure increased.

Flow test terminated. Shut-in.

Test region packer pressure increased. 
$12 / 25 / 90$

$1 / 9 / 91$

$2 / 12 / 91$

$3 / 12 / 91$

$4 / 2 / 91$

$4 / 23 / 91$

$5 / 15 / 91$

$6 / 12 / 91$

$6 / 25 / 91$

OAC and CAC

$6 / 20 / 89-7 / 20 / 89 \quad 56.6-76.4$
Test region packer pressure increased.

Test region packer pressure increased.

Test region packer pressure increased.

Test region packer pressure increased.

Test region packer pressure increased.

Test region packer pressure increased.

Test region packer pressure increased.

Test region packer pressure increased.

791 Test region packer pressure increased. 
TZP

\begin{tabular}{|c|c|c|}
\hline $4 / 25 / 89-5 / 6 / 89$ & $0-11$ & Test initiated by shutting in test region. \\
\hline $5 / 19 / 89$ & 24 & $\begin{array}{l}\text { Checked test region for trapped air and then shut- } \\
\text { in. }\end{array}$ \\
\hline $5 / 31 / 89$ & 36 & Pulse test conducted. \\
\hline $7 / 12 / 89-8 / 8 / 89$ & $78-105$ & Mining. Test region open to flow. \\
\hline $2 / 21 / 90$ & 302 & Flow test initiated. \\
\hline $5 / 1 / 90$ & 371.2 & Brine accumulator drained. \\
\hline $7 / 18 / 90$ & 449 & Flow test terminated. Shut-in. \\
\hline \multicolumn{3}{|l|}{ BIN } \\
\hline $2 / 21 / 90$ & 302 & Flow test initiated. \\
\hline $5 / 1 / 90$ & 371.2 & Brine accumulator drained. \\
\hline
\end{tabular}

\section{TPP}

22.6

75.7

90.7

105.7

128.3

154.6
Leaking packer. Packer pressure was increased many times.

Test region packer pressure increased.

Test region packer pressure reduced.

Test region packer pressure increased.

Test region packer pressure increased.

Test region packer pressure increased.

Test region packer pressure increased. 
$10 / 25 / 89$

183.4

$12 / 14 / 89$

233.8

$1 / 21 / 90$

$7 / 16 / 90$

GZP

$5 / 19 / 89$

$5 / 30 / 89-6 / 20 / 89$

$35-56$

$6 / 21 / 89-8 / 1 / 89$

$8 / 1 / 89$

98

301.9

GPP

\section{GPP}

22.6

74.4

232.9

272.7

$7 / 14 / 90$

OAC and CAC
Test region packer pressure increased.

Test region packer pressure increased.

Test region packer pressure increased.

Test region packer pressure increased.

Checked test region for trapped air and then shutin.

Data gap - data channels in use for flow meter calibration. Guard region pressure history is identical to test region pressure history.

Guard region open.

Guard region shut-in.

Guard region pressure lowered.

Guard region packer pressure increased.

Guard region packer pressure increased.

Guard region packer pressure increased.

Guard region packer pressure increased.

445.8 Guard region packer pressure increased.
$6 / 20 / 89-7 / 20 / 89 \quad 56.6-76.4$
Power supply problems. 


\section{QPP24}

TZP

$4 / 25 / 89-5 / 6 / 89$

$0-11$

$5 / 31 / 89$

36

$7 / 10 / 89$

76

$7 / 12 / 89-8 / 8 / 89$

78-105

$7 / 26 / 89$

$2 / 21 / 90$

$7 / 18 / 90$

$5 / 15 / 90-7 / 16 / 90$

$385-447$

$7 / 16 / 90$

447

TPP

$7 / 6 / 89$

$7 / 16 / 90$

OAC and CAC

$6 / 20 / 89-7 / 20 / 89$

56.6-76.4

$5 / 13 / 90-7 / 16 / 90$

$383-447$
Test initiated by shutting in test region.

Pulse test conducted.

Test region pressure reduced prior to mining.

Mining. Test region open to flow until day 92.

Test region shut-in.

Flow test initiated.

Flow test terminated. Shut-in.

QPP24 test region pressure was measured using the QPP25 test region pressure transducer during this period. The pressure excursions at those two days result from changing the transducers.

Test region packer pressure increased.

Test region packer pressure reduced.

Test region packer pressure increased.

Power supply problems.

QPP14 test region pressure was measured using the QPP15 test region pressure transducer during this period. Closure data are compensated for test region pressure and should therefore be ignored in this period. 


\section{QPP25}

\section{TZP}

$4 / 25 / 89-5 / 6 / 89$

$0-11$

$5 / 19 / 89$

24

$5 / 31 / 89$

36

$7 / 10 / 89$

76

7/12/89-8/8/89

78-105

$7 / 26 / 89$

$2 / 21 / 90$

92

302

$5 / 15 / 90-7 / 16 / 90$

$385-447$

$7 / 18 / 90$

449

\section{BIN}

$2 / 21 / 90$

302

$4 / 30 / 90$

370

$7 / 18 / 90$

449

TPP

$5 / 18 / 89$

$7 / 24 / 89$

$9 / 26 / 89$

$10 / 25 / 89$
23.6

90.7

154.1

183.4
Test initiated by shutting in test region.

Checked test region for trapped air and then shutin.

Pulse test conducted.

Test region pressure reduced prior to mining.

Mining. Test region open to flow until day 92 .

Test region shut-in.

Flow test initiated.

QPP24 test region pressure was measured using the QPP25 test region pressure transducer during this period. The pressure excursions at those two days result from changing the transducers

Flow test terminated. Shut-in.

Flow test initiated.

Brine accumulator drained.

Flow test terminated. Shut-in.

Test region packer pressure increased.

Test region packer pressure reduced.

Test region packer pressure increased.

Test region packer pressure increased. 
$11 / 12 / 89$

$1 / 22 / 90$

$6 / 3 / 90$

$7 / 2 / 90$

$7 / 15 / 90$

$10 / 1 / 90$

$11 / 5 / 90$

$1 / 27 / 91$

$4 / 2 / 91$

$5 / 16 / 91$

$6 / 25 / 91$

\section{GZP}

$5 / 19 / 89$

$5 / 30 / 89-6 / 20 / 89$

$6 / 20 / 89-8 / 1 / 89$

$8 / 1 / 89$

$2 / 21 / 90$

\section{GPP}

$5 / 18 / 89$

$7 / 9 / 89$

$10 / 25 / 89$

$11 / 2 / 89$
201.1

272.6

404.5

433.9

446.2

524.9

559.2

64.?.1

707.4

751.7

791.5

24

$35-56$

$56-98$

98

301.7

23.6

75.3

183.6

201.7
Test region packer pressure increased.

Test region packer pressure increased.

Test region packer pressure increased.

Test region packer pressure increased.

Test region packer pressure increased.

Test region packer pressure increased.

Tesł region packer pressure increased.

Test region packer pressure increased.

Test region packer pressure increased.

Test region packer pressure increased.

Test region packer pressure increased.

Checked test region for trapped air and then shutin.

Data gap - data channels in use for flow meter calibrition.

Guard region cornected to brine inflow system.

Guard region shut-in to evaluate flow meter system.

Guard region pressure lowered.

Guard region packer pressure increased.

Guard region packer pressure reduced.

Guard region packer pressure increased.

Guard region packer pressure increased. 
$1 / 21 / 90$

$10 / 2 / 90$

$6 / 25 / 91$

\section{OAC and CAC}

$6 / 20 / 89-7 / 20 / 89 \quad 56.6-76.4$

$5 / 13 / 90-7 / 16 / 90 \quad 383-447$
Guard region packer pressure increased.

Guard region packer pressure increased.

Guard region packer pressure increased.
Power supply problems.

QPP14 test region pressure was measured using the QPP15 test region pressure transducer during this period. Closure data are compensated for test region pressure and should therefore be ignored in this period. 


\section{DISTRIBUTION}

\section{Federal Agencies}

US Department of Energy, (5)

Office of Civilian Radioactive Waste

Management

Attn: Deputy Director, RW-2

Associate Director, RW-10

Office of Program

Administration and

Resources Management

Associate Director, RW-20

Office of Facilities

Siting and Development

Associate Director, RW-30

Office of Systems

Integration and

Regulations

Associate Director, RW-40

Office of External

Relations and Policy

Forrestal Building

Washington, DC 20585

US Department of Energy (4)

WIPP Project Integration office

Attn: W.J. Arthur III

L.W. Gage

P.J. Higgins

D.A. Olona

PO Box 5400

Albuquerque, NM 87115-5400

US Department of Energy

Attn: National Atomic Museum Library

Albuquerque Operations Office

PO Box 5400

Albuquerque, NM 87185-5400

US Denartment of Energy (4)

WIPP Project Site Office (Carlsbad)

Attn: R. Becker

V. Daub

J. Lippis

J.A. Mewhinney

PO Box 3090

Carlsbad, NM 88221

US Department of Energy

Research \& Waste Management Division

Attn: Director

PO Box E

Oak Ridge, TN 37831
US Department of Energy

Attn: E. Young

Room E- 178

GAO/RCED/GTN

Washington, DC 20545

US Department of Energy

Office of Environmental Restoration and Waste Management

Attn: J. Lytle, EM-30 (Trevion II)

Washington, DC 20585-0002

US Department of Energy (3)

Office of Environmental Restoration and Waste Management

Attn: M. Frei, EM-34 (Trevion II)

Washington, DC 20585-0002

US Department of Energy

Office of Environmental Restoration and Waste Management

Attn: S. Schneider, EM-342 (Trevion II)

Washington, DC 20585-0002

US Department of Energy (3)

Office of Environment, Safety and Health

Attn: C. Borgstrom, EH-25

R. Pelletier, EH-231

Washington, DC 20585

US Department of Energy (2)

Idaho Operations office

Fuel Processing and Waste

Management Division

785 DOE Place

Idaho Falls, ID 83402

US Environmental Protection Agency (2)

Radiation Programs (ANR-460)

Attn: M. Oge

Washington, DC 20460

US Geological Survey (2)

Water Resources Division

Attn: R. Livingston

Suite 200

4501 Indian School NE

Albuquerque, NM 87110 
US Nuclear Regulatory Commission Attn: H. Marson

Mail Stop 623SS

Washington, DC 20555

\section{Boards}

Defense Nuclear Facilities Safety Board

Attn: D. Winters

Suite 700

625 Indiana Ave. NW

Washington, DC 20004

Nuclear Waste Technical Review

Board (2)

Attn: D.A. Deere

Suite 910

$$
\text { S.J.S. Parry }
$$

1100 Wilson Blvd.

Arlington, VA 22209-2297

Advisory Committee on Nuclear Waste

Nuclear Regulatory Commission

Attn: R. Major

7920 Norfolk Ave.

Bethesda, MD 20814

\section{State Agencies}

Environmental Evaluation Group (3) Attn: Library

Suite F-2

7007 Wyoming NE

Albuquerque, NM 87109

NM Bureau of Mines and Mineral

Resources

Socorro, NM 87801

NM Energy, Minerals, and Natural Resources Department

Attn: Library

2040 S. Pacheco

Santa Fe, NM 87505

NM Environment Department (3)

Secretary of the Environment

Attn: J. Espinosa

1190 St. Francis Drive

Santa Fe, NM 87503-0968
NM Environment Department

WIPP Project Site

Attn: P. McCasland

PO Box 3090

Carlsbad, NM 88221

\section{Laboratories/Corporations}

Battelle Pacific Northwest

Laboratories (2)

Attn: H.C. Burkholder, P7-41

R.E. Westerman, P8-37

Battelle Blvd.

Richland, WA 99352

IN'TERA Inc .

Attn: J.F. Pickens

Suite 300

6850 Austin Center Blvd.

Austin, TX 78731

INTERA Inc. (3)

Attn: W. Stensrud

F. Holzmer

$\mathrm{J}$. Palmer

PO Box 2123

Carlsbad, NM 88221

IT Corporation

Attn: R.F. Mckinney

Regional Office - Suite 700

5301 Central NE

Albuquerque, NM 87108

Los Alamos National Laboratory

Attn: B. Erdal, CNC-11

PO Box 1663

Los Alamos, NM 87544

$\mathrm{RE} / \mathrm{SPEC}$, Inc.

Attn: C. Howard

c/o Sandia National Labs

501 South Main

Calrsbad, NM 88221

$\mathrm{RE} / \mathrm{SPEC}$, Inc.

Attn: W. Coons

4775 Indian School, NE

Suite 300

Albuquerque, NM 87110-3927 
RE/SPEC, Inc.

Attn: J.L. Ratigan

PO Box 725

Rapid City, SD 57709

Savannah River Laboratory (3)

Attn: N. Bibler

M.J. Plodinec

G.G. Wicks

Aiken, SC 29801

Southwest Research Institute (2)

Center for Nuclear Waste

Regulatory Analysis

Attn: P.K. Nair

6220 Culebra Road

San Antonio, TX 78228-0510

S-Cubed

Division of Maxwel1 Labs

Attn: E.W. Peterson

P.0. Box 1620

La Jo11a, CA 92038-1620

SAIC

Attn: D.C. Royer

101 Convention Center Dr.

Las Vegas, NV 89109

SAIC

Attn: H.R. Pratt

10260 Campus Point Dr.

San Diego, CA 92121

SAIC (2)

Attn: M. Davis

J. Tollison

2109 Air Park Rd. SE

Albuquerque, NM 87106

Tech Reps Inc. (3)

Attn: J. Chapman

C. Crawford

T. Peterson

5000 Marble NE

Albuquerque, NM 87110

Westinghouse Electric Corporation (5)

Attn: Library

C. Cox

L. Fitch

R. Kehrman

L. Trego

PO Box 2078

Carlsbad, NM 88221

\section{National Academy of Sciences, WIPP Panel}

Howard Adler

Oak Ridge Associated Universities Medical Sciences Division

PO Box 117

Oak Ridge, TN 37831-0117

Ina Alterman

Board on Radioactive

Waste Management, GF456

2101 Constitution Ave.

Washington, DC 20418

John D. Bredehoeft

Western Region Hydrologist

Water Resources Division

US Geological Survey (M/S 439)

345 Middlefield Road

Menlo Park, CA 94025

Fred M. Ernsberger

250 0ld Mill Road

Pittsburgh, PA 15238

Rodney C. Ewing

Department of Geology

University of New Mexico

Albuquerque, NM 87131

Charles Fairhurst, Chairman

Department of $\mathrm{Civil}$ and

Mineral Engineering

University of Minnesota

500 Pillsbury Dr. SE

Minneapolis, MN 55455-0220

B. John Garrick

PLG Incorporated

Suite 400

4590 MacArthur Blvd.

Newport Beach, CA 92660-2027

Leonard F. Konikow

US Geological Survey

431 National Center

Reston, VA 22092 
Peter B. Myers

National Academy of Sciences

Board on Radioactive

Waste Management

2101 Constitution Ave.

Washington, DC 20418

Jeremiah O'Driscoll

Jody Incorporated

505 Valley Hill Drive

Atlanta, GA 30350

Christopher G. Whipple

Clement International

Suite 1380

160 Spear St.

San Francisco, CA 94105

\section{Universities}

University of New Mexico

Geology Department

Attn: Library

Albuquerque, NM 87131

University of Washington

College of Ocean

and Fishery Sciences

Attn: G.R.Heath

583 Henderson Hall

Seattle, WA 98195

\section{Individuals}

P. Drez

8816 Cherry Hills Rd., NE

Albuquerque, NM 87111

D.W. Powers

Star Route Box 87

Anthony, TX 79821

\section{Libraries}

Thomas Brannigan Library

Attn: D. Dresp

$106 \mathrm{~W}$. Hadley St.

Las Cruces, NM 88001

Government Publications Department

General Library

University of New Mexico

Albuquerque, NM 87131
Hobbs Public Library

Attn: M. Lewis

$509 \mathrm{~N}$. Ship St.

Hobbs, NM 88248

New Mexico Junior College

Pannell Library

Attn: R. Hill

Lovington Highway

Houbs, NM 88240

New Mexico State Library

Attn: N. McCallan

325 Don Gaspar

Santa Fe, NM 87503

New Mexico Tech

Martin Speere Memorial Library

Campus Street

Socorro, NM 87810

WIPP Public Reading Room

Carlsbad Public Library

$101 \mathrm{~S}$. Halagueno St.

Carlsbad, NM 88220

\section{Foreign Addresses}

Studiecentrum Voor Kernenergie

Centre D'Energie Nucleaire

Attn: A. Bonne

SCK/CEN, Boeretang 200

B-2400 Mo1, BELGIUM

Atomic Energy of Canada, Ltd. (3)

Whiteshel1 Research Estab.

Attn: B. Goodwin

M. Stevens

D. Wushke

Pinewa, Manitoba, CANADA ROE 1 LO

Francois Chenevier, Director (2) ANDRA

Route du Panorama Robert Schumann

B.P. 38

92266 Fontenay-aux-Roses, Cedex

FRANCE

Jean-Pierre Olivier

OECD Nuclear Energy Agency

Division of Radiation Protection and Waste Management

38 , Boulevard Suchet

75016 Paris, FRANCE 
Claude Sombret

Centre D'Etudes Nucleaires

De La Vallee Rhone

CEN/VALRHO

S.D.H.A. BP 171

30205 Bagnols-Sur-Ceze, FRANCE

Gesellschaft fur Reaktorsicherheit (GRS) (2)

Attn: B. Baltes

W. Muller

Schwertnergasse 1

D-5000 Cologne, GERMANY

Bundesanstalt fur Geowissenschaften und Rohstoffe

Attn: $M$. Langer

Postfach 510153

3000 Hanover 51, GERMANY

Bundesministerium fur Forschung und Technologie

Postfach 200706

5300 Bonn 2, GERMANY

Institut fur Tieflagerung (2)

Attn: K. Kuhn

Theodor-Heuss-Strasse 4

D-3300 Braunschweig, GERMANY

Physikalisch-Technische Bundesanstalt

Attn: P. Brenneke

Postfach 3345

D-3300 Braunschweig, GERMANY

Shingo Tashiro

Japan Atomic Energy Research Inst.

Tokai-Mura, Ibaraki-Ken, 319-11

JAPAN

Netherlands Energy Research

Foundation ECN

Attn: L.H. Vons

3 Westerduinweg

PO Box 1

1755 ZG Petten, THE NETHERLANDS

Svensk Karnbransleforsorjning $A B$

Attn: F. Karlsson

Project KBS

Karnbrans lesakerhet

Box 5864

10248 Stockholm, SWEDEN

Nationale Genossenschaft fur die

Lagerung Radioaktiver Abfalle (2)

Attn: S. Vomvoris

P. Zuidema

Hardstrasse 73

$\mathrm{CH}-5430$ Wettingen, SWITZERLAND

AEA Technology

Attn: J.H. Rees

D5W/29 Culham Laboratory

Abington, Oxfordshire OX14 3DB

UNITED KINGDOM

AEA Technology

Attn: W.R. Rodwe 11

044/A31 Winfrith Technical Centre

Dorchester, Dorset DT2 8DH

UNITED KINGDOM

AEA Technology

Attn: J.E. Tinson

B4244 Harwel1 Laboratory

Didcot, Oxfordshire OX11 ORA

UNITED KINGDOM

D.R. Knowles

British Nuclear Fuels, plc

Risley, Warrington, Cheshire WA3 6AS

1002607 UNITED KINGDOM

\section{Sandia Internal}

1502

6000

6119

6119

6119

6121

6121

6300

6302

6303

6303

6305

6306

6341

6342

6342

6343

6343

6345

6345

6347
J.C. Cummings

D.L. Hartley

E.D. Gorham

Staff (14)

A.L. Jensen (20)

J.R. Tillerson

Staff (7)

D.E. Miller

L.E. Shephard

W.D. Weart

S.Y. Pickering

S.A. Goldstein

A.L. Stevens

WIPP Central Files (10)

D.R. Anderson

Staff (20)

S.A. Orrell

Staff (2)

R.C. Lincoln

Staff (9)

D.R. Schafer 
6348 J.T. Holmes

6351 R.E. Thompson

6352 S.E. Sharpton

7141 Technical Library (5)

7151 Technical Publications

7613-2 Document Processing for DOE/OSTI (10)

8523-2 Central Technical Files

9300 J.E. Powell 

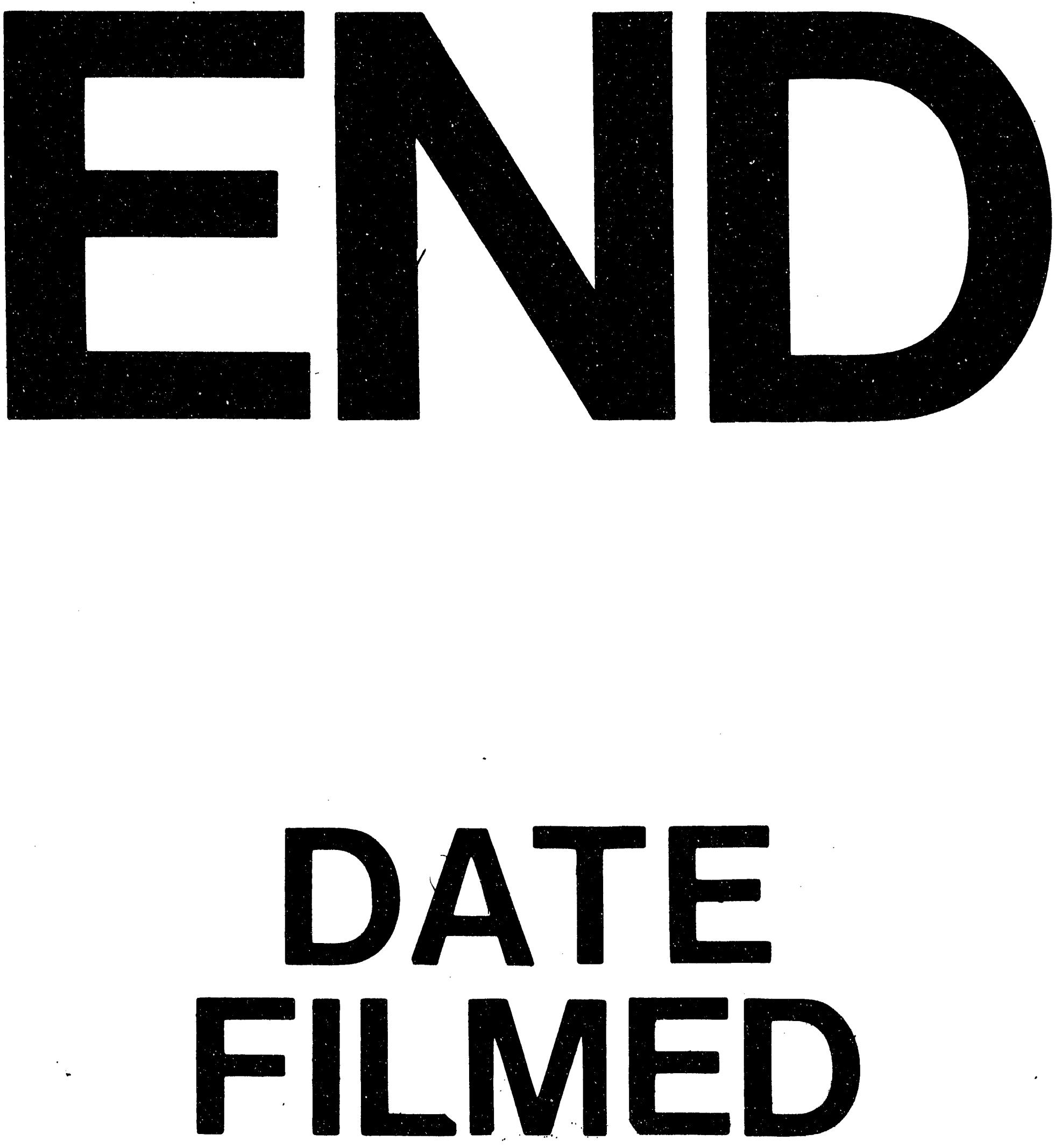

I

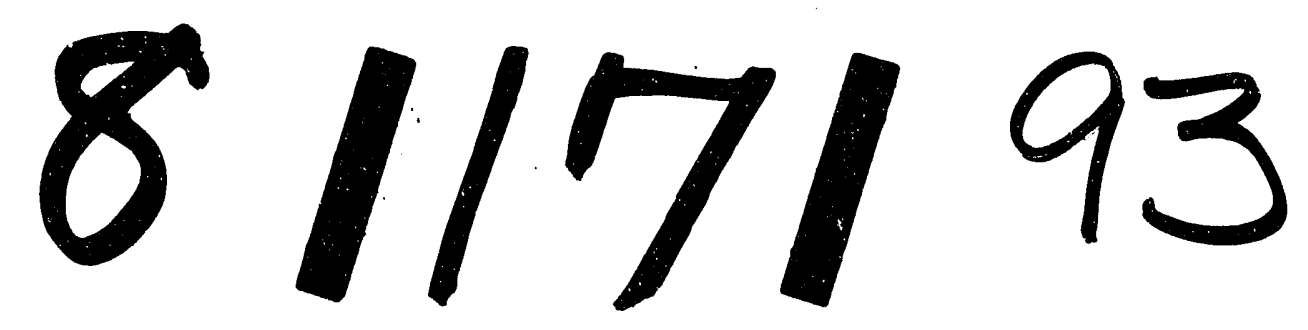


